
PBÓ2882

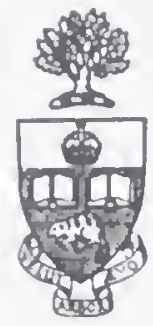

Library

$$
\text { of the }
$$

University of Toronto 
Digitized by the Internet Archive in 2018 with funding from University of Toronto 




\section{INTERNATIONAL SCIENTIFIC SERIES.}

Each Book Complete in One Volume. Crown 8ro. cloth.

I. FORMS of WATER: a Familiar Exposition of the Origin and Phenomena of GLACIERS. By J. TrxdAL,, LL.D., F.R.S. With 25 Illustrations. Ninth Edition. 5s.

II. PHXSICS and POLITICS; or, Thoughts on the Application of the Principles of 'Natural Selection' and 'Inheritance' to Political Society. By Walter Bageiotot. Seventh Edition. 4s.

III. FOODS. By Edward Smith, MI.D., LL.B., F.R.S. With numerous Illustrations. Eighth Edition. 5s.

IV. MIND and BODY: the Theories of their Relation. By ALexander Baix, LL.D. With Four lllustrations. Seventh Edition. 4s.

V. The STUdy of SOCIOLOGY. By Herbert Spexcer. Twolfth Edition. 5s.

VI. On the CONSERVATION of ENERGY. By BALFOUT STEWART, M.A., LL.D., F.R.S. With 14 Illustrations. Sixth Edition. 5s.

VII. ANIMAL LOCOMOTION; or, Walking, Swimming, and Flying. By J. B. Pertigrlew, M.D., F.R.S., \&c. With 130 Illustrations. Third Edition. $5 s$.

VIII. RESPONSIBILITY in MENTAL DISEASE. By HENRY MAUDSLEx, M.D. Fourth Edition. 5s.

IX. The NEW CHEMISTRY. By Professor J. P. Cooke, of the Harvard Unfversity. With 31 Ilustrations. Eighth Edition, remodelled and enlarged. 5s.

X. The SCIENCE of LAW. By Professor Sheldon Amos. Sixth Edition. $5 s$.

XI. ANIMAL MECHANISM : a Treatise on Terrestrial and Aërial Locomotion. By Professor E. J. MAREY. Witli 117 Illustrations. Third Edition. 5s.

XII. The DOCTRINE of DESCENT and DARWINISM. By Professor OSCAR SCHMIDT (Strasburg University). With 26 Illustrations. Sixth Edition. 5s.

London: KEGAN PAUL, TRENCH, \& CO, 1 Paternoster Square. 


\section{The International Scientific Series-continued.}

XIII. The HISTORY of the CONFLICT between RELIGION and SCIENCE. By J. W. Drarkr, M.I., LL.D. Nineteenth Edition. $5 s$.

XIV. FUNGI: their Naturo, Influences, Uses, \&c. By MI. C. Cooke, M.A., LL.D. Edited by the Rer. M. J. Brikelex, M.A., F.L.S. With numerous Illustrations. Third Edition. 5s.

IV. The CHEMICAL EFEECTS of LIGHT and PHOTOGRAPHY. By Dr. InEmaxy Vogen, (Polytechnic Academy of Berlin). Translation thoroughly revised. With 100 Illustrations. Fourtl Edition. 5s.

XVI. The LIFE and GROWTH of LANGUAGE. By WhiAM Dwont Whitsiy. Fiftı Edition. 5s.

XVII. MONEY and the MECHANISM of EXCHANGE. By W. STANLEY Jevoxs, M.A., K.R.S. Seventh Edition. 5s.

XVIII. The NATURE of LIGHT, with a General Account of PHYSICAL OPTICS. By Dr. EEGRE ToMMEr. With 188 Illustrations and a Table of Spectra in Chromo-lithography. Fourth Edition. 5s.

XIX. ANIMAL PARASTTES and MESSMATES. By Monsicnl VAx BWenex. With 83 Illustrations. Third Edition. 5s.

XX. FERMENTATION. By Professor Scuützenbrger. With 28 Illustrations. Fourth Edition. 5s.

XXI. The FIVE SENSES of MAN. By Professor Bersitein, With 91 Illustrations. Fifth Edition. 5s.

XXII. The THEORY of SOUND in its RELATION to MUSIC.

By Professor PIETno Blaskixa. With numerous Illustrations. Third Eulition. 5s.

XXIII. STUDIES in SPECTRUM ANALYSIS. By J. Normay LockYer, F.IR.S. With Six Photographic Illustrations of Spectra, and numerous Engravings on Wood. Third Edition. $6 s, 6 r$.

XXIV. A HISTORY of the GROWTH of tho BTEAM ENGINE. By Professor R. H. Truvns"ros. With numerous Illustrations. Third Edition. 6s, $6 d$.

London: KEGAN PAUL, TRENCH, \& CO., 1 Paternoster Square. 
The International Scientific Series-continued.

XXV. eduCation as a SCience. By Alexandfr Bain, Ll.D. Fifth Edition. 5s.

XXVI. The HUMan SPeCies. By Professor A. de Quatrefages, Membre de l'Institut. Third Edition. $5 s$.

SXVII. MODERN CHROMATICS. With Application to Art and Industry. By OGDEx N. RooI). Second Edition. With 130 original Illustrations. 5s.

XXVIII. The CRAYFISH: an Introduction to the Study of Zoology. By T. H. Huxlex, F.R.S. Fourth Edition. With 82 Illustrations. 5s.

XXIX. The BRAIN as an ORGAN of MIND. By H. Cirarlton Bastian, M.D. Third Edition. With 184 Illustrations. 5s.

XXX. The ATOMIC THEORY. By Professor A. Wurtz. Translated by E. Cleminshaw, F.C.S. Fourth Edition. $5 s$.

XXXI. The NATURAL CONDITIONS of EXISTENCE as they affect Animal Life. By KarL SeMprn. Third Edition. With 2 Maps and 106 Woodcuts. $5 s$.

XXXII. GENERAL PHYSIOLOGY of MUSCLES and NERVES. By Prof. J. Rosenthal. Third Edition. With Illustrations. 5s.

XXXIII. SIGHT: an Exposition of the Principles of Monocular and Binocular Vision. By Joseph Le Conte, LL.D. Second Edition. With 132 Illustrations, $5 s$.

XXXIV. ILLUsions: a Psychological Study. By James Sully. Second Edition. 5s.

XXXV. VOLCANOES: what they are and what they teach. By JoHx W. Judd, F.R.S. Third Edition. With 92 Illustrations. $5 s$.

XXXVI. SUICIDE: an Essay on Comparative Moral Statistics. By Professor H. Morsell.. Second Edition. 5s.

XXXVII. THE BRAIN AND ITS FUNCTIONS. By J.LuYs, Physician to the Hospice de la Salpettrière. With numerous Illutrations. Second Edition. 5s.

XXXVIII. MYTH AND SCIENCE: an Essay. By Tito Vignol. Second Edition. 5 s.

XXXIX. T'HE sUn. By C. A. Young, Ph.D., LL.D. Second Edition. With numerous Illustrations. 5s.

London: KEGAN PAUL, TRENCH, \& CO., 1 Paternoster Square. 
XL. ANTS, BEES, and WASPS. A Record of Observations on the Irabits of the Socinl Ifrmenoptern. By Sir Joll Lumbock, Bart, M.P. Seventh Eatition. With 5 Chromo-lithographic Plates, 5s.

XI. ANIMAL INTELLIGENCE. By Grokgh J. Romanks, LL.I), F.I.S. 'Third Edition. 5s.

XIII. The CONCEPTS and THEORIES of MODERN PHYSICS. By J. B. Sralro. Thirl Edition. 5s.

XLIII. DISEASES of MEMORY. An Essay in tho Positivo Psirhology. Bу Th. Rниот. Second Edition. 5s.

TLIV. MAN BEFORE METALS. By N. Jory, Correspondent de l'Institut de France. Third Elition. 5s.

XIV. THE SCIENCE of POLITICS. By Prof. SHridox A.rus. Third Ldition. $5 s$.

XLVI. ELEMENTARY METEOROLOGY. By Ronert $H$. Scorr. Third Edition. 5 s.

XLVII. THE ORGANS of SPEECH. By Grorg Irrmaxit vоч MLEYE?. 5s.

SIVIII. FALLACIES. A View of Logic from the Practical Sido. By AlktiD SIDGWICK. $5 s$.

IIIX. THE ORIGIN OF CULTIVATED PLANTS. By Alimoxse De Canidulie. 5.s.

L. JELLY FISH, STAR FISH, AND SEA URCHINS. Being a Research on Primitive Nervons Systems. By G. J. Romaxis, I.T.I., F.R.S. 5 s.

II. THE COMMON SENSE OE THE EXACT

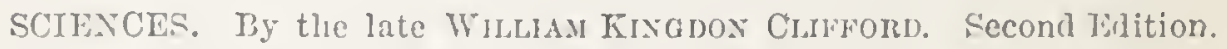
With 100 Figures, 5s.

LII. PHYSICAL EXPRESSION: its Moles and Principles. By Fiaicis Warxir, M.D., F.R.C.P. With 50 Illustrations. 5 s.

LIII. ANTHROPOID APES. By RoIBRT HARTMAN. With 63 Illustrations. 5s.

LIV. THE MAMMALIA IN THEIR RELATION TO

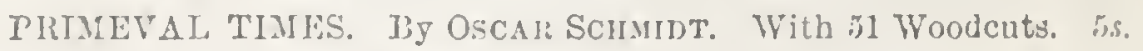

London: KEGAN PAUL, TRENCH, \& CO., 1 Paternoster Square. 


\section{International Soinentific Series.}

VOL. XXVI. 



\title{
THE HUMAN SPECIES.
}

$B Y$

\begin{abstract}
A. DE QUATREFAGES,
MEMBRE DE LiNSTITUT (ACADEMIE DES SCIFACES), ANT FOLEION MEMBER OF THE BOYAT, SOCIETY.
\end{abstract}

THIRD EDITION.

LONDON :

KEGAN PAUL, TRENCH, \& CO., 1, PATERNOSTER SQUARE. 1883. 
[The rights of translation and of reproduction are reserved.] 


\section{CONTENTS.}

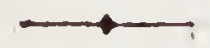

\section{BOOK I.}

UNITY OF THE HUMAN SPECIES.

\section{CHAPTER I.}

EMPIRES AND KINGDOMS OF NATURE.-THE HUMAN KINGDOM.ANTHROPOLOGICAL NETHOD . . . . . . . . 1

\section{CHAPTER II.}

GENERAL ANTHROPOLOGICAL DOCTRINES; MONOGENISM AND TOLYGENISM

CHAPTER III.

gPECIES AND RACE IN THE natural SCIENCES

\section{CHAPTER IV.}

NATURE OF VARIATIONS IN ANIMAL AND VEGETABLE RALE:;

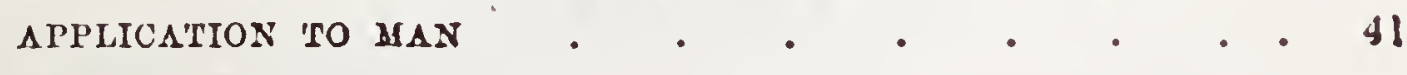

\section{CHAPTER V.}




\section{CHAPTER VI.}

PAQR

IXTERCROSSING AND FESION OF CHARACTERS IN ANIMAL RACES;

APPLiCation tO MAN . . . . . . . . . 56

\section{CHAPTER VII.}

CROSSING OF RACES AND SPECIES IN THE ANIJAL AND VEGETABLE KINGDOMIS.-MONGRELS AND HYBRIDS . . . . . 63

\section{CHAP'TER VIII.}

CROSSING BETWEEN VEGETABLE AND ANIJAL RACES AND SPECIES; MONGRELS AND HYBRIDS; REALITY OF SPECIES . . . T)

\section{CHAPIER IX.}

CROSSIYG BETWEEN HUMAN GROUPS.-UNITY OF TEE HUSAN SPECIES

\section{BOOK II.}

ORIGIN OF THE HUMAN SPECIES.

CHAPTER $\mathrm{X}$.

ORIGIN OF SPECIES.-EYPOTHESES OF TRANSMOTATION.DDARWINISM

\section{CHAPTER XI.}




\section{BOOK III.}

ANTIQUITY OF THE HUMAN SHECILS.

CHAPTER XII.

Parse

AGF OF TIIE HUMAN SIECIES.-PRESENT GEOLOGICAI EPOCH . - I

CHAPTER XIII.

$\triangle G E$ OF THE HUMAN SPECIES.-PAST GEOLOGICAL EPOCH\$ •

- 142

\section{BOOK IV.}

ORIGINAL LOCALISATION OF THE HUMAN SPECIES.

\section{CHAPTER XIV.}

AGASSIZ'S THEORY.-CENTRES OF CREATION . . . . . 154

\section{CHAPTER XV.}

PROGRESSIVE LOCALISATION OF ORGANISED BEINGS.-CENTRES OF APPEARANCE.-ORIGINAL IOCALISATION OF MAN • • . 168

\section{BOOK V.}

PEOPLING OF THE GLOBE.

\section{CHAPTER XVI.}




\section{CHAPTER XVII.}

P.1)K

MIGRATIONS BY SEA.-POLTNESIAN MIGRTIONS.MIGR.TTIONS TO

NEW ZEALAND

- $15 \%$

CHAPTER XVIII.

MiaRATIONS BY SEA.-MIGRATIONS IN AMERICA • • • 199

\section{BOOK VI.}

ACCLIMATISATION OF THE HUMAN SPECIES.

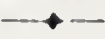

\section{CHAPTER XIX.}

I:FLCENCE OF CONDITIONS OF LIFE AND RACE • • • . 214

CHAP'TER XX.

CONDITIONS OF ACCLIMATISATION • • . • • • • . 224

\section{BOOK VII.}

PRIMITIVE MIAN -FORDLATION OF THE HUMAN RACES.

\section{CHAPTER XXI.}

PRIJITIVE MLAT •

\section{CHAPTER XXIT.}

Formation OF HejaN RACES UNDER THE SOLE INFLUENCE OF CONDITIONS OF LIFE AND HEREDITY • • • • • 24.4

\section{CHAPTER XXIII.}




\section{BOOK VIII.}

FOSSIJ ${ }_{i}$ HUMAN RACES.

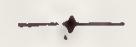

CHAP'TER XXV.

CHAPTER XXVI.

TIIE CANSTADT RACE

\section{CHAPTER XXVII.}

THE CRO-MAGNON RACE

\section{CHAPTER XXVIII.}

RACES OF FURFOOZ .

\section{BOOK IX.}

PRESENT HUMAN RACES.-PHYSICAL CHARACTERS.

CHAPTER XXIX.

GENERAI OBSERVATIONS.-EXTERNAL CHARACTERS . - . 349"

CHAPTER XXX.

ANATOMICAL CFARACTERS

CHAPTER XXXI.

PHYSIOLOGICAL CHARACTERS . - 403

CHAPTER XXXII. 


\section{BOOK X.}

PSYCHOLOGICAL CHARACTERS OF THE IUUAN SPECIES.

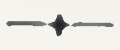

CIIAPTER XXXIII

INTELLECTUAL CHARACTERS TAGE

131

CHAPTER XXXIV.

MORAT, CHARACTERS

\section{CHAPTER XXXV.}

RELIGIOCS CHARACTERS

- $\quad 473$ 


\title{
THE HUMAN SPECIES.
}

\author{
BOOK I. \\ UNITY OF THE HUMAN SPECIES.
}

\begin{abstract}
CHAPTER I.
EMPIRES AND KINGDONS OF NATURE.-THE HUMAN KINGDOM.-ANTHROPOLOGICAL METHOD.
\end{abstract}

I. 'THe naturalist who meets with an object for the first time, instinctively asks the question:-What is this object? This question leads to another:-With what other objects shall I class it? To what group, and, in the first place, to what kingdom does it belong? Is it a mineral, a plant, or an animal ?

The answer is not always easy. We know that, in what may be called the basis of each kingdom, there are ambiguous forms, whose nature has long been, and still is, the subject of contention among naturalists. We know that polyps were long regarded as plants, and that nullipores, at first taken for polyps, are now divided between the vegetable and mineral kingdoms; and, finally, we know that even now, botanists and zoologists dispute over certain diatoms and transfer them from one kingdom to the other.

Similarly the question has been asked:-What is man? and it has been answered from several points of view. To, the naturalist it has but one meaning, and signifies, in which kingdom must man be placed? or hetter : is man an animal? 
In spite of all the differences which a comparison of man with the mammalia presents, should he be classed with them? This question is similar to that which Peysonncl is said to have asked himself, when, struck by the special phenomena presented by the coral, he asked himself whether the object before him was a vegetable.

It is evident that, in order to solve the first problem which arises from a study of the natural history of man, we must have a clear idea what are these great groups of beings, which are called kingdoms; we must give an account of the characters which distinguish and separate them from each other, and then of their true scientific meaning. It will be sufficient for the purpose to explain the well-known laws of Linnæus, supplementing the theory of the immortal Swede by some ideas borrowed from Pallas and de Candolle, and by one of the fundamental conceptions which Adamson and A. L. de Jussieu have almost equally contributed to introduce into science.

II. It is impossible for anyone, whether learned or otherwise, not to recognise at once the difference between two kinds of objects very distinct from each other: inanimate bodies and organised beings. These are the two groups into which Pallas has divided kingdoms under the name of empires. Their distinction is generally easy, and I shall confine myself to recalling some of the most essential differences.

Inanimate bodies, when placed under favourable circumstances, last for an indefinite time, neither taking nor giving anything to the surrounding world; organised beings, under whatever conditions they are placed, only last for a fixed period of time, and, during this existence, undergo every moment losses of substance which they repair by means of materials taken from without. Inanimate bodies, even when they assume the fixed and definite form of crystals, are formed independently of all other bodies resembling them; they have from their commencement fixed forms; and increase simply by superposition of new layers. Every organised being is connected either directly or indirectly 
with a similar being, in the interior of which it first appeared in the form of a germ, theid grew and acquired its definite form by intussusception.

In other words, filiation, nutrition, birth and death, are so many characteristics of the organised being, of which no trace is found in inanimate bodies. I agree with Pallas in making inanimate bodies compose the Inorganic Empire, and organised beings the Organic Empire.

I must here make an observation, the importance of which will be easily understood.

The existence of the two groups which have been recognised by the good sense of the general public as well as by the science of Pallas, is a fact absolutely independent of all hypothesis. Whatever explanation we may propose to account for the differential phenomena which distinguish them, these phenomena will not the less exist; the inanimate body will never be an organised being.

To attempt, under any pretext whatever, to reconcile or confound these two kinds of objects with each other, is to go in direct opposition to all the progress made for more than a century, and especially during the last few years, in physics, chemistry and physiology. It is inexplicable to me that some men, whose merits I otherwise acknowledge, should have recently again compared crystals to the simplest living forms, to the sarcodic organisms, as they were called by Dujardin, who discovered them, and was the first to give a comprehensive theory of them from minute observations. A change of name is useless; the things remain the same, and protoplasm has the same properties as sarcode. The animals, whose entire substance they seem to form, have not altered their nature; whether monera or amœbœ, these forms are the antipodes of the crystal from every point of view.

A crystal, as M. Naudin has well remarked, closely resembles one of those regular piles of shot which may be seen in every arsenal. It only increases from the exterior, as the pile is increased when the soldier adds a fresh layer of shot; 
its molecules are just as immovable as the balls of iron. It is exactly the contrary with the organised being, and the simpler its composition the greater the contrast. The small size of the moneron and the amœba prevents, it is true, certain observations. I appeal, however, to all those naturalists who have studied certain marine sponges in a living state. They must like myself have remarked the strange activity of the vital whirlpool in the semi-sarcodic substance which surrounds their siliceous or horny skeleton; they will have seen the sea water in which they are placed move with a rapidity which it never exhibits when in contact with any other animal.

The reason is that, in the organised being, the repose of the crystal is replaced by an incessant movement; that; instead of remaining immovable and unalterable, the molecules are unceasingly undergoing transformation, changing their composition, producing fresh substances, retaining some and rejecting others. Far from resernbling a pile of shot, the organised being may much rather be compared to the combination of a number of physico-chemical apparatus, constantly in action to burn or reduce materials borrowed from without, and ever making use of their own substance for its incessant renewal.

In other words, in the crystal once formed the forces remain in a state of stable equilibrium, which is only interrupted by the influence of exterior causes. Hence the possibility of its indefinite continuance without any change either of its forms or of its properties. In the organised being the equilibrium is unstable, or rather, there is no equilibrium properly so called. Every moment the organised being expends as much force as matter, and owes its continuance solely to the bulance of the gain and loss. Hence the possibility of a modification of its properties and form without its ceasing to exist.

Such are the bare facts which rest upon no hypothesis whatever; and how can we, in the presence of these facts, compare the crystal which grows in a saline solution to the germ which 


\section{Empires and Kingdoms of Nature.}

becomes in succession embryo, fœtus, and finally a complete animal? How can we confuse the inanimate body with the organised being.

The two groups are easily separated by the phenomena they exhibit. It is the same with the causes of the phenomenon.

Naturalists and physiologists are here divided. Some would have it that the cause, or the causes, are identical, and that conditions, which are almost accidental, alone determine the difference in the results by changing their mode of action. In their opinion the formation of a crystal or of a moneron is only a question of resultant.

Others consider living beings as the result of a cause entirely different from those which act in inanimate bodies, and refer to this cause alone everything which takes place in these beings.

These two methods appear to me, from the exclusive element in each, to be equally ill-founded. It cannot be denied that phenomena identical with those characteristic of inanimate bodies are found in organised beings, and wo have, therefore, no scientific reason to attribute them to different causes.

But organised beings have also their special phenomena radically distinct from, or even opposed to, the former. Is it possible to refer all of them to one, or to several, identical causes? I think not. For this reason, I admit with a great number of eminent men of every age and country, and, I believe, with the majority of those that respect modern science, that organised beings owe their distinctive characteristics to a Special Cause, to a Special. Force, to Life. which in them is associated with the inorganic forces. For this reason I consider it legitimate to call them Living Beings.

I shall often, however, return to this class of considerintions, in order to make it quite clear in what sense I take these words, Force, and Life.

III. The two Empires of Pallas are themselves sub- 
divided into Kingdoms, which are characterised by special facts and phenomena, becoming more and more complicated as we ascend the scale of nature.

And, in the first place, I distinctly admit with de Candolle the existence of a Sidereal Kingdom. To any one who considers, as far as we are able, the little that we know of the universe, the celestial bodies, suns, planets, and comets or satellites only appear as molecules of the great All which fills indefinite Space. One general phenomenon which is unchangeable, however varied in its forms, is, as it were, the attribute of these bodies. All, whether gaseous or solid, obscure or luminous, hot or cold, move within curves of the same nature, obeying the laws discovered by Kepler. It is now well known that fixed sturs do not exist.

In order to explain this phenomenon philosophers have admitted the existence of a force which they have called Gravitation, the effect of which is to precipitate the stars towards one another, as if they mutually attracted each other, whilst obeying the laws of Newton. Now it is well known that the great Englishman himself gave no opinion upon the mode of action of this force, and that he hesitated between the hypothesis of Attraction and that of Impulsion. The first sheuld prevail as being more in accorlance with the immediate results of observation; but the second also has had serious partisans, among whom I will only mention M. de Tessan.

Thus Newton, in spite of all his genius, cannot tell us what was the cause of the movement of the stars; he was not even able to determine the immediate mode of action of this cause; and yet there is not a scientific term more universally received than that of Gravitation, there is not a case in which the expression Force is more generally accepted. 'The reason of this is, that in the presence of general facts and groups of phenomena, it is necessary to make use of terms as simple as possible. We must, however, aroid the delusion of thinking that naming is equivalent to explaining. 
In cases analogous to that of which we have been treating, the word Force merely indicates the presence of an $U_{n}$ known Cause, which gives rise to a group of fixed phenomena. In assigning names to each of the Forces or Unknown Causes to which we consider ourselves able to refer certain groups of phenomena, we facilitate the demonstration and discussion of the facts. The scientific man knows very well that he cannot go beyond this.

It is in this sense, and in this sense alone, that I have used above the expressions Force and Life. Astronomers consider gravitation the unknown cause of the movement of the stars; I consider Life as the unknown cause of the phenomena which are characteristic of organised beings. It may be that both gravitation and Life, as well as the other general forces are merely as $x$, of which the equation has not yet been discovered. I shall presently return to these considerations.

Be this as it may, whatever our real ignorance, whatever the Cause of which we are here treating, and though Impulsion should one day replace Attraction in our Theories, the facts would still remain the same. The stars would still be distributed through space, and subject to the laws of Newton and Kepler; they would still constitute a perfectly distinct whole, in the part assigned to the bodies which compose it, and in the nature of the relations which unite them. They would still form the Sidereal Kingdom.

This kingdom is then characterised by a general phenomenon, the Keplerian Movement, which may be attributed to a single force, namely that of gravitation.

IV. Let us now return to the Earth, the only celestial body which we can study in detail. Modem discoveries, however, judging from the relation of the elements and their mutual action, make it almost certain that the greatest similarity exists between the stars distributed in space, between all those at least which form part of our heavens.

Let us first establish the fact that upon our globe we again meet with the Keplerian Movement in falling bodies. 
Attraction is here represented by Weight. Gravitation reappears with all its laws, acting upon grains of dust as it acts upon worlds. The parts of the whole, of cosmos, as Humboldt would have said, cannot escape from the force which governs the whole.

But upon the surface of our Earth and in its interior, as far as we have been able to penetrate either by direct observation or scientific induction, we notice the appearance of other movements which are not subject to the laws of Kepler or Newton; phenomena appear which are entirely new and perfectly distinct from those due to gravitation. They are the physico-chemical phenomena. From their number and their difference in character they were long attributed to the action of distinct forces which were called Electricity, Heat, Magnetism, etc. Modern science, however, by transforming, so to speak, one into the other, has demonstrated their original unity. Physicists refer them all to nothing more than so many manifestations of the undulations of ether. The vibration of the latter is then the fundamental phenomenon from which all the others rise.

But this ether is absolutely hypothetical; its nature is perfectly unknown; no one knowing whence it acquires this quantity of movement, which, according to actual theory, should be subject neither to increase nor diminution. Now, in reality, we have here the Unknown cause of all physico-chemical phenomena. For this reason, and also for convenience, we shall give a name to this unknown cause, to this force, and call it Etherodynamy (Ethérodynamie).

But is not Etherodynamy only a particular form, a simple modification, or an effect of gravitation? Are not these two forces only different manifestations of a more general force? Many eminent men are much inclined to admit one or other of these hypotheses. Still, up to the present time, the facts do not seem to me to shew much agreement with thern. Etherodynamy is displayed even in space and anong the stars by variable, localised and temporary phenomena; the action of gravitation is one, universal and 


\section{Empires and Kingdoms of Nature.}

constant. Man has always been able to exercise a certain amount of control over the former; he can produce at will iight and heat; modern science cannot act upon the second. We can neither augment nor diminish, reflect or refract, or polarise weight; we cannot arrest its action. Even in the fall of bodies the regularity in the acceleration of the motion proves that the cause of this movement is subject to no alteration. Here then is no transmutation of force similar to that in a machine worked by electricity or heat.

But whatever be the progress of science, and though $M$. de Tessan's theory should be confirmed by experiment, the difference between the phenomena would not be diminished; the conclusions to be drawn from the facts in connection with the question we are here discussing would remain the same.

It is scarcely necessary to remark that the physicochemical phenomena produced by etherodynamy can act upon masses or be exclusively molecular. They are in all cases similar to those which depend upon gravitation, they are subject to invariable laws and are always repeated in a similar manner when produced under similar circumstances.

No antagonism, it is true, exists between gravitation and etherodynamy. It is no less true that the action of the first is always disturbed in a peculiar manner by that of the second, and that in some phenomena it seems as if the latter would neutralise the former. This fact is most strikingly shown in some of the commonest experiments in physics. The gold leaves of the electroscope separate, the pith-balls are attracted towards electrified bodies in spite of their weight, and are repelled with a rapidity greater than that which would result merely from their own weight. And yet these bodies have no more ceased to possess weight than those masses of iron raised by the powerful magnets of M. Jamin. Etherodynamy in these two cases merely overcame gravitation and either modified or imitated its action 
'Those terrestrial bodies which present no other phenomena than those which can be referred to either gravitation or etherodynamy have, since the time of Limmeus, been termed Inanimate Bodies. Together they constitute the Mineral Kingdom. We see that the existence and the distinction of this group are perfectly independent of any hypothesis intended to explain the phenomena.

Two kinds of phenomena then are characteristic of the mineral kingdom: phenomena of the Keplerian movement and physico-chemical phenomena, which may be attributed to the action of two forces: gravitation and etherodynamy.

$V$. The sidereal and mineral kingdoms form the Inorganic Empire. Passing from it we enter the domain of organised and living beings. We have already seen the essential phenomena by which they are distinguished. These phenomena differ essentially from all those which we have observed in inanimate bodies. It seems to me, therefore, necessary to attribute them to a special cause,- to Life.

I know that in the present day any one making use of this word is readily accused by a great number of physicists and chemists, and by an entire physiological school, of introducing into science a vague and almost mysterious expression. There is, however, nothing in it more vague or mysterious than in the word gravitation.

It is very true that we do not know what Life is; but no more do we know what the force is that set the stars in motion and retains them in their orbits. If astronomers have been right in giving to the force, or unknown cause, which gives the worlds their mathematical movements, naturalists have a perfect right to designate by a special term that unknown cause which produces filiation, birth and death.

It will be apparent that my idea of Life is not the same as it was with many ancient vitalists, that it is no more the arche of van Helmont than the vital principle of Barthez. Its function appears to me very different to that attributed 
to it by most of our predecessors, and which is still attributed to it by some physiologists.

Far from merely animating the organs, it is closely associated with the forces of which we have already spoken. Living beings are heavy, and therefore subject to gravitation; they are the seat of numerous and various physico-chemical phenomena which are indispensable to their existence and which must be referred to the action of etherodynamy. But these phenomena are here manifested under the influence of another force. It is for this reason that the results of these phenomena are often quite different to those in inanimate bodies, and that living beings have their special products. Life is not antagonistic to the inanimate forces, but it governs and rules their action by its laws. Therefore it makes them produce tissues, organs and individuals instead of crystals; it organises germs, and maintains through space and time, in spite of the most complex metamorphoses, that unity of definite living forms which we call Species.

If the anti-vitalists would only seriously reflect upon the matter, they would acknowledge that, considered from this point of view, there is nothing more mysterious in living beings than in some of the commonest phenomena presented by inanimate bodies. The intervention of Life as a modifying agent of actions purely etherodynamic may be as easily admitted as that of etherodynamy itself modifying and overcoming the action of weight. It is just as strange to see a piece of iron attracted and supported by a magnet, as to see carbon, oxygen, hydrogen and nitrogen combine and dispose themselves so as to form an animal or vegetable cell instead of any imaginable inorganic composition.

I have repeatedly, and for many years, maintained the doctrine which I have summed up here. It seems to me confirmed in the highest degree by the researches undertaken for the elucidation of the problem of which we are treating. The experiences of M. Bernard in particular, relative to the action exercised by anæsthetics upon plants as well as upon animals, makes it inipossible for us to doubt for a moment 
the intervention of an agent distinct from physico-chemical forces in organic beings. In employing the word Life to designate this agent, I only make use of an established expression, without pretending to go beyond the information gained from experiment and scientific observation.

Beings, in which life alone is added to gravitation and etherodynamy constitute the Vegetuble Kingdom. Now there is one general fact displayed by this group, the significance of which has not, it seems to me, been sufficiently understood. With the exception of certain phenomena of unconscious irritability which have long been known in some plants of a superior order, and of facts, probably of the same class, which have been established chiefly with reference to some reproductive organs of plants of an inferior order, every movement which takes place in plants appears to be produced solely by inanimate forces. The transfer of matter in particular, which is necessary for the developinent and sustenance of every vegetable, belongs to actions of this kind. Can we believe that these forces, as they are known to us from innumerable experiments, could, if left to themselves, have formed an oak, or even raised a mushroom? Can we believe that they could have organised the acorn or the spore, and hidden in those minute bodies the power of reproducing the parent? And yet without thein the vegetable cannot exist. But, in my opinion, nothing makes their real subordination more apparent than the importance of their part in the process of execution. They may be compared to workmen raising an edifice under the eye of the architect who has made the plan.

Are we then to conclude that life is an intelligent force, conscious of the part it plays, and enjoying the dominion it exercises over the subordinate inanimate forces? Not at all. Like these forces, it is ruled by general and fixed laws. Nevertheless, we do not find in the application of these laws, and in the results to which they lead, the mathematical precision of the laws and phenomena of gravitation and etherodynamy. Their mode of action merely seems to oscil- 
late between limits which remain impassable. This kind of liberty, and the bounds imposed upon it, are conspicuous in the constant diversity of the products of life, a diversity which contrasts in so striking a manner with the uniformity of the products of etherodynamy. Crystals, when similar in composition, and when formed under similar circumstances, resemble each other perfectly; but we never find two leaves exactly alike upon the same tree.

The vegetable kingdom is, therefore, characterised by three kinds of phenomena: the Keplerian movement, physicochemical phenomena, and vital phenomena, which may be ascribed to the action of three forces: Gravitation, Etherodynamy, and Life.

VI. We find repeated among animals all the phenomena which we have noticed amongst plants, and, especially in the highest orders, those movements due to unconscious irritability, of which examples are presented by plants. Some eminent men, Lamarck among the number, have even wished to refer all acts performed by inferior animals to this order of phenomena. But here the author of La Philosophie Zoologique has fallen into an anatomical error, which has been long since recognised; and whoever has lived, even for a short time, by the sea-side, or has followed closely the habits and actions of worms and zoophytes will certainly protest against this manner of regarding them.

Passing from the plant to the animal, the latter executes movements belonging either to the part or to the whole which are perfectly independent of the laws of gravitation and etherodynamy. The regulating and determining cause of these movements is evidently within the animal itself. It is the Will. But the Will itself is intimately connected with sensibility and consciousness. To everyone who judges animals by what he finds takes place within himself, personal experiment and observation prove that the animal feels, judges, and wills, that is to say reasons, and consequently is intelligent.

This proposition will, I know, be contested by men whose 
learning I profoundly respect, and objections will be made on all sides. On the one hand the Automatism of Descartes will be revived in some schools, and will now be supporter by physiology and the experiments of vivisection. I am far from denying the great interest which is attached to the latter, and to the phenomena of reflex actions. But the conclusions which are drawn from them appear to me singularly exaggerated; Carpenter has rightly opposed them with personal experiment. I will add that the study of animals placed far below, and certainly inferior to, the frog, would doubtless lead to very different interpretations. Moreover, Huxley himself admits that animals are probably sensible and conscious automata. But if they were merely machines we should be obliged to allow that they performed their functions as if they felt, judged, and willed.

On the other hand, in the name of philosophy and psycho$\log y$, I shall be accused of confounding certain intellectual attributes of the human reason with the exclusively sensitive faculties of animals. I shall presently endeavour to answer this criticism from the standpoint which should never be quitted by the naturalist, that, namely, of experiment and observation. I shall here confine myself to saying that, in my opinion, the animal is intelligent, and, although a rudimentary being, its intelligence is nevertheless of the same nature as that of man. It is, moreover, very unequally distributed among the animal species; in this respect there are many intervening stages between the oyster and the dog.

In addition to the phenomena which spring from the intelligence and reasoning, we find in animals other impulses which arise from Instinct, a blind impulse, or at least apparently so, which often is the characteristic of animal species, and with which each individual is endowed. These two orders of facts are very often confounded, but the confusion can be explained as follows. In the first place, instinct has as its object the attainment of a determined and fixed result, but in the multitude of ways and means necessary to attain this result 


\section{Empires and Kingdoms of Nature.}

a portion which is often very large is due to the intelligence. The distinction is not always easy. It will, moreover, be apparent that I cannot here enter into the details required by the examination of this question, so entirely foreign to that which is before us.

Besides the acts of intelligence and instinct, phenomena have been established among animals which are closely connected with what we call character, sentiment, or passion. The familiarity of the terms is in itself a proof that upon this point ordinary observation has outstripped scientific examination.

All these phenomena are perfectly new and have no analogy with those which we have noticed in the preceding kingdoms. They evidently justify the formation of an equally important group. The animal lingdom is thus universally admitted, independently of every theory which attempts to explain its characters.

Facts radically different cannot be attributed to the same cause. We must admit, then, that the characteristic phenomena of the animal depend upon something different to those met with in the vegetable or mineral kingdoms. They are, moreover, united by such intimate relations, that it would be impossible not to attribute them to a single cause. From motives already mentioned we will give a name to this Unknown Cause, and, making use of an expression already established, though open, I can see, to more than one criticism, we will call it the Animal Mind (l'âme animale).

Does the animal mind liberate the beings it animates from the inferior forces? By no means, for we find them repeated with all their characteristics. In order to raise the least of its organs, the animal must contend with weight; it cannot perform the smallest movement without the intervention of physico-chemical phenomena ; it cannot breathe, and, therefore, cannot live, without constantly consuming some of its constituents. In the animal, moreover, just as much as in the plant, the inanimate forces, etherodynamy especially. 
appear in their donble character of constancy and of ubiquity in the accomplishment of phenomena, and of subordination to life, which governs their action in the animal as in the plant.

Moreover, a large part is reserved for purely vegetative life in animals of the highest order. 'The entire organism is formed without any intervention of the animal mind. Again, a certain number of organs always escape more or less from the influence of the latter, and seem to be subject to life alone. Now these organs are precisely those upon which mutrition, and consequently the constitution and duration of the whole, depend. Thus life, which reigned supreme in the vegetable kingdom, now in its turn, appears in a subordinate character. We might say that it was essentially entrusted with the organisation and maintenance of the instruments of the animal mind.

As to the latter, even where its intervention is most questioned, it is only revealed to observation by voluntary movements. Now personal experiment and the faculty of reasoning, are necessary to enable us to comprehend the nature, and appreciate the signification of these movements. It is only by regarding himself as normal, that man can judge of the animal, a subject to which I shall presently return.

Phenomena of four linds are then characteristic of the Animal Kingdom: phenomena of the Keplerian movement; physico-chemical phenomena; vital phenomena; and phenomena of voluntary movement; attributable to the action of four forces: gravitation, etherodynamy, life, and the animal mind.

VII. Athough the preceding statements are so much abridged, I have thought it well to give the condensed results in the following table: 


\begin{tabular}{|c|c|c|c|c|}
\hline & EMPIRES. & KINGDOMS. & PHENOMENA. & CAUSES. \\
\hline 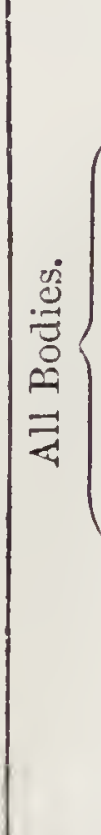 & $\begin{array}{c}\text { Inorganic } \\
\text { (Pallas). } \\
\\
\text { Organic } \\
\text { (Pallas). }\end{array}$ & $\begin{array}{l}\left\{\begin{array}{l}\text { Sidereal } \\
\text { (de Candolie) } \\
\text { Mineral } \\
\text { (Linnieus) }\end{array}\right. \\
\left\{\begin{array}{c}\text { Vegetable } \\
\text { (Linnæus) }\end{array}\right. \\
\begin{array}{c}\text { Animal. } \\
\text { (Limnæus) }\end{array}\end{array}$ & $\begin{array}{l}\left\{\begin{array}{c}\text { Phenomena of the Kep- } \\
\text { lerian movement }\end{array}\right. \\
\left\{\begin{array}{c}\text { Phenomena of the Kep- } \\
\text { lerian movement } \\
\text { Physieo-chemical phe- } \\
\text { nomena }\end{array}\right. \\
\left\{\begin{array}{c}\text { Phenomena of the Kep- } \\
\text { lerian movement } \\
\text { Physico-chemical phe- } \\
\text { nomena. } \\
\text { Vital phenomena. }\end{array}\right. \\
\left\{\begin{array}{c}\text { Phenomena of the Kep- } \\
\text { lerian movernent } \\
\text { Physico-ehemical phe- } \\
\text { nomena. } \\
\text { Vital phenomena : } \\
\text { Phenomenaof : } \\
\text { movement } \cdot\end{array}\right.\end{array}$ & $\begin{array}{l}\text { Gravitation. } \\
\text { Gravitation. } \\
\text { Etherodynamy. } \\
\text { Gravitation. } \\
\text { Etherodynamy. } \\
\text { Life. } \\
\text { Gravitation. } \\
\text { Etherodynamy. } \\
\text { Life. } \\
\text { The Animal } \\
\text { Mind. }\end{array}$ \\
\hline
\end{tabular}

From this table, and the expansions which it sums up, rise the following conclusions.

1. Each kingdom is characterised by a certain number of phenomena, whose existence is independent of all hypothesis and theory.

2. The phenomena increase in number from the sidereal to the animal kingdom.

3. In passing from one kingdom to another, and proceeding from the simple to the composite, a number of phenomena appear, which are entirely unknown in the inferior kingdoms.

4. The superior kingdom presents, independentiy of its special phenomena, the characteristic phenomena of the inferior kingdoms.

5. Each group of phenomena indicated in the table is connected with a small number of fundamental phenomena, which can, in some cases with certainty, in other's with more or less probability, be referred to a single cause.

6. All these causes are equally unknown to us as regards their nature and mode of action. We know them merely by phenomena. We can, therefore, make no conjecture as 
to the relations, more or less close, which may exist between them.

7. We nevertheless give names to these causes for the sake of convenience, and of facilitating the discussion of the facts.

VIII. We can now return to the problem which gave rise to these expansions, and ask the question: Whether Man should take his place in the animal kingdom? a question which evidently leads to another: Is man distinguished from animals by important and characteristic phenomena, absolutely unknown in the latter? For more than forty years I have answered this question in the affirmative, and my convictions, tested by many controversies, are now stronger than ever.

But it is neither in the material disposition, nor in the action of his physical organism, that we must look for these phenomena. From this point of view, man is neither more nor less than an animal. From an anatomical point of vicw, there is less difference between man and the superior order of apes, than between the latter and the inferior orders. The microscope reveals equally striking resemblances between the elements of the human organism and those of the animal organism; and chemical analysis leads to the same result. It was easy to foresee that the action of elements and organs would be exactly the same in man and beast, and such was found to be the case.

Passions, sentiments, and characters, establish between animals and ourselves equally close relations. The animal loves and hates; we recognise in it irritability and jealousy; unwearying patience, and immutable confidence. In our domestic species, these differences are more apparent, or perhaps we only notice them more closely. Who has not known dogs which have been playful or snappish, affectionate or savage, cowardly or courageous, friendly with everybody, or exclusive in their affections.

A gain, man has true instincts, were it only that of suciability. Facnlties, however, of this order, which are so fully 


\section{The Human Kingdom.}

developed in certain animals, in man are evidently very much reduced in comparison with the intelligence.

The relative development of the latter certainly establishes an enormous difference between man and animal. It is not, however, the intensity of a phenomenon which gives value to it from our present point of view, but simply its nature. The question is whether human intelligence and animal intelligence can be considered as of the same order.

As is rule philosophers, psychologists, and theologians, have replied in the negrative, and naturalists in the affirmative. This opposition can be easily understood. The former make the human mind, considered as an indivisible whole, their principal study, and attribute to it ail our faculties. Unable to deny the similarity, external at least, between certain animal and human acts, and yet being anxious to clearly distinguish man from the brute, they have given to the acts different interpretations as they have been performed by one or the other. Naturalists have regarded the phenomena more closely without thinking of anything else, and when they have seen the animal behave in the same manner as they themselves would have done under the given circumstances, they have concluded that the motives of the action must be fundamentally the same. I must ask permission to remain a naturalist, and to recall some facts, and regard them from this point of view.

The theologians themselves allow that the animal possesses sensation, formation and association of images, imagination, and passion (R. P. de Bonniot). They allow that the animal feels the relation of fitness or of unfitness between sensible objects and his own senses; that it experiences sensible attractions and repulsions, and acts perfectly in consequence, and that in this sense the animal reasons and judges (l'Abbé A. Lecomte). Therefore, they add, we cannot doubt but that the animal possesses a principle superior to that of mere matter, and we may even give it the name of mind (R. P. Bonniot). But in spite of all, 
theologians and philosophers maintain that the animal cannot be intelligent, because it has neither innate sense, consciousmess nor reason.

Let us leave for a moment the last term, with which the idea of phenomena which we shall presently discuss, is connected in the mind of our opponents. Is it true that animais are wanting in innate sense, and are not conscious of their actions? Upon what facts of observation does this opinion rest? We each one of us feel that we possess this sense, that we enjoy this faculty. By means of speech we can convey to another the results of our personal experience. But this source of information is wanting when we come to deal with animals. Neither in them nor in ourselves are innate sense and consciousness revealed to the outer world by any special characteristic movement. It is, therefore, only by interpreting these movements, and by judging from oursclves, that we can form an idea of the motives from which the animal acts.

Proceeding in this manner, it seems to me impossible to refuse to allow animals a certain amount of consciousness of their actions. Doubtless, they do not form such an exact estimate of them, as even an illiterate man can do. But we may be very certain that when a cat is trying to catch sparrows on level ground, and creeps along the hollows, availing herself of every tuft of grass however small, she knows what she is about, just as well as the hunter who glides in a crouching attitude from one bush to another. We may be equally sure that kittens and puppies when they fight, growl and bite without hurting each other, know very well that they are playing and not in earnest.

I must here beg permission to relate the remembrance of my struggles with a mastiff of pure breed, and which had attained its full size, remaining, however, very young in character. We were very good friends, and often played together. As soon as ever I assumed an attitude of defence before him, he would leap upon me with every appearance of fury, seizing in his mouth the arm which I liad used 


\section{The Human Kingdom.}

as a shicld. He might have marked my arm deeply at the first onset, but he never pressed it in a manner that could inflict the slightest pain. I often seized him by his lower jaw with my hand, but he never used his teeth so as to bite me. And yet the next moment the same teeth would indent a piece of wood, I tried to tear away from them.

This animal evidently knew what it was doing when it feigned the passion precisely opposite to that which it really felt; when, even in the excitement of play, it retained sufficient mastery over its movements to avoid hurting me. In reality it played a part in a comedy, and we cannot act without being conscious of it.

It is useless for me to insist upon many other facts which I could bring forward, and I refer my reader to the works of those naturalists who have studied the question, especially those of F. Cuvier. But the more I reflect upon it, the more is my conviction confirmed that man and animals think and reason in virtue of a faculty which is common to both, and which is only far more developed in the latter than in the former.

What I have just said of the intelligence I do not hesitate to say also of language, the highest manifestation of the intelligence. It is true that man alone possesses speech, that is to say the articulate voice. But two classes of animals possess voice. With us it is, again, only a high degree of perfection, nothing radically new. In both cases the sounds, produced by the air which is thrown into vibration by the voluntary movements accorded to the larynx, convey impressions and personal thoughts. which are understood by individuals of the same species. The mechanism of the production, the object and the result are fundamentally the same.

It is true that the language of animals is most rudimentary and, in this respect, in harmony with the inferiority of their intelligence. We might say that it was almost entirely composed of interjections. Such as it is, however, this 
language is sufficient for the wants of the mammalia and birds who understand it perfectly, while man himself can learn it without very much trouble. The hunter can distinguish the accents of anger, love, pleasure, sorrow, the call and the signal of alarm and makes use of these indications as an unfailing guide, and often imitates these accents and cries in such a manner as to deceive the animal. Of course I exclude from the language of brutes, the song, properly so called, of birds, that of the nightingale for example. It appears to me void of all meaning, as are the notes of a singer, and I do not believe in the interpretation of Dupont de Nemours.

It is not, therefore, in the phenomena connected with the intelligence that we shall find the basis of a fundamental distinction between man and animals.

But in man the existence has been proved of fundamental phenomena of which nothing either in living beings or inanimate bodies has hitherto been able to give us any conception. 1st. Man has the perception of moral good and evil independently of all physical welfare or suffering: 2nd. Man believes in superior beings who can exercise an influence upon his destiny. 3rd. Man believes in the prolongation of his existence after this life.

The last two phenomena have always been so closely connected that it is natural to refer them to the same facilty, to that namely of Religion. The first depends on Morality.

Psychologists attribute religion and morality to the reason, and make the latter an attribute of man. But with the reason they connect the lighest phenomena of the intelligence. In my opinion, in so doing they confound and refer to a common origin, facts entirely different. Thus since they are unable to recognise either morality or religion in animals, which in reality do not possess these two faculties, they are forced to refuse them intelligence also, although the same animals, in my opinion, give decisive proof of their possession of this faculty every moment. 
The generality of the phenomena which we are discussing is, I believe, indisputable, especially since the investigation to which it has been subjected by the Society of Anthro- pology in Paris, where the question of the human kingdom - has been long and seriously discussed. I cannot hore reproduce the discussion, even in an abridged form, but refer my readers either to the summary in my Rapport sur les progrès de l'anthropologie en France, or to the Bulletins of the Society. I shall, moreover, go into this subject in some detail in the chapters devoted to the moral and religious characters of the human races.

A host of manifestations of human activity are derived, as so many consequences, from the three facts which I have pointed out. Customs and institutions of every lind are connected with them; they alone explain some of the great events which change the destiny of nations and the face of the earth.

For reasons which I have several times pointed out already, we must give a name to the Unknown Cause from which are derived the phenomena of morality and religion. We will call it the Human mind (l'âme humaine).

I must here repeat the formal declaration which I have often made already. When I employ this term, which is established by custom, it is with the understanding that I strictly confine myself within the limits imposed upon anyone who intends to be exclusively faithful to science, experiment and observation. I consider the human principle as the Unknown Cause of exclusively human phenomena. To go beyond that would be to encroach upon the domain of philosophy or theology. To them belongs the solution of the formidable problems raised by the existence of the 'something' which makes a man of an organism entirely animal, and I give everyone leave to choose from the proposed solutions the one which agrees most satisfactorily with the demands of his own feelings and reason.

But whatever this solution may be, it will in no way affect the phenomena; those which I have just described will 
neither be diminished nor modified. Now they exist in marı alone, and it is impossible to deny their importance. Thus they distinguish man from the animal as much as the phenomena of intelligence distinguish the animal from the plant, and as the phenomena of life distinguish the plant from the mineral. They are, therefore, the attributes of a lingdom, which we will call the Human Kingdom.

From this conclusion it will seem that $I$ am at variance with Linnæus, whose idea I have, however, only developed and stated more precisely. In fact, the immortal author of the Systema Naturce has placed his Homo sapiens amongst the mammalia in the class of primates, and has made lim congenous with the gibbon. This is because Linnæus had recourse to the System in order to establish his nomenclature. To classify man as well as other beings, he has made an arbitrary choice of a certain number of characteristics, and only taken those into consideration which were furnished by the body.

But the language of Linnaus is very different, even in his remarks relating to the genus Homo, and still more so in the kind of introduction entitled Imperium Naturce. He there almost places man in opposition with all beings, and particularly with animals, and in such terms as necessarily to suggest the idea of a human lingdom.

The reason of this is that here Linnwus no longer speaks of pliysical man, but of man as a whole. Now, thanks to the labours of Adanson, Jussieu and Cuvier, naturalists now know that this is the right course to pursue in judging of the relations which exist between beings. The Natural Method no longer allows the choice of such or such a group of characteristics; it demands, together with an appreciation of their relative value, a consideration of all. It is on this account that I have been led to admit the existence of this human kingdom, which has been already proposed under several appellations by some eminent men, but to which I believe myself to have given a more precise and rigorous determination. 
The table given above must then be completed in the following manner :-

\begin{tabular}{|c|c|c|}
\hline & PHENOJIENA. & CAUSES. \\
\hline $\begin{array}{l}\text { Human } \\
\text { Kingdom }\end{array}$ & $\left\{\begin{array}{l}\text { Phenomena of the Keplerian morement } \\
\text { Physieo-chemical phenomena. } \\
\text { Vital phenomena } \\
\text { Phenomena of roluntary morement } \\
\text { Phenomena of morality and religion }\end{array}\right.$ & $\begin{array}{l}\text { Gravitation } \\
\text { Fitherodynamy } \\
\text { rife } \\
\text { Animal mind } \\
\text { Human mind }\end{array}$ \\
\hline
\end{tabular}

Thus in the human kingdom we find by the side of the phenomena which characterise it all those which we have met with in the inferior kingdoms. We are consequently forced to admit that all the forces and all the unknown causes to which we have attributed these effects are acting in man. From this point of view man deserves the name which has sometimes been given to him of microcosm.

We have seen that in the vegetable kingdom the inanimate forces perform their functions under the control, so to speak, of Life, which afterwards, in the animal, showed incontestable signs of its subordination to the animal mind. Life now appears under similar conditions with regard to the human mind. In the most characteristic human actions, the intelligence almost always plays the most prominent part from the executive point of view; but it is manifestly under the direction of the human mind. All legislation affects to rest upon the one foundation of morality and of justice, which is only a form of it; the immediate cause of the Crusades, of the spread of the Arabs, and the conquests of Islam, was religious fervour. The true Jegislator and the great leader are indeed necessarily men of high intelligence, but is it not clear that in the cases mentioned the intelligence has been placed at the service of morality or of religion, and consequently of the Unknown Cause to which man owes these faculties?

But however preponderating the part claimed by this 
Bause in acts exclusively human may be, it has nothing to do with those phenomena which have their origin in the intelligence alone. The learned mathematician who seeks by the aid of the most profound abstractions the solution of some great problem, is completely without the moral or religious sphere into which, on the contrary, the ignorant, simpleminded man enters when he struggles, suffers, or dies for justice or for his faith.

IX. It was necessary to recall all the facts and theories which I have just summed up, in order to facilitate the comprehension and the justification of the method which alone can guide us in anthropological studies.

The object of anthropology is the study of man as a species. It abandons the material individual to physiology and medicine; the intellectual and moral individucl to philosophy and theology. It has, therefore, its own special field of study, and on that account alone its special questions, which often could not be solved by processes borrowed from cognate sciences.

In fact, in some questions, and in some of the most fundamental ones, the difficulty lies in the interpretation of phenomena connected with those which are characteristic of all living beings. For the very reason that they are to a certain extent obscure in man, we cannot seek for an explanation of them in man, since he becomes, so to speak, the unknown quantity of the problem. An endeavour to solve the problem by the study of man, who is the object of it, would be equivalent to a mathematician representing the value of $x$ in terms of $x$ itself.

How does the mathematician proceed? He seeks in the data of the problem for a certain number of known quantities equivalent to the unknown quantity, and by means of these quantities he determines the value of $x$.

The anthropologist must act in the same manner. But where must he seek for the known quantities which will enable him to state the equation?

'The answer to this question will be found in what we have 
said above, and in the table of kingdoms. Man, although he has his special and exclusively human phenomena, is above all an organised and living being. From this point of view he is the seat of phenomena common to animals and plants; he is subjected to the same laws. In his physical organisation he is nothing more than an animal, somewhat superior in certain respects to the most highly developed species, but inferior in others. From this point of view he presents organic and physiological phenomena identical with those of animals in general, and of mammalia in particular; and the laws which govern these phenomena are the same in both cases.

Now plants and animals have been studied for a much longer period than man, and from an exclusively scientific point of view, without any trace of the prejudice and party feeling which often interferes with the study of man. Without having penetrated very deeply into all the secrets of vegetable and animal life, science has acquired a certain number of fixed and indisputable results which constitute a foundation of positive knowledge, and a safe starting point. It is there that the anthropologist must seek the known quantities of which he may stand in need.

Whenever there is any doubt as to the nature or signification of a phenomenon observed in man, the corresponding phenomena must be examined in animals, and even in plants; they must be compared with what takes place in ourselves, and the results of this comparison accepted as they are exhibited. What is recognised as being true for other organised beings cannot but be true for man.

This method is incontestably scientific. It is similar to that of modern physiologists, who, since they are unable to experiment upon man, experiment upon animals, and form their conclusions upon the former from the latter. But the physiologist devotes his attention to the individual only, and, therefore, examines little more than those groups which in their organisation approach most nearly to the being whose history he wishes to explain. The anthropologist on the con- 
trary studies the species. The questions with which he has to deal are much more general, so he is forced to direct his attention to plants as well as to animals.

This method is accompanied by its criterion; it allows the control of the various answers which are often made to one question. The means of estimation are simple and easily applied.

In anthropology, every solution to be sound, that is to say, true, should refer man in everything which is not exclusively human to the general recognised laws for other organised and living being6.

Every solution which makes or tends to make man an exception, by representing him as free from those laws which govern other organised and living beings, is unsound and false.

Again, when we reason and form our conclusions in this manner, we remain faithful to the mathematical method. To be received as true, a solution of a given problem must agree with admitted axioms, with truths previously proved. Every hypothesis which leads to results at variance with these axioms or these truths, is, on that account alone, declared false. In anthropology, the axiom or the truth which serves as a criterion is the fundamental, physical, and physiological identity of man with other living beings, with animals, with mammalia. All hypotheses at variance with this truth should be rejected.

Such are the absolute rules which have always acted as my guide in anthropological studies. I do not pretend to have invented them. I have scarcely done more than formulate what has been more or less explicitly admitted by Linnæus, Buffon, Lamarck, Blumenbach, Cuvier, the two Geoffroy St. Hilaire, J. Miiller, Humboldt, etc. But, on the one hand, my illustrious predecessors have seldom treated the subject with sufficient precision, and have too often omitted to give the reasons for their decisions. On the other hand these principles have been, and are daily forgotten by men who, in other respects, enjoy with 
justice the title of great authorities. As I shall be compelled to disagree with them, I thought it necessary to show clearly the general ideas which serve as a foundation for my own scientific convictions. The reader will thus be able to appreciate and discern the causes of this difference of opinion. 


\section{CHAP'IER II.}

\section{GENERAL ANTHIOPOLOGICAL DOC'TRINES; MONOGENISM}

AND POLYGENISM.

I. As soon as we have determined the place which should be assigned to man in the great order of the universe, the first question which rises is, whether there is one human species, or several.

It is well known that this question has caused a division amongst anthropologists. The Polygenists regard the differences of height, features, and colour, which distinguish the inhabitants of different countries of the globe, as fundamental; the Monogenists consider these differences merely as the result of accidental conditions, which have modified, in various degrees, a primitive type. The former hold that there are several human species perfectly independent of each other; the latter that there is but one species of man which is divided into several races, all of which are derived from a common stock.

However slight may be our familiarity with the language of zoology and botany or their applications, it is evident that the question before us is a purely scientific one, and entirely within the province of the natural sciences. Unfortunately the discussion has by no means been confined to this ground.

A dogma supported by the authority of the Book which is held in almost equal respect by Christians, Jews and Mussulmars, has long referred the origin of all men without opposition to a single father and mother. Nevertheless, the first blow aimed at this ancient belief was founded upon the same book. In 1655 La Peyrère, a Protestant gentle- 
man in Conde's army, interpreting to the letter the two narratives of the creation contained in the Bible as well as various particulars in the history of Adam and of the Jewish nation, attempted to prove that the latter alone were descended from Adam and Eve; that they had been preceded by other men who had been created at the same time as the animals in all parts of the habitable globe; that the descendants of these Preadamites were identical with the Gentiles, who were always so carefully distinguished from the Jews. Thus we see that polygenism generally regarded as the result of Free Thouglut was biblical and dogmatic in origin.

La Peyrère attacked the Adamic dogma in the name of the respect due to the text of a sacred Book. The philosophers of the eighteenth century spoke in the name of Science and Reason. It is to them that the school of Polygenists in reality owe their origin. But it is easy to see that the greater number of them were only guided in their writings by a controversial spirit, their chief aim was the destruction of a rogma. Unfortunately, the same prepossession appears in too many works published in our own day. On the other hand certain monogenists are guilty of seeking in religious doctrines arguments in favour of their theory, and anathematising their adversaries in the name of dogma.

Social and political prejudices in addition to dogmatic and anti-dogmatic prejudices have helped to make still more obscure a question already very difficult in itself. In the United States in particular the advocates of slavery and its opponents have often fought upon this ground. Further still in 1844 Mr. Calhoun, Minister of Foreign Affairs, when replying to the representations made to him by France and England on the subject of slavery, did not hesitate to defend the institutions of his country by urging the radical differences, which, according to him, separated the Negro from the White man.

Besides those polygenists who are influenced by pre- 
judices almost or entirely unscientific, there are sincere and disinterested men of science who believe in the multiplicity of human origins. Foremost among the latter are medical men, who are accustomed to the study of the individual and who only possess a slight familiarity with the study of the species. Then again there are palrontologists, who from the nature of their work are compelled only to take into account morphological resemblances and differences, without even turning their attention to facts of reproduction or of filiation. Finally, there are entomologists, conchologists, etc., who, exclusively interested in the distinction of innumerable species by purely external characters, are entirely ignorant of physiological phenomena, and judge living beings as they would fossils.

On the other hand, monogenism reckons among its partisans nearly all those natuialists who have turned their attention to the phenomena of life, and among them some of the most illustrious. In spite of the difference of their doctrines, Buffon and Linnæus, Cuvier and Lamarck, Blainville and the two Geoffroys, Müller the physiologist and Humboldt agree upon this point. Apart from any influence which the name of these great men might exercise, it is clear that I share their opinion. I have on different occasions explained the purely scientific reasons for my convictions. I shall now endeavour to sum them up in as few words as possible.

II. Let us first establish the importance of the question. It escapes many minds and I have heard a doult expressed upon it by men who have enthusiastically followed anthropological studies. It is, however, easily proved.

If the human groups have appeared with all their distinctive characters in the isolated condition, and in the various localities where geography teaches us to seet them; if we can trace them up to stocks originally distinct thus constituting so many special species, then the study of them is one of the most simple, presenting no more difficulty than that of animal or vegetable species. There 
would be nothing singular in the diversity of the groups. It would be sufficient to examine and describe them one after the other, merely determining the degree of affinity between them. At most we should have to fix their limits and to discover the influence which groups geographically brought in contact had been able to exercise upon each other.

If, on the contrary, these groups can be traced to one common primitive stock, if there is but one single species of man, the differences, sometimes so striking, which separate the groups, constitute a problem similar to that of our animal and vegetable races. Further, man is found in all parts of the globe, and we must account for this dispersion; we must explain how the same species has been able to accommodate itself to such opposite conditions of existence as those to which the inhabitants of the pole and the equator are subject. And lastly, the simple affinity of naturalists is changed into consanguinity; and the problems of filiation are added to those of variation, migration, and acclimatisation.

It is clear that, independently of every religious, philosophical, or social consideration, this science will differ entirely in character as we consider it from a polygenistic point of view, or according to theories of monogenism.

III. If the former of these doctrines claims such a large number of adherents, the reason may for the most part be found in the causes mentioned above. But its seductive simplicity and the facility which it seems to lend to the interpretation of facts also stand for a great deal. Unfortunately these advantages are only apparent. Polygenism conceals or denies difficulties; it does not suppress them. They are suddenly revealed, like submarine rocks, to anyone who tries, however little, to go to the root of the matter.

The case is the same with this doctrine as with the Systems of classification formerly employed in botany and zoology which rested upon a small number of arbitrary data. They were undoubtedly very convenient, but possessed the serious 
fault of being conducive to most erroneous opinions from is destruction of true relations and an imposition of false connections.

Nonogenism acts in the same manner as the Natural Method. The zoologist and the botanist are by this metlod brought face to face with each problem which is put before them under every aspect. It often displays the insufficiency of actual knowledge, but it is the only means of destroying illusions, and of preventing a belief in false explanations.

It is the same with Monogenism. It also brings the anthropologist face to face with reality, forces him to investigate every question, shows him the whole extent of each, and often compels him to confess his inability to solve them. But by this very means it protects him against error, provoking him to fresh investigation, and from time to time rewards him with some great progress which remains an acquisition for ever.

I shall return to these considerations, the truth of which will be better understood when the principal general questions of anthropology have been reviewed. Henceforward I shall attempt to justify as briefly as possible the precedinir criticisms and eulogics. 


\section{CHAPTER III.}

SPECIES AND RACE IN THE NATURAL SCIENCES.

I. The question of the unity or multiplicity of the human species may be stated in the following terms: are the differences which distinguish the human groups characteristic of species or of race?

It is evident that the question depends entirely upon the two words species and race. It is then absolutely necessary to determine as accurately as possible the sense of each, and yet there are anthropologists, such as Knox, for instance, who declare that any discussion or investigation in connection with this subject is idle. There are others, like Dr. Nott, who would suppress the race and only establish various categories of species. In order to support their doctrines these authors ignore the work which has been carried on for nearly two centuries by the most illustrious naturalists, and the innumerable observations and experiments made by a vast number of eminent men upon plants and animals.

In fact the theory of species and race has not been formed $\grave{a}$ priori, as it has been too often falsely asserted, but has been gradually acquired, and in a strictly scientific manner.

II. The word Species is one which exists in all languages which possess abstract terms. It represents, therefore, a general common idea. The idea is, in the first place, that of a great outward resemblance; but even in ordinary language: that is not all. The idea of filiution is connected, even in the most uncultivated minds, with that of resemblance. No peasant would hesitate to regard the children of the same parents as belonging to the same species whatever real or apparent differences might distinguish them. 
Science has in reality done nothing more than define the idea of which the public harl merely a vague consciousness, and it was not till very lately, and after a very curious oscillation, that she succeeded in doing so. In 16is6, Jean Ray, in his Historia Plantamm, considered that those plants which had a common origin and could be reproduced by seed belonged to the same species, whatever their apparent differences might be. He only took filiation into account. 'Tournefort, on the contrary, who in 1700 was the first to make a clear statement of the question, termed the collection of plints a species which were distinguished by some particular character. He relied only on resemblance.

Ray and 'Tournefort have had from time to time a few imitators, who, in their definition of species, have clung to one of the two ideas. But the immense majority of zoologists have been aware of the impossibility of separating: them. 'To convince ourselves of this fact it is only necessary to read the definitions which they have given. Each one of them, from Buffon and Cuvier to MM. Chevrenl and C. Vogt has, so to speak, proposed his own. Now, however they may liffer in other respects, they all agree in this. The terms of the definitions vary, each endeavours to represent in the best manner possible the complex idea of species; some extend it still further, and connect with it the ideas of cycle and rariation: but in all the fundamental idea is the same.

In a case of such difficulty as that of finding a good definition for a combination of ideas, the latest comer always hopes to improve upon his predecessors. For this reason I have also given my formula: "Species is a collection of individuals more or less resembling each other, which may be regarded as having descended from a single primitive pair by an uninterrupted and natural succession of families."

In this definition, as also in that of some of my colleagues, among others of M. Chevreul, the idea of resemblance is made of less importance and subordinate to that of filiation. The fact is that there never is an identity of characters between one individual and another. Putting aside the 
variations resulting from age and sex, it is at once evident that all representatives of the same specific type differ in some points. Although these differences are very slight, they constitute individual traits, shades as Isidore Geoffroy said, which enable us to distinguish between two of the same species.

But the differences are not confined within these limits. The specific types are variable, that is to say, every kind of physical character is modified in their derivatives and, under the influence of certain conditions, to such an extent as to make it often very difficult to recognise their unity of origin. This, again, is a fact upon which all naturalists agree. Blainville even, who, defined species as "the individual repeated and continued through time and space," distinctly recognised this variability; for the individual is perpetually undergoing modification, and does not retain its similarity during the various stages of life. He admitted, moreover, the existence of distinct races.

The variability of species has also been the subject of animated discussion among naturalists. The memorable contention which arose upon this subject between Cuvier and Geoffroy is not yet forgotten, a struggle considered by Goethe as more important than the gravest political events. In the present day a school to which many of the most illustrious names in England, Germany and elsewhere belong, has taken up, with certain modifications, the ideas of Lamarck and Geoffroy; it gives support to them from retaining the term variability of species.

There is a grave confusion of words in this formula. Lamarck, Geoffroy, Darwin and his school, consider the species not only as variable but as transmutable. The specific types are not merely modified, they are replaced by new types. Variation is in their estimation only a phast: of the very different phenomena of transmutation.

I shall discuss these theories presently. I shall now confine myself to the remark that true variability, admitted even by the defenders of dogmatic invariability, by Blain- 
ville, for example, a variability which I fully accept, has nothing in common with the transmutability of Lamarck, Geoffroy and Darwin. Let us briefly determine the limits of this variability.

III. When an individual trait is exaggerated and passes a limit always very loosely defined, it constitutes an exceptional character which clearly distinguishes the individual aftected by it from all those most nearly resembling it. This individual constitutes a Variety.

The same term must be applied to all those individuals, which, like certain plants reproduced by slips, grafts, or shoots, derive their origin from the first exceptional individual, without having the power of transmitting their distinctive characters by means of normal generation. I borrow from M. Chevreul a curious example of these multiple verieties. In 1803 or 1805, M. Descemet discovered in his garien at Saint Denis, in the midst of a bed of acacias (Robinia pseudo-acucia) an individual without thorns which he describes under the epithet spectabilis. It is to the multiplication of this individual by the art of the gardener that all the thom mess acacias, now distributed over every part of the globe, owe their origin. Now these individuals produce seeds, but if the seeds are sown they only yield thomy acacias. The acacia spectabilis has remained a Variety.

The latter may then be defined as:- "An individual or a number of individuals belonging to the same sexual generation, which is distinguished from the other representatives of the same species by one or several exceptional characters."

It will readily be scen how great the number of varieties in one species may be. 'There is, in fact, scarcely any either external or internal part of an animal or plant, which cannot be exaggerated, diminished or modified in a thousand ways, and each of these exaggerations, diminutions or modifications will characterise a fresh variety, with the one condition of its being sufficiently marked. 
IV. When the characters peculiar to a variety become hereditary, that is to say, when they are transmitted from generations to the descendants of the first modified individual, a race is formed. For example, if a thornless acacia ever reproduced by seed, trees resembling itself and enjoying the same power, then the Acacia spectabilis would cease to be a simple variety, and would have become a race.

The race, then, will consist of :- " A number of individuals resembling each other, belonging to one species, having received and transmitting, by means of sexual generation, the characters of a primitive variety.

Thus the Species is the point of departure; the variety appears amongst the individuals of which it is composed, and, when the characters of this variety become hereditary, a race is formed.

Such are the relations which, according to all naturalists, "from Cuvier to Lamarck himself," as Isidore Geoffroy said, exist between these three terms. We have here a fundamental idea which we should never lose sight of in the study of the questions with which we are engaged. From neglect of it men of the highest distinction have failed to understand most significant fircts.

We see that the idea of resemblance, which is much curtailed in the species, reassumes in the race an importance equal to that of filiation.

We see also that the number of races which spring directly from one species may be equal to the number of varieties of the same species, and consequently very considerable. But this number has a tendency to increase still further to an indefinite extent. In fact, each of these primary races is susceptible of fresh modifications, which may either extend no further than one individual, or become transmissible by means of generation. Thus secondary and tertiary varieties or races come into existence. Our plants and domestic animals furnish innumerable examples of these facts.

$\mathrm{V}$. By reason of races originating in this manner from one another, and from their multiplication, they may assume 
differential characters which become more and more decided. But however numerous they may be, and whatever differences there may be between them, and however far they may secm to be removed from the primitive typc, they nevertheiess, still form part of the species from which the primitive races derived their origin.

On the other hand, every species comprises, independently of the individuals which have preserved their primitive characters, all those, which compose the primary, secondary and tertiary, etc., races, derived from the fundamental type.

In other words the species is the unit and the races are the fractions of this unit. Or again, the species is the trunte of the tree, of which the several series of races represent the principal and lesser branches and the twigs. The general unity and relative independence of the trunk and the branches of the tree represent in an obvious manner the connections existing between the species and its races. 


\section{CHAPTER IV.}

NATURE OF VARIATIONS IN ANIMAL AND VEGFTABLE. RACES; APPLICATION TO MAN.

I. 'l'He meaning of the question stated above is now intelligible. We have to discover whether the human groups, which we know to be distinguished by characters which are often very marked, are fractions of a single unit, branches of the same tree, or so many units of different value, so many trees of various nature.

Historical documents are absolutely incapable of solving this problem. On the other hand, man being the subject of the problem, it is evident that the solution must be sought elsewhere.

Where then must we turn in order to obtain a definite answer to this question which concerns us so closely? Clearly to naturalists and to naturalists alone. The Species and the Race have, for more than two centuries, been the subject of their studies; they have amassed observations, multiplied experiments. They have, in their studies, been guided by a scientific spirit alone, and from being placed beyond the reach of controversy, have preserved all their freedom of judgment. The results thus acquired, deserve the greatest confidence, and supply reliable data for the application of our anthropological method.

Anyone really desirous of forming an opinion upon the unity or multiplicity of the human species, should therefore discover what are the facts and phenomena which characterise race and species in plants and animals; then turn to man and compare the facts and phenomena there presented with those which botanists and zoologists have observed in 
the other kingdoms. If the facts and phenomena which distinguish the human groups are those which, in other organised and living beings differentiate species, he will then legitimately infer the multiplicity of human species; if, however, these phenomena and facts are characteristic of race in the two inferior kingdoms, he must conclude in favour of specific unity.

It is the pursuance of this course which has convinced me of monogenism, and I am certain the result will be the same with anyone who will follow it.

II. The idea of species rests, as we have seen, upon the two distinct ideas of resemblance and filiation. Let us first turn our attention to the former as being the greater stumbling-block of the two. No one would hesitate to consider two individuals resembling each other very closely as belonging to the same species; if, however, they present somewhat marked differences, and the necessirly information is wanting, we hesitate to give our decision in the negative. The mind readily accepts the latter conclusion when man is the object of discussion. A continual, though unconscious study, has endowed us with a perception which appreciates, in those around us, the most delicate gradations in features, the colour of the skin, and in the appearance of the hair. Now this delicacy of appreciation has, in the present instance, a serious inconvenience. It inevitably conduces to the exaggeration of differences existing between different groups, and by this very means leads us to regard them as so many species.

For this decision to have a real value, however, it should be shown beforehand that the variations between one human group and another, are greater than those which have been established between groups of animals and plants, which are positively known to be only races of one species.

Now this is not the case. However slight an attempt we may have made to become acquainted with the nature and the extent, of variations, we shall very soon see that in animal and regetable races they attain limits, which are never over- 
stepped, and but rarely attained, by the differences between numan groups.

III. I shall not insist at any length upon the morphological and anatomical changes of plants. It will be sufficient to call to mind how numerous and different are those varieties of vegetables, flowers, fruit-trees, and ornamental shrubs, the number of which is always on the increase. Amongst the latter, the variety, it is true, very rarely attains to the condition of a race. Grafting, propagation by layers, etc., make it possible to multiply them rapidly and with certainty, as in the case of the thornless acacia, and gardeners have always been in the habit of resorting to this method. Nevertheless, even among fruit trees, a few of these varieties have become fixed, and can be reproduced by seed. The plum, the peach, and the vine, may be quoted as examples. As to annuals, garden vegetables especially, they can only be preserved and multiplied by this method. Here we only find races, and it is well to know how numerous and varied they are. The cabbage alone (Brassica oleracea) numbers forty-seven principal races, each of which is sub-divided into a number of secondary and tertiary races. Now it is quite useless to insist upon the distance which separates the headed cabbage, of which sauerkraut is made, from the turnip-cabbage, of which the root is eaten, and from the cauliflower or the brocoli

It is very evident that this camot be due to the mere alteration of primitive forms. The elements of the organism undergo modification, and are differently associated and combined according to the race. But these elements themselves often undergo most fundamental disturbance. Certain acids are diminished or disappear, and are replaced by sugar, a sweet taste and perfume, which develop and characterise certain races of vegetables and fruits, and show that the vital forces of these plants have been subjected to very substantial modifications faithfully transmitted from generation to generation.

The objection will perhaps be made that there is too little resemblance between vegetable and animal organisms for the 
above comparison of anatomical facts to be really useful. It is different in physiological phenomena.

Vital activity in our cultivated plants sometimes presents very remarkable differences in different races. In our several races of corn, the rapidity of development varies from simple to triple. In temperate climates barley requires five months to germinate, grow and ripen. In Finland and Lapland it only takes two months to accomplish the same phases of growth. And, finally, it is well known that in our kitchen and fruit gardens we find races and varieties, some of which are fast and some slow growers.

The energy of the reproductive organs often varies in a singular manner in different races. We have, for instance, roses which bloom two or three times a year, and strawberries which remain in fruit nearly the whole year. There are oranges crammed with pips, and others in which they are almost entirely wanting. Lastly, in some bananas and in the currant-grape the seeds have completely disappeared. We see at once that these latter products of human industry only exist as varieties.

IV. In animals we meet with facts which correspond exactly with those which we have just observed in plants. Further, we find that they experience modifications connected with the manifestations of the something which we have called the Animal Mind.

The diversity of races in our domestic species is too well known to make it necessary to insist upon this point. I shall only mention that Darwin reckons 150 distinct races of pigeons, and declares that he is not yet acquainted with all. These races are, morcover, sufficiently different to render a redivision into at least four distinct genera necessary, if they are considered as so many species. Among mammals analogous facts are noticed, in the case of the dog. At the Dog Show of 1863, the Society of Acclimatisation, which had been very strict in its rules of admission and only received perfectly pure types, collected no fewer than seventy races of dogs. 'The greater number, however. 
belonged to Europe, and to France and England in particular; almost all those of Asia, Africa, and America, were absent from the collection, so that altogether we are justified in assuming that there are at least as many races of dogs as of pigeons. As to morphological differences we need only mention bull-dogs and greyhounds, beagles and Danish carriage dogs, mastiffs and King Charles's. It is scarcely necessary to remark that these external differences suggest the idea of corresponding modifications in the skeleton, in the proportion and form of the muscles. Anatomical differences are indeed even greater. For example, the skull of the water-spaniel is proportionately double the size of that of the bull-dog.

There are among animals, as among plants, some races which develop slowly, and others which increase in sizo rapidly. As in plants, fecundity is diminished in some and increased in others. When they are too perfect, that is to say, when they are too far removed from their natural type, animal races, like vegetable races, only propagate with great difficulty, or even not at all.

Our ordinary races of sheep only give birth once a year to a single lamb; the "hong-ti" twice a year to two lambs each time. The wild sow only litters once a year with but six or eight young, but when domesticated litters itwice a year with from ten to fifteen. Her fecundity is therefore at least tripled. In the Indian pig, derived from the "Aperea," it is more than seven times as great.

In dogs, habits imposed by education, transmitted and strengthened by heredity, finally assume the appearance of so many natural instincts by which races are as nicely characterised as by physical peculiarities. This has been established beyond a doubt by the experiments carried on by Knight during more than thirty years. The mention of the beagle and the pointer will be sufficient to recall the contrast which in many cases exists between these acquired instincts. Considered as the relative development of the intelligence, properly so called, the difference between races 
is also very marked in many cases. From this point of view we need only compare the greyhound and the spaniel.

V. If from animals and plants we pass to man, we shall find in him, as in the two inferior lingdoms, groups distinguished. by anatomical, physiological and psychological differences. In most cases the same organs and the same functions present analogous modifications. What reaso:i can be alleged for the idea that, if their nature is considered, these differences and modifications have a greater signification in man, and that they characterise species and not rece? Clearly none; it would be reasoning against the laws of analogy. An argument based upon the variations presented by the manifestations of morality and religion, would be a neglect of the fact that these faculties are the attributes of the human kingdom, that they are wanting in the other kingdoms, and are not in consequence susceptible of any comparison of this kind. In that which is exclusively human, man can only be compared with man.

In conclusion, the facts of the variations and differences existing in man between different groups, are of the sume nature as those established between different ruees of animals and plants. 'The nature of these phenomena cannot then be bronght forward as an argument in fiuvour of the theory that these groups are so many species. 


\section{CHAPTER V.}

EXTENT OF VARIATIONS IN ANIMAL AND VEGETABI,E

RACES; APPLICATION TO MAN.

I. THe question to which this chapter is devoted is one of those which I shall treat most fully in this course. In fact, it has a special importance. Nearly all the polygenistic arguments are included in the following:- "The difference between the Negro and the White is too great for them to belong to the same species." These types are the two extremes in the human series. Therefore, if it can be shown that between the two extremes, the limits of variation are almost always greater in plants and animals than in man, we shall have undermined the foundation of the whole polygenistic doctrine.

Now, even if we leave plants out of the question, and there can be little doubt in respect to them; if we merely compare man and animals, organ for organ, function for function, we shall have no great difficulty in arriving at the conclusion, that this is really the case; so much so that we shall be led to ask the question, why the variability is less in man than in animals. 'The complete demonstration of this general fact would require more extended treatment than I am able to give. I shall, therefore, confine myself to citing some examples.

II. The colouring of the skin is one of the most striking characteristics, and one which is most apparent to the eye. This has given rise to the expressions White, Yellow, and Black, which are most improperly used to designate the three fundamental groups of mankind. We will first prove that these names possess the grave inconvenience of giving 
rise to ideas which are entirely erroneous. Amongst the Whites there are entire populations, whose skin is as black as that of the darkest Negro. I sliall only quote the Bishareen and other tribes imhabiting the African coasts of the Red Sea, the black Mloors of Senegal, etc. On the other hand, there are yellow Negroes, as the Bosjesmans, who are the colour of light mahogany, or of café au lait, as Livingstone tells us.

It is no less true that colour is by far the most variable characteristic in man, and when we place the coal blact; Negro side by side with the fuir White with his pinkish complexion, the contrast is striking. But this contrast is repeated in several races of animals, in the dog, for example, whose skin is generally blackish, but white in the white poodle. It is the same among horses, a fact which was known eren to Herodotus, who pronounces white horses with a black skin as superior to all others.

'The races of our domestic fowls alone present the three extreme colours observed in man. The French fowl has a white skin; in the cochin-china it approaches to yellow; it s. black in black fowls. Sometimes they present a peculiarity similar to that which I mentioned in reference to the horse: a dark skin accompanying a white plumage as in the sill hen of Japan.

These same black fouls possess several interesting peculiarities from our present point of view. In Europe, melanism appears from time to time in our poultry-yards, and would infallibly spread if the fowls attacked by it were not destroyed. It is perhaps from want of this precaution that black fowls have been developed in various parts of the globe, among others in the Philippines, in Java, in the Cape Verd Islands, and upon the plateau of Bogota, all of which have been derived from European stocks. Melanism appears moreover, in groups of fowls which differ most strikingly in other respects, in the silk hen as well as in our ordinary races.

We see that blach fowls are in no sense a distinct species, and that the appearance of the black colour is merely an 


\section{Extent of Variations in Races.}

accidental character, which may be produced in races very dissimilar in other respects, and afterwards propagated by heredity. Why then admit that it has been otherwise in man?

Again, melanism is more highly developed in fowls than in man. It has long been held as a recognised fact that the skull of the Negro is more darkly coloured than that of the White. The fact is true. But M. Gubler has proved tha' the skull of a very dark complexioned White was coloured exactly in the same manner as that of the Negro, and that this peculiarity was sometimes individual, and sometimes hereditary in certain families. In fowls also, melanism penetrates to the interior; but it is not only the meninges which present peculiarities similar to those presented by the black man. With them all the mucous, fibrous, and aponeurotic membranes, even to the muscular sheaths, possess the same colouring. The flesh also assumes a repugnant appearance, and it is for this reason that the propagation of black fowls is prevented as much as possible.

The difference in colouring is easily explained. We now know beyond a doubt that the skin of the Negro is exactly the same in composition as that of the White. We find the same layers in both; the dermis, the mucous layer and the epidermis present exactly the same structure. The layers are merely thicker in the Negro. In these two great races, the mucous layer, situated between the other two, is the seat of colour. It is formed of cells which are of a pale yellow colour in the fair White, of a more or less brownish yellow in the dark White, and of a blackish bromn in the Negro. External causes have, moreover, an influence ripon the organ and modify the coloured secretion. Simon has shown that freckles are rothing more than spots upon the skin of the White presenting the characteristics of the skin of the Negro, and we know that an unusual exposure to the sun in the men and women of our race, and pregnancy in the latter, is sufficient to determine the formation of these spots.

Why, then, should it be thought strange that a number of 
circumstances, a constant heat, a bright light, \&c., should influence the whole body and perpetuate those modifications which in us are only circumscribed and transitory. In treating of the formation of the human races we shall have to bring forward facts which will clcarly prove that this is not merely hypothesis.

Finally, the colour of the skin depends upon a simple secretion which is subject to modification under a number of circumstances, as is the case with many others. There is, therefore nothing strange in the fact that some human groups, differing widely in other respects, should resemble each other in the matter of colour. 'This is the reason why the Hindoo (Aryan), the Bisharee and the Moor (Semitic), although belonging to the White race, assume the same, and even a darker hue than the true Negro. It also explains the fact that the colour of the Negro approximates in certain cases, to that of peoples belonging to the white stock who are more or less of a brown colour, or assumes a hue which exactly recalls that of the yellow races.

'Thus, in man, as in animals, the aphorism is verified which was formulated by Linnæus in regard to plants:nimium ne crede colori.

III. I shall not dwell at any length upon the modifications of the hair and villosities. They are much more apparent than real in man. Whether fair or black, fine and of a woolly appearance, as in the Negro, or coarse and stiff, as in the yellow and red races; whether the transverse section is circular as in the Yellow race, oval, as in the White, or elliptic, as in the Negro, the hair remains hair. The woolly fleece of our sheep, on the contrary, is in part of Africa, replaced by a short and smooth hair. In America the same is the case with the sheep of the Iladeleine whenever they are left unshorn; and on the other hand, in the high plains of the Andes, the wild boars acquire a kind of coarse wool.

The practice of certain natives of shaving off all hair has made some travellers believe in the existence of human 
races which are entirely hairless; the error has however been recognised. All men possess hair in the normal places. Hairless dogs and horses are, however, known to exist. In America, where the oxen have a European origin, the hair commences with becoming very fine and few in number with the pelones, and disappears entirely with the calongos: and if the latter do not increase in number, it is due to their being systematically destroyed from an idea that they are a degenerate race.

It is evident that in these several respects the variations are more extensive in animals than in man.

IV. This fact becomes more evident when it is possible to substitute exact measurements for merely general ideas, and to compare figures. The variations in size present this advantage, and it is interesting to compare from this point of view the extremes of some animal races with the extremes admitted in human groups.

\begin{tabular}{|c|c|c|c|c|c|}
\hline SPECIES. & RACE. & & & DIFFERNCE. & PATIO. \\
\hline $\begin{array}{l}\text { Dogs (length } \cdot \\
\text { Rabbits"(length) } \\
\text { Horse (height) } \\
\text { Sheep (height) }: \\
\text { Man (mean height). } \\
" \text { " }\end{array}$ & 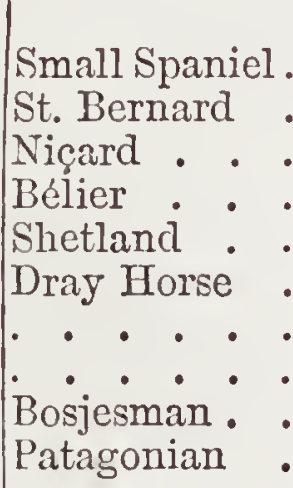 & $\begin{array}{l}\mathrm{m} . \\
0 \cdot 305 \\
1 \cdot 328 \\
0 \cdot 20 \\
0 \cdot 60 \\
0 \cdot 76 \\
1 \cdot 80 \\
0 \cdot 325 \\
1 \cdot 040 \\
1 \cdot 37 \\
1 \cdot 72\end{array}$ & $\begin{array}{lr}\text { ft. } & \text { in. } \\
1 & \\
3 & 4 \cdot 27 \\
& 7 \cdot 87 \\
1 & 11 \cdot 62 \\
2 & 5 \cdot 92 \\
5 & 10 \cdot 85 \\
1 & 0 \cdot 79 \\
3 & 4 \cdot 94 \\
4 & 5 \cdot 93 \\
5 & 8 \cdot 11\end{array}$ & 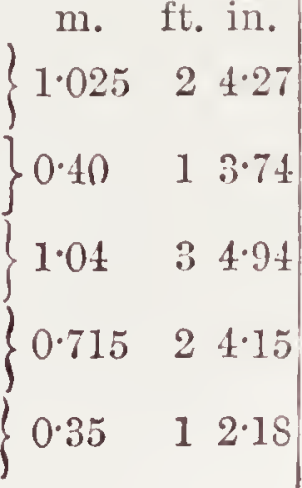 & $\begin{array}{l}0.2 \\
0.3\end{array}$ \\
\hline
\end{tabular}

We see that the variation between races is in the horse twice as great as in man, nearly three times in the sheep and rabbit, and four times as much in the dog. The differance is perhaps even more striking in the goat and ox, judging from the terms of comparison used by several traveller's.

If, after having studied the various dimensions of the body, we compare the differences in proportion presented on the 
one hand by animals and on the other by human groups, we shall arrive at similar results. Without, however, entering into details it will be sufficient to mention the greyhound and the beagle.

$V$. One of the most singular external characters, and one which has often been insisted upon as being necessarily a character of species, is that presented by the Bosjesman women. It is generally known that at the lower extremity of the loins they develop a fatty mass which sometimes increases to a considerable protuberance, as may be seen in the Hottentot Venus, the model of which is in the Paris Museum. This steatopygic reappears however in certain tribes situated much further north than the Houzouana races, while Livingstone states that certain women of the Boors, incontestably of Dutch origin, had begun to be affected by it. From this fact alone, this exaggerated development of the adipose tissue loses the value which many wished to attach to it.

If, however, the steatopygia were to exist only among the Houzouanas we could not, on that account, regard it as a character of species, for it has been proved in animals where it is only a character of race. Pallas has proved this fact in certain sheep of Central Asia. In these animals the tail disappears and is reduced to a simple coccyx, to the right and left of which are situated two hemispherical fatty masses weighing from twenty to thirty pounds each. Here, again, the variation is proportionally greater than in the Bosjesman woman.

We cannot regard these sheep as a different species, for when the Russians removed the same animals from the country in which they were born, the steatopygia disappeared in a few generations. It is, therefore, merely a character of. race which can only be preserved in the place where it was developed, as may be seen in a number of other cases.

$V I$. It is evident that the preceding character is just as much internal as external; it is also evident that neither the size, nor the proportions of the trunk and limbs, can vary, 
unless the skeleton and the accompanying muscles experience corresponding modifications. The anatomical characters change then with the race in animals, as well as external characters. There are, however, certain facts which relate more directly to anatomy. I will quote a few cases.

A dog's fore-paw possesses normally five well-formed toes, while the hind-paws have only four with a rudimentary fifth. This latter disappears in some races, mostly of a diminutive size. In certain large races, on the contrary, it is developed, and becomes equal to the other four. There must be then a formation of bone, corresponding to the tarsus and metatarsus.

Something analogous to the appearance we have just remarked may be observed in the pig, complicated, however, by a fresh phenomenon. Here the normal foot bears two small rudimentary lateral toes, and two medial toes, each with its own hoof. Now in certain races, already known to the ancients, a third medial toe is developed, and the whole is enveloped in a single hoof. Instead of being cloven-footed, which is the normal type of the species, the race becomes solidungulate.

Nothing of this kind is ever seen in man. In every race the feet maintain their ordinary composition, in the Bosjesman. as in the Patagonian. Some teratological exceptions with a tendency to heredity are nevertheless occasionally displayed, of which we shall speak in another chapter.

VII. The vertebral column is, so to speak, the fundamental portion of the skeleton, and yet it does not vary the less on that account. I shall not insist upon the differences presented by its caudal portion, merely remarking that there are races of dogs, sheep, and goats, in which the tail is so reduced as to be nothing more than a short coccyx.

The central portions themselves are known to be liable to change. Philippi tells us that the oxen of Piacentino had thirteen ribs instead of twelve, and, consequently, an extra dorsal vertebra. In the pig Eyton has observed the dorsal vertebræ vary from thirteen to fifteen, the lumbar from four 
to six, the sacral from four to five, and the caudal from thirtecn to twenty-three, so that the total is forty-four in the African pig and fifty-four in the English pig.

In man, the presence of one extra vertebra has occasionally been observed. These have always been isolated cases, except in one Dutch family, quoted by Vrolich. But it does not approximate to a constant character in any human group, and if such a group did exist, it is evident that the variation would here again be less than in animals, for without even reckoning the tail, it is three times stronger in the latter.

Of course, I do not take into consideration what has been so often said of men asserted to have tails. We now know better how much credit to attach to this statement. But the variations which take place in the caudal region among animals teaches us that even a considerable elongation of the coccyx in a human group, and the multiplication of the vertebre which compose it, must not be considered à priori as a specific character.

VIII. It might have been expected that the head would have escaped modifications, on account of the importance of the organs which belong to it. But such is not the case, and here again the modifications are much greater in animals than in man. Blumenbach remarked long ago that there was more difference between the head of a domestic pig and the wild boar than between that of the White and the Negro. There are no domestic species to which the same remark camnot be applied. But I shall only remind the reader of the heads of the bull-dog, greyhound and spaniel.

The extent to which the modifications of the head can be carried is nowhere more plainly shown than in the niatc cattle of Buenos Ayres and La Plata. This ox exhibits the modifications of the specific characters similar to those which the bull-dog presents among dogs. All the forms are shortened and thickened, the head in particular sceming to have experienced a general movement of concentration. 'The inferior maxillary bone, although itself shortened, so far exceeds the superior in length that the animal is unable to browse the 
trees. The cranium is as much deformed as the face; not only are the forms of the bones modified, but also their relations, not one of which, according to Professor Owen, has been strictly preserved. This race, though perfectly established, is not therefore necessarily of less recent origin; for, as I remarked above, all the American oxen are descended from European stocks. It is already represented in the New World by two sub-races, one of which, that of Buenos Ayres, has preserved the horns, while that of Mexico has lost them.

It is scarcely necessary to remark that no human group presents anything at all analogous to this.

IX. The several facts which I have here enumerated seem to me sufficient to justify the proposition which I asserted at the commencement of the chapter, namely:- that the limits of variation are almost always more extensive between certain races of animals than between the most distant human groups.

Consequently, however great the differences existing between these human groups may be, or may appear to be, to consider them as specific cluaracters is a perfectly arbitrary estimation of their value. It is, to say the least, quite as rational, quite as scientific, to consider these differences only as characters of race, and even on that account to refer all the human groups to a single species.

The legitimacy of this conclusion is incontestable. Now, I repeat, that this conclusion is sufficient to destroy the very foundation of the polygenistic theory. In reality this theory rests entirely upon morphological considerations. Its partisans, struck only by the material differences presented by the human groups, have thought it impossible to account for them, except by the admission of the existence of several species. By showing that facts of this nature can be equally well interpreted under the hypothesis of the Unity of the Species, monogenism and polygenism are, so to speak, placed on an equal footing. 


\section{CHAPTER VI.}

\section{INTERCROSSING AND FUSION OF CHARACIERS IN ANIMAL}

RACES; APPLICATION 'IO MAN.

Without even quitting the ground of morphology, it will be easy to prove which theory is most probably the correct one.

We know that naturalists consider that all individuals which pass from one to another by invisible shades belong to the same species, however different the extremes may be. All great museums contain examples of this fact.

The grounds for this conclusion are much stronger when there exists an intercrossing of character's. This intercrossing exists when a very decided and apparently exclusive character reappears in one or several individuals differing widely in other respects, and undoubtedly belonging to distinct groups. It is a case of intercrossing again, when the same character varies in such a manner as to lead, if considered apart, to the division of a natural group, and to the separation of the fractions into very different groups.

Now there is no animal species which presents these essentially morphological characters in a higher degree than man. When the human groups are studied in some detail, the difficulty does not consist in finding resemblances, but in clearly defining the differences. The more carefully they are considered, the more they disappear and become obliterated. We then understand the accounts given by most trustworthy travellers, such as d'Abbadie, of countries where the Negro and the White live side by side. In their extremes these two types are certainly very distinct. But in Abyssinia, for example, where they have long lived in contact, and intermingled, the Negro is no longer cha- 
racterised by either colour; features, or hair, but simply by the exaggerated protruberance of the heel. This character in its turn, however; loses its value on the Eastern coast of Africa, where whole Negro tribes have the heel formed like ours.

This is an example of intercrossing, and they could easily be multiplied. I have already observed how closely the Aryan or Dravidian Hindoos, African or Melanesian Negroes and manifestly Semitic populations may resemble each other in colour. The following is a still more striking example. Desmoulins regarded the perforation of the olecranon process as one of the most decided characters of his Austro-African species of man. Now this perforation reappears in Egyptian and Guanche mummies, in a large number of European skeletons of the neolithic period, the crania of which moreover, exhibit no other relations with those of the Bosjesmans, and even in some Europeans of the present epoch.

The intercrossing of character's between human groups becomes still more evident from the comparison of numerical data taken from a number of different groups. I shall confine myself for the moment to giving the results arrived at by the study of the stature when the representative numbers are placed in order. We shall presently meet with other examples.

I here reproduce the table published in the Voyage of the Novara, by Dr. Weisbach. I have added to the figures of the Austrian savant a few data relating especially to the smallest races. I have also given the maxima and minima where I have been able to procure them, so as to make the extent of the variation more appreciable than is possible from the average alone :

STATURE OF DIFFERENT HUMAN RACES.

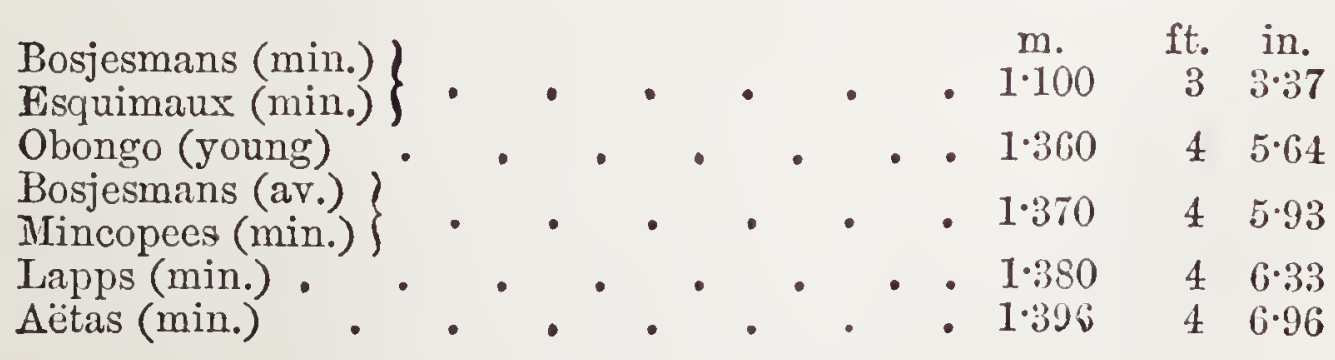




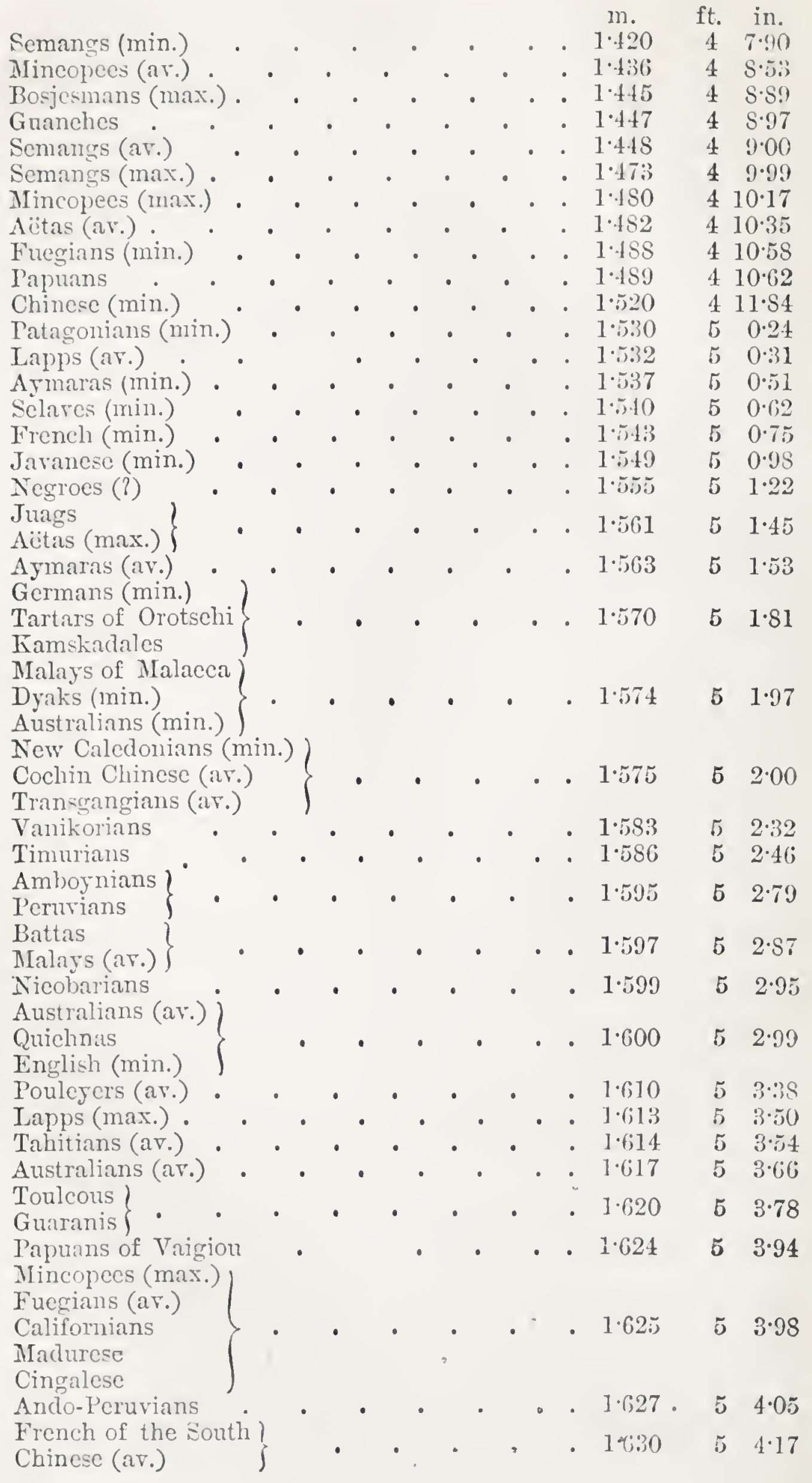


Nicobarians m. ft. in.

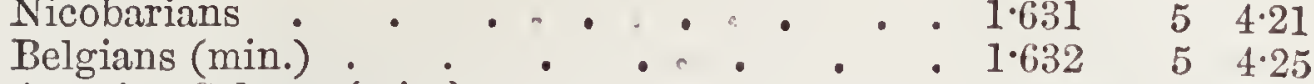

Austrian Sclares (min.) . . . . . . 1.634 54.33

Austrian Roumanians
Magyars

Jews . . . . c . • . • $1.637 \quad 5445$

Dravidas (av.) . . . . . . . $1.640 \quad 54.57$

Araucanians . . . . . . . . $1 \cdot 64154.61$

Bavarians . . . . . . . . $1 \cdot 643 \quad 54.68$

Antisians . $\quad . \quad$ : . . $1.645 \quad 5476$

$\left.\begin{array}{l}\text { Fuegians }(\max .) \\ \text { Crees }\end{array}\right\} \begin{gathered}\cdot \\ .\end{gathered}$

Dyaks (max.) $\}, \cdot, 1650$ 54.96

Bugis . . . . . . . 1.653 55.08

Negroes (?) • • . . . . $1.655 \quad 55.16$

French, working classes (aю). . . . . $1 \cdot 65755.24$

Austrian Germans • • • . • 1.658 55.27

Esquimaux of Melville Is. . . . . . $1.659 \quad 55.31$

Roumanians (min.). . . . . . 1.660555

Fuegians (max.) )

Chiquitos

Hottentots

French of the North ?

Algerian Arabs

New Caledonians

Moxos $\}$

Pampeans (av.) •. . . . . . . 1.673

Hawaians

New Californians

Malays of Soolo

Austrian Sclaves (ar.)

Russians

Javanese

Germans

$\left.\begin{array}{l}\text { Negroes } \\ \text { Charruas }\end{array}\right\}$

French, upper classes (av.) . . . . . . 1.681

$1 \cdot 676$

$5 \quad 5 \cdot 56$

$5 \quad 5 \cdot 75$

$5 \quad 5 \cdot 87$

Ojibbeways (min.)

Natives of Madras

Fijians

$1 \cdot 682$

$1 \cdot 678$

$5 \quad 5 \cdot 98$

Negroes of Sokoto . . .

Belgians (av.) . . . . . . . . . 1.686

English (av.)

Pampas Indians

$\left.\begin{array}{llll}\text { Marquesas Islanders } & \\ \text { Esquimaux of Boothỉa sound }\end{array}\right\} \cdot$. . . $\quad . \quad 1 \cdot 689$

Somalis . • • • • • • • . 1.690

New Zealanders

Puelches

- $1 \cdot 695$

$5 \quad 6.06$

$56 \cdot 10$

Comma Negroes

Tahitians (min.)

Letts
Rotuma Islanders

Courouglis (av.) 


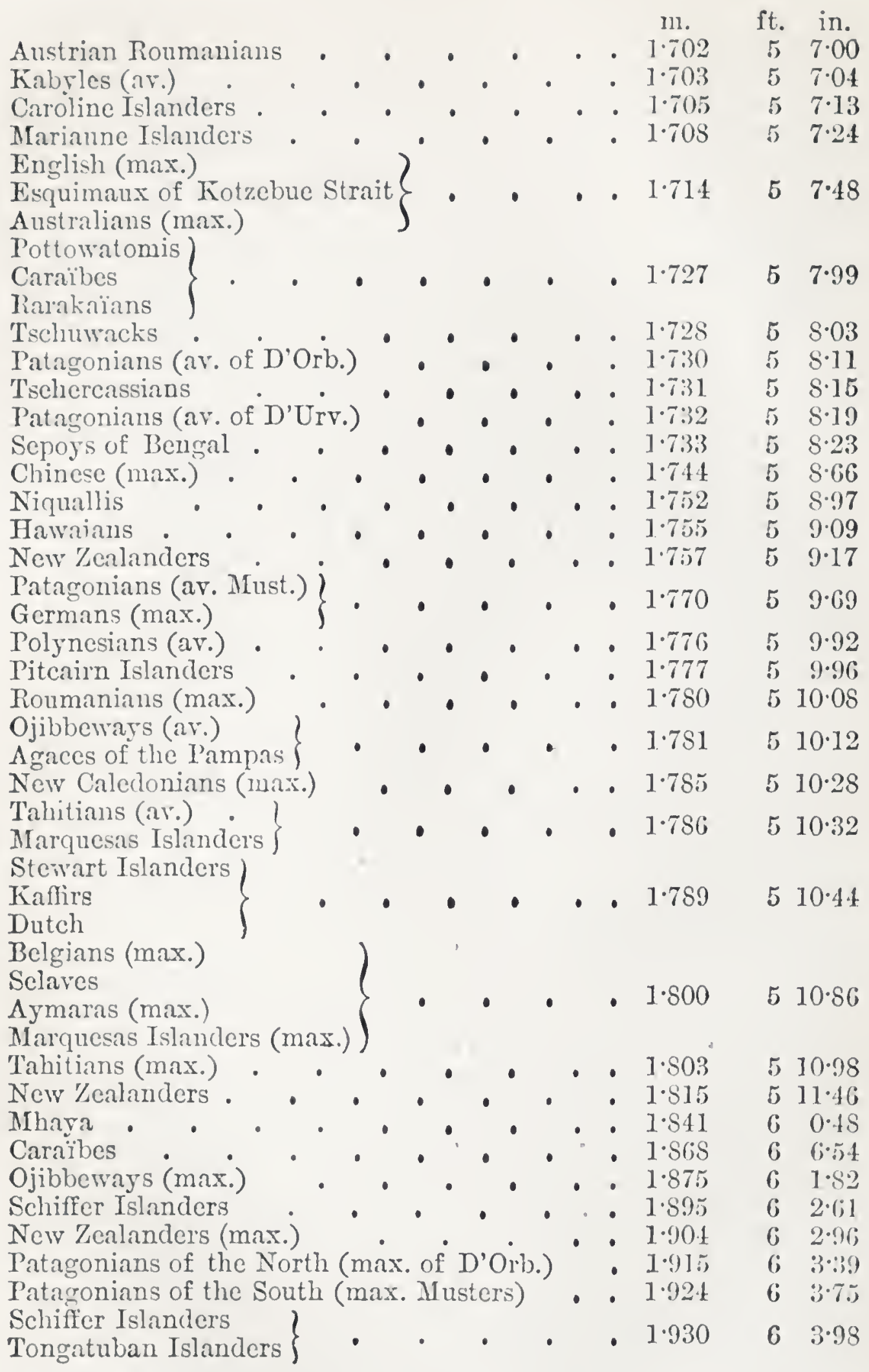

We here see what strange relations and what a singular confusion rise from a consideration of the stature. Numbers given in the same order, representing the size of the skull, the cephalic indices, the weight of the brain, will give the same striking result. 
We must also observe that there is a great majority of means in this table. Now we see that the discrepancies between these means are less than the discrepancies between the maximum and minimum of a single race, so much so that races widely distinct from each other intervene between them.

Now let us mentally compare instead of these groups, the individuals of which they are composed. Is it not clear that if they were placed according to height, we should pass from one to the other with scarcely the difference of a millimetre; but is it not also clear that the confusion would become much greater than it appears even in the table?

I ask anyone who possesses even the smallest knowledge of zoology and zootechny whether it would be in a collection of species that he would expect to find the most evident affinities destroyed by the application of this method? Would it not be rather in a collection of races that similar facts would be met with, as, for example, in canine races, where the mastiff and its young, the greyhound of Saintonge and the Italian greyhound, the large and the small carriage dog would be separated from each other by a number of other races if stature alone were taken into account.

The intercrossing and fusion of characters, so marked between human groups, are inexplicable if we consider these groups as species, unless we admit that the morphological relations between these human species are of an entirely different nature to the relations established between animal species. But this hypothesis makes an exception of man; we have, therefore, the right to regard it as false.

If, on the contrary, we look upon these groups as nothing more than races of a single species, all these facts of intercrossing and fusion agree with what may be observed in plants and animals and replace man under the dominion of general laws.

Thus, without quitting morphological considerations, which correspond to the idea of resemblance contained in the definition of species, we are justified in concluding in 
62 The Human Specics.

favour of monogenism. 'To confirm this conclusion, however, we must turn our attention to other facts which correspond to the idea of filiation, and consider the teachings of physiology concerning the phenomena of generation. 


\section{CHAPTER VII.}

CROSSING OF RACES AND SPECIES IN THE ANIMAL AND VEGETABLE KINGDOMS.-MONGRELS AND HYLRIDS.

I. Sexual unions in plants, as in animals, can take place between individuals of the same species and the same race; further, between different races of the same species, and, finally, between different species. In the two latter cases we have what is called a cross. This crossing itself is differently named according to whether it takes place between different races or different species. In the first case it produces a mongrel, in the second a hybrid. When the cross unions are fertile the product of the union of mongrels is called a mongrel, the product of the union of hybrids a hybrid.

If the difference of the relations existing between the race and the species has been properly understood, we ought to be inclined to admit that mongrels and hybrids would not present the same phenomena; experience and observation confirm this presentiment.

We have, therefore, in this crossing a means of judging whether the human groups are only races of a single species, or rather distinct species. For this purpose it will be sufficient to study the phenomena which, in other organised and living beings, accompany the production of mongrels and hybrids, and then to compare with both the phenomena which characterise the crosses effected between human groups. If, in the latter case, the phenomena are those which characterise hybridism, we must conclude that the groups are specifically distinct, and admit the multiplicit? of human species. If, however, crosses between human 
groups, morphologically different, are accompanied by phenomena peculiar to the production of mongrels, we shall only be justified in considering these groups as races of one species; we must take our stand upon the doctrine of the Specific Unity of all mankind.

The question before us becomes then entirely a physiological one, and depends simply upon observation and experiment. For its solution we must again turn our attention to plants as well as to animals. It is in the phenomena of reproduction that the two kingdoms show the greatest resemblance. This is not a case of mere analogy, but almost of identity, and it is not the superior which lowers itself but the inferior which is raised. We might say that, ennobled by the importance of the function, the plant, as far as its reproductive system is concerned, becomes, for the time, animal.

II. In these lingdoms the unions between races of the same species, that is to say, the production of mongrels, may be accomplished without any intervention on the part of man, or it may take place under his direction. It is consequently either natural or artificial.

Mongrels among plants could only be recognised after the discovery of the distinction of the sexes in 1744. The honour of this great discovery belongs to Linnæus. He at once comprehended the importance of the subject, and even exaggerated it, as we shall presently sec. Linnæus admitted that cross-unions, which had been observed for centuries between animals, might be repeated between plants. And he thus explained the appearance of variegated tulips in the midst of borders originally formed of uniformly coloured flowers. Observation and experiment have confirmed the views of the founder of the natural sciences again and again. Moreover, it has been observed that the crossing may become apparent in all parts of the plant by a mixture of characters similar to that exhibited by the colouring of the tulips. M. Naudin, among others, who, during one year, watched the development of more than 1200 gourds, saw the seeds of a single fruit reproduce all the races contained in the garden 


\section{Crossing of Races and Species.}

in which his observations were made. Superfetation had taken place. It is a fact of great importance, as it demonstrates the equality of action enjoyed by the pollen of all these races, which, morphologically, differ so widely from each other. No better example could be given of the faculty of crossing between races.

The natural and spontaneous production of mongrels among animals presents the same characters. Facilitated by locomotion it is accomplished every day in our houses, our pouitry-yards, and our farms. The difficulty does not consist in the accomplishment of the cross but in its prevention, and in the preservation of the purity of the race. The careful observations made by Isidore Geoffroy at the Paris Museum, have shown that with sheep, dogs, pigs, and fowls, mongrels between the most different races were invariably fertile. Here again the phenomena of superfetation was often proved. Bitches produced, by males of several races successively, young which showed three or four distinct sources. Here the case was the same as with the gourds of M. Naudin.

We see that man has found no difficulty in breeding mongrels, and that, when he has wished to do so for any purpose whatever, he has been able to regulate it by merely choosing the animal or plant. This kind of union has, indeed, been long in daily practice for the amelioration, modification, and diversification of the living beings upon which human industry is exercised. It is useless to insist upon facts which are known to all gardeners and breeders, and I shall confine myself to one remark, the importance of which will be understood later.

We have already seen that in the endeavour to perfect a vegetable or animal race, the physiological equilibrium has sometimes been destroyed at the expense of the reproductive power. In such cases, crossing with another race which is less modified, generally revives the extinguished fertility. For example, the English pigs imported into the middle of France by M. de Ginestous became sterile after several 
generations. Upon crossing them with a leaner and less perfect local race, their fertility returned.

All these facts, and their inevitable consequences, have been admitted by every naturalist who has studied the question. Even Darwin has recognised the truth of them in his valuable work upon the Variation of Animals and Plants. At that time he confined himself to the conclusion that the crosses between some races of plants are less fertile than between others, a proposition which no one would think of denying. He has gone further in the latest editions of his work upon the Origin of Species. Without bringing forward clear facts, the meaning of which would go further than the wise conclusions he had previously admitted, he inrokes our relative ignorance of what takes place among wild varieties, and concludes that we must admit that the crosses between varieties must always be perfectly fertile. This is one of those appeals to the unknown, one of those arguments where even our ignorance is invoked as a proof, which we too often meet with in Darwin, who is often carried away by his convictions. I shall have to return to this point, but I here make the statement as an established fact, on the anthority even of Darwin, that all linoun facts attest the perfect fertility of mongrels.

Finally, the formation of crosses between races, or the production of mongrels, is spontancous, and may be promoted by man without the least difficulty; the results are as certain as those with the union of individuals of the same race; in certain cases, indeed, fertility is increased or revived under the influence of this crossing.

Crosses between species, or hybrids, will exhibit fiacts of an entirely contrary nature.

III. 'The formation of hybrids, as of mongrels, may be either natural or artificial.

The former is so rare that eminent naturalists have doubted its reality. There are, however, according to M. Decaisne, a score of well proved examples among plants. What is this number compared with the thonsands of 
mongrels produced every day under our eyes. And yet the material conditions of fertility are identically the same with races as with species, and our botanical gardens, which group numbers of species side by side, facilitate crossing still more.

Among wild animals living in liberty hybrids are still more rare. It is unknown, for example, among mammalia, according to Isidore Geoffroy, whose experience has here a double value. The order of birds alone presents some facts of this kind, nearly all of which are in the order of Gallinx. According to Valenciennes, they are unknown among fishes. In domestication and captivity spontaneous crossing between different species is a little less rare.

The intelligent intervention of man has multiplied unions of this kind in a remarkable manner, especially among plants, but without being able to extend their limits. Linnæus thought crossing was possible between species of different families. But in 1761 Koebreuter showed that he was mistaken. From these investigations, which were carried on for twenty-seven years, and from those of M. Naudin, his worthy rival, it appears that artificial crossing between species of different families never succeeds, and very rarely between species of different genera; that it is always very difficult, and demands the most minute precautions to insure success; that it often fails between species of the same genus closely allied in appearance, and finally, that there are whole families among which hybrids are impossible. Amongst the latter figures the family of the cucurbitaceæ, so thoroughly studied by M. Naudin, where the most perfect mongrels were produced spontaneously. We could not imagine, evidently, a more complete contrast.

This contrast is carried into the minutest details. For example, any flower which has in the least possible degree undergone the action of pollen of its own species becomes absolutely insensible to the action of pollen of a different species. How different to the equality of action displayed by the several pollens of most distant races! 
All experimenters agree further in declaring that even in the unions between species which have been most successful, the fertility is constantly diminished, and often in immense proportions. The head of the Papaver somnifera generally contains 2000 seeds or more. In a hybrid of this species Gœrtner only found six which had been matured; all the rest were more or less abortive. Here again, what a contrast between the crossing productive of such fertility in M. De Ginestous' English pigs.

Hybridism in animals presents exactly the same phenomena as in plants. Man has been able, by diverting and deceiving animal instincts, to multiply crosses between species. But he has not been able to extend the very narrow limits at which these phenomena cease. Not one fertile union has taken place between different families; they are very rare totween genera, and even between species they are far from numerous, a fact the more remarkable as animal hybridation is an ancient institution. The mule was known to the Hebrews before the time of David, and to the Greeks in the age of Homer. Titives and musmons, products of crossings between the he-goat and the sheep and the ram with the she-goat, received their distinctive names from the Romans.

The uncertainty of the result is another point of resemblance between animal and vegetable hybrids. The same experiments executed with the same care and by equally clever experimenters have sometimes succeeded and sometimes failed without any apparent cause. Buffon and Dauhenson often tried to reproduce titires and musmons. They succeeded twice, while Isidore Geoffroy has invariably failed. The formation of crosses between the hare and the rabbit, which has frequently been attempted in various parts of the globe, appears only to have been successful four or five times at the most. 'The pretended cross between the camel and the dromedary, admitted by Buffon and quoted by Nott, is certainly a fable, after the details which M. De Khanikoff kindly gave me, and which I have published elsewhere. We may, therefore, draw this conclusion from known facts, that 


\section{Mongrels and Hybrids.}

there are only two species of mammals, the ass and the horse, the crossing of which is almost universally and invariably fertile.

Finally, crossing between species, or hybridation, is extremely exceptional among plants and animals when left to themselves; man can only produce them with great difficulty in the two kingdoms, and then only between a very limited number of species; when he has succeeded, the fertility is almost constantly diminished, and often to a very considerable extent. 


\section{CHAPTER VIII.}

CROSSING BETWEEN VEGETABLE AND ANIIAT, R.ACES ANI) SPECIES; MONGRELS AND HYBRIDS; REAITTY OF SPECIES.

I. Frone the very first, in the union of two individuals belonging to different stocks, the race and the species display very distinct and characteristic phenomena. We shall now see this opposition as strongly marked in the product of these unions in mongrels and hybrids.

Several questions are raised by the mixed nature of these beings. I shall confine myself to those which refer to filiation, and which have therefore a special interest for us. They may be stated generally as follows:- are mongrel races, that is, those derived from two distinct races, and hybrid races, that is those which are derived from the crossing of two species, formed naturally, or can they be obtained artificially? In other words, do mongrels and hybrids retain, during an indefinite number of generations, the faculty of reproducing and transmitting to their descendants the mixed character they inherited from the first parents which effected the cross?

II. In regard to mongrels there is not a shadow of doubt. Facts which frequently occur, often without our intervention, and sometimes in spite of our precautions, prove again and again that the mongrels of the first generation are as fertile as the parents, and transmit equal fertility to their offspring. Our gardeners and breeders always take advantage of this property of mongrels in order to vary, modify or ameliorate from their point of view the plants and animals in which they are interested; the careful experiments of Buffon, of Geoffroy St. Hilaire, father and son, and 
the testimony of Darwin, on this point very significant, prove beyond a doubt that unions between different races remain fertile, whatever morphological differences there may be between them. I shall confine myself to quoting one example from Darwin. The niata will unite indifferently in both senses with the ordinary ox, and the offspring is fertile.

If several races of a single species are in habitual contact and left to themselves, they will intermix in every degree. This results in bastard offspring, devoid of definite characters, but which, when methodically studied, would lead through insensible shades to the different primitive types. In this manner our street dogs and cats have come into existence, which remain perfectly fertile in spite of innumerable crossings of every kind.

With human intervention it is possible, when care is taken, to regulate the crossing between two races, and to obtain a mongrcl race. After a few oscillations between the paternal and maternal types it becomes consolidated and settled. But whatever constancy it may have acquired as a whole, it almost always happens that some individuals reproduce, to a varying extent, the characters of one of the types originally crossed.

This phenomenon is designated by the name of Atavism. It sometimes occurs in the midst of a race considered to be perfectly pure, and is the result of a single crossing several generations back. Darwin quotes the case of a breeder, who having crossed his fowls with the Malay race, wished afterwards to free them from the strange blood. After spending forty years in the attempt, he is still umsuccessful, the Malay blood always reappearing in some of his fowls.

In animals as in plants, universal, free and indefinite fertility, whether between themselves or between all the races of the same species, is one of the characters of mongrels. Atarism attests the physiological bond which unites all mongrels. 
III. In hybrids we shall meet with some very differend phenomena.

Let us first, with M. Godron, establish the fact that in the vegetable hybrid the physiological equilibrium is destroyed in favour of the organs conducive to the life of the individual, and at the expense of those conducive to the life of the species. The stalk and leaves are always developed in an exaggerated manner relatively to the flowers. The most common animal hybrid, the mule, is an entirely similar case, being invariably stronger, more robust, more hardy than its parents, but sterile.

This sterility is not absolute, however, among all hybrids of the first generation. It generally affects the male organs in an entirely special manner. Koehreuter, to whom we should always refer when treating of plants, states that the anthers scarcely ever enclose veritable pollen, but merely irregular granulations. It was not quite so unusual to find ovules in good condition in the ovary. Guided by these observations, Koelreuter artificially fertilised hybrid flowers with pollen from the male species, and thus obtained a vegetable quadroon. By continuing this process he soon brought back again to the original male type the descendants of the first hybrid, which regained all their generative faculties, but at the same time lost all trace of the female type. These experiments have been repeated and varied, but always with the same result.

In a small number of hybrids of the first generation the elements which characterise the two sexes remained capable of reproduction. Nevertheless the fertility is always immensely reduced. From his hybrids of the datura, II. Naudin only obtained five or six fertile seeds from each piant. Ali the others had completely failed, or were without an embryo. The capsules themselves were only half the normal size.

If two of these first hybrids are united they produce hybrids of the second generation. In most cases, however, the latter are either sterile, or present the phenomenon of a 
spontaneous return to one or the other of the parent types, or to both. M. Nandin crossed the large-leaved primrose with the primula officinalis, and obtained an intermediate hybrid between the two species, having seven fertile seeds. When these were sown they produced three primroses of the male species, three of the female, and a single hybrid plant which was perfectly barren.

In some still rarer cases fertility continues during several generations. Then, however, a curious phenomenon is exhibited, called by M. Naudin, who discovered it, Disordered variation. With the Linaria communis and the Linaria purpurea he produced a hybrid, the descendants of which he was able to follow through seven generations, in each of which several individuals reverted to the characters either of the original male or female. The others neither resembled the primitive types nor the hybrid resulting from their crossing, nor the plants of which they were the immediate offspring, nor was there any resemblance between the plants themselves.

Thus the crossing does not produce a race, even in cases where it allows a certain amount of fertility ; it only produces varieties incapable of transmitting their individual characters. In order to establish a series of generations presenting a certain amount of uniformity, the hybrid must lose some of its mixed characters, and resume the normal livery of the species, as M. Naudin says; in other words, it must return to one of the parent types.

IV. The same facts which we have just noticed among plants, occur also among animals. We must observe in the first place, that the only two species, the crossing of which displays anything approaching to regular fertility, the horse and the ass, merely produce a hybrid almost entirely devoid of fertility. It is more than 2000 years since Herodotus regarded the fertility of mules as a prodigy, and almost 1800 years since Pliny expressed the same opinion.

And yet in some works we read that the fertility of the mule is displayed in the present day; that it often propa. 
gates in hot countries, especially in Algeria. The true value of these singular assertions will be recognised if we recall the effect which was produced in IS:S upon the whole Mussulman population of Algeria by the announcement that a mule had conceived near Biskra. The astonishment was general ; the Arabs gave themselves up to long fasts to conciliate the wrath of heaven, thinking the end of the world had come. Fortunately the mule miscarried; but long afterwards the Arabs still spoke with terror of this event.

If this fact were occasionally repeated in Algeria it would never have produced such an impression upon a people so curious about everything connected with the horse. The impression itself proves that the facts are in our days similar to what they were in the time of Herodotus.

Examples of fertility in the hybrids of the ass and the horse have never been observed except in the female mule. There is not a single known example in the male. Wo meet with something analogous to this in birds, where the sterility of certain hybrids is less absolute. Thus vertebrata are similarly affected with plants; and in their case also the inequality between the two sexes can be explained by anatomical and microscopic examination. The male organs are generally but slightly developed, even the essential elements of the fertilising liquid undergo alteration. The female organs and elements, though modified, are relatively inaffected.

There are some hybrids among animals, as among plants, which are not subject to the general law. Among birds in particular, a certain number, always however very limited, of more or less fertile hybrids have been obtained. But, with the males the faculty of reproduction is constantly weakened, and habitually disappears before the usuai arge; the female lays more rarely, and the eggs are fewer in number, and very often cleur. This is an exact repetition of what took place in MI. Naudin's datmra seeds, which he observed to become abortive or deroid of embryo.

We must, moreover, exclude from the numbur of fertile 
hybrids a certain number of examples quoted by some authors, and which statements are proved by facts, now either better known or better appreciated, to have an erroneous foundation. Thus Hellenius thought he had crossed the Finnish ram with the Sardinian doe, but he had confounded the then little known moufflon with the roebuck. He thus obtained a mongrel, which having been crossed for two generations with the male parent, returned to the type of the latter. We have here evidently only a companion experiment to those of Koelreuter, which resulted in a reversion ef the hybrid to the male type under a similar series of crossings.

There are, however, some examples among birds and among mammalia of hybrids which have propagated inter se for several generations, four or five at the most. The celebrated experiment of Buffon upen the crossing of the dog with the wolf in particular, belongs to this order of facts. It was unfortunately interrupted by the death of the great naturalist at the fourth generation. It is clear that there is nothing here which does not perfectly agree with our observations upon hybrid plants, which, although exceeding this number of generations, have never produced hybrid races.

Fertility, and the number of succeeding generations is increased, when a superiority is given to one of the crossed species over the other. This fact has been recognised in plants, and we meet with it again in animals. By crossing and recrossing in a fixed manner the goat and the sheep, hybrids called chabins are obtained which possess threeeighths of the paternal and five-eighths of the maternal blood. These animals produce a fleece much valued in South America, and are the source of real industry. They can be maintained for several generations, but at length all the crossings to which they owe their existence must be recommenced, they having returned to the parental types, 'like plants,' as M. Gay said.

This proportion-three-eighths to five-eighths-appears to be very favourable to the maintenance of hybrid races; 
it is the proportion which characterises the famous leporides, the result of the crossing of the hare and the rabbit. But can these hybrids, of which so much has been said, maintain themselves without reverting to the parentai types? M. Roux evidently believed it, and it is still asserted by M. Gayot. But the testimony of those who have established and impugned their assertions leaves scarcely any room for doubt. Isidore Geoffroy, who had at first believed in their fixity, and had spoken of it as a conquest, did not hesitate afterwards to admit the reversion. The fact has been established in the Jardin d'Acclimatation, and M. Roux himself, upon the assertion of MI. Faivre, appears to have abandoned his previous assertions. The observations and experiments made by the Agricultural Society of Paris clearly show that the leporides, sent or presented by the breeders themselves, had entirely reverted to the rabbit type. Lastly, MI. Sanson, discussing the anatomical side of the question, has arrived at the same conclusions. Moreover, whoever will credit the observations made by M. Naudin upon the Linariæ, will easily recognise the reversion and the disordered variation exhibited by the leporides of the Abbé Cagliari, who was the first to obtain a fertile crossing between the hare and the rabbit.

These phenomena appear in an equally well marked manner in the result of the cross between the sillsmoth (Bombyx cynthia) and the castor-oil silkmoth (Bombyx arrindia), obtained by M. Guérin Méneville. 'The hybrids of the first generation were almost exactly intermediate between the two species, and resembled each otlier. In the second this uniformity disappeared, in the third the dissinilarity had increased, some of the insects having reassumed all the characters of the paternal or maternal types. In the seventh generation this curious experiment was destroyed by ichneumons. But, as MI. Valée, their intelligent breeder, told me, nearly all the moths had returned to the type of the Bombyx arrindia. The resemblance to what tonk place in the case of M. Naudin's Linariæe is hẹre complete. 
$\mathrm{V}$. The phenomenon of the reversion of the descendants of a hybrid to the paternal or maternal type, or disordered variation, has given rise to some interpretations which it will be well to rectify, and has also raised important questions.

The attempt has been made to assimilate the latter to the oscillations presented by mongrels for some geverations. But daily experience should suffice to refute this opinion. Breeders are crossing races every day for some purpose or other, and they would never do so if the crossing were to result in the production of a disorder which would exhibit the smallest resemblance to that displayed by the Linarix of M. Naudin, and the silkmoths of Guérin Méneville. They expect, however, a few irregularities more or less marked, in the first generations, but they know that the race will soon settle while the disorder would only increase if the crossing had taken place between species.

Again, an attempt has been made to consider the facts of atavism and reversion as identical. There is, however, a fundamental difference between them, for the mongrel which by atavism reassumes the characters of one of its paternal ancestors, for example, still preserves its mixed nature. This is proved by the possibility of its offspring of the first or second generation reproducing; on the contrary, the essertial traits of its own maternal ancestors. Darwin gives many examples of facts of this nature from the agricultural history of his country. One of the best to quote is that furnished by the genealogy of a family of dogs observed by Girou de Buzareingues. These animals were crosses between the setter and spaniel. Now one male, a setter to all appearances, united with a female of pure setter breed, produced spaniels, which makes it evident that the latter blood was by no means annihilated, and that the return to the setter type was only apparent.

It is different in the cases of reversion displayed by hybrids, for one of the two bloods is irrevocably expelled. We are justified in making this assertion in the case of mammalia, 
by experience extending as far back as the Roman period, or at least as far as the seventeenth century. Titires and musmons have never since those times had offopring affected by atuvism. A ram and sheep have never been known to produce a kid, nor a male and female goat to produce a lamb. It is the same with plants, according to statements with which M. Naudin has kindly furnished me.

Far from being similar, the phenomena of atavism and reversion are absolutely different and characteristic, the one of crossing between races, the other of crossing between epecies. The first proclaims the persistency of the physiological connections between all the representatives, more or less modified, of one species; the second proves the complete rupture of the same connections between the descendants of two species accidentally brought into contact by the promoter of the hybridism.

VI. In none of the preceding cases has hybridism, no matter in what degree, given rise to a series of individuals descended the one from the other, and preserving the same characters. An exception is, however, known to this general fact. It is unique, and is produced in the vegetable kingdiom from the crossing of wheat with Eigilops ovata.

The hybrid of the first generation from these two species is sometimes produced naturally, and was regarded by Requien as a species. Fabre, who frequently met with it in the fields, considered it to be the commencement of the transmutation of the Egilops into wheat. Afterwards a quadroon hybrid, accidentally obtained and cultivated during several years, gave him descendants resembling the beardless wheat of the South. It was the result of reversion. Fabre, however, who did not recognise the hybrid, thought it was is transmutation, and flattered himself that he had discovered wild wheat in the Egilops.

MI. Godron, on the contrary, understood the nature of the phenomenon, and demonstrated it experimentally. He crossed the Egilops and the wheat, and obtained the first p)lant of Requien, the Elgilops triticoüdes of Fabre. He 
again crossed this hybrid with the true wheat, and reproduced the pretended artificial wheat of the Montpellier botanist. He gave to it the name of Agilops speltaformis.

It is this latter form, having as we see three-fourths of the true wheat, and a fourth of the Egilops, that M. Godron has cultivated at Nancy since 18.57. The clever naturalist who has produced it, believes that he has not had one case of reversion like those at Montpellier and those of Fabre. But at the same. time he informs us that the most minute and special precautions alone can preserve this artificial plant. The ground must be prepared with the greatest care, and each seed placed by hand in the desired position. If put into the ground carelessly, or scattered over the bed, the seeds never germinate. M. Godron considered that the Egilops speltæformis would entirely disappear, perhaps in a single year, if left to itself.

VII. Finally, the characters of hybrids are: infertility, as a general rule, and, in the exceptions, a very limited fertility; series suddenly cut short either by infertility, by disordered variation, or by reversion without atavism.

The Egilops triticoïdes alone seems to stand in opposition to all other known facts. This exception is undoubtedly remarkable, but does not in any way impair our general conclusions. A product of human industry, this hybrid plant only exists by virtue of the same industry, and cannot, from any point of view, be compared to the succession of mongrel individuals which are unceasingly propagated without our aid, and in spite of our precautions, in the midst of our animal and vegetable races.

"But," say those writers who deny the reality of a distinction between species and race, "what man has done nature inust be able to do also, for she governs space and time, and is therefore more powerful than man." This form of argument rests upon a confusion of ideas and a strange neglect of the most ordinary facts.

Most true, nature is more powerful than man in certain cases and for certain ends, but man also has his domain, in 
which he is much superior to nature. Natural forces act in virtue of blind and necessary laws, the result of which is constant. Now man has acquired the knowledge of these laws, he has made use of them to constrain and master the natural forces one after another, he now knows how to exaggerate some and to weaken others. In this manner he changes their resultants, and obtains products which nature herself could not realise. Give to the latter all the time and space that you will, she would never be able either to produce or preserve potassium or sodium in a metallic form ; in spite of the physico-chemical forces, or rather by directing them, man has obtained and preserved these two metals, as he has obtained and preserved the Agilops triticoïles, which is destroyed by the inflexibility of natural forces as soon as it is exposed to their action.

VIII. The infertility, or, if you will, the restricted and rapidly limited fertility between species, and the impossibility of natural forces, when left to themselves, producing series of intermediary beings between two given specific types, is one of those general facts which we call a law. 'This fact has an importance in the organic world equal to that rightly attributed to attraction in the sidereal world. It is by virtue of the latter that the celestial bodies preserve their respective distances, and complete their orbits in the admirable order revealed by astronomy. The law of the sterility of species produces the same result, and maintains between species and between different groups in animals and plants all those relations, which, in the palæontological ages, as well as in our own, form the marvellous whole of the Organic Empire.

Imagine the suppression of the laws which govern attraction in the heavens, and what chaos would immediately be the result. Suppress upon earth the law of crossing, and the confusion would be immense. It is scarcely possible to say where it would stop. After a few generations the groups which we call genera, families, orders, and classes would most certainly have disappeared, and the branches also would rapidly have become affected. It is clear that only a few 
centuries would elapse before the animal and regetable kingdoms fell into the most complete disorder. Now order has existed in both kingdoms since the epoch when organised beings first peopled the solitudes of our globe, and it could only have been established and preserved by virtue of the impossibility of a fusion of species with each other through indifferently and indefinitely fertile crossings.

IX. There are some writers, very often entirely unacquainted with the natural sciences, who, labouring under the most varied prejudices, especially that of exaggerating the transmutation doctrines which I shall presently discuss, have denied the reality of species; they affirm that there are no serious barriers between the groups designated by this term, and have compared it in a more or less formal manner to the groups always somewhat arbitrarily called genera, tribes, families, orders, etc. Though only a brief recapitulation, the preceding facts would be sufficient to answer them. It is, however, necessary to mention the principal objections which are brought forward against such ideas, and to shew how they may be refuted.

1st. It is useless to take any notice of the good humoured or malicious banter, of the raillery and sarcasm too often made use of by some writers against those who admit the reality of species. It is evident that those who employ such weapons do not address themselves to men of science, but appeal directly to the passions. We cannot sufficiently express our regret at seeing men of undoubted merit resorting to such means.

2nd. At the present time, perhaps more than ever, those who believe in species are reproached with being orthodox: I could never myself understand why there should be this mixture of scientific discussions and dogmatic and antidogmatic polemics.

3rd. I shall, moreover, refuse to dispute with those who, rejecting on their own authority a whole century of work accomplished by the greatest naturalists, and by a number of men distinguished in botany and zoology, declare that it 
is useless to try and discover what species and race are, and langh at those who take the trouble to do so. I say the same to those who regard species and race as more or less arbitrary groups which may be compared to the genus, family and order. It will be enough to remark that they themselves incessantly employ the word species and race, and we must not be surprised if they take one thing for the other.

4.th. After what we have said, discussion is uscless with hose naturalists who only base the distinction of species apon external characters. They forget all the experiments made from Buffon to the two Geoffroys, from Kolreuter to M. Naudin; they forget the innumerable observations made in our orchards, gardens and stables. 'To refuse to abandon morphological considerations, and to neglect the data of physiology and the lessons of filiation, is clearly going further back than Ray and Tournefort, and all disciission becomes impossible.

5 th. Some of our opponents allow that things are now what we think them to be. "But," say they, "it is possible that at some other time it was different." What answer can be given to those who base their arguments upon possibitities? Is modern science composed of possibilities?

6th. Naturalists have often been reproached with multiplying the definitions of species. From the variety of terms employed by them in expressing ideas, it has been inferred that they were not agreed as to the ideas themselves. We may easily convince ourselves of their mistake, if we give these definitions a careful reconsideration. We shall see that their several authors have only endeavoured to express with greater clearness and precision, the double idea resulting from the facts of resemblance and filiation. In reality, divergencies only begin where experiment and observation cease. It is this which caused Isidore Geoffroy, however interested he might be in discussions of this nature, to remark - "Such are Species and Races, not only for one of the schools into which naturalists are divided, but for all." 


\section{Reality of Species.}

7th. It has been asserted that the distinction of species and race rests upon a syllogistic circle; that naturalists decided a priori upon calling all those groups incapable of intercrossing, species, and all those amongst which crossing was possible, races. To appeal to the difference of the phenomena presented by the hybrids and mongrels is therefore only solving the question by the question. - This is an historical error. Naturalists came into contact with species, races and varieties, before they gave names to them. It was by experiment and observation that they learnt te distinguish them. Knowuledge of facts preceded termin ology.

8th. Again, it has been said, that the discussions which are always arising between naturalists as to whether a species should be preserved or regarded as a race, as to the genus, family, order, and sometimes the class iri which it should be placed, betray a want of precision in general ideas.-Those who talk in this manner forget the immense number of species and races accepted and classified without discussion. They shut their eyes to all cases except those in which divergences of opinion occur. If, however, facts of this nature prove anything against a science and its fundamental data, then even mathematical theorems must be considered as wanting in precision, for there are disputes among mathematicians.

9th. I have already replied to the arguments drawn from the fertility of certain hybrids by showing to what it is reduced. Writers who insist upon this point invariably forget the lesson taught us by disordered variation and reversion without atavism. I regret being obliged to place among them Darwin, who, in his later writings, has shewn much less reserve than in his earlier publications. In the last edition of his book, he quotes what I have said of the cross between the Bombyx cynthia and the Bombyx arriadia; he speaks of the number of generations obtained, but he forgets to mention that disordered variation appeared in the second generation, and that reversion to one of the parental 
types was almost complete at the termination of the experiment.

$\mathrm{X}$. Species is then a reality.

Let us take a group of individuals more or less similar, but always capable of contracting fertile unions, and let us, with M. Chevreul, trace it in imagination to its origin. We shall see it divided into families, each of which will have risen either mediately or immediately from one pair of parents. We shall see that the number of these families decrease at each generation, and rising still higher we shall at length find the initial term of a single primitive pair.

Has this really been the case? Has each species indeed arisen from one single pair, or have several pairs, resembling each other perfectly both morphologically and physiologically, appeared simultaneously or successively? 'These are questions of fact which science neither can nor ought to approach, for neither experiment nor observation is able to furnish us with the smallest data requisite for the solution.

But what science may affirm is that from all appearances each species has had, as point of departure, a single primitive pail. 


\section{CHAP'TER IX.}

CROSSING BETWEEN HUMAN GROUPS.-UNI'TY OF 'THE HUMAN SPECIES.

I. WE now know what are species and race; the phenomena exhibited by mongrels and hybrids furnish us with an experimental means of distinguishing them. We can, therefore, now reply to the question which has necessitated this discussion: Are there one or many human species? Are the human groups races or species?

Unless we pretend that man alone of all organised beings is free from the laws which, in every other case, govern and regulate the laws of reproduction, and consequently, unless we make him a solitary exception precisely in that order of facts which most closely unites all other beings, we shall be forced to admit that he also obeys the laws of crossing.

Thus, if the human groups represent a more or less considerable number of species, we ought to prove in the crossings of their species the existence of the characteristic phenomena of hybridism. If these groups are only races of a single species, we ought, in crossings between them, to meet with the phenomena exhibited by mongrels.

II. It is scarcely necessary to recall what nearly four centuries of experience and observation have taught us. It may be recapitulated in a very few words.

Since Colombus commenced the era of great geographical discoveries, the White, the highest division of mankind, has penetrated to almost every part of the globe. He has everywhere met human groups which differed considerably from himself in every kind of character; he has everywhere 
mixed with them, and mixed races have everywhere sprung up in his track.

Further still, thanks to an institution, detestable indeed, but the results of which have been favourable to anthropology, the experiment is complete. The White has enslaved the Negro and taken him away with him to all parts of the globe, and where the local races have consented to intermix with the enslaved race, in every case they have produced mixed races of this inferior division. In America the Zambo is born side by side with the Minlatto and the Mamaluco.

'This crossing commenced less than four centuries ago, and some time has elapsed since M. d'Omalius estimated that mixed races constituted at least $\frac{1}{80}$ of the entire population of the globe, and he emphatically declared that he had only taken the half-breeds of extreme races into consideration.

In South America, where Whites, Blacks and natives have long been in contact and have intermingled more freely, there are whole States in which half-breeds are in the majority, and in which it is extremely difficult to find a native of pure blood.

Have subterfuges or precautions been necessary to form these unions and to insure the fertility of the offspring? Quite the contrary. The tyranny of the Whites, the crimes of slavery, afford quite sufficient proof that in this case fertility was not dependent upon circumstances, but simply upon the physical connections existing between all men from the lowest of the Negroes to the first of the Whites.

Has such facility, such certainty as this been experienced in the production of chabins and leporides?

If another proof were necessary of the facility with which human groups intercross, it might be found in one of those testimonies the value of which is undisputed because they give the result of a daily experience. In 1861, the Californian legislature declared that any white person convicted of having cohabited with or married a Negro, Mulatto, Chinese or Indian, had forfeited all his rights, and became 
subject to all the constitutional incapacities imposed upon men of colour. The local press announced very plainly that the object of this measure was the prevention of the fusion and amalgamation of the races.

The Californian legislature acted on this occasion like the proprietor of a flock of pure breed which he is anxious to keep free from all mixture. It was even more severe, ejecting from legal society, not only the offspring of the cross, but also the transgressing parents of the white race.

Do not our breeders take similar precautions in the case of races only, and not in the case of species?

Far from being sterile, unions between human groups apparently the most distinct are sometimes more fertile than those between individuals taken from the same group. "Hottentot women," says Le Vaillant, "with husbands of their own race have three or four children. With Negroes this number is tripled, and it is still further increased with Whites." M. Hombron, during four years which he spent in Brazil, Chili and Peru, studied this phenomenon in a large number of families. "I am able to state," he says, "that unions of Whites with American women have given the highest average of births. Next come the Negro and Negress. And thirdly the Negro and the American woman." Unions between Americans themselves gave the lowest average.

Thus, the maximum of fertility is here presented in a case which would constitute a hybridism in the opinion of polygenists; the minimum is exhibited between individuals of the same group, and it is with the woman belonging to the latter, that, owing to the cross, the maximum is obtained.

These facts are significant. In no case of crossing between species has fertility been observed to increase; on the contrary it is almost always diminished, and often, as we have seen above, in an immense proportion. Crossings. between races have alone presented facts analogous to those mentioned by Hombron and Le Vaillant.

III. Thus, in every case crossings between human groups 
exhibit the phenomena characteristic of mongrels and never those of hybrids.

Therefore, these human groups, however different they may be, or appear to be, are only races of one and the sume species and not distinct species.

Therefore, there is but one human species, taking this term species in the acceptation employed when speaking of animals and plants.

IV. Anyone who refuses to accept these conclusions must either deny all the facts of which it is the necessary consequence, or reject the method employed in the examination and appreciation of these facts.

But these facts are borrowed entirely either from scientific experiments, made without any discussion or controversy by men of the highest authority, or drawn from the innumerable experiments which are daily practised by agriculturalists, horticulturalists, and breeders. It is therefore very difficult to deny them.

As to the method, it is erident thet it rests entirely upon the identity of the general laws governing all organised and living beings. Few true men of science will, I am sure, refuse to admit such a starting point as this.

Now I wish that candid men, who are free from partyspirit or prejudices, would follow me in this view, and study for themselves all these facts, a few of which I have only touched upon, and I am perfectly convinced that they will, with the great men of whom I am only the disciple,-with Linnæus, Buffon, Lamarck, Cuvier, Geoffroy, Humboldt and Muiller, arrive at the conclusion that all men belong to the sume species, and that there is but one species of man. 


\section{BOOK II.}

\section{ORIGIN OF THE HUMAN SPECIES.}

\section{CHAPTER X.}

ORIGIN OF SPECIES.-HYPOTHESES OF TRANSIIUTATION.DARWINISM.

I. THE unity of the human race raises some general questions, and entails consequences which we must now examine.

The first question which is suggested to the mind is evidently that of origin. Without abandoning the strictly scientific aspect of the subject, that is to say, confining ourselves to the results of experiment and observation, can we explain the appearance on our globe of a being which forms a kingdom by itself? I do not hesitate to reply in the negative.

Let us admit at starting that we cannot consider separately the question of the human origin. Whatever may be the cause or causes which preside over the birth or the derelopment of the organic lingdom, it is to them that the origin of all organised and living bodies must be traced. The similarity between all the essential phenomena which they exhibit, the identity of the general laws which govern them, render it impossible to suppose that it can be otherwise. The problem then of the origin of mankind becomes identical with that of all animal and vegetable species.

II. This problem has been approached very frequently and by many methods. But here we can only take into account 
the attempts which have been made in the name of scicnce. Nor can these possess any interest for us until the time when it was at least possible to make a clear statement of the question, which was impossible as long as no clear definition had been given of organic species. In an historic account of the attempts which have been made to solve the question, it is useless, therefore, to go further back than Ray and Tournefort. 'The publication of Maillet in 1748 is the first attempt which deserves passing attention.

I do not intend to repeat here the account which I have given elsewhere of the different theories proposed by that talented author, by Buffon, Lamarck, Et. Geoffroy St.-Hilaire, Bory de St.-Vincent, and by Naudin, Gaudry, Wallace, Owen, Gubler, Kölliker, Hacckel, Filippi, Vogt, Huxley, and Mme. Royer. They all have this point in common; they connect the origin of the more highly developed species with transmutations undergone by inferior species. But there the resemblance ceases, and their theories frequently differ entircly on all other points. In short, their ideas may be arranged in two principal groups according as their authors fivour a rapid or a gradual transmutation. The former ardmit the sudden appearance of a new type produced by a being entirely different: according to them the first bird came from the egg of a reptile. The latter maintain that the modifications are always gradual, that between one species and another a number of links have intervened which unite the two extremes. They consider that types are only multiplicd slowly, and by a progressive differentiation.

In reality the first of these two theories has never been stated in such a mamner as to form a real doctrine; it has never formed a school. The philosophers who promoted it confined themselves most frequently to pointing out, in a general manner, the possibility of the phenomenon, while they attributed it to some accident. At most they involie in aid of this possibility, some analogies borrowed from the listory of ordinary individual development, from that of 
aiternate generation, or of hyper-metamorphosis; they produce no definite fact in justification of their assertions.

With the exception perhaps of the hypothesis of M. Naudin, which we shall presently discuss, all these theories which favour a rapid transmutation deserve a still graver reproach, that, namely, of neglecting the great general facts exhibited by the organic kingdom. An explanation of the multiplication and the succession of principal or secondary types by some hypothesis is not sufficient. Special account must be taken of the relations which connect these types, of the order which rules the whole and which has been maintainerl from remote geological periods through all the revolutions of the globe, and in spite of changes in fauna and flora.

Accident, without rule or law, when invoked as the immediate cause of special transmutations, is obviously incapable of explaining this important fact; it gives no explanation whatever of the generality of fundamental types, and of the direct or lateral affinities which exist between their derivatives.

It is different with the theories which favour gradual transmutation. They deal with all these important questions, and give a more or less plausible solution of them. They start from a certain number of principles whose consequences more or less explain the whole question and many of its details. In a word, they constitute genuine doctrines and it is but natural that they should have gained a certain number of adherents.

Unfortunately these theories all have the same radical fault. They agree with a certain number of important facts, connected essentially with the morphology of beings; but they are in direct contradiction with the fundamental phenomena of general physiology, which are no less general or fixed than the former. This contradiction is not evident at first sight. This is the reason why these doctrines have influenced not only the public at large, but even men of the highest intellect, whose sole error consists in their having allowed themselves to consider one side of the question only. 
All these theories have been consolidated into the doctrine which rightly bears the name of Darwin. At the hands of this illustrious naturalist, the hypothesis of gradual transmutation has assumed a force and appearance of truth which it never possessed before. Doubtless, long before Darwin, Lamarck had formulated his law of heredity and his law of development of organs, to which the English naturalist has added nothing; M. Naudin had compared natural selection to artificial selection; Etienne Geoffroy St.-Hilaire had promulgated the principle of the balance of organs; Serres and Agassiz had recognized in embryogenic phenomena the representation of the genesis of beings. But by taking as a starting point the struggle for existence; by explaining in this manner selection; by fixing the results of heredity; by replacing the pre-established laws of Lamarck by the laws of divergence, continuity, permanent characters and of finite heredity; by giving by these means an explanation of the adaptation of beings to all the conditions of existence, the expansive power of some, the localisation of others, the successive modifications of all, under the dominion of the laws of compensation, economy and of correlation of increase; by applying these facts to the past, present and future of animate creation, Darwin has formed a complete and systematic theory, the whole, and often the details, of which it is impossible not to admire.

I understand the fascination exercised by this profound and ingenious conception, which is supported by immense knowledge, and ennobled by his loyal honesty. I should doubtless have yielded as so many others have done, if I had not long understood that all questions of this kind depend especially upon physiology. Now, my attention once aroused, I found no difficulty in recognising the point at which the eminent author quits the ground of reality and enters upon that of inadmissible hypothesis.

I have thought it right to publish my criticisms upon the theory of transmutation, and upon Darwinism in particular. I was authorised to do so by the numerous attacks which 
have often been made, in no measured terms, against what I consider to be the truth, and against every opponent of the new theory. But while refuting theories I have always respected the authors and done justice to their work. I have quoted the good as well as the bad, and have always held aloof from the ardent and lamentable polemics raised by transmutation.

I have liad great pleasure, when occasion has offered, in defending the splendid researches made by Darwin in the natural sciences. For this very reason, and at the risk of being considered narrow minded, enslaved to prejudices and unable to leave an old groove, etc., etc., I consider myself entitled to attack Darwinism, if I employ none but the weapons of science.

III. There are some points in Darwinism which are perfectly unassailable. We may consider as the most important the struggle for existence, and selection which is the result of it. It is not the first time, certainly, that the former has been established, and the important part it has to play in the general harmony of the world has at least been partly comprehended. I will here only recall to the mind of my readers the fables of La Fontaine. But no one had insisted, as Darwin has done, upon the enormous disproportion which exists between the number of births and the number of living individuals; no one had investigated, as he has, the general causes of death or of survival which produce the final result. By pointing out the fact that each species tends to increase in number in geometrical progression, which is proved by the number of offspring to which a single mother can give birth during the whole course of her life, the English naturalist makes it easy to comprehend the intensity of the struggles, direct or indirect, which are undergone by animals and plants against one another and the surrounding world. It is, most certainly, entirely orving to this struggle for existence, that the whole world, in a few years, is not overrun by some species, or the rivers and ocean filled in the same manner. 
It is no less evident to me that the survivors camnot always owe their preservation to a combination of happy chances. Among the immense majority the victory can only be due to certain special advantages, which are not enjoyed by those who succumb. The result of this struggle for existence is, then, the destruction of all the inferior individuals, and the preservation of those individuals only which possess some kind of superiority. This is what Darwin calls Natural Selection.

I can scarcely understand how these two phenomena can be doubted or even denied. They do not constitute a theory, but are facts. Far from being repugnant to the mind, they seem inevitable, the consequences follow with a sort of necessity and fatality resembling the laws of the inorganic world.

The term selection gives rise to criticism, and the language of Darwin, at times too figurative, renders plausible the objection of those who have reproached him with attributing to nature the part of an intelligent being. The word eliminution would have been more exact. But much of this should have been prevented by the explanations given by the author. Besides, it is evident that the struggle for existence entails the elimination of individuals who are less able to sustain it, and that the result exactly resembles that produced by unconscious human selection. Then heredity intervenes among beings which are free as well as among those which we bring up in captivity. It preserves and accumulates the progress made by each generation in any direction, and the final result is the production in the organism of certain appreciable anatomical and physiological modifications.

The words superior and inferior should here only be. taken as relative to the conditions of existence in which animals and vegetables are placed. In other words the individual which is best adapted to those conditions, will bi superior and will conquer in the struggle for existence. For instance, the black rat and the mouse have both to struggle against the brown rat which entered France during the last 
century from the banks of the Volga. The black rat was almost as large and as strong as his adversary, but less ferocious and less prolific. It has been exterminated in spite of refuges which are inaccessible to its enemy. The mouse, which is much weaker, but at the same time much smaller, can retire into holes which are too small for the brown rat; it has therefore survived the black rat.

Is it possible to admit that selection and heredity act equally upon that indefinable something which is connected with the rudimentary intelligence and instincts of animals? With Darwin I unhesitatingly reply in the affirmative. With animals, as with man, all the individuals of the same species hare not an equal amount of intelligence and do not invariably possess the same aptitudes; certain instincts, like certain forms, are capable of modification. Our domestic animals furnish a number of examples of these facts. The wild ancestors of our dogs were certainly not accustomed to point at game. When left to themselves and placed under new conditions of existence, animals sometimes change their manner of life entirely. Beavers, from being disturbed by hunters, have dispersed; they have now abandoned the construction of their lodges and dig out long burrows in the banks of rivers. The struggle for existence must have been favourable to the first discoverers of this new method of escaping from their persecutors, and natural selection, while preserving them and their descendants, has converted in sociable and constructive animal into a solitary and burro:?ing one.

Up to this point it is evident that I agree in all that Darwin has said on the struggle for existence and natural selection. I disagree with him when he attributes to them the power of modifying organised beings indefinitely in a given direction, so that the direct descendants of one species form another species distinct from the first.

IV. The fundamental cause of the disagreement arises evidently from the fact that Darwin had formed no clear conception of the sense which he attributed to the word 
species. I have been unable to find in any of his works a single precise statement on this point. The accusation is more severe from being brought with justice against an author who claims to have discovered the origin of species.

More frequently Darwin seems to adhere to a purely morphological idea, which is also somewhat vague. He often opposes species and race, which he also calls variety, but without ever stating clearly what he understands by one or the other. He endeavours, moreover, to bring them together as closely as possible, though occasionally recognising some of the points which separate them. "The species," he says in drawing one of his conclusions, "must be treated as an artificial combination which is necessary for convenience." His disciples have followed him faithfully in this direction, and those who use the most explicit language on this subject, join their master in declaring that a species is only a kind of conventional group similar to those which are used in classification. As for races, they are only species undergoing transmutation. Now from what he has already learnt, short though the study has been, the reader knows, I hope, to which view he should adhere, and understands to what confusions such a vague kind of theory must lead.

In spite of the inevitable uselessness of a discussion of this kind, let us follow our adversaries into this unstable ground, and see whether morphological facts furnish their theory with the least probability.

Darwin himself, on several occasions, states that the result of selection is essentially to adapt animals and plants to the conditions of existence in which they have to live. Upon this point I agree with him entirely. If, however, harmony is once established between organised beings and the conditions of life, the struggle for existence and selection could only result in consolidating it and consequently their action is preservative.

If the conditions of life change they will again come into play in order to establish a new equilibrium, and modificatious more or less marked will be the result of their action. 
But will these modifications be sufficiently great to give rise to a new species? The following fact will serve as a reply.

At the present time there is a stag in Corsica, which from its form has been compared to the badger-hound: its antlers differ from those of European stags. Those who confine themselves to morplological characters, will assuredly consider this as a distinct species, and it has often been considered to be so. Now Buffon preserved a fawn of this pretended species, and placed it in his park; in four years it became both larger and finer than the French stags which were older and considered finer grown. Moreover, the formal evidence of Herodotus, Aristotle, Polybius and Pliny attest that in their time there were no stags either in Corsica or Africa. Is it not evident that the stag in question had been transported from the continent to the island; that under the new conditions the species had undergone temporary morphological modification, though it had lost none of its power of resuming its primitive characters, when placed in its primitive conditions of life?

Are we, then, to conclude that in time nature could have completed the action, and entirely separated the Corsican stag from its original stock? We may answer in the negative, if any weight is to be attached to experience and observation.

Species partially subject to the rule of man furnish a number of facts which enable us to compare the power of natural forces, when abandoned to their own action, with that of man in modifying a specific type. In all artificial races varieties are infinitely more numerous, more varied and more marked than wild races and varieties. Now the result of these transmutations of organisms has only consisted in the formation of races, never in the formation of a new species. Darwin himself accepts this conclusion implicitly in his magnificent work on pigeons; for when speaking of the races of pigeons he only says that the difference of form is such that if they had been found in a wild state, we should have been compelled to make at least three or four genera of them. The wild rock pigeons, the original stock of all our 
domestic pigeons, only differ, on the contrary, in shades of colour.

'The result is always the same, whenever we can compare the work of nature with our own. When he has anything to do with any vegetable or animal species, man always changes its character, sometimes, after a lapse of some years, the change being much greater than that produced by nature since the species first came into existence. The effect of the conditions of life (milien), of which we will speak presently, the struggle for existence and natural selection understood as I have just described it, the power which man possesses of directing natural forces and changing their resultant, easily explain this superiority of action.

Consequently, without leaving the domain of facts, and only judging from what we know, we can say that morphology itself justifies the conclusion that one species has never produced another by means of derivation. To admit the contrary is to call in the unknown, and to substitute a possibility for the results of experience.

Physiology justifies a still stronger assertion. Upon this ground also man is shown to be as powerful as nature, and for the same reasons. With our cultivated plants and domestic animals, it is not only the primitive form which has undergone change, but certain functions also. If we had only enlarged and deformed the wild carrot and the will? radish, it would not have become more eatable. To render it agreeable to our taste, the production of certain substances had to be reduced, and that of others enlarged, that is to say, nutrition and secretion had to be modified. If the functions in wild animal stocks had remained permanent, we should have had none of those races which are distinguished by a difference in the colour of the hair, in the production of milk, in aptitude for work, or in the production of meat. If instinct itself had not obeyed the action of man, we should not have had in the same kennel, pointers, grey-hounds, truffle dogs and terriers.

Nature produces nothing like this. To admit that similar 
results will one day follow from the action of natural forces is to appeal to the unknown, to possibility, and runs counter to all laws of analogy, and all the results furnished by experience and observation.

Man's superiority over nature is quite as clearly shown in the group of phenomena, which relate to the question with which we are now dealing.

We have seen how rare are the cases of natural hybrids among plants themselves; we have also seen that no cases are known among mammalia. Now since man has begun to make experiments in this direction, he has increased the number of hybrids among plants, and among animals also. Moreover, he has succeeded in preserving for more than twenty generations, a hybrid which he has been able to protect from reversion and disordered variation. But we know the care that was necessary to insure the continuance of cegilops speltaformis. If this plant had been left to itself, it would soon have disappeared.

The single exception which is known confirms therefore the law of steritity among species left to themselves. Now this law is in direct opposition to all the theories, which like Darwinism, tend to confuse species and race. This has been clearly understood by Huxley and has caused him to say, "I adopt the theory of Darwin under the reserve that proof should be given that physiological species can be produced by selective crossing."

This proof has not yet been given, for it is a strange abuse of words to call by the name of species, the series of hybrids whose history I have given above, viz.: the leporides and the chabins. But even if the proof demanded by Huxley were furnished, it does not follow that the greatest objection to the Darwinian theories would be removed.

In fact, in this theory, as in all those which rest upon gradual transmutation the new species derives its origin from a variety, possessing a character which is at first rudimentary, but which is developed very gradually, making some progress in each generation. The result of this is that 
between successive individuals the only difference is that of race. Now, as we have seen, the fertility among races of the same species remains constant, and consequently, in the hypothesis of Darwin, as in that of Lamarck, etc., the fertile crossings would in every sense of the word constantly confuse the original and the derived species which was in process of formation. The same cause having produced the same effects since the commencement of the world, the organic world would present the greatest confusion instead of its well-known order.

Darwin, then, himself and his most enthusiastic adherents must admit that at some given moment these races became suddenly incapable of crossing with their predecessors. Whence then arises the sterility which separates species? When, and at what moment will the physiological bond be broken, which unites the original species with its modified descendants, even when this modification is carried as far as the ordinary $o x$ and the niata? What will be the determining cause of this great fact which obtains through the whole economy of the organic kingdom?

In his work upon the Variation of Animals and Plants, Darwin replies: "Since species do not owe their mutual sterility to the accumulative action of natural selection, and a great number of considerations show us that they do not owe it to a creative act, we ought to admit that it has been produced incidentally during their gradual formation, and is connected with some unknown modification of their organisation."

We have seen that, in the last editions of the Origin of Species, he refuses to admit that fertility among mongrels is general, taking his stand upon our ignorance on the subject of crossings between wild varieties (races).

Thus, in order to admit the physiological transmutation of race into species, a fact which is contrary to all positive facts, Darwin and his followers reject the secular results of experience and observation, and substitute in their place a possible accident, and the unlinown. 


\section{Daruinism.}

The Darwinian theory relies entirely upon the possibility of this transmutation. We see upon what data the hypothesis of this possibility rests. Now, in a truly liberal spirit, I ask every unprejudiced man, however little he may be conversant with science, the question, is it upon such foundations that a general theory in physics or chemistry would be founded?

V. Moreover, the argument, of which we have just seen an example, may be found in every page of Darwinian writings. Whether a fundamental question, such as we have just been examining, or a minor problem, as the transmutation of the tomtit into the nuthatch, is under discussion, possibility, chance, and personal conviction are invariably adduced as convincing reasons. Is modern science established upon such foundations?

Darwin and his disciples wish that even our ignorance on the subject of certain phenomena should be considered as in their favour. The question has often been argued on the ground of palæontology, and they have been asked to point out a single instance of those series which ought, according to them, to unite the parent species with its derivatives. They admit their inability; but they reply that the extinct fauna and flora have left very few remains; that we only know a small part of these ancient archives; that the facts which favour their doctrine are doubtless buried under the waves with submerged continents, etc. "This nanner of treating the question," Darwin concludes, "diminishes the difficulties considerably, if it does not cause them to disappear entirely."

But, I again ask the question, in what branch of human knowledge, except these obscure subjects, should we regard problems as solved, for the very reason that we possess none. of the requisite knowledge for their solution?

I do not intend to reproduce here the entire examination which I have made elsewhere of the transmutation theories in general, or of Darwinism in particular. The above observations will suffice, I hope, to show why I could not accept 
even the most seductive of these theories. In certain points they agree with certain general facts and give an explanation of a ccrtain number of phenomena. But all without exception attain this result only by the aid of hypotheses which are in flagrant contradiction with other general facts, quite as fundamental as those which they explain. In particular, all these doctrines are based upon a gradual and progressive derivation, upon the confusion of race and species. Consequently they ignore an unquestionable physiological fact; they are entirely in opposition with another fact, which follows from the first, and is conspicuous from crery point of view, the isolation, namely, of specific groups from the carliest ages of the world, and the maintenance of organic order through all the revolutions of the globe.

Such are my reasons for refusing my adherence to Darwin's theories.

VII. The theory of the English naturalist is certainly the most vigorous effort which has been made to trace back the origin of the organic world by processes analogous to those which we have discovered in the genesis of the inorganic world, that is to say, in only having recourse to secondary causes. He has failed, as we see, like Lamarck. These eminent men will be succeeded by others who will attempt the solution of the same problem. Will they be more fortunate?

No one is less inclined than I am to place any limit upon the extension of human knowledge. Yet the extension of our scientific knowledge, in the widest sense of the term, is always subordinate to certain conditions. The most attentive cxamination, even of a human work, will never teach us anything of the processes which have permitted its realisation. The cleverest watchmaker, if he has not followed studies perfectly foreign to his vocation, will know nothing of the origin of iron, of its transformation into stecl, of the rolling and tempering of a main spring. The minutest study of that metallic ribbon which he knows so well, will tell him nothing of its origin, nothing of the process of its fabrication. 
To know more he must leave his shop and visit the furnaces, the forges, and the rolling mills.

In the works of nature it is the same. With nature as well as with ourselves, the phenomena which produce are very different from those which preserve, and from those displayed in the object produced.

The most complete anatomical and physiological study of an animal or of a full-grown plant will certainly teach us nothing about the metamorphoses of the microscopic cell from which sprang the dog, the elephant, and man himself.

Now hitherto we have only directed our attention to species already formed. We can therefore learn mothing more relative to their mode of production.

But we know that the unknown cause which has given birth to extinct and living species has been manifested at different times and intermittingly upon the surface of the globe. Nothing authorises us to suppose that it is exhausted. Although it appears to have generally acted at times which correspond to great geological movements, it is not impossible that it may be at work on some point of the earth even at this epoch of relatively profound rest. If this is the case, perhaps some happy chance will throw a little light upon the great mystery of organic origins. But until experience and observation have taught us something, all who wish to remain faithful to true science, will accept the existence and succession of species as a primordial fact. He will apply to all what Darwin applies to his single prototype; and, in order to explain what is still inexplicable, he will not sacrifice to hypotheses, however ingenious they may be, the exact and positive knowledge which has been won by nearly two centuries of work. 


\section{CHAPTER XI.}

ORIGIY OF THE HUMAN SPECIES.-DIFEERENT HYPOTHESES.

I. THE preceding chapter might enable me to dispense with a discussion of the applications which have been made of Darwinism to the history of man. Nevertheless, apart from the curious points in the subject itself, some discussion of it will be necessary, for it will not be devoid of instruction.

Lamarck endeavoured to show how, by means of his theory of habit, it was possible to conceive the direct transmutation of the chimpanzee into man. The Darwinists also agree in connecting man with the apes. Nevertheless none of them point out any of the species at present existing as our immediate ancestor; on this point they differ from their illustrious predecessor. It might be supposed that Vogt had determined this point if we take literally some passages of his Leçons sur l'homme. But the Genevese savant has clearly expressed his theory in his Mémoire sur les Microcéphales. He carries back the point of departure common to the two types to an anterior ancestor. Darwin, Wallace, Filippi, Lubbock, Haeckel, etc., connect man still more closely with the apes. The latter states his conclusions in the following terms:-

"The human race is a branch of the catarrhine group; he was developed in the old world, and sprang from apes of this group, which have long been extinct."

II. Vogt disagrees with his scientific colleagues in an important point. He admits that different simian stocks may have given rise to different human groups. The populations of the old and the new world would thus be descendants of the different forms which are peculiar to the two continents. On this hypothesis, Australia and Polynesia, 
where there never have been apes, must necessarily have been peopled by means of migration.

The eminent professor of Geneva, moreover, always confines himself to a somewhat vague statement of his ideas relative to the genealogies which he thinks fit to attribute to the different groups of mankind.

III. Darwin and Haeckel have been bolder. The former has published an important work upon the Descent of Man, and the latter in his History of the Creation of Urganised Beings has treated the same subject in detail, and given the genealogical table of our supposed ancestors, starting from the most simple known animals. The master and the disciple agree almost invariably, and it is to Haeckel himself that Darwin refers the reader who is curious to know the human genealogy in detail. Let us glance rapidly at the origin assigned to us by the German naturalist.

Haeckel considers as the first ancestor of all living beings the monera, which are nothing more than the amocbce as understood by Dujardin. From this initial form man has reached the state in which we now find him, by passing through twenty-one typical transitory forms. In the present state of things our nearest neighbours are the anthropomorphous or tailless catarrine apes, such as the orang, the gorilla, the chimpanzee, etc. All are sprung from the same stock, from the type of the tailed catarrhine apes, the latter are descended from the prosimice, a type which is now represented by the macaucos, the loris, etc. Next come the marsupials, which form the 17th stage of our evolution; further examination is useless.

Although the distance between anthropomorphous apes and man appears to be but small to Haeckel, he has nevertheless thought it necessary to admit the existence of an intermediate stage between ourselves and the most highly developed ape. This purely hypothetical being, of which not the slightest vestige has been found, is supposed to be detached from the tailless catarrhine apes, and to constitute the 21st stage of the modification which has led to the 
human form, Haeckel calls it the ape-man, or the pithecoid-man. He denies him the gift of articulate speech as well as the development of the intelligence and self-consciousness.

Darwin also admits the existence of this link between man and apes. He says nothing as to his intellectual faculties. On the other hand he traces out his physical portrait, basing his remarks upon a certain number of exceptional peculiarities observed in the human species, which he regards as so many phenomena of partial atavism. "The earliest ancestors of man," he says, "were without doubt once covered with hair; both sexes having beards; their ears were pointed and capable of movement; and their bodies were provided with a tail laving the proper muscles. Their limbs and bodies were acted on by many muscles, which now only occasionally reappear in man, but which are still normally present in the quadrumana. The great artery and nerve of the humerus ran through a supracondyloid foramen. At this, or some earlier period, the intestine gave forth a much larger diverticulum or cœcum than that now existing. The foot, judging from the condition of the great toe in the fotus, was then prehensile, and our progenitors, no doulut, were arboreal in their habits, frequenting some warm forest-clad land; the males were provided with canine teeth which served as formidable weapons."

IV. In attributing a tail to our first direct ancestors Darwin connects him with the type of tailed catarrhines, and consequently removes him a stage backward in the scale of evolutions. The English naturalist is not satisfied to take his stand upon the ground of his own doctrines, and, like Haeckel, on this point places himself in direct variance with one of the fundamental laws which constitute the principal charms of Darwinism, whose force I am far from denying.

In fact, in the theory of Darwin, transmutations do not take place, either by chance or in every direction. They are ruled by certain laws which are due to the organisation 


\section{Theorics of Darwin and Haeckel.}

itself. If an organism is once modified in a given direction, it can undergo secondary or tertiary transmutations, but will still preserve the impress of the original. It is the law of permanent characterisation which alone permits Darwin to explain the filiation of groups, their characteristics and their numerous relations. It is by virtue of this law that all the descendants of the first mollusc have been molluses; all the descendants of the first vertebrate have been vertebrates. It is clear that this constitutes one of the foundations of the doctrine.

It follows that two beings belonging to two distinct types can be referred to a common ancestor, whose characters were not clearly developed, but the one cannot be the descendant of the other.

Now man and apes present a very striking contrast in respect to type. Their organs, as I have already remarked, correspond almost exactly term for term; but these organs are arranged after a very different plan. In man they are so arranged that he is essentially a waller, while in apes they necessitate his being a climber just as strongly.

There is here an anatomical and mechanical distinction which had already been proved, as regards the inferior apes, by the works of Vicq d'Azyr, Lawrence, Serres, etc. 'The investigations of Duvernoy on the gorilla, of Gratiolet and M. d'Alix upon the chimpanzee, have established the fact that the anthropomorphous apes possess the same fundamental character in every point. Moreover, a glance at the page where Huxley has figured side by side a human skeleton and the skeletons of the most highly developed apes, is a sufficiently convincing proof of the fact.

The consequence of these facts, from the point of view of the logical application of the law of permanent characterisation, is that man cannot be descended from an ancestor who is already characterised as an ape, any more than a catarrhine tailless ape can be descended from a tailed catarrhine. A walling animal cannot be descended from a climbing one. This was clearly understood by Vogt. In placing man among the 
primates he declares, without hesitation, that the lowest class of apes have passed the landmark (the common ancestor) from which the different types of this family have originated and diverged.

We must then place the origin of man beyond the last ape if we wish to adhere to one of the laws most emphatically necessary to the Darwinian theory. We then come to the prosimia of Haeckel, the loris, indris, etc. But these animals also are climbers; we must go further, therefore, in search of our first direct ancestor. But the genealogy traced by Haeckel brings us from the latter to the marsupials.

From man to the kangaroo the distance is certainly great. Now neither living nor extinct fauna show the intermediate types which ought to serve as landmarks. This difficulty causes but slight embarrassment to Darwin. We know that he considers the want of information upon similar questions as a proof in his favour. Haeckel doubtless is just as little embarrassed. He admits the existence of an absolutely theoretical pithecoid man, and it is not the only instance in which he proceeds in a similar manner in order to complete his genealogical table. Take as an instance his words upon the sozoura (14th stage), an amphibious animal which is equally unknown to science. "The proof of its existence arises from the necessity of an intermediate type between the 13th and the 14th stage."

Thus, since it has been proved that, according to Darwinism itself, the origin of man must be placed beyond the 18th stage, and since it becomes, in consequence necessary to fill up the gap between marsupials and man, will Haeckel admit the existence of four unknown intermediate groups, instead of one? Will he complete his genealogy in this manner? It is not for me to answer.

V. Darwin and Haeckel will most certainly think it very strange that a representative of the old school, a man who believes in the reality of species, should have the pretension to be better acquainted with the application of the laws of Darwinism than themselves, and to point out serious lapses 
in the applications they have made. Let us take our stand then on the ground of facts. There we shall at once find proof that this genealogy is wrong throughout, and is founded on a material anatomical error.

Both Darwin and Haeckel connect the simian series with a type which would now be represented by the lemuridoe, which the latter designates by the term prosimia. The only grounds which Darwin assigns for this opinion are certain characters taken especially from dentition. Haeckel gofs back to embryogenesis.

We know that with the exception of the marsupials (kangaroos, sarrigue), and the monotremata (ornithorhynchus, echidna), all mammals have a placenta, an organ essentially composed of a network of blood-vessels, which unites the mother to the foetus, and serves for the nutrition of the latter. With the ruminants, the edentata, and the cetacea, the placenta is simple and diffuse, that is to say, the tufts of the blood-vessels are developed upon the entire surface of the fotal envelope, and are in direct communication with the inner surface of the uterus. In the rest of the mammals the placenta is double; half being derived from the mother, and half from the fœetus, or rather its external envelope. A special membrane called the Decidua covers the interior of the uterus, and unites the placentæ. Haeckel, correctly attaching great importance to these anatomical differences, divides mammals into two great groups: the indeciduata, which. have no decidua, and the deciduata, which possess it.

Among the latter the placenta can surround the mammalian ovum like a girdle (zonoplacentalia), or form a kind of circular disc more or less developed (discoplacentalia). Man, apes, bats, insectivora, and rodents, present the latter arrangement, and thus form a natural group to which no zonoplacential, and, of course, no indeciduate mammais can be admitted.

Haeckel, without the least hesitation, adds his prosimice to the groups which I have just enumerated, that is to say, he attributes to them a decidua and a discoidal placenta. 
Now the anatomical investigations of MM. Alphonse Milne Edwards and Grandidier upon the animals brought by the latter from Mradagascar place it beyond all doubt that the prosimiæ of Haeckel have no decidua and a diffuse placenta. They are-indeciduata. Far from any possibility of their being the ancestors of the apes, according to the principle laid down by Haeckel himself, they cannot even be regarded as the ancestors of the zonoplacential mammals, the carnivora for instance, and ought to be connected with the pachydermata, the edentata and the cetacea.

Darwin and Haeckel will, perhaps reply that when they made their genealogies, the embryogenesis of the prosimix was not known. But why then represent them as one of the intermediate links to which they attach so much importance? Their process is always the same, considering the unknown as a proof in favour of their theory.

VI. 'The necessity, which I think has been clearly proved, of secking elsewhere than among the prosimix for the link which is required between the marsupials and the apes, would not invalidate the relationship between the latter and man. There are, however, other facts which are irreconcilable with the theory.

M. Pruner Bey, resuming the descriptive and anatomical works which have been carried on till within the last few years, has shown that the comparison of man with the anthropomorphous apes brings to light a fact which is subject to very few exceptions, the existence, namely, of an inverse order in the development of the principal organs. The researches of Welker upon the sphenoïdal angle of Virchow lead to the same conclusion, for in man the angle diminishes from the time of birth, whilst in the ape it is always increasing, so much so that sometimes it is effaced. It is upon the base of the cranium that the German anatomist has remarked this inverse order, the importance of which cannot escape notice.

A similar contrast has been remarked by Gratiolet upon the brain itself. The following are his observations upon 
this subject. In the ape the temporal sphenoïdal convolutions, which form the middle lobe, make their appearance and are completed before the anterior convolutions which form the frontal lobe. In man, on the contrary, the frontal convolutions are the first to appear, and those of the middle lobe are formed later.

It is evident, especially after the most fundamental principles of Darwinism, that an organised being cannot be a descendant of another whose development is in an inverse order to its own. Consequently, in accordance with these principles, man cannot be considered as the descendant of any simian type whatever.

VII. I have said above that palæontology has never shown anything which recalls in the slightest degree the hypothetical pithecoid man of Haeckel. A hope was felt that what could not be found among extinct forms might be found among living ones. Vogt has compared the brain of microcephali to that of the anthropomorphous apes, and Haeckel has represented in his genealogical table of idiots, crétins and microcephali as actual representatives of his speechless man. These beings, with their small brain and incomplete faculties, are, according to these two naturalists, cases of atavism, and recal the normal state of our most remote direct ancestors.

Here we have another instance of the curious method of reasoning familiar to Darwinists. Microcephalism, idiotcy, and crétinism constitute so many teratological or pathological states. They belong, consequently, to the very numerous groups of facts which have long been studied. If some of these facts can be regarded as phenomena of atavism, why should it be otherwise with the rest? Why attribute to atavism a single character only in crétins and microcephali, and refer the other to teratology and pathology? This is evidently an entirely arbitrary kind of treatment, and as much opposed as possible to the true scientific method.

After the works of teratologists, after the experiments of Geoffroy, so ably resumed and completed by M. Dareste, the part played by pathogenic causes, even by external causes, in 
arrested development cannot be denied. Now microcephalism is nothing else than arrested development acting on the cranium and its contents. But this is not an isolated case. Other organs and functions in microcephali suffer in the same manner. They have been proved to be always sterile, and certainly sterility is not a phenomenon which can be referred to atavism.

Thus among microcephali a teratogenic cause is clearly proved to have acted on part of the organism, viz., the generative organs. What reason can be alleged for attributing alterations of the cranium and brain to an entirely different cause? By virtue of what principle can two facts be separated, which observation has shown to be so intimately connected with each other? Why should the first be appealed to as an argument and nothing said about the second? Is it not evident that this is an entirely arbitrary kind of procedure, and actuated solely by the requirements of theory?

The general plan of the brain is fundamentally the same in all the mammalia and in man. Upon this point, as upon every other, the resemblance is greatest when the latter is compared with the anthropomorphous apes. When, for some reason or other, his brain is altered and reduced, as in the microcephali, is it at all surprising that fresh resemblances should arise. The contrary would be unintelligible.

This is a fact upon which Vogt has especially insisted, and he has described from this point of view several interesting details which render less general some of the results obtained by M. Gratiolet. But it is a remarkable fact that these new relations are not established with the most highly developed apes, but with the tailed apes of the new world, with the platyrrhini, which are excluded by Hacckel and Darwin from the human ancestral series. 'Thus, the Darwinian theory itself protests against the comparison between the microcephali and our pretended pithecoid ancestors

The relations which we are discussing do not, moreover, reach a similarity which would authorise the conclusions of 
the Genevese savant. The brains of microcephali, though often less voluminous and less convoluted than those of the anthropoid apes, according to Gratiolet, do not become at all similar to them. This proposition is confirmed by the work of Vogt.

The case is the same with the skeleton as with the brain. I will here appeal to an authority, which none of my adversaries can reject, that, namely, of Huxley. After having protested against the statements of those who declare "that the structural differences between man and apes are small and insignificant," the eminent anatomist adds that "every" bone of the gorilla bears a mark by which it can be distinguished from the corresponding human bone, and that, in the present state of creation at least, no intermediary being fills the gap which separates man from the troglodyte.' In the general conclusion of his book, Huxley moreover recognises the fact that the fossil human remains hitherto discovered do not indicate any approach towards the pithecoid form.

VIII. After the formal declarations of a naturalist, whose Darwinian convictions place him beyond all suspicion of partiality, how is it that we continually find the expression simian character employed à propos of the most insignificant modifications of some human type of which no one gives a precise description? It is, to say the least, an abuse of words, against which $I$ have often protested. We have just seen that this expression assumes an anatomical fact which does not exist, and which, consequently, constitutes an error: It has, moreover, the inconvenience of being understood literally by the ignorant, and sometimes of deceiving even educated men, and of giving rise to a belief in imaginary degradations and comparisons.

In fact, man and the rest of the vertebrata are constructed upon the same fundamental plan. Between him and the other members of this group numerous relations exist. Organised beings are not crystals whose forms are mathematically defined; with the former the whole of the body 
and each part of this whole oscillate between limits whose extent has not yet been fixed, but which is at times considerable. By these very oscillations the customary relations are continually modified, not only between man and the apes, but between man and the rest of the vertebrata. If we compare man to any animal type whatever, if we apply the same method to this comparison, and the same terminology, we shall arrire at singular conclusions. I will quote a single example.

The most important fact in connection with the brain is certainly not its absolute development. It is the relation of this development to that of the rest of the body. 'The agreement upon this point, when animals are the subject of discussion, is general. It should be the same when the discussion is on man. Undoubtedly upon this ground of relative superiority or inferiority, upon which certain anthropologists so readily take their stand à propos of races or individuals, the relations of which I speak constitute one of the most striking and essential character's.

I subjoin some of these relations taken from a table of Duvernoy, and in which the weight of the brain is takex ass unity.

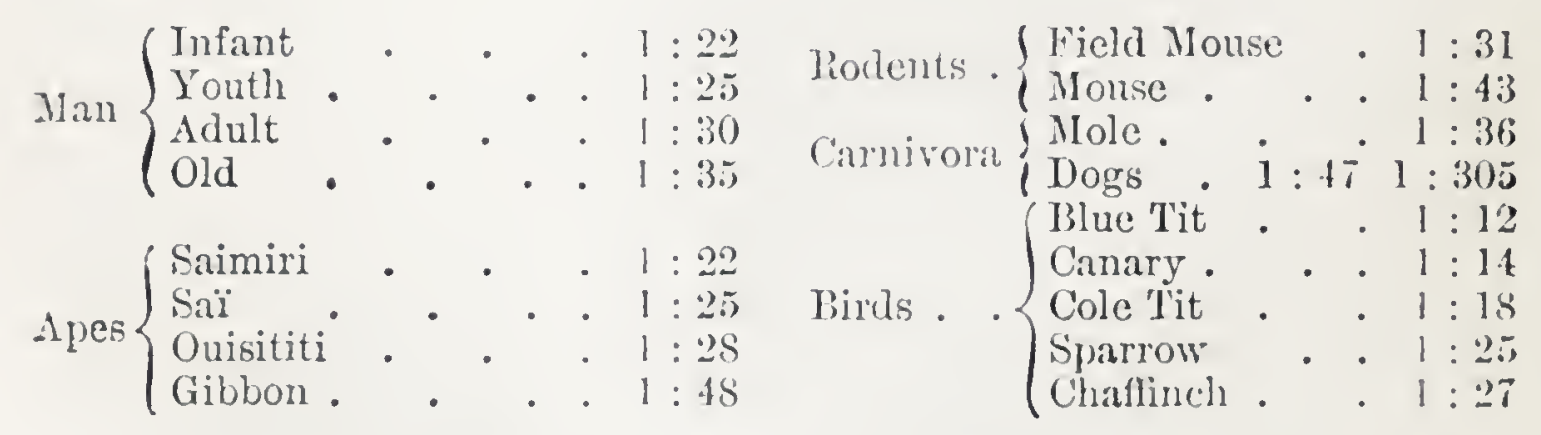

The man in question is the European White. Now from this table we see that from infancy to old age the relation of the brain to the rest of the body keeps diminishing. Are we to conclude then from this that the youth is degraded relatively to the infant, and that the adult or the old man has assumed a simian character?

We see, moreover, that there ought to be some understanding as to the word simian itself. If the gibbon, which 
belongs to the type of our supposed ancestors, has a brain relatively smaller than ours, it is otherwise with the three members of the genus cebus given in the table. The latter are superior to the anthropoid; the two first show exactly the same relation as the infant and youth; the third surpasses the adult man. But all three are surpassed by the two tits and the canary.

Cousequently, if we are right in regarding the human race, or the human individual whose brain is below the mean by several grammes, as tending towards the anthropoid ape, we ought to consider the race, or the individual whose brain is above the mean as approximating to the cebus, or even the passerines or conirostres. If the first. comparison is admissible, the second is equally so.

We can then say with the learned anatomist whose authority I have so often appealed to: "The microcephali, however reduced their brain may be, are not brutes; they are merely undeveloped men." Or again, we may say with M. Best, whose testimony cannot be suspected in such a matter, that in their development apes do not resemble man, and, conversely, that the human type when degraded does not resemble the ape.

IX. From the pithecoid man of Darwin and Haeckel, from the speechless man who used lis teeth as weapons, to the man of our age, the distance is still very great. How has it been filled up? How has this intelligence been developed which is able in many cases to hold nature herself in subjection? It is Wallace who has especially answered this question in the name of the theory of which he is one of the founders. We shall see at the same time that he admits the imperfection of this theory, when he discusses the peculiar attributes of the human species.

It is well known that this naturalist shares with Darwin and M. Naudin, the honour of having sought in natural selection for an explanation of organic origins. But our fellow countryman has confined himself to a sketch the fundamental character of which he has recently entirely 
modified. Darwin has embraced the problem as a whole and in its details; he has addech to his first work severai publications upon subjects very different in appearance, but all of which tend to the same end. He may with justice be considered as the chief of the school.

Wallace, who almost anticipated Darwin in the publication of ideas which are common to both, recognises him as his master on all occasions. He has discussed a small number of points in special memoirs which never cover much ground. From not attempting the solution of all the questions suggested by the theory, he has neither met with so many or such serious difficulties as his eminent rival. This, perhaps, explains the fact that he generally shows himself more precisc and logical. He therefore, always possessed considerable authority among the partisans of Darwinism, until he published his special views on man.

According to Wallace, immediate and personal utility is the only cause which sets selection in action. 'This is fundamentally the theory of Darwin; but the latter has allowed himself to be influenced by comparisons or metaphors, which have raised sharp criticisms, which have perhaps deceived him, and which he employs more or less to evade his difficulties. We never meet with the same in Wallace, who accepts all the consequences to which his absolute principle leads him.

According to Wallace, utility clone is ablc to account for the manner in which inferior animal forms could have produced apes, and afterwards a being having almost all the physical characters of man as he is now. 'This race liver! in herds scattered throughout the hot regions of the ancient continent. It was not, however, wanting in true sociability; it possessed the perception of sensations, but was incapable of thought; moral sense and sympathetic feelings were unknown to it. It was still only a material outline of the luman being, yet superior to the tailed man of Darwin, and to the pithccoid man of Hacckel.

'Towards the earlier part of the tertiary period, adds 
Wallace, an unknown cause began to accelerate the de velopment of the intelligence in this anthropoid being. It soon played a preponderating part in the existence of man. The perfection of this faculty became incomparably more, useful than any other organic modification. Henceforward the powerful modifying agent of selection acted necessarily almost entirely in this direction. The physical characters already acquired remained almost unaltered, while the organs of the intelligence and the intelligence itself were perfected more and more in each generation. Animals unaffected by this unknown cause which separates us from them, continued to undergo morphological transmutations, so that since the Miocene epoch there has been a great change in the terrestrial fauna. With man only did the form remain the same. We ought not, therefore, to be surprised to find in the Quaternary epoch skulls like those of Denise and Engis, resembling those of men of the present age.

'The superiority acquired by the intelligence has, moreover, removed our race for ever from the law of the action of morphological transmutations. His intellectual and moral faculties only are from this time subject to the power of selection, which will cause the disappearance of inferior races and their replacement by a new race, the lowest individual of which would be, in our time, a superior man.

After having read the pages, of which I have just made a summary, we cannot but be surprised to find Wallace declare that natural selection by itself is incapable of producing from an anthropoid animal, a man such as we find in the most savage nations known to us. He thus makes the human species an exception to the laws, which, according to him, rule all other living beings. There is a double interest in following Darwin's rival in this new path.

Wallace begins by reminding us that matural selection rests entirely upon the principle of immediate ulility, relative only to the conditions of the struggle maintained at the time by the individuals constituting the species. Darwin in all his works declares, on different occasions, this same 
principle, upon which rests, in fact, all his statements upon adaptation, the possibility of retrogressive transmutations, etc.

It results necessarily from this principle, that selection cannot produce variations in any way injurious to any being whatever. Darwin has often declared that a single well-attested case of this kind would destroy his whole theory.

But it is evident, adds Wallace, that selection is as incapable of producing a useless variation; it cannot then develop an organ in proportions which would go beyond its degree of present utility.

Now Wallace shews very clearly that in the savage there are organs whose development is out of all proportion with their present utility, and even faculties and physical characters which are either useless or injurious, at least to the individual. "But," says he: "if it can be proved that these modifications, though dangerous or useless at the time of their first appearance, have become much more useful, and are now indispensable to the complete development of the intellectual and moral nature of man, we ought to believe in the existence of an intelligent action, foreseeing and proviaing for the future, just as we should do, when we see a breeder set to work to produce a definite improvement in any direction in any cultivated plant or domestic animal."

The relative development of the body and the brain, the organ of intelligence, is one of the points upon which our author insists most strongly. The height of the orang, he says, is almost equal to that of man; the gorilla is much taller and bigger. Nevertheless, if we represent by ten the average volume of the brain in the anthropoid apes, this same volume will be represented by twenty-six in savages, and by thirty-two in civilised men. The English naturalist also makes the remark, that among savages, the Esquimaux, for instance, we find individuals the capacity of whose skull almost reaches the maximum which is given for the most highly developed nations.

Finally, Wallace, relying upon the experiments and 
calculations of Galton, admits distinctly that though the brain of savages is to that of civilised man in the proportion of five to six, the intellectual manifestations are, at the most, that of one to one thousand. The material development is, then, out of all proportion to the function. A. brain, a little more voluminous than that of the gorilla, would, in the eyes of the eminent traveller, be perfectly sufficient for the inhabitants of the Andaman Islands, of Australia, Tasmania, and Tierra del Fuego.

Wallace explains the development of the ideas of justice and benevolence by the advantages which would result from them to the tribe and to each individual. But faculties essentially individual, and without immediate utility to others, are not subject, according to him, to selection. "How," says he, "could the struggle for existence, the victory of the most fitted and natural selection give any aid to the development of mental faculties," such as ideal conceptions of space and time, of eternity and infinity, the artistic feeling, abstract ideas of number and form, without which arithmetic and geometry are impossible?

For a much more cogent reason, the development of the moral sense in the savage cannot be accounted for by considerations taken from utility, whether individual or collective. Wallace insists upon this point at some length; he quotes examples which prove that this feeling exists, in all which is most delicate and most opposed to utilitarian notions, among the most savage tribes of Central India. We could give many examples of this fact; among others, that the Red-skins have the greatest respect for their word of honour, though it should entail torture and death.

Our author bases numerous arguments upon the physical examination of man. "It is perfectly certain," he says, "that natural selection could not have produced the present naked body of man from an ancestor covered with hair, for such a modification, far from being useful, would be injurious, at least in certain respects;" in civilised man a number of movements are executed by the hand of which savages 
have not the slightest idea, although no anatomical difference exists in the structure of the superior members; the larynx of our singers is constructed similarly to that of sarages, and, nevertheless, what a contrast between the kounds produced!

From all these facts Wallace concludes that the brain, hand, and larynx of savages possess latent uptitudes, which bcing temporarily useless cannot be attributed to natural selection. Man, moreover, has not the power of acquiring them himself. Foreign intervention therefore is necessary, for the explanation of their existence. Wallace attribittes this intervention to a superior intelligence which acted on the human species, just as the latter has acted on the rock-pigeon to produce from it the pouter or the carrier, and which employed analogous processes.

In short, natural selection, regulated by the laws of nature only, is sufficient to produce wild species; artificial or human selection can produce improved races of animals and plants; a lind of divine selection must have produced the present man, and can alone bring him to the highest pitch of intellectual and moral development.

In advancing this latter hypothesis, Wallace declares that it no more impairs the theory of natural selection than the latter is weakened by the fact of artificial selection. Few, I think, will accept this proposition. 'The chief apology for Darwinism in the eyes of men of science, its great charm to all its partisans, lies in the pretensions which it puts forward of connecting organic origins, those of man as well as those of plants, with the single action of second causes; and to explain the present state of living beings by physical and physiological laws, just as geology and astronomy explain the present state of the material world entirely by the general laws of matter. In making the intervention of an intelligent will necessary for the realisation of the human being, Wallace has set himself in opposition to the very essence of the theory. Such is the opinion of most Darwinist.:, who have treated him somewhat as a deserter. 
I am not therefore called upon to examine this latter hypothesis of Wallace. I am, however, at liberty to state that most of the facts, which have induced one of the founders of Darwinism to separate from his chief upon so important a point, retain all their value as objections. The mistake of Wallace consists in failing to see that his statements upon the subject of man apply equally to unimals, and Claparède has justly reproached him with a want of logic on this point. He has been lesis happy in tice answers which he has made to his old ally. Doubtless, he who regards the question exclusively from a Darwinian point of view, and accepts as true everything which I have endeavoured to shew to be false, will readily find a solution for many of the difficulties raised by Wallace. But his statements upon latent aptitudes, upon the superior ficulties of the human mind, and upon the moral sense, are very difficult to refute. Claperède has only alluded to the former. Darwin has attempted to go further; but his theories and hypotheses upon these important questions do not appear to me to have given much satisfaction to the most devoted of his followers. I cannot here enter into a discussion, which, to have any value, should be carried to some length, and I refer the reader to the work upon the Descent of Mran, and to my articles in the Journal des Savants.

$\mathrm{X}$. I cannot close this short account of the origins, which have been attributed to man during late years, without mentioning the new theory which has lately been put forward by an eminent botanist, to whose works I have often had to allude. M. Naudin has been one of the most important of Darwin's precursors. Six years before the English naturalist, he compared the action exercised by natural forces in the production of species to the methods ised by man in obtaining races; he admitted the derivation and filiation of species; he compared the vegetable kingdom to a tree "where roots, mysteriously hidden in ihe depths of cosmogenic time, have produced a limited 
number of branches successively divided and subdividecl. The first branches represent the primordial types of the kingdom, the subsequent ramifications the existing species." We cannot fail to recognise in these words an idea very similar to J)arwinism.

M. Naudin now proposes an evolution theory which is very different. He "entirely excludes the hypothesis of natural selection, unless the sense of the word is changed so as to make it synonymous with survival." He rejects no less strongly the idea of gradual transmutations, which require millions of years to effect the transmutation of a single plant. He insists, on the contrary, upon the sudden. ness with which most of the variations observed in plants have been produced, and regards it as a representation of what must have taken place in the successive genesis of living beings. Let us remark in passing, that Darwin, in the last edition of his work recognises the reality of these sudden leaps, which have taken place without transitions between one generation and another, and confesses that he has not taken sufficient account of them in his earlier writings.

M. Naudin admits the existence of a protoplasma or primordial blastema, the origin of which he does not pretend to explain nor its entrance into action. Under the influence of the organo-plastic or evolutive force there were formed proto-organisms of a very simple structure, asexual, and endowed with the power of producing by buds and with a great activity meso-organisms, similar to the first, though already more complicated. With each generation forms are multiplied, and become more pronounced, and nature rapidly passes on to the adult state. The beings in? question were not, however, species. They were not complete beings, but merely a kind of larve, whose sole duty was to serve as transitions between the primitive blastema and the definite forms. Dispersed in different regions of the globe, they have carried everywhere the germs of future forms which evolution had to produce from them. From 
the creative character which distinguished it at first, the evolutive force cxhausted by its very action, acquired a prescrvative character. Forms are now integrated. 'They' preserve, however, a residue of plasticity; they vary under the influence of certain conditions, and hence results the multitude of forms which the same species now presents.

The proto- and meso-organisms contained in themselves, each according to its position in the order of evolution, the rudiments of kingdoms, branches, classes, orders, families, and genera. Points where they were fixed, became so many centres of creation. Moreover, they have not engendered simultaneously all the forms which they were capable of producing. There have been considerable intervals between the production of living beings, which explains why groups of the same order have not been contemporaneous.

Organic types, even those least marked, have not passed into each other. 'The paths followed by the evolutive force have always been divergent. "Let us picture to ourselves," says M. Naudin, "the meso-organism which has been the source of the mammalia; ever since its appearance, all the mammalian orders, including the human order, were fermenting in it. Before their appearance, they were virtually distinct, in the sense that the evolutive forces were already distributed, and the method of their effecting, each in its proper time, the production of these different orders, already defined. This is a similar phenomenon to that of the evolution of organs in a growing embryo, where we see springing from a common and uniform origin, parts at first similar, but which are impelled in a determinate direction each by its own particular future."

M. Naudin, as we see, in order to support his theory, appeals to the embryogenic phenomena, to which the Darwinists also look for testimony in favour of their doctrines. The learned botanist, however, attaches much more importance to the metamorphoses which take place subsequently to the egg. He recognises true proto-organisms in the pro-embryo of mosses, in the larvæ of insects, and of 
many other inferior animals. He lays particular stress upon the phenomena of alternate generation, as representing what has already taken place, or better, as representing in part "the ancient and general process of creation."

According to M. Naudin, man was subject to the common law, and the Mosaic account is at the same time very true and full of instruction. In its first phase, mankind was concealed within a temporary organism, already distinct from all others, and incapable of contracting an alliance with any of them. 'This is Adam, who sprang from a primordial blastema called clay in the Bible. At this epoch, he was, jroperly speaking, neither male nor female; the two sexes were not yet differentiated. "It is from this larval form of mankina, that the evolutive force effected the completion of the species. For the accomplishment of this great phenomenon, Adam had to pass through a phase of immobility and unconsciousness, very analogous to the nymphal state of animals undergoing metamorphosis." This is the slecp mentioned in the Bible, during which the work of differentiation was accomplished, to use the words of M. Naudin, by a process of germination, similar to that of medusie and ascidians. Mankind, thus constituted physiologically, would retain a sufficient evolutive force for the rapid production of the various great human races.

Passing over the comparisons established by M. Naudin, I will confine myself to a single observation upon all these ideas; properly speaking, they do not form a scientific theorig.

When we fertilise by artificial means the egg of a frog, we know that we determine an entire series of phenomena, which results in the formation of a germ, then in that of an embryo, which will be established by a succession of meta. morphoses, in that of a tadpole, which will be equally subject to metamorphoses, and in that of a definite animal which will assume all the characters of the species. So far as man can make a being, we muke a frog when we fertilise an egg. If the first cause, with which M. Naudin immediately 
connects his primordial blastema, has made potentially in this blastema all past, present, and future beings, as well as the power of producing them at the proper time, with all their distinctive characters, It has, in reality, created. all these beings en masse. We do not see what kind of action is reserved for second causes; unless it is, perhaps, the power of accelerating or retarding, of obstructing or favouring the appearance of types of different value, when number and relations have been immutably determined beforehand. But M. Naudin has not even mentioned their part in this evolution of the organic world. That science which is only occupied with second causes has, therefore, nothing to say to the theory of M. Naudin. It can neitherpraise nor criticise it.

XI. To explain the origin of the world in which we live, that of beings surrounding us, and our own, is evidently one of the most general aspirations of the human mind. 'The most civilised nations, as well as the most savage tribes, have satisfied this want in one way or another. Even Australians, whatever may have been said to the contrary, have their rudimentary cosmogony, which those who have taken some interest in the matter, have made them relate.'

In all cases, man has at first connected his cosmogonic conceptions with his religious belief. Then among the most advanced ancient nations, independent spirits have sought for an explanation of nature in natural phenomena. But from want of precise knowledge, all their hypothetical conceptions have no fundamental value.

With us also, the purely religious cosmogony has lone been accepted as an article of faith. What was called science was confounded with dogma, itself relying upon interpretations of the Bible in harmony with the knowledge of the time.

Science, properly so calied, is entirely the creation of modern times. The rapidity, the grandeur of its developments, fill one of the most magnificent pages of humans history. Relying entirely upon experiment and observation, 
it could not fail to contradict certain beliefs, which were drawn from a book written in an entirely different sense to its own, and explained by the aid of data which were incomplete or false. Between the representatives of the past and those of the new era, the strugghle was inevitable. It needed to be shaip, and it was so. It is now keener than ever.

Circumstances of every kind have lestroyed in many minds the old faith of our ancestors. Carrjed away by the general stream, many in the matter of religious belief, have arrived at absolute denial. 'The need of an explanation of the universe is still felt by these uneasy minds; and since they have no belief in the Bible, they have turned their attention to science.

The latter has already given them magnificent answers in astronomy and in geology. Before irrefutable facts, the later upholders of the ancient biblical interpretations have either been obliged to withdraw, or to be silent. No one believes in the immobility of the earth, in creation having taken place in six days of twenty-fom hours each, or in the simultaneous appearance of all animals, or all plants. Astronomy has made known to us the genesis of worlds; geology has taught us how continents and seas, valleys and mountains are formed, thus evolving some of the grandest results due to the action of second causes in the inorganic empire.

There remains the organic empire, plints, animals, and man himself. Here curiosity is excited, and the want of explanation becomes more pressing, but unfortunately observation and experiment are equally at fault.

Some men, eminent in science and in the richness of their imaginations, have thought themselves able to do without it. Reviving the methods of the Greek philosophers, they have thouglit it possible to explain living nature and the entire universe, by connecting certain facts with conceptions, which are almost entirely intellectual. Once started in this path, ihey are readily elated at their own thoughts. When the positive knowledse which has been accumulated by the long 


\section{Scientific Doctrines and Rcligions Dogmas. I2T}

continued labours of their illustrious predecessors, has embarrassed their speculations, they have at once, so to speak, thrown it overboard; they have pushed to the utmost the more or less logical development of their it priori, and have nothing but irony and disdain for those who hesitate to follow them.

These men could not but excite admiration. They spoke in the name of science alone; by its means they replied to aspirations perfectly justifiable on such a topic; they produced theories which charmed by their fulness and the apparent precision of their explanations. They were able consequently to influence even those men of science who had not gone to the bottom of things, and much more so the general public, who are always satisfied to believe what they are told.

The nature of the resistance which they have met with from time to time was calculated to increase the splendour of their triumph. Men as imprudent as ill-judged have attacked them in the name of dogma. Scientific discovery has degenerated into controversy; both parties have become excited, and in the two camps it has been considered necessary to deny ail the statements of the enemy; they have vied with each other in violence, and savants, who pretended to speak in the name of free thought, have not shown themselves the less intolerant.

I will only remind the one party of the trial of Galileo, and the other of the theories of Voltaire denying the existence of fossils.

Others have resisted the impulse of the time; they have remained faithful to method, the mother of modern science; they have carefully preserved their inheritance of solid and precise knowledge, acquired from past centuries. They cannot on that account be accused of acting from routine or be considered as retrograding. As warmly as the most ardent partisans of the so-called advanced theories, they have ipplauded all the progress, and have received with equal lavour new ideas, on the condition of exposing them to 
experiment and observation. But when they meet with questions the solution of which is at present impossible, and will perhaps always be so, they have not hesitated to answer:-Wl Do NoT KNow; - and when they find purely metaphysical theories are being imposed upon them, they have protested in the name of experiment and observation.

I venture to say that I have always remained faithful to the ranks of this phalanx, to which the future distinctly belongs. For this reason, to those who question me upon the problem of our origin, I do not hesitate to answer in the name of science:-I Do NoT KNow.

I do not on that account anathematise those who consider they ought to act otherwise, nor do I greatly blame their boldness. The study of second causes has enabled man to explain scientifically the present constitution of the inorganic world; and it is quite legitimate to attempt to accomnt for the present state of the organic world by causes of the same nature; perhaps success will one day crown our efforts, and should they for ever remain unrewarded, as they have hitherto done, they will still possess a certain utility. These efforts of the imagination provoke new rescarch, make new openings, and thus render a service to real science in the world of facts, as well as in that of ideas. If Darwin had not been actuated by his preconceptions, he would probably never have accomplished his excellent work upon the 150 races of pigeons, nor developed his theory of the struggle for existence and natural selection, which accounts for so many facts.

Unfortunately, from having forgotten the works of thei: predecessors, Darwin and his followers have drawn erroncons: conclusions from these premises. They imagine they hare given explanations when they have given none. 'I'his is what I have endeavoured to show. I have been obliged to resume the debate; it is for the impartial and unprejudiced reader to decide between us. 


\section{BOOK III.}

\section{ANTIQUITY OF THE HUMAN SPECIES.}

\section{CHAPTER XII.}

AGE OF THE HUMAN SPECIES.-PRESENT GEOLOGICAL EIOCH.

I. Without prejudging the future, we have been obliged to acknowledge that the problem of the specific origin of man cannot be solved, or even attempted, with the scientific data which we at present possess. This is not quite so much the case with certain questions which are naturally suggested to the mind by the preceding.

We know that our globe has passed through several geological and palæontological epochs; that living beings have not appeared simultaneously, and that the present fauna and flora have been preceded by very different ones. It is natural to ask the question, when man began to inhabit the earth, and to endeavour to determine the moment of the appearance of this being, so similar to other beings in many respects, so exceptional in his most noble faculties, and superior to everything around him.

This question of time should be stated precisely; we must understand the sense which may be attributed to it.

Let us observe, in the first place, that here we can have no dates properly so called. They only exist in history. Now primitive mankind can have no history in the scientific sense of the word. Most great religions bave endeavoured to fill up this gap. But my readers are already aware that I 
have refused all considerations drawn from such a source, and that I intend to bring forward here none but the results of experiment and observation. I shall then try how far back we can go with the aid of these guides alone, quoting in the first place a few historic dates as terms of comparison.

II. 'The Greeks and Romans, with whom classical education too often terminates, do not take us very far. The cormer had much more ancient records than the latter, and yet the era of the Olympiads only brings us to the year 776 before our era; according to Hecateus of Miletus, it was in the ninth or tenth century before our era that the gods ceased to intermarry with mortals, and the Trojan war is regarded ipproximately as having taken place in the eleventh or twelfth century. Beyond this period, it is evident that we are led by Greece into mere mythology, or rather into those legendary times where truth and fable are confounded.

The Aryan traditions go further. M. Vivien de Saint Martin, summing up the works of which he is so good a judge, refers the arrival of the Hindoos on the river of Cabul to about the sixteenth or eighteenth century before our era. These tribes were only an offshoot of the great emigration which the Zend Avesta takes back almost as far as the Bolor. We can, therefore, refer the latter to the twentieth or twentyvighth century before our era.

Jewish history, starting with Abraham, goes back almost to the same period (2296 years); the deluge of Noah, according to the estimation generally received, to the year 3308 . Say about thirty centuries.

In China, the Chou-King places the reign of Hoang-ti in the year 2698, and that of Jao in the year 2357 before our era. This would correspond almost to a century, with the date of the migration of Abraham.

Egypt had no Chou-King, but her monuments are the most magnificent of books. Champollion has taught us how to read them, and we can decipher them page by page. Now Lepsius and Bunsen place the fifth dynasty about the fortieth century, and according to Mariette Bey, the lists of 
Manetho, upon the subject of which the eminent Egyptologist makes formal reserves, go back to the year 5004 before our era. We should, then, be separated from the earliest historical times of Egypt by an interval of about seventy centuries. If, instead of counting by years, we count by the human life, which we will estimate at about twenty-five years, we find that we are only separated from these times, which constitute the extreme limit of past history, by 280 generations.

These numbers are undoubtedly interesting. They tend to modify some of the impressions which we have received in our childhood; but they tell us nothing of the antiquity of the human race. At most, in showing us that at this period there existed people in the valley of the Nile sufficiently civilised to possess the art of writing, and to raise monuments worthy of our admiration, they refer the first appearance of man far beyond the limits which they reach themselves.

III. The Egyptians themselves have, then, a past anterior to all history. With much greater reason is this the case with the Chinese, Hindoos, Greeks, and still more so with nations less well endowed, or accidentally retarded in their evolution. To plunge into this obscurity with the hope of finding in it any certain land-marks, and to discover facts of which even legends say nothing, would thirty years ago have appeared a senseless enterprise. It is, nevertheless, the work accomplished by one of the most recent of sciences, Prehistoric Archoology. We should therefore regard the year 1847 as a memorable date, when three Danish savants, a geologist, a zoologist, and an archæologist, were charged by the Society of Northern Antiquaries to carry out the studies which have served as its foundation. By a study of the Kitchenmiddens and peat mosses of their country, Forchammer, Steenstrup and Worsaar have done for the history of man what De Buch, Elie de Beaumont, and Cuvier have done for the history of the globe.

The Kitchenmiddens are essentially formed by the accumulation of shells strewn on the sea-shore, which sometimes 
attain considerable proportions. With the shells are found the remains of fish, and bones of birds and mammalia. Min alone could have formed this accumulation, and his presence, moreover, is revealed by the implements, tools, and weapons, winich he once mislaid, and which are now found among the remains of his meals. They consist of stone, almost always rudely shaped. In some of these artificial hills, among the traces of a very rudimentary industry, we meet with other stone objects which betray workmanship of the most remarkable perfection.

'The Kitchenmiddens, then, reveal the existence of a population now forgotten, which at first lived in an entircly savage state, but afterwards acquired a certain amount of civilisation. From a chronological point of view, however, this information is still very imperfect. The mixture of implements, sometimes almost without form, and sometimes again showing wonderful workmanship, permits of various interpretations, which have in fact been given.

It is different with the objects found in the peat-mosses, and especially in those which the Danes call slioumoses, that is, forest mosses. These formations are found in hollows of irregular form which have been excavated in Quaternary clays, reaching at times a depth of thirty feet or more. 'The detailed study which Steenstrup especially has made of them led him to distinguish among them the central region or peut-moss, and the exterior region or forest region.

The first is formed by the cavity itself. It is the peatmoss properly so called, formed by the layers of peat which fill the cavity, and have been deposited subsequently to its formation. A meagre vegetation grew upon the surface, which divides this mass of vegetable débris into distinct zones. They are, proceeding downwards:-1st, certain trees, such as the birch, alder, and hazel, etc., mixed with heaths; 2nd, small stunted, but sturdy pines (Pinus sylvestris), which had grown upon peat in which mosses of a high organisation, such as the hypnum, were found; 3rd, compact, amorphous peat, the elements of which for a long time it was considered 
impossible to discover, but in which MM. Steenstrup and Nathorst discovered in 1872 undoubted remains of five species of plants now confined to the Arctic circle, such as, Salix herbacea, S. polaris, S. reticulata, Betula nana, Dryas octopetala; 4th, a bed of clay evidently resulting from material washed down by rain from the sides of the hollow, when the latter were still bare.

The forest region occupies the sides themselves. 'The trees were there protected from the wind, and extending their roots into a fertile clay they attained a magnificent development. Now we at once meet with a very remarkable fact, the beech tree is not found in the skormoses. At the present day it is the essential constituent of the Danish forests; it is the national tree, and the most ancient traditions give no suspicion that it has ever been wanting in Denmark. In its place the peat-mosses contain at first nothing but oaks (Quercus robur sessilifolia) which disappeared from the country in prehistoric times, and is only found in a few places in Jutland. Then, as we descend deeper into the peat, the oaks give way to pines. In their turn the latter gain the ascendant, and occupy the lowest parts of the peat exclusively.

Oaks and pines, when they fell from old age, axcident, or human agency, generally fell towards the interior of the bog. Their interlaced branches supported and consolidated the peat, which was then in the best condition for preserving, as they fell, any solid substances which may have been dropped or thrown into the bog.

Man used to frequent the skovmoses, and it is well known that he cannot live in any place without losing a number of objects, even those upon which he sets most value. He lost in the bogs weapons, tools, and instruments of all kinds, and they all remain where they fell. The skovmoses have thus become a kind of chronologically stratified museum, where each generation has left its trace in the contemporaneous peat. We have only to explore it layer by layer to obtain many definite ideas about the predecessors of the present 
Danes, and to find in this prehistoric past relative dates or epochs. In this manner the Scandinavian savants have arrived at the idea of the Ages of Iron, Bronze, and Stone, which are now universally adopted. I shall not here follow the development which these fundamental ideas have received, nor the manner in which they have been applied to the Lake dwellings of Switzerland and elsewhere. I shall not insist further upon the different degrees of civilization betrayed by the use of two metals and of polished or ground stone. I shall confine myself to the remark that in Denmark the Iron age entirely corresponds with that of the beech tree, while the Bronze age corresponds with the entire period of the oak, and the close of that to the pine. Lastly, the pine is the tree of the Stone age.

The presence of objects formed by human industry proves the presence of man. 'Thanks to their irrefutable testimony, there is no difficulty in tracing him through the zones of the oak and the pine. 'The immense number of objects, which have been left by him in the peat period, points to the existence of a somewhat dense population. These objects, on the contrary, become very rare, and at the same time ruder, in the layer of amorphous peat. 'They were, for some time, even thought to be wanting altogether, till they were finally discovered by Steenstrup associated with the remains of the reindeer.

Man, then, was living in Denmark when Arctic plants, such as Betula nuna and Salise polaris grew at the bottom of the skovmoses; he was accompanied by the reindeer, which completes the resemblance between the past state of that country and the present state of Lapland. Now we know that such a state of things could only have existed in J)enmark in the latter part of the Quaternary epoch, when the ice, retreating from the south northwards, would still be far removed from its present limits. We can then affirm that man existed and lived in Europe at the very dawn of the present geological epoch.

This fact is again proved by the discovery of a human station, made by II. Fraas, at Schussenried in Wurtemberg. 
Here man, whose presence is attested by worked flints of various forms, by weapons and instruments of bone, by phalanges of reindeer made into whistles, lived with the reindeer, the glutton, and the polar fox, and gathered mosses which are now confined to Northern Europe, such as Hypmum sarmentosum, fluitans, and aduncum. As in Denmark, he seems to have followed the glaciers step by step, as the melting of the latter opened out new lands to his activity.

IV. Without claiming such accuracy for the historic dates, or even such an approximation as that derived from the Aryan traditions on the most ancient monuments of Egypt, is it possible to estimate the number of years which have elapsed since the times we have just been discussing?

'This question has often attracted the attention of geologists and anthropologists, and several attempts have been made to solve it. But the results are still far from being satisfactory. They are none the less interesting, and calculated, to a certain extent, to encourage fresh research. The method is good; it has only been hitherto wanting in sufficiently precise dates, and we may hope that they will be sooner or later forthcoming.

This method is easily comprehended. For example, let us admit that the peat has a regular growth in the skormoses, and suppose, in addition, that a coin, recognised as belonging to the twelfth century, has been found at a depth of 1.50 metres ( 4.9 feet); we shall conclude that the layer of peat has only required about 600 years for its formation. The age of a bronze hatchet found at greater depth, 8 metres ( $2\left(i \cdot 24\right.$ feet), will be given by the proportion $1^{\mathrm{m}} 50: 6:: 8^{\mathrm{m}}: \mathrm{x}$. 'The hatchet would then be 3,200 years old, and would date from the fourteenth century before our era.

Many natural phenomena are available for calculations of this kind. Such are the alluvium of a river, the silting up of a lake, the erosion of a hill or platean, etc. But in order that the results of these calculations may have a real value, the phenomenon which serves as the basis, and the calcula- 
tions resulting from the data must satisfy three conditions which have been very clearly stated by M. Forel.

1. The phenomenon shoukd be perfectly constant and regular, which is never the case. At least, it ought to be possible to. regard its action as giving an annual mean or constant centemuial result, by means of compensations which are produced naturally.

2. When super-imposed strata are used as a means of estimation, the age of the strata serving as a term of comparison, ought to be rigorously determined; the nature of the objects compared should leave no doubt.

3. We ought to be certain that the objects found in any stratum really belong to it, that they have not been displaced by any reformation or by their mere weight. (Peat.)

Should even one only of these conditions be unfulfilled, the calculation is necessarily erroneous. Now, hitherto, we cannot be absolutely certain that the conditions laid down by II. Forel are satisfied. Nevertheless, I repeat, it is interesting to know what results have been obtained by these attempts at prehistoric chronology.

It would seem, at first sight, that the skormoses must be useful for researches of this kind. It is not so. Steenstrup, an excellent judge of these matters, after having estimated at forty centuries the time necessary for the formation of the peat accumulated in these bogs, declares that it might be twice, or even four times as much.

In reality, the uncertainty as to the results obtained from the growtl of peat, is very much greater than the Janish savant admits. In adding to the data collected by Brandt, those kindly presented to me by my colleague, M. Bésal, I find that for a period of 443 years the mean annual growth of peat is 0.032 metre $(1.26$ inch). But this mean is the result of numbers whose extremes are 0.065 metre $(2.56$ incl $)$ and 0.0065 metre $(0.26$ inch). That is to say, that the means found by different observers for the annual growth of peat, vary from one to ten.

'The calculations of MM. Gillieron and Troyon, resting upon 
the deposition of silt, which has caused the retreat of the Lakes of Bienne and Neuchâtel, have but little connection with the present subject. Both have sought to determine the age of the Lake dwellings, which belong, probably, to a much later period than the one which we are now endeavouring to determine. We may, however, notice the numbers, 6,000 years and 3,300 years, found by these observers.

The chronological results derived from the littoral accumulation of silt, of which I have just spoken, exhibit chances for error which Vogt has rightly pointed out. For some time the results have been thought more worthy of confidence which were based upon the researches made by M. Morlot upon the conical accumulation of silt deposited by the Tinière. This cone, which was cut through by the railway for a distance of $133^{\mathrm{m} \cdot}$ (436 feet), and to a depth of $7 \cdot 7 \mathrm{~m} \cdot$ (25 feet), exhibited in the midst of the mass of gravel three undisturbed soils, the highest of which contained Roman instruments and coins; the second, pottery of the Bronze age; and the third, split bones, charcoal, and different objects referable to the close of the Stone age. Fixing the commencement of the Roman period in Switzerland at the first century of our era, and the end of it at the year 563, and making some corrections which cannot be detailed here, M. Morlot has considered himself able to propose the following numbers as approximate dates:-

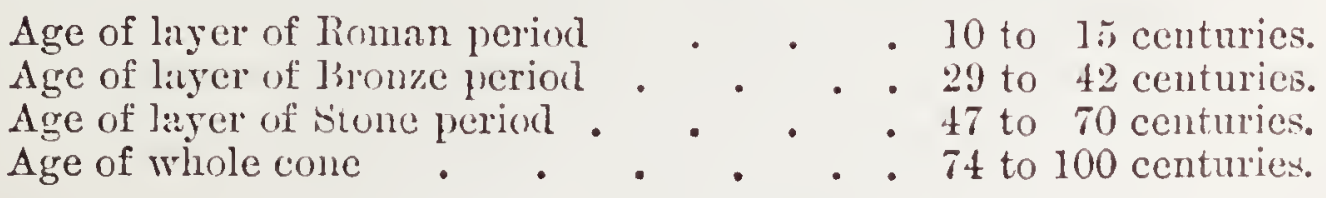

These numbers are not high. The number given by $\mathbf{M}$. Morlot as the age of the Stone period in Switzerland, leads us back to an antiquity which does not exceed that given by the Egyptian monuments ; and it is impossible to avoid being struck with the differences of civilization exhibited by the two countries. Nevertheless, this fact cannot constitute a reason for doubting the results of the Swiss savant. It is well known that man during the same time has not every- 
where equally advanced in civilization, and that the Eskimas are still in the Neolithic period.

But other criticisms have been brought forward against M. Morlot, the result of which is that the numbers furnished by the cone of the Tinière cannot be accepted as giving a real approximation to the date which we are seeking for.

V. M. Forel, who has taken an active part in this discussion, has tried to solve the problem in an indirect way. Instead of seeking directly for the age of a prehistoric fact, he has proposed to have recourse to the rule of false position, which allows the determination either of a maximum which the numbers cannot possibly exceed, or a minimum below which they camnot fall. He has applied this plan, which is as correct as it is ingenious, to the Lake of Geneva.

It is well known that the waters of the Rhone, especially luring the floods caused by the melting of the snow, enter the lake in a very turbid condition, and flow on remarkably clear. The mud thus deposited evidently tends to fill up the lake, and has already silted up a part of the great depression which was filled by the ice of the Quaternary epoch. M. Forel has first determined the annual volume of the deposit. He has then calculated the volume of the present lake, basing his calculations on the soundings made by La Bieche. $\mathrm{He}$ has thus been enabled to calculate the time necessary for the sediment of the Rhone to fill up the entire lake. 'Then, admitting that the part of the original lake already filled up had a mean depth equal to that of the present lake, he lias compared the surface of the alluvial deposits already formed with the surface of the lake itself. The proportion is almost one to three. These deposits have then been formed in a third of the time necessary to fill up the present lake. Now their formation commenced immediately after the retreat of the glaciers. The date thus obtained is, then, that of the modern geological epoch.

Such is the method by which M. Forel arrives at the number of 100,000 years. This is a maximum which is probably much exaggerated. MI. Forel shows this himself 
very clearly. He has always taken the lowest numbers for the estimation of the increase of alluvium; he has considered on the whole year ninety days only as contributing to this increase ; he has only included the Rhone in this estimation, and taken no account of other rivers, streams, etc.; he has not taken into consideration inundations, extraordinary falls of rain, landslips, etc. ; he has assumed the floods of the Rhone have always resembled the present floods, while they must originally have been much more considerable, and have carried away much more material from mountain slopes but recently reheved from their covering of ice; he has said nothing of the gravel and sand which must necessarily be carried along the bed of a rapid stream like the Rhone, etc.

M. Forel's result must therefore undergo serious reduction before it approximates to the truth. Without attempting a precise statement, we can (at least) admit with almost absolute certainty that the present geological epoch commenced less than 100,000 years ago.

On the other hand, M. Arcelin has sought for a solution of the same problem in the deposits of the Saone. The present river flows in a channel hollowed out in the alluvium of the Saône of Quaternary times, the banks of which have been raised by the sediment deposited during floods. The two deposits are very easily distinguished. The homogeneity of the modern alluvium indicates, moreover, a remarkably regular phenomenon. The banks of the Saone at different points form more or less abrupt hills which constitute so many natural geological sections. The erosions of the river have laid bare objects easily recognised as belonging to the Roman period, the Bronze age, and the Neolithic age. These objects are found at a constant height, showing that they are in situ. The hills of the Saone, then, constitute one of those means of estimating prehistoric chronology, which are so valuable to us. MM. Arcelin and De Ferry have attempted first to determine the age of the different layers. The numbers so obtained show a certain amount of discordance, undoubtedly due to the fact that M. de 
Ferry has based his calculations upon a single section, while those of M. Arcelin represent the mean taken from $3: 3$ points. 'The latter has, however, afterwards had recourse to the method of M. Forel, and to the rule of false position. But instead of seeking a maximum, he has enlearoured to determine a minimum. This calculation srives the following results :-

Age of Roman layer • 1,500 years A Age of Neolithic layer • 3,000 years Age of Bronze layer . 2:250 years! Age of Quaternary clay 6,750 year's

This represents a very moderate antiquity, and corresponds almost entirely with the dates of Manetho. But the minimum of M. Arcelin appears to me to be too low, and the error greater than in the case of the inaximum of M. Forel. I shall only point out the most important of the causes which have led to this result. The calculations of the author are based upon the hypothesis of the equality of the floods, and of the alluvial deposit in the period between the present and the Roman period, and in times previous to that. He thus confounds the epochs when the basin of the Saone was left to Nature alone, with other epochs when the same basin was stripped of its forests, cleared and cultivated as it is at present. Now everyone knows how much more powerful the action of atmospheric agents, of rain in particular, are upon cultivated land than upon uncultivated. The upper layer's, which served as the basis for the calculations of M. Arcelin, have necessarily diminished to a considerable extent the final result, since they must have been formed much more rapidly than a great part of the lower layers.

I shall say, then, of the minimum of M. Arcelin what I have said of the maximum of M. Forel. It leaves us the certainty that the present geological period goes back much further than 7- 8000 years.

VI. What corrections ought the extreme numbers which I have just quoted to undergo in order to approximate to the truth? It is still impossible to say. But the path which should be followed in order to diminish the space 
which separates them is henceforth clear. The alluvium of the Saône has always appeared to me to present conditions of uncertainty which it would be difficult to overcome, and the best means of determining the age of the present period by prehistoric chronology, appears to me to be the Lake of Geneva.

In order to correct the first results obtained by M. Forel, it would be necessary to take into account all the circumstances pointed out above, and several others also. It would be especially necessary, at different seasons of the year, in dry and wet weather, to gauge the smallest rivulets and ravines all round the lake, to measure the amount of mud their waters contain, and the amount of gravel and sand they carry down with it. This task is beyond the power of a single man; it would require the formation of an Association for this end. The problem would be worth the trouble, and the Swiss savants, so justly proud of their beautiful lake, might easily make arrangements to obtain its solution.

Such as they are, the works of MM. Arcelin and Forel lead to some important conclusions. The total age of our globe, used till lately to be restricted to a little more than 6,000 years; the alluvial deposits of the Saone show that the present geological epoch alone surpasses this by several centuries. On the other hand, under the influence of Darwinian prejudices, men have begun to handle time with a strange laxity, and it has been affirmed that millions of years separate us from glacial times. The deposits of silt in the Lake of Geneva show that these times terminated less than 100,000 years ago. As M. Forel well says, "This does not yet constitute historic chronology ; it is, nevertheless, a little more than simple geological chronology;" and we see once more experience and observation doing justice to theoretical conceptions. 


\section{CHAP'TER XIII.}

AGE OF THE HUMAN SPECIES.-PAST GEOLOGICAT, EPOCHS.

I. THe skovmoses and the remains at Schussenried have shown that man existed in Europe at the close of the Glacial Epoch. But did he live through this epoch? Did he precede it? Has he, therefore, been contemporary with vegetable and animal species, which have long been considered as fossils? We know that we can with certainty reply in the affirmative to these questions. We know also that the proof of this great fact, one of the grandest scientific conquests of modern times, dates, so to speak, from yesterday.

This demonstration rests on proofs which are now so well known that the enumeration of them will be sufficient. It is evident that human bones, buried beneath an undisturbed layer of soil, prove the existence of man at the time when the layer was formed. It is no less clear that flints worked by human hands and made into hatchets, knives, etc., bones of animals made into harpoons and arrow-heads, are so many irrefutable testimonies of the existence of the workers. Lastly, when human bones are found associated with bones of animals in the same undisturbed layers, it is again evident that man and these animal species have been conternporaneous.

Many facts included in these three categories were proved in the earlier years, and during the course of the last century. Since 1700, excavations made by the order of Duke Eberhard Louis de Wurtemberg, at Canstadt, near Stuttgard, brought to light a great number of bones of animals, among which was found a human cranium. The nature of this precious relic 
was, however, only recognised by Jaeger in 1835. About the same time an Englishman, Kemp, found in London itself, side by side with the teeth of elephants, a stone hatchet similar to those of Saint Acheul. Some time after Esper in Germany, and John Frere in England, discovered more or less analogous facts. But none of them were able to recognise their significance, for geology was quite in its infancy, and palæontology not yet in existence.

II. It was not till 1823 that Amy Boué gave Cuvier some human bones which he had found in the loess of the Rline, near Lahr, in the Duchy of Baden. Boué regarded these bones as fossils. Cuvier refused to admit this conclusion. He has often been reproached with this, but the reproach is unjust. Cuvier had too often seen pretended fossil men change either into mastodons or salamanders, or even into simple contorted blocks of sandstone, not to be on his guard, and, in presence of a fact hitherto unique, he thought it wiser to admit a disturbance which would have carried into the loess bones of much later date than that of the formation of this layer.

But Cuvier, whatever may have been said of him, never denied the possibility of the discovery of fossil men. He has, on the contrary, formally admitted the existence of our species as anterior to the latest revolutions of the globe. "Man," he says, "may have inhabited some country of small extent from which he repeopled the earth after these terrible events." We see that the praises and reproaches which have been addressed to our great naturalist on account of an opinion which he never held, are equally undeserved.

The reserve, perhaps exaggerated, which Cuvier imposed upon himself, and the confidenoe which was placed in him, weighed heavily upon science by impeding the comprehension of the value of observations made by Tournal (18281829) in L'Aude, by Christol (1829) in Le Gard; by Schmerling (1833) in Belgium; by Joly (1835) in Lozère; by Marcel de Serres (1839), in L'Aude, and by Lund (1844) in 
Brazil. In 1St.5 almost all the savants, properly so called, shared the opinion so well stated by Desnoyers. Without regarding the existence of fossil man as impossible, they did not think that the discovery had as yet been made.

It is to the persevering efforts of a distinguished archeologist, Boncher de Perthes, that we owe the proof of a fact so long denied, and now universally admitted. Under the influence of certain philosophical ideas, little calculated to procure him followers, he had admitted $a$ priori the existence of human beings anterior to the present man, from whom they must have differed considerably. He hoped to find either their remains themselves, or the products of their industry, in the ipper alluvial deposits. Watching either himself or through his agents the excavation of the gravel pits near Abbeville, he collected there a number of flints, more or less rudely worked, but bearing the unmistakable impress of the hand of man. Some of his publications (1847) brought him visitors, who in their turn carried on the search. Snon after, M. Regollot (1855) and M. Gaudry (1856) obtained from the gravel of Saint Acheul hatchets similar to those of Abbeville, and declared themselves convinced. 'The English savants, Falconer, Prestwich, and Lyell, after having visited the collection of Boucher de Perthes, did the same, and had many imitators.

III. In spite of the discoveries which were multiplied in caverns and gravel-pits, even in the neighbourhood of Paris, the same objections were brought against the believers in fossil man which Cuvier had opposed to Amy Boué. 'The juxtaposition of the remains of extinct animals and human bones, or articles of human workmanship, were attributed to a reformation effected by water. The high authority of M. de Bramont lent new force to this argument. He compared the alluvium of the neighbourhood of Abbeville to his terruins des pentes, formed, he said, by storms of an exceptional violence, which only happened once in a thousand years, and which heap up together materials derived from different beds. As for the objects discovered in caverns they 
inspired still less confidence than the others, on account of the ease with which the bed might be undermined by eddies, which would tend to deposit in the heart of a subjacent layer objects derived from the upper layers, without destroying either the one or the other.

Many men of high intellect still hesitated, until M. Lartet published his remarkable work upon the grotto of Aurignac (1861). Here doubt was impossible. This grotto, or rather rock-shelter, was closed at the time of its discovery by a slab of stone brought from a distance; M. Lartet discovered, either in the interior or at the entrance, the bones of eight or nine species of animals which are essentially characteristic of quaternary deposits. In his memoir he gives details of all the remains. Some of these animals had evidently been eaten upon the spot, their bones, partly carbonized, still bore the trace of fire, the charcoal and ashes of which were discovered; those of a young tichorhine rhinoceros showed marks made by flint implements, and their spongy extremities had been gnawed by carnivora; the species of the latter was shown by his excrement, which was recognized as that of the hyena speloca.

The grotto or rock-shelter of Aurignac is excavated in a small mountainous group, a spur of the plateau of Lanémézan, which the Pyrenean drift has never reached. It is, therefore, free from the objections drawn from the intervention of aqueous currents. Thus the facts made known by M. Lartet were generally accepted at once in their fullest signification. These facts show that man lived in the midst of a quaternary fauna, which he used as food, including the rhinoceros, and was followed by the hyena of this epoch, who finished the remains of his meals. The coexistence of man with these fossil species was proved.

A few ill-judged attacks were still made by savants, who did not accept the testimony of these facts, among others that of the discovery of a human jaw made by Boucher de Perthes. But the discoveries became so numerous that the last among them was soon reduced to silence, and haci to 
submit to the mention of fossil man without raising the slightest protest.

IV. It would be too tedious and, indeed, useless to enumerate here all these discoveries. I will only mention some of the most striking ones associated with the names of Lartet and Christy, his enthusiastic colleague. At Les Eyzies, these indefatigable investigators discovered a staligmitic layer formed of a veritable breccia, which contained worked flints, ashes, charcoal, and bones of different quaternary animals. Large slabs of this breccia now figure in many collections. In this same grotto they found a vertebra of a young reindeer pierced by a flint which had broken in the bone, thus causing the death of the animal. Finally, in 1S64, M. Lartet had the pleasure of being present at the discovery of a plate of mammoth ivory, upon which a representation of the animal itself had been carved with a sharp flint by an artist of La Madeleine. In this drawing are found the characteristic traits of the mammoth, as they are known to us from the remains of the animal which are at times found preserved, with its thick fur and long hair, in the ice of Siberia.

For man to be able to draw the portrait of any animal species, he must have been contemporaneous with it. Now proofs of this nature have rapidly become more numerous and striking. In l'Ariége M. Garrigou found a representation of the cave bear traced on a pebble. M. de Vibraye extracted from the grotto of Laugerie Basse a sketch of a fight between reindeer remarkably well drawn upon a piece of schist. The same animal has been discovered represented in sculpture in the same rock-shelter, and again in the rock-shelter of Montastruc, where M. Peccadeau de l'Isle found his wonderful dagger-handles.

I need not speak here of the weapons, tools, and instruments of every kind, from the simple knife to barbed arrowheads, and harpoons, to laurel-leaf shaped lance-heads, and daggers toothed and grooved, which equal the finest specimens found in Denmark. I will only remark that all these objects 
prove the existence of man, and that we now count by tho thousand articles made by him during the geological period preceding our own.

Without being nearly so abundant, the remains of man himself have been discovered in every part of the quaternary formation. Although several European states have contributed towards this mass of discoveries, by far the greater number occurred in France and Belgium.

I cannot here enter into details, some of which will be more advantageously discussed in another part of the book. I will only mention the cave of Cro-Magnon, which was discovered by the railway engineers in 1860 , not far from the station of Les Eyzies, and which has given us the type of one of the best characterized fossil races. Nor can I pass over in silence the successful and laborious researches made by M. Martin from 1867 to 1873 in the quarries near Paris, the results of which enabled M. Hamy to fix the succession of types in our immediate neighbourhood. Lastly, I would allude to the investigations of $M$. Dupont in the valley of the Lesse. Commenced in 1864, and continued during seven years with an unequalled activity, they have presented to the Museum at Brussels about 80,000 worked flints, 40,000 bones of animals, now all named, the crania of Furfooz, and twenty-one jaws, including the now celebrated jaw of Nculette.

It is not only in Europe that the existence of fossil man has been proved. Even in 1844 Lund had announced that he had found in certain caverns in Brazil human bones associated with remains of extinct animals. He afterwards withdrew his statement, doubtless owing to the distrust with which every announcement of this kind was received. But his observations, which, unfortunately, were never published in detail, were probably correct. In 1867 M. W. Blake announced to the Congress of Paris that in the auriferous deposits of California, and especially near the village of Sonora, weapons, instruments, and even stone ornaments were frequently found associated with the bones of the mammoth and the mastodon. Dr. Snell, who lives in this 
Incality, possesses a large and rich collection of them. Dr. Wilson published some facts of the same nature in 1865.

$\mathrm{V}$. It became necessary, in order to prevent our being lost amidst these riches of every description, to distribute them in a methodical manner, and arrange them in order of time. The universal preponderance of weapons, tools, sculpture, drawings, etc., has led archæologists to propose different classifications essentially founded upon the difference of the types presented by these articles, and upon the material from which they were made. The classification which M. de Mortillet has applied to the Museum of St. Germain is of this kind. But such classifications, though very convenient for the arrangement of a public collection, have the inconvenience of being rather artificial. The naturalist and the anthropologist ought to give the preference to palæontological or geological data.

Lartet preferred the former. He comnected the division of quaternary times with the predominance and extinction of the great mammalia. 'The cave-bear, which was the first to disappear, he employed to mark the most ancient period; the mammoth and the tichorhine rhinoceros, which survived it, characterised the second; the reindeer and the aurochs have served to mark the third and fourth.

This classification has the inconvenience of being purely local, since the disappearance of quaternary species did not take place everywhere at the same time, and was not general. In reality the age of the reindeer still continues in Lapland, and that of the aurochs is prolonged, a little artificially it is true, in the forests of Lithuania. But Lartet's method connects human groups with animal types; it characterises the epochs by an event palæontologically important; it preserves the relation between the succession of periods and biological events; it offers, therefore, serious advantages if taken for what it is. 'This was very clearly understood by the eminent author of the theory; he has only applied it to France.

Since M. Lartet made his splendid investigations, fresh 


\section{Past Geological Epochs.}

facts have come to light, and, as it often happens, distinctions, which at first were apparently most pronounced, have now been partly effaced. Therefore M. Dupont has proposed to reduce to two the four ages of Lartet, which is perhaps excessive even for Belgium. M. Hamy, again, has admitted three ages as corresponding to the mean and new river levels of $\mathbf{M}$. Belgrand. This division of quaternary times has the advantage of being connected with geological phenomena; it at least partly loses the too exclusively local character, and it ought for this reason to be preferred.

Let us, nevertheless, consider the subject for a moment from Lartet's point of view, which permits of an interesting comparison. We have seen in Denmark the succession of three vegetable species; the beech, the oak, and the pine bring us to the commencement of the present modern epoch. In France the successive disappearance of four animal species, the cave-bear, mammoth, reindeer, and aurochs, which at first were contemporaneous on our soil, characterises so many epochs which embrace the whole quaternary period. Man has been contemporaneous with them all; he made use of their flesh for food, and has left representations of them in sculpture and drawings.

VI. Can we go further and find traces of man even in tertiary times? Falconer, the celebrated English palæontologist, prematurely lost to science, did not hesitate to reply in the affirmative. But he only expected to find tertiary man in India, and M. Desnoyers has discovered him in France.

It was in 1863, in the gravel-pit of Saint-Prest, near Chartres, that M. Desnoyers himself found a tibia of rhinoceros bearing marks of incision and grooves similar to those which had been so often noticed in the bones of bears and reindeer eaten by quaternary man. A careful comparison and numerous facts of the same nature, shown in different collections, authorised him to announce that man might be traced beyond the glacial epoch, and had lived in pliocene times. 
But M. Desnoyers only brought forward proofs of a single kinl, and such as are not appreciated at their full value until we are used to them. 'Thus his work was at first received with a certain amount of distrust. He was asked to produce, if not pliocene man himself, at least some objects of his industry, and, in particular, the weapons which would cuable him to attack, and the knives with which he could cut up the elephant and rhinoceros, or the great decr, whose bones all bear the marks of more or less deep incision which he attributes to man. M. l'Abbé Bourgeois soon replied to these demands, and in the presence of the worked flints which he placed before competent judges, all doubt disappeared.

Unfortunately, the gravel of Saint-Prest is considered by a sufficient number of geologists to belong rather to quaternary deposits, which are more recent than undoubted tertiary formations. It ought probably to be placed in the period of transition which separates two distinct epochs. Perhaps it is contemporaneous with the deposit of the Victoria cave in Yorkshire, from which Tiddeman extracted a human fibula, and which this naturalist regarded as having been formed a little before the great glacial cold. In short, the discoveries of MLI. Desnoyers and Tiddeman take back the existence of man to the confines of the tertiary period.

The discoveries in Italy take us still further. On different occasions, and since 1863, some Italian savants thought that they had discovered in undoubted pliocene deposits traces of human industry, and even human bones. These results were, however, for different reasons successively doubted and rejected by the most competent judges.

But M. Capellini has just discovered, in 1876, clearer proofs of man's existence in pliocene times in the clay deposits of Monte Aperto, near Sienne, and in two other places. The eminent professor of Bologna has found in these localitics, the age of which is not contested, bones of the balonotus bearing numerous deep incisions, which it seems to me could only have been produced by the action of a cutting 
irstrument. In some cases the bone has been broken off upon one of the faces of incision, whilst the other is smooth and sharply defined. Judging from woodcuts and casts, it is impossible to avoid admitting that the cuts have been made apon fresh bones. These incisions differ entirely from those found upon the bones of halitherium found in the miocene falunian strata of Pouancé. I have always thought it impossible to attribute the latter to man, as decidedly as I think those which we are now discussing ought to be attributed to his agency. The existence of pliocene man in Tuscany is, then, in my opinion, an acquired screntific fact. Nevertheless, I should admit that this conclusion is not yet unanimously accepted, and that it is disputed by M. Magitot, among others, who relies upon his own experience.

VII. The researches of M. l'Abbé Bourgeois take us still further back. This practised and persevering observer has discovered in the department of Loir-et-Cher, in the Commune of Thénay, flints, the shape of which he thinks can only be attributed to man. Now geologists are unanimous in considering these deposits as miocene, belonging to the mean tertiary age.

But the flints of Thénay, generally of small size, are almost all very roughly shaped, and many palæontologists and archæologists have considered the fractures to be due to nothing more than accidental blows. In 1872 , at the Congress of Brussels, the question was submitted to a commission of the most competent men of Germany, England, France, Belgium, and Italy, and the judges disagreed. Some accepted and some rejected all the flints exhibited by M. l'Abbé Bourgeois. Some considered that a small number only could be attributed to human industry. Others, again, thought it right to reserve their judgment and to wait for fresh facts.

I joined the ranks of the latter. But since then fresh specimens discovered by M. l'Abbé Bourgeois have removed my last doubts. A small knife or scraper, among others, which shows a fine regular finish, can, in my opinion, only have been shaped by man. Nevertheless, I do not blame 
those of my colleagues who deny or still doubt. In such a matter there is no very great urgency, and doubtless the existence of miocene man will be proved, as that of glacial and pliocene man has been-by facts.

VIII. 'Thus, man was most certainly in existence during the quaternary epoch and during the transition age to which the gravels of Saint-Prest and the deposits of the Victoria cave belong. He has, in all probability, seen miocene times, and consequently the entire pliocene epoch. Are there any reasons for believing that his traces will be found further back still? Is the date of his appearance necessarily connected with any epoch? For an answer to these questions I only see a single order of facts to which we can apply.

We know that, as far as his body is concerned, man is a mammal, and nothing more. The conditions of existence which are sufficient for these animals ought to have been sufficient for him also; where they lived, he could live. He may then have been contemporaneous with the earliest mammalia, and go back as far as the secondary period.

Palæontologists of high merit shrink from this proposition. They do not admit even the possibility of the existence of man in miocene times. All the mammalian fauna of this period have, they say, disappeared; how should man alone have resisted against causes which were sufficiently powerful to cause a complete renewal of all the beings with which he was most nearly connected?

I recognise the force of the objection; but I also take into account human intelligence, which they seem to forget. It is evidently owing to this intelligence that the man of SaintPrest, of the Victoria cave, and of Monte Aperto has been able to survive two great geological epochs. He protected himself against cold by fire, and so survived till the return of a more genial temperature. Is it not possible, therefore, to imagine that man of an earlier period should have found in his industry the necessary resources for struggling against the conditions which the transition from the later 


\section{Past Geological Epochs.}

secondary times to the earlier tertiary must have imposed upon him.

In fact, the most careful judges acknowledge that man has seen the accomplishments of one of the great changes on the surface of the globe. He has lived in one of the geological epochs to which he was but lately thought to be a complete stranger; he has been contemporary with species of mammalia which have not even seen the commencement of the present epoch. There is then nothing impossible in the idea that he should have survived other species of the same class, or have witnessed other geological revolutions, or have appeared upon the globe with the first representatives of the type to which he belongs by his organisation.

But this is a question to be proved by facts. Before we can even suppose it to be so, we must wait for informatiou from observation. 


\section{BOOK IV.}

ORIGINAL LOCALISATION OF THE HUMAN SPECITS.

\section{CHAP'TER XIV.}

AGASSIZ'S THEORY.-CENTRES OF CREATION.

I. With the exception of Australasia, with which we are out very imperfectly acquainted, and of some islands and ieserts which we need not take into account, all the regions visited by man since the commencement of the era of modern discoveries have proved to be more or less inhabited. In wandering over the globe of which he took possession, the European has met with man everywhere, and quaternary palieontology reveals him to us upon the most distant shores of the two continents.

Are ail these different populations indigenous? Is man a native of the countries where he is represented by history, and where travellers have met with him? or has he rather invaded by degrees the surface of the globe, starting from a certain number of points, or from a single one? In other words, has man, who is now cosmopolitan, originally been more or less localised?

'I'hese questions have been answered alternately in the different senses which they admit of. Unfortunately these solutions have too often been influenced by considerations entirely foreign to science. It has been thought necessary to adopt either the one or the other in the name of dogma or philosophy, and this question has been confounded with 


\section{Agassiz's Theory.}

that of monogenism and polygenism, without seeing that upon this particular point the two doctrines must lead anyone who remains faithful to the data of science to the same result. Science has already been shown to be our only possible guide; let us examine her teaching on this subject.

II. The doctrine which admits the multiplicity of the geographical origins of man, has been more frequently asserted, than sustained by more or less serious arguments. Agassiz is the only naturalist who has developed and defined it, by supporting it with general data. We must, therefore, first examine these data. A very short account will explain the reasons why I must, with regret, oppose one of the men whose learning and character I have always held in the highest estimation.

There are singular points of resemblance, and no less striking contrasts between Agassiz and the most extravagant disciples of Darwin. The illustrious author of the Essay on Classification is as exclusive a morphologist as the latter; neither in his opinion nor in theirs, does the idea of filiation form any connection with that of species; he declares, as they do, that the questions of crossing, of constant or limited fertility, have no real interest. We are justified in attributing these opinions, so strange in such an eminent zoologist as Agassiz, to the nature of his early works. It is well known that he commenced his career with his celebrated researches upon fossil fishes. We have already remarked upon the influence which is almost inevitably exercised by fossils, where form alone has to be considered, where nothing calls attention to the genealogical connection of beings, and where we meet with neither parents nor offspring.

But while Darwinists admit the perpetual instubility of specific forms and their transmutation, the illustrious professor of Cambridge believes in their absolute immutability. Upon this fundamental point he is in exact opposition to Darwin. In 1840, whilst proclaiming the unity of the human species, he admits that the diversity which it presents 
is the result of original physical differences. This is really nothing more than a mitigated polygenism; and, like every polygenistic doctrine, compels its author to place man in contradiction to general laws. In 1845, Agassiz himself accepted this consequence in a memoir upon the geographical distribution of animals and man. He attributed the diversities of both to the same causes. "But," he adds, "whilst in every zoolugical province animals are of different species, man, in spite of the diversity of his races, always forms one and the same species." The following year he declared his belief in "an indefinite number of primordial races of men created separately."

Agassiz has collected and developed all his theories in a memoir inserted at the beginning of the great polygenistic work entitled Types of Mankind. It is clear that Nott and Gliddon, the authors of this work, were perfectly aware of the real meaning of a doctrine which proclaims the specific unity of man, while at the same time admitting that the human races have been created separately with all their distinctive characters. We, also, must not be deceived, but recognise Agassiz as a true polygenist.

I shall, therefore, be obliged to make all those objections to the theory of the eminent naturalist which have already been stated. Moreover, the singular association which he has endeavoured to establish between the unity of species and the original characterisation of races, has led him into sontradictions and consequences which are peculiar to him, and which it would scarcely be possible to pass by in silence.

Agassiz, like the greater number of polygenists, gives no intimation of what he means by the word race. Yet he makes use of it incessantly and declares, for example, that he is ready to show that "the differences existing between human races are of the same nature as those which separate families, genera, and species of apes or other animals. . . . " "The chimpanzee and the gorilla," he adds, "do not differ from each other more than Mandingoes from the Negroes of Guinea; there is less difference between either of them and 
the orang, than there is between the Malay or the White and the Negro."

Must not the logical consequence of such positive language be, that man forms a zoological family comprising several genera and many species, precisely similar to the family of anthropoid apes? But no ; Agassiz devotes a new paragraph to declaring that this opinion, which he has expressed so clearly, agrees entirely with the theory of unity, and in no way brings human fraternity into question. In one of his first memoirs upon questions of this nature, he declared that man is an exceptional being, and we shall see how far he pushes this unavoidable consequence of his theories.

In a letter addressed to the same authors, and printed in the Indigenous Races of the Earth, Agassiz returns to the same subject. He here insists upon considerations which, in his first work, he had merely alluded to, and which we are truly astonished to receive from his pen. In order to show that the same local causes have acted upon man and animals, he draws attention to the resemblance of colour, which, according to him, exists between the complexion of the Malay and the colour of the hair of the Orang; from the same point of view he compares the Negrittoes and Telingas with the gibbons.

If it were possible to consider seriously this comparison between the skin of a human group, and the colour of the hair of an animal, we should have no lack of arguments to bring against the author. I shall only remind my readers that black gibbons are found in Sumatra, which is one of those islands where men are considered by Agassiz to resemble the orang in colour.

Carried away by the heat of controversy with those naturalists who admit the unity of the geographical origin of man, Agassiz goes much further than this. He considers the various languages as being of primitive origin as well as all other characters. Men, he asserts, were created by nations, each of which appeared upon the globe with its own language. He draws a comparison between these 
linguages and the voices of animals; he laughs at philologists for their belief in the discovery of any connection between one language and another. In his opinion, there is just as much relation between one human language and another, as between the growling of different species of bears, the mewing of the cats of the two continents, the quacking of ducks, or the song of thrushes, who all pour forth their gay and harmonious notes, each in its dialect, which is neither inherited nor derived from another.

Philologists will most certainly reject the law as laid down by Agassiz. But I must also protest against the comparison admitted by this illustrious naturalist. If $I$ attribute a language to animals, I do not forget how rudimentary it is. I recollect that no animal has ever learnt the language of another. I know too well the distance there is between animal interjections and articulate speech, and I am as well aware as anyone that to use such an instrument, so as to produce from it true languages, can only be accomplished by the superior intelligence of man.

Agassiz, when he had arrived at this point, must have felt that he had lost himself, and that, in trying to harmonise the idea of a single human species with that of several races of distinct origin, he was entering an endless labyrinth. His last work betrays the signs of this embarrassment only too clearly. It is probably in the hope of escaping from it that the author has finally even denied the existence of species. After having again rejected the criterion drawn from crossing and degrees of fertility, he adds: "With it disappears in its turn the pretended reality of species as opposed to the mode of existence of genera, families, orders, classes and branches. Reality of existence is, in fact, possessed by individuals alone." Thus, from adhering solely to morphology, from a disregard of the physical side of the question, from having allowed themselves to be guided by a logic which is only founded upon incomplete data, Agassiz and Darwin have arrived at a similar result. Both have disregarded this great fact, intelligible to common sense, demonstrated by science, and 
which governs everything in zoology, as it lloes in botany, the division, namely, of organised beings into elementary and findamental groups which propagate in space and time. But Darwin, starting from the phenomence of variations which are presented by these beings, considers species as only races. Agassiz, entirely preoccupied with the phenomena of fixity, finally considers individuals only as existing in living nature. Both forget that the great Buffon passed successively to both these extremes only to return again to the doctrine which includes and explains all facts, and which may be summed up in these words: distinction of race and species.

III. In spite of these dogmatic assertions, when it comes to application of any kind whatever, Agassiz, like Lamarck in former times, and Darwin in our own day, is obliged to use the word species in the sense in which it is employed by so many others. In the memoir, from which I have already quoted, animal and regetable species are constantly being discussed. Their geographical distribution serves as a foundation to the theory of human origins. The author admits that they could not have arisen upon one and the same point of the globe; that the centres of creation were numerous, and that the species diverging from these centres give to the actual flora and fauna all their characteristic features.

Up to this point Agassiz has only accepted the doctrine of centres of creation, a doctrine entirely French in origin, having been formulated by Desmoulins and developed by M. Edwards.

What is due to Agassiz is the reproduction, in the name of science, of a theory at first proposed by La Peyrère in the name of theology: giving to man the whole world as his original home: the admission that the human races originated in the same places as the groups of animal and vegetable species, and the connection of one of these races with each centre of creation; the multiplication of the number of human creations to such a degree as to profess that "man was created by nations," endowed from the first with al! 
their distinctive characters, and each speaking its own special language.

There is, at first sight, no absurdity in the idea itself, nothing at all contradictory to anything which we have as yet met with. We have seen above that physiology leads to the conclusion that "human groups are to all appearance descended from one primitive pair." It goes no further than that. Anyone who confines himself to inferences draw from this order of facts might, therefore, accept the theory of Agassiz as, it is true, a very gratuitous hypothesis, but convenient in order to account for the distribution and actual diversity of human types.

'This is no longer the case when we turn to another branch of the natural sciences, zoological and botanical geography. We then can easily prove that the theories of Agassiz tend to make an exception of man, to place him at variance with the general laws of the geographical distribution of all other organised beings, and, consequently, that they are false.

IV. I fully agree with the views of Agassiz, as far as centres of creation, or rather centres of appearance are concerned.

All who confine themselves to the data of observation and experiment will see at once that all animal and vegetable species could not have originated upon any one spot of the globe. 'The former shows us, in various regions, different types and species, living naturally in countries which present almost precisely the same conditions of existence. 'The latter teaches us that we can transport the greater number of species from one region to another, and that they will prosper there, if the conditions of existence are the same; that, on the contrary, arctic and tropical species cannot, even temporarily, be submitted to the action of the same conditions; that neither can withstand the action of a temperate climate. It is impossible with all these facts to avoid the conclusion that plants and animals had several points of appearance.

But if I accept this doctrine as the only one reconcilable with facts, it is upon the condition of adopting it entircly, 
and as developed by studies upon the geographical distribution of all living beings. Now, works of this kind are numerous at the present time.

For all phanerogamous plants we have the work of M. Ad. de Candolle, which has been a standard work ever since its appearance.

Animals have not yet had their de Candolle. The great work of M. Alphonse Edwards will partly fill up this gap for the more southern regions of the glohe. In the meantime, important investigations have been made in some of the principal classes. Buffon, by his admirable researches upon the geography of mammals, opened the way, in which he has been followed by the two Geoffroy Saint-Hilaires, Fr. Cuvier, and Andrew Murray; Dumeril and Bibron have studied reptiles from the same point of view; Frabricius, Latreille, Macley, Spence, Kirby, and Lacordaire have done the same for insects; M. Milne Edwards has worked out the distribution of the crustacea; I have endeavoured to do as much for the annelids. Finally, a great number of works bearing upon the lower groups have long been known to science, and Agassiz himself has largely contributed to increase our knowledge in this direction.

A certain number of general facts stand out from this mass of research, which we call laws. If the theory of Agassiz is true, it ought to agree with these laws. Now the disagreement is apparent from the outset.

Let us prove, in the first place, that this theory includes two very distinct ideas: that of the original cosmopolitanism of the human species; and, secondly, that of a geographical connection between the human race and the animal or vegetable groups observed in a common centre. Let us examine the truth and error contained in this last statement.

Agassiz holds that the influence of the centre of appearance is general and absolute. It extends to all the products of the soil as well as to those of fresh and salt waters. A. country is just as much characterised by its plants and animals as by its human beings. In his opinion, an essen- 
tially local force seems to have produced all beings, or at least to have imprinted upon them a common mark.

This generalisation was inevitable. Any one who wishes to attach a human race to each centre of appearance is compelled to localise in each one of them the original cause of all the animal and vegetable forms which are indigenous in it. For all living beings geographical coincidence must be absolute.

Now there is generally no such coincidence. From the waters of a river to the banks which enclose it, the contrast may be striking. This is exactly what was shown by the discoveries of Agassiz himself in the ichthyology of the Amazon. To anyone who accepts the results published by the illustrious traveller, it is evident that this fauna may be divided into groups much more narrowly confined than those of terrestrial fauna. The same fact may be observed upon the shores of two seas separated by even a very narrow strip of land. The terrestrial fauna and flora are the same throughout the whole extent of the isthmus of Suez, whilst M. Edwards has not found a single species of crustacea common to both the Mediterranean and the Red Sea, and the study of annelids has led me to the same result.

Moreover, the same region may be the centre of appearance for one class of animals, but by no means for another. Australia, for example, is one of the most characteristic centres for mammals, and stands alone from this point of view among the surrounding countries. With respect to insects Australia agrees, on the contrary, with New Zealand, New Caledonia and the neighbouring islands. I have borrowed this last fact from Lacordaire. It has the more value since this entomologist has multiplied the centres of appearance to a much greater extent than Agassiz, and has, therefore, made their characterisation easier.

Thus the coincidence admitted by Agassiz, far from extending to all the organised beings of a region, does not even exist in certain cases between the different classes of animals alone. $\mathrm{V}$. Agassiz divides the entire surface of the globe into nine 
great regions or lingdoms. I cannot here give in detail the rumerous criticisms to which the fixed limits and characterisation of these centres are open. I shall confine myself to a few short remarks upon each.

1. Polynesian Kingdom. We shall see presently that it is impossible to regard Polynesia as a centre of human appearance. This region has been entirely peopled by migration from the Indian Archipelago, the history of which has been partly preserved. The first kingdom of Agassiz must be struck out as far as we are concerned; it is an exclusively animal and vegetable centre. Agassiz, moreover, though he supports it in the text and upon the map, does not assign it a place in the illustrated table, in which he sums up his ideas.

2. Australiun Kingdom. Agassiz includes New Guinea in this kingdom. He thus destroys the homogeneity of the mammalogical fauna. At the same time he unites the several human races of Australia with the Negrittoes and Papuans. This alone destroys all unity of type.

3. Malay or Indian Kingdom. This kingdom comprises India, the Malay Archipelago, and the Andaman Islands. Now, anterior to the Aryan conquest, Yellows and Blacks lived in India. The latter are still found in a pure state in the peninsula of Malacca, and in the Andaman Islands; Malaysia presents a perfect mixture of most different races, from the White to the Negro. The Malays, properly so-called, are much rather a population levelled by the action of Islamism, than a race in the true sense of the word; they present in a high degree the characters of intercrossing. All these facts protest against the idea of making these regions a centre of human appearance.

4. Hottentot Fauna. Agassiz abandons the expression kingdom in speaking of the south of Africa, without giving any reason for the change. Whatever the cause may be, this is one of the least unfavourable regions for the application of his theory. From a geological or botanical point of view, South Africa constitutes a veritable centre. The 
Bosjesman and the Hottentot might be considered as the characteristic human type. But the Negroes of Delagoa and the Kaffirs still protest against this partial coincidence.

5. African Kingdom. This region is considered by Agassiz to comprise the rest of Africa, with the exception of the shores of the Mediterranean. He adds Madagascar and the southern half of the Arabian peninsula. Now, from a mammalogical point of view, Madagascar forms a little centre of itself, whilst the human population is very mixed. The Hovas are very slightly modified Malays, and the languages of the Sacalaves themselves indicate relations with the Malayo-Polynesians. As to the continental portion of the kingdom, it is enough to remark that it includes Negroes, Abyssinians, Arabs, etc. History, as well as the present state of things, protests against the connection made in this case by the author.

6. European Kingdom. This division Agassiz considers as comprising the entire circumference of the Mediterranean, Persia and Beloochistan. Consequently it embraces very different fauna and flora; it mixes up Aryan, Semitic and Chamitic populations, and takes no account of history. Agassiz himself recognises this fact, and declares that he has only taken into consideration pre-historic times. Since the Quaternary epoch, however, France alone has supported tribes which were tall and dolichocephalic, and others which were short and brachycephalic. Finally, although Agassiz includes the Persians with the Europeans, he leaves out the Hindoos who are ethmologically connected with them, and places them in an entirely different kingdom.

7. Mongotian or Asiatic Kingdom. This kingdom excloses all the central portion of Asia, beginning at the Bolor and the Himalayas, and extending as far as Japan. The Mongol is taken as the human type of this vast extent of country. But Agassiz forgets the Aryans of the Bolor, the white Jutchis, the Japanese of the same type, the Ainos, etc. He unites, therefore, people which belong to at least two extreme types of mankind. 
8. American Kingdom. Agassiz makes but one kingdom of the whole of America, whilst all zoologists and botanists are agreed in dividing it into at least two great and distinctly characterised centres. He adopts the opinion of Morton, who only admits one human race in America, with the exception of the Esquimaux. Now, since the publication of d'Orbigny's Homme Americain, it is no longer possible to believe in this uniformity. The numerous investigations which have been undertaken upon this question have, moreover, proved still more strongly the multiplicity of races admitted by this traveller. Again, if the human races of America are compared with those of the old world, we shall find, with a few exceptions, a very close connection with Asia, especially in certain populations of Central America: if we compare the fauna and flora, the connection is, on the contrary, closer in North America. These facts are in direct opposition with the theory of Agassiz.

9. Arctic Kingdom. 'This latter kingdom deserves a little more attention than the others. It comprises all the northern regions of the two continents. The southern limit is somewhat arbitrarily fixed by Agassiz at the zone of forests. In no region of the world does man meet with such identical conditions of existence, for. all are governed by cold. It would seem, therefore, to be better able than any other to justify the author's theory, and yet facts agree but very slightly with it.

Agassiz characterises this kingdom by the existence of one plant and six species of animals, five mammals and one bird. The plant is the Iceland lichen (cenomyce rangiferina). Now, this lichen is so little characteristic of polar regions that it is found in many parts of France, and even in the neighbourhood of Paris at Fontainebleau. M. Decaisne believes that our hares and rabbits live upon it in winter, as the reindeer do in Lapland. Further, the observations recently made in Greenland by the German Polar Expedition, show that in this country, which, of all countries in 
the Arctic Kingdom, should most readily adapt itself to the conceptions of Agassiz, and which is inhabited by pureblooded Esquimaux, possesses scarcely one vegetable species which can be said to be peculiar to it, and that a great number of them are found in the Alps, and upon the summits of the Vosges. It is a result of the return of heat after the glacial epoch, the species which resisted it having emigrated in altitude as well as in latitude.

In animal species, the white bear and the walrus are really polar. The same may be said of the Greenland seal considered as a species. But as a type we meet with it everywhere; as a genus it inhabits all the seas of Europe. The reindeer inhabited France in the Quaternary epoch; it was living in Germany in Cæsar's time; it descended yearly to the Caspian Sea during the lifetime of Pallas. 'The true whale used to visit our coast before it was driven away by man. Finally, at this day, the eider duck builds yearly in Denmark, ten to fifteen degrees south of the Polar circle. 'Thus, in the six species mentioned by Agassiz as peculiar to his Arctic Kingdom, three at least belong equally to his Ė̈ropean Kingdom.

Agassiz was certainly more capable than anyone else of nicely characterising the region in question, if it had been possible to do so. He failed, because there is in reality no such thing as a true Arctic fauna. The cause of this lies in the extension of more southern fauna, which become impoverished as they advanced northwards, but change their character very slightly. In reality, this kingdom is broken up into independent provinces, or rather, is connected with regions situated more to the south, and consequently better divided. The Polar region, says Lacordaire, in speaking of insects, is characterised less by the speciality of its products than by their scarcity. All these facts, again, are the consequence of the peopling of the Arctic regions after the glacial epoch.

It would seem that man at least might present at the pole the homogeneity supposed by the theory. It is not so, 


\section{Agassiz's Theory.}

however, whatever may be the assertions of Agassiz upon this subject. "A peculiar race of man," he says, "live there, known in America by the name of Esquimaux, elsewhere by that of Lapps, Samoyedes or Tchouktchis. . . The uniformity of their characters throughout the whole extent of the Arctic seas unites them in a striking manner with the fauna with which they are so closely connected."

There are, in these words of Agassiz, grave ethnological and anthropological errors. The uniformity of characters of which he speaks does not exist at all. It will suffice to remind my readers that the Lapps are one of the most brachycephalic, and the Esquimaux one of the most dolichocephalic races with which we are acquainted. In fact, these two races are so entirely distinct that no anthropologist has ever dreamt of establishing a connection between them.

As to the Samoyedes and Tchouktchis, they have not always inhabited the icy lands where we now meet with them. The former have still a recollection of having come from the south, and M. de T'chiatchef has discovered the original stock upon the confines of China. The latter settled at Behring's Straits but a short time ago to free themselves from Russian conquest, against which they had bravely struggled. They subjugated and absorbed the Yukagires, their predecessors. They differ, moreover, equally from Esquimaux and Lapps.

Thus, in the Arctic Kingdom, where all the most favourable conditions for the display of any truth which the ideas of Agassiz may possess are brought together, everything protests against these ideas. In spite of his vast knowledge, he could not characterise it zoologically in a precise manner; the special fauna which he admits does not exist; the identity of populations which he proclaimed disappears under the slightest examination.

Finally, the theory which attaches a human race to every centre of appearance as a local product of that centre, ought to be rejected by anyone who sets the least value upon the results of observation. 


\section{CHAPTER XV.}

PROGRESSIVE LOCAIISATION OF ORGANISED BEINGS.CENTRES OF APPEAIANCE.-ORIGINAL LOCALISATION OF MIN.

I. Ax eminent man may draw incorrect conclusions from the existence of centres of appearance without their existence being any the less real. Unconnected with animal or vegetable centres, the human races might have their own; man might have come into existence wherever we meet with him. But, before we accept this original cosmopolitanism, we must assure ourselves that it subjects man to general laws. Now we shall see that this hypothesis is, on the contrary, at variance with all general facts presented by plants as well as animals.

II. Let us first prove that no animal or vegetable species inhabits, as man does, almost the entire globe.

The assertion of $\mathrm{Ad}$. de Candolle could not be more precise as far as plants are concerned. "No phanerogamous plant," he says, "is distributed over the entire surface of the earth. There are only eighteen whose area extends to half the globe. No tree or shrub figures among these plants, which are so widely distributed." 'This latter remark belongs to an order of considerations which we shall meet with again.

Being unable to enter into an examination of all the facts which are offered by the various classes of the Animal Kingdom from this point of view, I shall confine mysclf to a few details upon birds and mammals.

We should expect to find the former presenting very extensive areas of habitation by reason of their mode of locomotion. It is, in fact, among them that we find some of the 
species which most deserve the epithet of cosmopolitan. They do not, however, equal man in this respect.

The stock-dove, the parent stock of our domestic pigeon, extends from the south of Norway to Madeira and Abyssinia, from the Shetland Islands to Borneo and Japan; but it does not reach as far as either the equator or the polar circle; and it is wanting both in America and Polynesia.

The fulvous vulture is found in all the temperate regions of the old world, crosses the equator in Africa and descends as far as the Cape. But we do not meet with it either in our polar regions, in America or in Polynesia.

The peregrine falcon has perhaps of all animals the widest area. It is found in America, as also in all the warm or temperate regions of the old world. It is supposed to exist in Australia, but we do not meet with it either in Polynesia or in the polar regions.

Among mammals, whales, on account of their immense powers of locomotion and the continuity of seas, would seem to be adapted to true cosmopolitanism. 'This, however, is not the case. They are almost all confined within relatively very limited areas, and rarely pass beyond their customary boundaries. Commodore Maury regarded the equatorial sea as forming an invincible obstacle to their passage from one hemisphere to the other. 'Two exceptions have, howover, been observed to this rule. A rorqual (Megapterce longimana) and a Sibaldius laticeps are said to have crossed this barrier, and to have passed from our seas to those of the Cape and of Java. These exceptions might easily be explained by various accidental circumstances. Supposing however we were to accept them as testifying an exceptional relative cosmopolitanism, we still have the fact that they have never been met with in the Pacific Ocean.

With the exception of whales, we shall find nothing at all resembling cosmopolitanism. Setting aside the whole of Oceania, we only find, as common to both the Old and the New World, two or three ruminants, perhaps a bear, a fox and a wolf. All these species are, moreover, more or less 
polar, and are wanting in the central regions of the two worlds. Finally, there is not one species of cheiroptera or quadrumana which is indigenous both in America and the Old World.

Beyond those species which man has disseminated by making them follow his migrations, animals and plants evidently occupy their natural area, wherein lies the centre from which they have spread. We see that even after this, dispersion none of them have acquired an area of habitation which can be compared to that of man.

The admission that the human species appeared in every place in which it is found, attributing to it an original cosmopolitanism, would make it a solitary exception in contradiction to the facts presented by all other species. An hypothesis which leads to such a conchusion should be rejected as irreconcilable with the results of observation. If man is now to be found everywhere, it is owing to his intelligence and industry.

III. 'This conclusion is forced even upon polygenists themselves; unless, indeed, they would reject, as inapplicable to man, the laws of zoological and botanical geography.

In fact, to whatever extent they may have multiplied their human species, they have been obliged, upon even the shightest study of natural history, to unite them into a single genus. Now, all that has just been said of species applies equally to genera. The area of habitation is doubtless increased, and, for example, some genera of cetaceans, as dolphins and rorquals, are found in all seas; and amongst terrestrial mammals, some genera of ruminants and carnivora inhabit, in a greater or less degree, both the Old and the New World. But they are all absent in the greater part of Oceania.

Moreover, the higher the types, the fewer is the number of these genera of widely extended areas. Cheiroptera, which are not provided with a nasal membrane, have some genera common to both the Old and the New World. 'This is no longer the case in cheiroptera, in which the nose is provided 
with a membrane. There is not a single genus among them, any more than among quadrumana, which inhabits both America and the Old World.

Consequently, polygenists must admit that the species of which their human genus is composed could not have come into existence in every place where man is now found, unless they wish to make a striking exception of this luman genus.

IV. Should we wish to regard the human races as forming a family composed of several genera, or even as an order comprising several families, the same difficulties would present themselves.

Setting aside the marsupials and edentata, to which we shall return, it is true that the great normal orders of terrestrial mammals, the ruminants, rodents, insectivora, and carnivora are almost as cosmopolitan as man. But this is no longer the case with the cheiroptera, not one of which passes the polar circle. As to the quadrumana, it is well-known that they are wanting in Europe, with the exception of the Rock of Gibraltar, in North America and in the greater part of Asia and Oceania. Thus it appears that, even in the extreme hypothesis which I have here indicated, it would not be in the animal types which present the greatest resemblance to man, but among the carnivora or ruminants that we should be forced to seek for geographical analogies in favour of the pretended cosmopolitanism of the human order.

$\mathrm{V}$. This limitation of the areas of habitation of animals, which is evidently related to their degree of elevation in the scale of beings, is a general fact which we also meet with in plants. On this point Ad. de Candolle speaks as follows :"The mean area of species is smaller according as the class to which they belong has a more complete, a more highly developed, or, in other words, a more perfect organisation."

The progressive localisation of organised beings, increasing in degree as they become more perfect, is, then, a general law. Physiology will readily account for this fact. 
The perfection of organisms is the result of division of labour, which demands the multiplication of functional apparatus. As the anatomical instruments become more numerous and special, the functions do the same. From this cause alone the conditions of harmony between the living being and the conditions of life which surround it become more and more definite. Consequently, the animal or the plant only finds its really favourable conditions in a constantly diminishing area. Beyond these limits the conditions of life change, the struggle for existence becomes more hazardous, and the spread of the species, genus, family, or even order is arrested. Man alone, armed against the conditions of life by his intelligence and industry, is capable of overcoming conditions of existence which would be an impassable barrier to lis material organisation.

The law of progressive localisation is in direct opposition to the doctrine of the original cosmopolitanism of the human species. In putting it aside, polygenists, properly so called, might draw attention to the diffusion of the genera of dolphins and rorquals; polygenistic monogenists of the school of Agassiz might argue from the facts mentioned above in connection with the genera of megaptera and sibaldius; they might both say: The general law of localisation offers two exceptions; why should not man form a third?

The analogy, it is clear, is fundamentally wrong. Dolphins, rorquals and sibaldius belong to the lowest order of mammals; man, even if his body alone is considered, belongs incontestably to the highest order. Unless we make him a solitary exception, it is to the laws of the superior groups that he should be subject, and not to those of the inferior.

Thus, we are so far justified in affirming that man could not have been originally cosmopolitan. But we can go further:

VI. Without having come into existence in every place where we now meet with him, man may have had several centres of appearance. Let us examine this latter question. 
The laws of progressive localisation and the characterisation of centres enable us both to put the question and to solve it.

Let us re-examine from this point of view the animal groups, setting aside all inferior groups and confining our attention to anthropoid apes. In this family, which most closely resembles man in its organisation, there are degrees also. The law of progressive localisation applies to this limited group equally with the entire kingdom.

We meet with the entire family in Asia, in the peninsula of Malacca, in Assam to $26^{\circ} \mathrm{N}$. Lat., in Sumatra, Java, Borneo and in the Philippine Islands; in Eastern Africa from $10^{\circ} \mathrm{S}$. to $15^{\circ} \mathrm{N}$. Lat. The gibbon genus, however, which is the lowest, is the only one which occupies the whole of Asia. The orang is confined to Borneo and Sumatra. In Africa the chimpanzee extends almost from the Zaïre to Senegal; the gorilla has only been found on the Gaboon, and perbaps in Ashantee. Were he to occupy all the space which is still left blank upon that part of our maps by travellers, his area of habitation would even then be very limited. Thus, the higher the anthropoid type, the more limited the area of habitation.

If we consider the material organism alone, the human type is incontestably superior to that of the orang or gorilla. $\mathrm{He}$ must then have been originally localised just as much as these animal types. It will perhaps be objected that the great apes are gradually disappearing, and that the few survivors do no more than show that they once existed in greater numbers. This would be an entirely gratuitous hypothesis having no foundation in facts, and we shall at least be permitted to reply, that the gorilla and the orang might very well have continued to exist in those places where the chimpanzee and gibbon are still living. Now, what are the areas occupied by the latter compared with the human area?

VII. I have, as yet, neglected exceptional types, such as the marsupials, the edentata, the makis, etc.; I did not wish to argue from aberrant forms; I confined myself to demon- 
strating the laus in action in species of a so-called normal organisation. Aberrant types have, however, a very high value, and furnish us with further instruction.

These types almost always characterise either the great centres of appearance, or the secondary centres or geographical regions. Not to mention mammals, I must remind my readers that Australia has its marsupials; South Australia, the ornithorynchus; polar America, the musk-ox; central America, the edentata; Africa, the giraffe; Asia, the yak; the Cape, the gnu; Madagascar, the makis and ayeaye; the Gaboon, the gorilla, etc.

Man, also, is evidently an exceptional or aberrant type among mammals. He, alone, is constructed for a vertical position; he, alone, has true hands and feet; he, alone, exhibits the highest degree of cerebral development, and possesses that superiority of intelligence which makes him master of all around him.

To allow that the human type, though the most perfect of all types, the exceptional genus in the midst of all others, has come into existence in several centres of appearance without characterising any, would be to make him a solitary exception.

However strong may be our polygenistic tendencies, and however many species we may admit, we cannot help acknowledging that the original localisation of the human genus in a single centie of appearance and the characterisation of this centre by him are the logical consequence of all the facts attested by zoological geography.

With still greater reason the monogenists will consider the privileged species which predominates over all others as one of those special types which characterise the centre, or the region in which they have appeared, as the ornithorynchus, the aye-aye, and the gnu characterise South Australia, Madagascar and the Cape.

Finally, the laws of zoological geography lead us to consider the human species as unmistakably characteristic of a single centre of appearance. Moreover, they justify us in con- 
cluding that this centre cannot have been of greater extent than that of the gorilla and the orang.

VIII. Is it possible to go still further and to endeavour to determine the geographical position of the human centre of appearance? I cannot here enter into the details of this problem. I shall confine myself to determining its meaning, and to indicating the probable solutions of it from the data of science of the present time.

I must observe, in the first place, that in considering an animal or vegetable species, even those whose area is most circumscribed, no one thinks of trying to discover the precise spot upon which it may have first appeared. There is always something very vague in such a determination and it is necessarily approximative. It is still more difficult when the species in question is of universal distribution. Within these limits we are justified in at least forming conjectures which, as such, have a certain amount of probability.

The question presents very different aspects according as we confine ourselves to the present or take into consideration the geological antiquity of man. Nevertheless, the facts are of the same order and seem to indicate two extremes. The truth lies, perhaps, between the two.

We know that in Asia there is a vast region bounded on the south and south-west by the Himalayas, on the west by the Bolor mountains, on the north-west by the Ala-Tau, on the north by the Altai range and its offshoots, on the east by the Kingkhan, on the south and south-east by the Felina and Kuen-Loun. Judging from the present state of things, this great central region might be regarded as having contained the cradle of the human species.

In fact, the three fundamental types of all the human races are represented in the populations grouped round this region. The black races are the furthest removed from it, but have, nevertheless, marine stations, where we find them either pure or as mixed races, from the Kioussiou to the Andaman Islands. Upon the continent they have inter- 
mixod with almost every inferior caste and class of the two peninsulas of the Ganges; they are still found pure in both, ascend as high as Nepaul, and extend west as far as the Persian Gulf and Lake Zareh, according to Elphinstone.

The yellow race, either pure or in places mixed with white elements, secms to be the only one which occupies the space in question; it peoples all the north, east, south-east, and west. In the south it is more mixed, but forms, nevertheless, an important element in the population.

The white race, from its allophylian representatives, seems to have disputed the central area itself with the yellow race. In early times, we find the $\mathrm{Yu}$-tchi and the $\mathrm{Ou}$-soun to the north of the Hoang-ho; and in the present day cases of white populations have been observed in Little 'Thibet and in Eastern Thibet. The Miao-Tsé occupy the mountain region of China ; the Siaputh are proof against all attack in the gorges of the Bolor. Upon the confines of the area we meet with the Ainos and the Japanese of high caste, the Tinguianes of the Phillippine Islands; in the south with the Hindoos. In the south-west and west the white element, either pure or mixed, reigns supreme.

No other region of the globe presents a similar union of extreme human types distributed round a common centre. This fact, alone is sufficient to suggest to the mind of the naturalist the conjecture which I have expressed above; but we may appeal to other considerations.

One of the most important is drawn from philology. The three fundamental forms of human language are found in the same countries and under similar relations. In the centre, and south-cast of our area, the monosyllabic languages are represented by those of China, Cochinchina, Siam and Thibet. As agglutinative languages, wo find in the north-east and north-west the group of Ougro-Japanese, in the south that of the Dravidian and Malay, and in the west the Turkish languages. Lastly, Sanscrit with its derivatives, and the Iranian languages represent in the south and south-west the inflectional languages. 


\section{Original Localisation of Man.}

It is to the linguistic types gathered round the central region of Asia that all human languages must be referred; whether from their vocabulary or their grammar, some of these Asiatic languages bear a close resemblance to languages spoken in regions often very distant, or separated from the area in question by entirely different languages. We know that several philologists, M. Maury among others, establish an intimate connection between the Dravidian languages aud Australian idioms, and that M. Picot has discovered numbers of Aryan words in our oldest European languages.

Finally, it is from Asia again that onr carliest domesticated animals are derived. Isidore Geoffroy is entirely agreed with Dureau de la Malle upon this point.

Thus, the present epoch alone considered, everything points to this great central plateau, or rather to this great enclosure. There, we are inclined to say, the first human beings appeared and multiplied till the populations overflowed as from a bowl and spread themselves in human waves in every direction.

IX. Palæontological studies have, however, very recently led to results which are capable of modifying these primary conclusions. MM. Heer and de Saporta have informed us that in the Tertiary perior Siberia and Spitzbergen were covered with plants, indicating a temperate climate. Mi. Murchison, Keyserlink, de Verneuil, and d'Archiac tell us that, during the same period, the barren lands of our day supported large herbivorous animals, such as the reindeer, the mammoth, and the tichorhine rhinoceros. All these animals made their appearance at the commencement of the Quaternary period. It seems to me that they did not come alone.

I have said above that the discoveries of M. l'abbé Bourgeois testify, in my opinion, to the existence of a tertiary man. But everything seems to show that as yet his representatives were but few in number. The Quaternary populations, on the contrary, were, at least in distribution, quite as numerous as the life of the hunter permitted. Are we justified in imagining that during the Tertiary period mas 
Iived in polar Asia side by side with those species which I have just mentioned, and that he supported himself by hunting them as he afterwards did in France? 'The fall of temperature compelled the animals to migrate southwards; man must have followed them to find a milder climate, and to be within reach of his customary game. Their simultaneous arrival in our climates and the apparently sudden multiplication of man would thus be easily explained.

The centre of human appearance might then be carried considerably to the north of the region I have just been discussing. Perhaps prehistoric archæology or palæontology will some day confirm or confute this conjecture.

However this may be, no facts have as yet been discovered which authorise us to place the cradle of the human race elsewhere than in Asia. There are none which lead us to seck the origin of man in hot regions either of existing continents, or of one which has disappeared. 'This view, which has been frequently expressed, rests entirely upon the belief that the climate of the globe was the same at the time of the appearance of man as it is now. Modern science has taught us that this is an error. From that time there is nothing against our first ancestors having found favourable conditions of existence in northern Asia, which is indicated by so many facts borrowed from the history of man, and from that of animals and plants. 


\section{BOOK V. \\ PEOPLING OF THE GLOBE.}

\section{CHAPTER XVI.}

MIGRATIONS BY LAND.-EXODUS OF THE KALMUCTS FROM THE VOLGA.

I. AT the point which we have now reached, the connection of facts and of their consequences proposes a fresh problem. Physiology has proved that there exists but one species of man, of which the human groups are races. Zoological geography has taught us that this species was originally localised in a relatively very limited space. It is now met with everywhere, because it has spread by irradiation in every direction from this centre. The peopling of the globe by migrations, is the necessary consequence of the preceding facts.

Polygenists, and the partisans of the autochthony of nations have declared that these migrations are impossible in a certain number of cases, and have brought forward this pretended impossibility as an objection to the doctrine which I uphold. Here, again, I turn to facts for my answer.

II. I confess that I never understood how any value could be attached to this argument. Migrations are almost universal in history, and in the traditions and legends of the new as well as of the old world. We find them among the uncivilised nations of our time, and among tribes which are still lingering in the lowest stage of savage life. With every 
increase and cxtension of knowledge, we learn to appreciate better the wandering instincts of man. Human palwontology and prehistoric archeology are daily adding their testimony to that of the historic sciences.

To judge from this kind of information alone, it scems more than probable that the cntire globe was peopled by means of migrations and colonisations. The primordial and uninterrupted immobility of any human race would be a fact at variance with all analogy. It would, once constituted, doubtless establish, except under exceptional circumstances, a more or less considerable number, generally the great majority of its representatives; but in the course of ages it could not fail to have cast off swarms.

III. The supporters of autochthony lay especial stress upon two orders of considerations, the one drawn from the social condition of nations when still in their infancy and unprovided with the means of action which we now possess, the other from the obstacles which a hitherto invincible nature would oppose to their movements.

'ihe first objection evidently rests upon an imperfect appreciation of the aptitudes and tendencies developed in man through his different modes of life. 'The very imperfection of the social condition, far from arresting the diffusion of the human species, must rather have been favourable to it. Agricultural nations are of necessity settled; to pastoral nations, less bound to the soil, special conditions are indispensable. Hunters, on the contrary, by reason of their mode of life, of the necessitics which it imposes, and the instincts which it develops, cannot but spread in every sense. A vast space is necessary to their existence; as soon as the numbers increase, even in a slight degree, they are forced to separate or to destroy each other, as is shown so clearly in the history of the Red Skins. Nations of hunters and shepherds are then alone fitted for great and distant migrations. Agricultural nations are rather colonists.

Ancient history itself cntirely confirms these theoretical inductions. We know what the invaders of the Roman world 
were, the destroyers of the Eastern Empire, the Arab conquerors. The case was the same in Mexico. The Chichimequi here represent the Goths and Vandals of the Old World. If Asia has so often overrun Europe, if North America has so often sent devastating hordes into more sonthern regions, it is because in these two countries man was still in a barbarous or savage state.

IV. Were natural obstacles indeed insurmountable to nations destitute of our perfected means of locomotion? This question must be considered from two points of view, as the migrations in question are by land or sea.

The former demands but little attention. The weakness of man, and the strength of the barriers which the acciaents of land, vegetation, or fauna might oppose to him, have unquestionably been much exaggerated. Man has always been able to vanquish ferocious animals, the rhinoceros having formed part of his food as early as the Quaternary period. His course has never been arrested by mountains, even when encumbered by everything which could make the passage most difficult. Hannibal crossed the Alps with his elcphants, and Bonaparte with artillery. The progress of the Asiatic hordes was no more stopped by the Palus Meotides than that of Fernand de Soto by the marshes of Florida. Deserts are daily traversed by caravans; and as to rivers, there is not a savage who does not know how to cross them upon some raft or other.

The truth, as is too well proved by the history of travel, is, that man alone stops man. Where the latter did not exist, there was nothing to oppose the progress of tribes or nations advancing slowly and at their own leisure, outstripping or passing cach other in turn, establishing secondary centres, from which, after a time, fresh migrations would tale place. Even in an inhabited country, a superior invading race wouid not act otherwise. It was thus that the Aryans conquered India, that the Paouians advanced, who, starting from a centre still unknown, arrived at the Gaboon with a line of front of about 2.50 miles. 
V. I might dwell upon these general considcrations, but it will be better to recall briefly a fact which, though of recent date, is too generally forgotten, and which shows how an entire population can effect a great migration although they meet with obstacles of every kind over a great tract of country.

About the year 1616 a horde of Kalmucks, impelled by motives with which we are macquainted, abandoned the confines of China, and crossed Asia in order to establish themselves in the Khanate of Kazan, upon either shore of the Volgn. They placed themselves under the dominion of Russia, who readily received the new colonists and respected their patriarchal government. In return, the Kalmucks proved themselves faithful subjects, and on several occasions, furnished the Russian army with numerous and valuable detachments of cavalry. This good feeling lasted till the time of the Empress Catherine, when she, having to choose between two aspirants named Oubacha and Zebeck-Dorchi, nominated the former to the government of the horde. 'The infuriated Zebeck determined, in revenge, to lead his fellowcountrymen back to China. Seconded by the chicf Lama, he eren persuaded Oubacha himself to join, and the conspiracy, though it included the entire nation, was conducted with such secrecy that it escaped the interested vigilance of Russia.

On Jan, 5th, 1771, the Kalmucks might have been seen assembling on the left bank of the Volga. Every half liour groups of women, children, and aged numbering from 15,000 to 20,000 , set out in waggons or upon camels, escorted by a body of cavalry 10,000 strong. A rear-guard of $\$ 0,000$ picked men covered the retreat of the emigrants. A Russian officer, who was detained a prisoner for part of the journey, and has preserved these details for us, estimated the whole assemblage at more than 600,000 souls.

The Kalmucks felt the necessity for haste, in order to escape the attempts which would assuredly be made by Russia to detain thom. In seven days they lad accon- 


\section{Exodus of the Kalmucks from the Volga. I 83}

plished more than 100 leagues, with the weather dry but cold. Many of the cattle had succumbed, and the want of milk was beginning to be felt, even for the children. On arriving at the banks of the Djem, they met with their first serious disaster; an entire clan, numbering 9000 horsemen, was massacred by Cossacks.

At the first intelligence of this flight, however, Catherine had despatched an army with instructions to bring back the fugitives. The latter had to pass, at a distance of eighty leagues from the Djem, a defile which must be taken at any price. They advanced by forced marches. Unfortunately snow set in, and they were obliged to stop for ten days. On arriving at the defile, they found it occupied by Cossacks, who were however routed, defeated, and massacred by Zebeck.

The defile was passed, but they were forced to redouble their speed, for the Russian army was upon them. They killed and salted all the remaining cattle, and left behind every incapable woman or child, and all their aged or sick. The winter increased in severity, and though they burnt all their saddles and waggons, every encampment was marked by hundreds of frozen corpses. At length the spring came to alleviate their sufferings, and in the beginning of June, they crossed the Torgai, which flows into Lake Aksakal, to the N.N.E. of Lake Aral. In five months the emigrants had accomplished 700 leagues; they had lost more than 250,000 souls, whilst the camels alone remained of all their animals. The Russian officer, Weseloff, who was shortly after set at liberty, was able to regain the Volga with no other guide than that of the trail of corpses left upon the route.

The unfortunate fugitives had hoped to enjoy a rest after having crossed the Torgai. But the Russian army still followed, and was even reinforced by terrible auxiliaries, the Bashkirs and Kirghises, hereditary enemies of the Kalmucks. This light cavalry was now in advance, and it would be necessary to fight with them while still flying from the Russians. They were also obliged to skirt the desert, where 
they would have perished from hunger, and to cut their way through countries where the inhabitants rose in arms to protect their territories against the famished invaders. Winter had given place to Summer; the emigrants suffered as much from the heat as they had done from the cold, so that the rate of mortality was unaltered.

At length, in the montl of September, the horde reached the frontiers of China. For many days they had had no water. At the sight of a small lake they all rushed forward to quench their thirst; the confusion was general, when the Bashkirs and Kirghises, who had never for a moment ceased to harass the fugitives, threw themselves upon the infatuated crowd, and would, in all probability, have amnihilated them. Fortunately, the Emperor Kien-long was liunting in the neighbourhood, accompanied, as usual, by a small army. Informed of the arrival of the Kalmucls, he had recognised them in the distance. The sound of his artillery restored the courage of those who were allowing themselves to be massacred, and their persecutors suffered a bloody defeat. It should be alded that Kien-long distributed amongst those whom he had saved, the lands which are occupied by their descendants at the present time.

The exodus of the Kalmucks is a sufficient answer to every argument that can be advanced on the subject of primitive migration by land. In eight months, in spite of the intense extremes of cold and lieat, of incessant attacks from implacable enemies, and in spite of hunger and thirst, this nation had accomplished a distance equal in a straight line to one-cighth of the circumference of the eartl. If we take into consideration all the enforced detours, we ought probably to double the amount. With such facts as these, how can we doubt the possibility of still longer expeditions for a tribe advancing peacefully by stages, and having only to contend against the difficulties presented by the soil or wild beasts? 


\section{CHAFTER XVII.}

MIGRATIONS BY SEA.-POLYNESIAN MIGRATIONS.-MIGRATIONS TO NEW ZEALAND.

I. The greater number of the defenders of autochthony allow that there is no fundamental impossibility in migration by land, but maintain that it is different in migrations by sea. The peopling of America, and especially that of Polynesia, by emigrants from our great continent, is, in their opinion, far more than could possibly be undertaken or accomplished by nations unacquainted with the science of astronomy, and the improved method of navigation. According to them, geographical conditions, winds and currents, must oppose an insurmountable obstacle to any enterprise of this nature.

Starting from Polynesia, let us see how much truth there is in these assertions. This will be taking, so to speak, the bull by the horns, for no other part of the globe seems to justify to such an extent, the opinions of autochthonists.

II. Polynesia is not quite so isolated as we are accustomed to think. A study of the map alone should be sufficient to justify us in holding that a maritime people, accustomed to the navigation of the Malay Archipelago, might, on some occasion, have pushed as far as New Guinea. This fact is now established above all dispute. Beyond New Guinea, the Archipelago of New Britain and the Salomon Islands would put, so to speak, any fairly adventurous navigators on their way to the Fiji Islands; once arrived at this archipelago, however little they may have been impelled by the spirit of discovery, they must easily have reached Polynesia properly so called. New Zealand to the south, and the Sandwich 
Islands to the north, remain, however, beyond the limits of this route, as it is pointed out by geography.

For bold mariners to be stopped in their advance, winds and currents must have been invariably contrary and irresistible. The stronger the belief in the universality and absolute constancy of the trade winds in these regions, the more was this action attributed to them. But the investigations which have been carried on in the interests of science, the writings of Commander Maury, and the charts of Captain Kerhallet, have taught us that the variable winds due to the cloud-ring extend over almost twenty degrees in the maritime area in question. We know, moreover, that every year the monsoon drives back the trade winds and blows beyond the Sandwich and Tahiti Islands, so that instead of the winds being contrary, they are, for many months, very favourable for ships sailing castward.

Considerations drawn from currents lead almost to the same conclusions. In the Pacific, the equatorial current running from east to west forms in reality two great listinct occanic streams separated by a large counter current flowing in the reverse direction. The latter skirts almost the whole northern portion of the Polynesian area; it thus, as it were, forms the outlet from the Indian Archipelago. There is every indication of its having played some part in the history of the dispersion of races in all parts of Occania and to the east of the Malay peninsula.

Finally, we know that there is no absolute regularity in the atmospheric phenomera in the regions of the Pacific, any more than elsewhere. This ocean has in common with others its typhoons and its tempests, which suddenly change the direction of the winds and carry ships before them in spite of currents. Islands, both large and small, with which it is beset, must often have been visited by sailors who had thus lost their way, of which we shall presently quote examples.

Far from being impossible, the peoplings of Polynesia by navigators starting from the Indian Archipelago is relatively 
casy at certain times of the year, provided only that the navigators are courageous and not afraid of losing sight of land. Now we know the character of the Malay populations in this respect.

Again, those who have taken all these circumstances into consideration, Malte-Brun, Homme, Lesson, Rienzi, Beechey, Wilkes and others, have not hesitated to regard Polynesia as having been peopled by migrations advancing from west to east.

III. Writers, on the contrary, who bave only consulted the imperfect knowledge which we till lately possessed of these seas, and the ordinary direction of the winds, have either believed in autochthony or have invented varrious theories to explain the presence of man in this multitude of islands and remote islets.

Ellis held that the Polynesians had been conveyed from America to Oceania by winds and currents, but this hypothesis has had scarcely any adherents. It is in too direct contradiction with all the physical, philological, and social characters, which refer the Polynesians to the Malay races as strongly as they separate them from the Americans.

Dumont d'Urville has proposed a theory which, at first sight, is more satisfactory, and still has a few supporters. In his opinion, Polynesia is the remains of a great continent which was originally connected with Asia. This land sank after some geological revolutions; the sea covered the plains and hills, the highest summits only being now visible and forming the present archipclago. The Polynesians are the descendants of those who survived the catastrophe.

This hypothesis has the advantage of preserving those relations which were broken by that of Ellis. And, curious to relate, it agrees with the tradition of the deluge as preserved by the Tahitians. They say that the great inundation happened without either rain or tempest. It was the sea which rose and covered the whole earth with the exception of a flat rock where one man and a woman took 
refuge. We might say that there was nothing in this account but a mistake which is easily understood. The sea never rises, but the land may sink, and other people besides the 'Tahitians have been deceived.

Nevertheless, we cannot accept the theory of Dumont d'Urville. It is in contradiction to the zoological facts so thoroughly investigated by Darwin and 1)ana. If some of the atolls of Occania shew signs of subsidence, a great number of islands offer incontestable proofs of upheaval, and 'Tahiti itself is one of the latter'.

But the most serious argument which can be brought against d'Urville is derived from the inhabitants themselves. If travellers agree upon one point, it is that from the Sandwich Islands to New Zealand, from the 'Tonga Islands to Easter Island, all the Polynesians belong to the same race, and speak the same language with mere variations of dialect.

Now the Polynesian area, the limits of which I have just pointed out, is of greater extent than the whole of Asia. What would an Asiatic Polynesia be like, if that continent were to sink beneath the waters and leave only the summits of its mountains visible, where some representatives of the present inhabitants might take refuge? Is it not at once evident that each archipelago, and often each island, would have its own race and language?

The considerations drawn from the identity of populations and languages in Polynesia are of themselves sufficient, to justify the assertion that all the Islanders have a common origin; and consequently, that, starting from solne unknown point, they have, in their advance from archipelago to archipelago, peopled by degrees the maritime world in which we find them.

Horatio Hale, the eminent anthropologrist of the scientific expedition of the United States, was the first to approach the problem from a general point of view; he solved it as far as he was able with the data collected by himself, and sketched the first chart of Polynesian migrations. Fresh 
facts have been obtained sirce that time. Sir George Grey has published the historical songs of the Maories; Thomson, Shortland, and Hochstetter have brought to light fresh traditions; M. Remy published a history of Hawaii arranged by a native. M. Gaussin has carried off the prize in philology by his admirable work upon the Polynesian language; the Dépôt of the French Marine has received special documents from Tahiti to which General Ribourt, Admiral Lavaud, and Admiral Bruat have added the results of their own researches. These unpublished materials have been liberally placed at my disposal, and I have added to them some facts which have been forgotten. I have thus been able to confirm, from a general point of view, the conclusions of Hale, making, however, some important modifications, and to complete, again with some modifications, his chart of migrations. My readers will understand that I cannot here enter into a detailed discussion, and I must beg to refer them to my work upon The Polynesians and their Migrations. I shall confine myself to a short summary of the results which, I believe, it demonstrates.

IV. Both physical and philological characters show that the Polynesians are a branch of those Malay races which are divided into numerous groups by shades of difference, sometimes strongly marked. It is to one of these groups which are least distant from the white type that the nations in question must be referred.

The starting point of these migrations, which were to extend so far into the east, was Boeroe Island, which is represented in all maps between Celebes and Ceram. This conclusion, already proposed with some diffidence by Hale, seems to me to be placed beyond a doubt by all the traditions collected at 'Tonga by Mariner, with whose work the learned American seems to have been unacquainted.

On quitting the Malay seas, the emigrants must have followed as nearly as possible the course given above. Repulsed doubtless by the black races which then, as now, occupied Nerw Guinea, they passed Melanesia. Some unnoes, 
however, probably separated from the others, reached the eastern extremity of this great island, and there founded a colony recently discovered by Commander Moresby. It is this colony which has doubtless furnished the several archipelagos of Melanesia with at least a part of the Polynesian elements which have been observed by several travellers. We know, however, thanks to the researches of M. de Rochas, that the Polynesian elements of the little archipelago of the Loyalty Islands is due to an emigration passing in $1770 \mathrm{from}$ the Willis Islands to New Caledonia.

The great stream of emigration must liave left all Melanesia to the south, and have separated into three branches. One would arrive at the Samoa Islands, another at the 'Tonga Islands, and a third at the Fiji Islands. 'The two first archipelagos were evidently uninhabited, the latter already possessed by a black population. An alliance was at first made, however, between the aborigines and the emigrants, but before long the vear of races broke out, the Malays were expelled, probably leaving behind them some of their women. In this manner the mixed character of the Fijian population was produced, with which all travellers have been struck. The ejected Malays gained the Tonga Islands. Finding them occupied by fellow-countrymen they attacked and defeated them. Instead of massacring or enslaving them they invented serfdom, an institution which has only been met with in this archipelago.

Whilst the Malay colonies founded in the Fiji and Tonga Islands were dispersed and desolated by a fratricidal war, those in the Samoan archipelago prospered. The population became denser: the spirit of adventure was not as yet extinguished, fresh emigrations took to the sca, advancing in the direction which had led to the first discoveries. At this period the island of Savaï played an important part, according to the universal testimony of Polynesian traditions. Its name appears in almost all the archipelagos, scarcely modified by local dialects, in the Sandwich Islands and in New Zealand, in the Marquesas 
Islands as well as in Tahiti, and as far as the Manaïa Islands. Finally, Tupaïa, in drawing the curious map, which has been preserved by Forster, designates Savaï as the mother of all the others, and represents it as much larger than Tahiti. This is an error, but this very error proves beyond a doubt the importance of this locality from our present point of view.

With the exception of a single emigration, which passed arrecriy from Tonga to the Marquesas Islands, it is from the Samoan archipelago, and from Savaï in particular, that all the great expeditions appear to have started, which formed secondary centres elsewhere. Tahiti and the Nanaïa Islands are the two principal. The former peopled the north of the Pomotous and part of the Marquesas, which, in turn, sent out colonists to the Sandwich Islands, where, however, they had been preceded by the Tahitians. The latter, in which there were both Tahitians and Samoans, pushed their colonies as far as Rapa, to the Gambier Islands, to the south-east extremity of Polynesia and to New Zealand in the south-west.

$\mathrm{V}$. We have only isolated and very incomplete accounts of the greater number of these migrations. Though sufficient to remove all doubt as to the fact, they tell us nothing of the circumstances which accompanied or followed them. It is quite otherwise when we come to consider New Zealand. Thanks to the songs collected by Sir George Grey, we possess the detailed history of this colonisation. This exception is doubly fortunate as giving us information upon a number of important points, and precisely in reference to those islands which, from being situated at a great distance from Polynesia, properly so called, favour autochthonic hypotheses more than all the rest of the area. It seems to me, therefore, to be advisable to enter into a few details upon the subject.

It is the inhabitants of Rarotonga, one of the principal islands of Manaĩa, who had the honour of discovering and colonising New Zealand. An emigration from Tonga maty, 
however, at some unknown period have possibly joined them.

The Christopher Columbus of this little world was a certain Nigahué, who was compelled to fly from his comntry to escape the persecutions of a queen, who wished to rob lim of a jasper stone. It was doubtless chance which led him to New Zcaland. He here discovered several pieces of jasper, which probably restored him to the favour of the female chief, for we do not hear that he was molested on his return to Rarotonga.

During the absence of Ngahué a general war had broken out in his island. The vanquished party followed the advice of the traveller, who persuaded them to go and occupy the recently discovered land with him. Several chiefs joined together and constructed six canoes, the names of which are still preserved. The song translated by Sir George Grey informs us that one of them, the Aravect, was made of a tree which had been felled in Rarotonga, situated on the other side of Hawaiki. This was one of those secondary Sarairs which I have mentioned above, and the place from which the emigrants started. "Once," says one of those songs already quoted, "our ancestors separated; some were left at Hawaiki, and others came here in canoes."

The same song describes the accidents of the voyage, the storms which the navigators met with, the care bestowed upon the first culture of the soil, the exploring expeditions undertaken in the new country, and the disagreements which occurred between the different crews. They show that the connection with the mother country continued to exist for some time, so much so indeed that a young woman accomplished the voyage with only a few companions, ano warlike expeditions started sometimes from Hawailki and sometimes from the colony to avenge some of those outrages which were considered by these races as demanding the life. of the offonder.

There is nothing astonishing in these passages. The Polynesians knew perfectly well how to direct their course 
at sea by the stars, and the route from one point to another once observed was inscribed, if we may use the expression, in a song which would never be forgotten. They had a very correct general idea of the whole of their maritime world. The map drawn by Tupaïa, which I have reproduced in my book, is equal to those of our savants of the Middle Ages, while it embraces a considerable area. Tupaiia had seen for himself several of the islands which he represents. According to the calculations of Cook, he must have gone westward to a distance of 1,600 miles. But it was from the sacred songs of his country that he acquired his knowledge of the rest of Polynesia, and was able to sketch it with tolerable accuracy.

As to the canoes in question, they were the same as the pirogues, which are mentioned by all travellers with admiration, and are declared by Cook to be very suitable for long voyages. This is a fact which is often established by the very precise details contained in some of the songs translated by Sir George Grey. We see, for example, one of the emigrant chiefs, Ngatoro-i-Rangi, "mount upon the roof of the hut constructed upon the platform which joined the two canoes." We have only to add that the Arawa and other similar vessels generally carried $\mathbf{1 4 0}$ warriors, and it will at once appear how devoid of foundation are the assertions of those writers who declare these voyages to have been impossible for want of sufficient means of transport.

VI. The various documents which we now possess have not only been of service in proving beyond a doubt the general fact of migrations, and in acquainting us with the circumstances by which some of them were accompanied; they even enable us to indicate with very tolerable exactness the date of some of the most important.

This result is generally obtained by the genealogies of the principal families. Each forms a kind of litany, which is sung in fixed rhythm, and of which each verse contains the name of a chief and those of his wife and son. Anyone, therefore, cavable of remembering a song of one hundreds 
verses may easily learn the longest of these genealogies. Confided to memory by the Arepos or Keeper's of the Archires, they were preserved with jealous care. 'Thomson informs us that in New Zealand a scrious inquiry was made into these verbal documents, and their authenticity was so well established, that they have an equal value in matters of justice with our deeds.

Now, in the Marquesas, Gattanewa, the friend of Porter, who was descended from the first colonists of the 'longan portion of the archipelago, had only eighty-eight predecessors. At Hawaï, the genealogy of the Tamehameha, according to M. Remy, is contained in seventy-five verses. In 1840, according to Williams, Rarotonga was governed by the twentyninth descendant of Karika, the founder of the colony. In the Gambier Islands MI. Maigret saw the twenty-seventl reigning chief since the arrival of the first colonists from Rarotonga.

Hale has shown very clearly that the Hawaïan genealogy contains at the outset, like many others in Europe, some fabulous personages. He considered it necessary to remove the first twenty-two verses. Some such correction should very probably be made in that of the Marquesas Islanders. As to those of Rarotonga and the Gambier Islands they are too recent to have been already contaminated by fable.

Hale, guided by considerations which I cannot here discuss, attributes to each verse of these genealogies the value of a generation, from twenty-five to thirty years. 'Thomson and M. Remy, however, having had time to gather more precise information, regard them as indicating merely reigns. Calculating the mean duration of these reigns from that given by the list of French kings from Clovis to Louis XVII., we obtain as a result $21 \cdot 13$ years.

According to these data, the arrival of the Tongans in the Marquesas Islands must have taken place in the year 417 of our era; that of the 'Tahitans in about 701; Karika must lave colonized Rarotonga in 1207, and the Gambier Islands have been peopled in 1270 .

For New Zealand we have a double source of information. 


\section{Polynesian Migrations.}

and the results thus obtained agree so well that we cannot doubt their accuracy. The genealogies of the greater number of the Maori chiefs go back as far as those bold pionecrs whose history I have related. Thomson, who has examined several, considers that the number of chiefs who have succeeded each other in every family since the colonization, may be estimated at about twenty. Taking the kings of England as a term of comparison, he attributes to the reign of each chief a duration of $22 \frac{1}{3}$ years. These data took him back to the year 1419. The list of French kings would only give the year 1457 .

On the other hand, in one of the songs preserved by Sir George Grey, there is an account of the history of the son of Hotunui, one of the colonizing chiefs of New Zealand, and of his immediate descendants. At the fourth generation a daughter was born, "from whom," the legend adds, "are descended in eleven generations all the principal chiefs now living of the tribe of Ngalipaoa." Taking thirty years for each generation, we find that the migration of Hotunui took place 4.50 years before the time when Sir George Grey received the document (about 1850), which carries us back to the year 1400 .

Thus, these Maories, whom autochthonists regard as children of the soil, cannot have landed in New Zealand earlier than the beginning of the fifteenth century.

VII. I have hitherto only spoken of more or less voluntary migrations, such as might be induced by a spirit of adventure, civil troubles, or the authority of a priest despatching an excess of population in search of new countries. But in treating of Polynesia, we must, as I have already remarked, take accidents by sea into consideration. Sereral examples are known. It was in this manner that Toubouai was peopled, which at the close of the last century, within an interval of a few years, received three canoes from different islands, one of which was Tahiti. All three had been carried away by a storm and driven ashore upon this island, which. till then, had been uninhabited. 
Such, again, is the history of the chief 'Touwari and his companions, men, women, and children, discovered by Captain Beechey upon Byam-Martin Island, which they had begum to colonize. They had started from Anaa, an island situated two hundred and forty-five miles to the east of 'Tahiti, to go and pay homage to Pomare, but were surprised at Mairatea by the monsoon, which had come sooner than usual. Driven to the south-east into the midst of the Pomatou Islands, they landed at first on Barrow Island. Finding, however, no means of subsistence, they took to the sea agrain, and fell in with the island where they were found by the English navigator.

This example is perfect, since it realises all the circumstances indicated by the theory. It establishes the existence of regular relations between islands situated at great distances from each other; it proves one of those occurrences which must more than once have caused these bold navigators to wander from the usual route; it shows how a remote island was able to receive all the elements of a colony; it leaves no doubt as to the possibility of dispersion going on in an exactly opposite direction to that of the trade winds. We need only add that the passage from Maïatea to Barrow and Byam-Martin Islands is more than five hundred and sixty miles, and we shall understand without any difficulty how Polynesia was peopled by voluntary or accidental colonization.

VIII. 'There is one more circumstance which it is important to observe, and which is completely at variance with all autochthonist hypotheses, that, namely, on approaching the islands where they have been discovered by us, the Polynesian found them uninhabited.

The songs, for which we are indebted to Sir George Grey, show that in New Zealand the greater number of the firs: emigrants met with no traces of a previous population. One only, named Manaïa, found upon a promontory aborigines of the country. This exception, from the very reason that it is unique, proves that this population could not have 
been very numerous. It has slightly altered the type of the lowest grades of the Maories, to which it has been confined. The portrait published by Hamilton Smith, and one of the skulls in the possession of the Museum, inform us that these supposed aborigines were Papuans. It is evident that they had reached New Zealand in consequence of some mischance similar to those I have just mentioned, and had not even had time to multiply sufficiently to occupy the entire shores of the North Island.

The traditions of the Sandwich Islands furnish us with a fact of the same nature. They tell us that the first colonists coming from Tahiti found in these islands gods and spirits, who inhabited the caves and with whom they entered into alliance. It is evident that we have here a troglodyte people, whose importance the legend has been pleased to exaggerate, and whose origin it is not difficult to find. If Kadou, whose history has been preserved by Kotzebue, instead of leaving the Caroline Islands for the Radak Islands, had started from the latter, and if he had made almost the same passage in the same direction, he would have landed in the Sandwich Islands.

The mixture of Polynesian and Micronesian races at once explains the darkness of colour and want of purity in the features of the Hawaïans. Perhaps the same cause may account for the difference in features, manners, and industry which is presented by some tribes of the Low Archipelago.

Apart from these few and, as we see, very feeble exceptions, all the islands of Polynesia appear to have been uninhabited when the navigators from Boeroe or their descendants landed. This fact is distinctly proved by traditions in Kingsmill, Rarotonga, Mangarewa, the Toubouaï Islands, etc. Purity of race testifies that this was also the case with the Tonga, Samoa, and Marquesas Islands.

IX. Finally, the facts to which I have been obliged to confine myself are entirely opposed to the theories of autochthonists, and lead to the following conclusions: Polynesia, a region which, from its geographical conditions, seems at first 
sight to be isolated from the rest of the world, has been peopled by means of voluntary migrations and accidental dispersion, passing from west to east, at least as a general rule. The Polynesians, coming from Malaya, and the Isle of Bocroe in particular, first established and settled themselves in the Archipelagos of Samoa and 'T'onga. 'Thence they invaled by degrees the maritime world open before them; they found, almost without an exception, that all the countries where they landed were uninhabited, and only on two or three occasions met with very small tribes of a more or less black type. 


\section{CHAPTER XVIII.}

\section{Migrations BY SEA.-MIGRATIONS IN AMERICA.}

I. The peopling of Polynesia and America is a problem which presents, if I may use the expression, inverse conditions. There is, in reality, no geographical difficulty in the latter. 'The proximity of the two continents at Behring Straits, the existence in this channel of the Saint Laurence islands, the largest of which is situated exactly half-way between the two opposite continents, the connection formed between Kamschatka and the peninsula of Alaska by the Aleutian Islands; the maritime habits of all these peoples; the presence of the Tchukchees on the two opposite shores; the voyages which they undertake from one continent to the other on simple inatters of commerce, leave no doubt as to the facility with which the Asiatic races could pass into North America through the Polar Regions.

More to the south, the current of Tessan, the kouro-siro, or black stream of the Japanese, opens a great route for navigators. This current has frequently cast floating bodies and abandoned junks upon the shores of California. Instances of this fact have been observed in our own time. It is impossible that they should not also have happened before the period of European discoveries. Asiatic maritime nations must at all times have been carried to America from all those places which are washed by the Black Stream.

The Equatorial current of the Atlantic opens a similar route leading from Africa to America, and there are some evidences, rare it is true, showing that wrecks have been carried in this direction. It is possible, therefore, that the same may also have happened to man. 
II. We shall not, therefore, be surprised at finding in the New World representatives of races which seem to belong originally to the Old World; we shall easily understand the multiplicity of American races, which is perhaps still contested by some of Morton's followers, but firmly established in the opinion of every unprejudiced person by the testimony of Humboldt and d'Orbigny's classical work on L'Homme Américain.

Black populations have been found in America in very small numbers only, and as isolated tribes in the midst of very different nations. Such are the Charruas of Brazil, the black Carabees of Saint Vincent in the Gulf of Mexico, the Jamassi of Florida, the dark-complexioned Californians, who are, perhaps, the dark men mentioned in Quiché traditions, and by some old Spanish adventurers.

Such, again, is the tribe of which Balbao saw some representatives in his passage of the Isthmus of Darien in 1.513. Yet it would seem, from the expressions made use of by Gomara, that these were true Negroes. This type was well known to the Spaniards, and if they had encountered black men with glossy hair, like the Charruas, they would undoubtedly have been much impressed by it, and would have mentioned the fact.

The white type is more widely represented in America than the black. Along the whole of the north-west coast, Meares, Marchand, La Pérouse, Dixon and Maurelle have observed populations, which, judging from some of their descriptions, would seem to be of pure white race. Upon the Upper Missouri, the Kiawas, Kaskaïas and the Lee Panis possess, we are assured, the attributes of the purest white races, including their fair hair. The Mandans have, from our present point of view, always attracted attention. Captain Graa, again, found in Greenland men speaking Esquimau, but tall, thin, and fair. In South America, Ferdinand Columbus, in his relation of his father's voyages, compares the inhabitants of Guanaani to the Canary Islanders, and describes the inhabitants of San Domingo as still more beautiful and fair. In Peru, the Charazanis, studied by 
M. Angrand, also resemble the Canary Islanders, and differ from all the surrounding tribes. L'Abbé Brasseur de Bour.. bourg imagined himself surrounded by Arabs when all his Indians of Rabinal were around him, for they had, he says, their complexion, features, and beard. Finally, Gomara and Pierre Martyr offer a similar testimony, and the latter speaks of the Indians of the Parian Gulf as having fair hair (capillis flavis).

It is useless to insist upon the anthropological relations between America and Asia. Most travellers have insisted upon this point. I have heard M. de Castelnau say, "When I was surrounded by my Siamese servants, I imagined myself in America;" and M. Vavasseur, assisting at the visit of the Siamese ambassadors, remarked, "But those are my Botocudos." I should, however, observe that the skull in the Collection in the Paris Museum indicates less resemblance than the external characters.

America has, moreover, its distinct races with which the foreign elements have more or less blended. She has also had her quaternary man. This is a fact which must not be overlooked, and by which the problem is singularly complicated. We shall presently see that geological revolutions do not involve the disappearance of existing human races. There can be no doubt that in America there are descendants of men who were contemporary with the mastodon, just as, in Europe, we find the descendants of those who were contemporaries of the mammoth. Unfortunately our knowledge of the physical characters of the American fossil man is as yet very slight.

III. It does not, however, seem to me the less probable that the most pronounced ethnological elements, such as White, Yellow, and Black, which we encounter at the present time, have overspread this continent by means of migration. This fact is proved by history in a certain number of cases; and some very simple considerations seem to me to render others no less probable.

For example, we only find black men in America in those 
places which are washed by either the Kouro-sivo, or the Equatorial Current of the Atlantic or its divisions. A glance at the maps of Captain Kerhallet will at once show us the rarity and the distribution of these tribes. It is evident that the more or less pure black elements have been brought from the Asiatic Archipelagos and from Africa through some accident at sea; they have there mixed with the local races, and have formed those small isolated groups which are distinguished by their colour from the surrounding tribes.

The presence of Semitic types in America, certain traditions of Guiana, and the use in this country of a weapon entirely characteristic of the ancient Canary Islanders, can be easily explained in the same manner, and the explanation rests upon positive facts. Twice during the last century, in 1731 and 1764, small ships passing from one point of the Canary Islands to another have been driven by storms into the region of the trade winds and equatorial current, and have drifted as far as America. What has happened in our time must often have happened before. We cannot then be surprised at finding upon the shores of the Gulf of Mexico, tribes which are more or less related to the African Whites by their physical characters.

IV. The geographical position of the continents at once explains why the yellow type has so many representatives in America. Supposing, which seems to be contradicted by some evidences, that the coast-lines have not altered since the latest geological era, the facilities presented by the passage are quite sufficient, and the Asiatic races have profited by them to a considerable extent. America was known to them long before Europeans possessed anything beyond legends on this subject, the meaning of which is still hotly disputed.

It is to De Guignes that we owe the discovery of this fact, the importance of which is evident. He revealed to Europe what he had learnt in Chinese books. These books speak of a country called Fou-Sang, situated at a distance, to the east of China far beyond the limits of Asia. De Guignes 
did not hesitute to identify it with America. To the proofs drawn from the Chinese books, he added some isolated and hitherto forgotten facts which were borrowed from Europeans, from George Horne, Gomara, etc.

The work of the French Orientalist was received with a very singular, yet accountable repugnance. Apart from the mistrust excited by every unexpected discovery, many people were annoyed to find that Europeans had been preceded by Asiatics in the New World; it seemed to them to be dethroning Christopher Columbus. A Prussian, who had become a naturalized Frenchman, gave the support of his great learning to all who required no more than the contradiction of the fact, and it was almost unanimously agreed that De Guignes had deceived himself. More justice is now done to him, and anyone who will study the question in an unprejudiced spirit, cannot but acknowledge that he is right.

Klaproth held that Fou-Sang was nothing else than Japan. He forgot that the country of which the Chinese writers spoke contained copper, gold and silver, but no iron. This characteristic, which is inapplicable to Japan, agrees, on the contrary, in every respect with America. To support his assertion, he maintained that the Chinese could neither recognize their direction nor measure distances in their voyages with precision. $\mathrm{He}$ forgot that they were acquainted with the compass 2000 years before our era, and that they possessed maps far superior to the vague conjectures of the Middle Ages.

As to the supposed error in distance of which Klaproth speaks, there was no such thing. Paravey informs us that Fou-Sang was placed at a distance of 20,000 $\mathrm{Li}$ from China. Now a $\mathrm{Li}$, according to $\mathrm{M}$. Pothier, is equal to 44.5 metres (486 yards). In following the course of the Kouro-Siro, these numbers would exactly bring us to California, where the abandoned junks were stranded; they prove what was indicated by the theory, that this current had been the route for voyages to and from America. 
Paravey has published a facsimile of a Chinese drawing representing a lama. This at ouce answers one of the objections of Klaproth, and carries us considerably to the south of California. Amongst the productions of Fou-Sang the Chinese authors mention the horse, which, as we know, did not exist in America. It is clear that they called by this name the animal which in Peru was used as a beast of burden. 'This habit of calling by a common name species which are known and new species which resemble them in certain respects, certainly existed elsewhere than in China. This habit led the Conquestadores to call the puma a lion, and the bison a corv.

But did the Chinese then extend their voyages as far as Peru? 'This can hardly be doubted after the preceding testimony, and after that which is contained in the Geografia del Peru by Paz Soldan. The following is the translation of a passage for which I am indebted to M. Pinart: "The inhabitants of the village of Eten in the province of Lambayéque, and the department of Libertad, seem to belong to a different race from those of the surrounding countries. They live, and intermarry, only amongst themselves, and speak a language which is perfectly understood by the Chinese, who have been brought to Peru during the last few years."

The Chinese books studied by De Guignes and Paravey speak of religious missions, which, towards the close of the fifth century, left the country of Ki-Pin to carry to FouSang the doctrines of Buddha. The researches of M. G. d'Eichthal have fully confirmed these accounts. The strongest resemblances have been pointed out between the monuments and the Buddhist figures of Asia and the same products of American art. The comparison of legends has led the author to the same result.

Finally, according to an encyclopædia, from which M. de Risny has translated a passage, the Japanese were acquainted with Fou-Sang, which they called Fou-So, and with the missions which had left the land Ki-Pin for that country. 
Although its real position must still be doubtful, they snow that Fou-So and Japan are two different countries.

To this formal testimony derived from the Chinese, we must add that of Europeans. The first is Gomara, who witnessed the conquest of Mexico, and was a contemporary of the expedition which followed. He tells us that companions of Francesco-Vasquez de Coronado, in sailing up the Western Sea as far as $40^{\circ} \mathrm{N}$. lat., met with ships laden with merchandise, which, as they were led to understand by the sailors, had been at sea for more than a month. The Spaniards concluded that they had come from Cathay or Sina.

'The primary object of the ships in question was evidently that of commerce. Such pacific relations did not, however, always exist between the native Americans and the strangers from the west. This is proved by the testimony of an Indian traveller, preserved by Le Page du Prat. Moncacht-Apé (the pain-killer) was certainly a remarkable man. Impelled by the desire which drove Cosma from Körös to Thibet, the wish to discover the original home of his tribe, he went at first in a north-easterly direction as far as the mouth of the St. Lawrence, returned to Louisiana and started again for the north-west. Having ascended the Missouri to its source, he crossed the Rocky Mountains and reached the Pacific Ocean by descending a river, which he called the beautiful river, and which can be no other than the Oregon.

There he heard of white, bearded men, provided with arms hurling thunder, who came every year in a great boat to look for wood which they used for dyeing, and carried off the natives to reduce them to a state of slavery. Moncacht-Apé, who was acquainted with the nature of firearms, advised his friends to prepare an ambuscade. The plans which he suggested were a complete success. Several of the aggressors were slain. The Americans at once saw that they were not Europeans. Their clothes were quite different, and their arms more clumsy, while their powder was coarser, and did not carry so far. Everything tended to show they were 
Japanese, accustomed to make descents upon this coast of America exactly similar to those undertaken by some crews in search of sandal wood in Melanesia, who seize the blacks whenever they have an opportunity, and give them up to cotton planters under the name of coolies.

The narrative of Moncacht-Apé was given in the year 1725, three or four years before the discovery of the Behring Straits, and more than thirty years before European voyages had acquainted us with the north-west of America. 'The exact details which he gives as to the general direction of the coast, and of its bend at the peninsula of Alaska, are a sure proof of the correctness and truth of this narrative. Thus, however much it may wound European pride, we must acknowledge that Chinese and Japanese Asiatics knew and, in different ways, explored America long before Europeans.

V. Nevertheless, these civilized nations, whose ships visited America, do not seem to have founded large settlements, which could become the starting point of a new colony. Had it been so, they would have left more traces of their passage in the language. Now, with the exception of the small Chinese colony of which I have spoken above, there is scarcely one fact of this nature which can be considered as established. Some Californian colonics are mentioned as speaking a Japanese dialect. M. Guillemin Taraire has reproduced this information in reference to a tribe of Santa Barbara; he adds that the language of some others includes Japanese and Chinese words. Unfortunately the researches of M. Pinart, far from confirming these results, only tend to contradict them; we can, thercfore, only speak with great reserve upon this point.

It scems to ine to have been principally in the north that the great migrations took place, and that they were undertaken by savage nations. The traditions borrowed by l'Abbé Brasseur de Bourbourg from the sacred books of the Quichés, and those of the Delawares which have been preserved by Heckewclder, appear to me to offer much information on 
this point. By comparing the missionary's narrative with some facts of Mexican history anterior to the conquest, I have been enabled to determine approximately the date of the arrival of the Red-Skins in the basin of the Missouri. It seems to me that we cannot refer it to an earlier date than the ninth, or at most the eighth, century.

These traditions bring to light another and no less important fact: namely, that the Alonquins and Iroquois, after having crossed the valley of the Mississippi, from which they drove the people, whose singular monuments are now the object of study, had no more fighting to do, and found the country uninhabited as far as the coast, and far away to the south. The traditions of some tribes of South America point, though not so plainly, to the same conclusion. Thus, probably in the two halves of the New World, and certainiy in the northern portion, thuse uninhabited lands existed which we have already noticed in Polynesia, and the pretended American autochthon of Agassiz, Morton, Nott, and Gliddon was, on the contrary, one of the latest arrivals upon this continent.

These facts of thin populations, and of their low social condition, which was everywhere the case except in those centres where legislators had appeared who were perhaps entirely foreign to the soil, involuntarily lead us to the conclusion that the general peopling of America by the existing races, though it may be traced to an earlier period than that of Polynesia, is, nevertheless, much more recent than that of the Old World.

VI. It is not from Asia alone that America has received its population. They came from Europe also long before the era of great discoveries; I am not now alluding either to the story of Atlantis, of which many interpretations are still possible, or to Phœnician and Carthaginian traditions, nor again, to the pretentions of the Basques and Dieppois, although they appear to be supported by facts, which are, to say the least, curious; nor to Irish and Welsh traditions, though Humboldt considers them well worthy of attention. 
I shall only speak of the royages accomplished by the Scandinavians as related by Rafn from Irish sagas, and which have been lately republished in detail by M. Gravier.

We are not now dealing with isolated facts belonging to the darkness of those ages which they only occasionally illuminate. It is a detailed history embracing several generations, and sometimes giving circumstantial details which explain, and are confirmed by certain modern discoveries.

In 877 , according to M. Gravier, perhaps as early as 770 , according to M. Lacroix, Gunnbjorn discovered Greenland. In 886 Erick the Red doubled Cape Farewell, and built at the head of a fjord his house Brattahilda, the lately discovered ruins of which have been compared to those of a town. In 986 Bjarn Meriulfson, when on his way to Greenland, was carried by a storm as far as the shores of New England. In 1000, Leif, the son of Erick the Red, started for the country discovered by Bjarn. Accompanied by 35 men, he ran down as far as Rhode Island, where he found the vine, and gave the name of Vin-land to the country of which lie took possession; he built Leifsbudir, passed the winter there, and noticed that the shortest day began at halfpast seven and ended at half-past four. 'This observation, which agrees with all the other details, places Leifsbudir near the present town of Providence, $41^{\circ} 24^{\prime} 10^{\prime \prime} \mathrm{N}$. lat.

Thorwald succeeded his brother Leif. Followed by 30 warriors, he reached Vinland and passed the winter at Leifsbudir. In the spring of 1003 he ran down as far as Long Island, explored the neighbourhood, and returned in the autumn to his starting-point. The following summer he turned his steps northwards. Near Cape Alderton, his companions surprised three boats made of osier, and covered with leather, and slew eight of the men by whom they were manned. The ninth escaped; he soon returned, however, accompanied by a great number of his fellow-countrymen, who showered upon the Scandinavians a cloud of arrows and then flerl. But Thorwald, mortally wounded, was interred in this land which he had expressed a desire to inhabit. It, 
may possibly have been his tomb which was discovered at the end of the last century in Rainsford Island, near to Hull and Cape Alderton; a tomb of solid masonry, containing a skeleton, and a sword with an irom hilt, indicating a period anterior to the fifteenth century.

In 1007 Thorfinn, accompanied by his wife Gudrida, started with three ships carrying 160 men, some women, and cattle. This time the object was to found a colony. They settled not far from Leifsbudir at Mount Hope Bay. 'The strangers were soon visited by some of the natives, who are easily identified with the Esquimaux from the description given in the Saga. The relations maintained with these Slerellings were at first pacific. But the following year an act of brutality on the part of a Scandinavian led to war, and Thorfinn, although victorious, did not feel his position to be secure, and resolved to return to his country with his companions, his wife, and his son Snorre, the first Scandinavian born in Vinland.

Before quitting his settlement, the chief was anxious to leave some trace of his presence. Such, at least, is the opinion adopted by Scandinavian savants, and by M. Gravier; on the subject of the famous Dighton Writing Rock. This block of gneiss, situated upon the right bank of Truton River, and alternately covered and left bare by the tide, bears a certain number of characters engraved upon it to the depth of eight millimetres (one-third inch). This inscription, which has given rise to many discussions, has, probably, a double origin. Schoolcraft tells us that an old Indian, who was familiar with American pictography, recognized the hand of his countryman in a certain number of signs which he was able to explain, though at the same time he confessed that others were quite new to him. On the other hand, Magnusen and his followers have also only been able to interpret some of these same signs. They were, in their opinion, a mixture of runic and cryptographic signs, and of figures referring to the adventures of Thorfinn. They thought they could recognize Gudrida with her son Snorre, 
and the phonetic portion might, it seemed, be translated in the following manner:-131 MEN OF THE NOR'TI HAVE oCCUPIED THIS COUNTRY-WITH THORFINN. I should add, however, that Mr. Wittlesey does not admit the existence of a single alphabetical inscription in the United States. Yet we must not suppose that the opinion of the American antiquarian at all affects the authenticity of the Sagas which relate the history of Thorfinm.

I cannot here repeat all the adventures of Thorvard and Freydisa, of Ari Marson, Bjorn Asbrandson, Gudleif and Hervador . . . . , but I must remark, in reference to the latter, that, through the indications contained in the Skalholt Saga, the American savants have been able to find upon the shores of the Potomac the tomb of a woman who fell by the arrows of the Skrellings in 1051.

VII. The colonies founded in Greenland by Erick and his successors multiplied rapidly; both the east and west coasts were peopled. 'These two centres bore the names of Osterbygd and Vesterbygd. From the documents consulted by M. F. Lacroix, it appears that the former possessed a cathedral, eleven churches, three or four monasteries, two towns called Garda and Alba, and 190 Gaards or Norwegian villages; in the second, there were four churches and 90 or 110 gaards. These figures clearly indicate a considerable population. This is still more strongly proved by the fact, that as early as 1121, an Irishman, Erick-Upsi, was created Bishop of Greenland, and had eighteen successors. Vinland was in the jurisdiction of this diocese. The tithes of this country figured among the revenues of the Church in the fourteenth century, and were paid in kind.

This prosperity, and the regular relations between Europe, Greenland, and Vinland seem to have lasted till towards the middle of the fourteenth century. About this time the Skrellings attacked Vesterbygd; the succour sent by the other settlements arrived too late, and the western colony was destroyed. Osterbygd had a much longer existence. In 1418 it still paid to the Holy See as tithes and Peter's 
Pence 3600 pounds of walrus' tusks. At a period anterior to this epoch, however, Queen Margaret, sovereign of the Scandinavian dominions, impelled by motives which have been differently interpreted, had interdicted all commerce with the Greenland colonies. Shortly afterwards flects of pirates, springing from some unknown quarter, came down upon and pillaged them; the temperature of both land and sea gradually fell; voyages became more and more difficult, and, at last, ceased altogether. Thus, when in 1721, the Norwegian Pastor, Hans Eggede, led to those frozen lands the first modern colony, he found nothing but ruins, and not a single descendant of Erick and Thorfinn. What had become of them?

A letter addressed to Pope Nicholas V., quoted by M. Lacroix, throws some light upon their fate. It is dated 1448, and informs us that, thirty years previously, some strangers coming from the American coasts had pillaged the colony, and massacred or carried into slavery the greater number of the inhabitants of both sexes. A great number had, however, returned to their homes, and asked for help.

It is hardly possible to avoid referring to the latter, the white population, tall, and with fair hair, which Captain Graa met with on the east coast of Greenland, during his expedition in search of Osterbygd. Notwithstanding their adoption of the Esquimaux language, they certainly did not belong to their race.

But were all the descendants of the bold navigators who had discovered America content to live, like the Skrellings, by the side of ruins which recalled the relative grandeur of their fathers? This hypothesis appears to me inadmissible. It seems evident to me, that the greater number of the survivors must have emigrated and sought refuge in Vinland, of the existence of which they were aware. Perhaps they were repulsed by the mixed population of Scandinavians and Esquimaux, who seem very early to have come into existence, and who were, perhaps, the invaders mentioned in the letter quoted by M. Lacroix; perhaps, again, they 
may have encountered warlike and inhospitable tribes, like those mentioned in the Saga of Gudleif. But the Norwegians would then only have pushed on further, till they met with some hospitable shore where they could settle.

VIII. However this may be, the history of Scandinavian voyages is sufficient to explain the appearance of the white trpe, even of the fair type, in the midst of American populations. I do not hesitate to refer to this Aryan stock, the white Esquimanx of Charlevoix, the fair-haired men of Pierre Martyr, the fair men spoken of in some Mexican traditions, the White Savage Chief whom the Spaniards met with in their Cibola expedition . . . etc.

Besides, the discovery and the repeated invasions of the American coasts by the Scandinavians show the estimation in which we ought to hold the pretended impossibility of the peopling of America. Here, we have no longer the double pirogues of the Polynesians, carrying 150 warriors; it was in boats manned by thirty or forty men that Leif and Thorwald faced the Greenland seas, reached, and returned from Vinland. In the presence of such facts, can we regard our improved method of navigation as indispensable to long sea voyages?

Modern civilization has placed in our hands an immense power of action unknown to our ancestors. It enables us to accomplish works which they would have thought could only be expected from supernatural powers. Science has placed in our hands the magic ring, and we have become so used to employing it for the satisfaction of our smallest wants, that it seems to us impossible to do without it. We too often forget the resources which man possesses in himself, and which form part of his original nature. Thus, we regard less advanced, less lecurned races as incapable of accomplishing that which we should not dare to undertake without the aid which wo have been able to create for ourselves.

We have just seen how fully the history of the Polynesians and Scandinavians contradicts these false ideas, and how they justify the words of Lyell:-"Supposing the human genus 
were to disappear entirely, with the exception of a single family, placed either upon the Ocean of the New Continent, in Australia, or upon some coral island of the Pacific Ocean, we may be sure that its descendants would, in the course ist ages, succeed in invading the whole earth, although they might not have attained a higher degree of civilization than the Esquimaux or the South Sea Islanders." 


\section{BOOK VI.}

\section{ACCLIMATISATION OF THE HUMAN SPECIES.}

\section{CHAPTER XIX.}

INFLUENCE OF CONDITIONS OF LIFE AND RACE.

I. THe human species, springing originally from a single centre of appearance, is now universally distributed. In their innumerable travels, its representatives have enconntered the widest difference of climate and the most opposite conditions of life, and now inhabit both the polar and equatorial regions. It must, therefore, have possessed the necessary aptitudes for accommodating itself to all the natural conditions of existence ; in other words, it must have had the power of becoming acclimatised and nuturalised in every place where we meet with it.

The possibility of man living and prospering in other regions than those in which his fathers lived, has been denied in a more or less emphatic manner by the greater number of polygenists. Without going as far as this, certain monogenists have held that a human race, when constituted for given conditions of life, was, so to speak, a prisoner to them, and could not effect a change without losing his life. Other writers liave maintained precisely opposite opinions, and have held that any human group could at once become acclimatised in any given spot.

There are exaggerations and errors in all these extreme ductrines. 


\section{Infuence of Conditions of Life and Race. 215}

II. In spite of the assertions of Knox, Frenchmen can live perfectly well in Corsica, provided only, that they avoid the marshes of the eastern coast, which the islanders themselves cannot inhabit. After the revocation of the Edict of Nantes, the fugitives from Provence and Languedoc founded villages in the valley of the Danube, thus contradicting beforehand one of the assertions of the English doctor. English and French emigrants to the United States, and to Canada, have not degenerated, in spite of the assertions of the same author. 'Though modified, often in a very striking manner, as we shall presently see, the Yankee squatters and the Canadian backwoodsmen are certainly not inferior to the first colonists who planted the European standard in the midst of the Red-Skins.

Knox, and the anthropologists who agree either entirely or partially with him, attribute to cmigration alone the maintenance and growth of the white population in America and elsewhere. In their opinion the European emigrant loses, after several generations, the power of reproduction. If the human current, which sets from Europe towards the Colonies were to be stopped, they maintain that the population would rapidly diminish, and the local races regain the ascendancy, that the United States would return to the Red-Skins, and Mexico to the descendants of Montezuma.

This assertion will easily be answered by a few statistics. They are taken from the history of French races, which, since the treaty of Paris in 1763 , have, although in a slight degree, directly contributed to the peopling of Canada. There were in this country:

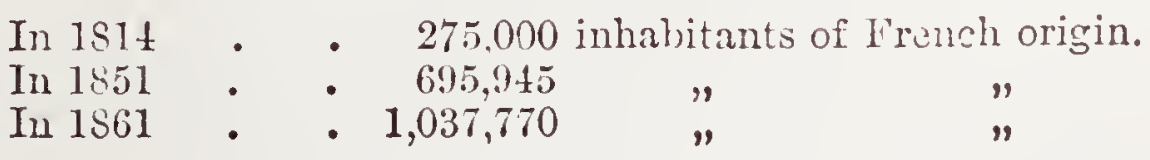

In Ottawa State there were:

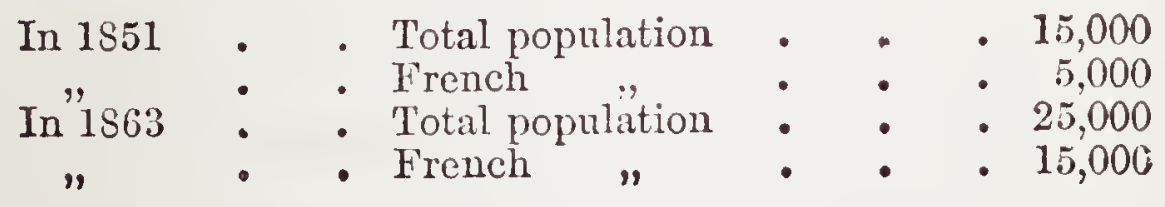


The history of the Acadians furnishes statistics which are quite as convincing. From the information obtained by $\mathrm{M}$. Kameau, it appears that the entire population was descended from forty-seven families, numbering 400 souls in 1671. In 17.55 there were 18,000 . Dispersed and driven out by the Tinglish they were reduced to only 8,000 . In 1861, the number rose to $9.5,000$ persons.

If we calculate from the preceding figures the annual increase of French populations in America, we shall find the ratio equal or superior to that furnished by the most faroured European pepulations. This proves that the French race shows no sign of disappearance, even in the country chosen as an example by Knox.

Without entering into too many details, let us remember that the French have lived and increased in number at Constantia, not far from the Cape, since the revocation of the Edict of Nantes; that this same region has been colonized by the Dutch, whose descendants, the Bocrs, have migrated, and now form the Transvaal Republic; that they have been succeeded at the Cape by the English, who, by degrees, have overrun the whole country. We must also remember the rapid growth of the Anglo-Australian colonies, etc.; and, finally, let us not forget those nine families of missionaries visited by M. de Delapelin in Polynesia, which, in all, numbered sixty-nine children, that is to say, a mean of more than seven and a half each, and we shall be forced to acknowledge that the most highly characterised European white can live and increase in number in both hemispheres, at the antipodes, and in the native countries of the most different races.

Further, the great race to which he himself belongs was not originally European. It probably sprang from the mountain district of the Bolor and the Hindoo-koh, where the Mamogis still represent the original stock. In any case, the Zend-Avesta informs us that it issued from a region where the summer lasted but two montlis, a climate which almost corresponds to that of Finland. Step by step it advanced, 


\section{Infuence of Conditions of Life and Race. 2 I 7}

on the one hand as far as the Gangetic peninsula and Ceylon, on the other to Iceland and Greenland. Afterwards, when the era of great discoveries had commenced, it distributed its colonies over the whole world, peopling continents, and replacing indigenous races.

The consideration of these general facts alone, and the result of this perpetual activity, make it impossible to deny to the Aryan race the faculty of acclimatisation, under the most diverse conditions of existence. All the assertions of Knox, and of his more or less avowed disciples, fall before these facts.

What is true for the Aryan race is equally true for the Negro. The White has transported the Black to almost every part of the globe, and in the most distant places the Black lives side by side with his master. Our experience as to the Yellow Races is still slight, but we can already foresee that the result will be the same. Chinese and Coolies have passed over into America from Asia; we shall perhaps soon see them in Africa and in Europe.

Certain branches detached from the great ethnical stocks have already offered similar evidences. The Gipsies, Aryans mixed, perhaps, with Dravidians, have overrun the whole of Europe, and are now met with everywhere. As to the Jews, we know that they are really cosmopolitan, and that almost everywhere, in Prussia as in Algeria, their fecundity surpasses that of the local races.

III. I do not mean by this that I consider the Aryan, or any races, capable of always becoming at once acclimatised in any given locality. On the contrary, there are regions which are fatal to man, to whatever group he may belong, and however weli prepared he may seem to be to brave their influence. Such is the great estuary of the Gaboon, where the Negro himself cannot live. The general constitution of the inhabitants grows sensibly weaker; the reproductive organs appear to be particularly affected, and the number of women greatly surpasses that of the men. We know how dangerous the climate of this country is to the European, and it will be 
interesting to see whether the Paouins will in their turn yield to the deleterious influence of these coasts, which they are gradually approaching.

We need not, moreover, go so far for examples. Who does not know the reputation of the Naremma, and the marshes of Corsica? At one time the swamps of the Dombe, and the mouth of the Charente, in France, were scarcely less dangerous.

Even where the conditions are much less severe, acclimatisation almost always demands numerous and melancholy sacrifices, which some anthropologists have done wrong to overlook. 'The fact is but too natural. A race, which has settled under the influence of certain conditions of existence, cannot effect a change without undergoing modification, and hence suffering. This fact will be noticed in some detail in the chapter dedicated to the formation of these derived groups from the species. I can here only point out the general law.

IV. Thus, every colonization of a distant country must be regarded in the first place as a conquest attempted by the immigrating race. Now, whether the battle has to be fought with man or with the conditions of life, the victory is only gained at the cost of human life. We must not, however, exaggerate the extent of inevitable losses, and deny the possibility of acclimatisation. We must put the problem clcarly, and seek for experimental data. whence the solution may be naturally deduced.

Every question of acclimatisation comprises two terms, which are, so to speak, the components of the resultant which we are seeking for or studying. 'Ihese terms are race and conditions of life. We already know the exact significance of the former of these two words, and we shall presently consider in some detail what we are to understand by the latter. At present we will take it as simply representing all the conditions of existence presented by a given place, and proceed to point out its influence in acclimatisation.

We have seen that certain conditions of life appear to be 


\section{Influence of Conditions of Life and Race. 2 I9}

fatal to all races. In cases of this kind, we should distinguish how much of this insalubrity is due to the regions, and how much is the result of accidental circumstances, sometimes provoked by man himself. The plain of the Dombe in France was once as salubrious as the surrounding country. 'The exaggerated industry of the marshes transformed it into a pestilential region, where it was quite as fatal for foreign populations to live as it would have been in the swamps of the Senegal. Sanitary measures are now tending to restore it to its former condition. It is evident that we cannot reproach the Dombe with the deleterious influence which human intelligence seems to have undertaken to develop.

Even when the latter does not step in to vitiate the conditions of life, we cannot charge a country with opposing unfavourable conditions to an indigenous or foreign race, when these conditions may be attributed to the negligence of the inhabitants, or to some special cause, which human intelligence might modify. Deprived of the care which rendered it healthy and luxuriant, the Campagna of Rome has become a branch of the Pontine Marshes. On the other hand, the environs of Rochefort have become healthy; Bouffarik, once one of the most dangerous spots in Algeria, has become the centre of a flourishing population. It was not, therefore, the general natural conditions which rendered these localities dangerous, especially to strangers, but simply accident. As soon as the cause is removed, acclimatisation becomes not only possible, but easy.

Considered from this point of view, many countries, which now appear to repel all attempts at immigration, will, perhaps, at some future period, be particularly favourable to the development of colonizing races. It is clear that in all cases of this kind we must distinguish between normal and accidentally vitiated conditions of life.

I cannot enter into all the details which this distinction would allow, and shall confine myself to quoting a few facts.

The very progress of civilization sometimes results in the 
vitiation of certain conditions of life. Such is the almost inevitable result of the crowding together of human beings in a relatively limited space. This is one of the points most clearly demonstrated in the statistical researches of M. Boudin upon the comparative mortality of the country and of barracks, for example. A comparison of our large towns and rural dist icts leads to the same result, and points to a special action upon the organs of reproduction. M. Boudin could not find a pure-blooded Parisian whose gencalogy could be traced for more than three generations. At Besançon, town families become extinct in less than a century, and are replaced by others from the country. London, I have been assured, presents a similar phenomenon.

Do not ships, in which men live crowded together for months under very unsatisfactory sanitary conditions, develop deleterious principles, to which the crews become accustomed by degrees, but which are, nevertheless, capable of producing the most serious affections in the midst of surrounding populations, which, till then, had been in a flourishing condition. Have we here one of those phenomena to which, according to Darwin, we must attribute the terrible mortality and increasing sterility of the Polynesian races? Among the diseases introduced by European sailors, onght we not to reckon phthisis, which is said to have become epidemic, as well as hereditary, in those islands? The probabilities seem to me to be in favour of an answer in the affirmative. Neither land nor sky have changed in these archipelagoes since the time of their discovery, and yet the Polynesian Islanders disappear with a terrible rapidity, whilst their mixed races and even pure-blooded Europeans show a redoubled fertility - a double contradiction given by facts to autochthonic doctrines.

It is not always easy to determine, in judging of the more or less deleterious action of given conditions of life, what should be attributed to normal conditions, and what is the result of accidental vitiating elements. The soil, cold, heat, dryness, or humidity of a country are not all. The difference 


\section{Infuence of Conditions of Life and Race. 221}

presented from the point of view of acclimatisation by the two hemispheres is a striking example.

The hot regions of the southern hemisphere are, as a rule, more accessible to white races than those in similar latitudes in the northern hemisphere. From 30 to 35 degrees of $\mathrm{N}$. lat. we find Algeria, and especially the southern part of the United States, which present serious difficulties against our acclimatisation. In the same latitude of the southern hemisphere, lie the southern portion of the Cape and New South Wales, where all European races prosper almost immediately. M. Boudin's calculations give the differences exactly. He has found that the mean mortality of French and English. armies was about eleven times greater in our hemisphere than in the southern hemisphere.

Struck by this contrast, M. Boudin endeavoured to discover its cause, and found that it lay in the greater or less frequency and gravity of marsh fevers. North of the equator these fevers may be traced in Europe as far as the 59th deg. of latitude. In the south they rarely pass the tropics, and often cease at an even smaller distance. Tahiti, which is only 18 deg. from the geographical equator, and almost beneath the thermal equator, is free from them. In the southern hemisphere, the mean annual number of cases of fever in the united English and French colonies was 1.6 in 1000 ; in the northern hemisphere it was $224: 9$ in 1000.

Thus, marsh fevers are almost 200 times more frequent to the north than to the south of the equator, although in South America and Australia, for example, vast tracts are covered with standing water under a burning sum. They are, moreover, of a far less serious nature in the southern hemisphere. The immense lagoons of Corrientes only occasion slight fevers. We know how dangerous, on the contrary, are those of the Pontine Marshes, which are situated at a much greater distance from the equator. It would be much more difficult for a European to live in Italy upon the banks of the Carigliano, than in America upon those of the Parana.

In spite of some experiments and ingenious theories, these 
differences between localities, apparently presenting almost identical general physical conditions, have not yet been explained. The researches of M. Boudin, however, justify U.S in regarding these marsh miasmata as very probably the greatest and often the only obstacle to the acclimatisation of Europeans in the greater number of those places to which the spirit of enterprise has led them. There is something very encouraging and instructive in this fact. We know by what combination of circumstances these pestilential miasmata are engendered; we know how it is possible to resist them. Man can, then, wherever he may go, fight against nature, and at least somewhat ameliorate the conditions of acclimatisation. It has, until now, been impossible to make a whole country healthy in a short space of time. This was a work which time alone seemed to be able to accomplish, very often at a heavy cost of human life. It seems as if the introduction of the encalyptus would, in a great measure at least, tend to diminish these sacrifices.

Should, however, the tree brought from Australia by M. Ramel justify all our hopes, we shall find that some care must still be taken in the choice of station. I shall presently show how, in countries which are apparently most dangerous, there are circumscribed spots where acclimatisation takes place almost immediately. It is clear that new comers ought to look carefully for these favoured localities, and pitch their tents there. The contrary has almost always been, and still is, the case. 'They allow themselves to be seduced by the beauty and fertility of the alluvial lands situated at the mouth of some river, or upon the shores of some bay calculated to facilitate commerce, without considering their unhealthiness. They settle down and build there, without being disturbed by the losses which overwhelm fresh arrivals; and thus it is that pestilential flats, like that of Batavia, have become inhabited.

V. I cannot here consider in any detail the action of conditions of life upon human races, without anticipating considerations which will be more appropriate in another chapter. 


\section{Infuence of Conditions of Life and Race. 223}

I shall only point out a very general fact, and one of great interest in the problem of acclimatisation.

We know that the animal and vegetable races of one species, although in reality subject to the same influences. have, nevertheless, their special aptitudes; and, more especially, some affection which is very general in one will be very rare in another. The case is precisely similar with human races.

Marsh fevers act in the same manner upon all men. The Negro suffers and dies from fever on the banks of the Niger, but in a much less degree than the White. Moreover, the two races, when transposed to India, preserve, in this respect, almost the same relations. Compared with local races, the Negro still retains the ascendancy; he is everywhere the last attacked by malarious emanations. Born in a country where he is obliged almost incessantly and universally to breathe them, descended from ancestors, who from prehistoric times have lived in this poisoned air, he has become acclimatised to it more than any other race; on this account alone, he is able to prosper in places where the White would suffer for a long time.

On the other hand, the Negro has a delicate chest, and no race is so subject to consumption, whilst this malady is much more rarely fatal to the White or to the Malay.

From the extreme differences presented by the White and the Negro it follows that the general conditions of acclimatisation are reversed in the two races. A moderately warm air which is impregnated with malarious emanations is dangerous to the European. A moderate degree even of damp cold will be fatal to the Negro.

These few facts are sufficient to show that the conditions of acclimatisation vary with the race; that the same climate cannot exercise the same kind of action upon different races, and that complete acclimatisation, that is to say, naturalisation, can only follow upon the harmony of these two termsrace and conditions of life. 


\section{CHAPTER XX.}

\section{CONDITIONS OF ACCLIMATISATION.}

I. THe possibility of establishing the harmony, of which I have spoken in the preceding chapter, has been denied. It has been argued that it must exist beforehand, and that instead of becoming acclimatised, people merely become accustomed to a given place. It will be easy to show from what takes place in animals and plants, that there is, in their case, something more than this, and that the organisation is sometimes modified in its most intimate relations so as to conform to the exigencies of conditions of life, which are by nature inflexible.

The chrysanthemum (Pyretrum sinense), which adorns our gardens, came, as we know, originally from China. Introduced into France in 1790, it flourished there and produced fruit which it was unable to ripen, so that commerce alone supplied our flower gardens with the necessary seed for more than sixty years. The attempt to rear it in hothouses and frames met with very small success. In 18.52 a few plants were observed to flower and to fruit sooner than the others; the seeds ripened, and France now produces all the seed which she requires. A small number of accidentiblly precocious plants have, therefore, acclimatised this beautiful flower.

The history of the Egyptian goose (Anser egypticucus) is still more striking. Brought to France in 1801, by Geoffroy Saint-Hilaire, this species at first laid in December, as in its native country. It reared its hrood in the depth of winter, and consequently under very unfavourable circumstances. Several generations were, nevertheless, reared at the MLuseum. 
Now in 1844 the birds laid in February, the following year in March, and in 1846 in April, the time at which our common goose lays. Is it not clear that the organisation of the Egyptian goose had accommodated itself to the conditions imposed by our climate?

This marvellous faculty of living beings is sometimes even inconvenient. French vines when removed to the island of Bourbon yield grapes continually, so that the mixture of clusters in every stage of development and maturity has been a serious obstacle in the manufacture of the wine. Silkworms have acted in a similar manner; they have laid their eggs and spun their cocoons with perfect indifference as to the season of the year, and in such an irregular manner as to force breeders to give up rearing them.

Acclimatisation, that is to say, physiological adaptation to new conditions of life, is an incontestable fact. All our domestic races which have been imported into America are prospering there. When the conditions of existence have been almost the same as those of their native country, they have changed but little. When the new conditions have differed too widely from the old ones, local races have been formed; and thus, though perhaps assisted by human industry, pigs with fleece are to be found on the cold plateaux of the Cordilleras, sheep with hair in the warm valleys of the Madeleine, and hairless cattle in the burning plains of Mariquita. Is it not clear that these pigs, sheep, and oxen, these descendants of our races in temperate climates, have established a harmony between themselves and the conditions of life?

II. But, as I said before, this harmony is scarcely ever obtained without struggles and sacrifices. In this respect again man resembles plants and animals. Let us see, in the first place, what may be learnt on this subject from these beings of inferior organisation.

It is well known that two kinds of wheat are recognised by agriculturalists, one of which is sown in spring and the other in autumn, both being reaped at about the same time. 
It is evident that the conditions of development are very different in the two cases. 'Lo sow a spring wheat in autumn, was, so to speak, changing the condition of existence, and, consequently, attempting an experiment in acclimatisation. 'This was done by the celebrated Abbé Tessier. A hundred seeds of autumn wheat were sown in spring; they all came up and produced young plants, which passed through the usual stages of vegetation. Only ten plants, however, formed seeds, which only ripened upon four plants. A hundred seeds of this first crop produced fifty fertile plants. In the third generation the hundred secds produced corn. 'The inverse experiment gave similar results.

The acclimatisation of wheat at Sierra Leone offers still more instructive peculiarities. The first year almost all the seed ran to leaf; the ears were very few, and poorly filled. The seeds of this first crop were sown; a great number did not come up at all. Those which survived were a little more fertile. Much patience was, however, required, and many generations passed before normal crops were obtained. We see that in 'Tessier's experiment all the seeds of wheat and their germs lived, but the grain was wanting, or was more or less abortive. There was, then, a loss of generations. The same thing occurred at Sierra Leone. Moreover, the second time the seed was sown, some of it never came up at all. Here, therefore, the loss of individuals was added to that of generations.

'The history of our poultry which has been imported into America, presents equally significant facts. At Cuzco the broods are just as large as in Europe. Garcilasso de la Véga tells us, however, that in his time the eggrs were few; and the chickens difficult to rear. The species has, since then, become acclimatised.

When M. Roulin made his observations upon the reese imported into Bogota, it was more than twenty years since they had been first brought to that high plateau, and, even then, they had not attained their normal fecundity. They wore not, however, far from it, while at first the egrgs were 
very rare. A quarter, at the most, of the eggs were hatched, and half the goslings died before the end of the first month. Thus, on the one hand, the Bogota breeder did not obtain nearly as many egrgs as he would have done in Europe, while, on the other hand, at the end of a period scarcely equal to the two-hundredth part of the life of the goose, he obtained from these eggs scarcely one-eighth of what they would have produced in Europe.

The history of these Bogota geese is most instructive. At. the outset we meet with all those circumstances which would seem to justify us in the prediction of a failure. The infertility of the females, as attested by the rarity of the eggs, and that of the males, as shown in the strong proportion of addle eggrs, point to a serious physiological injury to the organs whose action alone insures the permanence of the species. The enormous mortality among the young birds betrayed a no less serious alteration in the components of individual life. Nevertheless, at the time of M. Roulin's journey, acclimatisation had been almost realised, and must without doubt now be completed.

More than twenty years were, however, necessary for the organisation of this European bird to establish a harmony between itself and the conditions of existence on the high plateaus of America. The breeders were consequently forced to submit to many losses, affecting both generations and individuals.

We see what took place in the case of the fowls and geese as well as in that of the wheat. Shortly after their emigration the climate killed all those who were unable to conform to the new exigencies. A certain number offered sufficient resistance to live almost as long as they would have done under their natural conditions of existence; but their weakened organisation was unfitted for generation, or could only produce beings which at once succumbed. Through all these disasters, however, a few privileged organisations conformed, from the first, more or less to the new exigencies. With slight modifications they transmitted their own 
acquirements combined with the suitable aptitudes to their progeny, who in turn made further advances in the direction opened by their parents; and from year to year the adaptation was more complete, the acclimatisation more nearly realised.

But it is evident that years here represent generations. It is only from parent to offspring, through heredity and accumulation, that the living being becomes modified, and by degrees harmonises with the conditions of life. When, however, we are no longer studying an animal, plant, or a bird, which has the faculty of yearly reproduction, but species or races of a more tardy reproduction, we must remember that it is necessary to reckon by generatious, and not by years.

III. Such are the data by which we are enabled to judge of the attempts at acclimatisation made by man himself. I cannot too often repeat the fact that, in common with organised and living beings, we are subject to all the general laws which govern life and organisation ir animals and plants. Our intelligence is unquestionably of assistance to us in our struggles with nature, but, unfortunately, the power which we derive from her is limited, and in no case are we placed at greater disadvantage than in the increasing struggle demanded by a considerable change in conditions of life. The most ingenious efforts are then unable to free man from vicissitudes more or less analogous to those suffered by the wheat of Sierra Leone, the fowls at Cuzco, and the geese at Bogota.

We must, then, almost always be prepared for sacrifices, the extent and gravity of which will be proportionate to the differences, as regards conditions of existence, between the two countries, and we must almost always expect to lose a certain number of individuals and generations. Everything depends upon judging facts fairly, not exaggerating their importance, and seeing how far they justify a hope of success in spite of appearances. If the losses are merely equal to those I have just mentioned, or, better still, if they are fewer in number, we may prophesy a favaurable result; and, if the 
victory is worth the price, we must leave the rest to perseverance and time.

IV. Events in Algeria confirm these observations. After the conquest it was everywhere, as also in France, a question whether it would be possible to colonise the country taken from the Turks and Arabs. Dr. Knox declared most emphatically that such a colonisation was impossible, and that the French would never be able to increase or even live in Africa. It must be confessed that this opinion found many and strong supporters. After the first few years of occupation the generals, as well as the doctors, were almost all of the same opinion. M. Boudin supported, with distressing statistics, the views of his colleagues, Marshal Bugeaud and Generals Duvivier and Cavaignac.

Relying upon what I know to have taken place with regard to birds, I did not hesitate to attack these discouraging prophecies. Military and civil mortality was in 1845 doubtless much more considerable in Algeria than in France, and the number of deaths must again have exceeded that of births. But emigration was at that time abundant and continual. Now, if the influx of new arrivals filled the voids caused by the change in conditions of existence, it at the same time augmented the mortality by continually bringing forward recruits to this war against conditions of life. The rate of deaths amongst children was almost double that reported by French statistics; but the proportion of deaths was still much less than that among the first geese at Bogota. Finally, far from having been weakened, the fertility of the women had increased; the sources of life were therefore much less affected in this case than upon the high plateaus of America.

From all these considerations, I felt justified in concluding that the acclimatisation of the French in Algeria was certain of success, and would not require twenty generations. My opinion has been corroborated by events much sooner than I expected. The census of 1870 showed in the European population of Algeria an increase of $2.5,000$, due almost 
entirely to the superiority of the number of births over that of deaths. 'The action of the first generation born in the country began to make itself felt, and from that time the result has been still more striking. In two or three more generations the French Creole will live in Algeria quite as well as his ancestors have lived in France.

There are, however, distinctions which must be drawn with regard to the facility of acclimatisation in Algeria, Letween the different European races, and even between the inhabitants of the north and south of France. The statistics offered by MMI. Boudin, Martin, and Foley show clearly that the Spaniards and Maltese stand the Algerian climate infinitely better than the English, Belgians, or Germans. Now, the inhabitants of the north of France strongly resemble the latter nations in race and habits. In both these respects the inhabitants of southern France are connected, on the contrary, with the inhabitants of Malta and Spain. We might, therefore, without much fear of error, prophesy that the latter had, either for themselves or their descendants, a much greater chance of surviving than the French of Alsatian and Flemish origin. Experience has again fully confirmed these deductions of theory.

$T$. The information which we derive from these facts taking place, so to speak, at our very doors, and among races with which we are very closely connected, may, with perfect justice, be applied to conditions of life more widely different in character, to races which are inuch more distinct from each other than the French and the Belgians. Nevertheless, the conclusion so obtained would have the same value as that drawn from a general formula, the signification of which changes with the data. When the question is one of acclimatisation, thesc data always rise from the two elements mentioned above: conditions of race and life. If either vary, even though it be but slightly and within narrow limits, the result is necessarily altered, and often in a very unexpected manner. Every question of acclimatisation, in reality then, forms a separate problem, which often, again, is 
subdivided into a number of particular cases, each of which demands a special solution. Without leaving the French colonies, we can quote on this subject another most striking example.

Anthropologists, as well as doctors, have often questioned the possibility of the acclimatisation of Europeans in the archipelagoes of the great Mexican Gulf, which, through yellow fever and the influences by which it is developed, is particularly fatal to him. At first sight, it is true, a number of general facts seem to leave no doubt that the answer should be in the affirmative. Since the discovery of America Europeans have always occupied these islands, and the White race, bringing with it the Negro, have everywhere replaced the Caribean race. In answer to this statement, it has been argued that these islands are one of the most favourite parts of the globe for emigration, and that by this means alone a population is maintained, which, if left to itself, would soon disappear. Calculations are opposed to calculations, statistics to statistics, and were we to approach the subject without analysing facts, the question would appear most obscure.

To solve it in those cases only in which France is interested, we will speak only of Guadeloupe and Martinique. We know that these islands were colonised by the French only 235 years ago. Even allowing the very liberal ratio of four generations to the century, we find that, at the most, ten generations have elapsed in these islands, the climate of which is of all others the most fatal to Europeans. Now, more than twenty generations were necessary to acclinatise the geese at Bogota. The experiment, therefore, is not complete. Nevertheless, in presence of the facts of longevity and fecundity attested by M. Simonot, we do not hesitate to share his opinions. Although the French race may not yet be acclimatised in Martinique and Guadeloupe, we may be certain that it soon will be.

It is no less true that statistics attest an excess of deaths over births. The information which they furnish has, how- 
ever, been presented without distinction. Old and new creoles have been mixed together, as well as the latest emigrants, in a common estimate. Elements, which are fundamentally very different have thus been confounded. For a work of this kind to have any real value, it is absolutely necessary to divide the population into classes determined by the time of emigration, and to estimate the length of time itself by the number of generations. By proceeding in this manner, we shall undoubtedly establish in the mortality of groups striking differences, more or less analogous to those displayed by the generations of plants and animals transported into Africa or America.

The statisties in question are still further vitiated by a fault, which is completely exposed by M. Walther in his work upon Guadeloupe. He, also, has drawn up tables of mortality; only, instead of taking the population en masse, he studied each district separately. Very significant differences then made their appearance. Considered as a whole the population of Guadeloupe offers an amnual excess of 0.46 deaths over births, that is to say, nearly one-half per cent. In presence of these facts, the statisticians whose views I am attacking, would certainly have concluded that the European is not acclimatised in Guadeloupe, and have declared, that, after a certain time, which might easily be calculated, this colonial population would become extinct, if the voids were not incessantly filled by fresh immigrants.

When, however, we examine the table of mortality taken by districts, we arrive at very different conclusions. 'These districts number thirty-one. Now, in fifteen the number of births is greater than that of deaths. In the little island of Marie-Galante this is the case in two districts out of three. 'Thus, the terrible calculations of the mean mortality are due entirely to the exaggeration of mortality in certain districts, while the European has become acclimatised in the others.

'The tables of mortality drawn up in Algeria by M. Boudin present analogous facts. Out of sixty-nine localities, fiftyfive have shown, since 1857, an excess of births over deaths. 
The general result obtained by M. Walther may be thus explained. The French race is acclimatised in Guadeloupe in fifteen localities, but not in the remaining sixteen. Of these two statements, the first should be considered as definitely proved; the second requires confirmation, for a closer examination of the populations of the most unhealthy districts, and a study of them in classes, is still required.

However this may be, every unprejudiced person will acknowledge that we can no longer question the fact of acclimatisation in Guadeloupe as a whole. It should now only be a question of acclimatisation at Basse terra, at Pointe-à-Pitre, at Pointe-Noire, etc.

VI. The French Antilles, as also the greater number of the sister islands, are the scene of valuable experiments upon the aptitude of different human races to stand this exceptional climate, which is one of the most difficult to overcome. The Negro was carried there by force very shortly after the occupation of the islands by the Whites, and has lived there in a state of slavery till within the last few years. As the condition of the parents was inherited by the children, there is little room for doubt, but that after a given time the local multiplication of the Blacks would have sufficed for all the wants of agriculture and industry, if the race had become acclimatised. The incessant activity of the slave trade, seems to show that the number of deaths must have greatly exceeded that of births. There appears to be no doubt as to the truth of the fact for the island of Cuba or for Jamaica. General Tulloch, struck by the mortality of the Negroes in the English Antilles, has not hesitated to declare that if the trade were once suppressed, the whole race would disappear in these islands before the close of a century. The researches of M. Boudin justify us in regarding this assertion as an exaggeration, at least as regards the French possessions.

Neither the English nor the French author has, however, taken into consideration a circumstance, the importance of which cannot be denied. I allude to the conditions imposed upon the Negro by slavery. It is clear that the character 
and conduct of the master played an important part in the probability of the life or death of the slave. Without feeling himself to be, and without being inhuman, the master might demand more labour from him than his nature could support, or violate those instincts, the free play of which is necessary to health. This was certainly the case in Cuba, where it was the general practice to get as much out of the slaves as possible, thus creating the necessity for more frequent renewal. We have here, doubtless, one of those causes by which the mortality of a race, better fitted than ours for intertropical climates, is so immoderately increased. Facts seem to justify these conjectures. "Since the abolition of slavery," says M. Elisée Reclus, "the Negro population has been on the increase in the English islands.

However singular this fact may appear to some anthropologists, it is only a repetition of what took place in Brazil. There again, it was said, that the slave trade alone maintained a black population, which was destined to diminish and disappear as soon as this enforced immigration. should cease. Authentic documents show that the opposite has taken place. The slave trade was abolished long before slavery in this great Fmpire. For many years the proprietors, being unable to purchase fresh slaves, took care of those in their possession, and from that time the Negroes have multiplied. Thus it was that during the period in which the missionaries of the Jesuits flourished, that portion of the black race in which they were interested was observed to increase in an extraordinary manner, whilst in the rich haciendas, where it was uncared for and overworked, it dwindled away.

By the side of the Negro Creole, there are now in the French Antilles labourers engaged more or less voluntarily from the same coasts of Africa, representatives of the Semetic white race from Madeira, Chinese of yellow race, and Indian coolies, who are almost all dravidian, and consequently a cross between the black and the yellow. It will be interesting at some future time, to show what resistance each of these 


\section{Conditions of Acclimatisation.}

nations has offered to the terrible climate they are confronting. The experiment is, at present, only begun. Nevertheless M. Walther has already obtained some interesting data at Guadeloupe. The mean annual mortality of the Creoles is 3.28 per 100 ; that of immigrants, 9.66 for the Chinese; $7 \cdot 68$ for Negroes; $7 \cdot 12$ for Hindoos; and $5 \cdot 80$ for the natives of Madeira. Unfortunately, the statistics are doubtful, and differ from those which M. Du Hailly has given for Martinique. They must, however, both be recorded as the starting-point for new study. There is, moreover, no cause for despair. It is clear, for example, that the natives of Madeira will very quickly become acclimatised in Guadeloupe, as is already the case in Cuba, and the much more serious mortality of the Negro, Chinese, and Hindoo races does not prove the impossibility of their ever inhabiting these islands.

VII. The conditions of life and the nature of the race are not all in the numerous problems raised by acclimatisation. Man, even individually, brings his special elements to bear upon it. The savage and the modern European are placed, by the mere fact of the social differences which separate them, in conditions often opposite, and not always in favour of the latter.

Even the marvels of modern industry, whilst facilitating immigration into distant lands, make it more dangerous. Railways and steamers have reduced the longest journeys to a mere nothing. Lands, which it took our ancestors centuries to people, distances which our own fathers could only travel over in several months, are accomplished by us in a few days. We have here, then, yet another to be added to the many difficulties of acclimatisation. It is a common thing in Paris to hear men complain of the effects of a mere journey from Algiers. The rapidity of the transit gives a shock to the organisation, although tending to replace it under its natural conditions of life. The shock is necessarily greater when the journey is made in the other direction, and we go against our physical habits, instead of returning to 
them. And, when after a few diays' voyage, instead of Algiers, we land at Rio de Janciro or the Antilles, the shock must be great indeed.

Modem civilisation is also answerable to a great extent for the losses involved by every settlement in a climate differing too widely from our own. By reason of the security with which she surrounds the poor as well as the rich, of the at least relative ease which is enjoyed by all classes of society, we are little prepared for the struggle for existence. Without going so far back as primitive man or the Aryans, let us simply call to mind Balbao, Pizarro, Cortez, Soto, Monbars, and their rough companions; can the present generation offer such a resistance as theirs?

It is not, however, by its luxuries only that civilisation renders us unfit to confront the chances of acclimatisation. It is also, and principally, by the vices which too often accompany it. M. Bolot, who was in charge of a number of men employed for the construction of a pier at Grand Bassam, said to Captain Vallon: "A Sunday will put more of my men in the hospital, than three days of work in the full heat of the sun." This was because Sunday was given up to debauchery.

Hore, again, is a fact forming, so to speak, an experiment such as might have been imagined by a physiologist. The Isle of Bourbon passes for one of those disastrous climates to which the European cannot become acclimatised. 'The tables of mortality which relate to the whole population do, in fact, show that the deaths exceed the births to a formidable extent. 'This is, however, another of those sweeping results, into which we must inquire if we wish to understand its true meaning.

The Whites of Bourbon form, in reality, two classes, or rather two races, distinct in their manners and customs. The former includes the population of towns and large settlements, whio lead the ordinary life of colonists, and especially avoid agricultural labour, considered by Creoles as degrading as well as fatal. The latter includes the Mecen 
Whites, descendants of the original colonists, who, too poor to buy slaves, were forced to cultivate the land with their own hands.

Now, of these two classes of colonists, it is the former alone which supply the mortality to which attention is so often drawn. The Mean Whites live as their fathers lived; they inhabit and cultivate the less fertile districts of the island. Far from having deteriorated, their race has improved, and the women, in particular, are remarkable for beauty of form and feature. The race maintains itself perfectly, and scems to be on the increase. Crossing, moreover, has no influcnce in the matter, for the Mean White, proud of the purity of blood which constitutes his nobility, will not, at any price, ally himself with the Negro or Coolie.

Thus at Bourbon, indolence, and the habits which it involves, destroy the rich, and those who try to imitate them, while the poor become acclimatised through sobriety, purity of manners, aud a moderate amount of work. From the latter, anthropologists and all the world may learn a lesson of grave importance, at once scientific and moral.

VIII. Finally, acclimatisation and naturalisation are as universal in history as migration, of which they are the consequence. We see them daily accomplished under our very eyes, and with the most different races, though almost invariably at the price of human life. In many places, they are purchased very cheaply, so much so, that study alone teaches us that new conditions of life in no case entirely lose their rights. In others, specially in countries characterised. by an extreme climate, they involve considerable losses. But there is nothing to authorise us to deny the existence of acclimatisation and naturalisation. Everything, on the contrary, proves that if they are willing to submit to the necessary sacrifices, all human races may live and prosper in almost every climate which is not vitiated by accidental causes.

IX. In this case, as in many others, the present explains the past, which also contributes its share of infomation. 
Relying upon our own daily experience, and upon facts borrowed from history, we can form a general idea of the mamner in which the world has been peopled.

The history of the Aryan race alone, gives us, so to speak, that of the whole species. We see it starting from the Bolor, and Hindoo Koh, from the Ecriéné Veedjo, where the summer only lasted two months, descending into Bokhara, and overrunning Persia and Cabul before reaching the basin of the Indus. Eleven stations mark this route followed by the Aryans before reaching the Ganges. We there find them again slowly advancing, though all the time sending forth as a vanguard, those pious heroes, who slew the Rakchassas, and prepared the way for conquests. The race is now in the tropics in India, in the Polar circle in G:eenland, where the Norwegians and Danes have replaced the Sea-Kings; it spreads over an immense region of more or less temperate climate, and possesses colonies in every part of the world.

The human species must have made a beginning like the Aryans. Upon leaving their centre of creation, it was by slow stages, that the primitive colonists, ancestors of all existing races, marched forth to the conquest of the uninhabited world. They thus accustomed themselves to the different conditions of existence imposed upon them by the north, the south, the east, or the west, cold or heat, plain or mountain. Diverging in every direction, and meeting with different conditions of life, they gradually established a harmony between themselves and each one of them. 'Thus acclimatisation, advancing at the same rate as geographical conquest, was less fatal. The struggle, however, though mitigated indeed by the slowness of the advance, still existed, and many pionecrs must have fallen upon the route. But the survivors had only nature to face, and, therefore, succeeded, and peopled the world. 


\section{BOOK VII.}

\section{PRIMITIVE MAN.-FORMATION OF THE HUMIAN RACES.}

\section{CHAPTER XXI.}

\section{PRIIITIVE MAN.}

I. The primitive type of the human species must necessarily have been effaced, and have disappeared. The enforced migrations, and the actions of climate, must of themselves have produced this result. Man has passed through two geological epochs; perhaps his centre of appearance is no longer in existence; at any rate, the conditions are very different to those prevailing when humanity began its existence. When everything was changing round him, man could not avoid being changed also. Crossing, also, has certainly played its part in this transformation. I shall shortly return to these different points which I only allude to here.

But, on the other hand, we shall see that the skull of the most ancient Quaternary race is repeated not only in some Australian tribes, but in Europe, and in men who have played an important part among their fellow-countrymen. The other races of the same epoch, judging from the skull, have many representatives amongst us. They have, never-' theless, passed through one of the two geological revolutions, which separates us from our original stock. It is then not impossible that the latter may have transmitted to a certain 
number of men, perhaps scattered in time and space, at least i part of its characters.

Unfortunately, we do not know where to seek for reproductions, bearing more or less resemblance to the primitive type; and, for want of information it would be impossible to recognise them as such, if we were to meet with them. Here, therefore, observation alone can furnish no data. But, when it is aided by physiology, some conjectures are possible.

II. We know that among animals atavism often causes the reappearance of ancestral characters, even when a car:ful selection has acted upon hundreds of generations. The silkworms of the Cevennes which yield white cocoons, and the black sheep of Spain furnish examples. In man, where selection does not exist, such facts would be much more likely to be produced. Some characters of our first ancestor's ought to appear in isolated cases or collectively in all human races; perhaps, there are some which have been preserved in one or more groups. Consequently, by searching for them, and classifying those which appear in a more or less erratic manner among races which are most dissimilar in all other respects, we shall probably be able to form a partial reproduction of the primitive human type.

In this respect, it is difficult to aroid attaching a real importance to the prognathism of the upper jaw. 'This anatomical feature is very pronounced in almost all Negro races: it is also strongly marked in certain Yellow races. It is considerably diminished among Whites: but, nevertheless, it appears at times almost as strongly marked as in the two other groups: it existed in Quaternary man. Everything seems to indicate that it must have been as strongly developed in our first ancestors.

Phenomena of atavism acting on the colouring are of frequent occurrence among animals.

They are equally provalent in the human species. 'This consideration causes me to attach real importance to the opinion of $\mathrm{H}$. de Salles, who attributes red hair to the earliest 
men. In fact, among all human races, individuals have been noticed whose hair more or less approaches to this tint.

The experiments of Darwin upon the effects of crossing between very different races of pigeons led to the same conclusion. He found that the crossings resulted in the reappearance of certain peculiarities of colour in the mongrels, which were peculiar to the original species, and which had disappeared in the two parent races. Now in our colonies the offspring of a Mulatto and a White frequently has red hair. In Europe also, M. Hamy has remarked that children are born with red hair, when one of the parents is decidedly dark and the other decidedly fair. In all cases of this nature, we should say that the primitive character reasserts itself, being accidentally acquired by the reciprocal neutralisation of opposed ethnical characters.

When examined under the microscope, the cutaneous pigment which gives the human body its characteristic colour; doubtless shows different tints, but yellow is always present as a colouring element. If we apply to man the laws which Isidore Geoffroy has deduced from his observations upon animals, we are led to conclude that this colour originally predominated. When the White is crossed with the Negro, the yellow colouring element at once asserts itself and generally appears to predominate. In the colonies the general term of yellows is sometimes given to mulattos. This result is again explained by the experiments of Darwin; and the conclusion is admissible that the original colour of man more or less approximated to this tint.

Certain facts which have been observed among Negroes seem also to confirm this conclusion. Among the most strongly characterised peoples belonging to this type, the appearance has been noticed of individuals of a lighter. colour, sometimes almost resembling the Whites in this: respect, sometimes tending more or less to yellow, without: presenting any of the phenomena of teratological albinism. These individual peculiarities of colour may be attributed to atavism. Now among no white or yellow race, have facts 
been noticed which can be regarded as reciprocal to the preceding.

Nothing therefore authorises us to regard the Negro race as having preceded the other two; and, on the contrary, the contrast which I have just pointed out leads to the conclusion that the ancestors of the negro were a race of a much lighter colour.

On the other hand, we know that the Aryan race is the latest. The question of priority thus lies between the Semitic, the Allophylian, and the group of yellow races. What I have said above of the fundamental colour being present as an element in the colour of all races, and the phenomena of crossing, point with some probability in favour of the latter.

Philology seems to confirm this view. Monosyllabic languages, which imply the first attempts at human speech, only exist among the yellow races. All the Negro races and the Allophylian Whites speak agglutinative languages, which answer to the second form which man gave to the expression of his thoughts. Aryans and Semites both have inflectional languages.

Philology then seems to lead to the same conclusion as physiology, and even to give an appearance of greater probability to these conjectures, which I only give for what they are worth.

III. We know nothing of primitive man; we acknowledge that, from want of information, it would be impossible to recognise him. All that the present state of our knowledge allows us to say is that, according to all appearance he ought to be characterised by a certain amount of prognathism, and have neither a black skin nor woolly hair. It is also fairly probable that his colour would resemble that of the yellow races, and his hair be more or less red. Finally everything tends to the conclusion that the language of our earliest ancestors was a more or less pronounced monosyllabic one.

These are only conjectures, and they amount to but little, but this little is founded upon experiment and observation.

IV. We can also only form very vague conjectures upon 
the degree of intellectual development which man exhibited at lis birth and during his first generations. At any rate it is possible to believe that he did not enter upon the scene of the world with innate knowledge, and the instinctive industries which belong to animals. Still less did he appear in a fully civilised state "mature in body and mind" as thinks the Comte Eusèbe de Salles. All traditions point to a period when human knowledge was very small, when man was ignorant of industries, to our eyes very elementary, and which we see appear in succession. Upon this point the Bible agrees with classical mythology. The Hebrews have their Tubal Cain, and the Greeks their Triptolemos. Prehistoric studies confirm this progressive development in Western Europe upon every point. Tertiary industries precede quaternary. The whole history of races seems to me to give, at least in part, a representation of that of the Species; and our thoughts go back almost irresistibly to the time when man found himself face to face with creation, armed solely with the aptitudes which were destined to undergo such a marvellous development.

Thanks to these aptitudes, at a very early period he satisfied at least the first wants of existence. The miocene man of La Beauce already knew the use of fire and worked flint. However rough and rudimentary his instruments may have been, he had even then an industry, and according to all appearance fed partly upon cooked food. The man of SaintPrest, with his small lozenge-shaped arrow-heads, worked only on one side, with his rough hatchets, could undoubtedly attack and kill the great contemporary mammalia. He possessed scrapers which he used to prepare their skins with, and awls, which perhaps served as needles. From this distant period, upon which science has thrown as yet but little light, man reveals his existence by two great facts, and shows his superiority to the whole animal creation. 


\section{CHAP'TER XXII.}

FORIIATION OF HUMAN RACES UNDER THE SOLE INFLUENCE OF CONDITIONS OF LIFE AND HEREDITY.

I. The first men who peopled the centre of human appearance must at first have differed from each other only in individual features. At their beginning and during an indefinite lapse of time, mankind could only have been homogeneous, as is every animal and vegetable species which is restricted to an area of small extent.

At the present time, we find mankind composed of numerous groups, which have peculiar characters, and constitute so many distinct races. How have these races originated? and how have they grown and multiplied?

To give a definite reply to these questions, by going back from recent effects to first causes, is still impossible, and perhaps will always be so. Nevertheless, science may even now approach the general aspects of the problem. We are well acquainted with the circumstances under which varieties originate and races are formed among plants and animals: we have established in man the occurrence of a number of phenomena, which are in this respect identical, or very similar to those exhibited by the two inferior kingdoms. We are therefore clearly authorised to apply inferences drawn. from them to ourselves, connecting particular with general facts. This study is instructive in many respects. Unfortunately, we cannot fully enter upon it here; we can only select some facts in the history of animals to justify our conclusions.

II. The problem of the formation of human races presents two very distinct cases. Man at first was subject to the sole 


\section{Action of Conditions of Life and Heredity. 245}

action of natural modifying agents. Under this influence pure races were formed. When these races came in contact, they were crossed; this resulted in the formation of mixed races. Without being antagonistic to the natural forces, crossing modifies them by its peculiar phenomena, and sometimes masks their manifestations. The two cases, therefore, require separate examination. We will begin with the first.

III. Every organic species considered as a whole appears to be subjected to the action of two forces, one of which tends :to maintain and the other to modify its characters. To what cause can this double action be referred? This is a question put by the greatest thinkers and the most eminent physiologists, from Aristotle and Hippocrates to Burdach and J. Müller.

It is not the resemblances existing between the members of the same species, or between the members of one family, which perplex philosophers: all agree in referring them to heredity. The problem lies rather in the differences. Not only in the considerable differences which are established between races; but more especially in the shades constituting the individual traits which distinguish father from son, or brother from brother. This is in reality the fundamental difficulty, and many hypotheses have been proposed for its solution. Prosper Lucas, after having discussed them separately, regarded them all as insufficient, and believed that, side by side with heredity, which maintains types, we ought to admit a special force, innateness (l'innéité) which diversifies them.

We can, however, account for the double tendency exhibited by living beings, without having recourse to a new force. For this purpose it is sufficient to push the analysis of phenomena a little further than is customary, and to obtain a clear idea of the part played by the conditions of life (milieu) and heredity. As a general rule an action is attributed to the first, which everywhere and at all times is a modifying one, and to the second a purely conservative 
action. Now it may be easily shown that this is not the case; and that each of these causes acts in an inverse manner according to circumstances.

IV. By virtue of the laws of heredity, the father and mother tend equally to transmit to their offspring their own character. However similar they may be supposed to be, there are always some differences between them; and the nature of the new being is necessarily a compromise between two different tendencies. The son cannot, therefore, always resemble his father exactly. In him the characters common to both parents will easily be exaggerated; the opposite characters will be neutralised; and the different characters will produce a resultant, as distinct from the two components as green is from yellow and blue. Thus even by virtue of its own tendencies, and in consequence of the enforced cooperation of the sexes, direct and immediate horedity becomes, in some respects, a cause of variation.

Mecliate and indirect heredity, justly compared by Burdach to geneagenetic phenomena, as well as atavism, which suddenly reproduces with great exactness the characters of an ancestor, sometimes after hundreds of generations, have certainly considerable influence in the variation of individual traits, and in the differences which distinguish parents from their children.

'Their action, added to that of direct heredity, is sufficient to explain the appearance of certain varieties, without appealing to innateness.

V. But the hereditary force, although it is manifested from one generation to another, or through several generations, is ahways influenced by the conditions of life (milieu), and this has evidently greater force.

'This term ought to be taken in a much more general sense than is usually the case. Buffon himself only took into account climate, varying quantities of food, and the hardships of servitude, when he was treating of domestic animals. I understand by the conditions of life something much more complex. They comprehend the sum of all the conditions 


\section{Action of Conditions of Life and Heredity. 247}

under whose sway a plant, an animal, or man, is formed and grows as germ, embryo, youth, and adult. To make a selection from these conditions, to admit some and take them into consideration, to reject and exclude the rest, is evidently an entirely arbitrary procedure. The consideration of only a certain period of life, the neglect of the whole intra-ovarian or intra-uterine period, deserves the same reproach. From this point of view, the existence of a being cannot be severed, any more than the conditions of life under whose rule this existence is accomplished.

A number of cases do away with all doubt as to the action of the conditions of life upon the germ, or upon the embryo, however much it may appear to be protected by the envelopes of the ovum, or by the tissues of the mother. The two Geoffroy Saint-Hilaire have clearly proved that monstrosity dates from the earliest stages of the formation of the being, and indicates in certain cases the external causes which have produced it. 'The experiments of $\mathrm{M}$. Dareste have confirmed and enlarged in a singular manner these first conclusions, while giving them greater precision. By mixing madder with the food of a female mammal, Flourens produced a red colour in the bones of the fœtus. By placing the eggs of a salmon-trout in waters which only nourished whitetrout, Coste noticed the eggs become gradually paler, and produce trout which had lost the characteristic colour of their race. In order to increase the height of our excellent small horses of the "camargue" race, it is sufficient to give the mare during the period of gestation a more plentiful diet than that to which she is accustomed in her half-wild state.

Thus it is established in the clearest manner and by exact experiments that the conditions of life, when acting upon the embryo during the intra-uterine or intra-ovarian part of its existence, are capable of producing either the gravest teratological disorders, or simple and slight deviations. We are, therefore, clearly justified in attributing to the same cause modifications which are placed between these extremes 
according to.their importance. 'To invoke innateness, in order to explain their appearance, is obviously superfluous. We shall connect, therefore, with actions of this kind the appearance of the first spineless Acacia of which we have spoken before, of the first Ancon sheep in Massachusetts in 1791, that of the first Mauchamp sheep in France in 1828, etc.

The Ancon and Mauchamp races are only propagated by human industry. But these sudden deriations from a given :type can also extend and multiply their numbers by themselves. It is well-known that South American oxen are descended from a horned Spanish race. Now, in 1770, a hornless ox was produced in Paraguay. In several years, according to d'Azara, this exceptional form had, as it were, invaded several provinces. Nevertheless, the race is far from being in favour, because the absence of horns renders it less liable to be caught by the lasso, so that its destruction was attempted. It was, therefore, evidently propagated spontaneously.

Whoever has the smallest acquaintance with embryogenesis will have no difficulty in understanding that conditions of life act especially upon organisms in respect to their formation and evolution. However, their influence upon an animal, even when full-grown, is sometimes quite as marked. Our sheep, when transferred to America, generally become acclimatised without undergoing great changes. Their fleece, particularly, is retained. But in the plains of the Meta it is only retained on condition of the sheep being regularly shorn. If they are left to themselves, the wool becomes of a felty nature, is detached in flakes, and is replaced by a short, stiff, and shining hair. Under the influence of this burning climate, the same individual becomes in turn a woolly and a hairy animal. Now, innateness, as Prosper Lucas conceives it, cannot be appealed to in the case of changes undergone by a full-grown animal, whilst the action of conditions of life is here incontestable.

VI. We have just pointed out how heredity and conditions of life can give rise to a variety. Now, the individual which 
has commenced to deviate from its original type becomes in its turn a parent; it tends to transmit to its offspring the exceptional characters which distinguish it. The same facts are repeated in its offspring; and, at each generation, the actions of the conditions of life are added to each other. Thus every time heredity transmits the sum of these actions to the following generation. The faintest modification increased from father to son sometimes leads to most marked changes. Our European oxen, in the hot plains of Mariquita and Neyba gradually lost their hair, at first became pelones, and would soon have formed an entirely naked race, if the calongos had not been regularly killed. Again, pigs which have become wild in the Paramos have acquired a kind of wool under the action of a continuous, but not excessive cold. The Guinea dog and the Esquimaux dog present an analogous contrast between races of the same species.

In the preceding examples, and in many others which must be omitted, the actions in question modify organisms in order to place them in harmony with the conditions of life. Now it is intelligible that when the maximum of possible effect has once been attained, they can only fix the result obtained more fully, but can never determine a change in the opposite direction. The heat, which has by degrees deprived calongo cattle of their hair, will never restore it again; and the cold which has made our pigs woolly, will never deprive them of wool. Here, then, we find conditions of life acting as an agent of preservation and stability.

VII. In the preceding passage allusion has been made to natural forces left to themselves. It is to them that the formation is due of the wild races of all the species whose geographical area is very extended, such as the fox, jackal, lion, etc.

These races are sometimes so different that they were regarded as distinct species, as long as the intervening geographical and zoological terms were unknown. Frederick Cuvier himself made this mistake in the case of the jackals 
of India and those of the Senegal. Wild races have, however, never been so numerous or so distinct from each other as domesticated races.

Are we to infer from this that man exercises around himself and of himself a kind of magnetic action, as some authors seem to admit? Certainly not. In reality, he only acts upon an animal by setting in action, sometimes intentionally, sometimes unintentionally, the two agents which, hitherto, we have met with everywhere, conditions of life and heredity. By the single fact of domestication, by the confinement which is almost always the result of it, he changes entirely the natural conditions of existence. By leading in his train the animals which he has enslaved, he diversifies still more the influences which act upon them. Prompt to seize every means of rendering them most useful, he profits by the smallest modifications which show the least advantage, pushes them to their utmost limits and produces the extreme races, of which our exhibitions of animal races give such curious examples.

The chief means which man uses for the attainment of these results, which at times seem to border on the marvellous, is selection. Ever since he has possessed domestic animals he has marked out among them individuals which are better adapted than the rest to his intentions. By some kind of instinct, or unconsciously, as Darwin says, he has chosen them to breed from. By rejecting the types which he considers inferior, and only employing the higher types wherewith to propagate the species, he has directed the action of heredity in a definite direction, and has readily created races. Now, man has acted in this manner since the times spoken of in Genesis and by Chou-King, that is, for thousands of years. Is it then surprising that he should have multiplied around him hereditary forms which are more or less distinct from the primitive types?

Progressive selection would doubtless lead to numerous and varied results. Would it allow of the creation of races whose characters almost reach hemitery? 'The answer to 
this question is at least doubtful. But we have not to ask it. When by one of the actions of the conditions of life, whose origin remains obscure, an almost teratological animal form is produced, it soon disappears by the mixture of blood from different sources, if unions are left to chance. This is the reason why analogous facts are not observed in feral races. But if this form appears in a domestic animal, if it answers to any want or caprice, selection intervenes, preserves it, and multiplies it. This explains the origin of the Ancon sheep, which were all descended from a single ram of which we have spoken above; also the means by which M. Graux de Mauchamp has raised his race of sheep with silky fleeces from a single ram. These two examples show how all those peculiar races have been obtained, which in some of their characters seem to clash with the very type from which they were derived. In the canine species the beagle corresponds to the Ancon sheep; the niata cattle, which have appeared in South America since its conquest, correspond to the bull-dog, etc.

VIII. Races, when once formed under man's influence, are fixed by the same causes which produced them. Their characters, which at nirst were entirely artificial, become more and more fixed, so much so, that even a very considerable change in the conditions of existence, hever effaces them entirely. The acquired nature is, so to speak, welded to the original nature of the being.

This is a fact not generally recognised by naturalists and anthropologists who have touched upon these questions. For instance, it has been admitted as proved that domestic races, when they have returned to the feral state, reassume all the original characters of the species. This is a mistake. The fact is, that both with animals and plants, escaped races lose a certain number of characters, and frequently the most apparent ones, which they owe to domestication; they reassume others which they had lost during their period of servitude, but the former are more frequently only diminished and masked by the latter. If fruit-trees escaped from our 
orchards, if our horses, dogs, cattle, and pigs, when they have becone wild, had really reassumed the original type of the species, they ought to present in every area which they inliabit the marked uniformity characieristic of animals who were never subject to man. 'This is not the case. 'They ought in particular to preserve no trace of their acquired characters. Now, the latter are partly persistent. Vans Mons has found apple-trees and pear-trees of Belgium, in a wild state, in the forest of the Ardennes. 'The prickles had reappeared, the fruit had become small and bitter again, but the principal cultivated varieties were still to be recognised. I have established an analogous fact with regard to clingstone and free-stone peach-trees in a valley of the Cevennes. Similarly Martin de Moussy has recognised in the troops of dogs which have become wild in America, all the chief races from which they had been derived, although they reassumed the general characters of the tan-coloured type.

IX. From the number of observations which have been collected among plants and animals, and of which I can only notice a small number, it is easy to understand the appearance and multiplication of human races, and to account for certain general facts, some of which are closely connected with our history. Let us state at starting that with man, as with animals, varieties have appeared at times which may be classed among hemitery. Individuals, exhibiting from their birth exceptional characters, are none the less healthy, and sometimes have very remarkable power of transmission. Edward Lambert, born in 1717 of perfectly healthy parents, had all his life a kind of carapace more than an inch thick, and irregularly fissured, which gave him the name of the porcupine man. All his clildren, to the number of six, and his two grandchildren, inherited this strange modification of the skin, although his wife and his daughter-in-law did not show the least trace of it. In the Colburn family, four generations were marked with polydactylism which was derived from the grandmother of the great calculator. At the fourth generation, four children out of eight still had 
supernumerary fingers, though at each generation normal blood was mixed with the teratological blood.

Evidently, if the descendants of Lambert and Colburn had been treated like those of the first Ancon or Mauchamp sheep, two human races would have been obtained, one characterised by a cutaneous carapace, and the other by the possession of six fingers. But here selection was wanting, and the exceptional blood, from being diluted at each fresh marriage, did not fail to be rapidly exhausted.

$\mathrm{X}$. Man does not subject himself to the selection, which he applies with so much success to animals and plants. In his species, therefore, the extreme variations which are obtained elsewhere are not produced. It is thus easily explained why the limits of variation are not so extensive with man as with domesticated or cultivated races. But if, for some motive or other, he were to apply the process of selection to himself, we should not lave to wait long for the result. By marrying the tallest women to the giants of their guard, Frederick William and Frederick II. had created at Potsdam a real race distinguished for its tall stature. In Alsace a Duke de Deux-Ponts, who imitated the Prussian sovereigns, obtained the same result.

There is another cause which contributes powerfully to restrict the limits of variation in man, namely, the power which his intelligence gives him of partly escaping from the effects of the conditions of life. He is always struggling, as much as he is able, against the external influences capable of disturbing the equilibrium which constitutes his well-being. In the tropics, he uses contrivances for avoiding the heat; in the polar circle, he perfects his means of heating; if he emigrates, he carries with him, as far as he can, his manners and customs, and struggles with redoubled care against the new conditions of life. There is nothing strange in finding him successful in neutralising to a certain extent the modifying influences of the external world.

XI. Nevertheless, the conditions of life do not surrender their rights; although diminished, their action is none the 
less real. This is a fact which can be affirmed by what occurs in our great western colonies. Each great European race is there represented by derived sub-inces which vary according to the locality. 'The islands in the Gulf of Mexico, North and Soutl America, and Australia itself, which has been so recently colonised, have at this time their own peculiar races, some of which are remarkably characterised.

Suge I am unable to treat in detail all these facts of transmutation, I will only notice some of the facts which have been established in the United States. We know that the English race was only definitely settled there at the time of the Puritan emigration, about 1620, and from the arrival of Penn in 1681. 'Two centuries and a half, twelve generations at the most, separate us from this epoch, and nevertheless, the Anglo-American, the Yankee, no longer resembles his ancestors. The fact is so striking that the eminent zoologist, Andrew Murray, when endeavouring to account for the formation of animal races, finds he cannot do better than appeal to the condition of mankind in the United States.

The subject, moreover, is not wanting in precise details, which are vouched for by a number of travellers, by naturalists, and doctors. At the second generation the English Creole in North America, presents, in his features, an alteration which approximates him to the native races. Subsequently the skin dries and loses its rosy colour, the glandular system is reduced to a minimum, the hair darkens and becomes glossy, the neck becomes slender, and the size of the head diminishes. In the face, the temporal fossæ are pronounced, the cheek-bones become prominent, the orbital cavities become hollow, and the lower jaw massive. The bones of the extremities are elongated, while their cavity is diminished, so much so, that in France and England gloves are specially made for the United States with exceptionally long fingers. Lastly, in the woman, the pelvis, in its proportions, approaches to that of the man.

Are these changes signs of a degeneration already accomplished, and of an approaching extinction, as Knox 
asserts? I think a reply to this assertion is hardly necessary. We are sufficiently acquainted with American men and women to know that, although modified, the physical type is not on that account lowered in the scale of races; and the social grandeur of the United States, the marvels they have accomplished, the energy with which they pass through the rudest crises, prove that from every point of view, the Yankee race has retained its rank. It is simply a new race, formed by the American conditions of life, but which remains worthy of its elder sisters in Europe, and will perhaps some day surpass them.

The Negro transported into the same countries has also undergone remarkable changes. His colour has paled, his featureshave improved, and his physiognomy is altered. "In the space of 150 years," says M. Elisée Reclus, "they have passed a good fourth of the distance which separates them from the whites, as far as external appearance goes." Lyell's opinion is almost the same. Moreover, when visiting two Negro churches, at Savannah, he remarked that the odour so characteristic of the race was scarcely appreciable. A long medical experience at New Orleans has shown Dr. Visinié that the blood of the Negro Creole has lost the excess of plasticity which it possessed in Africa. With MM. Reiset, de Lisboa, etc., with even Nott and Gliddon, let us add that, while the physical type has undergone modification, the intelligence has improved, and we shall have to recognise that in the United States a sub-Negro race has been formed, derived from the imported race.

XII. Thus the European White and the African Negro, when under the influence of new conditions of life, have both undergone modification. Moreover both, according to M. Reclus, whose statements are confirmed by those of M. L'abbé Brasseur de Bonbourg, approximate to the indigenous races. Both of these authors seem to admit that at the end of a given time, whatever be their origin, all the descendants of Whites or of Negroes who have immigrated to America will become Red-skins. 
When two such intelligent observers arrive at an identical and certainly quite unexpected conclusion on such a question, the facts must be very patent. Yet they have forced their meaning, from not having taken sufficient account of the nature of the problem. That the Negro and the White should replace some of their features and characters by some of the features and characters belonging to the indigenous races, is quite natural. When subject to the action of the conditions of life which have formed the local races, they could not help being influenced by it to a certain extent. But they will never on that account be confused with the local races nor with each other, any more than the White transported to Africa would ever become a true Negro, or the European descendants of a Negro would ever become true Whites.

This impossibility of one race being transformed into another is often brought forward as an objection against Monogenism. It is nevertheless the natural consequence of the phenomena, of which I have endeavoured to give a short account, and is easily explained. Every race is a resultant whose components are, partly the species itself, partly the sum of the modifying agents which have produced the deviation from the type. We cannot separate those two elements, and races which have run wild show us to what extent the fusion can go. Every race which is fixed, when brought under the conditions of life which have formed another, will doubtless approximate to the latter; but it will partly retain its former impress, as the fruit-trees of Van Mons and the wild dogs of Martin de Moussy have done.

Such is what would take place even among primary races directly detached from the primitive type, and which have only been subject to the action of one fixed condition of life. But with the Negro and the White, the question is much more complex. These two extreme types represent the last product of two series of long-continued actions, whose diversity and multiplicity are indicated by the geographical stations themselves. Europe and tropical Africa have given them, if 


\section{Action of Conditions of Life and Heredity. 257}

the expression may be used, the last touches; but their outline was sketched out long before they reached their present habitat. By their transposition, we only submit each of them to a part of the influences which have formed the other, and consequently a complete exchange of characters could never take place:

XIII. Without denying absolutely the influence of the conditions of life upon man, most polygenists refuse to admit that they have the power of producing new races. To support their statements, they appeal to the persistence of certain types for a considerable lapse of time, and insist most strongly upon certain facts derived from Egypt. On this latter point I readily agree with them. It is quite true that pictures and Egyptian sculptures point to the existence in the valley of the Nile of a type, or rather types, which are remarkably uniform; and whoever has visited these countries has certainly been struck, as I was, with the great resemblance of the peoples of the present to those of the past.

But what reasons are there why the inhabitants of the valley of the Nile should change? What cause, except intercrossing, could determine any modification in their physical characters? In this region, which is exceptional in so many respects, nothing has changed since historic times, neither the earth, the sky, nor the river; habits, customs, and daily life have remained as they were in the time of the Pharaohs; the Egyptian even uses implements in our days, which are exactly like those which were used fifty or sixty centuries ago by his ancestors.

In Egypt, all the conditions of existence, and, consequently, the actions of the conditions of life, are the same in our days as they were in those distant times, the history of which is preserved by the monuments. Far from tending to modify a race which is already fixed, they have only helped to fix it more and more. In the order of ideas which I support, a change in the Eyyptian type would be inconceivable.

The persistence of a type, far from being an objection to the manner in which I understand the conditions of life to 
act, viz.: the formation and maintenance of races, is a confirmation of it.

XIV. In conclusion; like all animal and vegetable species, the human species can vary within certain limits; like plants and animals, man has his varieties and races, which have appeared and been formed by the action of the same causes.

In the liuman kingdom, as in the two other urganic lingdoms, the first causes of variation are, conditions of life and heredity.

In phenomena of this kind, conditions of life act as the supreme ruler. If they vary, they become modifying agents, if they remain constant, agents of stabilisation.

In both cases their result is to harmonise organisms with the conditions of their existence.

Heredity, which is essentially a preserving agent, becomes an agent of variation, when it transmits and accumulates the modifying actions of the conditions of life.

$\mathrm{XV}$. It is now casy to understand, in the general sense, the formation of hrman races.

Man at first doubtless peopled his centre of appearance and the countries immediately adjoining. He then commenced the immense and varied dispersion which dates from tertiary times and continues to the present day. He has passed through two geological cpochs, and is now in his third. He has seen the mammoth and rhinoceros flourishing in Siberia in the midst of a rich fauna; he has at least secn them driven by the cold into the midst of Europe; and he lias assisted in their extinction. Later on, he has retaken possession of the barren-lands himself; he has pushed hi: colonies as far as the neighbourhood of the pole, perhaps to the very pole itself, while at the same time he has invaded the forests and deserts of the tropics, reacled the extremity of two great continents, and peopled all the archipelagroes.

For many thousands of years, man has therefore been subject to the action of all the external conditions of life with which we are acquainted, to that of the conditions of life 
of which we can at the utmost only form an idea. The various kinds of life to which he has been subjected, and the different degrees of civilisation at which he stopped or to which he has reached, have all diversified still more his conditions of existence. Was it possible that he should retain everywhere and for all time his original characters?

Experience and observation lead to an entirely opposite conclusion. When we see the Anglo-Saxon of our days, although protected by all the resources of an advanced civilisation, subjected to the American conditions of life, and changed into a Yankee, we must admit that at each of his great stages, when man is submitted to new conditions of existence, he has had to harmonise himself with them, and in so doing undergo modification. Each of these principal stations has necessarily witnessed the formation of a corresponding race. The original characters, thus successively affected, have become more and more altered, by reason of the length of the journey, and the difference of conditions. When they have reached the end of their journey the grandchildren of the first emigrants would certainly only retain very few of the characters of their ancestors.

The original human type has probably presented, for an indefinite time, its original characters in the tribes which remained fixed to the centre of appearance for our species. When the glacial epoch began, which, according to all appearance, made the earliest country of man uninhabitable, these tribes were forced to emigrate in their turn. Since that time the earth has no longer had autochthones, but has only been peopled by colonists. At the same time the modifying: action of the conditions of life was felt by these last comers, who themselves were also transformed.

From this moment, the original type of man has been lost; the human species was only composed of races, all of which differed more or less from the first model. 


\section{CHAPTER XXIII.}

\section{FORMATION OF MIXED HUMAN RACES.}

I. 'TirE races which had been developed by the sole action of the conditions of life and of heredity, did not remain isolated. The earliest emigrants from the centre of appearance certainly did not pass at once to the extremity of the area determined by their first stages. They stopped on the way; they formed secondary centres, round which fresh emigrations spread. The history of the Lenni Lenapes, as of the Polynesians, proves that this must have been the case. Consequently, in many cases, the races first formed must frequently have come in contact. Then, as the waves of emigration followed each other, the last comers would meet on their way with those who preceded them. It will further on be proved that facts of this nature have occurred since Quaternary times.

Whether peaceful or otherwise, these contacts would result in reciprocal penetrations, and consequently in intercrossings.

The founders of anthropology, Buffon, Blumenbach, and even Prichard, have taken very little notice of crossings between human races, and have neglected their importance. It can scarcely be brought as a serious reproach against them. The two former were unacquainted with many of the facts which we possess at present. Prichard was neither a naturalist nor a physiologist. Moreover, nothing forcibly directed their attention towards crossings which might have occurred in more or less distant times, or among nations still insufficiently known.

At the present time this indifference is impossible. On 
the one hand, the better the various nations are known, the greater becomes the number of those which derive their origin from intercrossing; on the other hand, it is impossible not to pay attention to everything which happens to mankind in consequence of the impulse to expansion and mixture which takes place on every side. From seeing the phenomena which occur in the present times, we are naturally led to investigate those which may have taken place in times past.

II. Are mixed human races formed now? In the presence of the general facts which I have related in a preceding chapter, this question might appear strange. Nevertheless, the question has been asked, and in a more or less formal manner has been answered in the negative. A few words on the subject are therefore necessary.

We may consider the era of modern crossings as dating from the discovery of the new world. Nevertheless the mixture of bloods has only taken place on a large scale at a later period, at the utmost after the conquest of the Indies in 1515, that of Mexico in 1520, and that of Peru in 1534 . We are not separated from this epoch by more than three centuries and a half. And yet M. d'Omalius, only counting the products of the crossing of the European White with the different coloured races, estimates the number of half-breeds at eighteen millions. The population of the globe being estimated as 1200 millions, the product of cross-unions is already represented by about $\frac{1}{65}$ th.

We know, moreover, how irregular is the distribution of half-breeds. Immense tracts of country have not been affected. But where the peoples are in intimate contact, the proportion is much greater. In Mexico and South America half-breeds constitute at least one-fifth of the popur lation.

But, say Knox and the other anthropologists who more or less explicitly adopt his views, the number of half-breeds is entirely kept up by incessant cross-unions. If abandoned to themselves, and if they no longes had access to the pure 
races, they would rapidly disappear. I will confine myself to quoting a few facts in opposition to these assertions.

At the Cape, the intercrossing of the Dutch and the Hottentots has resulted in half-breeds called Basters, who soon became sufficiently numerous to inspire alarm. They were banished beyond the Orange river. Here they settled under the name of Griquas, and they increased in numbers rapidly. A portion remained behind in the colony, and formed villages, among others that of New Platberg. The Basters intermarried between themselves, and travellers testify to the fertility of these unions.

Martins has seen the Cafusos, the result of the crossing of escaped Negroes with the Brazilian indigenes. Having retired into the woods, where they found a refuge, they have formed a separate race there.

Admiral Jurien de la Gravière informs us that at Manilla the half-breeds of Spaniards, Chinese, and Tagals, are much more numerous than the original stocks. At Mindanao half-breeds of Spaniards and Tagals form the majority of the inliabitants. "The fusion of races," he adds, "has talien place with marvellous facility in this isolated corner of the earth."

The Marquesas Islands, suffering the fate of the other Polynesian countries, have been depopulated by that mysterious malady which seems capable of annihilating oceanic populations. M. Jouan informs us that they are repeopled by half-breeds.

Upon the whole of the littoral zone of South America, according to M. Martin de Mlonosy, mixed peoples are prospering and rapidly on the increase.

We may close this enumeration by a detailed account of a fact which is well known, and which has all the value of a precise experiment.

In 1789, in consequence of a mutiny, nine English sailors went and established themselves upon the small island of Pitcairn, in the Pacific Ocean, accompanied by six Tahitian men and fifteen Tahitian women. In consequence of the 
Whites becoming tyrannical, the war of race began. In 1793 the population was reduced to four Whites and to ten Tahitian women. Soon war broke out afresh between the four chiefs of the colony, and Adams only was left. But marriages had been fruitful; the first half-breeds grew up, intermarried, and had numerous children. In 1825, Captain Beechey found sixty-six individuals on Pitcairn Island. Towards the end of 1830 the population numbered eightyseven. In spite of the deplorable conditions of the outset, the mixed Pitcairn race had then almost doubled in twentyfive years, and almost tripled in thirty-thrce ycars. Now England, the most favoured country in Europe in this respect, only doubles its population in forty-nine years. Thus the half-breeds of banished English and Polynesians had on Pitcairn Island about double the number of offspring that pure Anglo-Saxons have when placed in their customary conditions of life.

Thus the white race, when crossed with races most different in characters and habit, have given rise to mixed peoples, which have continued to increase since their appearance. No reason can be given why this movement of increase should stop or even slacken.

III. There remains the intercrossing of the White and the Negro. It is with reference to this that some facts have been quoted tending to prove that half-breeds cannot propagate among themsclves. Let us examine thom rapidly.

Etwick and Long, in their History of Jamaica, have asserted that Mulattoes cease to be reproductive in that island beyond the third generation. Dr. Yvan has pointed out an analogous fact in Java. Dr. Nott has found that in South Carolina, Mulattoes are endowed with low fertility, that they have a shorter life than other human races, and that they frequently die at an early age. Without going so far, Dr. Simonnot attributes to these half-breeds a sort of ethnological neutrality, "which only assures them an ephemeral duration as soon as they are abandoned to themselves."

Nothing is easier than to oppose contrary facts to the 
foregroing. I can even invoke the testimony of some of the same authors whom I have just quoted. Nott, after having in a general manner formulated the aphorisms which I have just summed up, admits that they only apply to South Carolina, whilst in Louisiana, Florida, and Alabama, the Mulattoes are robust, fruitful, and energetic. I find that Dr. Yvan himself states that his observations only concern Java, and that he had pointed out the fact as exceptional.

On the other hand, Hombron declares that in our colonies "Negresses and Whites show a moderate fertility; Mulatto women and Whites are extremely fertile as well as Mulatto men and women."

"Even in such conditions of life as those of the Gulf of Mexico, the Mulatto," according to MI. Rufz, "is well developed, strong, alert, more adapted than the Negro for industrial application, and very productive." According to M. Audain, in the Dominican Republic of St. Domingo, "onethird are Negroes, two-thirds Mulattoes, and an insignificant proportion Whites." For a long time this population has not been fed by any fresh arrivals; its continuance is entirely due to itself.

More quotations, I think, are useless. When added to the numbers of M. Martin de Moussey, who makes no exception concerning Mulattoes, they are sufficient to demonstrate the following general fact, viz, that the Mulatto is as energetic and as fruitful as other races, at least in a very great majority of those parts of the globe where this mixed population has been formed.

IV. Nevertheless, I do not deny the facts advanced by Etwick, Long, Nott, Yvan, and Simonnot. I accept them without so much as discussing them. But what do they prove in the presence of the remaining facts which are so numerous and so conclusive? At the most that the development of the mulatto race can be favoured, retarded, or hindered by local circumstances. In other terms, that, it depends upon the influences exercised by the whole of the conditions of life (milieu). 
We see, then, in the formation of the mixed races, the reappearance of this element, whose action plays so large a part in the natural history of man, and great attention should be paid to it.

In the result of the crossing of the Negro and the White in Jamaica, Java, \&c., its intervention could be foreseen. The two races are strangers to these countries, which are known to be very destructive to foreign races. The question of crossing is complicated in these cases, by the phenomena and difficulties of acclimatisation. Can we feel surprised that unions contracted under such conditions of existence should only present precarious guarantees for the future?

We must here, moreover, take into account an element which is constantly neglected, and whose importance in questions of this nature has always struck me strongly. I mean morality. It therefore forms one of the conclitions of life (milieu). Now, if we pay attention to the details, which are not numerous, but which are very significant, given by some travellers upon the existence of Europeans in the colonies, in Jamaica in particular; if we compare these melancholy facts with those furnished by daily observation, an entirely new light will be thrown upon the questions of crossing and acclimatisation. We shall be obliged to recognise that the death of the fathers, and the extinction of the descendants, are often only the consequence of, and the punishment for, the deplorable moral conditions of life, in which they have lived.

$\mathrm{V}$. But the physical conditions of life have also their peculiar action. The following example may be quoted as a proof.

M. Simonnot has noticed natives of Senegambia, "who combine a perfectly black skin, with all the characteristic forms of the Moor, even at all ages." According to him, these black Moors are a mixed race. If this is the case, it must, at least, be recognised that the white blood predominates considerably, since all the forms belong to this type. In order that the colour of the Negro should be persistent, in spite of 
this profound semitic influence, a local action, that is, an action of the conditions of life, must have neutralised the ordinary laws of the mixture of races, sund united the colour of one race with the features and forms of another.

If this conclusion requires confirmation, the facts quoted by Prosper Lucas will be sufficient. He treats of unions between Negroes and Whites accomplished in Europe. In the same family we find the black blood predominate at first, then lose its influence, and by degrees become effaced almost entirely in the children of the later generations. In one of these observations, the mother belonged to the black race; so that infidelity was unable to effect any change in the conditions of the experiment. It was then the conditions of life which gradually blanched these half-breeds, who would all have been black upon the borders of Senegal.

VI. Some anthropologists, although recognising the multiplicity and fertility of the crossings between human races, only see in this fact a confusion of blood, and complain that nowhere do they find a mixed race of recent origin which is well characterised. Consequently they deny that the crossing: can have any influence in the formation of the races with mixed but constant characters which form part of the population of the globe.

This objection rests upon a disregard of the phenomena which accompany the formation of animal races by the production of mongrels. All breeders know well that a determinate and settled race cannot at once be produced by crossing. In such a case, the conflict and the compromises, of which I have spoken above, become more marked, for the very reason that we have to blend two natures which are dissimilar in some respects. Immediate and direct heredity alone continually produces phenomena of fusion or of juxtaposition, or else causes the appearance of new features, the resultunt of two different characters. Mediate and inclirect heredity, as well as atavism, continually intervene and produce numerous irregularities in the succeeding generations. The more the races differ and are equal in respect to 
blood, the more marked and persistent are these irregularitics. In 1800 the Ancon race still gave irregular products. For more than twenty years M. Malingié has failed in settling his charmois race, so that it might itself serve for fresh crossings.

The clever breeder, whom I have just mentioned, as well as all other breeders, have moreover only attained their end by means of minute care in the choice of the animals from which they breed. Now, between human races there can be no question of selection. The unions have always taken place by chance. Moreover, in the immense majority of cases, the continual intervention of individuals of pure race increases, and prolongs the confusion. This absence of uniformity, which astonishes polygenists, is easily explained by those who only consider human groups as races. From a general point of view it is very instructive; if it brings forward diversity of races, it attests specific unity. It is not between species that crossing presents similar phenomena. But nevertheless, through this disorder, there appear in the mixed populations of our colonies, general common characters, which have attracted the attention of travellers, and have been described.

Moreover, when, in consequence of some circumstance, the products of these crossings are isolated and protected from new mixtures, the race becomes characterised with rapidity. The Cafusos, Basters, and Griquas, may be quoted as examples. Even the Pitcairn islanders, at the time of Bcechey's visit, were beginning to become uniform.

VII. In the crossings between unequal human races, the father almost always belongs to the superior race. In every case, and especially in transient amours, woman refuses to lower herself; man is less delicate.

From the point of view of the future of the mixed races, the predominant action of one sex over the product should have then great importance. The question has been put since the origin of societies, as is testified by the laws of Manou; it has been repeatedly discussed by thinkers and 
physiologists. Each sex has had its champions; and rumerous facts have been quoted on both sides. Considering everything, it appears to me impossible to avoid deciding in favour of equality of action.

Nevertheless this equality is purely virtual ; it can, in fact, only exist on the condition of an equal generating energy in both parents. As soon as the equilibrium is interrupted, the stronger sex predominates, and the product shows this superiority. The experiments of Giron de Buzareingue upon the procreation of the sexes, appeared to me to be most decisive in this respect.

Now what is true of the whole of the organism is equally true of its different parts, functions, and energies. In the formation of a new being, the action of heredity is divided into as many cases as there are characters to transmit. Both father and mother tend to reproduce themselves in their offspring; there is, consequently, a struggle between both natures. But the battle, if we may use the expression, results in a number of single combats in which each parent rnay be in turn victor or vanquished.

This very simple consideration, which is deduced from a number of facts of detail, explains many results which cause surprise to physiologists, anthropologists, etc. After having attributed a preponderating action to the mother, Nott declares with surprise, that, in point of intelligence, the Mulatto approaches more to his white father. But is not the intellectual energy of the latter superior to that of the mother? And is it not natural that it should gain the ascendant in the struggle between the two hereditary powers? We know how far this victory can go, and how the two natures can, so to speak, divide the product of this crossing between them. Lislet Geoffroy, entirely a Negro physically, though entircly a White in character, intelligence, and aptitudes, is a striking example of it.

This victory of the superior energies is again shown in inother very remarkable manner, in the crossing of white and black races. The former is, of all races, most sensible: 
to malarious influences, the latter best able to resist them. On this account it is almost exempt from yellow fever. The Mulatto inherits this double power of resistance. Nott assures us that a proportion of one fourth of black blood is as sure a protection against the yellow fever, as vaccination against the small-pox.

We may now understand, that, in crossing between different races, the half-breeds possess the characters which, in each of them, predominate over the corresponding characters of the other. If the energies are in equilibrium, there will generally be a compromise. The Negro and the White differ essentiaily in colour and the texture of the hair; the colour of the eyes varies almost as much in one as in the other. In the Mulatto, the two first characters almost always betray the double origin of the individual ; the third is uncertain.

On the contrary, in half-breeds of the white and the indigenous American, the eyes and hair are almost always derived from the latter. Humboldt has remarked that these two characters are persistent even after several generations, in unilateral crossing towards the White. M. Ferdinand Denis recognised a descendant of the caciques by the eyes. On the other hand, in the same crossings, the colour of the White overcomes that of the American at the second, and sometimes even at the first generation.

The crossing of the Slav and the Bouriate presents similar facts. The half-breeds invariably have the hair and eyes of the second.

VIII. "In Brazil," says Martin de Moussy, "mixed races of every origin increase, and form a new population which becomes more indigenous every day, if we may use the expression, and always more similar to the white type, which, according to what takes place in the whole of South America, will, in the end, absorb all the rest." An analogous fact has been pointed out at Buenos Ayres, in Paraguay, etc.

Can we then consider this result as a sign of the ascendancy of the white race? I do not think so. I rather 
consider it as the consequence of the general tendency pointed out above.

In the countries which we are discussing, the Negress or Indian woman readily crosses with the White. 'The female issue of these unions, proud of the blood of her father, would consider herself degraded if wedded to an individual of coloured race, and reserves all her favours for those to whom she approximates by reason of the crossing. The Quadroon reasons and acts in the same manner. In these regions, where colour decides caste, it is ahways men of whiter race, and especially the pure white, that the women prefer to marry.

The consequence of this is, that the crossing, although apparently left to chance, is in reality unilateral, and always directed towards the superior race. It is accomplished under the influence of a real unconscious selection, and the predominance of the white blood is the result of this selection.

Sooner or later it will also result in the fulfilment of the prediction of Martin de Moussy. The mixed races will in a great measure return to the superior race. But, when brought back to the white type by this circuitous path, and through all these degrees of crossing, they will possess one very great advantage over thcir European counterpart: they will be acclimatised.

The reverse phenomena appear, according to Squiers, to be taking place in Peru. Here the mixed population tends to return to the indigenous type. The fact is explained, at least in part, by the relations which, since the commencement of the conquest, were established between the conquerors and the conquered race.

The former could not affect unlimited contempt for a conquered race who were as civilised as themselves. Their leaders made alliances at an early period with the families of the Incas, and this example was followed. Consequently colour cannot exercise the same influence in Peru as in Brazil or at Buenos Ayres. The numerical predominince of 


\section{Formation of Mixed IInman Races.}

the local race and the conditions of life had then a free field, and their double influence is shown in the result pointed out by Squiers.

IX. Can human crossing, so general in our days, be a new phenomenon in the history of mankind? Evidently not. In the past as in the present, every contact between two races of any continuance, every immigration, and every conquest has led to the formation of a mixed race. It is one of the inevitable consequences of human instincts and of physiological laws.

It is quite natural that polygenists should have neglected facts of this nature. In their opinion a population with mixed characters is a species as much as any other, which is intermediate between two given specific types. But the indifference or the mistake of monogenists is less easily explained. They are evidently ignorant of the phenomena of crossings among plants and animals. When they mect with a race of undecided characters, and which presents more or less distant analogies with two different types, they have generally felt embarrassed, and have put the question on one side, or have at most invoked the action of conditions of life in a vague manner.

It is quite true that the latter, when effecting a rescmblance between foreign races and the local race, leads to results analogous to those which result from crossing. We have seen an cxample of it in the United States. Yct crossing has its peculiar phenomena, which are persistent even after several generations. Moreover, to the indications drawn from physical and physiological characters we may add others borrowed from very different orders of facts, and which, in many cases, permit us to draw a conclusion with remarkable certainty. The mixture of beliefs, customs, and manners often furnishes valuable information. But the comparison of languages generally throws an unexpected light upon problems apparently most difficult. From time to time legends and history confirm inductions drawn from the orders of facts which I have just pointed 
out, and testify to the correctness of views which, at first sight, might appear conjectural.

As an example I will qunte the Zulu Kaffirs. They are. one of the groups of which some polygenists make a distinct species. They are in fact distinguished from other negro races by several characters. But by these characters they are brought nearer to the white type. Moreover, various traveller's inform us that they present a great variability of feature. Missionaries who have lived among them add that, in the same family, and under conditions which render all crossing impossible, individuals are met with who have the hair and colour of a Negro, and others whose hair is smooth and whose colour is brown. These facts alone would authorise the conclusion that the Zulus are a mixed race.

Philology confirms this conclusion. Philologists agree in placing the Kaffir languages in the group of Zimbian languages, whose grammar and vocabulary are fundamentally negro, but which also include arab, nilotic, and malgach elements. 'Thus language, as well as physical characters, points to a mixture of blood.

The chronicle discovered by Captain Guillain justifies these conclusions by giving the history of the arab colonies from Quiloa to Sofala. It relates the wars which were laised for the possession of the gold mines; it shows the conquerors driving out the conquered, and compelling them to go southwards to seek a new country. It is evident that the latter have crossed Delagoa Bay, where they have left the black race in its state of original inferiority, and have gone further to ally themselves voluntarily or involuntarily with tribes whose type has thus risen.

In fact, far from being a species, the Zulus are a mixed race of Negroes and Arabs, whose formation is so recent that mediate heredity and atavism still betray the double origin, which is also attested by philology, but in which the negro element preserves a very great superiority.

$\mathrm{X}$. 'The investigation of mixed populations, the determination of the part played by each of the elements which 
have assisted in their formation, belong to the most interesting questions of anthropology. This study ought not to stop at populations in which the mixture of characters is evident at first sight. It ought also to bear upon those which are generally regarded as quite pure. We should then find that mixture of races has penetrated where it was scarcely suspected.

In China and especially in Japan, the white allophylian blood is mixed with the yellow blood in different proportions; the white semitic blond has penetrated into the heart of Africa; the negro and houzouana types have mutually penetrated each other and produced all the Kaffir populations situated west of the Zulus of Arabian origin; the Malay races are the result of the amalgamation, in different proportions, of Whites, Yellows, and Blacks; the Malays proper, far from constituting a speeies, as polygenists consider them, are only one population, in which, under the influence of Islamism, these various elements have been more completely fused, etc.

I have quoted at random the various preceding examples, to show how the most extreme types of mankind have contributed to form a certain number of races. Need $\mathrm{I}$ insist upon the mixtures which have been accomplished between the secondary types derived from the first? In Europe'what population can pretend to purity of blood? The Basques themselves, who apparently ought to be well protected by their country, institutions, and language against the invasion of foreign blood, show upon certain points, in the heart of their mountains, the evident traces of the juxtaposition and fusion of very different races.

As for the other nations ranging from, Lapland to the Mediterranean, classical history, although it does not go back a great distance; in point of time, is a sufficient proof that crossings are the inevitable result of invasions, wars, and political and social events. Asia presents, as we know, the same spectacle; and, in the heart of Africa, the Jagas, playing the part of the hordes of Gengis-Khan, have 
mixed together the African tribes from one ocean to the other.

XI. I need scarcely allude here to the general facts which follow from the detailed history of races. Short though it be, this appeal to the reader's memory will, I hope, give a sufficient motive for the following conclusions.

Conditions of life and heredity have fashioned the first human races, a certain number of which, on account of their isolation, have been able to preserve for an indefinite time this first characteristic.

Perhaps it was during this very distant period that the three great types of the Negro, the Yellow, and the White were characterised.

The migratory and conquering instincts of man have brought about a meeting between these primary races, and consequently a crossing between them.

Since the appearance of mixed races, crossing itself has only acted under the domination of the conditions of life and heredity.

The great movements of nations have only taken place at long intervals, and as it were form so many crises. In the interval between these crises, the races which have been formed by the crossing have had time to settle and become uniform.

The consolidation of the mixed races, the relative uniformity of characters effected by the crossing, have taken place very slowly, in consequence of the absolute want of selection. Consequently every mixed race which has become uniform is also very ancient.

Human instincts have produced the mixture or mixed races, just as they have produced that of the primary races.

Every mixed race, when uniform and settled, has been able to play the part of a primary race in fresh crossings. Mankind, in its present state, has thus been formed, certainly for the greatest part, by the successive crossing of a number of races at present undetermined. 


\section{Formation of Mixed Human Races. 275}

The most ancient races which we know, the quaternary races, are still represented in our own days, either by populations generally small in number, or by isolated individuals, in whom atavism reproduces the characters of our remote ancestors. This is a fact which will be proved further on. 


\section{CHAPTER XXIV.}

-INFI,UENCE OF CROSSING UPON MIXED HUMLAN RACES.

I. Has the crossing of human races been, or will it be, advantageous or detrimental to the species considered as a whole? The followers of Morton in America, and of MM. de Gobineau and Perrier in France, have stated that human crossing had, or would have in the future, disastrous consequences. Has this opinion any foundation? Let us study the facts.

M. Gobineau appeals to history, and goes back to the earliest ages of mankind. According to him, three fundamental races, the black, the yellow, and the white, were formed originally. The yellow race occupied the whole of America; the negro race all the southern parts of the old continent as far as the Caspian Sea; the white race was localised in Central Asia. The two former, degraded from an intellectual and moral as well as from a physical point of view, and unable to elevate themselves unaided above the savage state, only existed as tribes. The third was the only one which united bodily beauty with a warlike spirit, to the faculty of initiative, of organization and progress, which gives rise to societies and to civilization. The day came when the yellow race burst upon Asia, and, avoiding the central region sccupied by the whites, went to people the western regions of the old world. Then, this wave, continuing its course, submerged the white race, which, in its turn, began to emigrate; and by the mixture of its blood with that of the inferior races, produced all the peoples who have succeeded each other upon the earth. At the beginning of this new era, the white blood, being more pure and more abundant, 


\section{Influence of Crossing.}

produced superior civilizations. Becoming rarer at each new emigration, it lost its influence, and civilization diminished in every respect. The last effort of this renovating race was the Germanic invasion which destroyed the Roman world. It is now exhausted. The white blood, vitiated by the mixture, has everywhere lost its first efficacy. Mankind for this very reason is in a full decline. The fusion will soon be complete. Every individual will have in his veins onethird of white blood and two-thirds of coloured blood, and we shall then inevitably return to barbarism. Finally, the repeated crossings will have rendered the human species barren; it will then die out and disappear.

Such is, in a few words, the theory of M. de Gobineau. Let us accept it with all its hypotheses, including that of the migration from America to Asia, which is contrary to all our knowledge upon this point. Does it follow that the author is consistent? In order to be so, he ought to point out the privileged race, founding by itself one at least of those great societies, one of those civilizations, as M. de Gobineau calls them, recorded by history. Now the author is unable to point out a single example, and is obliged to admit that the exclusively white civilization has existed in Central Asia without leaving any other trace than the tumuli which have for a long time been attributed to Scythians, Tchoudes, etc. But everyone knows the state of the whites, when they left their Asiatic centre. In India they were the Aryans, still a half-pastoral race; in Europe, the barbarians who destroyed the Roman world. Had either of them a civilization equal to that of the Egyptians or the Greeks?

M. de Gobineau enumerates ten civilizations, namely, Assyrian, Indian, Chinese, Egyptian, Greek, Italian, German, Alleghanian, Mexican, and Peruvian. All, according to him, were produced in consequence of the mixture of whites with coloured races. But admitting that such has been the case, is it not evident that this mixture has everywhere given rise to an immense progress. The ruins of Nineveb 
Thebes, Athens, Rome, and even those of Palanqué, certainly point to populations of a different civilization to that of the people who raised the tumuli in Central Asia.

In order to draw their logical consequences from the facts which he admits or supposes, M. de Gobineau should regard the formation of half-breeds as the most powerful element of progress. As we have seen he adopts the opposite opinion. He considers that all these civilizations, which were splendid in the case of the Assyrians and Egyptians, have been dwindling away and diminishing, and what remains in our own days, only deserves our scorn.

Without being blinded by self-conceit, we may protest against this conclusion. Doubtless we no longer raise towers of Babel, nor do we build pyramids. Gigantic works which are useless, or undertaken for the glorification of a single man, do not belong to our time. But when some generally useful work arises, do we recoil before the magnitude of the task? The time truly has been badly chosen to accuse us of feebleness. The Suez Canal has been made on a different scale to the small trench of the Pharaohs, and in tunnelling the Alps for a railway, we have accomplished what antiquity had never dared to dream of.

It is stili true that, taken en masse, we are less artistic than the Athenians. But without leaving the domain of the arts, there are points in which we surpass them. To judge from the anecdotes which throw light upon the nature of the talent of their greatest artists, painting and music among the Greeks were not up to the level of sculpture. If we have not our Phidias, they had not their Raphael, their Michael Angelo, their Beethoven, nor their Rossini.

But, when he condemns us to a radical inferiority, M. de Gobineau especially forgets the most striking character of modern times. He disregards the scientific development, which is without example or analogy in the past, and which 
gives an absolutely fresh appearance to our civilization. We who are sprung from races crossed a hundred times, are at least the equals of our forefathers, but no longer resemble them. Inferior in some respects, we make up for it thoroughly in other respects. We manifest human power under different aspects.

Highly gifted though man may be, he cannot at once reach all the limits of the field which is open to his activity. For this reason, in time as well as in space, we find by the side of inferior peoples and races, other peoples and races which are superior, equal among themselves, but different. Such is the real information gained by a comparison of the present and past condition of mankind.

II. M. Perrier is a polygenist and an autochthonist; he makes use of the expression pure race as equivalent to the term species. Being a physician, and a learned one, he touches upon anatomical and physiological questions, and upon the limited fertility and sterility of half-breeds, and reproduces some of the opinions which I have already attacked. He pays particular attention to present populations, and endeavours to prove the superiority of those which he regards as pure. He quotes the Arabs in particular, and praises their ancient and modern civilizations. But on this point I make the same objection to him which I made to M. de Gobineau. We know very little of the Himyarites and the Adites. Caussin de Perceval shows them to have played at different times the part of conquerors; but they were conquerors who were barbarians, and whose mar: thoroughly savage. When they left their deserts under the impulse of Islamism, did they appear with the marks of civilized peoples? Certainly not. It was only after their conquests, and in consequence of the crossings which they mnderwent, that we find the great Arabian civilizations rise in Africa, Asia, and in Spain. Was the civilization, which was developed upon the spot, and which has been brought to light by Palgrave, equal to that of the Almohades, the Almoravides, or the Abassides? Evidently not. Here, 
again, crossing is found to have given rise to most striking progress.

NI. Perricr lays especial stress upon physical perfection, and particularly upon that of women. Let us accept this criterion. Is purity of blood the sole cause of this beauty? If this were so, in the same country, the purest populations should show the fairest women. But in France, for example, the inhabitants of Auvergne, secluded among their mountains, are undoubtedly of a purer race than the inlrabitants of the plains in Southern France, where so many different races have come in contact. Well, can the women of Upper Auvergne dispute the prize with the grisette of Arles, Toulouse, or of Montpellier? These three feminine types are very distinct; they clearly point to a mixture of blood. They are not the less remarkable in the matter of beauty, and are undoubtedly superior to the women of Auvergne. In Sicily, where all the Mediterranean populations are confused together, I have observed analogous facts at Taormina, Palermo, Trapani, etc.

As to the possibility of meeting with women remarkable for their personal attractions among mixed races, even when the Negro enters as an element in their composition, the reputation of women of colour, mulattoes and quadroons, is a sufficient proof. All travellers bear witness to the charm which they excrcise upon Europeans. 'Taylor is most explicit upon this point, and it is at Tristan d'Acunba, a distant island half way between the Cape and South America, that he makes his observations. In this isolated spot, a mixed population of Whites and Negroes has settled. The English traveller speaks as follows: "All who are born in the island are mulattoes, though of a very slightly pronounced type, and of very fine proportions. Almost all have the European, much more than the Negro type. I do not recollect ever having seen such splendid heads and figures as among their young girls. And yet I know all the coasts of the earth: Bali and its Malays, Havana and its Creoles, Tahiti and its nymphs, and the United States with their 
distinguished women." It is evident that we here have a most impartial judgment in favour of mulattoes, and given by an experienced judge.

Thus female beauty is met with among certain mixed races, and is wanting among other races which are rightly regarded as the purest, the Bosjesmans and the Esquimaux. The adversaries of human crossings cannot then regard it as an argument in their favour.

III. Although modern crossings only go back three centuries, they have already produced results which make it certain that races remarkable from every point of view may be produced by crossing. The Paulists of Brazil are a striking example of the fact. The province of Saint Paul has been peopled by Portuguese and inhabitants of the Azores from the old world, who have formed alliances with the Gayanazes, a hunting and pacific tribe, and with the Carijos, who are warlike and agricultural. From these unions, which have been regularly contracted, there has sprung a race whose men have always been remarkaole for their fine proportions, their physical power, indomitable courage, and endurance of fatigue. As for the women, their beauty has given rise to a Brazilian proverb which proves their superiority. This population shows its pre-eminence in every respect. If it was once remarkable for the expeditions of adventurers in search of gold or slaves, it was also the first to plant the sugar-cane in Brazil, and to breed immense herds of cattle. "In the present day," says F. Denis, "the highest moral development as well as the most remarkable intellectual movements appear to come from Saint Paul."

Such praises paid to a population which is almost entirely the result of a mixture of races, by a sagacious observer, who has long lived in Brazil, form a contrast to the reproaches cast upon American half-breeds by an immense majority of travellers. As a general rule they are painted in the blackest colours. Although they aro allowed to possess physical beauty, and perhaps also a prompt and 
ready intelligence, they are said to be almost entirely without morality. Let us admit that they differ as much from the Paulists in this respect as has been stated : the explanation of the contrast is not difficult to find.

At Saint Paul, the earliest unions were from the first regularly contracted, thanks to the intervention of Fathers Nobrega and Anchieta. In consequence of different circumstances, the mamalucos, who were the result of these marriages, were at once accepted as the equals of the pure Whites. Here the crossing then was accomplished under normal conditions, a fact, perhaps, unique in the history of our colonies.

In reality, the mixture of races elsewhere owes its origin to the worst passions; prejudices of blood have caused halfbreeds to be regarded as tainted by the vice to which they owed their origin, as outcasts from society, or one might say, outlawed. Now what branch of the pure white race being born, growing, and thriving under contempt and oppression, would preserve an elevated and moral character? Moreover, would the white fathers furnish examples capable of influencing for good the children which they had abandoned? The contrary is evidently the case. Unrestrained debauchery on one side, and servile submission on the other, are the elements in the production of a half-breed race. What could heredity transmit in the way of moral character to the products of such unions?

If anything should surprise us, it is that half-breeds produced under such detestable conditions should already have been able to raise themselves. Now this has happened, even with the mulattoes, in all cases where prejudices of race have been less deeply rooted, and have yielded to personal merit. In Brazil, most of the artists and musicians are mulattoes, say MLI. Troyer and de Lisboa. In confirmation of this testimony, MI. Lagos added that the political capacity and scientific instinct are scarcely less developed among them than artistic aptitude. Several are doctors and medical practitioners of the highest distinction. Lastly, Mr. Torres Caïcedo 
enumerated to me among the mulattoes of his country, orators, poets, public men, and a vice-president of New Grenada, who was at the same time a distinguished author.

If the case is not the same where a sccial condemnation weighs upon the man of colour, the reason is that the moral and social conditions of life never lose their rights any more than the physical conditions. But the preceding will, I think, be a sufficient proof that, when placed under normal conditions, the half-breed of the Negro and the European would certainly justify in every place the words of the old traveller Thevenot: "The mulatto can do all that the white man can do; his intelligence is equal to ours."

IV. Although I protest against the doctrines which tend to depreciate mixed races, I am far from pretending that the crossing is at all times and in all places fortunate. Undoubtedly, if the union has taken place between inferior races, the product will remain at the level of the parents. But these unions are few in number. Even in South America, the Zambo is relatively rare. The Negro appearing everywhere in slavery, has been despised by the indigenous populations, who, in spite of their dependent condition, have preserved their individual liberty, and have avoided union with the Negro.

It is the White who, impelled by his restless ardour, has iuvaded the world, and is every day multiplying his conquests and colonies. It is he who has searched out the home of the coloured races, and who everywhere mingles his blood with their own. Almost all the half-breed populations recognize him as their father, and this gives rise to a double result. These races are at once raised above the maternal race, and the two brought closer together, as if they possessed a common element.

Will this connection extend as far as fusion, as Serres and Maury have admitied? Will all our present races sooner or later be replaced by a single homogeneous race, everywhere endowed with the same aptitudes and governed by a common civilization? I do not think so; and what has just 
been said justifies the statement that this uniformity is impossible.

Doubtless the mixture of races, favoured and multiplied by the growing facility of communication, appears to me to prepare a new era. The races of the future, differing less in blood, and brought together by railways and steamers, will have far more inclinations, wants, and interests in common. Hence a state of things will rise superior to that with which we are acquainted, although our civilization ought, it seems to me, to continue growing in spite of present evils and approaching storms. We know how the Greek, Roman, and the modern world were developed in succession; the modern future will embrace the entire globe.

But, although this civilization will become more general and more widely spread, it will not suppress certain differences in the conditions of life. As long as there are poles and an equator, continents and islands, or mountains and plains, races will exist distinguished by characters of every kind, and superior or inferior in a physical, intellectual, and moral point of view. In spite of crossings, varieties and inequalities will continue. But as a whole, mankind will be perfected; it will have grown; and the civilizations of the future, without causing those of the past to be forgotten, will outstrip them in some as yet unknown direction, just as ours have outstripped those of our predecessors.

V. I have just closed the statement of the most general questions raised by the history of the human race.

The principal point to determine is the unity or the multiplicity of the species. There are some anthropologists, even men of high distinction, who regard it as almost an idle question, as merely a question of dogma or of philosophy. Nevertheless, a little reflection is sufficient to make it intelligible, that the science is entirely changed according as it is regarded from a monogenist's or a polygenist's point of view. I have already pointed out this fact; and beg permission to return to it in a few words. 
After the fundamental question of unity comes that of antiquity. This is put similarly in the two doctrines. But the problem is simple and absolute for the monogenist, but multiple and relative for the polygenist

The question of the place of origin, which next presents itself, only exists in reality for the believer in the specific unity of human groups. The doctrine of autochthonism, though greatly multiplying the question, reduces it to very simple terms, since it declares that all the populations were born upon the spot whose foreign origin it does not establish, and only admits movements of expansion.

For the polygenist the genercal question of migrations does not exist. For particular cases autochthonism supplies everything. He who regards the Polynesians as having appeared on the islands of the Pacific has not to seek whence they might have come.

The question of acclimatisation for the polygenist is reduced to a small number of facts almost exclusively modern, human populations being in his eyes naturally formed for living under the conditions of life in which they were born.

The question of the formation of races disappears entirely for the polygenist, since the different species admitted by him have appeared with all the characters which distinguish the different human groups. At most he has to concern himself with the results of some modern crossings which are too evident to be denied.

The question of primitive man does not exist for the polygenist, since he recognizes all his species with the characters which they have had-from the commencement.

No one, I think, will dispute the truth of these propositions, which compel the conclusion that anthropology is an entirely different science to the monogenist and the polygenist.

Polygenism seems to simplify the science in a singular manner; it will be said that it suppresses its most apparent difficulties. In reality it only does so by veiling or denying 
them, and thus conduces to inaccuracy. At the same time it gives rise to others, which, although less easily perceived, are nevertheless more important, for they are essentially of a physiological nature, and cannot be solved by the general laws of physiology.

Monogenism seems at first to complicate and multiply the problems. In reality it only states them clearly. By that very means, it causes the necessity of long and persevering studies to be felt, which it rewards from time to time with great discoveries. It has required almost a century and the combined efforts of travellers, geographers, physicians, linguists, and anthropologists to establish the origin of the Polynesians, to follow their migrations, and to determine the date of them. But when this work is once set on the right track, human history is found to be enriched by a magnificent page, which gives another testimony to the intelligent activity of the human race and its conquests over nature. 


\section{BOOK VIII.}

\section{FOSSIL HUMAN RACES.}

\section{CHAPTER XXV.}

\section{GENERAL OBSERVATIONS.}

I. Tertiary man is only known to us from a few faint traces of his industry. Of tertiary man himself we know nothing. Portions of his skeleton have been discovered from time to time, it has been thought, in France, Switzerland, and especially in Italy. Closer study has, however, always forced us to refer to a comparatively much later period these human remains, which, at first sight, were regarded as tertiary.

It is different with quaternary man. We have much better and more precise information about him than about many existing races. The caves which he inhabited, those in which he buried his dead, and the alluvial deposits formed by rivers, which have borne away his corpses, have preserved numerous bones for our study. As many as forty different places in all, especially in the western portion of Europe, have supplied our museums with as many as forty skulls, more or less intact, and numerous fragments of the cranium and face, which science has been able to utilize, as well as a great number of the bones of the trunk and limbs, and even some entire skeletons. The most remarkable specimen, freed from the earth which covered it, but still left in its place, was brought from Mentone by M. Rivière and is now to be seen in the Anthropological Gallery of the Paris Museum. 
Such is the accumulation of facts, already very considerable, which M. Hamy and I have consulted in arranging the first part of our Cranica-Ethnica. The importance of the skull in anthropology is well known. It is of itself sufficient to furnish the principal elements of the distinction of human races. The study and comparison of quaternary skulls enables us, therefore, to form a tolerably definite conception of these ancient populations, of the principal relations and most striking differences which, from this period, have distinguished human groups. The examination of the bones of the trunk and limbs tends, moreover, to confirm the results furnished by that of the skull. Thus we feel ourselves justified in expressing the hope that the future, by completing our work in many respects, by modifying it perhaps in others, and by filling up gaps in it, will at least confirm the essential conclusions.

It is evident that I here speak in M. Hamy's name as well as my own. The truth is, that what I am about to say on the subject of fossil man is almost the summary, not only of our book, but of many other general studies and of many discussions. It belongs, in fact, as much to my coadjutor as to myself.

II. Let us, in the first place, briefly describe the climate in which the fossil human races lived.

The quaternary or glacial period imposed severe conditions of existence on man. What then existed of Europe was surrounded on all sides by the sea, and was subject to all the consequences of an insular climate, that is to say, it was very damp, and moderately uniform in temperature, but chilled, to a great extent at least, by the Polar ice which extended even into France. The heavy rains, frequent in all seasons, took the form of falls of snow upon the high lands, and supported vast glaciers, the traces of which may still be seen in all our mountain chains. Immense water-course hollowed out valleys in some parts, and deposited thick beds of alluvium in others. This vexed and watery land supported a fauna comprising, besides existing species, others which 
have partly disappeared, partly emigrated to distant countries. Thus, on the one hand, there were the mammoth (elephas primigenius), the woolly rhinoceros (rhinoceros tichorhinuss), the gigantic Irish elk (meguceros hibernicus), the cave bear (ursus spelceus), the cave hyæna (hycence spelcu), the cave tiger (felis spelcea), the horse (equus caballus); on the other hand, the reindeer (cervus tarandus), the elk (cervus alc's), the musk ox (ovibos moschatus), the aurochs (bison europar.', the hippopotamus (kippopotamus amplitivius), and the lion (felis leo spelcua).

All these animals lived side by side during the greater part of the quaternary period. They afterwards became by degrees either extinct or separated. At the commencement of the present period, France, in which at one time they were all to be found, only retains the horse; and we must admit further, with $\mathrm{M}$. Toussaint, that our beasts of burdec and draught, are descended from fossil species, an opinion which is far from universal amongst palæontologists. We may remark in passing, that the same uncertainty exists upon the subject of the spotted hyæna and the grizzly bear, regarded by some palæontologists as races referable to tho cave species.

Man was, in Europe, the contemporary of all these species.

The phenomena which have given to these countries their latest characters, have not always had the same violence, nor have they either commenced or terminated abruptly. 'They offered periods of repose and of relative activity, till the time when the continents assumed their definite proportions, when the glaciers were first confined within their present limits.

The modifications of living beings accord with these oscillations of the inorganic world. The principal animal species seem to predominate in turn; the human races appear in succession, increase and decline.

During the deposition of the lower alluvium (bas niveaux) of our valleys, the mammoth, rhinoceros, and great carnivora, seem to have played the principal part. Man disputed the 
ground with them, and fed upon their flesh. The struggle against the conditions of life, and the wild beasts of the ancient world was terrible. The race of these primitive times bears in a high degree the mark of this savage nature.

During the period in which the mean inferior alluvium (moyens niveaux inféricur's) were formed, the great animal species still inhabited the whole of Europe. The number of their representatives seems, however, to be diminishing ; less formidable species begin to multiply, and the horse, in particular, forms, at least in places, large herds, which offered an abundant source of nourishment to man. The latter was represented especially by a race endowed with remarkable aptitudes. At first, we find it struggling with as much vigour as the preceding one, and under almost identical conditions; but, by degrees, perfecting all its methods of action, and adapting them to the new conditions introduced by the advance of time.

A great modification in the fauna corresponds to the deposition of the mean upper alluvium (moyens niveaux supérieurs). 'The great carnivora and the manmoth become more and more rare, till at length they disappear altogether; the horse no longer predominates; the reindeer has taken its place, and wanders in vast herds over lands which are gradually subsiding. Man has profited by these changes. New races, perfectly distinct from the preceding ones, appear upon our soil. That of the preceding age develops and attains a certain degree of civilization, attested by true works of art.

At length, the bottom of the ocean rises, and Europe is complete. The polar ice is confined within its present limits, and the insular climate gives place to a continental one, with its extremes of heat and cold. The glaciers of our mountains gradually contract, and withdraw to higher regions. 'The animal species, no longer finding in the same latitude the temperature suitable to them, emigrate, some to the south, others to the north, or to the higher mountains.

Man must necessarily have felt the consequence of these 
changes. When the animals which formed the basis of his nourishment disappeared, never to return, a part at least of the population must have followed, and emigrated at the same time. The rising societies were thus shaken to their very foundations, and whilst some tribes went off in opposite directions, those which remained behind, experienced a decline of which we may observe the traces in the works which they have bequeathed to us. They were but too easily absorbed by superior races, who brought domestic animals with them, and substituted the pastoral life for that of the hunter.

III. The man of the quaternary period has left here and there a few of his bones by the side of those animals who were his contemporaries. The human bones in question belong, however, almost exclusively to Europe. The fossil man of other parts of the world is almost unknown to us. Lund is said to have discovered it in certain caves in Brazil. But unfortunately we have no other details of this discovery than a short note and two drawings of small dimensions, published quite recently by MM. Lacerta and R. Peixoto. Much has been said about the skull discovered by Witney in California. Unfortunately, the description of this specimen has not appeared, so that doubts have, on several occasions, been expressed as to the existence of the fossil itself. The recent testimony of $\mathrm{M}$. Pinart has removed them, but has, at the same time, created the most serious doubts as to the antiquity of this specimen, which seems to have been found in disturbed grounds.

The restriction of the discovery of human fossils to Europe is much to be regretted. We have no authority for regarding Europe as the starting point of the species, nor as the theatre of the formation of the primitive races. We should rather seek them in Asia. It was upon the slopes of the Himalaya, at the base of the great central mass, that Falconer hoped to find tertiary man. Assiduous and persevering search can alone verify the prophecies of the eminent palæontologist. This task might be performed by some of the learned officers 
of the English army, by some of the military surgeons sent out by the great institutions of London. Let us hope that they will set to work; that they will utilize for this end, the leisure they enjoy when on leave in some sanaturium of the IImalayas or Nilgheries. There is every reason to hope that they will enrich science with important and magnificent discoveries.

IV. A few general facts, the interest of which will at once be evident, may already be disentangled from details without leaving European soil. We will first establish the fact, that in quaternary ages, man did not present that uniformity of characters, which a recent origin would lead us to expect. The species is already composed of several races; these races appear successively or simultancously; they live side by side; and perhaps, as M. Dupont has thought, the war of ruces may be traced as far back as this period.

The presence of these clearly characterised human groups. in the quaternary period, is enough to furnish a strong presumption in favour of the previous existence of man. 'The influence of very dissimilar and long-continued actions, can alone explain the differences which separate the man of the Vézère in France from that of the Lesse in Belgium.

V. In spite of some opinions which were brought forward at a time when science was less advanced, and when terms of comparison were wanting, we may assert that no fossil skull belongs to the African or Mclanesian Negro type. Whe true Negro did not exist in Europe during the quaternary epoch.

We do not, however, conclude from this that the type must have come into existence later, and dates from the present geological period. Fresh research, especially in Asia, and in comntries inhabited by black nations, can alone decide this point with certilinty. Nevertheless, up to the present time, the results of observation have been but little favourable to the opinion of some anthropologists, who have regarded the Negro races as anterior to all others.

VI. In fossil, as well as in modern skulls, we find between 
races and individuals oscillations of a more or less striking character. It is, however, an important fact that these oscillations are often of less extent in known fossil races than those observed in existing populations. I shall only quote one example. The cephalic index of the most ancient European race, taken from the Neanderthal man, in which the characters are exaggerated, is 72 ; that of the La Truchère skull, which belongs to the latter part of the quaternary period, is 84.32 , a difference of 12.32 . Now, at the present time, the mean cephalic index of the Esquimaux is 69.30 , that of South Germans 86.20 , a difference of 16.90 . Thus, between the two extreme races separated by the greater part of the glacial period, the oscillation of the cephalic index is less than between two modern contemporary races. Moreover, the latter range between wider limits, both above and below the mean, than the two fossil races. This fact may perhaps be explained by several considerations, which I cannot enter into here.

I should, moreover, observe that the Lagoa Santa skull found by Lund, and which has just been described by MM. Lacerta and Peixoto, effaces in a great measure the differences which I have just pointed out. According to the Brazilian savants, its cephalic index is 6972 , descending almost as low as the mean index of the Esquimaux.

It is interesting to find that this smaller variability of fossil races is established in one of the very characters which has been the principal cause of the comparisons of some of our inferior existing races with apes. Among quaternary skulls there are some which may be considered as presenting the mean degree of orthognathism of the white races themselves. The Nagy-sap skull, the No. 1 of the Trou du frontal, one of the women of Grenelle, etc., may be quoted as examples. Others, such as the No. 2 of the Trou du frontal, another woman of Grenelle, the old man of Cro-Magnon several crania from Solutré, are more or less prognathous. There are some which equal, or even exceed, in this respect the mean of our Negro races. Nevertheless, there are none 
which attain a degree of prognathism equal to that presented by certain examples of the inferior Australian types, or of the Kaffir race.

Another order of facts, which, without possessing the importance of the preceding, are still of real value, present similar results. I allude to the stature and to its variations. M. Hamy has determined it by the measurement of the femur and humerus. It appears from his investigations that the maximum presented by the Mentone skeleton is $1.85 \mathrm{~m}$. (6.06 ft.), and the minimum, taken from one of the Furfooz skeletons, is $1.50 \mathrm{~m}$. (4.92 ft.) The difference between these two numbers, $0.35 \mathrm{~m}$. (1.14 ft.), is far smaller than that which exists between the extremes of the table given above.

The mean of the numbers found by M. Hamy, $1.764 \mathrm{~m}$. (5.839 ft.), places the race of Cro-Magnon very near to the Patagonians of Musters; but the Furfooz race, with its mean of 1.530 m. (5.019 ft.), stands well above the Bosjesmans and Mincopies. It occupies almost the same position as the Lapps.

Oscillations have taken place in time as well as in space. 'The most ancient race is not the tallest. The skeletons of Neanderthal and Brux give a mean of only $1705 \mathrm{~m}$. (5.593 ft.). The race of Cro-Magnon, superior in height to all others, is chronologically intermediate between them.

The preceding generalizations rest, it is true, upon a number of observations as yet too limited to be regarded as conclusive. But they at least confute some assertions, and tend to dissipate more than one prejudice.

VII. Dolichocephalic or brachycephalic, large or small, onthognathous or prognathous, quaternary man is always man in the full acceptance of the word. Whenever the remains have been sufficient to enable us to form an opinion, we have found the foot and the hind which characterised our species, the vertebral column has displayed the double curvature to which Lawrence ascribes such great importance, and which was made by Serres the attribute of the human kingdom, as he understood it. The niore we study the subject, the more are we convinced that every bone of the 
skeleton, from the most massive to the smallest, carries with it, in its form and proportions, a certificate of origin which it is impossible to mistake.

By reason of its special importance, the skull deserves consideration for a moment from this point of view.

We will first state that all the bones of the modern human skull are to be found in the fossil skull under the same forms, and presenting the same relations. Whether we consider them separately or as a whole, they cannot fail to awaken the recollection of what we see around us every day. Even the immense development of the superciliary ridges in the Neanderthal man cannot disguise the entirely human character of this exceptional skull, which I shall presently discuss more at length.

In all fossil races we find the essentially human character of the predominance of the cranium over the face. With them, as with us, the bony framework which contains the brain becomes longer, narrower, or shorter, at the same time increasing in size; it rises or is flattened, but always preserves a capacity comparable to that of the crania of the present day. In the Neanderthal cranium, which has been termed the most brutal known, the cranial capacity, calculated by men who, we may be sure, did not wish to exaggerate, was as much as 1220 cubic centimetres $(74.420$ cub. in.). Even M. Schaaffhausen considers it as equal to that of the Malays, and superior to that of Hindoos of small stature. In the Brazilian skull from Lagoa Santa it is 1388 cubic centimetres ( $84.66 \mathrm{cub}$. in.).

We can, therefore, with perfect safety apply to the fossil man, with which we are acquainted, the words of Huxley: "Neither in quaternary ages nor at the present time does any intermediary being fill the gap which separates man from the Troglodyte. To deny the existence of this gap would be as reprehensible as absurd."

The eminent naturalist who wrote this sentence did no the less seize every occasion which presented itself to point out, in the different human races, what are called simian 
traits and characters. Is there then in Huxley an unfortunate contradiction? Evidently not. It is in his case, as in that of all true naturalists, only an ahuse of language, against which I have already protested. Belonging to tho white race, which they naturally regard as the normal type, confining their attention to the very substantial anatomical similarities which exist between the man and the ape, they compare constantly and solely the white on the one hand, with the anthropoid ape on the other. 'They forget that the oscillutions of morphological characters, the inevitable result of the formation of the human races, must necessarily sometimes increase and sometimes diminish, in however small a degree, the distance which separates the extreme terms; they allow themselves to employ these figurative expressions, and I should let them pass without comment were they not sometimes understood literally, either voluntarily or involuntarily. We know that the English naturalist has himself been obliged to protest strongly against the conclusions which have been drawn from his words or writings.

Huxley allows that the oscillations are never so great as to cause confusion. 'The human character, therefore, does not alter in nature; it does not become simian. 'The oscillations to which I allude may sometimes be observed in the same individual and even in the same bone. In the old man of Cro-Magnon, of whom I shall presently speak at some length, the femur is the broadest and thickest that M. Broca has ever measured in man, and we have found others of still greater size. Now, in the chimpanzee this same bone is broader and much thinner. Are we therefore justified in sarying that the femur of Les Eyzies is partly simian and partly more than human?

Finally, what las really been proved, is the conclusion of Huxley which I have just quoted. Believers in pithecoid man must be content to seek him elsewhere than in the only fossil races with which we are acquainted, and to have recourse to the unknown. There may be some who will 
murmur at this necessity, and protest in the name of plitosophy. Let them say what they will, we are content with having experience and observation on our side.

VIII. If we consider the general formation of the skull, all fossil races may be referred to two fundamental types; the one distinctly dolichocephalic, and the other advancing by degrees from metacephaly to a very strongly marked brachycepbaly.

Animated discussions were held some years ago to decide which of these two types preceded the other. This question again is connected with a number of general ideas which may be designated as the mongoloid theory.

At the conclusion of some cxcavations among ancient tombs and a few dolmens, Serres announced in 1854 that the inhabitants of France reckoned Mongolians among their ancestor's. Some time previous to this, some Scandinavian savants, among others S. Nilson, Retzius, Eschricht, etc., had connected with the Lapps, that is to say with the Finnish race, round-headed skeletons which had been discovered in the neolithic tombs and the peat-bogs of Scania. M. Pruner Bey, combining these carlier notions with the data recently acquired concerning the antiquity of man, has formulated by degrees a complete theory, remarkable for its simplicity and for the light which it throws upon the whole past history of the populations of France.

In the opinion of this eminent anthropologist, there still exists at the present time a vast human formation which he designates mongoloid, because it appears to him to be connected in certain respects with the Mongol type, properly so called, whilst at the same time preserving a certain number of characters in which it resembles the white races. This great race, as it is understood by M. Pruner Bey, occupies the greater portion of the north of the old continent, and extends even into America. It is, moreover, represented in the centre and south of Europe by several more or less isolated groups, such as the Basques. Certain historical populations, such as the Ligurians, have belonged to it. 
'There is every indication of its having once occupied the whole of Europe. Now, this race itself is descended from the primitive quaternary race, as it is known to us through the fossil skulls found by M. Dupont at Furfooz in the valley of the Lesse. The parentage and filiation of these races appear to M. Pruner Bey to be attested by the general form of the skull and by its proportions, which in all these races are more or less brachycephalic.

The opponents of these general views brought forward the cxistence of the cranlia found in the Neanderthal in Prussia, in the Engis cave in Belgium, in the tufa beds of La Denise in Auvergne, in the loess of the Rhine at Eguisheim in Alsace. All these heads are dolichocephalic. They were said to be more ancient than those of Furfooz. But at this time there were doubts of a different nature with regard to nearly all these bones which might have appeared legitimate, and the theory of M. Pruner Bey gained by this means many strong adherents. When writing in 1875 my Rapport sur les progrès de l'Anthropologie, I felt obliged to ascribe anteriority to the brachycephalic type, though at the same time making formal reservations, especially in favour of the Eguisheim skull. The discovery at Cro-Mlagnon, in Perigord, which followed soon after, showed how carefully we must guard against drawing too hasty conclusions. It was evident, that, in presence of these great dolichocephali, incontestably anterior to the men of the Lesse, the mongoloid theory must undergo serious modifications which I did not hesitate to acknowledge.

Since then science has been enriched by new discoveries, and many points have been cleared up. 'The old beds of the Seine, studied with remarkable intelligence by M. Belgrand, have furnished us with a relative chronometer, the indications of which have been fully appreciated by M. Hamy The work presented by him at the Stockholm Congress leaves no room for doubt. Till the present time the dolichocephalic type only has been found in the lowest gravels of the plain of Grenelle. It is therefore represented by the 
Canstadt race. It reappears in the form of the Cro-Magnon race, in the alluvial beds at the level of and below the erratic blocks at a depth of from 3 to $4 \mathrm{~m}$. (10 to $13 \mathrm{ft}$.). Skulls which approach more or less to the brachycephalic type are only found above this level at a depth of from $2.50 \mathrm{~m}$. to $1.40 \mathrm{~m}$. ( $8 \mathrm{ft} .2 \mathrm{in}$. to $4 \mathrm{ft} .7 \mathrm{in}$.).

The superposition, and consequently the succession of types, is here evident. Does this authorise us to consider the dolichocephalic type as having everywhere preceded the brachycephalic? We ought perhaps still to retain some doubts on this point. Some fragments, belonging probably to the latter, have been discovered at Clichy, very little above a cranial vault of the Canstadt race, and the beautiful skull from Nagy-sap in Hungary was obtained from a well characterized loess, the age of which does not however appear to have been determined.

Perhaps, when fresh facts are forthcoming to dispel the latest doubts, we shall find that the two types appeared at almost the same time upon the lands which were one day to become Europe; but at present everything argues in favour of the anteriority of the dolichocephali. In America the only known fossil skull leads to the same conclusion.

However this may be, the mongoloid theory can no longer be accepted as absolute. The man of Cro-Magnon and that of Furfooz cannot be placed in the same group, and considered as belonging to the same race. The idea of M. Prumer Bey is, nevertheless, partly true; and the honour of having connected living with fossil populations cannot be denied to this eminent anthropologist. Still, what he lias said of one race must be applied to the rest. 'The inhabitants of Western Europe are connected with the quaternary period, not by a single root, but by six at least, and perhaps more.

IX. A methodical distribution of the different races of a species is never an easy task. The difficulty is very strongly felt in the study of living human races; it is still greater in dealing with fossil races. Even if the materials were as 
abundant as they are rare, we no longer have the perfect individual, and cannot attempt to apply the naturel method; we are forced to be content with a systematic classification. This is what M. Hamy and I have been obliged to do; and without sharing the absolute opinions which were once adranced by Retzius, we took the general form of the skull as the starting point for our classification. In so doing we have, morever, only imitated palæontologists in their studies upon fossil animals.

We have already seen that considerations drawn from this method lead to a division of fossil man into two groups, the one dolichocephalic, and the other brachycephalic. 'The Lagoa Santa skull, which must from all appearance be the type of a distinct race, is evidently comnected with the former. The accounts of this fossil are, however, at present so incomplete, that I cannot stop to consider it in such a rapid sketch as this.

In these two fundamental groups differences exist side by side with the common character. In the former these differences are very great and strongly marked; they are generally less so in the latter. Thus we have clearly distinguished the two dolichocephalic types, while we have placed in the same chapter, and as it were in a kind of family, part at least of the brachycephalic races.

Sereral objections may be raised against this nomenclature, of which we are well aware. We understood perfectly that the skull of La Truchere is as distinct from those of Furfooz as the Neanderthal skull is from that of CroMagnon. On the one hand, however, this skull is the extreme limit of a graduated series, from which it seemed to us difficult to detach it; on the other, this fossil, at the time when we were writing, was perfectly unique. Even at the present time it has only argain been met with in the neolithic period. 'Thus, in griving it a place in our table, we did not wish to separate in an absolute manner an individual case.

As to the other types which we have placed in the same chapter, they form a true natural group, each at the same 


\section{Dolichocephati and Brachycephati.}

time having its special characters, which by careful study we are able to recognise. The races may, therefore, be clearly defined. The Grenelle race, especially, will always be very distinct from the two Furfooz races. Nevertheless, we here no longer meet with decisive characters which strike us at the first glance, and the ethnical affinities are evidently closer. It will, perhaps, at some future time be possible to trace these three branches to the common source from which they have all sprung. In short, we must represent the present state of our knowledge without interfering with the rights of the future. Our nomenclature satisfies, we believe, this condition.

We admit then two dolichocephalic races, those of Canstadt and of Cro-Magnon. The more or less brachycephatic races are four in number. Under the title of Furfooz races we have included two races discovered in that famous locality. 'The Grenelle race and that of $\mathrm{La}$ Truchère also take their names from that of the localities where they were found.

Let us rapidly review all these races. 


\section{CHAP'TER XXVI.}

THE CANSTADT RACE.

I. Tre name of this race is that of the village near which the first human fossil was found. In 1700, Duke Eberhard Ludwig of Wurtemberg excavated a Roman oppidum in the neighbourhood of Stuttgard. A portion of the cranial vault of a man was discovered in the midst of a number of animal bones. Geology and palæontology were, however, still in their infancy; and the nature of this precious fragment was unknown till Jacger, in $18: 35$, recognised its value as an argument in favour of the coexistence of man with the great extinct mammals. After close study, thanks to the kindness of M. Fraas, M. Hamy and I have been able, without any difficulty, to connect it with the famous Neanderthal skull.

II. The latter was discovered in 1857 in a small cavern near Düsseldorf. The skeleton was perfect. Unfortunately, the workmen who discovered it, broke and dispersed the bones, of which part only were saved by Dr. Fuhlrott. When exhibited the same year at the Congress of Bonn, they became the subject of long continued study and discussion. M. Schaaffhausen, although himself sometimes going beyond the truth, took his position from the first upon the right ground. Some anatomists wished, however, to consider this specimen as a special species, and even a fresh genus. It was especially considered as intermediate between man and apes, and here and there traces may still be found of these opinions.

The only cause of these exagrgerations is a feature, striking it is true, which is presented by this cranial vault. In the Neanderthat man the frontal sinuses have an exceptional 
development, and the superciliary ridges, almost lost in the middle of the glabella, form a most strange protuberance above the orbit. This conformation has not failed to be compared to the bony ridges which the anthropomorphous apes possess in the same place. Then, starting from this fact, it has been thought necessary to find in the rest of the cranium characters in harmony with this simian feature. Stress has been laid upon its slight elevation, the lengthened form, the projection of the occipital region, etc.

With a little partiality, and by only comparing it with modern skulls, which are considered as normal, a separate species of being has been made of the Neanderthal man. - By degrees, however, other crania equally fossil have been connected with this type. Indeed, in several parts of Europe those characters which were too hastily declared to be unique have been observed in dolmens in less ancient burial places, in historical persons, and even in individuals living at the present time. There was, then, no alternative but to conclude that the Neanderthal man belonged to a formation which was unquestionably human, to a race, certain features of which were merely exaggerated in his case.

This race is none the less remarkable and perfectly characterized. In all individuals of the male sex we find a greater or less development of the superciliary prominences, which were so striking in the Neanderthal man. The low and narrow forehead appears still more receding in consequence of this contrast. The cranial vault is much flattened. Tolerably regular in its two anterior thirds, it rises towards the upper portion of the occiput, and is prolonged backwards. The entire skull is relatively narrow, and we have already seen that the cephalic index descends as low as 72. These bones are also remarkable for their thickness, which in the Eguisheim cranium reaches 11 millimetres $(0.43$ in.). Some of these features are modified in the female skull. The superciliary ridges disappear almost entirely. The occipital protuberance, and especially the prominence of its upper portion, are much less marked. The cephalic index 
rises one or two units, but the flattening of the vault and the other characters are persistent.

The Neanderthal cranimm, and all those which may also be connected with the Canstadt type, are incomplete and without the face. One skull alone, the age of which unfortunately is not determined with certainty, enables us to fill up this gap. It is that from Forbes Quarry near Gibraltar. In this case the clinnium, and particularly the forehead, exactly coincide with the description given above of the Neanderthal cranium. Immense and almost circular orbits, the index of which rises almost to 69.83 , well agree with the vestiges in the Neanderthal cranium, and hide by their external border the temporal region. Below, the malar bones descend almost vertically; the nasal bones are prominent; the masal orifices very broad. 'The superior maxillary bone is sensibly prognathous, and lastly the dental arch is of a horse-shoe shape narrowing backwards. The whole is rude and massive. A face recently discovered by M. Piette in the Gourdan grotto, and which will shortly be described by M. Hamy, confirms the connection which we have established between the Forbes Quarry skull and the remains of the Canstadt race. Found in the inferior beds of the cave, among flints of the Moustier type, this specimen reproduces with some modifications the characters which we have just described. The inferior maxillary bone recalls that of Arcy.

If these characters are mited to those presented by the celebrated maxillary bone of Naulette, we must add that the chin in the Canstalt man is but slightly prominent, and that the lower part of the face was sometimes more peculiar, in this respect, than the greater number of the skulls of Negroes from Guinea. 'The researches of M. Hamy have, however, shown that the singular maxillary bone discovered by M. Dupont, was again only the exaggerated realization of a type which is met with elsewhere under considerable modifications.

In short, the cranium ard face of the Canstadt man must, as a rule, have presented a strangely savage aspect. 


\section{The Canstadi Race.}

The body appears to have harmonised with the head. 'The few bones of the limbs, preserved more or less intact, indicate a stature of only $1 \mathrm{~m} .68$ to $1 \mathrm{~m} .72$ (.5t. $6 \mathrm{in}$. , to $5 \mathrm{ft}$. Sin.); yet their proportions are athletic. They are very thick relatively to their length, and the protuberances and depressions serving for muscular attachments are remarkably developed. Moreover, the tibia discovered in a quarry at Clichy by M. Bertrand, presented the flattened form which has been designated platyenemic, and the ribs of the Neanderthal skeleton were sensibly more rounded than is generally the case.

III. As far as we know at present, the Canstadt race is undoubtedly the most ancient European one. It disputed the ground with the great extinct mammals, with the mammoth, the woolly rhinoceros, the cave bear, and the cave hyæna. It belongs, therefore, to the earliest ages of the quaternary epoch. In the opinion of M. Schaaffhausen, it may be traced to an earlier period still, and is identical with tertiary man surviving the latest geological revolution.

The naturalist who has made us so well acquainted with the Neauderthal man, only invokes, in support of his opinion, what he calls the typical inferiority of this man, and of those who are connected with him. This reason would to many be an insufficient motive for the view which he has taken. But I have observed above, that we are justified in assuming that man followed into Europe the great mammals which were driven by the cold into more souther'n countries. There can, then, be nothing strange in the idea that the race, to which everything points as having been the most ancient upon our soil, should also have been the one to accomplish the migration. But were the Saint-Prest, the Monte Aperto, and especially the Thénay men only its pioneers? The future alone can answer this question either in the affirmative or negative.

However this may be, the remains of human industry indicate a well-marked progress since the earliest ages. 'Tools and arms became more numerous and perfect. Deer's 
antlers and bear's jawbones are worked into weapons and tools; in addition to scrapers and borers, the form of which becomes more and more marked, we find knives, chisels, and hammers, set in handles: hatchets of much greater size, sometimes comparatively thin, flat upon one side but retouched upon the other, sometimes thick and rudely cut on both sides, with or without a handle, belong to the. mourtierien and acheuléen types of M. de Mortillet; they assume definite forms by which we are able to recognise several modifications characteristic of certain localities; the arrow is larger and the lance has become a formidable weapon. In the midst of the lowest quaternary alluvial deposits, we meet with small heaps of coscinopora globuluris, and other small chalk fossils, all pierced either naturally or artificially. The only possible explanation is to consider these polypi and shells as having once formed necklaces or bracelets, the thread of which has disappeared. Thus, the taste for adornment, so largely developed in modern savages, was displayed as early as this period.

If we compare the industries, still very modest, with those of the present day, we shall be able to form for ourselves an approximate iden of what the race of Canstadt was when it occupied perhaps nearly the whole of Europe. With M. Lartet we see in the obsidian lances of New Caledonia, the flint heads of the lower alluvium of the Somme; the hatchet of certain Australians reminds us, as it did Sir Charles Lyell, of the Abbeville hatchet. It is with the latter and with the Bosjesmans, that I should be tempted to connect the Neanderthal man and his fellows. Like them, he seems to have most frequently led a wandering life. But few of his dwellings, or places of meeting, are known to us, such as the Naulette cavern. Nothing seems to indicate that he had places of burial such as we find later. Everything tends to show, moreover, that he lived entirely as a hunter, and there is nothing to justify us in supposing that he was acquainted with agriculture, which is carried to such a remarkal,le pitch by certain Melanesian negroes. 
IV. Judging from the geological distribution of the remains which have been met with up to the present time, the Canstadt race during the quaternary period principally occupied the basins of the Seine and the Rhine, and extended perhaps as far as Stängenäs in the Bohuslän; certainly as far as the Olmo in central Italy; as Brux in Bohemia; as the Pyrenees in France, and probably as far as Gibraltar.

This race is not restricted in point of geological time. The attention roused by the strange characters of the Neanderthal cranium was the means of instituting widespread investigations, which have rapidly drawn this specimen from the isolation in which, at first, it seemed to be placed. B. Davis, Busk, Turner, King, Carter Blake, Pruner Bey, Vogt, Huxley and Hamy have been particularly successful in these investigations, and have brought to light relations which are now generally adopted.

The result obtained from all these labours is that the Canstadt type, sometimes remarkably pure, and sometimes again more or less modified by crossings, is found in the dolmens and in the cemeteries of the Gallo-Roman period, in those of the Middle Ages, and in modern tombs from Scandinavia to Spain, from Portugal to Italy, and from Scotland and Ireland to the valley of the Danube, in the Crimea at Minsk, and as far as Orenbourg in Russia. This area of habitation comprises, we see, the entire space of time which has elapsed from the quaternary period to the present day, and the whole of Europe.

The remark has with justice been made by M. Hamy, that there probably exist in India, in the midst of populations driven back by the Aryan invasion, representatives of the Neanderthal type. Nevertheless, to find them with any degree of certainty, we must go as far as Australia. Our investigations have on this point confirmed those of Huxley. Among the races of this great island there is one, distributed particularly in the province of Victoria, in the neighbourhood of Port Western, which reproduces in a remarkable manner the characters of the Canstadt race. 
Finally, the Canstadt race has had representatives in America also. One of the drawings published by MLA. Lacerta and Peixoto leaves no room for doubt on this point. It represents almost the whole of the upper part of a cranial vault found in the province of Ceara, the resemblance of which with that of Eguisheim is very striking. Unfortunately, the Brazilian naturalists say nothing about the situation of this precious fragment at the moment of its discovery, and we do not know whether the cranium in question is a fossil or whether it belongs to the present epoch.

V. All these facts, which I have been obliged to sum up in a few lines, raise an important problem, and lead to an interesting conclusion.

Are we, in the first place, justified in connecting cthnologically the crania of a more or less Neanderthal type, discovered in the Antipodes as well as in Europe, with the races, the remains of which have been preserved by the quaternary alluvium? Is not the reproduction of this type purely accidental? Do not the most ancient crania owe their remarkable characters to some pathological condition, to a simple deviation from the normal development, and particularly to a premature union of the bones of the cranium?

These several opinions have been maintained, and the latter in particular has had adherents. It rests principally upon the condition of the ossified sutures of the Neanderthal cranium. But these same sutures may be observed in the Canstadt cranium. M. Sauvage found in the almost infantine frontal bone of La Denise all the Neanderthal characters, although the medio-frontal suture as yet only existed in part. It is entirely open in the cranium of the young man, discovered in a Poitou tumulus, described by NI. Pruner Bey, and which it is impossible not to connect with the preceding.

Thus we cannot attribute to the premature ossification of the sutures, the form of the crania of the men of Canstadt. For a much stronger reason, the clearly marked characters 


\section{The Canstadt Race.}

of the forehead and face which remain cannot support this theory, and we must allow that the whole constitutes a true ethnical type.

Since we meet with this type disseminated through time and space, always fundamentally the same, and sometimes reappearing in all its primitive purity, we are forced to choose between the two following interpretations; we have here either an example of atavism, the importance of which is attested by its generality: or else the reproduction of these exceptional forms, in the midst of the most varied populations and under the most different conditions of life, is due to mere chance.

The laws which govern the formation and maintenance of animal and vegetable races, and from which man cannot escape, do not allow the admission of the latter conclusion. This is why MI. Hamy and I have regarded the Canstadt race as one of the elements of modern populations. In Europe it has blended with succeeding races, but asserts its past existence by the marks which it impresses, even at the present day, upon some rare individuals. In Australia, perhaps, it has some direct descendints in the tribes of North Western.

VI. 'The epithets brutal and simian, too often applied to the Neanderthal cranium, and to those which resemble it, the conjectures made with regard to the individual to whom they belonged, might lead us to think that a certain morai and intellectual inferiority was naturally connected with this form of cranium. It can easily be shown that this conclusion rests upon a most worthless foundation.

At the Paris Congress, M. Vogt quoted the example of one of his friends, Dr. Emmayer, whose cranium exactly recalls that of Neanderthal, and who is nevertheless a highly distinguished lunacy doctor, In passing through the Copenhagen Huseum, I was struck by the Neanderthal character's presented by one of the crania in the collection; it proved to be that of Kay Lykke, a Danish gentleman, who played some part in the political affairs of the 17th century. M. Godron 
has published the drawing of the skull of Saint Mansuy, Bishop of Toul in the 4th century, and this head even exaggerates some of the most striking features of the Neanderthal cranium. The forehead is still more receding, the vault more depressed, and the head so long that the cephalic index is 69.41. Lastly the skull of Bruce, the Scotch hero, is also a reproduction of the Canstadt type.

In presence of these facts, we must assuredly acknowledge that even the individual whose remains were found in the Neanderthal cave was capable of possessing all the moral and intellectual qualities compatible with his inferior social condition. 


\section{CHAPTER XXVII.}

THE CRO-MAGNON RACE.

I. IN the year 1858 , in the valley of the Vézère, near to the village of Les Eyzies, which had already been rendered famous by the investigations of the elder M. Lartet and Christy, the workmen brought to light in the rock-shelter of Cro-Magnon the bones of three men, a woman and a child, which have been preserved to science by MLI. BertonMeyron and Delmarès. M. Louis Lartet, to whom the study of the deposit had been entrusted, determined their geological age; MM. Broca and Pruner Bey described them with all the precision which we should expect from their knowledge of the subject, and the discussions which arose between these two eminent anthropologists, brought the essential points still more strongly forward. The Cro-Magnon bones thus became classic almost within a day of their discovery; and M. Hamy and I could not do better than group around them the human remains which resemble them. This has been our reason for choosing the name which we have given to our second dolichocephalic race.

Like the preceding one, this also has its typical individual who exaggerates in certain respects the characters of the race, and thus presents an extreme term of comparison. The contrast is only the more striking. The only character common to both the Neanderthal man and the old man of Cro-Magnon lies in the proportions of the cranium. The cephalic index, here $73 \cdot 76$, differs but very slightly, as we see at once from what we have already stated. It descends, moreover, as low as 70.05 in a cranium of the same race found at Solutré; it is 70.52 in the famous Engis 
cranium. It was this elongation from the front backwards which led Schmerling to connect the fossil man which he had just discovered with the Ethiopian rather than with the European. This, at least, partly accounts for the theory which makes the Negro the starting point of our race. II. Hany, in connecting the Engis cranium with the CroIlagnon type, has added one more fact to those which are at variance with this doctrine.

In every other respect the Cro-Nugnon head and that of Canstadt are most dissimilar. Instead of a low and retreatng forehead above superciliary ridges which remind us of the ape, instead of a flattened vault like that of the Neanderthal skull and its companions, we here find a large forehead rising above fiontal sinuses but slightly marked, and a vault presenting the finest proportions. 'The frontal bone is remarkably developed from before backward. 'The frontooccipital curve is continued with a striking regularity till within a short distance above the lambla. It is there bent so as to form a surface which is prolonged upon the cerebral part of the occipital bone. The cerebral region of the same bone is carried abruptly downwed, and presents numerous; strong impressions of muscular insertions.

This skull, so remarkable for its fine proportion, is also remarkalule for its capacity. According to M. Broca, who could only work under precautions calculated to diminish the amount, it is equal to at least 1590 cubic centimetres $(96 \cdot 99$ cubic inches). I have already remarked that this numler is far higher than the mean taken from modern Parisians; it is equally so in comparison with the other European races.

Thus, in the savage of quaternary ages, who had to fight against the mammoth with storie weapons for arms, we find all those craniological characters generally considered as the sign of great intellectual development.

'The features of the face are not less striking than those of the skull. In the heads which M. Pruncr Bey calls harmomic, a face elongated from above dowward corresponds to 


\section{The Cro-Magnon Race.}

a skull elongated from behind forward. When there is a disagreement between these proportions the head is dysharmonic. This latter character is very strongly marked in the old man of Cro-Magnon. The bizygomatic transverse. diameter acquires an extent rare even in harmonic brachycephali. In his case the facial index descends as low as 63 .

This exaggeration in breadth is present also in all the upper and medial parts of the face. The orbits, almost recti-linear at their extremities, are remarkable for their slight elevation, being on the other hand very long. The orbital index descends lower than M. Broca has ever known it to be: it is only 61 .

But this tendency to breadth does not extend to the medial regions or to the inferior portion of the face. 'The nose, the bones of which are boldly projected forward and constitute a strongly marked protuberance, is narrow; from its index, 45.09 , it places the old man of Cro-Magnon amongst the lepthorhini of M. Broca. The superior maxillary bone is equally narrowed relatively to the face which it terminates, and the alveolar arch is projected outward in such a manner as to produce a very decided prognathism. The inferior' maxillary bone is especially remarkable for the breadth of its ascending branches which, according to the investigation of MI. Broca, surpass in this respect all other known human jaw-bones. The breadth in question is $49 \mathrm{~m} . \mathrm{m}$. (1.93 inch). Far from being obliterated and retreating, as in the Canstadt race, the slightly triangular chin projects forwards.

The cephalic character's of the old man of Cro-Magnon are to be found more or less strongly marked in all the men of the same race. They are generally modified in the women. Thus, even in that specimen, the head of which, unfortunately incomplete, was discovered not far from that of the old man, we see the beautiful lines of the skull preserved, and the forehead even rising a little higher still. But the posterior surface is less pronounced, the dysharmony is less strong. between the skull and the face. The latter is relatively longer, the orbits are higher, the nose is broader, and the 
prognathism is modified. We cannot, however, deny the ethnical relation of the two heads which were found together, and which thus constitute definite terms of comparison for the two sexes.

T'he Cro-Magnon race was tall. The mean height deduced from the measurements taken by M. Hamy upon a skeleton and the isolated bones of five men is $178 \mathrm{~m}$. (5 feet 10 inches. With the old man of Cro-Magnon it was about $1.82 \mathrm{~m}$. (5 feet $11 \cdot(j$ inches), and with the Nentone man, whose skeleton was found by M. Rivière entire and in situ, it was as much as $1.85 \mathrm{~m}$. (6 feet 0.8 inches). The Cro-Magnon woman measured $1.66 \mathrm{~m}$. (5 feet 5.3 inches). These bones and all those which have been connected with them, moreover, give indications of a remarkably strong race. They are thick and solid. In all cases the muscular impressions are very strongly marked. In the old man of Cro-Magnon the femurs are also the broadest and thickest that M. Broca lias ever measured, as we have ahready remarked. The linea aspera is also of an unusual breadth and thickness, and forms a sort of prominent column or buttress.

Finally, in the Cro-Magnon men, a fine open forehead, a large, narrow, and aquiline nose, must have compensated for any strangeness which the face may have acquired from the probable smallness of the eyes, from very strong masseters, and from a slightly lozenge-shaped contour. With these features, the type of which is in no way disagreeable, and allows of real beauty, this magnificent race combined a high stature, powerful muscles, and an atluletic constitution. It seems to have been fitted in every way for struggling against the difficulties and perils of savage life.

II. We have already seen that the Cro-Magnon race was discovered immediately above that of Canstadt in the alluvial deposits of Grenelle. It is therefore very old, and was contemporary with the great mammals, now either extinct or emigrated. More sociable, doubtless, and more settled than the preceding race, it inhabited caverns where it left numerous specimens of its handiwork; it buried its dead 


\section{The Troglodytes of the Versire.}

under the shelters where they are now found. A great number of eminent investigators have explored thesc scientific quarries. I cannot enumerate them all here, but there is one name, the omission of which would be unpardonable, that, namely, of Edouard Lartet. It is well known with what persevering intelligence, sometimes alone, sometimes accompanied by his friend Christy, this man, as modest as he is learned, has explored these caves, what treasures he has obtained from them, and the prudence and sagacity which he showed in the interpretation of his splendid discoveries, and only justice was done to him in awarding him the title of founder of human palcontology.

Thanks to him, and to those who have followed in his steps, we possess the essential elements of a history of the Cro-Magnon race. Almost without leaving this valley of the Vézère, the name of which stands so ligh in anthropology, we can, as M. Broca has done, follow it step by step. In fact, from the village of Les Eyzies to the rock-shelter of Moustier, within a distance of from seven to eight miles we meet with no less than eight human settlements, all of which have become more or less celebrated from the different records which they have furnished. 'They are the Moustier' cavern, the Moustier shelter, the shelter of La Madeleine, the Cro-Magnon shelter and burial-place, the Laugerie-Haute shelter, the Laugerie-Basse shelter, the Gorge-d'Enfer cavern, and the Les Eyzies cavern.

The most ancient, that of Moustier, is connected by its fauna with the lower alluvium (bas niveaux) of Grenelle, and dates at least from the close of the age of the bear; that of La Madeleine cannot be placed much before the present epoch. Between these two extremes are ranged the other six, and altogether they mark out, so to speak, the two last periods of the quaternary ages. Yet to obtain a clear idea of the social and intellectual development of the race, to learn how far it complied with the modifications of the climate, and what progress or what decadence these modifications imposed upon it, we must consult the evidences which 
it has left in many other localities, and especially in the cares and shelters of Bruniquel, in the burial-places of Solutré, in the cares of Gourdan, Duruty, and of L'Hommeilort, etc.

The men who frequented the Moustier cavern do not seem to have been much superior to the Canstalt race, with which they were perhaps associated, and whose industries they closely imitated. 'Their conditions of existence were almost. ilentical with those of the preceding age. 'They lived among the great mammals which served them for food. The horse and the aurochs were the general objects of their sport. But they fed upon the mammoth, the bear, and even the lion and the cave hymana 'To meet such enemies as these they employed a species of spear-head and small lance, smooth upon one side, cut upon the other, and sharp at the elges, constituting undoubtedly a formidable weapon. 'I'his special form characterises the Moustier type of M. de Mortillet. The hunters of this epoch cut their arrows upon the same model, but rarely made use of them; they seem to have despised birds and small game; the other impleinents remained almost the same as in the preceding age.

At Cro-Magnon, the progress is evident. Our fine old man and his companions had arms and implements of flint, which were more numerous, more varied and less massive. To judge from the remains of their kitchen, they must have made frequent use of the bow, to obtain birds and small mammals, while they still attacked large animals, and especially the horse, with the lance, spear-head, and perhaps the dagger.

At Laugeric-Haute, on the Vézère, at Solutré, in the Mâcomnais, and other contemporary settlements, the cutting of the flints reached a degree of perfection which was truly marvellous. Sometimes undoubtedly old types reappeared side by side with forms modified by intelligent experience, and by perfected workmanship. Still the predominance of the latter is so marked, that it distinctly characterises this epoch. The points of the lances and javelins are tapered off 
more or less in the shape of a walnut, laurel, or plantain leaf. They are very pointed, and become perfectly symmetrical. The arrow-heads are the object of most particular care. M. de Ferry has very well shown that the general form, the weight, the angle, etc., were calculated in such a manner as to be adapted to the different distances of flight, to the necessities of the chase. All these tools, finely cut upon both sides, present, moreover, a much more remarkable finish than what we mect with in any of the other implements. They were worthy of being taken for one of the terms of comparison admitted by M. de Mortillet, and constitute his Solutré type.

Essentially hunters, and certainly warriors, the men of this period bestowed their chief attention upon their arms. They probably felt a certain pride in possessing the finest or the best cut weapons; but the relative indifference which they betrayed in the matter of other objects, shows us that their chief aim in the finish of their work was to make their weapons more terrible by increasing their power of penetration. Several fragments of bone, discovered in places remote from each other, and belonging to several periods, prove that these weapons of flint, handled by strong hands, left nothing to be desired in this respect. I shall only mention the vertebra of a reindeer, which had been pierced through by a lance or a javelin, and a human tibia, through the head of which an arrow has passed near to the kncepan. In both cases the broken flint has remained, testifying to the good quality of the weapon and to the strength with which it was used.

At the time of the deposition of the upper river gravels, and when the predominance of the reindeer was most marked, the industry of the men of Cro-Magnon uncierwent a sudden change. Till then flint, and, in its absence, other hard stones, had furnished both the implement and the instrument formed by the aid of the former. Doubtless from the earliest times, bones and the antlers of the stag or reindeer, had been used from time to time; but they only played an almost insignificant part in the manufacture of tools or weapons. During the epoch of which we are speaking, they 
acquired a growing importance, and soon furnished almost the only material for weapons. Flint was now only used to make the implements, and these, on the other hand, became more numerous, and fitted for the most raried uses. It was with flints that the troglodytes of Les Eyzies, of LaugerieBasse, of La Nadeleine, and a great number of other settlements, sawed and carved their reindeer antlers to make strong harpoons, which were barbed on one side only. It was with flint that they pointed needles not much longer than our own, and pierced the eye. In some specimens the latter is so small that the piercing of it remained a problem, till Lartet reproduced it with his own hand, using one of the implements which he had discovered. But the most characteristic object of the Magdalenian type is the arrow-head, regularly barbed on both sides, the teeth of which contain little channels, probably intended as the receptacle of some poisonous substance.

The succession of industries which I have just pointed out is, moreover, by no means invariable. As the investigations and discoveries increase in number, we are more and more impressed by the fact that the several colonies of the race under consideration, yielding to local necessities, or carried away by the accidents of their development, do not present an unintelligible uniformity. 'The last excavations carried out at Solutré by MII. Arcelin and the Abbé Ducrost, show arms and instruments of the Magdalénian type which are anterior to those of the Solutré type. In this epoch, as at the present time, there existed a certain dirersity which explains the coincidence, in point of time, of different industrial types among this population of similar origin.

III. The lighter, more turusty, and more varied weapons, announce a change in the life of our troglodytes. They continue, it is true, to, hunt large game when it comes in their way; a few rare mammoths, survining the climatic modifications which were going on, still fell under their hand; the horse also often contributed to their repast. 'The 


\section{The Cro-Magnon Race-Life.}

reindeer, however, largely predominated in the débris of their kitchen. Mixed with them are found the remains of small mammals, such as the hare and the squirrel. Birds also began to be used for food to a considerable extent. From the bones discovered in the single grotto of Gourdan, so admirably explored by M. Piette, M. Alph. Edwards has been able to distinguish twenty distinct species. Lastly, the men of the Magdalénian age fed also upon fish; but fishing again was to them a kind of hunting. They evidently did not use the hook, and only harpooned the larger species, the salmon in Périgord, and the pike in the Pyrenees.

The conveyance of the large animals which fell under their hand to their usual dwelling place, would have been too much even for such stalwart hunters. They cut them up upon the spot, leaving only the skeleton of the trunk. We rarely find in the caves more than the bones of the head and limbs, which, again, are almost always broken. Like all savages, the troglodytes of the Vézère held the brain and marrow in high estimation. The long bones which enclosed the latter have evidently been split in a methodical manner, with a view to preserving the contents. MIM. Lartet and Christy even think that a special implement was employed in eating these delicate morsels. A kind of spatula made, from the antler of a reindeer, with a conical, richly carved handle, hollowed and rounded at the extremity, has been regarded by them as a marrow spoon.

The large amount of ashes and burnt wood found in the Vézère deposits, leaves no room for doubt that fire was used in the cooking of food. The manner in which it was used is, however, rather a difficulty. No trace of pottery has been found among these hunters, and there is nothing to show that they were acquainted with the oven of the Polynesians. They must, therefore, have gone to work hke the Siberians, who, at the close of the last century, had only vessels of leather or of wood, and nevertheless were able to boil the water which they contained by throwing in highly heated flints. 
We have no reason for thinking that the Cro-Magnon man was a cannibal. We find among the rebris of his kitchen, none of those long bones, broken so as to extract the marrow, which could not but have been mixed with those of the large mammals, had human flesh formed eren accidentally part of their repast. Nevertheless M. Piette has found at Courdan several remains of human skulls, bearing the mark of flint knives, and the trace of blows which seem to have broken them. Axes and atlases in great quantity, jaw-bones broken or whole, accompany these fragments of the cranial rault. These facts may justify the opinion of M. Piette. The Gourdan warriors after having killed an enemy, doubtless brought his head home, scalped it, and perhaps mixed the brain in sone lind of pottage, as some of the tribes of the Philippine islands do at the present day. But they did not eat the flesh of the vanquished, whose decapitated corpses were probably left on the field of battle.

IV. Needles, like those which I have mentioned above, would not have been made had there not been something to sew. 'This fact alone suggests the idea of clothes. 'The chase furnished the raw material. The art of preparing skins must have been carried by these tribes as far as it has been by the Red-Skins, to judge from the number of scrapers and smoothers which have been found in their stations. The marks left by flint knives at the poirts where long tendons taken from the limbs of the reindeer were inserted, show how the thread was procured. The clothes, when sewn, must have been ornamented in various ways, as they are by savages of the present diry. Upon the skeleton discovered at Laugerie-Basse by M. Massenat, twenty pierced shells were found placed in pairs upon different parts of the body. 'This was not an instance of either necklace or bracelet, but of ornaments arranged in an almost symmetrical manner upon a garment. 'The skeleton of Mentone, discovered by MI. Rivière, presented a similar appearance.

'Thus the taste for adornment, so striking at the present day in the most savage as also in the civilized nations 


\section{The Cro-Magnon Race-Arts.}

existed in the troglodytic tribes of the quaternary epoch. There are, moreover, numerous proofs of this fact. 'The fiagments of necklaces, bracelets, etc., have been found in a great number of stations. In most cases marine shells, sometimes fossil and obtained from the tertiary beds, formed these ornaments. But the Cro-Magnon man combined with these the teeth of the large carnivora; he cut also with the same intention plates of ivory, certain soft or hard stones, and even made beads of clay which were merely dried in the sun. Finally, he tatooed himself, or at least painted his body with the oxides of iron or manganese, small stores of which have on several occasions been found in different stations, and which have left their mark upon the bones of some skeletons, for example, upon that of Mentone.

V. The Cro-Magnon race has up to this point shown scarcely any superiority over the hunting tribes of America, unless perhaps it is in the dexterity which they displayed in flint cutting. But the artistic instincts which they showed almost from their first appearance, and the point to which they carried drawing and sculpture in the Madeleine age, gives them quite an exceptional position amongst those nations whose evolution has been arrested at the lowest stage of social life. The relative alleviation of climatic conditions, the diminution of large and ferocious animals involving the multiplication of useful species and especially that of the reindeer, placed at this epoch the Cro-Magnon man in conditions of welfare unknown to his predecessors. $\mathrm{He}$ profited by it in developing in a most unexpected manner his very superior talents.

As a general rule the greater number of sculptures representing animals leave, it is true, much to be desired. We can indeed recognise the reindeer represented in high relief; nor would it be difficult to recognise as a mammoth the little carving made from the antler of the reindeer discovered at Montastruc. Nevertheless, these specimens would give but a poor idea of Magdalenean art. The ivory 
dagger handles found by M. Peccadeau de l'Isle by the side of the mammoth fortunately confirm this impression. In both a reindeer is represented crouching, the legs bent, the head stretched out and the antlers lying along the body so as not to inconvenience the hand which should hold it. 'The attitudes are so natural, and the proportions so exact, that a decorative sculptor of the present day, in treating the same subject, could scarcely do better than copy his antique predecessor.

Drawing or rather engraving was much more commonly practised than sculpture. It offers also more points of interest. Armed with their point of flint, the quaternary artists engraved in turn the bone and the antlers of the reindeer, ivory from the mammoth, and stones of different linds. Sometimes they endeavoured to reproduce the plants or animals around them; at other times they followed their own fancy, and made designs of ornamentation, in which we meet with almost all the principles reinvented many centuries afterwards. The multiplicity and the variety of this kind of engraving show much imagination and a real faculty of invention.

The faculty of imitation is equally striking in drawings representing real objects, animals in particular. 'They are often very remarkable for firmness of touch, showing a perfect comprehension of the whole, and reproducing the details with such exactness that we are not only able unerringly to recognise the group but even the species represented by the artist. Thus we have found successively the ox, the aurochs, the horse, the reindeer, the elk, the stag, the steinbock, a cetacean, certain fishes, etc. After these faithful representations, the models of which we know, there is no reason to doubt the exactness with which certain extinct animals have been drawn. This very simple consideration gives great interest to the drawing of the cave bear found by M. Garrigou upon a piece of Massat schist, and to those of the mammoth discovered by $M$. Iartet in the Perigord caves. Thanks to the latter and to 
what we know from the mammoths preserved in ice in Siberia, an artist of the present day might produce in almost exact detail the portrait of this giant of the ancient world, which disappeared so long ago.

VI. Man figures very rarely in these drawings or sculptures, and the representations of our species which have been met with up to the present time, display a relative inferiority which is indeed most strange. The small ivory statue found by M. de Vibraye at Laugerie-Basse scarcely testifies to even the infancy of the art. It is a woman, whose sex we are able to recognise by a detail doubtless exaggerated, but long, stiff and with very strange protuberances at the lower extremity of the loins. The crouching human form foum by M. l'Abbé Landesque in the same locality is still more ill-formed. The drawings of men or women are scarcely better, and the contrast sometimes presented upon the same specimen between them and drawings of animals is most strange. M. l'Abbé Landesque's reindeer woman is grotesque, whilst the hind legs of the animal, which alono have been preserved, present all the qualities which I have noticed above and which may be observed in the splendid horse's head engraved upon the other side of the bone. In M. Massénat's aurochs man, the animal has much beauty both in form and movement; the man is stiff, without proportion or truth.

This contrast is too great and too constant to be accidental. It must be the result of a cause arising perhaps from some superstitious idea similar to certain modern superstitions. When Catlin had finished his first portrait of the Red-Skin, some of the tribe looked upon him as a dangerous sorcerer; who had robbed the model of part of himself. Perhaps some similar idea may have prevented the artists of the Vézère from studying the human figure, for it always happens that when they attempt to reproduce it their graving tool hesitates, and loses all its good qualities.

These imperfect representations, therefore, tell us nothing of the appearance or proportions of the race. The most we can 
say, if we accept the interpretations of M.M. l'Abbé Landesque and Piet,te, is that it was remarkably hairy. But this opinion, which rests chiefly upon the drawing of the reindeer woman, seems to me to be contradicted by that of the aurochs man whose small pointed beard scarcely extends as far as the angle of the jaw-bone. 'The horizontal hatching upon the legs and body cannot, it appears to me, be taken for hairs, because it crosses at right angles the direction which would have been taken by the latter. I should much rather consider them as lines of painting, a kind of decoration which we know to have been held in high estimation amongst these tribes.

VII. However bad they may be, the drawings which I have just described furnish us, nevertheless, with some facts respecting the mode of life pursued by these hunters. That of the aurochs man informs us that they followed the largest game naked, as is often the case with the Red-Skins, their hair raised in a tuft on the top of the head, and armed only with the lance or javelin. The whale man is also naked, and the immense arm which he stretches out as far as the fin of the fish, seems to indicate that he has fought and conquered this monster, which had doubtless run aground in some shallow. But, from this fact alone, it follows that the quaternary man of Périgord must sometimes have left his mountains and travelled as far as the sea-shore. His contemporaries in the Pyrenees did the same, as is proved by the drawings of seals discovered in the grottoes of Gourdan and Duruthy.

Again, those deposits which are situated at the greatest distance inland have often furnished objects which can only have been obtained upon the sea-shore. At Cro-Magnon more than three hundred shells of Littorina littorea, an oceanic species, have been found. On the other hand the Cyproea rufa and C. lurida found upon the Laugerie-Basse skeleton, which I have mentioned above, are unquestionably Mediterranean. Sometimes the molluscs peculiar to the two regions have been found in the same place. In the Gourdan 
grotto, in the middle of the central Pyrenees, M. Piette found five oceanic species, one Mediterranean, and five common to both seas. The fossil shells of the Périgord deposits were generally brought from the falun of Touraine, those of Gourdan must have been collected, partly in the Landes and in the neighbourhood of Dax, and partly near Perpignan. In this same grotto M. Piette discovered a pumice-stone, which had been used in polishing needles, and which he considered had come from the volcanic region of Agde.

From these, and some other analogous facts, M. Piette and M. de Mortillet have thought there is sufficient reason to suppose that the tribes of the Vézère had no fixed habitation, but led a nomad life, visiting in turn the shores of the two seas, hunting in the mountains during the summer the game of the season, and passing the winter in a warmer climate. We cannot adopt this hypothesis. The ever-increasing fauna among the cooking débris denotes a population, which, as it multiplied in every way, made more and more use of the resources of the country. These same heaps furnished Lartet with reindeer bones of every age, amongst which were those of young fawns. Our great authority concludes from this fact that the tribe was stationary during the entire year. and we believe him to be right. The man of Cro-Magnon, La Madeleine and Gourdan, must undoubtedly have always been within reach of the reindeer, from which they obtained nourishment, arms and clothing. But the migrations of this animal, under the influence of a but slightly varying maritime climate, could not have been very extensive, and the troglodytes of Périgord or the Pyrenees, if they wished to keep within its range, would not have had such expeditions to undertake, as those of the Red-Skins in pursuit of the bison.

This semi-stationary life did not exclude travels by land or even by sea. Among the fossil shells found at LaugerieBasse, there are some which could only have come from the Isle of Wight. Now, in the age of the reindeer, there was 
no longer land communication between France and England. As M. Fischer has remarked, the presence of these shells in a continental station proves the existence of navigation.

But, can it really have been the man of the Vézère who went to seek these objects of adornment on the other side of the chamnel? It is difficult to believe that these mountain tribes could have crossed the sea. It is much more likely that this voyage was accomplished by contemporaries, who, by long residence on the sea coast, had developed navigating instincts. They, doubtless, would bring from the English island those shells regarded as precious jewels, which would then pass in exchange from hand to hand, till at length they reached the valleys of Périgord. I'raffic of this kind can alone explain this existence of an oyster-shell from the Red Sea in the 'Thayngen grotto explored by M. C. Mayer, near to Scharffhausen. We know, moreover, that shells of the Pacific Ocean are in our day brought, by a perfectly similar commerce, as far as the tribes of Red-Skins inhabiting the shores of the Atlantic.

VIII. The history of the Cro-Magnon race, founded upon the industrial remains which it has bequeathed to us, still presents many questions answered in various ways by savants of the most different opinions. I shall only point them out cursorily.

Did the quaternary tribes confine themselves to hunting those animal species which are subject to us, and by which they were then surrounded. Did they never domesticate the horse, or the reindeer?

M. 'loussaint has answered the first question in the affirmative, and M. Gervais the second. 'The accumulation, often prodigious, of the bones of these animals is thus explained by all. At Solutré, a kind of bone hollow, formed almost exclusively of the bones of the horse, surrounds, so to speak, the space occupied by hearths and sepultures. It comprises the remains of at least forty thousand horses, amongst which we only occasionally meet with either foals or old animals. The immense majority were killed at the age of from four to 
eight years. This strange accumulation of remains furnished by one species, and the choice of animals in their prime, are, in the opinion of M. Toussaint, inexplicable facts, unless we admit the existence of great herds from which man could draw supplies at will. The arguments brought forward in favour of the domestication of the reindeer are almost of the same nature. M. Piette, however, admits that the latter, long hunted in a wild state, was only domesticated towards the close of the quaternary period. His opinion rests upon the proportion of reindeer bones which increase in number almost suddenly in the upper layers of the Gourdan grotto. M. Piette also draws attention to certain drawings in which reindeer are represented, having upon the neck the appearance of a halter.

To these arguments, which are evidently not devoid of value, it has been objected that man may very well have been able to tame some individuals, without necessarily domesticating the species; that the multiplication and utilisation of certain kinds of game under general and better understood conditions, readily account for the preference accorded to them at certain periods; and that a practised hunter would, without difficulty, choose from among the herd the one he wished to kill. All the facts brought forward by MM. Gervais, Toussaint, and Piette with regard to France, are thus explained without much difficulty. As to countries situated more to the north, the facts obtained by M. Fraas from the grottoes of Suabia, and his philological. researches seem to support the opinions of these savants. It is evident that the problem of the domestication of the horse and the reindeer by quaternary man demands further study, and may assume an entirely local character.

I should say almost the same with regard to social organisition. We cannot doubt but that the tribes of La Madeleine and of Bruniquel recognised chiefs, and that it was for themthose daggers of mammoth ivory were carved, of which $\$$ have spoken above. They were evidently state arms. But was this universally the case? Was there, even amongsi 
these tribes, a true hierarchy, every grade of which was marked by certain insignia? Certain large portions of reindeer antlers, presenting a tolerably uniform appearance, diminished in size by hand, and invariably decorated with special care, have, it has been thought, offered sufficient proof for these facts. In some cases they are whole, in others they are pierced at one extremity with from one to four round holes, which sometimes encroach upon the original drawing. These singular objects are certainly not arms. They have been regarded as commander's bâtons, an interpretation which appears to be plausible. Is it not, however, going rather too far, when the number of holes are regarded as indicating the dignity of the possessor, from which it would follow that these tribes recognised five district grades of chiefs?

Had the quaternary man in question any belief in another life? Had he a religion?

There can be no doubt as to the answer to the first of these questions. The care bestowed upon burial places shows that the hunters of Mentone, as also those of Solutré and Cro-Magnon, believed in the wants of their dead beyond the tomb. Our acquaintance with the customs of so many savage nations of the present epoch forbids any other interpretation of the interment of food, arms, and ornaments with the body.

The difficulty is greater in solving the problem of religion. It is very probable that the man of this age had a belief similar to that which we know to exist among nations leading almost the same kind of life. We can scarcely help regarding a great number of small objects, pierced so as to enable them to be worn round the neck, as amulets, nor doubt that the troglodytes of the Vézère or the Pyrenees attributed to them virtues analogous to those which are even now ascribed to them by many savage tribes. MI. Piette discovered one of these amulets consisting of a plate pierced in the centre, from which diverging lines took their rise; he found a similar emblem repeated three times upon a com- 
mander's bâton. He admits that they are so many representations of the sun, and I very willingly accept this interpretation. But does he not exceed the limits of legitimate induction, when he concludes from this fact that the man of Gourdan worshipped this heavenly body, and invented the Sun God, afterwards discovered by the Egyptians and Gauls.

IX. Finally the race of Cro-Magnon was not wanting in either beauty or intelligence. Taking its intelligence as a whole, it seems to me to present striking points of resenblance with the Algonquin race, as represented by the earliest travellers, and more especially by missionaries who have spent much time amongst these Red-Skins. It had undoubtedly both its good and bad qualities. Scenes of violence took place upon the banks of the Vézère, as is proved by the hatchet-cut in the skull of the Cro-Magnon woman. On the other hand, the burial places of Solutré, though containing many indented male and female heads, seem to show that old age received particular attention, and was, therefore, honoured among these tribes. This race believed in another life; and the contents of tombs upon the banks of the Vézère and the Somme, seem to prove that a happy prairie-land was looked forward to here, as upon the banks of the Mississippi.

The man of Périgord, like the Algonquin, did not rise above the very lowest stage in the social scale; he remained a hunter, at least till towards the close of that age, during which he appeared among the mountains of France. It is, then, an error to employ the term civilization in speaking of this race. Yet he was endowed with an intelligence both pliable and capable of improvement. We have seen that he made progress and changes by himself, a fact, of which no trace is to be observed in his American representative, so that, in this respect, he was undoubtedly his superior. And lastly, his artistic instincts, and the remarkable productions which he has left, gain for lim a special place among the savage races of all times.

$\mathrm{X}$. During all the first part of the reindeer age, the Cro- 
Magnon race supported itself in the state, of which $\mathrm{I}$ have just been pointing out the principal features. But from the commencement of the second half of the same age, during the deposition of the red diluvium and the upper loess, we observe an unmistakable decline, which becomes more and more striking as we proceed. The working of bone and reindeer antlers diminishes and returns to its former rudeness; flint cutting, on the contrary, gains in favour, and in some places, as in the grotto discovered at Saint Martin d'Excideuil by M. Parrot, acquires a most remarkable finish. But this very perfection seems to herald the approach of a new age, and to betray the influence of a strange element.

The fact is, that during this period an amelioration in the general conditions of life was taking place. Europe had at length risen above the waves; a continental climate was succeeding to the maritime climate; the weather was more settled; warm summers followed winters more severe, but less rainy; the glaciers consequently retreated and became confined within their present limits; and consequently again, the fauna became divided. Animals fond of cold, and organised for a mountain life, such as the chamois and bouquetin, were content to emigrate in altitude, and followed the glaciers in their retreat to our highest mountain summits. The reindeer, in no way adapted for climbing, was forced to emigrate in latitude and go further north. Its herds became more and more rare, and at length disappeared from our countries, where, even if domesticated, it could not have continued for long. The human population, who had, doubtless, for centuries lived upon this animal, and obtained from it their clothing, arms, and implements, must have felt the change intensely, losing with the reindeer, what we may call their staff of life.

What happened now? According to M.M. Cartailhac, Forel, and de Mortillet, man disappeared or emigrated with the animal which had become necessary to him, and the valleys of Périgord, Mâconnais, and the Pyrenees became 
uninhabited. They hold that, after the close of the reindeer age, there is an immense space, a great gap, during which the fauna was renewed, and after which a new race of men suddenly made their appearance, who polished stone instead of cutting it, and surrounded themselves with domestic animals.

In spite of the incontestable authority of the savants whom I have just named, their opinion has, I believe, gained but very few partisans, and has been hotly contested. It is indeed possible, and even probable, that a certain number of stations were abandoned diring the period in question, and that the inhabitants moved northwards to seek those conditions of climate and facilities for the chase to which they had been accustomed. But other tribes remained where they were, yielding to the new necessities, adopting the arms and customs of the immigrating populations, and becoming amalgamated with them. I cannot here enter into the geological, zoological and archæological considerations by which this view is justified. I shall confine myself to mentioning some facts which belong especially to anthropology.

M.M. Louis Lartet and Chapelain Duparc discovered near Sorde, in the department of the Basses-Pyrénées, a shelter in the lower bed of which, after methodical excavations, a human skull and bones were found, together with a necklace of the teeth of the lion and bear. Immediately above, and mixed with the latter, was a thick layer of charcoal from which the explorers obtained barbed arrows of the Magdalenean type, and numerous instruments and implements of the same age. Bones of the horse and ox were mixed with these products of human industry. The reindeer was not wanting among this cooking débris, but this species vas more rare than the others. Lastly, above the charcoal, and partly confounded with its upper portion, they discovered a layer which was, so to speak, composed of human bones. The learned explorers here obtained several cut flints similar to the preceding, but they also found a narrow, thin blade, as well as a triangular dagger, which, from its form and the 
nature of the work, is closely connected with the finest productions of the art of polished stone.

The upper burial place contained the remains of more than thirty individuals. These bones have been taken to the museum, and M. Hamy has not hesitated in referring them to the Cro-Magnon race. I had only to confirm this opinion, as there could be no possible ground for doubt. Upon the bones of the limbs as well as upon the skulls, all those characters were observed which have become classic since the great works of MM. Broca and Pruner Bey.

Thus, in this curious grotto at Sorde, we find the superposition of two archceological types, the cut stone (Palæolithic), and the polished stone (Neolithic); but there is only one human race, that of Cro-Magnon. Is it not evident that this race must have known both the latest times of the reindeer age, and the earliest of the present epoch?

Whilst accom modating itself to the new conditions of existence, and accepting the industries of strangers more advanced than its lf, the little tribe of Sorde seems to have preserved intact the purity of its blood. This could not, however, be universally the case, for the invasion must necessarily have occasioned crossing. Here, again, facts fully justify all that is indicated by the theory.

In the cavern of l'Homme-Mort, situated upon a high plateau of the Lozère, and so thoroughly investigated by MM. Broca and Prunières, animal bones of the present epocb alone have been found; there were neither reindeer, nor even horse, ox, or stag. Moreover, the head of a lance or javelin had been worked with a fragment of hatchet in polished stone. We here, then, find curselves in the presence of a population much posterior to the quaternary period, and very probably contemporary with that which raised numerous dolmens in the neighbourhood.

Now, the remains of this population betray in a high degree traces of the Cro-Magnon type, modified partly, perhaps, by the action of new conditions of life, but also by ethnological changes. The stature is sensibly diminished; 
having descended to a mean of $1.62 \mathrm{~m}$. ( $5 \mathrm{ft} .3 \cdot 7 \mathrm{in}$.). The breadth of the upper part of the face is less striking, and the whole head has become almost harmonic. But the dolichocephaly remains; the lines of the skull are almost unaltered, the orbits are always elongated, the nasal orifices narrow, the great majority of the bones of the limbs especially have preserved their very characteristic features. The same grooves are observed in the fibula as at Cro-Magnon; the tibia is platycnemic; in the femur may be observed that extraordinary prominence of the linea aspera which constitutes one of the most curious features of the race; finally, the ulna in every case possesses the sigmoid cavity, the curve so often pointed out as simian. But at the same time we observe a feature as yet foreign to the pure race of Cro-Magnon. The olecranon depression of the humerus is perforated in a number of specimens in as great a proportion as 26 , or, perhaps, 33 per cent. This feature, which we find in other fossil races, is of itself a sufficient indication of crossing, and confirms the inferences which we might have drawn from the diminution in height, modifications of the face, etc.

Similar facts are proved by the two skulls, and the group of bones from Géménos, near Marseille, which were saved from destruction by M. Marion.

Thus, both upon the Lozère and in the neighbourhood of Marseille, the Cro-Magnon race appears in the midst of the polished stone period, but with a mixture of characters which indicates the influence of a fresh element. We come upon it in the upper Cévennes and on the shores of the Mediterranean just at the time when its tribes were beginning to blend with those who had introduced among them the first elements of modern civilization. We cannot be surprised that these simple hunters should have been more or less absorbed by a denser population, who possessed domesticated animals and raised dolmens.

XI. It may, however, be said with equal, and even with greater truth, of the Cro-Magnon as of the Canstadt race, 
that it has not disappeared. It may be traced through intermediate ages, and met with again in certain populations of the present day.

In the neolithic tombs placed close beside the quaternary burial places at Solutré, the old hunters of the horse are represented by their descendants, of whom the more or less modified skulls have been discovered. In the sepulchral grottoes of the Marne, so intelligently and successfully explored by M. J. de Baye, the Cro-Magnon type is found associated with those of four other quaternary races, and with one neolithic race. In Germany, near the Taunus; in Belgium, in the caverns of Hamoir and at Nivelles; in the neighbourhood of Paris, in the recent alluvium of Grenelle; in the clays of the harbour of Boulogne, human remains lating from the same epoch, and belonging to the same race, have been found. M. Piette discovered a Cro-Magnon skeleton in the Aisne, whilst excavating a Gaulish cemetery of the iron age. At Paris even, the excavations of the Hotel Dieu, those of the Boulevard de Port Royal, etc., have brought to light skulls of the same race, of probably as late a date as the fifth century, and there are some more recent still. Modern specimens will most certainly be found. I have myself twice observed in women features which could only accord with the cranial and facial bones of the race under discussion. In one of them, the dysharmony between the face and skull was at least quite as striking as in the old man of CroMagnon: the eye depressed beneath the orbital vault had the same heavy appearance; the nose was straight rather than arched, the lips somewhat thick, the maxillary bones strongly developed, the complexion very brown, the hair very dark and growing low on the forehead. A thick-waisted figure, slightly developed breasts, hands and feet relatively small, served to form a whole, which, without being attractive, was in no way repulsive.

The labours of M. Hamy have extended and enlarged this field of research. He has again met with the type in question amongst the Zaraus collection of Basque skulls, 
collected by MM. Broca and Vélasco; lie has followed it even into Africa in the megalithic tombs explored principally by General Faidherbe, and to the Kabyles of the BeniMasser and the Djurjura. It is, however, chiefly in the Canary Islands, in the coliection of the Barranco-Hundo of Teneriffe, that he has met with skulls, the ethnical relation of which with the old man of Cro-Magnon is beyond discussion. On the other hand, some points of comparison, unfortunately very few in number, have led him to regard the Dalecarlians as connected with the same stock.

XII. However strange these results may appear, they are only a repetition in the human race of what has already been proved in the case of animals. It is now a long time since Lartet showed that at the close of the quaternary age, and as the species peculiar to this age were finally disappearing, the survivors were divided into three groups. Some remained where they were, others migrated to the north, and others again to the south. Perhaps the latter were only persistent in Africa, from whence they had despatched their representatives to us, and where we meet with them still, whilst their colonies, which were at one time in a flourishing condition in France, perished under the influence of the winters of the present period. Finally, as an explanation is given of the ancient fauna, and the cause which brought about their separation, we cannot be surprised to find human populations presenting analogous facts.

During the quaternary period, the race of Cro-Magnon had its principal European centre of population in the south-west of France. The little basin of the Vézère was, so to speak, its capital ; its colonies spread into Italy, the north of France, the valley of the Meuse, etc., where they encountered other races, to whom our attention will snon be turned. But they themselves were perhaps only a branch of an African population, which had emigrated to France with the hyæna, the lion, the hippopotamus, etc. In this case, there is no difficulty in explaining its existence at the present, day in the north-west of Africa, and in islands where it would be pro- 
tected from crossing. Some of its tribes, carried away in the pursuit of the reindeer, will have preserved, in the Scandinavian Alps, the tall form, black hair, and brown complexion which distinguishes Dalecarlians of the neighbouring populations; others, mixing with all the races by which France has been successively invaded, only betray their ancient existence by the phenomena of atarism, which lays upon some individuals the mark of the old hunters of Périgord. 


\section{CHAPTER XXVIII.}

\section{RACES OF FURFOOZ.}

I. Is giving the name of a locality justly celebrated in anthropology to this group of races, and in applying it especially to the two first, M. Hamy and I have been chiefly actuated by the desire to honour the long and conscientious labours, which have led to the discovery of quaternary man in Belgium. It is scarcely necessary to remind my readers that it is due, after Schmerling, to $\mathrm{M}$. Dupont, who during seven years, from 1864 to 1871, has excavated more than sixty caverns or rock-shelters, from which he has obtained, independently of his human fossils, about forty thousand animal bones and eighty thousand stones cut by the hand of man. The race of Grenelle was discovered by M. Emile Martin, in 1867, in the gravel pits opened in the neighbourhood of Paris, and afterwards characterised by M. Hamy. The race of La Truchère was found by M. Legrand de Mercey in a bank of the Seille, near to the locality of which it bears the name.

II. Considered from the point of view of the general form of the skull, these four types arrange themselves in an almost regular manner. The cephalic index $79 \cdot 31$ places the first Furfooz race among mesaticephali; the second Eurfooz race becomes sub-brachycephalic by its index $81: 39$; that of Grenelle, whose index rises to 83.53 in the man, and 83.68 in the woman, approaches very nearly to brachycephaly properly so calied. This is also the case with that of La Truchère, the index of which is $54: 32$.

Let us at once proceed to consider this latter, which, at present represented in quaternary times only by a head, is, 
on that account alone, far less interesting than its comnanions. The skull and face are here remarkable for a dysharmony as striking as that of the Cro-Magnon head; but the contrast is inverse. The skull, in this case, is broad and short, while the face is long. The face view of the former presents a very marked pentagonal appearance. The bones are all strongly developed in the transverse direction, with the exception of the inferior half of the coronal which slants rapidly inward so as to form a narrow forehead. The whole face is relatively small and narrow. The nose is very large and long; the massive cheek bones are slightly prominent, and the superior maxillary bones are slightly prognathous.

The two races of Furfooz, like that of Grenelle, have a certain family resemblance, which does not exclude the existence of distinctive characters. Thus, in the mesaticephalic race of Furfooz the antero-posterior arc of the sliull produces above the small but well marked superciliary ridges, a very retreating forehead, and is continued with no further inflexion than a slight depression at the sutures. The face is broad and the index almost the same as that of the race of Cro-Magnon. On account of the shortening of the skull, the head is, however, hammonic, instead of being dysharmonic as in the troglodytes of Périgord. A is lightly concave, but sufficiently prominent nose, square orbits, slightly marked canine fossæ, and an almost orthognathous superior maxillary bone complete this face, the bony framework of which has a somewhat finely cut and delicate appearance.

In this sub-brachycephalic race of the same locality, the forehead rises in a somewhat perpendicular line to the level of the frontal eminences. The are then becomes suddenly fiattened as far as the first third of the parietal bones where the curve becomes more inflected and is continued with almost unbroken regularity to the foramen magnum of the occipital. We meet with almost the same index in the face; but the orbits and the face are longer, the camine 


\section{Races of La Truchere and of Grenelle.}

fossæ form deep indentations, the superior maxillary bone projects forward, the teeth follow the same direction, and the prognathism is very striking.

In the race of Grenelle, the very prominent glabella and ful! superciliary ridges give a slightly oblique direction to the base of the forehead. But the arc soon rises and is regularly developed without either projection or depression. The skull, viewed from the face, appears as well proportioned as in profile. The face harmonises with it. The cheek bones are well developed and prominent; the canine fossæ high, but not deep; the orbits approach the square form; the bones of the nose are concave and sufficiently prominent. Finally, the maxillary bone and the teeth are equally prognathous, but less so than in the preceding race.

III. The men of Grenelle, and still more those of Furfooz, were of small stature. The former reached a mean of $1.62 \mathrm{~m}$. (5ft. $3.5 \mathrm{in}$.), but the latter descended to $1.53 \mathrm{~m}$. (5ft. $0.2 \mathrm{in}$.) This is almost exactly the mean height of the Lapps. Yet this reduced stature would neither exclude the vigour nor the agility necessary to savage populations. The bones of the limbs and trunk are strong, and the eminences and depressions of their surface indicate a very marked muscular development.

With the exception of this general appearance of strength superior to that which is generally met with, the skeleton of the men of Furfooz and Grenelle strongly resembles that of men of the present day. The tibia in particular assumes the prismatic triangular form which we are accustomed to observe in them. We remark, nevertheless, the appearance of a character which we have as yet only noticed in the cavern of l'Homme-Mort, where we considered it to be a sign of crossing. The olecranon depression is often perforated in the races now under discussion. In Belgium M. Dupont found this disposition to exist in the men of the Lesse in the proportion of 30 per cent. M. Hamy carries it to 28 per cent. in the fossil man of Grenelle, and to $4.66 \mathrm{per}$ cent. only in the French of the present day. 
IV. The races of Furfooz, coming after those whose history we have just sketched, must have come in contact, and sometimes have formed connections with them. 'The clearest demonstration of this fact is at Solutré, where, side by side with Cro-Mlagnon skulls, two heads were found belonging to the race of Grenelle. Intellectual and social development must have progressed almost equally among men united into a singte tribe.

Our brachycephali have, however, had their special centres of population where we can examine them in their home. The researches of MI. Dupont have been chiefly devoted to Belgium and the valley of the Lesse. To give an idea of what the men of Furfooz were, we need do no more than reproduce an abridged account of all that the learned explorer of these caverns has said upon the subject.

V. The men of the Lesse, like those of the Vézère, inlrabited caverns. One of their complete stations comprised the grotto where they lived, and a funeral grotto. MI. Dupont found them almost in juxta-position at Furfooz, where the 'Trou des Nutons presented all the characters of a human habitation, and the Trou du Frontal those of a place of sepulture. 'These two localities alone would have furnished many materials for the history of these ancient populations. Nevertheless the Trou de Chaleux excels them in this respect. It was long inhabited by man, who left there a considerable accumulation of that refuse which is now turned to such good account by science. The roof one day fell in; the inhabitants escaped, leaving all that was buried in their dwelling. Thus, when this heap of rubbish came to be disturbed by the pick-axe, all was found just as it had been left at the moment of the catastrophe, and it is with good reason that the Grotto of Chaleux has been called a little quaternary Pompeii.

The man of Chaleux chiefly employed flint and reindeer liorn to supply his several wants. The former was used for the greater number of his stock of implements; but he gave himself little trouble in varying or perfecting the form. 


\section{Races of Furfooz.}

Narrow, elongated blades cut with a single blow upon one side, with two or three upon the opposite face, and what are called knives, seem to be the model from which all the implements are worked. Notched upon one edgre they became saws; rounded and recut at one extremity they were transformed into scrapers, well adapted for scraping and taking the hair off skins; tapered and chipped to a point, they furnished bodkins, piercers, etc. As for reindeer horn, it was divided into pieces from 10 to 15 centimetres (3.9-5.9 inches) long, and then shaped so as to serve for lances or javelins. They may possibly have sometimes received a point of flint. But M. Dupont assures us that there are no grounds for supposing that the bow and arrow were in use among these troglodytes.

The arms of the tribe of Chaleux, were then much inferior to those of the Vézère or of Solutré. It still, however, hunted large game, and knew also how to obtain the small. Its ancient dwelling-place has furnished the remains of numerous horses, several oxen, some reindeer, sixteen foxes, five wild boars, three chamois, three auruchs, one brown bear, one Saïga antelope, etc.

The bones also of the hare, squirrel, water-rat and Norwegian rat, have been found here; the remains of several birds, amongst others those of the ptarmigan; and remains of fresh water fish. The fauna of the Trou des Nutons is almost identical, but the proportion of species is sometimes inverted. A much smaller number of horses and much greater number of wild boars have been discovered there. Here again, as in the stations of the Cro-Magnon race, the larger species are scarcely represented by more than the bones of the head and limbs, all those containing marrow having been carefully broken up.

Like the preceding race, that of Furfooz made use of the skins of slain animals for clothing. This is proved by the bone needles found at Chaleux. But they are here much ruder in form than those of La Madeleine and other similar stations. Short and thick, they might be taken for 
small bodkins were it not for the eye with which they are pierced.

VI. The Belgian troglodytes were, from many points of view, far behind those of P'erigord and Mâconnais. The monuments of their industry are much inferior to all that we have seen amongst their predecessors, and they show no indication of the artistic aptitudes so remarkable in the man of the Vézère. They surpass him however, in one essential point; they had invented, or received from elsewhere, the art of manufacturing a rude kind of pottery, of which M. Dupont has found the remains in all the stations which he has explored, and obtained in the Trou du Frontal fragments in sufficient number to restore the vase of which they had once formed part.

'This, and some other facts, which it would take ton lons to discuss here, have led some of the most competent savants, amongst others MLM. Cartailhac and Cazalis de Fondouce, to regard the Trou du Frontal and the other contemporary stations as belonging to the neolithic stone period, and not to the quaternary epoch.

But the character of the fauna discovered in the grottoes of Chaleux and Furfooz makes it impossible in our opinion to accept this opinion, which rests chiefly upon archæological considerations. To refer the arge of polished stone to an epoch when the chamois, bouquetin, and Saigga antelope lived in Belgium with the Norwegian rat and the ptarmigan, would be making it very distant. This question may perhaps call for further study; but the juxtaposition of these species in the neighbourhood of Dinant is, in our opinion, a proof that the quaternary period had not then drawn to a close.

VII. The troglodytes of Belgium painted the face and perhaps the body, like those of Périgord. The ornaments in use at Chaleux and Furfooz were almost the same as those which we have found in the south of France. We never, however, find amongst them any object borrowed from marine fauna. This is a curious fact, as the man of the Lesse journeyed in search of his jeuvels, as well as of the 


\section{Races of Frurfooz.}

rough material for his implements and arms much greate: distances than that which separated him from the sea.

In fact, the principal ornaments of the men of the Lesse were fossil shells. Some, it is true, were obtained from the Devonian rocks in their vicinity; but the greater part came from a considerable distance, chiefly from Champagne and from Grignon near Versailles. The flints, which our troglodytes used in such great numbers, were obtained, not from Hainault or the province of Liége, but almost entirely from Champagne. There are some even which could only have been collected in Touraine, on the banks of the Loire. Judging from the localities of these different objects, we might conclude that the known world of the troglodytes of the Lesse scarcely extended in a northerly direction for $1:$ to 2.5 miles, whilst to the south it stretched to a distance of 250 to 300 miles.

There is something very strange in this fact, of which, however, M. Dupont seems to have given what is, at least, a very plausible explanation. He holds that two populations, perhaps two races, were placed in juxtaposition in the countries in question during the quaternary period. There must have existed between them one of those many instances of, we may say, instinctive hatred similar to that which prevails between the Red-Skins and the Esquimaux. Encircled on the north and the east by their enemies, who occupied Hainault, the aborigines of the Lesse could only extend towards the south, and, through the Ardennes, communicate with the basins of the Seine and the Loire.

But did they themselves undertake the long and difficult juurneys, by which alone they could procure the shells which they used for ornaments, and the immense quantity of flint which they worked in their caverns? We do not hesitate to assert with M. Dupont that nothing is less probable. Everything, on the contrary, proves that they obtained their supplies by means of a veritable commerce, organised in a regular manner and upon a large scale; whether by the existence of populations devoted to this form of industry, of which there 
are several examples known to us in the present day; or by the shells and flints passing from hand to hand through successive exchanges, and reaching at length the banks of the Lesse. We cannot explain in any other way the abundance of foreign flints at Chaleux, Furfooz, etc., the prodigality with which they were used, and the evident carclessness displayed in the preservation of tools which had been manufactured from them.

VIII. In direct opposition to the men of Cro-Magnon, those of Furfooz appear to have been eminently pacific. II. Dupont has not discovered either in their grottoes or burialplaces any warlike arms, and he applies to them Ross's remarks upon the Esquimaux of Baffin's Bay, who did not understand what was meant by war.

In the sepulchral grotto of Le Frontal, where the tribe of Les Nutons buried their dead, a number of objects have been found, as at Cro-Magnon, proving the existence of a belief in another life. They consisted of a number of perforated shells, ornaments in spar, flat pieces of sandstone traced with sketches, the vase which we have mentioned above, and some selected flint implements. All these objects are, moreover, of the same nature as those in the Trou des Nutons. It is clear that they had been laid in the sepulchral vault under the impression that they would serve to supply the wants of the deceased in the new existence which was opening before them.

Another fact, upon which M. Dupont has with justice insisted, adds to the probability arising from various considerations, of our being right in attributing to these quaternary men a kind of religion more or less analogous to Fetishism. In the Trou de Chaleux, a mammoth's ulna was placed by the side of a hearth upon a slab of sandstone. Now the mammoth no longer existed in Belgium at the close of the age of the reindeer, and this bone must have been found in the alluvium of the preceding age. It had doubtless been the cause of an error which may be observed even at the present day, and had been looked upon as having belonged 
to a giant. The place of honour which was allotted to it in the dwelling of the troglodytes seems to intimate that it had become an object of veneration.

IX. Very few remains of the two races of Furfooz and that of Grenelle, have been discovered in other quaternary deposits than those which have just been mentioned. The former are, however, represented in the basins of the Somme and the Aude; the latter has been met with at two or three points in the basin of the Seine. We have seen that it existed at Solutré, and the skull of Nagy-Sap in Hungary must probably be referred to it. These facts are sufficient to show that since the glacial epoch the races in question have occupied an extensive area.

In the neolithic age, we find the mesaticephali of Furfooz extending from the Var and Hérault to Gibraltar; the subbrachycephali are represented from Verdun to Boulogne-surmer, and to Camp-Long from Saint-Césaire ; they intermingled with the ancient inhabitants of Cabeço d'Arruda in Portugal.

The brachycephalic race of Grenelle, has, however, left the most distinct traces. It has been discovered in France in several dolmens, and in the Round Barrows in England. In Denmark it constitutes the brachycephalic type of Eschricht, and in Sweden forms a dozen of the total number of the skulls found in dolmens by Retzius and his successors.

The intervention of these different races in the formation of existing races is equally evident. The exact demonstration of the fact is, however, often difficult. The crossing which took place between groups placed in such close contact with each other, more or less confused the types. Other brachycephalic types, amongst others the Celtic race, such as it has been described by M. Broca, came to add to the confusion. Nevertheless, when visiting the valley of the Lesse, several members of the Congress of prehistoric Anthropology recognised skulls and faces as bearing in the clearest manner, the distinctive marks of the local fossil races, and these traces are still more frequent in the rural population which supplies the markets of Antwerp. 
It is the race of Grenelle, again, which reappears most persistently in living populations. The numerous Parisian skulls in the Paris Museum present several examples of this fact. The type is, however, very rarely found pure, a fact, which is probably the result of two causes. On the one hand, the new conditions of existence imposed upon the quaternary races by change of climate, must have caused an alteration in some of their characteristics. On the other hand, fresh elements, differing but slightly from the fossil element, have been blended with it. If the skulls of Grenelle are compared, as they have been by M. Hamy, with Lapp skulls, we find that from the extent of the horizontal arc, from the length of the antero-posterior and transverse diameters, and from the cephalic indices, the former must be placed almost exactly half-way between the two great known orders of Lapp skulls. We observe indeed, certain differences between them. For example, the cranial vault is more flattened in the Lapp than in the man of Grenelle; but, on the whole, the analogies are far greater in number than the differences.

The elder Retzius, Sven Nilsson, Eschricht, and others, had already recognised, by means of their investigations of the ancieut burials of their country, the great extension of an ancient brachycephalic race, which they identified with the true Lapps. MI. Schaafhausen, at the last Stockholm Congress, brought forward another example in support of this opinion.

After considering these facts, M. Hamy and I have been led to admit a Lapp-like type, to which, with the race of Grenelle, a great number of populations scattered through time, and extending over nearly the whole of Europe, may be referred. In the Dauphiné Alps particularly, this type is represented in an almost pure state. A curious collection of skulls in the possession of M. Hoël leaves no room for doubt on this point. We have then confirmed, while giving it greater precision and tracing it to an earlier period, one of those general views, for which anthropology owes so much to the Scandinavian savants. 
$\mathrm{X}$. Thus, the races of Furfooz and that of Grenelle, the last to appear in the quaternary epoch, came in contact during the glacial ages with the dolichocephalic races which had preceded them. In certain respects they have become amalgamated with them; in others, they have preserved their autonomy; and they have shared the same fate. 'They also experienced that change of soil and climate, which we have seen causing such trouble to the rising societies of the Cro-Magnon race; they also witnessed a gradual change in the conditions of existence; and the results of these changes have affected them in the manner which we have already pointed out.

A certain number of tribes spread northwards, following the reindeer and other animal species which they had been accustomed to regard as necessary to their existence; they emigrated in latitude. Others from the same motive emigrated in altitude, accompanying the chamois and bouquetin into the mountain chains, which had been liberated by the melting of glaciers. Others, again, remained stationary. The two first groups were free for a much longer time from the influence of ethnical mixture. The tribes composing the third soon found themselves in the presence of brachycephalic and dolichocephalic immigrants of the polished stone period, and were easily subjugated and absorbed by them.

XI. On their arrival in Europe, the men of the polished stone period did not meet only with those races which we have been discussing. They came in contact with all the quaternary races. This is proved by many of the facts already mentioned; and is proved merely by the magnificent collection of skulls and skeletons collected by M. de Baye from the sepulchral grottoes of the Marne. With the exception of the Canstadt type, all those which we have just described seem to have met together in this remarkable locality. Even that of La Truchère is represented by a head almost as strongly characterised as that of the Seille. The foundation of this neolithic population still belonged, however, to a newly arrived type. It is scarcely 
necessary to add that, whether old or recent, all these races have intermingled, and that the crossing is betrayed sometimes by the fusion, and sometimes by the juxta-position, of characteristics.

Either by infiltration or conquest, new races mingled with the preceding, before even the arrival of the Aryans. The latter spread to the western extremities of the continent, leaving extensive regions on the north and the south, where their predecessors continued to exist. 'Then followed historic invasions. It is from the mixture of all these elements brought together by war, and fused by the experiences of peace, that our European societies have been formed.

XII. Man has been the sole essential agrent in the formation of fresh ethnical groupings. From the earliest times of the polished stone period, land and climate have remained unaltered in our western world. European man has then been at liberty to obey the laws of his evolution, to found, modify, or destroy his associations and his societies, to traverse the ages of bronze and iron as well as historic times, without having to battle with those invincible forces, which perhaps arrested the development of the hunters of CroMagnon.

In what degree does the anthropological past of the rest of the world resemble that of Europe? Science vill some day, undoubtedly, answer this question, but we could now only form conjectures. It is wiser to abstain, content witls having deciphered in less than half a century, almost a whole chapter of that prehistoric and palæeontological history of man, the existence of which was nut even suspected by our sathers. 


\section{BOOK IX.}

PRESENT HUMAN RACES.-PHYSICAL CHARACTERS.

\section{CHAPTER XXIX.}

GENERAL OBSERVATIONS.-EXTERNAL CHARACTERS.

I. I CONSIDERED that I ought to give a somewhat detailed account of our knowledge of fossil human races. The interest and novelty of the subject induced me to do so, and its moderate extent rendered it possible. But I cannot trea,t the history of present races in the same manner. If I wished to study them singly, I could scarcely devote more than a few lines to each. Even if I grouped them into families, I should only be able to give an incomplete and vague account of them, unless I went much beyond the limits of this work.

It seemed to me then preferable to adopt the practice of botanists and zoologists, who always begin with a general account of the nature and significance of the characters of the group which they wish to discuss. These notions, when affecting the whole group, are moreover always necessary. They alone allow us to grasp and comprehend certain general results. They become still more indispensable, when races derived from one and the same species are under discussion, because they bring forward and render evident the unity of specific origin of these races, just as much as direct proofs.

II. If we were familiar with primitive man, we should regard as characterising races, everything which separates them from this type. From want of this natural term of 
comparison, we have taken the European Wlite as normal, and compared the remaining human groups with him. 'This leads to a tendency, which must be pointed out at once.

Influenced by certain habits of thought, and by a self-love of race which is easily explained, many anthropologists have thought that they could interpret the physical differences which distinguish men from one another, and consider simple characteristic features as marks of inferiority or superiority. Because the European has a short heel, and some Negroes have a long one, they have wished to consider the latter as a mark of degradation. The remarks which were made upon this subject, with so much justice, by Desmoulins with reference to the Bosjesmans were forgrotten. Because the greater number of civilizations have risen among dolichocephalic nations, a head elongated from before backwards has been regarded as a superior form. It was forgotten that the Negroes and the Esquimaux are generally dolichocephali of the most pronounced type, and that European brachycephali are in every case the equals of their dolichocephalic brethren.

All analogous interpretations are absolutely arbitrary. In fact, superiority between human groups depends essentially upon intellectual and social development; it passes from one to another. The Chinese and Egyptians were already civilized, when all Europeans were true savages. If the latter had judged our ancestors as we too frequently judge foreign races, they would have found many signs of inferiority in them, commencing with the white skin of which we are so proud, and which they would have been able to regard as betraying an irremediable degeneration.

Is the fundamental superiority of one race really betrayed outwardly by some material sign? We are still in ignorance upon this point. But when we examine it more closely, we are led to think that it is not so. In expressing myself thus, I know that I am separating myself from the opinions which are generally admitted, and am at variance with men whose works I value most highly. But I hope to give decisive proofs in my favour further on. 
Differences of every kind nevertheless exist between one human group and another. 'These must be taken for what they are, for character's of race, for ethnical characters. It is the duty of the anthropologist especially to recognise these differences, to make use of them for defining the groups, then to connect or separate, according to their affinities, the races thus characterised. In other terms, his work is the same as that of the botanist or geologist describing and classifying plants and animals.

Men of an impatient or venturous disposition will perhaps reproach me with making anthropology too descriptive. I shall only make a partial defence against the accusation. Provided that the description embraces the entire being, it enables us to become acquainted with it. If we take our stand on this point of view, we remain on the ground of positive knowledge, and run less risk of losing ourselves in hypotheses.

I still consider it the right and almost the duty of the anthropologist, to investigate the causes which may have given rise to the appearance of the features which characterise races. The study of the actions of the conditions of life sometimes gives valuable indications on this subject. The evolution of the human being from his appearance in the embryonic state to the adult state, especially furnishes facts of great interest. A simple arrest, a slight excess in the evolutive phenomena, are, it appears to me, the causes of the principal differences which separate races, and particularly the two extremes, the Negro and the White.

I know full well that a wish has been felt to go further back. Under the more or less perceptible influence of transmutationist doctrines, terms of comparison in the estimation of these differences have too often been sought for among animals, and especially among apes. Eminent men, without even adopting these doctrines, frequently use the expressions, simian character, animal character. Why forget the embryo or the human foetus? Why not remember even the infant? Question their history. It furnishes all the elements of a human evolution theory, certainly much more precise 
and true than the simian theory. This is again a result which will be made clear, I hope, by the facts which I shall have to mention.

But whether or not I may be able to explain the appearance of the features which distinguish races from each other, and whatever origin may be attributed to them, I shall only take the word churacter in the sense which is given to it in botany and zoology.

III. An animal species is not characterised solely by the peculiarities manifested by its physical organism. No history of bees or ants omits to speak of their instincts, or to show how these differ in different species. With much stronger reason ought we to point out in the history of human races the characteristic points in their intellectual, moral, and religious manifestations. Of course, when approaching this order of facts, the anthropologist ought none the less to remain exclusively a naturalist.

This very simple consideration is sufficient to determine the relative value which ought to be attributed in anthropology to characters of different orders. Here, as in botany and in zoology, the first place ought to be given to the most persistent characters. Now, a man, tribe, or an entire population can in a certain number of years change its social state, its language, religion, etc. They do not on that account modify their external or anatomical physical characters. It is therefore to the latter that the anthropologist will attach most importance, contrary to what the linguist, the philosopher, or the theologian would certainly do.

Nevertheless we shall see that, in, some very rare cases, the linguistic characters preponderate over the physical characters, in the sense that they furnish more striking indications on the subject of certain ethnical affinities. Considered from a physical point of view, man exhibits characters which may be divided into four distinct categorjes, namely: external characters, anatomical characters, physiological characters, and pathological characters.

IV. Exterial characters. - Height. All breeders regard 
height as characteristic of race among animals. It is also one of the traits which are most striking in man. This character sometimes shows that it is very evidently dependent upon the conditions of existence. Sheltering and feeding somewhat carefully the mares of La Camargue, has been sufficient to raise the height of this excellent breed of horses. With man, M. Durand (de Gros), confirming an observation already due to Ed. Lartet, has shown that, in the Aveyron, the populations of the limestone cantons are sensibly taller than those of the granite or schistose cantons. He agreed with the statement of Dr. Albespy, that liming lands in the non-calcareous portions of this district has raised the height by two, three or even four centimetres $(78,1 \cdot 17,1.57$ inch) on the lands where the practice has existed for the longest time.

But on the other hand, it is indisputable, that races of very different height live side by side, without its being possible hitherto to point out the cause of this diversity. The dwarfed Negroes, the Akkas and Obongos, seem to be placed under conditions precisely similar to those under which much taller neighbouring tribes live.

I have given above 163 statures of human races. I have insisted with sufficient strength upon the consequences which follow from them; from the point of view of the gradation and intercrossing of characters. But we can extract from these numbers some other results which are not less interesting.

The general mean given by these numbers will be $1^{m} \cdot 635$ (5ft 4.37 inch). I regard it as a little too great, the measures being wrong rather for the short races, than for the tall. Nevertheless it cannot be very far from the truth, and may be accepted provisionally.

It is seen from the table that the Roumanians and the Magyars represent, from this point of view, exactly the mean stature.

The oscillations of the mean statures above and below this general mean, extend in the case of the Patagonians to $+0^{\mathrm{m} \cdot 115}$ ( 453 inch), and in the case of the Bosjesmans 
to $-0^{m} \cdot 26.5(10 \cdot 4.3$ inch $)$. The individual oscillations are + (0).295 (11.71 inch) for the inhabitants of Tongatabou, and - $0^{m}+95$ (1ft $7 \cdot 49 \mathrm{inch}$ ) or $-0^{m} \cdot 6.35$ (2ft, 1 inch) for the Bosjesmans.

We see from the table that the oscillations below the general mean, are less numerous than those above it. This result may be commected with the fact which I have just pointed out. Nevertheless it appears to me probable that the number of races above the mean stature, is greater than those below it. The difference in number is compensated for by the more than double extent of the oscillations below the mean.

Between the highest mean observed among the Southern Patagonians, and the lowest mean among the Bosjesmans, we find a difference of $0^{\mathrm{m}} \cdot 554$ ( $1 \mathrm{ft} 9.8 \mathrm{inch}$ ). The difference between individuals will be $0^{\mathrm{m}} \cdot 330$ ( $3 \mathrm{ft} 0.6$ inch). But I think that it ought to be reduced to $0 \mathrm{~m} \cdot 790(2 \mathrm{ft} 7 \cdot 1 \mathrm{inch})$, adopting as a mean the height $1 \mathrm{~m} \cdot 14$ ( $3 \mathrm{ft} 8.88$ inch) given by Barrow as the height of a Bosjesman woman who had had several children. We are thus certain that we are not taking a case of teratological dwarfishness as a possible normal state.

Travellers have not often measured separately the height of men and women. Uniting the fucts of this nature which I have been able to collect, we find $00^{\mathrm{m}} \cdot 141$ ( $5.57 \mathrm{inch}$ ) as the mean difference between the heights of the sexes, and 0.973 as the mean ratio, the woman being everywhere shorter than the man. Anong the Lapps, according to Capel Brooke and Campbell, the mean difference is as bigh as $0^{\mathrm{m}} \cdot 278(10.94$ inches); in Austria, it is as low as 0 m.0.37 ( 1.45 inch) according to Liharzik.

V. Proportion of the body and of the limbs. In all the races of our domestic animals, the relative development of the different parts of the body, the proportions, have a characteristic value, which is equal and frequently superior to that of height. No one would think of separating the greyhound from the harrier. It ought to be exactly the same with man. With the animal, races are formed by a 
selection more or less open, and undertaken for a fixed purpose. The proportions of the different parts of the body thus acquire a fixity, which cannot be found in human races on account of the absence of selection.

This variability is found even in the simplest relations, and in those which might be considered fundamental. Such is the relation of the height of the head to the total heig?! t. Gerdy, who has taken up this question in a special mauner; has found that the height of Frenchmen is rarely beyond $7 \frac{1}{2}$ heads, most frequently a little more than $S$ heads, and sometimes 9. The artistic ideal is no more fixed than the reality, in spite of the mathematical rules laid down, from Vitruvius to Liharzik and Silberman. The table drawn up by Audran shors the variation from $7 \frac{19}{4} 8$ heads (the Egyptian Termes) to $7 \frac{4}{4} \frac{3}{8}$ (the Furnese Hercules). The difference between these two extremes is exactly half a head. Painters have taken still more liberty. Raphael has only given a height of 6 heads to some of his figures, and Michacl Angelo has given them $S$ or more.

The Pythian Apollo ( $7 \frac{+2}{4} \frac{2}{8}$ heads), the Laocoon ( $\left.7 \frac{9}{8}\right)$, are nevertheless chefs-d'ouvre, and we rightly bestow an equal amount of admiration upon the two Italian masters. 'The reason is just the same as with the rest of organised beings : man's organism is not subject to absolute laws, nor to a rigorously fixed development.

Doubtless there have been noticed among some human races differences of proportion generally sufficiently marked to serve as characters. But it just as often happens that with some individuals the order of these differences is inverted. It is another example of intercrossing.

Thus the African Negro has generally the upper limb, from the shoulder to the wrist, relatively longer than the European White, and we shall return to this point further on. Nevertheless, from the measures of Quételet, it follows that a Negro, well known in the studios, where he acted as a model, had much shorter arms than the soldiers, and than a Belgian model, who were taken as terms of comparison. 
Moreover; the numbers found by Quételet place the individuals, upon whom his observations were made, in the following order:- 1st, mean of ten Belgian soldiers; 2nd, an Ojibbeway chief; 3rd, a Belgian model, and a Zulu Kaffir; 4th, an Amaponda Kaffir; 5th, the Negro model; 6th, three young Ojibbeways; 7th, Cantfield, the Hercules of the United States. Here intercrossing again appears in a well marked manner, and it is in the White race that the Brussels savant has found the two extremes.

In the general characteristic of negro races, we often find quoted the slight development and the relatively high position of the calf of the leg. I have no definite information upon the latter of these characters. As for the former, it has been represented to be too general. 'Two Blacks, the Amaponda Kaffir, and the Negro model in the tables of Quételet, present the maximum $0^{\mathrm{m} \cdot 410}$ ( $16 \cdot 14$ inches), and the minimum $0{ }^{113} 328$ (12.92 inches) of development of this part. They are separated from each other by the Belgians, the Ojibbeways, and Cantficld.

Finally, the means taken for the different parts of the body will doubtless give results useful for the distinction of races. But still, account will have to be taken of many of the conditions. All hunting peoples, including the Australians, according to travellers who have been among them, could furnish models for the sculptor, and are generally remarkable for the symmetry and beauty of their proportions. In this respect civilized populations, especially those of our great towns, present a deplorable inferiority. Is our fundamental type degraded in this respect? Certainly not. But civilization itself, by the facilities of existence which it procures, by the vices which it induces, by the weakly individuals which it preserves, introduces into the race the elements of degradation. Here again appears, in all its fulness, the influence of the conditions of life.

VI. Colouring. With all anthropologists I recognise the bigh value of the colour of the skin as a character. Nevertheless, its importance must not be exaggrerated. We now 
know that it does not result from the existence or disappearance of special layers. Black or white, the skin always comprises a white dermis, penetrated by many capillaries, and an epidermis, more or less transparent and colourless. Between the two is placed the mucous layer, of which the pigment alone in reality varies in quantity and colour according to the race.

All the colours presented by the human skin have two common elements, the white of the dermis and the red of the blood. Moreover, each has its own proper element, resulting from the colourings of the pigment. 'The rays reflected from these different tissues combine into a resultant which produces the different tints and traverses the epidermis. This latter plays the part of roughened glass. The more delicate and the finer it is, the more perceptible is the colour of the subjacent parts.

This arrangement explains why, among certain coloured races, for example, among the Sandwich Islanders, the upper classes, who do not live an exposed life, often exhibit the colour in a most pronounced form. Among them sun-burning masks the colour of the pigment, as it masks with us the colour of the dermis and its vessels.

From the preceding, we can also understand why the White alone can be said to turn pale or to blush. The reason is, that in him the pigment allows the slightest differences in the afflux of blood to the dermis to be perceived. With the Negro as with us, the blood has its share in the colouring, the tint of which it deepens or modifies. When the blood is wanting, the Negro turns grey from the blending of the white of the dermis with the black of the pigment.

It is well known that from the point of view of the colouring, human races can be divided into four principal groups: white, yellow, black, and red races. But we must guard against attaching an absolute sense to these expressions. Every grouping of races founded solely on colour would break close relations, and would lead to comparisons which 
would evidently be at variance with the sum of the remain. ing characters. Nevertheless, this systematic point of view brings to light some interesting general facts.

The races of a white colour present sufficient homogeneity. From the sum of their characters, they belong almost exclusively to the type which borrows its name from this kind of colouring. It is, moreover, useless to insist upon the differences of tint which the latter exhibit, from the English or German woman of the upper classes to the Portuguese, and especially to the Arab. Nevertheless, in the northern regions and in Central Asia, some populations, the Tchukchees for example, appear to unite with a white colour certain characters which connect them with the yellows.

In the purest white, the epidermis easily loses its transparency as soon as the colour deepens. The sub-cutaneotis veins can then only be recognised by their swelling. It is only with individuals whose skin is very fine and transparent, that the course of the veins is marked by the wellknown bluish colour. Whenever this trait is exhibited by any population whatever, it may with certainty be connected with the white type. For this reason I have not hesitated to place among the Allophylians some of the most savage tribes of the north western shores of North America, and the Tchukchees, of whom I have just spoken.

The populations with a black skin are far from being as homogeneous as the preceding. All black men are not Negroes; there are some, who, from the sum of their more important characters, are closely connected with the white stock. Such, for example, are the Bicharis and other negroid populations, on the borders of the Red Sea, whose skin is much blacker than that of some negroes, but whose hair and characters are perfectly semitic.

Among Negroes properly so called, the tints vary, perhaps, much more than with the White. Without going further than Cairo, individuals may be seen, who, without any traces of the mixture of races, are of a brown colour with 
a considerable mixture of black. The Yolofs are of a bluish black, resembling the wing of a raven, and Livingstone speaks of some tribes on the Zambesi who are the colour of café au lait. But, perhaps, mixture of races has some action in this extreme modification of the colour.

Populations with a yellow skin present facts analogous with the preceding, but not so numerous nor so striking. Perhaps this difference is only due to the difficulty of recognising the shades of the fundamental colour. Nevertheless, a more or less pronounced yellow colour equally characterises the great Mongolian stock, and the Houzouana or Bosjesman race, which it is impossible to separate from the Negroes. On the other hand, this same tint is so well marked among the mulattoes that they are often designated by the name of yellows, in distinction to the Blacks and the Whites.

Of the four groups into which the colour of human races may be divided, the least characteristic is the red. It has been attempted to make it the attribute of the Americans. This is a mistake. On the one hand, in America the Peruvian, Autisian, Araucanian, and other races are more or less deep brown, the Brazilio-Guaranians of a yellowish colour slightly tinted with red, etc. On the other hand, in Formosa a tribe has been found as red as the Algonquins, and more or less copper tints are met with among Corean, African populations, etc.

Moreover, the red tint appears as the sole effect of the crossing between races, neither of which possess it. Fitzroy informs us that in New Zealand it frequently characterises the half-breeds of English and Maories. This fact also explains why it should be met with among many of the populations mentioned above. With man it is one of those facts which show how intercrossing can give rise to the appearance of new characters.

Finally we see that the colour of the skin, althougl, furnishing excellent secondary characters, cannot be taken as a starting point in the classification of human races. 
For man, as well as for plants, we ought to recall the aphorism of Limneus: "nimium ne crede colori."

The same may be said still more emphatically of the colour of the eyes. Doubtless, the black colour is generally found among coloured races, and sky-blue scarcely exists except among fair populations. The former tint appears even to be constant among the yellows and certain allophylian Whites. But, even among the Negroes, we often meet with brown eyes, and sometimes with grey eyes.

Just as with the colour of the skin, the colour of the eyes is a resultant due to the combination of the tints reflected by the different layers of the iris, intensified by the colour of the blood and seen through the transparent cornea. Hence arises the difficulty experienced by painters in rendering the general effect.

VII. The shin and its principal annexes. The skin, which covers the entire body, is a real covering composed of organs which are anatomically and physiologically distinct. The principal one is the cutaneous organ or slin properly so called, to which are annexed the organs productive of villosities, the sudoriparous glands, the cutaneous glands, and some others which do not concern us.

In extreme cases, the surface of the skin is sometimes dry and rough, somatimes supple and like satin. The first variety is generally met with among Arctic races, the second among inhabitants of lot countries, as the Negroes and Polynesians.

The two facts are easily explained by the sole action of the temperature. Cold contracts the tissues, drives the blood towards the interior, or checks its circulation towards the surface of the body. It must consequently diminish the functional activity of the skin properly so called, and partially diminish perspiration. Heat, on the contrary, causes a flow of blood to the surface of the body, and renders the functions of the skin, and especially the perspiration, more active. The latter, by the produc- 


\section{Extemal Chavacters-Skin, Perspiration. 361}

tion of a constant evaporation on the surface of the body, maintains the suppleness of the epidermic layer, and the general freshness which causes Negresses to be sought after in harems.

From this action of heat, and the increased activity of the cutaneous organs which is its consequence, other results follow which explain some of the facts noticed by travellers and anthropologists.

Pruner Bey has insisted strongly upon the thickness of the cutaneous layers, and especially upon that of the dermis in the Negro. Is not this thickness the natural consequence of the flow of nutritive principles brought by the blood, which is incessantly passing to the surface of the body to keep up the perspiration?

It has long ago been remarked that the Negroes and other races inhabiting hot countries perspire much less than the inhabitants of temperate climates. This is accounted for by the preceding facts. The blood, which is constantly brought to the surface and into the cutaneous organs, does not flow so copiously in the sudoriparous glands, which are deeply buried beneath the adipose tissue. Between transpiration and perspiration, in consequence of the position of the organs, a real equilibrium should exist.

Probably, one of the difficulties of acclimatisation arises from the fact that the proportional activity of these two functions has to be changed when we pass from a temperate to a tropical climate, or vice versa. The researches of Krause show that the body of a European contains more than 2,281,000 sudoriparous glands. The total volume of all these small organs would amount to about 40 cubic inches. A sudden change in functions could not therefore be unimportant. Moreover, the sebaceous glands, which are smaller but more numerous than the sudoriparous, participate in this change, which can only result in a serious shock to the organism.

The villosities are either very rare or absolutely wanting 
on the surface of the body of a Negro, except some parts which in man are always covered with hair. On the other hand, the glandular cutaneous covering is highly developed in his case.

Both these facts may also be referred to the same cause, and are explained by the balancing of comnected organs. The blood, when brought to the surface of the body, abandons the bulbs of the hair which are too deeply planted; but, for the simne reason it flows into the sebaceous glands, which are situated near: the surface. It easily follows that the former suffer atrophy, and the latter experience an exceptional development.

This development accounts for the exaggerated odour which is peculiar to the Negro. It is known that a slaveship may be recognised by this smell. But African populations are not the only ones which are characterised in this manner. Humboldt informs us that the Peruvians distinguish the odour of a native, a white, and of a negro, calling them posco, pezuna, and graïo. Amongst ourselves, every individual has his own peculiar odour, which is easily detected by the delicate sense of smell of the dog.

VIII. Villosities, beard, hair. Villosities in man represent the hair of the mammalia; but whilst the latter are always covered, with the exception of some special races, such as chicns turcs, calongo cattle, etc., man is generally only covered to any notable extent upon certain places. In the African Negro, and most of the yellow races, it only exists upon the normal parts of the body. Nevertheless the practice of epilation, which is common to a great number of coloured populations, has caused the frequency and intensity of this character to be exaggerated. Eckewelder represents Red-Skin warriors, in their leisure moments, as occupied in tearing out the smallest hairs with pincers especially made for the purpose.

White races are generally more or less hairy, and this trait has long been known to be developed to a very exceptional degree among the Ainos. The photographs of Colonel 


\section{Exterial Characters-Beard, Hair.}

Marshall show that the Todas are their equal in this respect. In certain individuals among the latter the villosities form a real fur, especially on the lower limbs.

Of all the villosities of the liuman body, those which cover the face and cranium have justly attracted most attention. All races have hair; but a considerable number in Asia, America, and Africa, have been noticed to be entirely without beards. Pallas, Humboldt, Brasseur de Bourbourg and Pruner Bey, have contradicted these assertions, and shown that the absence of beards is entirely due to careful epilution. All human races are more or less provided with a beard. Nevertheless great differences are known, even among races belonging to the same fundamental type. Certain Melanesian Negroes present a striking contrast in this respect to their African brothers.

The hair of the head is much more constant in respect to quantity than that of the beard. Nevertheless it appears to be sensibly thicker among some arctic races, who have moreover a more abundant down than races in temperate climates. In this respect there is perfect agreement with the known facts among animals.

With certain Negro races, the Bosjesmans of South Africa, the Mincopies of the Andaman Islands, the Papuans of Melanesia, and some African tribes, the hair forms upon the head small islands, separated by spaces which are perfectly smooth. Hence results the heads of hair en grains de poivre noticed by different travellers. Amongst most African Negroes, and amongst the Yellows and the Whites, the distribution of the hair, on the contrary, is uniform.

The variation of the colour of the hair is well known. Some general facts may nevertheless be collected from the midst of all these special cases. I have said already that we find isolated cases in all races of individuals with hair of a more or less reddish colour. Fair hair has for a long time been regarded as the appanage of a small number of Aryan groups. Nevertheless, according to Pruner Bey, we also meet with it sometimes among the Asiatic Semites, and we 
know for certain that they are very frequent among the Kabyles. Facts such as Pierre Martyr, P. Kes, James, etc., have noticed among the Parians, the Lee-Panis, the Kiavas, etc., will no doubt one day be explained by migrations and intercrossings. It seems to me, for instance, almost evident that the Scandinavians must have introduced their fair hair among several tribes of the American shore, and that the facts noticed by Pierre Marty' are one of the proofs of their extension beyond the Gulf of Mexico.

There is also something characteristic in the form of the hair taken as a whole. Everyone knows the falsely called woolly head of the Negro, which is covered with very short and crisp hair. The very long and harsh hair of yellow, American, and other populations, contrasts in a striking manner with the preceding. That of the white races, which is frequently curly, almost takes the mean between these two extremes.

This general aspect ordinarily corresponds with the differences of structure and general form of the hair. Brown has already proved that a horizontal section of the hair varies from an elongated ellipse with the Negro, to a circle with the Red-Skin, and that the hair of the Anglo-Saxon is a mean between the two. Pruner Bey has resumed this study, and described the form of a horizontal section of the hair in several races belonging to the three fundamental types. $\mathrm{He}$ has proved that the elongated ellipse characterises Negro races in general, as well as the Hottentot-Bosjesman; that the oval forms belong essentially to Aryan populations; that more or less regularly circular forms characterise yellow, American, and other races, and that in this respect the allophylian white races (Basques) appear to resemble the preceding.

Brown and Pruner Bey moreover agree in the statement that a mixture of forms is found upon the heads of halfbreeds. Exactly the same often happens in the crossing of the merino with races of sheep with a coarse wool.

I have hitherto only spoken of the characters furnished 
by the beard and the hair when grown freely. But it is well known that the love of adornment, one of the most characteristic instincts of man, endeavours to modify nature in these two directions. This results in characters, which are doubtless artificial, but which have sometines a real value. This side of the question has often been attacked, and M. E. Cortambert has made it the object of a work, in which he has given a summary of the work of his predecessors in addition to his own.

IX. Characters of the cranium and of the face. From the point of view of descriptive anthropology as well as from an anatomical point of view, the head is composed essentially of two regions, the cranium and the face. The former is covered solely by the hairy skin which follows all its contours, and it in reality therefore only presents osteological characters. The general form, proportions, etc., are almost the same in the living man as in the skeleton. I will therefore go into greater detail upon this subject when treating of the latter. Here $I$ will only remark that the inequality of the skin and of some subjacent muscular fibres necessitates some corrections in the comparison of measurements taken from the living head and from the skull. For example, the presence of the temporal muscles increases to a sufficiently sensible extent the transverse maximum diameter. Consequently the ratio of the latter to the anterio-posterior diameter becomes raised. This ratio, which constitutes the cephalic index, is one of the characters which anthropologists employ most frequently, and it was important to determine the correction to be made in case of comparison. Broca has shown that it is two units when the ratio is expressed in the manner which $I$ shall mention further on.

The case is different with the face. Here the superimposed soft parts play a part of which the importance has been alternately exaggerated or neglected. William Edwards considered that races should be determined, as we judge of individuals, solely by the facial characters. Serres, starting 
from the fact that the bony framework determines the general form and the proportion of the face, required that osteological characters only should be taken into account. Both were too exclusive.

Doubtless the skeleton is important in the most superficial characters of the face. But the muscles, the cellular and adipose tissue, and the cartilages are much more developed on the face than upon the cranium; and from their greater or less extension, from their various relations, differences of feature result which constitute so many characters. Unfortunately it is often very difficult to define the latter. The most detailed descriptions are rarely sufficient, and the most exact measurements are far from giving an idea of certain variations of the human figure. For example, they cannot make the difference intelligible, which is nevertheless very sensible to the eye, which distinguishes the nose of a negro of Guinea from that of a Nubian negro.

The nose is nevertheless one of the features of the face which is best adapted for investigations of this kind. Its length is determined by the point of attachment of the nasal bones to the frontal bone and the position of the nasal spine; its breadth at the bridge depends upon the angle formed by the nasal bones; its breadth at the base is more or less related to the anterior opening of the nasal fossæ. But the form and development of the cartilages, as well as the thickness of the nostrils upon two very similar skulls, can modify considerably the type itself of this organ; and the exterior nasal index can give no idea of these variations. The study of Topinard upon this subject, nevertheless, possesses a real interest; but from the point of view of the characterisation of races, the researches made by Broca upon the nasal osteological index, which we will discuss further on, has a much more important value.

The characters drawn from the nose, which are observed upon the living body, are however most important. This organ is more or less pressed in, broad and flat among almost all Negroes, the greater part of the Yellow races, 
and certain allophylian Whites; it is on the contrary narrow and prominent in fair white races. These two general types moreover present variations of which drawings only can give any idea.

I may say the same with reference to the mouth. The thousand differences of form and dimensions which it can exhibit, from the negro of Guinea with his enormous and, as it were turned up lips, to certain aryan or semitic Whites can neither be measured nor described. We can only point out the general characters when they become very pronounced. It may, however, be remarked that the thickness of the lips is very marked among all negroes, in consequence of their projection in front of the maxillary bones and the teeth.

The mouth of the Negro presents another character which seems to me to have been generally neglected, and which has always struck me. It is a kind of clamminess at the outer border of the commissures, and which seems to prevent the small movements of the corner of the mouth which play such an important part in the physiognomy. The dissections of M. Hamy have explained these facts. They have shown that in the Negroes the muscles of this region are both more developed and less distinct than in the Whites.

Independently of the colour of the iris, the eye also exhibits differences which constitute so many characters, having at times a real value in the development of the eyelids, and in the dimensions of the palpebral fissure. Everyone knows Chinese eyes, which slope from below upwards, and from inwards outwards. They have been regarded as peculiar to Yellow races, whether pure or mixed. Nevertheless these oblique eyes are found pretty frequently in Europe, principally among women, and are united to a fairness and freshness of colour which are almost exceptional, as well as to features unanimously regarded as most pleasing.

The general form of the countenance, and some other peculiarities drawn from the prominence of the cheek bones, 
from the form and prominence or retreat of the chin, etc., favoured some considerations analogous to the preceding. But here again the external characters are wanting in the precision which we shall find in the ostenlogical characters.

X. Characters drawn from the trunk and limbs. When speaking of proportions I have already pointed out some of these cliaracters; I will return to them when speaking of the skeleton. I will here only make a few remarks, and point out two remarkable features.

One of the peculiarities, which, in our European eycs, chiefly contribute to bodily beauty, is the width of the chest, of the waist, and of the hips. $A$ body of a uniform breadth we consider ungraceful. It is a feature which is met with among several yellow and American races. The comparison of these dimensions will furnish indices which it is interesting to compare. But we have only taken that of the chest, or more generally its circumference. To judge from the numbers given by various authors, the Negroes of Fernando Po would have the most fully developed chest. With them, its circumference would be $95 \cdot 2 \mathrm{~cm}$. (37.4S inches). The English would come next, and the minimum observed would be among the 'Todas, whose thorax would only have a circumference of $\$ 1 \cdot 8$ c.m1. ( $32 \cdot 2$ inches).

The Hottentot, and especially the Bosjesman women, exhibit, in a high degree, two peculiaritics, which have for a long time been considered special to them, but which have becn met with elsewhere: I mean steatopygice and the Hottentot's apron (tablicr). 'The first consists of a strange development of the fatty folds in the buttocks, from which results an cnormous protuberance. The Hottentot Venus, of which a model cxists in the Paris Muscum, gives a good example of it, but it appears that this character can be still more cxaggerated. It is the reproduction in man of a feature noticed by Pallas as characteristic of certain races of sheep of Central Asia, among which the atrophy of the tail coincides with the appearance of enormous fatty protuberances. 
Steatopygia has been noticed among various black and Negröid populations. It was very noticeable in a queen of Poun, figured upon the Egyptian temple built by M. Nariette, for the Exhibition of 1867. Livingstone assured us that it had begun to manifest itself among certain women of the Boers, who are nevertheless of a quite pure white race. But nowhere is it so pronounced as among the Bosjesman women, and it constitutes one of the most striking characters of the race.

It is not exactly the same with "tablier," resulting from the exaggerated development of the labia minora, which project out of the vulva and hang down in front of the thighs. This feature is found more or less developed in a number of races, and has given rise to the practice of circumcision among women. In Europe there is doubtless scarcely an accoucheur who has not noticed it on some occasion in some perfectly pure Whites. Nevertheless it seems that among the Bosjesman women it sometimes reaches a development which is not noticed elsewhere. In the Hottentot Venus, of which the Paris Museum possesses a model, the length from the right reaches 55 millimetres $(2 \cdot 16$ inches), and from the left 61 millimetres ( 24 inches); the breadth is 34 millimetres ( 1.33 inch) from the right, and from the left 32 millimetres (126 inch). The thickness, which is uniform, is 15 millimetres ( $5 \mathrm{~S}$ inch). 


\section{CHAPTER XXX.}

ANATOMICAI, CHARACIERS.

I Osteological characters. - Without denying the very great value of external characters, I agree with almost all anthropologists, in attaching a greater importance to anatomical characters in the majority of cases. Unfortunately, the comparative anatomy of human races has, as yet, made but little progress. The fact is, that the solid portions, the skelcton alone, have, neccssarily, been the subject of serious examination. The study of the perishable portion has scarcely been begun. For this, and several other reasons, I shall distinguish these two orders of facts, and discuss separately our knowledge of osteological cliaracters and organic characters.

The skeleton, the framework of the body, presents the same regions as the latter: we can distinguish the head, the trunk, and the extremities. Each of these regions offers peculiarities more or less connected with the diversity of human groups. The best studied, and fortunately the most important, are furnished by the head. For some years craniological collections have been singularly on the increase; and throughout kurope, the study has been entered upon with equal ardour. Craniometrical methods and instruments have multiplied, perhaps a little beyond the actual need. MII. Vogt and Topinard have made an excellent summary of this mass of research. I can only refer to their publications. I cannot here cven repruduce all the results already acquired, and must confine myself to pointing out a few of the principal omes. 
II. Clearacters drewn from the cranium alone.-From an anthropological point of view, as well as in an anatomical sense, the skull is divided into two parts, the cranium and the face. Each of these regions has its special indications, while new characters again rise from their reciprocal relations. Let us bricfly review them.

The general form of the cranium depends, above all, upon the relation existing between the length measured from before backwards, and the breadth taken from one side to the other. The honour of having appreciated the importance of this relation belongs to Retzius. He made use of it to establish the distinction between dolichoceplactic, or longheaded races, and brachyccphalic, or short-headed races.

Retzius considered the relations $7: 9$ or $S: 10$ as representing the limit, left by him uncertain, of dolichocephaly and brachycephaly. M. Broca proposed the formation of a third group, which should comprise all crania, the length and breadth of which presented a relation comprised within these limits, and anthropologists now admit with him the mesaticephalic races. In expressing these relations by decimals, and in creating the term horizontal cephalic index, now universally adopted, M. Broca has, moreover, facilitated, to an extraordinary degree, the study of this character, and the ideas to which it may give birth. His subdivision of the two extreme groups into two has also, in certain cases, been an advantage. He has himself, however, shown that it is not wise to go too far in this direction.

The definitions of dolichocephaly, mesaticephaly, and brachycephaly have, it seems to me, been somewhat arbitrary. I draw this conclusion from the following tables, which I borrow from MM. Broca and Pruner Bey. They represent the means discovered by these eminent investigators. I have merely substituted the serial order for the purely geographical distribution adopted by M. Pruner. Moreover, I have continued the calculation to the second decimal place, thus rendering the distinctions more minute, and the general result more striking. 
INDICES OF HUMAN RACES AFTER M. PRUNER BEY.

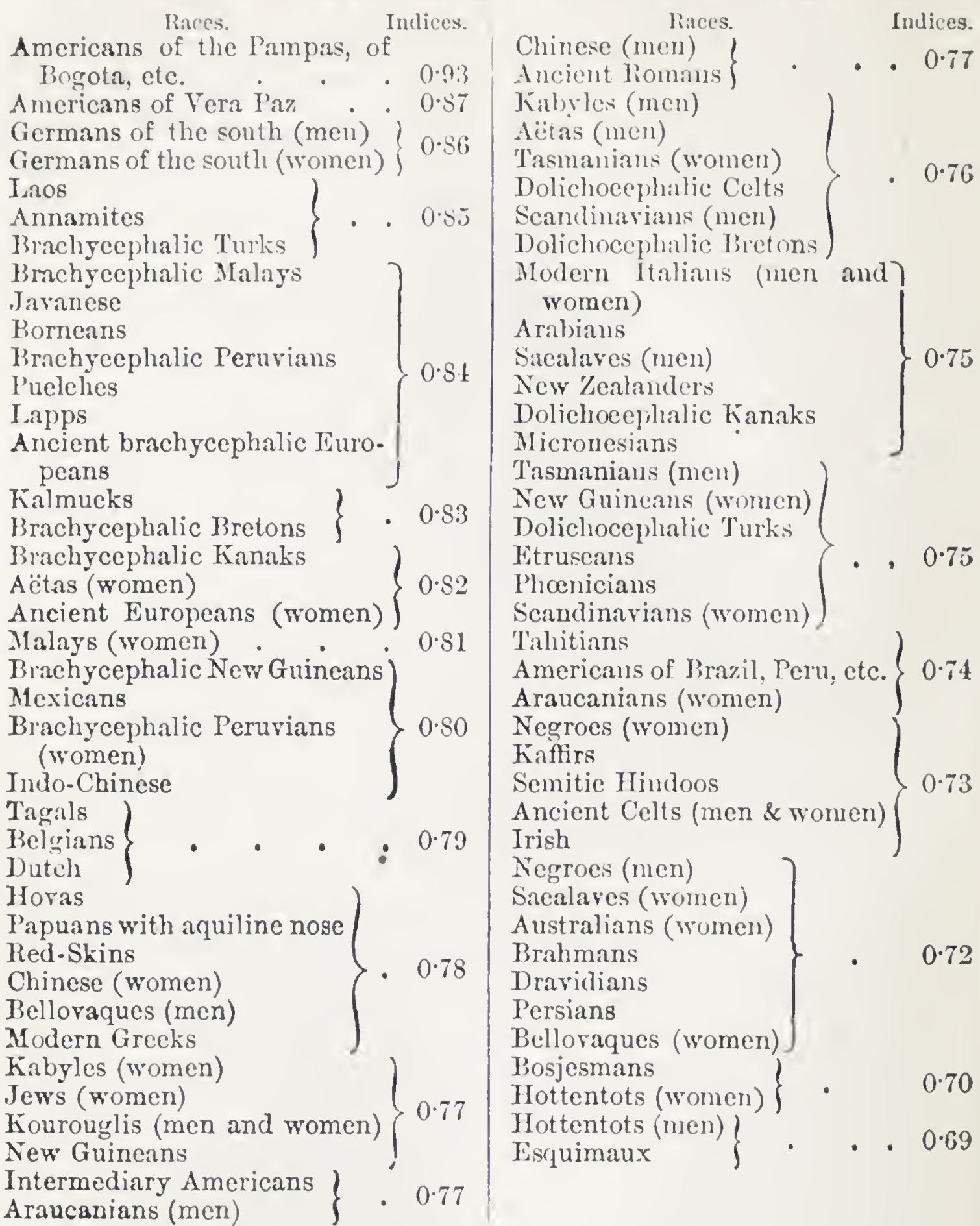

INDICES OF HUMAN RACES AFTER M. BROCA.

$$
\text { Races. Indices. }
$$

TRUE BRACHY'CEPHALI.

Americans (deformed crania) $\left\{\begin{array}{l}1 \cdot 0.3 \\ 0.93\end{array}\right.$ Syrians of Gébel Cheikh, ) Iapps slightly deformed

Bararia and Swabia Auvergnats of St. Nectaire
0.55

0.94

$$
\left.\begin{array}{l}
\text { Finns } \\
\text { Indo-China }
\end{array}\right\} \cdot \begin{aligned}
& \text { Indices. } \\
& \text { SUB-ISRACHYCETHALI. }
\end{aligned}
$$

Alsace and Torraine

European liussia $\left.\begin{array}{l}\text { Bretous of the Côtes du Nord } \\ \text { (Gaulish cantons) }\end{array}\right\} 0.82$

Javanese )

Turks 
Races.

Indices.

SUB-BRACHYUEPHALA-continned.

Different Mongols
Bretons of the Côtes du Nord
(Breton cantons) (Breton cantons)

$\left.\begin{array}{l}\text { Fitonians } \\ \text { French Basques }\end{array}\right\}$

\section{MESATICEPHALI.}

North Americans, undeformed South Americans, undeformed

Non-Javanese Malays

North Freneh, Bronze age

Parisians of 16 th cent.

Parisians of 12 th cent.

Parisians of 19 th eent.

Gailo-Romans

Roumanians
Aexicans, undeformed SUB-DOLICHOCLPHALI.

Spanish Basques of 'Zaraus

Gauls of the Iron age

Malgaehes

Chinese

Copts

Merovingian Freneh

Selaves of the Danube

Tasmanians
Races.

Indices

SUB-DOLICHOCEPIIALI- continued.

\section{Polynesians}

Ancient Eigyptians

Guanches

Corsicans of Arapezan of the 1 sth eent.

Bohemians of Roumania

Papuans

North French of the polished stone age

TRUE DOLICHOCEPIALI.

$\left.\begin{array}{l}\text { Kabyles } \\ \text { Arabs }\end{array}\right\}$

$0 \cdot 74$

Nubians of Elephantine

Nubians of Elephantine
South French; Neolithic age
(eare Honme-Nort)

France; I'aliwolithic age

Nerroes of West Afriea

Bengalese

Finflirs

Hottentots and Posjesmans $\}$ • 0.72

Australians
New Caledonians

Esquimaux

These tables mutually confirm and complete each other in general results. The secondary differences which distinguish them, are doubtless occasioned, on the one hand, by the number of crania employed by the two authors to obtain their means; on the other, from some diversity in the use of these materials. M. Pruner Bey distinguished the sexes, which are united by M. Broca: the latter has placed in one group the Hottentots and Bosjesmans, separated by $\mathbf{M}$. Pruner, etc.

From M. Broca's table it appears that the mean of all these indices, leaving deformed skulls out of the question, is 078 . From a numerical point of view this would be that of true mesaticephaly. The mean group ought, it seems to me, to descend equally as it rises, and consequently to absorb at least a part of M. Broca's sub-dolichocephali. In fact, upon inspecting the two tables, it appears that the indices above 0.74 and below 0.79 comprise the greater number of races belonging to the three fundamental types, and taken from all 
parts of the world. It seems to me that true mesaticephaly should be comprised within these limits. I do not, however, propose that those which have been adopted should be changed.

These tables give rise to many other observations, of which I shall only point out the principal.

M. Pruner Bey carried his calculations to the third place of decimals; M. Broca to the fourth. I have gone no further than the second, that the eye may be more easily attracted by the series formed by these numbers, so important in the characterization of races. It should be remembered that the greater number are means taken from a certain number of crania. Were there a sufficient number of subjects for each race, and all the indices taken from each arranged in serial order, the distance from one to the other would undoubtedly be no longer 0.01 , but would be diminished to 0.001 , or even less. The insensible shades observed in passing from one individual to another would here be as remarkable as in the comparison of stature.

There is no need to insist at any length upon the intercrossing, so strikingly betrayed by the two tables. We see that the same index places side by side the most dissimilar races, the South German with the Annamite, the Breton with the Kalmuck, the Belgian with the Tagal, the Parisian with the Malay, the Italian with the Maori, etc., and that by their several indices the white races are scattered throughont almost all the coloured races. I need not return to the consequences which may be drawn from these facts from a monogenistic point of view.

The yellow and black races are not so widely separated as the white; the former are either brachycephalic or mesaticephalic, the latter all dolichocephalic, with the exception of the Aètas. I have shown that the latter belong to a group of populations extending from the Andaman and Philippine Isiands to Torres Strait in Melanesia, penetrating New Guinea, and forming a special branch in the midst of the Nelanesian Negrn propulation. 
The case appears to be somewhat similar in Africa. This discovery, entirely contrary to the ideas generally maintained till the present time, is due to M. Hamy. This excellent investigator recognized brachycephaly in six skulls taken from the Paris collections, and obtained from Cape Lopez, or the mouths of the Fernand Vaz. Shortly afterwards, M. Duchaillu having brought from the same districts ninetythree skulls, the measurements of which were made public by Englishmen, M. Hamy calculated the indices, and found that twenty-seven of these crania were brachycephalic or mesaticephalic. There is then every indication that the Negro stock in Africa presents a special branch corresponding to the Negritoes. This result is confirmed by Schweinfurth, who places the Niams-Niams and some neighbouring tribes amongst the brachycephali.

We see that the horizontal cephalic index cannot serve as a starting point in the classification of human races, as Retzius imagined it might. We also see, however, that all the value which was attributed to it by its author, is preserved in the characterization of secondary groups.

The extreme means given in M. Pruner Bey's table were found in two American races, the Esquimaux and the inhabitants of the Pampas of Bogota, etc. Whatever the differences may be which separate these two races, it is evident that neither of them belong either to the black or the white type. They show the greatest affinity to the yellow type.

From one extreme mean to the other there is, according to M. Pruner, a difference of 0.246 between the cephalic indices; according to M. Broca of 0.14552 only. This difference rests chiefly upon the fact of M. Broca rejecting, as deformed, skulls which M. Pruner seems to accept without observation. Again, the individual indices present a much wider variation than would, at first sight, be expected. Huxley mentions a Mongol whose cephalic index rises to 0.977 , and a New Zealander, of unmistakable Melanesian origin, in whom it descends to 062.9. The difference is, therefore, 0.348 . 
The general relations of length and breadth in the cranium of human races is apparent from birth. Nevertheless, from the researches of Gratiolet, it appears that dolichocephaly is due to a relative development of bones, which varies with age. In the infant it is essentially occipital, in the child temporal, and frontal in the adult man. In the woman the elongation of the cranium depends essentially on the length of the temporal regions; in this respect, then, the woman remains a child all her life.

Starting from these primary results, the same observer has compared dolichocephalic Whites with African and Melanesian Negroes. He found that the frontal dolichocephaly of the former was replaced in the two black races by an occipital dolichocephaly. M. Broca has established the same fact in comparing Basques with Parisians. Thus the distinction proposed by M. Gratiolet furnishes a secondary character, which may be of use in certain cases, but which falls very short of the importance with which some have attempted to invest it. They would consider occipital dolichocephaly as a character which widely separates the Negro from the White; the observations of M. Broca show that this is not at all the case, and from the observations of M. Gratiolet it appears that we have here only the persistence of an anterior condition common to both. The Negro and the Basque preserve throughout life the cephalic character of the infant Parisian, thus forming one of the many examples of that cessation of evolution which, as we see more distinctly every day, plays a considerable part in the characterization of human races.

The study of the horizontal cephalic index might lead to many other remarks. I shall only recall the results obtained by M. Diétrici. It appears from his calculations that, the total population of the globe given at 1288 millions, there are 1026 millions of dolichocephali, and only 262 millions of brachycephali. But the Berlin savant places in the first category the Chinese, who are mesaticephali, and must alone be reckoned at 421 millions. All these facts considered, it 
appears to me, from the tables of MM. Pruner Bey and Broca, and other data, received up to the present time, that the mesaticephali are much more numerous than either the brachycephali or dolichocephali. If mesaticephaly is taken in the sense pointed out above, the latter in their turn predominate over the brachycephali, owing chiefly to African black populations, which we are daily learning to estimate as much more dense than they were formerly thought to be.

Retzius only compared the antero-posterior and transverse maximum diameters. Later investigators have sought the relation between the latter and the height of the cranium. The vertical cephalic index has thus been obtained, the importance of which is at once evident. It plays an equally important part in the table of $\mathrm{M}$. Pruner Bey, and gives rise to considerations analogous to those just discussed. I cannot, however, enter into all these details without exceeding the limits of this book. From the same motive I shall not mention the other measurements of the cranium, maximum and minirnum frontal diameters, total circumference, anteroposterior arc, and others.

The composition of the cranium can only vary within very narrow limits. Nevertheless, in Negroes, in ancient Egyptians, etc., the squamous portion of the temporal bone is sometimes united to the frontal without the partial interposition of the wings of the sphenoid. This is a remarkable fact, being in direct contradiction to the principles of connections, so justly regarded by Etienne Geoffroy as one of the most essential principles of comparative anatomy.

In the preceding case, the composition of the cranium is altered by the suppression of a normal suture. This may also be caused by the appearance of an abnormal suture, by which two distinct bones are formed from a single one. Such is the case when the occipital bone seems to divide, so as to leave its upper portion free. We then have what has been called the epactal bone, or bone of the Incas, because Rivers and Tschudy imagined this conformation to be a character pecu- 
liar to the race. MI. Jacquart, however, showed that it was merely the result of a cessation in the evolution of the occipital bone, of which examples are found in the most different human races. It is to a similar phenomenon that the persistence of the medio-frontal suture is due. This, again, is. doubtless universal, but much more frequent in the Aryan white race than in coloured races, and especially in the Negroes.

These facts are connected, moreover, with a group of observations and ideas which Gratiolet has brought forward on several occasions. According to this ingenious observer, the anterior sutures are the first to unite in inferior races, while. in superior races the obliteration commences with the posterior sutures. Again, the sutures, as a whole, have a tendency to disappear rapidly in savage races, while the isolation of the bones of the cranium is persistent in civilized races, and particularly in the European White. This disposition allows a continuance of the development of the brain, although it gradually becomes slower. Gratiolet thus explains the continuance of the intellectual power, so remarkable in men who have constantly exercised their intelligence. The statistic researches of Dr. Pomerol, while correcting all that is absolute in this theory, seems to confirm it in some respects.

Since I am unable to review all the cranial characters, I shall pass by those drawn from the prominence of different bones, the occipital indices of Broca, the cephalo-spinal of Mantegazza, etc. I shall only say a few words upon the position of the foramen magnum, and the sphenoidal angle of Welker, but I shall dwell more at length upon the capacity of the cranium.

D'Aubenton, in a special work, shows that the foramen magnum is always placed further back in animals than in man. Semmering remarked that it seemed more so in the Negro than in the White; and this opinion, which was apparently confirmed by some measurements, was at once accepted by a number of anthropologists, and regarded by them 
as a simian character, but this result was attained by considering the position of the aperture relatively to the entire length of the skull, including the face. Now it is at once evident that the forward development of the latter, by reason of prognathism, would increase the apparent retreat of the former.

The researches of M. Broca upon cranial projections enable us to state this problem correctly, and to give the solution of it. M. Broca compared 60 Europeans with 35 Negroes. Representing the total projection by 1000, he found that in the former the anterior projection was 475 , and in the latter 498. The anterior border of the foramen magnum is then further removed from the alveolar border in the Negro than in the White, the difference being 23. But this projection includes, with the anterior cranial projection, the facial projection, which is 65 in the Enropean and 138 in the Negro. If this is deducted from the former, we find that the White stands first in cranial projection alone, and that the difference is 50 .

We learn from these calculations that, relatively to the cranium to which it belongs, the foramen magnum is placed more forward in the Negro than in the White, which is by no means the case in apes. These same calculations demonstrate the real difference which here distinguishes the two, that, namely, of the forward prolongation of the face.

In drawing comparisons between men and apes, the splenoidal angle discovered by M. Virchow, studied by M. Welker, and which, thanks to M. Broca, may be measured without making a section of the skull, presents special interest. It presents an inverse evolution in man, and the Quadrumana during growth. This may be seen from the annexed calculations borrowed from M. Welker:- 
10 Children from 10 to 15 years 141

30 Adult Germans . . . $13 t^{\circ}$

Difference $\quad \cdot \overline{-\tau^{\circ}}$

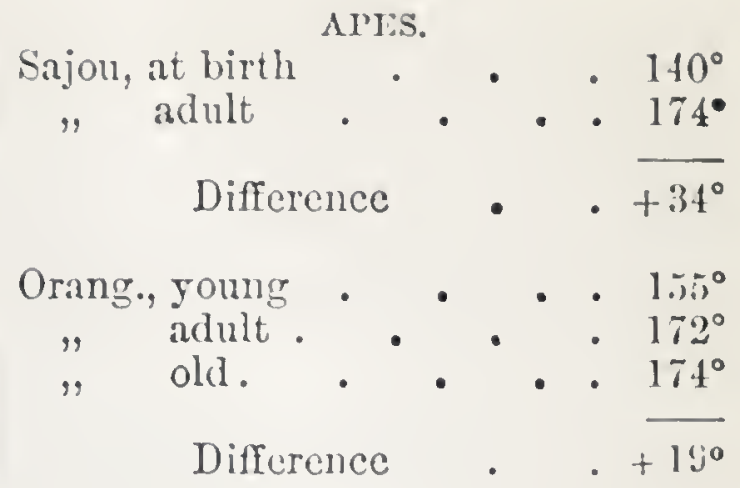

I have already insisted that facts of this nature are irreconcilable with those theories which attribute a more or less pithecoid ancestor to man.

In discussing the cranial cavity, our special object is to supply the deficiency of information upon the volume and weight of the brain. Now, from this point of view, we may easily fall into error. The bony cabinet and its contents are developed, to a certain extent at least, independently. This is very clearly demonstrated by a fact which was observed by Gratiolet, and is too frequently forgotten. The subject is an infant in whom the cranium presented the normal conformation. 'The brain was, nevertheless, almost eutirely wanting. In well-formed men the sinuses and coverings of the brain may very easily be more or less developed according to the individual or race, and influence the relative dimensions of the brain.

Moreover, the exact measurement of the capacity of the cranium is attended by difficulties which have not yet been entirely surmounted. In spite of the improvements introduced by M. Broca in his method of measuring with shot, consecutive measurements of the same cranium by the same observer will vary considerably in the result.

Again, there are peculiarities to be taken into consideration, the importance of which has long been neglected. We have known for several years that the stature has an influence upon the weight of the brain. It cannot be without influence upon the cavity by which the latter is enclosed. M. Broca has shown that sex is of itself a cause of variation. In the woman the mean cranial capacity is always less 


\section{Osteological Characters-Cranial Capacity. $3 S$ I}

than in the man, and the difference varies between different races.

Nevertheless, in examining a sufficient number of skulls, the causes of error may counterbalance each other, and the means may be accepted as giving results sufficiently near the truth. The results obtained by the same observer are especially favourable for comparison, and from them certain results may be obtained. There is no reason, therefore, why the cranial capacity should not be considered as a character well worthy of study. But its importance must not be exaggerated.

M. Broca arrived at the following result, in considering the distinction of extreme races. 'The cranial capacity of the Australian being represented by 100, that of the African Negro is 111.60 , and that of fair European races 124.8.

I borrow from my eminent colleague the following table, published by M. Topinard in his Anthropologie. 'This table

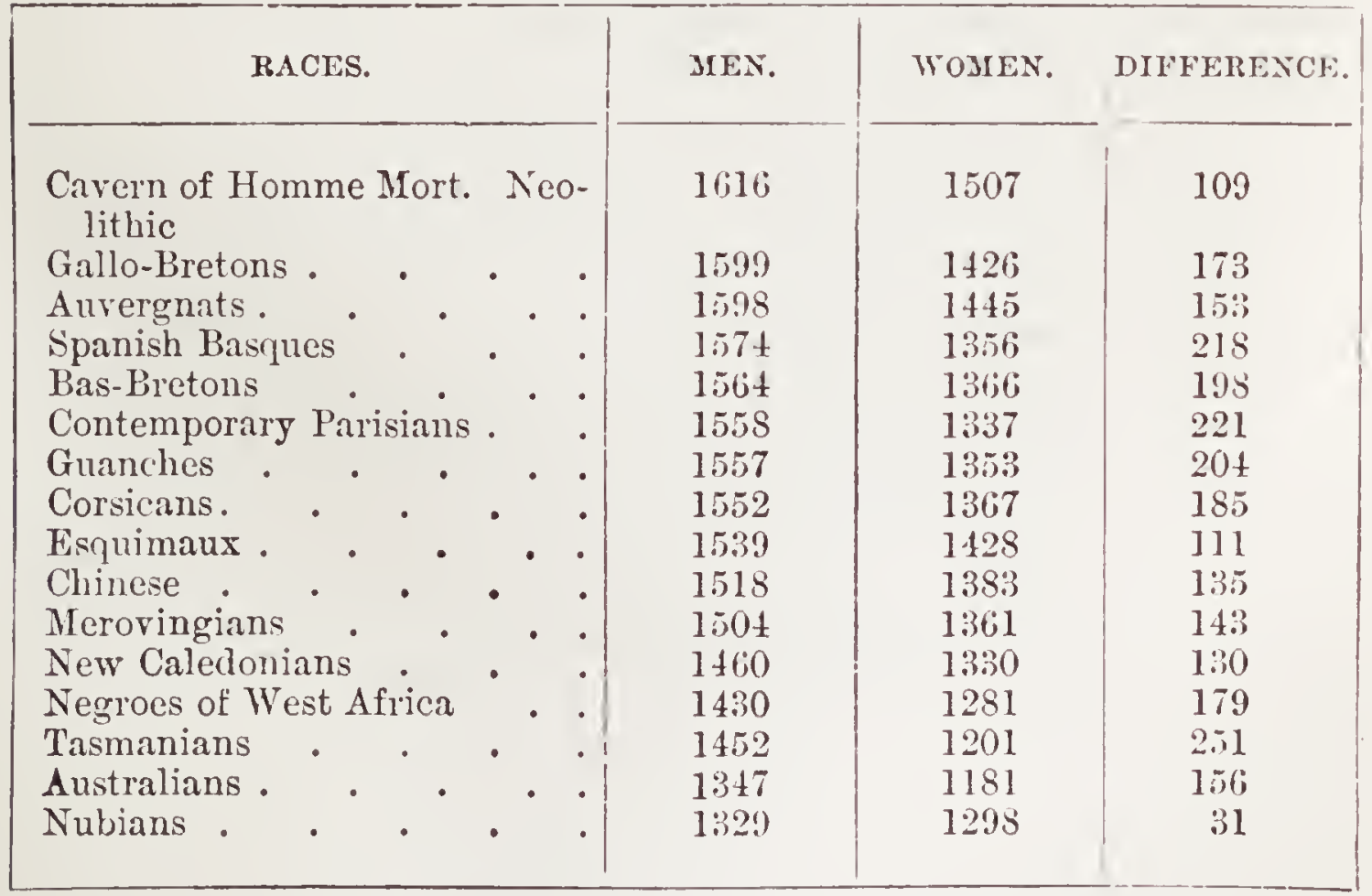

gives the mean cranial capacity, in cubic centimetres, for a certain number of races in both sexes. I have merely substituted the serial order in the men for the almost 
greographical division of the author, and calculated the difference between the sexes.

We here observe facts of intercrossing similar to those which I have so often pointed out. The Merovingians, a white race of the first order, are placed between the yellow Chinese and the New Caledonians, Melanesian Negroes.

But the chief value of this table is to show into what serious errors an estimation of the intellectual development of a race from its cranial capacity would lead us. By such an estimation, the troglodytes of the cavern of L'HommeNort would be superior to all races enumerated in the table, including contemporary Parisians, and the Chinese would come after the Esquimaux. The French populations occupy, it is true, the upper portion of the table, and the several Negro races are at the bottom. But here, again, when we find the Nubians following closely upon the Australians, we must confess that there can be no real relation between the dimensions of the cranial capacity and social development. We meet, moreover, with similar questions when we turn our attention to the brain.

The following table, which I borrow from Morton, is as instructive as the preceding. It includes a greater number of races. Moreover; the American sarant has not only given the means, but also the maxima and minima as established by his researches. His measurements are given in cubic inches. As they are only require $\bar{a}$ for comparison with those of other observers, I have not reduced them to cubic centimetres. I have again confined myself to arranging the means in a descending series, and to calculating the differences between the maxima and minima. 
Osteological Charactors-Cranial Capacity. ${ }_{3} S_{3}$

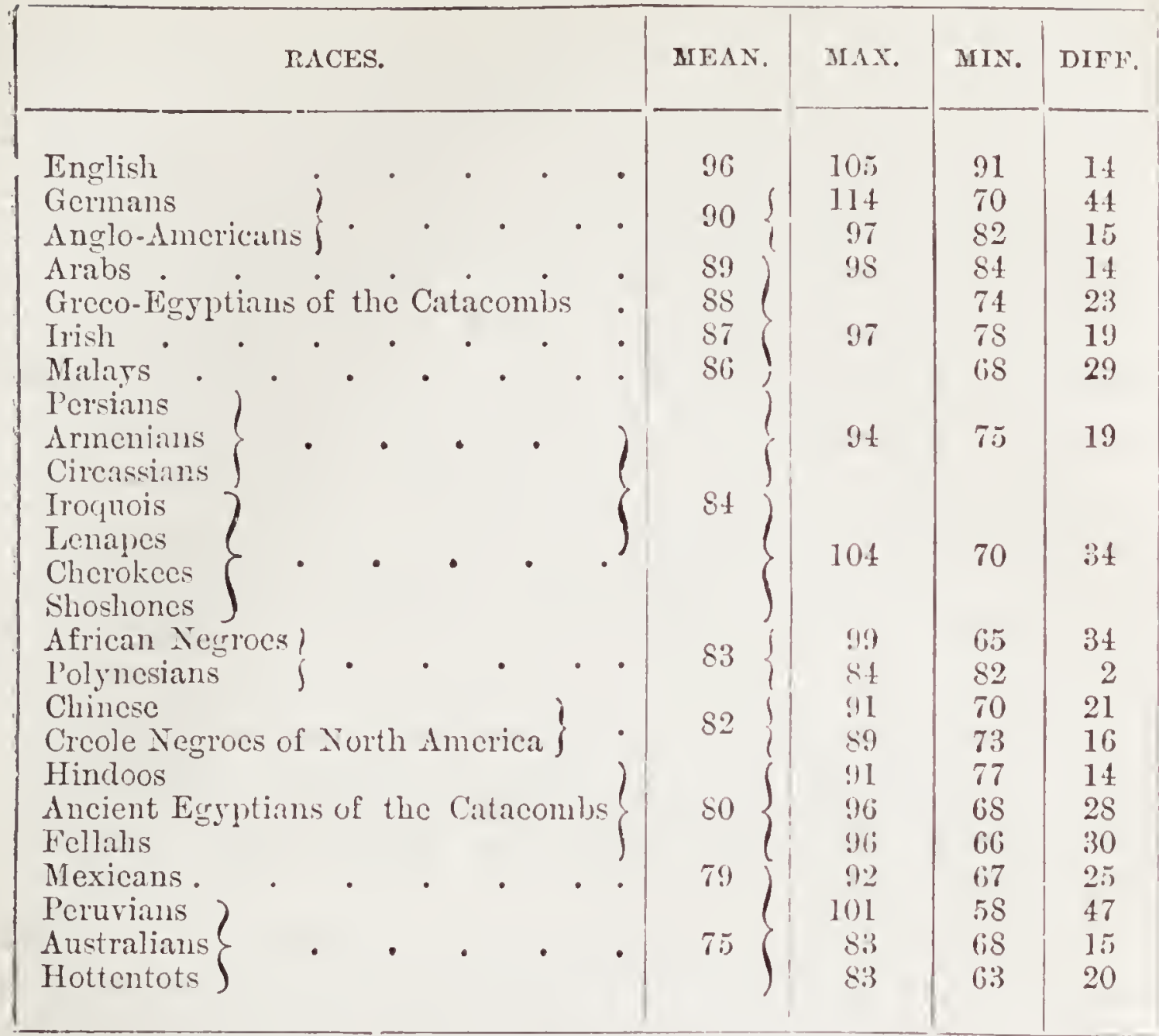

This table, borrowed from one of the most eminent supporters of polygenism, should, I think, excite reflections in all who pay any attention to facts.

We find the Chinese placed, by their mean cranial capacity, below the Polynesians, the African Negroes, and the savage tribes of North America. Is this really the position which their civilization assigns to them?

In Morton's table the Creole Negroes of America fall below the African Negroes by the lesser deve!opment of the same cavity. Meigs has confirmed this curious fact in several ways, and has even made the difference still wider; 80.8 for the former and 83.7 for the latter. And yet it is universally acknowledged that Negroes born in America are intellectually superior to their African brothers. Even Nott allows that it is so. With them, therefore, the intelligence increases, while the cranial capacity diminishes. 
'This fact is the more singular since the observations of M. Broca upon Parisian skulls of the thirteenth to the nineteenth century show that the cranial capacity increases with general intellectual progress. The measurements taken by the same observer upon individuals belonging to the educated and illiterate classes lead to the same conclusion.

Still, however, we cannot disregard the calculations of Morton and Meigs; and this experience, bearing upon numerous populations of the same race, seems to establish beyond a doubt the fact, which already clearly results from the comparison of different races, namely, that the development of the intellectual faculties of man is, to a great extent, independent of the capacity of the cranium and the volume of the brain.

I must here confine myself to the statement that the diminution of the cranium is, in North Ainerica, one of the characters of the Creole Negro race, derived from the African Negro race.

The intercrossing of races is again demonstrated in this table by the means. The Hindoos and ancient Egyptians are separated from the other White races of the Negroes, Chinese, Polynesians, and Red-Skins.

But the maxima and minima show still more clearly how far this confusion would be carried, if individuals were compared. Hottentots and Australians, by their maxima of 83, would stand before Germans and Anglo-Americans, whose minimum is not so high. With much greater reason would they be placed in the midst of all the other races, which, by their means, are placed above them. 'This is not all. Between the highest and the lowest mean, between the English and Hottentots, or Australians, the difference in cranial capacity is only twenty-one cubic inches. The difference between the maximum and ininimum of the Chinese is exactly the same. And it is much greater in nine other races, being more than double in the Germans and Peruvians.

Do we meet with facts like those resulting from the measurements of Morton in the species of a single genera of 
plants and animals? Certainly not; and this table is of itself sufficient to prove that the human groups are reces, which have little uniformity owing to the absence of selection, and in no sense species.

III. Character's drawn from the face alone.--Similar conclusions to those furnished by the examination of the cranium are suggested by that of the entire face. It may be either broad or long; and in order to distinguish these two forms by special epithets, we may employ the terms curyopse, dotichopse (owes, theatrical maski).

Since the face is much more irregular in form than the cranium, it gives rise to a fur greater number of observations. Each one of its features would deserve our attention, were we writing a detailed work, and the more so, as such close study as this can only boast an existence of a few years. Failing space, I shall confine myself to pointing out the nature of the characters, and commenting upon some of the principal results.

In the living subject the length of the face is estimated from the commencement of the hair to the extremity of the chin. But measurements of this kind are difficult to procure when exotic races are in question. Sliulls, therefore, have been examined. In the latter, the inferior maxillary bone is very often wanting, and even the teeth have, in too many cases, fallen out. The inferior limit of the length of the face could therefore be carried no further than the alveolar border of the superior maxillary bone. The point sus-nasal of M. Broca serves as the superior limit. The interval comprised within these limits is always less than the breadth measured across the zygomatic arches. In multiplying by 100 the length of the face and dividing it by the breadth, M. Broca has obtained the facial index. The following are some examples which I borrow from him with M. 'Topinard:

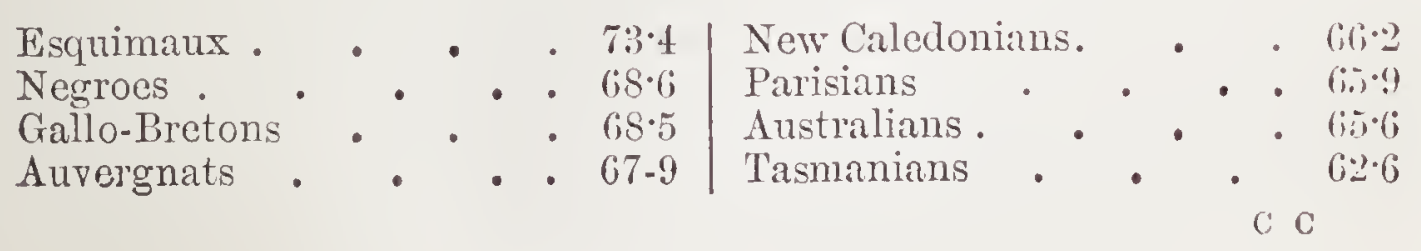


In spite of the smill number of these eximples, they might lead to remarks similar to those which I have already bronght forward on several occasions, and which I believe it to be minecessary to repeat.

The nose is one of the most striking features of the human face. Its general form and dimensions furnish some of the most special external characters in the distinction of races. But the morphological variations of this organ, presenting considerable difficulties, had long been neglected. II. 'T'opinard filled this gap, and showed that it is possible, even upon casts, to take measurements suitable for indices. Nevertheless, it is the skull that, up to the present time, has contributed the clearest indications. 'The breadth of the nose taken at the opening of the nasal fosse and multiplied by 1.00, compared with the length from the spine to the naso-frontal articulation, has furnished M. Broca with the terms of the relation expressed by his nasal index, the study of which has led him to important results.

Measurements, taken upon more than 1,200 skulls of all races, have enabled M. Broca to give $50 \cdot 00$ as the mean nasal index. In the entire number of races this index varies from 42:3:3 (Esquimaux) to 58:38 (Houzonanas). We see that the variation is only 160.5 . The individual differences are much wider, extending from $72 \cdot 22$ (Houzouanas) to 35.51 (Roumanians), thus giving a maximum variation of 36.51 .

'The difference between the maximum and minimum in: the same race is also very striking. When it exceeds ten, N. Broca seems to attribute it almost exclusively to crossing. He has made an ingenious application of this idea in the history of the crossing of the Franks with the races who preceled them in France. But we can scarcely allow that this is always the case when we see the difference rising to 21.98 in the Negroes of West Africa, and to 2.50.5 in the Hottentots and Bosjesmans. It seems to me that this is only the repetition of a fact which we have already proved with regard to the capacity of crania.

MI. Broca has made use of his nasill index to divide all 
human races into three groups from this point of view. In races of a mean nasal index, or Mesortiniun, it only varies from 48 to 53. Below these are ranged races with a long narrow nose, or Leptorkinian; and above, those with a broad and more or less flat nose, Platyrhinian.

The groups thus obtained are fairly homogeneous. 'T'he Leptorlimians would comprise only Whites, if the Esquim: ux had not most unexpectedly stepped in. The Platyrhinam group is composed exclusively of Negroes, and includes all the races of this type studied by M. Broca, with the exception of the Papuans, who are perhaps a mixed race. The Hlesorhinians embrace all the Yellow races, as well as the Polynesians, all the Americans and the Papuans, which I have just mentioned. We also find in this group Allophylian Whites, the Esthonians, and the Fimns, who are thus separated from the Aryans and Semites.

In short, if we take means alone into consideration, the nasal index, taken as a basis in the division of races, breaks a much smaller number of natural relations than the characters which we have as yet discussed. Apart from the exceptions which I have just alluded to, intercrossing here only appears between races belonging to the same type. But as soon as we take individual variations into account, the mixture, so often observed, reappears.

M. Broca has studied the nasal index not only in the adult. but also when in a state of evolution. He found that in an embryo of three months this index was 76.80 ; in a perfect fœutus, $62 \cdot 18$; in a child of six years, $50 \cdot 20$; in modern Parisians, 4681. Thus the index constantly diminishes as the body approaches its definite form. Our author concludes from this fact that the variations observed in the same race may often be referred to an arrest of development, or rather an arrest of evolution, and he seems disposed to attach the platyrhinism of Negroes to the same cause. He thus adopts the idea of Serres upon the general character of the Negro, which ideas we shall examine presently. This I regard as a very correct explanation of the origin of one of the distinctive 


\section{The Human Species.}

features which most clearly distinguishes the black race. It is not, however, to the nasal index alone that this fact is applicable, as I have already proved.

The orbital index, also studied by M. Broca, is obtained by multiplying the vertical diameter of the orbit by 100 , and dividing the product by the horizontal diameter. Considered from this point of view, races are divided into three groups, namely, the megusemes, whose nean index rises to 89 and higher; the mesosemes, whose index varies from $\$ 3$ to $\$ 9$ only; and the microsemes, whose index fall below 83 .

The highest mean index stated by M. Broca, is found in the Aymaras, in whom it rises to 98.8 . But we know that the cranium is artificially deformed by this people, and the practice nlay in some measure influence the form of the orbit. The maximum in normal skulls was observed in the Polynesians of Hawaï, where it was 9540. The minimum of 77.01 is presented by the Guanches of 'Teneriffe.

The mean maximum variation is then 18:30.

But here, as in all other cases, individual variations are much more considerable. Without even taking the Aymaras into consideration, whose index sometimes exceeds 109, M. Broca found 105.33 in a Chinese, 105 in a Chinese and an Indian Red-Skin, 100 in two women of the Marquesas Islands, a Peruvian woman, a Nalay, a Mexican, an Indo-Chinese, a woman of ancient Egypt, of Auvergne, and Paris. It is unnecessary to insist upon the meaning of these similarities.

The smallest orbital index known is that of the old man of Cro-Magnon, which we have seen to be 61:36. Above the latter, and at small distances from each other, may be ranged a Tasmanian, a Merovingian, the Mentone man (of the same race as that of Cro-Magnon), a Guanche of Teneriffe, a New Caledonian, an Australian, a Nubian, a Kaffir, a Spanish Basque, an Auvergnat, and lastly, the woman of Cro-Magnon, whose index is 7125.

The maximum individual variation is then 46.87 .

Upon examining the table of M. Broca, we find that the white races are represented in the three groups. 'The Dutch 
of Zaandam figure among the megasemes between the aborigines of Mexico and those of North-west America. The Gallo-Bretons are placed in the same group, between the Chilians and the Indo-Chinese. The Whites form the great majority in the group of mesosemes, and are much the most numerous in that of the microsemes. One of their races indeed, the natives of Teneriffe, terminates the series, immediately preceded by the l'asmanians and Australians.

Thus, as far as the white race is concerned, the mean orbital index proclaims an intercrossing comparable with all that we have hitherto observel. 'The case is different with the two other fundamental types. They are distinctly separated by this character. All the yellow races are megasemes, for in my opinion the Lapps, considered by M. Broca to belong to them, are in reality allophylian Whites. All the negro races are mesosemes or microsemes. There is a difference of 4.03 between the aborigines of Brazil representing the last megasemes which have not been deformed, and the Papuans of Toud Island, who have, of all Blacks, the highes" orbital index.

The usual intercrossing would undoubtedly reappear if we took individual variations into consideration. The difference 9.89 which separates the man of Cro-Magnon from the woman of the same race is sufficient proof.

M. Broca has studied the influence of sex and age upon the orbital index. I cannot follow him into these details, however interesting they may be. I will only remark, that, as in the case of the nasal index, it diminishes with the progress of evolution, and remains in all races greater in the woman than in the man. The latter preserves, then, throughout life, a certain infantile character.

This observation applies equally to races distinguished for the size of their orbital index. The yellow races, including the Chinese, present therefore, if compared with white races, an arrest of evolution. Yet the Chinese are far superior to all the microseme or mesoseme black races, and particularly the Australians and Tasmanians, who are only followed by 
the inhabitants of Teneriffe in the lowest places of the table. If we take the white as the normal type, we must regard these two populations as presenting an excess of evolution; but this excess is still more marked in the Guanches of 'T'eneriffe, who, in their mode of life, are considerably superior' to the Tasmanians and Australians.

A general conclusion follows from these facts, namely: that the characters resulting from an arrest or excess of evolution, are not of themselves a sign of superiority or inferiority.

N. Broca has, with great propriety, compared the orbital index of apes with that of man. As might easily have been foreseen, the laws of development are the same in the highest groups of apes as in man. "ithe influence of sex and age are as noticeable in the gorilla, the orang, and in the chimpanzee as in our own races. It seems to be less striking in the lower apes.

The orbital index groups apes, like man, into megasemes, mesosemes and microsemes. But this character connects the anthropomorphous apes with the lowest types, with the cebidx, and even the lemuridx, which we now, from their embryogeny, connect with the ruminants or edentata. 'The genera of simiade are divided into three groups. M. Broca draws from these facts the very first conclusion that no value, as characterising gradations, can be attributed to the orbital index.

It is well known that in the Negro the entire face, and especially the lower portion, projects forward. This trait has been termed prognuthism. In the living subject it is exaggerated by the thickness of the lips. But it is also apparent in the skull, and constitutes one of its most striking characters. M. Topinard has studied it in a special manner, and by a method of his own. He has with justice separated facial prognathism, which embraces the entire face, from the various maxillary and dental prognatleisms. which distinctions I proposed some time ago. The index is here furnished by the relation existing between the height, and the horizontal projection of the region under considera- 
tion. But M. 'Topinard has recently replaced this incex by the angle formed by the profile lines with the horizontal plane. 'This is a happy modification, as it presents a more precise idea to the mind.

The most important of the several prognathisms is that arising from the portion of the maxillary bone situated below the nose, and comprising the alveoli of the incisors and canines. 'This is the sub-nasal-alceolar prognathism, or the superior maxillary prognathism. It is this trait of the Negro which is opposed to the orthornathism of the White. This character suggests remarks similar to those which I have aheady made so often. It is the evident result of the following summary, which I borrow almost verbatim from M. Topinard's work.

All races and all individuals are more or less prognathons. As a rule, in European races it is only slight; it is much more marked in the Yellow and Polynesian races, and more strongly marked still in Negro races. Let us remark, however, that even mean indices place the Tasmanians $\left(76^{\circ} \cdot 28\right)$ above the Finns and Esthonians $\left(75^{\circ} .5 .3\right)$, and very near the Merovingians $\left(75^{\circ} \cdot 54\right)$.

The minimum prognathism, or maximum orthognathism, is found in the Guanches $\left(81^{\circ} \cdot 34\right)$, and the opposite extreme in the Namaquois and Bosjesmans (59 ${ }^{\circ}$ S $\$$ ). The means establish limits between the various sub-divisions of the great fundamental races. Individual variations, however, in this case, as in others, obliterate these distinctions. In all races there are exceptions, Negroes in whom prognathism is no more marked than in Whites, and Whites in whom it is very pronounced. M. Topinard regards these exceptional cases as examples of crossing, atavism, or as pathological phenomena. There is certainly some truth in this view. I have long referred the prognathism, sometimes so curiously marked in certain Parisian women, to atavism. But we must also take into consideration these oscillations of characters, which we everywhere meet with in races not subject to selection with any special aim. 
In any case we camnot consider cessation of development as explainirg the existence of a most striking prognathism in certain indiviluals of incontestably pure white race. In fact, far from diminishing with age, like the preceding characters, it rather increases. Even in the European, the child is manifestly more orthognathous than the adult. With regard to Negroes, Pruner Bey observed some time ago, and I have myself proved, that the child presents scarcely any trace of that feature, so characteristic in the parents. It is not till the period of puberty that it appears, and is rapidly developed. 'The forward projection of the maxillary bone is, therefore, in both races a fact of normal evolution, merely more marked in the one than in the other. Far from being the result of a cessation, prognathism betrays an excess of development.

The absolute theory of Serres, which would treat the Negro merely as a White, suljected to a cessation of general development, is then here at fault. 'The truth is, that in the black race, organic evolution is less advanced than the general type of white race in some respects, and more so in other's. 'This is a fact upon which I have long insisted in my lectures at the Museum, and which is confirmed, as we now see, by the more exact work of later years.

We see, also, that, in order to account for the differences separating the Negro from the White, it is by no means necessary to have recourse to phenomena of atavism as exhibited by animals. Simple oscillations, above or below the mean in the normal evolution of man, are sufficient to explain it. I feel myself, therefore, still more strongly justified in opposing the fuman cvolution theory to the simian erolution theory.

'The zygomatic arches, the malar bone, the superior and inferior maxillary bones also furnish the anthropologist with several more or less essential characters which sometimes acquire, in reference to a given race, a value superior to that which they have elsewhere. Such is the slight elevation of the pralatine vault in the Lapps. But I cannot here enter 


\section{Osteological Charactors-Facial Angle. 393}

into these details, and refer the reader to special books and memoirs.

IV. Characters drawn from the stull considered as a whole. When, instead of studying the face or cranium alone, we consider them in their reciprocal reiations, we see new traits appearing, furnishing a number of characters, some of which are of real importance.

Let us, in the first place, remark that there may be either harmony or dysharmony between these two great regions. The skull is harmonic in the Negro, whose cranium and face are equally long, and in the Mongol, who unites the two contrary characters; it is dysharmonic, as we have seen, in the old man of Cro-Magnon, and in the man of La 'Truchère, but for contrary reasons.

Cuvier endeavoured to find the relation of the skull and the face by making an antero-posterior section of the skull, and directly measuring the surfaces of the section. He found that in the White the face represented about 0.25 of the skull, 0.30 in the Yellow, and 0.40 in the Black. These results entirely accord with those furnished by the study of prognathism.

This relative difference of the development of the face led Camper to the conception of his celebrated facial angie. Struck by secing painters represent Negroes as Whites painted black, he studied the anatomical characters of the skull, and gave, as the proper distinction, the angle formed by two lines; the one passing from the auditory canal to the root of the nose, the other tangential to the forehead and to the nasal bone, both being represented upon a vertical projection of the model. Camper made use of his method to distinguish between the products of Greek and Roman art. He thus represented a decreasing scale from the works of art in statuary to non-adult apes. I reproduce it, not because of its real value, but on account of the importance which has been attributed to it. The following are the variations of the facial angle, according to Camper : 


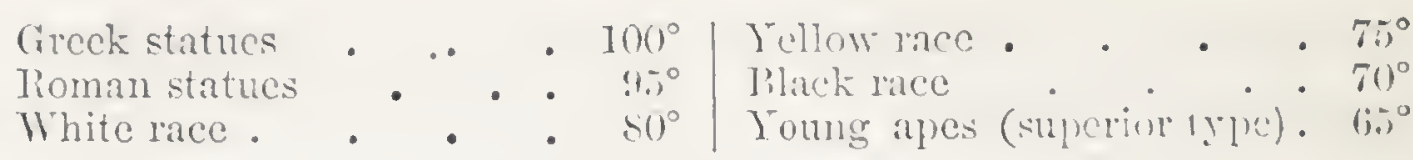

Geoffroy Saint-Hilaire and Cuvier, M. Jules Cloquet and Jacquard have adopted different methods in determining the facial angle. Morton, Jacquard, and M. Broca have invented instruments for measuring it directly. M. 'Topinard, after having examined the several methods, gives, with justice, his opinion in favour of that of Cloquet, which places the upper cxtremity of the angle at the alveolar border. M. Jacquard had chosen the nasal spine, remarking at the same time that the difference between the two angles might be of service in the calculation of prognathism.

Camper, or rather those who have followed him, wished to consider the size of the facial angle as a sign of superior intellectual power. His graduated scale has evidently given rise to this false idea. Pathological facts should have sufficed to show how great was the error. 'The work of Jacquard has, moreover; established this fact beyond a doubt. This author has proved a difference of more than $16^{\circ}$ in the educated White of Paris, that is to say, $6^{\circ}$ more than the distance established by Camper as separating the Negro from the White. Jacyuard, again, has proved in the French race the existence of an angle of $90^{\circ}$, an angle which Camper believed to belong only to the ideal representations of the human form. Now this remarkable angular superiority was by no means accompanied by an exceptional intelligence.

If we pass from the psychological to the anatomical meaning I shall hare similar remarks to make. There has been much discussion as to the position of the upper extremity of the facial line, which, with the horizontal line, forms the angle of Camper. It has been thought desirable to avoid the frontal sinuses, and to seek in the facial angle indications relative to the climensions of the encephalon, and not those of uny particular bone. I think, on the contrary, that we must be content with the latter, and not go further. It is evident that the dimensions of the encephalon are independent of the 
position of the frontal point, and that it may be more or less extended to the right, left, or behind this point without the facial angle being affected in any manner whatever.

The exact determination of the means of the facial angle will still, however, be valuable, like all those which it is possible to calculate upon the human body, provided there is a sufficient distance between these means. But M. Topinard has shown that this difference is not more than three degrees. Without altogether renouncing the ideas of Camper, we see that science now has characters preferable to those which he discovered.

A more important angle is the anterior parietal angle, formed on both sides of the skull by two lines tangential to the most prominent point of the zygomatic arch, and to the fronto-parietal suture. By taking the most prominent point of the parictal eminences as the second extremity, we obtain the posterior parietal angle. Prichard applied the term pypramidal skulls to those in which these lines converged. I have endeavoured to measure the angle directly with an instrument of my own invention, and my first researches have led me to results which I believe to be interesting. The angle is sometimes wide, sometimes narrow, and may be altogether wanting when the two tangents are parallel. It is, then, sometimes positive, sometimes negative. The latter is the case in the fotus and infants of all races. The negative angle is also met with in adults. This trait appears to have been very striking in Cuvier, judging from a fine portrait of the great naturalist when still young. I have found it to be $-18^{\circ}$ and $-22^{\circ}$ in two living persons, both remarkable for their intelligence. The positive maximum which I observed upon an Esquimaux cranium was $+14^{\circ}$. I have employed this character in my course of lectures to complete the characterization of a great number of races, but have never published any details.

M. Topinard has just filled this gap in a work which confirms, and at the same time, completes all my first results. His researches, bearing solely upon skulls, have given him 
as limits of individual variations, $5^{\circ}$ and $+30^{\circ}$; as limits of the means, $+2^{\circ} \cdot 5$ and $+20^{\circ} 3$. He found in the New Caledonians the most pyramidal heads. Finally, ho has seen in children from the age of four months to sixteen years, the angle decreasing from $-24^{\circ}$ to $0^{\circ}$ and rise to $7^{\circ}$.

Thus the negative parietal angle in the adult is nothing more than a persistent fœetal or infantile character. It is evidently the result of a cessution of development, or rather, a cessation of evolution. Now, we have just seen that this character may exist in individuals endowed with an intelligence above the average, and even in men of genius. A cessation of evolution, the persistent trace of a foctal or infantile condition, is not, therefore, necessarily a character of inferiority either in individuals or races.

'Two general views of the skull belong to the subject now under examination. Blumenbach regarded and represented the human skull from above. This is the norma verticalis, very valuable as permitting the appreciation of the general form of the cranium and some of its relations with the projections of the face. Owen has, so to speak, regarded it from below, and insisted upon the differences which the inferior surface offers between man and the lighest types of apes. Many characters of detail are brought to light by these two methods which I cannot even mention here.

In this necessarily very incomplete sketch, I have been obliged to pass by in silence a large number of characters which are often of a very substantial importance. The greater number are obtained by the method of projections so ingeniously perfected by M. Broca, and by means of instruments, some of which were already in existence, such as the diagraph, and others invented by various savants, amongst whom we must, again, especially mention M. Broca.

V. Slieleton of the trunk. I have dwelt at some length upon the characters drawn from the skeleton of the head; I shall be more brief in discussing the other regions. They furnish characters perhaps equally important, but they have been mucl less studied, and the fault does not altogether lie 
with anthropologists. It is not easy to procure skulls of the human races, even when we have to do with populations living close to us ; the difficulty of collecting a certain number of entire skeletons is far greater.

The thoracic cage presents some interesting facts sufficiently well proved. In consequence of the form of the sternum, the greater or less curvature of the ribs, it is generally broad and flattened in the White, narrow and prominent in the Negro and the Bosjesman. According to d'Orbigny, it is still more prominent in certain Americans. An analogous fact has been observed in some populations of Asia Minor.

The pelvis is the portion of the trunk which has been most thoroughly studied, by reason of the application which may be made of these researches to obstetrics. As a rule, comparisons have been limited to those between the Negro and the White. Vrolick, Weber, MM. Joulin, Pruner Bey, and, quite recently, M. Verneau, have gone much further. The latter, unfortunately, has not yet published his researches relatively to the distinction of races. Vrolick insisted upon some peculiarities of the pelvis of the Hottentot Venus, and endeavoured to establish certain relations between her and the ape.

Weber found that in each of the races which he had studied, the pelvis presented a predominant form, which, on that account alone, became characteristic. He regarded the inlet as being generally oval and of large transverse diameter in the White; quadrilateral and of large transverse diameter in the Mongol; round, and of equal diameters, in the American; cuneiform and of large antero-posterior diameter in Negroes.

M. Joulin has disputed nearly all the propositions of Vrolick and Weber, and seems unwilling to allow any characteristic value to the pelvis. M. Pruner Bey has shown without difficulty the great exaggeration of this view, and has determined the characters which distinguish, from this point of view, the White from the Black. 
The work of M. Ternean, much more complete than those of his predecessors, but with the anatomical part of which we are at present alone acquainted, will undoubtedly throw some light on the questions raised by their controversies. At present, moreover, the work of M. Verneau confirms the assertions of the greater number of his predecessors, as to the reality of the characters of race to be found in the pelvis.

Amongst these characters, there are some which have been pointed out in the Negro as indicutions of animalism. Even M. Pruner Bey, departing in this instance from his general practice, employs this expression, though at the same time restricting its meaning by his explanations. It seems to me much more natural to consider it as a trace of a condition, normal at a certain period, and more or less persistent according to the race.

In fact, the verticality of the ilia, and the increase of the antero-posterior diameter of the pelvis in the Negro, have been chiefly insisted upon as recalling characters which may be observed in mammalia generally, and particularly in apes. But we meet with the same anatomical characteristics strongly pronounced even in the foetus and children of the White. They, and especially the latter peculiarity, are persistent to the age of seven years or more. Their existence in the Negro is, then, nothing more than relative cessation in the evolution of this region of the skeleton. It is, again, a foetal or infuntile churacter, and not a character of animalism.

VI. Skeleton of the limbs. - When speaking of fossil races, I pointed out certain morphological characters of the bones of the limbs, and among others, that of the perforation of the olecranon depression. 'This character may be observed in the Bosjesman, the Guanches, ancient Egyptians, and our own races. It seems to make its appearance in Western Europe with the Quatemary brachycephalic races. M. Dupont met with it in the proportion of thirty per cent. among the men of the Lesse; according to M. Hamy, this proportion is twenty-eight per cent. in the fossil race of Grenelle and only +66 per cent. in the present population. 
I have already observed that the upper limb is a little longer in the Negro than in the White. The essential cause of this difference, is the relative elongation of the fore-arm. M. Broca, after comparing the radius and humerus of the two races, gives 79.43 for the Negro, and 7389 for the European. M. Himy, who had more numerous materials at his disposal, and followed a somewhat different method of measurement, obtained as result $75 \cdot 04$ and $72 \cdot 19$.

This elongation of the radius, relatively greater in the Negro than in the White, is one of the traits to which the expression simian character has been most frequently applied. We know, in fact, that there is less inequality between the two regions of the arm in the anthropomorphous apes than in man, and that in the orang the length of the radius equals that of the humeris.

The researches of M. Hamy enable us to consider this peculiarity of the Negro from an entirely human and truer point of view. This anthropologist has followed the evolution of this limb with a view of obtaining the changes which it involves in the relation under consideration. 'The following table gives the results of these investigations:

Embryo of $2 \frac{1}{2}$ months Foetus of :3-t montlis " $\quad 4$ 4-5 months

$" \quad, \quad$ " $" 7$ months

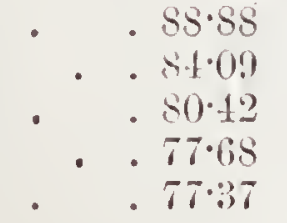

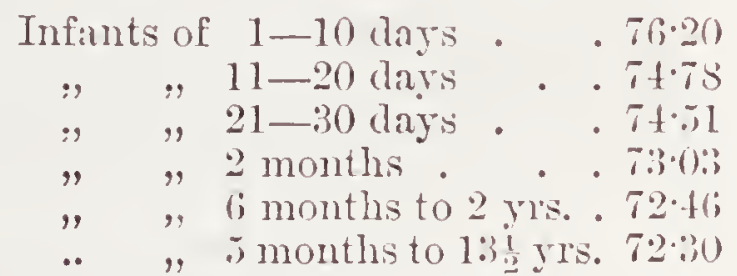

We see that in the development of the upper limb in man, there is a constant tendency to diminish the relation in question. We see also that the average of the Negro is almost that of a white foetus of five months. In his case, therefore, the elongation of the radius may be explained quite naturally by an arrest of evolution, without giving any occasion for comparing him with apes. Under what pretext should we return to the simian theory in connection with this character, after having seen that it is inapplicable in so many others? 
The lower member presents similar facts. According to the calculations borrowed by M. 'Topinard from ML. Broca, the tibia, when compared with the femur, gives a relation of $81.3: 3$ for the Negro, and 7.9.72 for the White.

By adding the figures which express the length of the radius and humerus, we have the total length of the whole arm, with the exception of the land; and by acting in the same mamner for the femur and tibia, we have that of the lower nember, with the exception of the foot.

The relation of the former to the latter is 69.27 in the Negro, and 69.7:3 in the White.

The following is a table of several races, drawn up by M. 'Topinard from his own researches and those of several other authors:

\begin{tabular}{|c|c|c|c|c|c|}
\hline Races. & & & $\begin{array}{l}\text { Relation of the } \\
\text { inf. to the } \\
\text { sup. member. }\end{array}$ & $\begin{array}{l}\text { Relation of the } \\
\text { femur to the } \\
\text { liumerus. }\end{array}$ & $\begin{array}{l}\text { Relation of the } \\
\text { tibia to the } \\
\text { femur. }\end{array}$ \\
\hline $\begin{array}{l}\text { Annamites } \\
\text { Tasmanians } \\
\text { Aïnos } \\
\text { Bosjesmans } \\
\text { Andaman Islanders . } \\
\text { Australians } \\
\text { Blacks of Pondichery. }\end{array}$ & $\begin{array}{l}\cdot \\
\cdot \\
\cdot \\
\cdot \\
.\end{array}$ & $\begin{array}{l}\cdot \\
\cdot \\
. \\
. \\
. \\
. \\
.\end{array}$ & $\begin{array}{l}67 \cdot 5 \\
68 \cdot 2 \\
68 \cdot 4 \\
70 \cdot 3 \\
70 \cdot 7 \\
71 \cdot 7\end{array}$ & $\begin{array}{l}7(6 \cdot 7 \\
8: 3 \cdot 5 \\
75 \cdot 2 \\
75 \cdot 5 \\
7(1 \cdot 9 \\
75 \cdot 9 \\
82 \cdot 9\end{array}$ & $\begin{array}{l}67 \cdot 5 \\
84 \cdot 3 \\
76 \cdot 8 \\
83 \cdot 5 \\
81 \cdot 8 \\
76 \cdot 9 \\
84 \cdot 4\end{array}$ \\
\hline
\end{tabular}

We see that, by this character, the European White is placed between the African Negro and the Andaman Islander.

I have already mentioned some remarkable morphological modifications, such as the prominence of the linea aspera in the femur, the platycnemism of the tibia, etc. I need not repeat them. 'The clavicle, foot and hand, also suggest many details which I must pass by in silence. I shall only observe that in Abyssinia it is neither by his colour nor his hair that the true Negro is preved to be claracterised, but merely by the relalively exaggerated prominence of the hecl. But this sign, which has been asserted to be infallible, is wanting in certain Negro 
races, not only in the Yoloffs, whose inferior member resembles our own, but also in the Bambaras, who have a flat foot.

VII. Characters drawn from the soft portions; nervous system. After having examined the external forms of the body, and reviewed the skeleton, we must take the organic apparatus one by one, and study them in their turn. Unfortunately the facts collected are here still more rare, when the observations should have been in larger numbers in order to give a definite value to the results. This study, which has been scarcely commenced, has in reality only been brought, till the present time, to bear upon the two most distant terms of the human series: the European White and the African Negro. This alone will justify me in giving a very cursory exposition of the results obtained.

The nervous system, of which Cuvier has said that it is the entire animal, is fortunately the part about which we possess, perhaps, the greatest number of comparative data. In the first place, we meet with a general fact noticed by Soemmering, and which is established beyond a doubt by the splendid preparations of Jacquard, exhibited in the galleries of the Paris Museum. Relatively to the White, the Negro presents a marked predominance of peripheral nervous expansions. 'The trunks are thicker, and the fibres more numerous, or perhaps merely easier to isolate, and to preserve on account of their volume alune. On the other hand, the cerebral centres, or at least the brain, appear to be inferior in development.

In fact, in spite of what Blumenbach and Tiedmann have said on this subject, the brain of the Negro is, as a general rule, less voluminous than that of the White. This fact is chiefly the result, it is true, of measurements of the capacity of crania. But determinations of the weight confirm this result.

Seven Negro brains weighed by M. Broca gave a mean of $1316 \mathrm{grm}$. (46.42 oz.). Upon uniting the weights of European brains I find, however, a mean of only $1248 \mathrm{grm}$. 
(44.02 oz.), that is almost exactly the average of the White woman. The average weight of adult European brains is 1405.85 grm. (49.59 oz.). But in both races, individual oscillations are very considerable. One of the skulls of the Black race examined by M. Broca weighed $1500 \mathrm{grm}$. $(52.910 z$.$) ; Mascagni had one of 1587 \mathrm{grm}$. (5.).94 oz.), and another of only $738 \mathrm{grm}$. (26.03 oz.).

The truth is that the European White alone has been seriously examined from the point of view of the estimation of cerebral development by weight. The merit of having furnished the elements of this study belongs incontestably to Rud. Wagner. Uniting the far more important results of his own researches with those of Tiedmann, Sims, Parchappe, Lélut, Huschke and Bergmann, this savant drew up a table containing the weight of 964 brains, which had been directly obtained after removing the coverings; he arranged them in order, commencing with the heaviest and finishing with the lightest. But he had not taken circumstances of sex, age, health, discase, etc., into consideration. The results which he obtained were, therefore, subject to alterations and corrections. M. Broca las accomplished this task. He took 347 cases of healthy brains from Wagner's table, and carried out his investigations entirely upon them.

A certain number of general propositions rise from all these researches, which may be formulated in the following manner :

1. Under similar circumstances, in other respects, the weight of the brain varies proportionately, or almost proportionately, to the lieight. According to Parchappe, the average weight of the brains of two groups of men with an average height of 1.74 metre $(5 \cdot 7$ feet) and 1.63 metre (5.2 feet), was 1330 grm. $(46.91$ oz.), and $12.54 \mathrm{grm}$. $(44.23$ oz.). In this example the differential relation, 6 per cent., is exactly the same for the height of the body and the weight of the brain. This influence of stature enables us to interpret and comprehend the facts brought forward by Mrr. Sandford Hunt. From the calculations of this anato- 
mist it rould appear that the average weight of the brain of Anglo-American soldicrs exceeds the average weight of European brains as deduced from Wagner's tables, by from 19 to 14 grms. ( 67 to $49 \mathrm{oz}$.), or from 1.33 to 99 per cent. But the American anatomist did not take into consideration the difference in stature, which he nevertheless notices. Now, from his calculations, it appears that American soldiers have, in this respect, the advantage over French and English soldiers to an extent of 3 per cent. The increase is, therefore, only apparent, and, indeed, rather points to a relative diminution.

2. Under similar circumstances in other respects, the female brain weighs a little less than the male. M. Broca has shown that this is the case at all periods of life. This difference appears to me, however, to arise almost exclusively from that of the stature of the body. Upon taking the woman as the term of comparison, and representing her neight and the weight of her brain by 100, we find 109. 43 and $109 \cdot 34$ as the result for the man. The latter relation is that given by Parchappe. M. Broca found 109.63; thus the relative heights are intermediary.

3. The maximum average of the European is observed between the thirtieth and fortieth years. It is then $1262 \mathrm{grms}$. ( $4.48 \mathrm{oz}$.) in the female, and $1+10.36 \mathrm{grms}$. ( $49.74 \mathrm{oz}$.) in the male, or, in percentages, 100 and 111.7 . The average for the entire period of maturity, between 30 and 50 , is $140.5 \mathrm{SS} \mathrm{grms}$. $(49.59 \mathrm{oz}$.) in the male, and $1261.5 \mathrm{grms}$. $(4.5 \mathrm{oz}$.) in the female.

4. Beyond this maximum the weight of the brain appears to decrease continually, and in a more or less constant manner. Such, at least, is the result arising from calculations bearing upon decemnial intervals, which show a constantly decreasing average in the male, as well as in the female. There is probably some relation between this diminution and that of the horizontal circumference of the cranium and the development of the frontal sinuses, observed long ago by Camper.

5. In the European White, a brain, to be capable of per- 
forming its functions, must weigh at least 975 grms. $(34.390 z$. in the female, and 1133 grms. $(39.96 \mathrm{oz}$.) in the male. 'These figures are the result of the discussion upon Wagner's table; they are, however, too high, to julge from some of Hunt's calculations. In the Bosjesman and Australian, and probably in many other races, the weight of the brain may descend as low as 907 grms. (31.99 oz.), without the intellectual faculties being destroyed.

Let us add that this organ may, moreover, fall much below this weight without causing cessation of life, or even the absolute disappearance of the intelligence, as in some microcephali. The smallest brains which have ever been weighed are those of 'Teite, quoted by Wagner, 300 grms. (10.58 oz.), and that of the woman who formed the subject of a memoir by Gore, 28375 grms. (10 oz.). These brains are appreciably inferior in weight to those of the gorilla and orang.

6. In the European White, the maximum weight of a healthy brain perhaps reaches 22.31 grms. (78.69 oz.) (Cromvell), or even 2238 grms. (78.94 oz.) (Byron). But there is not the certainty we should wish for about these figures. 'The weight of Cuvier's brain is, however, attested by the post-mortem examination conducted by Professor Bérard; it is 1829.96 grms. $(6843$ oz.). Mr. Sandford Hunt quotes another at $18+2$ grms. $(6.5 .32$ oz.). We may regard these figures as indicating the superior limit which can be attained by the brain in the White race without the general health appearing to be affected.

The figures obtained by Mr. Hunt from the calculations given by several authors for 278 brains of European Whites agree sufficiently well with the above. 'The average of the former is $1403 \mathrm{grms}$. (49.5.5 oz.). The maximum is that quoted ahove, 1842 grms. (64.97 oz.) ; the minimum falls to 963 grms. (3:3.97 oz.), which is very remarkable from its lightness, being below that which, in Wagner's table, seems to involve idiotcy. The results obtained by Mr. Hunt upon his Black and White fellow-countrymen, present, as regards comparison, a special interest. The brains of twenty-four 


\section{Anatomical Characters - Weight of Brain. 405}

American White soldiers gave an average weight of $1424 \mathrm{grms}$. $(43 \cdot 2 \mathrm{oz}$.$) in round numbers. 'The maximum was 1814 \mathrm{grms}$. $(65.98$ oz.) ; the minimum 1247 grms. (43.98 oz.). The brains of 141 Negroes gave an average of 1331 grms. $(46.98$ oz.), which is greater than the results of investigations made in Europe. The maximum was 1507 grms. ( $53.15 \mathrm{oz}$.); the minimum $1013 \mathrm{grms} .(35 \cdot 73 \mathrm{oz}$.).

The observations of $\mathrm{Mr}$. Hunt upon 240 crosses between the White and the Negro lead to interesting conclusions. The following is the result:

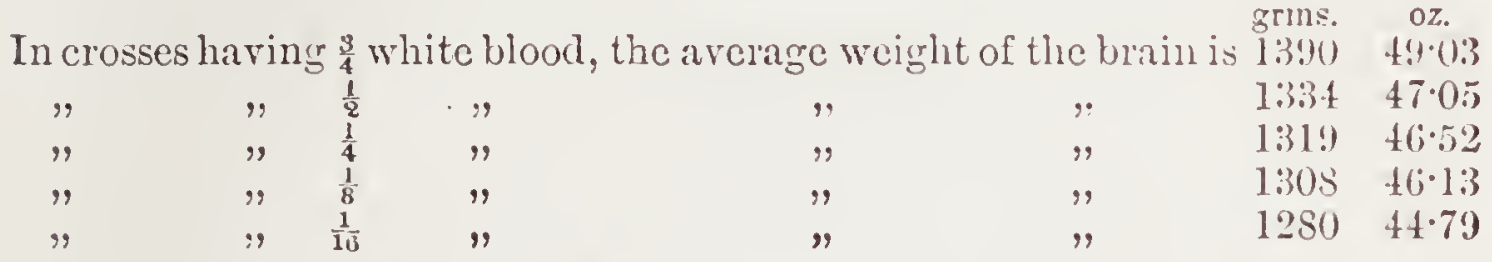

We see that the weight of the brain diminishes proportionately with the white blood. But it is especially curious to observe, that in crosses still possessing a tolerably strong proportion of superior blood, the weight falls below that of pure Negroes. The average was taken from twenty-two individuals, and the difference, $86 \mathrm{grms} .(3 \cdot() \cdot 3 \mathrm{oz}$.$) , is too$ great not to be taken into serious consideration. We should say that this is a phenomenon identical with that presented by colouring. Certain crosses, in whom the black blood predominates, are of a darker hue than the original Negro race.

To exhaust the little that we know of exotic races, I need only to add that in a Hottentot examined by Wyman the brain weighed 1417 grms. (49.96 oz.). This weight, which is greater than that of the average of Europeans, affords one more proof of that intercrossing to which I have so often called attention, and which has, in this case, perhaps a deeper meaning than elsewhere.

Since the publication of Gratiolet's admirable work Sur les plis cérébraux de l'homme et des primates, the study of screbral concolutions has assumed considerable importance 
in anthropology, although it has been somewhat exaggerated. The investigations of MLI. Dareste and Baillarger show that the development of these convolutions depends to a great extent upon that of the encephalon itself, and the influence exercised by stature at once explains certain facts which had formerly been the cause of some embarrassment. Under conditions similar in other respects, the brain of small races woukd be less convoluted than that of large reces.

But, apart from this influence, it appears as a well established fact, that in savage races the number and complication of the cerebral convolutions are less than in intelligent and civilized races. Intellectual culture would seem then to exercise an entirely special action upon the cortical layers, and to favour their development.

The known extremes at the present day of the character in question are offered by the Hottentot Venus and Cuvier. 'The brain of the former is the simplest that has ever been observed in an intelligent person. It recalls that of an idiot. The brain of Cuvier, which unfortunately has neither been modelled nor drawn, was, as we are told by the eminent anatomists who saw it, distinguished by the extraordinary complication of the convolutions and the depth of the sulci. Horeover, each convolution was, as it were, doubled by a kind of rounded ridge. In spite of these exceptional cases, no one would surely dream of placing the great naturalist in any other species than that to which his contemporaries belong. Neither can we consider the simplification of the brain of the Hottentot Venus as a specific character.

When comparative observations have sufficiently multiplied, we shall doubtless find more or less striking characters in the relative proportions of certain regions of the brain. For cxample, if Dr. Nott's observation be correct, the cerebellum in the Red-Skin extends beyond the cerebrum, while the latter, it is well known, extends beyond the cerebellum in the White and Negro. 'The same organ is longer in the Negro and broader in the White. 


\section{Anatomical Characters-Vessels, Glands. 407}

Naturalists, travellers, and anatomists announced long ago that the brain of the Negro is distinguished from that of the White by its blackish colour. An experiment performed at Paris under the superintendence of M. Rayer, upon which I have already made some passing remarks, confirms the general fact. I have already observed how M. Gubler, by whom it was prepared, wished to discover if there were no mean terms. He examined the colouring of brains obtained from individuals, all belonging to the White race, but whose complexions were differently coloured, and proved that the internal colouring was in direct relation with the external. In fair individuals with blue eyes and a pink and white skin, the pigment seemed to be entirely wanting. In individuals with a brown skin, black hair, and a very dark iris, "not only the brain enveloped by its membranes assumes a deeper shade, but a layer of black matter, in every way comparable to that of the Negro, covers the protuberance, the pineal gland, and some other points of the nervous centres."

Thus, internally, as well as externally, the colouring of tissues presents that graduated series to which I have so often called attention. This removes, therefore, the absolute nature which had been attributed to a peculiarity which had so often been insisted upon as separating the Negro from the White, to the extent of making him a distinct species.

VIII. Vascular and respiratory systems. Considered as a whole, the vascular system of the Black and that of the White present facts somewhat similar to those which we have observed in the nervous system. According to Pruner Bey, the venous system predominates visibly over the arterial in the Black; and here, again, the admirable preparations of Jacquard are a material proof of the correctness of the observations of the savant I have just quoted. This predominance seems to extend to the right cavities of the heart.

The lungs are less developed in the Negro than in the 
White. M. Pruner Bey has observed cases in which they seem to be pressed upwards by the abdominal viscera. 'The characters peculiar to the blood of the Negro, which were noticed in a preceding chapter, will, perhaps, at some future time, be connected with this group of anatomical conditions.

We have already seen that the cutaneous glandular system is more developed in the Negro than in the White. The investigations of M. Pruner Bey demonstrate that the same fact reappears throughout the whole length of the intestinal canal, the surface of which is everywhere marked by the prominence of secreting organs, especially in the stomach and colon. The large glands which are connected with the alimentary canal are also remarkably developed, particularly the liver. 'The case is also the same with the supra-renal capsules. All these organs are in a constant state of venous hyperemia. Finally, these intestinal mucous membranes are very thick, and present the appearance of adipose tissue. Facts of a similar nature will perhaps be observed in the greater number of intertropical races. We already know that in the Javanese the liver is as fully developed as in the Negro. 


\section{CHAPTER XXXI.}

PHYSIOLOGICAL CHARACTERS.

I. THE special history of human races presents a considerable number of interesting physiological facts which are sufficiently different and well marked, to serve as distinctive characters. We find in the tropics peoples remarkably abstemious, and living entireiy upon vegetables, without their organism being injuriously affected; in the polar regions there are others who eat fat in quantities which would be rejected by our digestive organs; there are also some slight variations between the respiration, circulation, animal temperature, secretions, etc. of the White man and the Negro; the muscular energy and the manner in which it is employed, sometimes vary considerably in different races; general sensibility, and consequently aptitude for feeling pain, are very unequally developed. The same surgical operation will not cause as much pain to a Chinese as to a European.

But the greater number of these traits arise from peculiarities which do not belong to general considerations. Many are the result of anterior facts, and are connected with conditions of life, habit, etc., sometimes even with beliefs and institutions. Even if we confined ourselves to a mere sketch, we should have to enter into details incompatible with the plan of this book, if we wished to discuss all these questions. I shall, therefore, here confine myself to pointing out some general phenomena to justify the above statements.

II. I will, in the first place, say a few words upon certain facts and ideas which have often been the occasion of ani- 
mated discussion. I mean the degree of relation admissible between the development of the intelligence and that of the brain. This question may seem at first sight to belong almost entirely to the study of the individual. But, from the manner in which it has been applied to the appreciation of the intellectual power of races, it has acquired a real interest in general anthropology.

On no occasion, perhaps, has this question been treated more thoroughly and by more competent julges than by the Paris Anthopological Society in the great discussion of 1861. Many speakers took part in it, but the two principal champions of the rival doctrines were Gratiolet on the one hand, and M. Broca upon the other. Some of their statements, if taken literally, would lead us to imagine that an impassable gulf lay between them. If, however, we read them again, after the excitement of the moment has passed away, we find, from the summaries which they themselves have drawn up, that such is by no means the case, and that, far from their being divided in principle, it would not be difficult to effect. an understanding between them.

Gratiolet considers "that power which lies in the brain, and which can only be estimated by its manifestations," far more important than weight or form. But he is far from absolutely refusing to recognise the influence of cerebral development; he allows that below a certain limit the human brain no longer performs its functions in a normal manner. This limit he places at $900 \mathrm{grms}$. (31.74 oz.) in the female.

M. Broca raises the number to 907 grms. (31:99 $0 \%$ ), and arlds that, in the male, the limit is 1049 grms. (37 oz.). He attributes great importance to the volume of the brain, estimated either directly, by weight, or by the capacity of the cranium. But on several occasions he protests most strongly agrainst the intention which might be imputed to him, of wishing to establish an absolute relation between the development of the intelligence and the volume or weight of the brain. "No well-instructed man," he says, "would ever 
think of estimating the intelligence by measuring the encephalon."

The two following tables, borrowed from M. Broca, will. suffice to show the truth of these words :

\section{AVERAGE WEIGHT OF THE BRAIN IN MAN.}

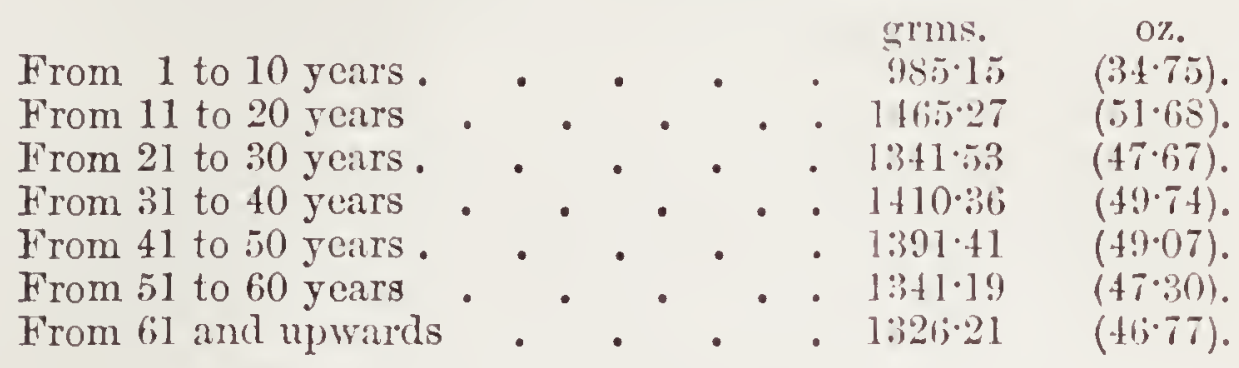

WEIGHT OF THE BRAIN IN SOME EMINENT MIEN.

NAMF. AGE. TROFESSION, WEIGHT OF BRATN.

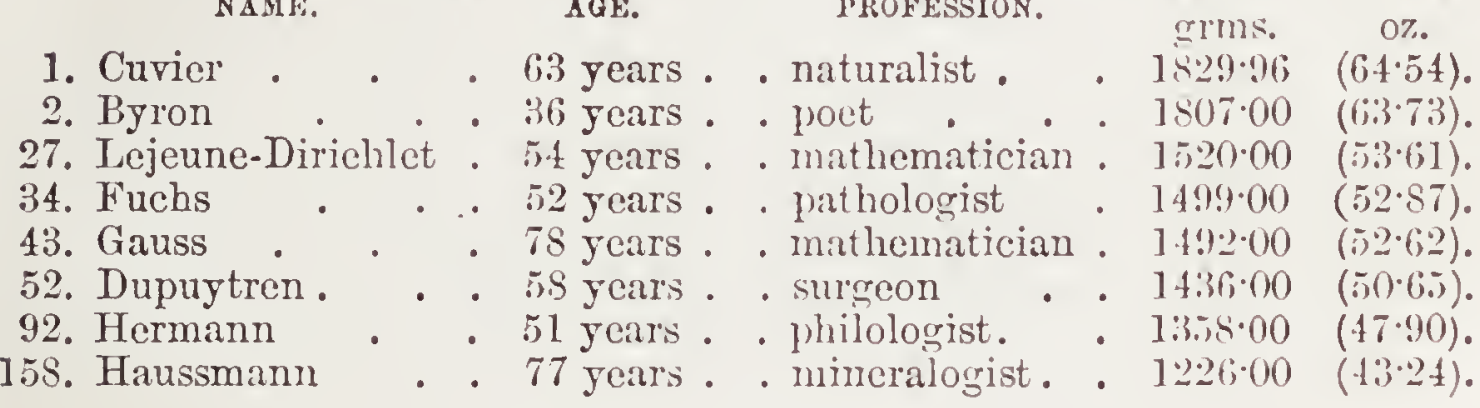

The numbers placed before the name of each person indicate the position held by the latter in the list of 347 cases of healthy brains taken by M. Broca from the general table of Wagner. We find that the celebrated mineralogist Haussmann stands almost half way down the list, and that he is separated from his eminent colleagues by a considerable number of unknown examples. Again, we observe that the weight of his brain is $100 \mathrm{grms}$. (35 oz.) below the average weight of men of his age. On the other hand, in all the other cases the weight of the brain was above the average.

The exception presented by Haussmann, the manner in which all these eminent men are scattered among their ordinary brethren, should be sufficient to make us reject all exaggerated connection of the magnitude of the intelligence and that of the brain. This result is still more striking if we group these same numbers as Gratiolet has done, calculating 
the mean of the contiguous weights. We thus obtain for the first group (Cuvier, Byron) an average weight of $1818+5$ grms. $(64 \cdot 14$ oz.) ; for the second (Dirichlet, Fuchs, Gauss, Dupuytren) 1487 grms. (5244 oz.); for the third (Hermann, Haussmann) 1292 grms. (45.57 oz.). 'The latter is below the average weight of German brains, that is to say, of the fellow-countrymen of the two eminent men in question.

'This remark is important. In the question under discussion it will not do to compare separately the celebrities who figure in Wagner's table; we must connect them with the rest of mankind, with diseased, as well as with other brains. To act otherwise would be to give rise to the idea that we had wished to evade a difficulty by neglecting to turn the attention to the fact that, immediately after the brain of Byron, and long before that of Gauss, stands the brain of a madman. Are, then, genius and madness in such close relationship? Are the volume, the weight, and the peculiar characters of Cuvier's brain indeed due to a hypertrophy which came to a standstill just at the right moment, as Gratiolet thought?

III. However abridged and curtailed this statement of facts may be, it seems to me sufficient to justify us in drawing conclusions equally applicable to individuals and to races.

We shall certainly not be accused of an exaggerated immaterialism if we estimate the action of the brain as we estimate the action of a muscle. Now experience and observation daily testify that in the latter volume and form are not everything. Functional energy often more than compensates for what is wanting with respect to mass. Many other organic systems would furnish similar facts, well-known to all doctors and all physiologists. 'To assert that the case is different with the brain would be, even in the absence of all direct observation, a purely gratuitons hypothesis, and, in the presence of Wagner's tables, a contradiction of evidence. With his small brain, Haussman, the correspondent of the 
French Institute, has evidently surpassed, in the matter of intelligence, almost all his large-headed contemporaries.

But, on the other hand, beyond a certain stage of decrease, the muscular apparatus becomes incapable of effort. We can readily understand that it should be so with the brain also. It is, therefore, most natural to find that, when it has fallen below a certain volume and weight, it gradually passes from weakness to impotence. Even M. de Bonald could not consider it strange, that an intelligence when provided only with imperfect or almost useless organs, should only manifest itself in an incomplete manner.

Thus, irrespective of all dogmatic or philosophic ideas, we are led to the conclusion that there is a certain relation between the development of the intelligence and the volume and weight of the brain. But, at the same time, we must allow that the material element, that which is appreciable to our senses, is not the only one which we must take into account, for behind it lies hidden an unknown quantity, an $x$, at present undetermined and only recognised by its effects.

IV. Thus from this fact alone it follows that we cannot act with too much caution in forming an estimate of a race from the dimensions of its cranium, and the relative development of the bones of which it is composed. Gratiolet proposed to distinguish frontal, parietal, and occipital races, characterised by the predominance of the anterior, medial and posterior regions of the cranium and the brain. If we accept the word character as it is understood by naturalists, we shall have no objection to make to these denominations But to go beyond that, to attribute to one or other of these races any kind of superiority by virtue of any one or other of these characters, would be mere hypothesis. In fact, the Basques, with their occipital dolichocephaly, are in no way inferior to the frontal dolichocephali of Paris.

V. In those phenomena, amongst which, à priori, we should be tempted to look for ethnological characters, we must give the first place to organic evolution at different periods of life. Now, the examination of facts establishes 
the important fact, that, in this respect, all human races present a remarkable uniformity. When some slight differences are manifested, they show such coincidence with the action of the conditions of life, that it is impossible not to recognise the relation of cause and effect, and this fact alone produced a most significant intercrossing between peoples evidently identical in origin. Thus, the whole mass of physiological phenomena, considered as characters, add one more proof in fivour of the monogenistic theory. A few examples will suffice to justify these statements.

VI. Let us first prove that the duration of gestation is the same in all human races. The importance of this fact wil! be readily understood.

It is generally known that the intra-uterine life presents a notable disparity in the same zoological group, and sometimes in nearly related species. If men constituted a genus, it would be very strange if they were exempt from this law, and that no differences should lave been olserved, as they certainly would have been, between groups. These differences may indeed exist to a certain extent without rising to a specific character, for they are observed in our races of domestic animals, where they appear to bear some relation to stature. Gestation lasts sixty-three days in large races of dogs; from fifty-nine to sixty-three in the small. This is the period observed in menageries for the gestation of the jackal, the wild stock of the dog. But it rises to something over a hundred days for the wolf, however nearly related it may morphologically be to some canine races.

The period of lactation is very variable as to duration in different human peoples. Without even going beyond France, we should have no difficulty in giving examples of such differences, in which the maximum would almost double the minimum. It is evident that in this case manners, customs, etc., play the most important part, and that the question of races scurcely enters at all. With the Negroes, lactation lasts, as a general rule, for two years, and the period is quite as long in all oriental populations. It lasts for five years in 
China. But as M. Morache tells us, the Chinese mother only prolongs it in order to retard the recommencement of the monthly courses, which, in this fertile race, is rapidly followed by a fresh pregnancy. There is nothing surprising in the possibility of such prolonged lactation. It is generally known that the secretion of the milk is supported by its use. Amongst ourselves, according to the evidence of Desormeaux, one nurse will sometimes suckle three or four infants in succession.

VII. The period of suckling is followed by that of cliildhood, a condition very distinct from those by which it will in turn be followed. The human being is as yet neither male nor female. The first manifestation of sex is one of the most important epochs of life, and it is interesting to observe that the arrival of this epoch varies within very wide limits.

The female, on account of the phenomena to which she is then subject, and which admit the possibility of direct observation, is, in this case, specially adapted for the researches of the anthropologist. Now, taking extreme numbers, obtained by different observers upon several peoples of the globe, we find that the minimum age at which the female becomes pubescent is that of eight to nine years, as observed by Oldfield in the Eboes, and the maximum age, that of eighteen to twenty years, noticed by Rush, among some tribes of North America. Setting aside these exceptional numbers, we find as general extremes, ten to eleven years on the one hand, and fifteen to sixteen on the other.

The variation we see is great, and we are naturally led to ask if it is at all constant in human groups. The numerous statistics which have been collected upon this subject, seem to justify us in giving an absolutely negative reply to the question.

And, in the first place, there is no doubt that here conditions of life play an important part. From the researches of M. Brierre de Boismont, it appears that, in the same locality, the higher or lower social position, and the consequent 
difference in mode of living, produces an average variation of fourteen months. In Paris, the women of the lower classes are pubescent at fourteen years and ten months, those of the middle class at fourteen years and five months; those of the upper class at thirteen years and eight months.

The mode of life is sufficient to produce differences of a very marked character in the age at which the female becomes capable of conception. At Strasbourg, as at Paris, the young country girl is behind those of the town. The difference is about $8 \frac{1}{2}$ months for Strasbourg and $4 \frac{1}{2}$ for Paris. In Alsace, as upon the banks of the Seine, the hardships of field labour render the functions of the individual life more active at the expense of those connected with the sexual.

Again, we cannot doubt the influence which is certainly exercised by temperature. M. Raciborski, adding to his own investigations those of a lirge number of other medical men, has even thought himself justified in drawing the conclusion that the age of puberty is advanced or retarded by a little more than a month for each degree of latitude, according as we calculate from the equator or the pole, with the condition only that the temperature increases or decreases with the satitude.

The action of the three causes I have just mentioned are most evident. But, as we have already remarked, food, temperature, and even mode of life do not alone form conditions of life. Many other influences besides these act upon the organism. The greater or less amount of light, and of actinic rays, cannot be without effect.

All these influences explain how it is that the age of puberty varies with the habits in the same race; how women, belonging to the same branch of the white aryan race, may present the extremes which I have alluded to above. From among the latter the Swedes and Norwegians are pubescent at from 15 to 16 years; the English at from 13 to 14 ; but the English Creoles of Jamaica at from 10 to 11 years. At Antigoa, Negro and White women, transported into the same 


\section{Physiological Characters-Puberty.}

common conditions of life, no longer present any difference in this respect. We see also how it is that women belonging to the most different populations and races, Swedes, Dacotas, Corfiotas, Potowatomies, English, and Chinese, become pubescent at the same age.

Does then race stand for absolutely nothing in the physiological phenomena under consideration?

Some facts seem to authorize us in holding a contrary opinion. The Esquimaux women of Labrador are as forward in this respect as the Negresses of our colonies. In the Potowatomies (Algonquins) and the Dacotas (Sioux) there seems to be an average difference of a year in the appearance of the first phenomena of puberty. Several other observations of the same nature might be quoted from various travellers. There is, however, nothing to astonish us in these facts. They are only the reproduction in the human species, of what we observe every day in our domestic animals and cultivated plants, all of which have forward and backward races.

M. Lagneau studied this question with particular reference to France. He came to the conclusion that the conditions of life are not sufficient to explain the differences which were proved by his investigations, and that the age of puberty, depending upon the rapidity of the development of the organism, varies slightly with the race. This opinion, which $t$ seems as if we might accept within the limits he himself has prescribed, M. Lagneau states with great reserve.

These limits are very narrow. They vary from fourteen years and five days to sixteen years, one month and twentyfour days. The minimum age is presented by the female pupulation of Toulon: the maximum, by that of Strasbourg: But between these two localities there is a difference of about three degrees of latitude and five degrees in the mean temperature. Toulon enjoys a very equable climate; the slimate of Strasbourg is, on the contrary, excessive; at Toulon the climate is sunny, while at Strasbourg there is much cloud; the Toulonaise lives in the open air, and 
breathes the stimulating air of the sea, the Strasbourgeoise lives in the house and breathes an air which is generally damp; the former drinks wine, the latter beer. All these conditions, stimulating on the one hand, and debilitating on the other, must exercise some influence. After taking all these circumstances into consideration, we see that, in France at least, the influence of race scarcely exceeds that exercised by difference in social position upon the population of the same town.

The researches of M. Lagneau also have reference to the time when, both in the male and in the female, the reproductive faculties become extinct. The evidences are here neither so numerous nor so definite. Nevertheless, from the little that we know on this point, the result would seem to point to conclusions similar to those which we have mentioned above.

VIII. We might easily be led to think that forwardness or backwardness in organic development, defined by the age at which puberty appears, should involve a proportionatcly longer or shorter duration of human life. Precise observations are far from being so numerous and complete as to solve this important problem with any degree of certainty. 'The greater number of facts with which we are acquainted, scarcely seem, however, to support the theoretical conclusions admitted by some anthropologists, by Virey among others. Everything seems to indicate, on the contrary, that the limits of life are almost the same for all human races, provided that they are placed in conditions of existence, which are relatively equally favourable. It is, in fact, evident that these conditions exercise a most marked influence upon the duration of organisms. When life is in question we do not deny the action of the conditions of life.

Here, again, appears the multiple nature of these conditions. We find from the statistical researches of Boudin that in sixty-seven years, from 1776 to 1843 , the average life of man in France was increased by eleven years. It has, therefore, gained sixty days a year; it has attained almost 


\section{Physiological Characters-Duration of Life. 4 I 9}

the highest limit gained in this respect by European peoples ( 34.45 years). The temperature has not changed, nor has there been any amelioration in the climate. But the general conditions of existence are modified and the result appears in these very significant figures.

The average life of European Whites, the only peoples concerning whom we possess sufficiently exact data, oscillates between 28.18 years (Prussia) and 39.8 years (SchleswigHolstein, Lauenbourg); a difference of more than eleven years.

The tables of average duration of life, collected by Boudin and borrowed from Hain and Bernouilli, prove beyond a doubt that, amongst our European peoples at least, mean duration of life depends to a very slight extent, if at all, upon the race. The German states present an average of from 28.18 years (Prussia) to 36.8 years (Hanover).

Temperature, at least when considered alone, seems to exercise hardly any notable influence, Naples standing almost midway between the preceding numbers ( 31.65 years).

These facts, obtained from among the best known peoples, justify us in thinking that, other things being equal, the duration of life must be almost universally the same. It will be understood that all strict comparison is here out of the question, for want of statistical documents, properly so called. Still, a number of facts obtained by various travellers amongst peoples of very different races, and, in some cases, placed under opposite conditions of existence, seem to justify this conclusion.

All travellers, who have been in a position to judge for themselves, have spoken of the Lapps as generally living to a. great age; men of from seventy to ninety years are not rare amongst them.

Upon the evidence of travellers of the highest reputation, it seems that the greater number of American peoples also reach an advanced age, and often without bearing any external traces of decrepitude. However rude and often precarious their mode of life may be, the representatives of 
these races are in no way inferior to Europeans, as regards duration of life.

Is it different in the case of the Negro, as Virey has thought? Everything seems to prove the contrary. Even when removed from his native land, and placed under conditions which we have seen to be very unfavourable to him, the Negro lives as long as the European. 'This result is obtained from the register of slaves consulted by Prichard in the West Indies. This anthropologist has shown, by examples drawn from different sources, that centenarians were far from rare among the individuals of this race scattered through different parts of America. From the documents which he quotes, it even appears that in the States of New Jersey, an official census gave a little more than one Negro centenarian in the thousand, but only one White centenarian in one hundred and fifty thousand.

Nevertheless Adanson, Winterbottom, and others, state that the Negro of the Senegal and Guinea age early in life, and the latter adds that individuals of this race rarely reach an advanced age. Dr. Oldfield, in the great English Expedition up the Niger, makes the same remark with reference to the part of the country which skirts the river Nunn, a marshy region, covered with a luxuriant vegetation supported by inundations. But higher up the river, in the country discovered by Nyffé, he met, on the contrary, with a large number of old men who must have been upwards of eighty, and visited an old chief, who, he says, was 115 years old.

There is nothing contradictory in these facts. 'I'hey merely show us that the Negro is subject to the law common to all other men. It is in vain that he has conformed to conditions of existence, which the White has so much difficulty in living under; when these conditions are aggravated and exceed a certain limit, he suffers, and his life is shortened. The native of the banks of the Nunn is placed, as a Negro, under concitions of existence similar to those to which, in former times, the Whites of the Dombe in France were subject, and in both crses the result was the same. 
Physiological Characters-Duration of Iiffe. $42 \mathrm{I}$

But beyond these exceptional localities, when the conditions are equally favourable, the duration of life seems to bo the same in the two typical races which are the most widely separated of all in the human species. In any case the same extreme limits have been proved for the Negro and the White. 


\section{CHAPTER XXXII.}

\section{PATHOLOGICAI CHARACTERS.}

I. THE pathological, as well as the physiological, condition in the various human groups presents peculiarities which may be considered as character's. These characters are sometimes even more clearly defined, because morbid phenomena are often very strongly marked. This question is one of great interest; but to treat it in the detail which it deserves, would require a greater amount of both time and space than can be given it here. I shall, therefore, confine myself to recalling a few general facts already known, and to quoting a few examples which will serve to fix the nature and meaning of pathological facts regarded from an anthropological point of view.

II. We have, as yet, in treating of the conditions of life, scarcely considered more than their modifying action, while it is universally known that they also exert a disturbing action. Actions of this kind are in most cases the fundamental cause of disease.

We are here, therefore, again led to considerations similar to those with which we have so often been brought in contact. We will therefore recall in a few words the general results of the preceding investigations.

1. The fundamental nature of all men is the same.

2. The formation of distinct races has been the sole cause of modifications in this fundamental nature of all human groups.

3. The several characters and special aptitudes which constitute a kind of acquired nature, have, in each of the 
groups, been developed under the influence of the conditions of life.

It is clear that when the disturbing action, the cause of disease, works upon the fundamental element, the same causes will produce fundamentally similar effects; when, on the contrary, this action is exercised upon the acquired and special element of each race, the same causes will produce different effects. In other words, unity of species and multiplicity of races involve the liability of all men to common diseases, which will, at most, vary as to accessory phenomena; but also allow the existence of diseases more or less peculiar to certain human groups.

Nevertheless, the great majority of diseases will be common to all men, and merely present modifications in the different groups. For example, one race may be either more liable to or more unsusceptible to certain affections than another.

Let me observe in passing, and without insisting upon facts known to all agriculturists and to all breeders, that similar phenomena are presented by the races of regetable species which have long been under.cultivation, and of animal species for centuries subject to domestication.

The propositions which I have just brought forward are the natural result of the facts to which $I$ have already drawn attention, and of the principles admitted at the commencement of this book. They are in remarkable accordance with the results of experiment and observation.

III. It becomes more and more evident, from investigations which are daily increasing in number, that all human races are subject to almost every disease.

The Negro and the White have often been contrasted from a pathological point of view, and it has been stated that localities in which the latter succumb, are not unhealthy to the former. It is said that marsh fevers, dysentery, and abscess upon the liver, so feared by Europeans, do not attack the inhabitants of the coasts of Guinea, and the banks of the Senegal and the Gaboon. These are exaggerated statements which were reduced to their true value by the observations 
of Winterbottom, Oldfield, and others. More recent works confirm these earlier observations in every respect: "Tho Negro race," says M. Berchon, "suffers from dysentery and abscess on the liver like the white race. . . The deadly fevers, which, with the two diseases just mentioned, form the pathognomonical trilogy of Senegalese pathology, will first attack Europeans; but the Blacks are by no means exempt from them."

The last remark is confirmed in a very remarkable manner by the numbers given in the accompanying table, which I borrow from MI. Boudin. He gives a summary of the English official documents upon the annual mortality in the thousand at Sierra Leone from 1829 to 1836.

DISEASES. NHITES. NEGRORS.

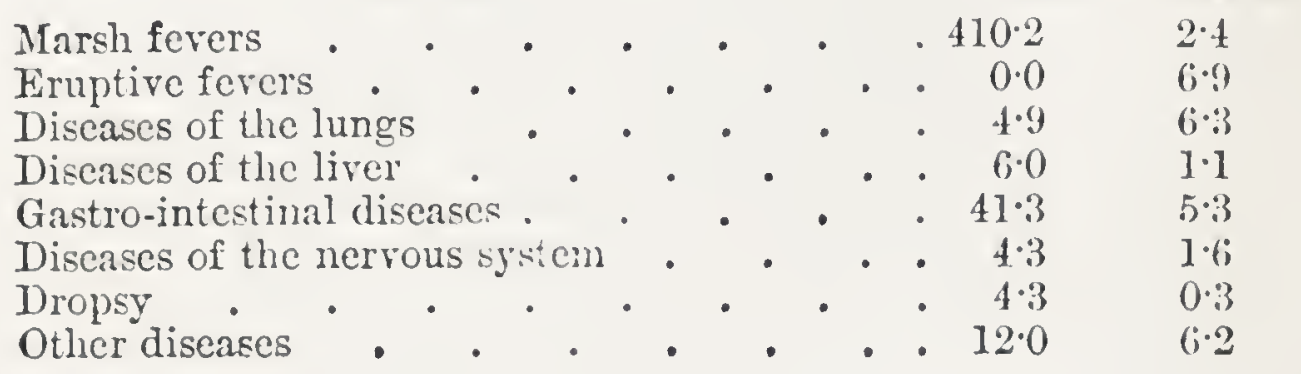

Sierra Leone is one of the most unhealthy stations for the White race, while for the Negro it is, on the contrary, one of the places where the rate of mortality is lowest. 'The relation which shows this difference is indeed most alarming (483.0 to $30 \cdot 1)$. Yet the nosological table is the same for the two races, for although in this statement there are no eruptive fevers given for the English soldiers, we know very well that the White races are by no means exempt from them.

Other tables drawn up by M. Boudin, with the assistance of the same documents, bring into still stronger relief the fundamental fact now under consideration. In one of them we learn the comparative mortality of the Negro and the Black from marsh fevers in seventeen localities, taken from nearly all parts of the globe, from Gibraltar to Guiana, and from Jamaica to Ceylon. The number of deaths is always considerably greater for the Europeans, but they almost 
always rise or fall simultaneously, and in the same place, for the two races, when both are immigrants.

It is almost unnecessary to repeat the remark that all the great epidemics are common to all races, and that the yellow fever attacks indifferently the White, Yellow, or the Black race. The yellow fever is so far from being special in character, and is so subordinate to the action of the conditions of life, that Mexicans from colder regions are as liable to it as even Europeans; and in the islands of the Gulf of Mexico the creole Whites easily withstand those influences which are so fatal to immigrants.

IV. Eruptive maladies, and particularly small-pox, seem to have been unknown in America till they were brought by Europeans to that continent. On the other hand, the latter gave them some of the most serious forms of syphilis, which characterised the terrible epidemic of the fifteenth century. In this fatal exchange, the character of the two diseases was remarkably aggravated in passing from one race to the other, so that populations attacked by them for the first time would suffer much more than those who had communicated the disease. In America, whole populations have disappeared from eruptive fevers, sometimes with terrible rapidity. The celebrated tribe of the Mandans, when blockaded by the Sioux, and unable to escape this scourge, was entirely annihilated in a few days, with the exception of a few absent individuals. Catlin, to whom we are indebted for these details, and who obtained them from Whites protected by vaccination, adds that those who were attacked by small pox, succumbed in two or three hours. On the other hand, we know what were the consequences in Europe of that infection, which, even at the present day, too often poisons the very sources of life:

'Thus, a human race may be unacquainted with one, or several diseases, or with certain morbid forms, though at the same time but too apt to contract them. Once attacked, it may even develop this disease, which is new to it, in a more violent form than any hitherto known. 
V. There are diseases which, though common to all human races, attack some in preference to others. The latter then enjoy, compared with the former, a relative immunity. This would necessarily result from what we have already seen. Let us add that these differences in the action of the same pathogenistic cause, are evident in cases of epidemics. When Guadaloupe was attacked by cholera in 1865 and 1866, the rate of mortality was 270 per cent. for Chinese, 3.86 for Hindoos, 4.31 for Whites, 6.32 for Mulattoes, and 9.44 for Negroes. These figures are the more interesting from the fact that all these races were immigrants.

It seems sometimes, as if two causes of death maintained a kind of equilibrium and reciprocity between two races. I have already, when speaking of acclimatisation, pointed out the contrast which is presented by the Negro and the White from this point of view. Of all human races the White is most sensitive to marsh fevers, and the Black least so. On the other hand, the Negro race suffers more than any other from phthisis, while the White race may, in this respect, be almost classed with other groups, with the Malays for example.

But, again, there are immunities more complete than that of the Negro, from marsh affections; and, further, these immunities may be lost, either in the case of an entire group of population, or in that of isolated individuals. I will here borrow two striking examples from M. Boudin's work.

Elcphantiasis, that affection by which certain parts of the body are sometimes deformed in so strange a manner, is found in the Indies and at Barbadoes. In the latter island, Negroes alone were attacked by this hideous disease till the year 170t. One White was, in that year, affected by it for the first time. But the disease made way, and in 1760 it had extended to the creole population. Whites of European origin have, as yet, escaped.

The elephantiasis of India is found in Ceylon. There, again, it only attacks natives, creoles and individuals of mixed blood. Hindoos and Europeans, strangers in the island, are exempt from it. Scott. quoted by M. Boudin, 


\section{Pathological Characters-Relative Immunity. 427}

states that only one case of this disease had been observed in a European White. But this individual had inhabited the island for thirty years; acclimatisation had been carried so far in his case as to cause him to lose his ethnological immunity.

On the other hand, we have seen, in speaking of acclimatisation, that creoles easily live and prosper in certain localities which are most dangerous to immigrants. They have, therefore, acquired, at the price of sacrifices made by preceding generations, a relative immunity which is not enjoyed by the majority of Europeans.

In the acquisition of one of these immunities, a race may lose another. In connection with the cholera which I have just mentioned, creole Whites and Negroes were attacked to an appreciably greater extent than Whites and Negroes who had recently immigrated, and were consequently not yet acclimatised. 'Thus, the conditions of life in Guadaloupe, and those of other Mexican islands, seem to exercise a double action. On the one hand, it diminishes in a considerable degree the aptitude to contract yellow fever; on the other, it renders the human organism appreciably more accessible to the influence of cholera.

VI. Such significant facts as these require no comment. It is clear that we have here those relative immunities which several polygenists wished to consider as specific characters. Without possessing anything approaching the importance which, from this point of view, is possessed ky physiological phenomena, they equally render evident the fundamentally identical nature of all human groups. Owing their special element essentially to acquired nature, they demonstrate the difference of races rather more clearly than physiological phenomena. Both, however, are equally functional; and the functions acting necessarily under the immediate influence of the conditions of life, demonstrate almost in the same degree the preponderating influence of the latter.

VII. We cannot touch upon questions of ethnological pathology without saying a few words upon the strange and 
fatal influence which the White race seems to exercise upon certain inferior races whose territories it has invaded.

Nowhere is this melancholy phenomena more striking than in Polynesia. Figures here speak with touching eloquence.

In the Sandwich Islands Cook calculated the population at 300,000 . In 1861 there were but $65,08 \mathrm{~s}$, about 22 per cent. of the original population.

In New Zealand Cook found 400,000 Maories. In 1858 there were only 56,049 remaining, 14 per cent. of the former population. Depopulation has continued from that time. From 18.55 to 1864 the loss was 22 per cent. for the province of Rotorua, the Lakes and Maketou; it was 19 per cent. in two years, from 1859 to 1861, in the Chatham Islands.

In the Marquesas Islands, in 1813, Porter calculated there were 19,000 warriors, giving a population of from 70,000 to 80,000 . In 1858 M. Jouan found 2,500 or 3,000 warriors and about 11,000 inhabitants, a decrease of 86 per cent.

From a comparison of the estimates of Cook and Forster, it appears that the population of 'Tahiti must have been at least 240,000. In 1857 the official census only gave 7,212, that is to say, a little more than 3 per cent. of the original population.

These facts would be equally strange, were they purely local. But they are universal, appearing even in the most isolated islands, in the Bass islands, which form the extreme limit of Polynesia on the south-east. At the beginning of the contury Davies counted 2,000 inlabitants; in 1874, Mœrenhout only found 300,15 per cent. of the former population.

The preceding calculations have all been taken from eastern Polynesia, which, as we know, was the first to attract Europeans. A few years ago, however, the western archipelagoes were in their turn invaded, and the population is already sensibly decreasing in the islands of Tonga, Vavau, Tongratabou, etc. The case seems to be the same in the Fijis.

Not only does the rate of mortality increase in this un- 
fortunate Polynesian race; there is also a decrease in the number of births. The fact has long been noticed in $a$ general manner. The following figures give it a strange precision. In the Marquesas Archipelago, at Taïo-Hae, MI. Jouan saw the population fall in three years from 400 to 250, during which time only three or four births were registered. In the Sandwich Islands, from among 80 women legitimately married, M. Delapelin found that only 39 had children. There were only 19 children in the twenty principal families of chiefs. Finally, in 1849, the official statistics quoted by M. Remy, give 4,520 deaths, and only 1,422 births. The case is the same at the other extremity of Polynesia. In New Zealand, says M. Colenso, marriages are rarely fertile. The seven principal chiefs of Ahuriri are without children, with the exception of Te-Hapuku; but of the four married sons of the latter, three are as yet without a family. Nine out of eleven marriages were here barren.

Many causes have been proposed in order to explain these melancholy phenomena. Wars, famines and epidemics have been suggested in turn, but these scourges are only local in their effects. Some have mentioned syphilis, but they forget that the mother of Edidée had died of this disease before even Wallis undertook his royage. The blame has been laid on drunkenness introduced, it is said, by Europeans; but before the importation of our spirits the Polynesians were quite able to inebriate themselves with their kava, more terrible even than our brandy. As to debauchery, we know to what an extent it was carried by the natives, who had, in that respect, nothing to learn from Europeans.

Can it be that a higher civilization bears within itself something which is incompatible with the existence of inferior races? Do the dominion exercised by the stranger, the invasion of the land, and the violence done to religion and customs inspire these men, once so free and proud, with such. despair that they refuse to have any posterity? We may allow some consideration to these moral causes in the phenomena which occur in Tahiti, the Sandwich Islands and 
New Zealand. But how can we apply this explanation to those archipelagoes where the local race has remained dominant, and where, with its ancient mode of life, it has preserved all the traditions of its ancestors? Now this was the case in the Marquesas during the time that M. Jouan and P. Mathias were there; European inhabitants are still rare in the Samoan and Tongan Islands.

Two naval surgeons, MM. Bourgarel and Brulfert, have alone been able to throw some light upon this melancholy problem. The former found that tubercles were invariably present in the lungs of bodies submitted to post-mortem examination. The latter tells us that almost all Polynesians suffer from an obstinate cough, and that in eight cases out of ten tuberculosis follows these bronchial catarrhs. Now phthisis does not appear in the list of diseases drawn up by the old voyagers. Have we, then, imported it into these islands? Developing in a new region, in a race to whom it was formerly unknown, has this disease assumed a more terrible form, with examples of which we are acquainted? Already hereditary in our own case, has it become endemic or epidemic in Polynesia? If it is so, we may say that it is all over with the Polynesian race. In another half century, or at most a century, it will have disappeared, at least as a pure race; it will have been replaced by a cross, which in the Marquesas Islands has already begun to increase the population. 


\section{BOOK X.}

\section{PSYCHOLOGICAL CHARACTERS OF THE HUMAN SPECIES.}

\section{CHAPTER XXXIII.}

\section{INTELLECTUAL CHARACTERS.}

I. IN this book I propose to give under a common title a concise examination of the characters due to intelligence, morality and religion. I shall thus, perhaps, be reproached with having connected too closely phenomena which, elsewhere, I have attributed to different causes, and consequently with having, apparently at least, contradicted myself. But, on the one hand, after what I have said upon this subject in the first chapter, there can be no doubt as to the manner in which I regard this question; and, on the other hand, intellectual phenomena acquire such a development in man, that sometimes they almost rise to the dignity of attributes, and therefore deserve to be placed by the side of phenomena which are entirely human.

II. In the preceding chapters we have reviewed physical man. But man is not merely a certain portion of organised and living matter like a plant. Besides this there is in man a something which feels, judges, reasons, and wills. This something, the origin and nature of which it is not the duty of the naturalist to discover, is manifested by actions and by facts. These facts differ in different human races. They may, they ought to be, looked upon as characters, equally with. 
the actions of our animal races, such as the pointer, the greyloumd, the terrier or the collic.

We shall see that, although approaching ground generally regarded as belonging by right to philosophy, anthropology does not on that account show any less respect for the domain of the latter: The philosopher is concerned with the distinction to be established between mind and matter, and with the discovery of the mysterious link which unites the physical with the intellectual being; the anthropologist with the investigation of the several manifestations resulting from this comnection, and with the recognition of the distinctive characteristic marks of the groups which he is studying. The former goes back to causes; the latter confines himself to effects, and therefore does not exceed the limits of natural science.

For this very reason, in treating of man, we meet with a difficulty at starting, which has been already pointed out. When entering upon the examination of psychological facts, science has scarcely more than details to study, as in the examination of physiological characters. Here, as elsewhere, the conditions of life play a considerable part. If they exercise an influence upon the manifestations of organic life, they influence to an almost equal extent those actions which interpret the acting and reacting element in us. And not only does our intelligence conform to present conditions, but indefinitely multiplies their influence by accumulating and combining all anterior facts by means of memory, and imposes upon itself new conditions from which new phenomena incessantly result.

The study of intellectual characters must, therefore, for the most part be carried out by the detailed examination of races. Nevertheless, we may notice in passing the most general features of some races, if only in order to explain more fully the truth of the statements which have just been made.

III. Language. "Animals have voice, man alone has speech." This truth, proclaimed by Aristotle, is universally 
accepted at the present day. Every one acknowledges that speech is one of the highest attributes of the human species. Languages, that is to say, the various forms assumed by speech among the different human races and their subdivisions, have, on this account, a separate importance as differential characteristic facts.

Without being a linguist, the anthropologist can well avail himself of the results obtained by philology, and compare them with those obtained by the study of physical characters. When by two such different methods we arrive at the same conclusions, we are evidently very probably in the right.

While giving the detailed history of the different races in my course of lectures at the Paris Museum, I was often obliged to extend considerably the comparison which I have just mentioned. I have almost invariably found the most striking resemblance between descriptive philology and anthropology. When, as an exception to this rule, we find a want of resemblance, or, better still, a contrast, such as that which exists between the physical characters and the language of the Basques, when compared with the neighbouring population, the problem always, as in their case, presents special difficulties, from whatever point of view it is approached.

It it more especially amongst the mixed races that the general agreement which I have mentioned is exhibited. Language often betrays at once the mixture of races, their succession, and the nature of the influence exercised by the different elements which have assisted in their formation. I will here give a striking example.

All polygenists have regarded the Malays as one of their human species; many monogenists have considered them as one of the principal races. I showed long ago that, in reality, they are only a mixed race in which white, black and yellow elements are associated, and that they are closely allied to the Polynesians. These facts become more striking every day as we know more of these two families which have 
sprung fiom a common stock. And further, as we study more thoroushly the history of these countries, we find that the relations between the insular and the continental regions. must have been much closer than it was long thought could ever have been the case. Such are the results arrived at by anthropology.

On the other hand, philologists have only been able to form one linguistic fomily from all the Malayan and Polynesian languages, when considered from a grommatical point of view. As to rocabulary, the following are the results given by Ritter.

The Malay language comprises in every 100 words-

50 Polynesian words, all answering to a very inferior social condition, only designating arts and objects for which all languages have names (heaven, earth, moon, mountain, hand, eye, etc.).

27 Malayan words, giving evidence of a more advanced civilization, and of the existence of arts already in a state of perfection (kiss).

16 Sanscrit words expressing religious ideas and abstract terms (time, cause, wislom, etc.).

5 Arabian words relating to mythology, poetry, ctc.

2 Javanese, Dravidian, Persian, Portuguese, Dutch or English words, all relating to commerce.

We see, therefore, that the language of the Malays explains, so to speak, under another form, the same facts as their physical characters.

IV. Although a naturalist, and therefore habitually disposed to attribute to the characters drawn from physical man a preponderating importance, I cannot allow that this superiority is absolutely constant. There are some facts which speak too strongly. Had it not been for their special language no one would have hesitated to consider the Basques as belonging to the same family as other Southern Europeans. Had their special dolichocephaly been discovered, as it has been by M. Broca, no one would have thought of making them allopholiun whites. It is the same 
with the peoples of the Caucasus, who were long considered, entirely on account of their physical characters, as the pure stock of White European populations. We must, therefore, acknowledge that in some cases language has a characteristic importance superior to that of external features and anatomical facts, or, at least, that it furnishes indications more readily understood.

This altemation of value between certain characters will cause no surprise to naturalists who are familiar with the results of modern zoology. 'They know that it is the same with animal species. In the vertebrata the respiratory organs furnish characters of the first order, which are dominant: in annelids, and in secondary types in which this function is less rigorously localized, families, perfectly similar in other respects, have the branchia very highly developed or altogether wanting. In their case the characters drawn from the respiratory organs are evidently secondary and subordinate. If this is the case between different species and different grouns, we must not be surprised if, with still greater reason, it should be the same between different races.

V. In anthropological applications of the science of language, every one will allow that far more importance must be attributed to grammar than to vocabulary; it is clear that it cannot be otherwise. But have we not in certain cases, despised too much the information which may be derived from the latter? The results to which Young has arrived from the calculation of probabilities may, it seems to me, be very aptly quoted here. The object of the illustrious author was to discover, how many similar words in two different languages were necessary to authorize us in considering these words as having belonged to the same language. From these calculations it appears that the common possession of one word has no meaning. But the probability of unity of origin is already three to one when there are two words common to both: and more than ten to one when there are three. When the number of words common to both is six, 
the probability is more than 1,700 , and almost 100,000 when there are eight.

It is, therefore, almost certain that eight words common to two different languages have originally belonged to the same language, and when isolated in the midst of a language to which they do not belong must be regarded as imported. These conchusions of the learned Englishman are of extreme importance. 'They tend to make anthropologists regard the relations between various peoples in a different manner from that to which many anthropologists have been accustomed, and force us to admit the existence of communications which we should otherwise be inclined to doubt.

VI. Whilst fully recognising the undoubted importance of linguistic characters, we must not trust to them entirely as guides in the estimation of ethnological relations. A language may become extinct and be replaced upon the same spot. The mere linguist would then assume the annihilation of a race or population which was in reality flourishing. 'I'his was the case with the Canary Islanders. The descendants of the Guanches having all adopted the Spanish language, it was thought that they no longer existed, till MI. Berthelot showed that in reality they formed the basis of the population of the whole archipelago.

VII. Monogenism and polygenism have fought, and are still fighting upon linguistic as well as upon organographical grounds. Thus it has very often happened that the scientific question has been obscured by considerations entirely foreign to science; and with the less reason as the opposed doctrines have really less connection with this subject than has generally been supposed.

From a linguistic point of view the problem may be stated in the following terms:-Was there in times past, a single primitive language, from which all languages, living or dead, have sprung? Or rather, have languages existed, and do languages still exist, which cannot be traced to a common origin?

We shall at orice understand the reply of the polygenistic 
philologist. Arguing from the differences by which certain families of languages are separated, they declare them to be irreducible, and with Crawfurd, M. Hovelacque, and others, state their belief "in the original plurality of the races which have been formed with them." On the other hand, this irreducibility is denied by Max Miiller, who, without as yet affirming the existence of a primitive language, allows us to see that, in his opinion, all philological researches are tending, to the demonstration of this fact.

Being a complete stranger to studies of this nature, I cannot express an opinion upon special questions. I shall confine myself to the statement of some general facts, and to pointing out the sense in which they seem to me to claim most attention.

This irreducibility, upon which the polygenistic philologists rely, recalls the argument, which is based upon physical characters, and consists in contrasting the Negro with the White. This argument long possessed a certain appearance of strength, which it has lost as more numerous intervening links were discovered between these two extremes. It seems to me that the general progress of philology is tending to the same result. All linguists now place side by side languages which would have been considered irreducible at the beginning of the century.

A certain number of languages may remain isolated without this fact affording any evidence against the specific unity of man. In all philological schools it is acknowledged that languages are variable and perishable. Now we do not know all the dead languages, and if some of the links in the chain are wanting it will at once be evident that relations which formerly existed have been lost to us for ever.

Let anyone, moreover, refer to the observations of Lubbock upon roots, and he will at once admit that a certain number among them can scarcely be common to all languages. Those who hold that language is not of divine origin, but a human invention and creation, cannot help adopting the conclusions of the learned Englishman on this point. Now, 
however few these radical differences may be, they necessarily involve irreducibility, which cannot, however, on that accomit be invoked as an argument against monogenism.

In support of this conclusion, I an fortunate enough to be able to appeal to the testimony of a judge, both competent and trustworthy. Whitrey, in his work upon "The Life of Language," has examined the same question. With Crawfurd and M. Hovelacque, the American linguist admits that there are linguistic fimilies which camnot bn referred to a common origin. He does not, however, stop at the bare fact; he demonstrates and discusses the causes of it. He then gives, in the following terms, the general conclusion of this discussion: "The incompetency of the science of philology to decide upon the unity or diversity of human races appears to be completely and irrevocably demonstrated."

However this may be, the results thus acquired bring to light a fact, the importance of which ought not, it seems to me, to be overlooked. Taking as guide the work of a man whose sompetency is above dispute, arranging the tables of the linguistic families admitted by M. Maury, and representing by lines the relations pointed out by this learned writer, we see that there exists betweeu one language and another in intercrossing of claracters extremely analogous to that which I have so often pointed out in human groups. No one has supported the hypothesis of the multiple origins of limguages more resolutely than Agassiz. In the memoir, which I attacked from a geographical point of view, he expressed himself very clearly upon this point. Since then he has developed the same ideas. I have already said that, in his opinion, mankind was created by nutions, that each received, with its physical features, its particular language, developed in every direction, and just as chanacteristic as the voice of an animal species. I feel it necessary to insist upon this point here, and to quote the text itself: "Let anyone fullow upon a map," says Agassiz, "the geographical distribution of the bear, the felide, the ruminants, the gallinaceie, or of any other fimily: we can prove, with just as 
much evidence as any philological research can for human languages, that the growling of the bear of Kamschatka is allied to that of the bear of Thibet, of the East Indies, of the Sonda Islands, of Nepaul, Syria, Europe, Siberia, the United States, the Rocky Mountains, and the Andes. Yet all these bears are considered to be distinct species, having in no way inherited voice from each other. Nor lave the different human races done so. All this is equally true of the crowing of the gallinacex, of the quacking of ducks, as well as of the song of thrushes, who ali pour forth their gay and liarmonious notes, each in their own dialect, which is neither inherited nor derived from another, although all sing in thrush language. Let philologists study these facts, and if they are not absolutely blind to the signification of analogies in nature, they will themselves come to doubt the possibility of placing any confidence in philological arguments employed to prove genetic derivation."

Agassiz is logical, and he exhausts the consequences of his theory. But he forgets one important fact which may be opposed to all those who, either fully or partially, embrace this order of ideas.

No animal species has ever changed its voice for that of a species nearly allied to it. An ass's colt, reared by a mare and isolated in the midst of lorses, never forgets its bray or learns to neigh. While, on the contrary, it is well known, that a White, if placed in earliest infanicy in the midst of Chinese or Australians, will only speak their language. The converse is equally true.

The reason of this is that the animal voice is a fundamental character, adhering evidently to the nature of the being, susceptible of slight modification, but incapable of disappearing, or of transference as a whole; it is a specific character.

Human language is entirely different. It is essentially variable, and sulbject to modification from one generation to another; it is subject to transformation; it borrows and loses; it may be replaced by another; it is evidently sub- 
orlinate to the intelligence and to the conditions of life. We can only, therefore, regard it as a secondary character; a churacter of rece.

from the linguistic point of view, the specific attribute of man is not the special langrage which he employs, it is the fuculty of articulution, speech, which has given him the power of creating a primitive language, and to vary it infinitely by means of his intelligence and will, more or less influenced by innumerable circumstances.

Here, again, I am fortunate enough to be able to support opinions, which I have long maintained, by the conclusions of Whitney upon this point. "Now" says this learned linguist, "to pretend, in order to explain the variety of languages, that the power of expression has been virtually different in different races, that one language has contained, from its origin and in its primitive materials, a formative principle which is not in others; that the elements employed for a formal usage were formal by nature, and so on, -all this is pure mythology."

VIII. General relations between languages and human recees. It is generally admitted that human languages may be traced to three fundamental groups; the first, monosyllabic, or isolating languages; the second, agghutinative, or suffix languages; the third, inflectional languages. Thus, there are three linguistic types, as there are also three physical types. It will not be without interest to discover what relations are displayed by the characters drawn from these two orders of considerations.

The inonosyllabic languages represent the most rudimentary concition of human language, which, moreover, has only arrived at inflection after passing through the period of agglutination. Considered from this point of view, linguages have arrived at perfection by degrees, and it is only natural to inquire if the general degree of elevation of races corresponds with that of the development of language.

From a comparison of the results of philological and physical studies, it is at once evident that this is not the 
case. Chinese, the most monosyllabic language, is spoken by one of the earliest civilized nations, belonging fundamentally to the yellow type. Tribes holding the lowest place, springing from the Negro type, speak, on the contrary, agglutinative languages, that is to say, have attained the second stage. I have already pointed out this fact, and insisted upon the consequences which arise from it with reference to the relative antiquity of human groups.

Nevertheless, we must remark that the greater number of Whites speak languages which have attained the highest degree of perfection-inflectional languages. Allophylian Whites, alone, are still in the agglutinative stage.

If, after having read the information which is given by philologists upon the distribution of races, we look at the map, we shall again meet with some very interesting general facts.

Monosyllabic languages are only found in Asia, as it were localized, and only occupy a very limited space. They were at one time even restricted to a kind of island, bounded by the sea on the east, and on all other sides by agglutinative languages. It is entirely due to the Aryan conquest that they have been placed in contact with inflectional languages.

The latter, now universally distributed, were for a long time confined to the old continent, of which, moreorer, they were far from occupying the greatest part. Their expansion lates from the great modern discoveries.

Languages of intermediate development, the agglutinative languages, occupied before this epoch, as they still do, the larger portion of the surface of the globe. We do not know at what period they lost ground in Europe, but we can already almost assert as a fact, that they predominated there in former times. They probably occupied the whole of this part of the world before the Aryan invasion or infiltration. Perhaps they were spoken by quaternary man. However this may be, before the great and quite recent emigrations of European races, agglutinative languages reigned throughout the greater part 
of Asia, almost the whole of Africa, and all Ancruca and Occania.

In pointing out approximately the areas occupied by the three findamental groups of languages, we find that the agghutinative languages alone occupied but a short time ago about $\frac{2}{2}$, of the carth's surface, inflectional languages $\frac{3}{15}$, and monosyllabic languages $\frac{1}{25}$; or nearly $\frac{7 \pi}{100}$, $\frac{20}{100}$ and $\frac{6 i}{30}$.

Agglutinative languages, again, have the adrantage over the other's in number. Finally, the number of nations, peoples or tribes, speaking these languages, is also superior to that of the groups which speak monosyllabic or inflectional languages.

But it is rell known how slight a relation there is between the population of a country, and either its cxtent or the number of human groups by which it is peopled. In order to gain an idea of the importance, or of the part played upon the surface of the grlobe, by one, or by a group of languages, we must calculate the number of individuals by whom it is used. Now, in comparing statistical and linguistic lata, for which we are indevted to MII. d'Omalius and Maury, we find that inflectional languages are spoken by $5: 36,900,000$ human beings; monosyllabic languages by $449,000,000$; and agglutinative languages only by $216,5.5(0,000$.

IX. Wriling. Writing is, so to speal, to speech what speech is to thought. Nevertheless, by its very nature it furnishes the anthropologist with but very few precise data. Invented in a very limited number of places, it has been communicated from place to place, and by initiation. In their passage from one nation to another, the graphic represcutations of languages are often sensibly modified, and, from this point of view, they may undoubtedly be of real assistance to ethnology. But there is no real relation between the several forms which they assume, and the human groups by which they are employed.

We can hardly connect with writing the various arrangemeuts of stories which were used by the Nexican Neoplyytes 
to recall to memory their praycrs, or the purely mnemotechnical process observed by different travellers, such as the Wumpum of the Red-Skins. But the latter, and especially the Chinese, Thibetian and Peruvian Quipos, were something more than this. Here the colour and the mode of juxtaposition of straws, shells, or wood, the knots and the colour of the threads, had a conventional value permitting the ex. pression of idcas, of great and multiple numbers, etc. In Peru it secms that real books were written in this manner. Unfortmately, as M. Maury remarks, it is now impossible to decipher these singular productions.

Pictography, even, in a form as rudimentary as that which existed and which still exists among the Red Skins, where Schoolcraft has studied it very thoroughly, was probably the universal starting point for writing properly so called. It is well known that pictography bcars a strong resemblance to our rebus, and that it has its monuments, which have been discovered by several travellers in Siberia, North America, the basin of the Orinoco, and even as far as Patagonia.

When symbolism was introduced into pictography, it would scem that a step had really been made, although grave errors may result from this manner of representing events, when the sense of the symbol is forgotten. The Virginians represented the Europeans, their ships and arms, by a white swan vomiting fire. There was here evidently the germ of some lesend. This obscrvation alone, enables us to comprehend and interpret some of the traditions, fabulous in form, but having a foundation of truth, which have been collected with reference to the past history of certain Amcrican tribes. Nevertheless, symbolism has the advantage of accustoming the mind to detach itself from the material reproductions of objects. It is then an easy mattcr to pass to the graphic reduction of the symbol, and afterwards to the idiographic sign. At length, spurred on by the stimulus of necessity, the phonetic sign is reached.

Even when the representation of the syllable is attained, 
witing has made immense progress. It seems as if certain races, in spite of contact with more advancel nations, and though they may have before their eyes examples of alphabetic writing, can never get beyond this. So at least it is at the present time with the Cherokees in Florida and the Veï on the coast of Africa. Sequoyah and Doala Bukara, in their efforts to imitate the Yankees and Arabs, only invented spelling-books. And yet the papers printed by the former bore, by the sicle of the Cherokee text, the English alphabetic translation.

It is unnecessary to insist upon the immense superiority of alphabetic writing. 'This means of fixing speech, at once so simple and so complete, has always presented an appearance of the marvellous to those who were unacquainted with it; and the ancients, struck with its utility, and not knowing that man had gained the art by slow stages, did not hesitate to regard it as a divine invention. Cicero himself seems inclined to share this opinion. We now know that the honour of this great discovery really belongs to the Phonicians.

But the Phœnicians did not make this discovery at once or by their own efforts. MLI. Wuttke and Lenormand have rightly given the honour of having prepared the way for, and of almost achieving the discovery, to the Egyptians. Egyptian writing, with its figurative, idiographic and phonetic signs, displays the whole course traversed by the human mind in rising from simple pictography to the alphabet. Unfortunately the Egyptians, fettered by the combined influences of their past, and by the very mass of ideas and facts represented in their complicated writing, especially perhaps by their religious traditions, could not free themselves from the cumbersome element in their system of writing. A strange people, free from these restraints, could alone, as M. Maury has remarked, take this step.

The Phonician alphabet once discovered spread rapidly. At the same time, however, it necessarily underwent modifications to suit, sometimes veritable necessities, sometimes simple conrenience or caprice. M. Lenormand admits five 
great families of writing, as representing this filiation. These are the Semitic, Greco-Italian, Western or Iberian, and Northern or Indo-homerite. The latter, perhaps, owed its origin to the alphabet of Yemen, which, introduced into India about the third or fourth century of our era, has engendered almost all the Oriental alphabets.

Egypt and Phonicia were not the only centres in which the art of writing took its rise. It also came into existence in the Old World in Mesopotamia and China, and in Mexico in the New World. Hieroglyphic writing, itself arising out of pictography, has been the universal starting-point, but in each case writing has stopped short at different stages.

Cuneiform writing has not attained the alphabet, and seems to consist of a mixture of idiographic and syllabic signs. In China writing has remained idiographic. Under the influences, however, of Buddhist missionaries, who made known the Devânagari alphabet in the extreme East, the Japanese and the Coreans, after having servilely imitated the Chinese, were the first to reach syllabism, the second to attain a veritable alphabet.

In Mexico, writing consisted of the mixture, still very confused, of symbolic, idiographic and phonetic signs, the latter representing, in some cases syllables, in others, simple letters. The discoveries made by l'Abbé Brasseur de Bourbourg seem to indicate that in Yucatan greater progress had been made, and that the Palanqué inscriptions are really alphabetic. It is much to be regretted that up to the present time the important facts, for which we are indebted to the aged curé of Rabinal, have not been utilized. The reading of the inscriptions of Central America would have a very different interest to the deciphering of a few more Egyptian tablets. However this may be, it is evident that the multiplicity, the variety of alphabets, and even their filiation furnish the anthropologist with characters of great importance, and specially fitted to establish ancient relations between human groups in some cases widely separated.

X. Social condition. Man is essentially a social being. 
"Wore any one to ascend to heaven alone, and listen atome to the harmony of the spheres, he would not onjoy these marvels," a Greek philosopher has said. 'Thus we find the, limman species everywhere collected into more or less bumerous societies. In exceptional cases, which may be grenerally explained by a violent dispersion, these societies always consist of a more or less considerable number of fimilies, and deserve at least the designation of peoples.

However limited or numerous peoples, tribes, or nations may be, the existence of three elementary social conditions has long been accepted as a fact, each of which is connected with the satisfaction of the first and most imperious of all necessities, that, namely, of nomishment. A certain gradation may, moreover, be observed in these conditions. Man at first only depended upon daily industry for his subsistence: he hunted either terrestrial or aquatic aninals: he became a hunter or a fisherman. He afterwards bronght the herbivorous species under his power, and found an unfailing resource in lis flocks: he became a shepherl. Finally he directed his attention to the earth; he multiplied and cultivated certain plants which he learnt to know by experience; he became an agriculturist. In the latter. case his diet would be fundamentally vegetables; in the two former flesh would form the basis of his food.

It is clear that these several kinds of existence place man under very different conditions of life, and impose upon him certain necessities, by demanding the development of physical and intellectual faculties which sometimes bear but a very slight resemblance to each other. In this manner certain physical and intellectual peculiarities are engendered, which, developed by exercise and heredity, finally become characters of races.

The hunter and fisherman present some points of resemblance in their manner of life. Both are obliged to clisplay in turn, and occasionally at the same moment, according to the animal they are pursuing, a great amount of patience aud conrage; they must never be at a loss for a resource. Pioth, 
even when placed in the most favourable circumstances, pass alternately from extreme activity to almost complete repose. But the fisherman's field of action is on the whole less extensive than that of the hunter, and he is not like the latter, forced to exercise all his physical faculties. He will probably never possess the same delicacy of hearing, or the same agility. Moreover, neither of them are placed in conditions favourable to intellectual development properly so called.

The shepherd is much more independent in certain respects, while at the same time he is subject to greater regularity. $\mathrm{He}$ is always sure of his morrow. The daily duties to his charge once fulfilled, he is at liberty to abandon himself to reflection and revery, so that his intellectual faculties have every facility for development.

This is still more strongly the case with the agriculturist Seed-time and harvest are to him times of inevitable physical activity. Between the two he can rest at leisure, and apply the faculties with which he is endowed to something entirely different.

These three elementary modes of human socicty involve immediate consequences.

Game, in the true acceptance of the term, is nowhere so abundant as to afford an indefinite amount of nourishment to populations, however small, accumulated upon one spot. A great extent of country is absolutely necessary to the hunter, so that he can only form very limited communities. As soon as they increase in size they are forced to separate. Fishermen may form larger communities, particularly upon the shore of a productive sea. Even in their case, howerer, the size of the population is necessarily confined within somewhat narrow limits.

The pastoral condition allows the formation of more numerous societies; but it also involves the existence of rast tracts entirely given up to grazing. Like the chase, therefore, though in a less degree, it enforces subdivisions.

The culture of the soil permits the derelopment of a population at snce dense and continuous. 
The hunter, as a natural consequence of his warlike habits, is ineritably a warrior; war is, in fact, nothing more than a "man-hunt." Any discussion about a hunting-ground may easily result in war, as the subsistence of the hunter is in question. This war would be conducted without mercy, for every prisoner would not only be useless, but an incumbrance to the conqueror; another mouth to feed. The liunter would kill him, and however little may be due to passion on the one hand, and pride on the other, he will put him to death with torments endured with heroic firmmess.

'The shepherd also will often be involved in armed conflict, for he must defend his pastures and his flocks. But, in his case, war will be less bitter; the prisoner may be useful to him. He can be forced to attend to the flocks, and, in return, be fed without involving any sacrifice: he can be a slave.

Were it not for the necessity of mutual destruction, which seems to be innate in man, and which, as yet, civilization has not been able to extirpate, agricultural tribes would have no cause to make war upon each other; indeed, it would he much more to their interests to avoid it. All that can be said, howerer, is that in their case it becomes by degrees less cruel. Here, again, the prisoner can be utilized. He is first reduced to slavery. Then it becomes evident that a certain amount of liberty miglit be profitable to the master, so he passes from the condition of a slave to that of a serf.

'The three conditions which I have just described still exist upon the globe; and in each of the three great types of mankind, examples may still be pointed out at the present day. The White tribes of the north-west coast of America are fishers; some Arab tribes are still in the pastoral state, through which the Aryans, the progenitors of the present Indians, who are so essentially agricultural, have passed. Among the Yellows, the 'Tunguses of Daouria, are perhaps the most perfect type of a hunting people, as the hordes of Central Asia are of a shepherd people, and the Chinese of an agricultural people. Finally, among the Negroes 


\section{Intellectual Characters-Soczal Condition. 449}

the Tasmanians were exclusively hunters and fishers, the Kaffirs are essentially shepherds, and the natives of Guinea agriculturalists.

Thus the fundamental nature of the social condition is not a character of race. The three physical types present the three social types.

From this fact alone we might conclude that between the three human types, regarded from the point of view of civilization, there are none of those radical differences which have been admitted, a priori, by some authors.

This conclusion can only be distinctly shown by a detailed study of the races. I can here merely state it, insisting upon this point that, in spite of the assertions of M. de Gobineau to the contrary, there still exist Whites in a distinctly savage state. We need only read the details given by Cook, La Pérouse, Meares, Marchand, Dixon, Dr. Scouler, and others, upon some Kolushes, and we shall be forced to recognise these fishers, whose women besmear themselves with grease and soot, and wear a girdle, as both true Whites and true savages, who in many respects must rank below the Negro of Ardra or Juida.

On the other hand, the very names which I have just mentioned, especially those of Ghanata, Sonrhaï and Melle. with which Barth has made us acquainted, suffice to prove that the most strongly characterized Negro, the typical Negro, has the power of raising himself to a considerably advanced social condition. It has been said, that, without being a savage, he has remained a barbarian, as was the case with our German or Gaulish ancestors. 'This view is not a just one; the Negro has risen much higher. The annals of Amed Baba show that in the Middle Ages the basin of the Niger contained empires very little inferior in many respects to European kingdoms of the same epoch.

As to the Yellow races, it will be sufficient to remember that the whole of the Aryan race was plunged in harbarism at the time when China was acquainted with the calendar, had determined the form of the earth, and recognised the 
flattening of the poles, had woven materials in silk, and possessed a coinage.

XI. Ought we to conchude from these and from many analogous facts which I cannot quote, that there exists a perfect equality between human races, that they all possess the same aptitudes, and can all rise, in every respect, to the same degree of intellectual development? Not so, for this would be a departure from the truth, and an evident exaggeration. Here, again, we must return to the comparison of man with animals. Does it follow that, because all the races of logs belong to one and the same species, they all have the same aptitudes? Will a hunter choose indifferently a setter, or a blood-hound to use as a pointer or in the chase? Will he consicler the street-cur as of equal value with either of these pure-breecls? Clearly not. Now we must never forget that, while superior to animals and different to them in many respects, man is equally subject to all the general laws of animal nature. 'The law of heredity is one of those from which he cannot escape, and it is this law which, under the influence of the conditions of life, fashions races and makes them what they are.

When centuries have passed over a group of men, when from generation to generation, and under the influence of certain physical, intellectual and moral conditions, the whole being has contracted a certain habit, we camnot form any definite idea as to what length of time and what fresh circumstances would be necessary to efface this impression and form the race anew. In any case, it can only rise by undergoing modifications, and this fact alone produces a new or a derived race.

The result of all the conditions by which races have been formed has been to establish between them a present inequality which it is impossible to deny. Such, however, is the exaggeration into which negroplieles by profession have fallen, when they maintain that the Negro in former arges, and in his present condition, is the equal of the White. A single fact will be a sufficient answer to them. 
The discoveries of Barth liave placed beyond a shadow of doubt the existence of a political history among the Nergroes, which had previously been a matter of doubt. But this very fact alone only serves to place in still stronger relief the absence of that intellectual history which is demonstrated by a general progressive movement, by literary, architectural and artistic monuments. The Negro race, left to itself, has produced nothing of this kind. An attempt has been made, in order to disguise this too manifest inferiority, to refer to the Negro race those peoples of black colour, who can only be said to be comected with it by crosses in which the superior blood predominates.

XII. Must we therefore pass to the opposite extreme, and admit that there are races radically incapable of elevating themselves above the social condition in which their ancestors have lived? This question has often been proposed, and has been answered in two different ways.

The attempt has been made, by means of a certain number of facts taken from America and Oceania, as well as from Africa, to show that certain human populations were irrevocably destined to a savage condition. The upholders of this opinion have chiefly quoted as examples the indigenous inhabitants of North America and Australia. Yet whoever will consider the matter from an unprejudiced puint of view, will see at once, sometimes in the very facts brought forward by those who depreciate them, a clear proof that, plased in favourable conditions, these races would be able to raise themselves far above the condition in which we have found them, and would, in some respects at least, very quickly reach our level.

As far as the Red-Skins and the allied groups are concerned all doubt has been dissipated by the great work of Schoolcraft, and several reports since published.

There is, at the present day, upon the banks of the Cattaraugus, an agricultural and laborious population, formed from the remnints of the Iroquois, which has its schools, its printing establishments, and its journals. It is useless to 
insist upon what the Kreecks, Cherokees and Choctaws have become. We know that these nations of the South had, of their own accord, started on the high road of settled civilization, that they cultivated and exported cotton, and published journals witten in their own language, and printed in characters invented by one of their own nation. 'The governinent of Washington drove them from their lands, and transported them to the basin of the Arkansas. 'They there set themselves to work again, and travellers tell us that some of their farms even lival those of the Yankees.

But in reply to this the objection will be made that the Algonquins and the Dacotahs have resisted every attempt which has been made to assimilate them to Whites, and to civilization. This is an error, or rather it is but half the truth, and for this very reason affords important information to those who are inclined to receive it. The Algonquins (true Red-Slins), and the I) acotahs (Sioux) separated. Some renounced their ancient mode of life, and imitated that of the Cherokees, other's adhered to it; how variable, then, is this supposed indelible character ; how conpletely subordinate to a thousand insignificant local circumstances!

In fact, nothing has taken place with regard to the American Aborigines which could not also be observed among Whites. Side by side with the Arab of the town, dwells the Arab of the desert and the tent. In the same manner the natives of North America, when left to themselves, differed upon certain points. In the basin of the Rio del Norte, and beyoud it, side by side with the urban and agricultural inhabitants of the pueblos, dwelt nomad and hunting tribes. The latter sometimes pillaged the former, but they did not the less recognise the kimship existing between them.

What here took place spontaneously still takes place under the pressure of the White. Is there anything strange in this? In every case when the half of a nation transforms its social condition, we cannot draw our conclusion from the backwardness of the other half, and say that it would be 
incapable of doing so as a whole. We might, with equal reason, maintain that a great number of Europeans wore incapable of learning to read.

There remain the Australians.

I approach this subject very unwillingly. In no part of the globe has the White shown bimself so merciless towards inferior races as in Australia; nowhere has he so audaciously calumniated those whom he has plundered and exterminated. In his opinion, the Australians are not even men. They are beings "in whom are combined all the worst characters which mankind could present, at many of which, monkeys, their congeners, would blush." (Butler Earp.) Noble minds have doubtless protested against these terrible words, addressed to convicts who were about to scek their fortunes in Australia; but what could be expected of them when every evil passion was called forth and supported by similar arguments, which, again, rested upon assertions given as scientific? The result of these experiences in Australia and Tasmania is well known; and those who wish for further information have only to consult travellers of every country, Darwin as well as Petit-Thouars.

To maintain at the present day that the Australians are what Bory de Saint-Vincent and the anthropologists of that school endeavoured to prove them to be, is to deny unquestionable facts established by travellers of every description. This race has no more shown itself to be absolutely savage than any other human race. It organised the family and divided the tribe and nation into true clans, the account of which is still extant. The Australians, more advanced upon this point than the Tahitians, understood the division of land amongst themselves, and the fixed limits agreed upon were religiously respected, except in time of war. I shall speak about their religious and moral characters at another time. We have here only to consider their intellectual characters, and I shall only add that these savages possessed villages of from 800 to 1000 inhabitants, that they knew how to hollow out canoes, and made nets for hunting and fishing, which 
were sometimes 80 feet long and of sufficient strength to resist the struggles of a kangaroo.

It will, however, be objected that all this does not constitute a well advanced social condition. Granted; but are the Australians incapable, as it has so often been said, and as it still is asserted, of raising themselves above this condition?

We have only to consult the writings of Dawson, who made a kind of farmers out of these savages, those of Salvado, who found them to be both devoted and useful workmen, those of Blosseville, declaring that he thought himself fortunate to be able to tum to them when the gold feres robbed him of European hands, and we shall be convinced of the inaccuracy of the assertions made on the subject of the radical incapacity of the Australians. Finally, if we still retain some feeling of doubt, we need only look back upon those tribes which were settled and civilized by William Buckley, the deserter, and we shall be forced to allow that the faculty of raising themselves above their past condition exists among the Australians as among other liuman populations.

XIII. There are two causes which tend to lead us into error when we are dealing with the question of the appreciation of the social condition of races.

The first arises from the manner in which we regard, as a whole, the population to which we belong: The offspring of instructed and civilized classes, we forget that part of the nation which we left so far behind, which doubtless profits sy the work of the intelligent classes, but does not follow them at all, or but very little, in the path of progress. There is not a country in Europe where numbers of facts, justifying what I have briefly stated here, may not be met with. If Lubbock had taken more notice of the facts around him, he would most certainly have modified many conclusions in his book.

The other cause proceeds from our pride of race, from the prejudices of our education, which altogether prevent us from going to the root of the matter, and from recognising extreme 
resemblances, almost identities, if they are in the least degree obscured by the slightest difference of forms or words. It was a long time before the resemblance was observed between the organisation of the Maories and that of the ancient Scotch. And yet if we deduct anthropophagy from the one people and from the other all that it has borrowed from the neighbouring nations, we shall be forced to admit that at the period when Cook visited the New Zealanders, the latter offered strange points of resemblance to the Highlanders of Rob Roy and Mac Ivor. As to the Children of the Mist, akin to the other Scotch clans, were they much above the Australian tribes?

We must conclude, therefore, that civilization, with improvements and learning of every kind, is an exceptional fact, even in the midst of a most privileged people, and that upon their own territory they have had, and still have, their savage representatives. We must add that this fact is exhibited in different degrees among yellow and black tribes. Lastly, in reflecting upon our past history, we must avoid denying to other races aptitudes, which remained latent for centuries in our ancestors before they were developed, and which are still in the same condition in too many of our fellow-countrymen, and of our contemporaries.

XIV. In his remarkable work upon Origins of Civilization, Sir John Lubbock admits that the "primitive condition of man was a state of absolute barbarism." But he does not say what he means by this expression. Have there indeed ever been men living for centuries in the state depicted in Chinese traditions, men acknowledging no law, destitute of industry, ignorant of the use of fire, abandoning their dead without sepulture, living in trees. ...? There is every reason to doubt it, for all established facts protest against this conclusion.

Whenever it has been possible to attain even a slight knowledge of the life of savage tribes, they have been found subject to laws, which, although not written, are still rigorously observed. This fact is proclaimed by Lubbock himself. 
True, these laws may often appear to us iniquitous or barbarous, but sometimes there is, even in their severitics towards certain classes of the population, a trace of the most just and praiseworthy sentiments. We cannot indech approve of the Austrulian colle as regards the enactions which make a miserable slave of the woman; the privileges which it leserves to the chiefs are perhaps excessive; but how can we help being struck when we see it grant to are the same advantages as to rank. Respect for old age was a feature in the manncrs of the Spartans which met with the admiration of the Athenians; we may well recoguise its value in the Australians.

Mention has sometimes been made of races or populations drelling in trees, such as the Orang-Kubus, certain Blacks of New Guinca, etc. 'They have been described as making their homes in trees after the mamer of monkeys. Eirle has reduced these exaggerations to their true value. He has shown that upon certain coasts, lined with a belt of mangrores, it is easier to walk upon the crowded, interlaced branches, than to force a passage along the network of aërial roots plunging into a bed of mud. He saw European sailors several times, with their muskets slung, passing over inarshes of this nature in single file, in the same way as the Indians. Tre sce, therefore, that it is not at all necessary to be absolutely savage and nearly allied to monkeys to trarel in this manner.

The 'Tasmanians, as good an example of a nomad people as it would be possible to mention, only erected temporary shelters, and yet they burnt their dead, and raised to them mausoleums of branches and bark, which have been described and figured by Péron. I have just remarked that the Australians had their institutions and their industries. Undoubtedly in Tasmania and Australia man is exhibited with the smallest amount of human development. And yet we nowhere observe that absolute barbarism which is apparcntly admitted by the learned Englishman.

However firr we go back into our past history we shall 
meet with similar facts. The little that we know of tertiary man sherrs him to be in possession of fire and the art of cutting flints. He already has his industries, and this fact alone proves that his mode of life was different to that of the brute.

It could not be otherwise. Whatever the cause may have been which determined the appearance of man upon the surface of the globe, he has, from the first, always been in possession of his specific nature. He has had from the outset his intelligence and his aptitudes which, though at that time in a torpid and slumbering state, were ready to start into life under the spur of necessity. 'To procure nourishment and to defend himself against the external workd, he could only have recourse to them, and the smallest manifestations of these superior faculties have of necessity traced from the commencement a line of demarcation between him and the brute.

$X V$. The intelligence and the aptitudes of man have manifested themselves in a thousand ways, which may be included under the general name of industries. Pacific or warlike, relating to the individual or to the whole population, they very often differ in different races, in different peoples, sometimes almost in different tribes. The greater number may consequently be considered as so many characters by which the different groups of the human species may be distinguished. It will, however, at once be understood that questions of this nature can only be discussed in a detailed history, and I must here confine myself to stating one of those general facts which, by themselves, are sufficient to separate man from animals.

The latter have only physical wants which they satisfy as completely as possible. But, this end once attained, they go no further. The animal, when left to itself, does not know, or has scarcely a suspicion, of the superfluous. His wants are, therefore, always the same.

Man, on the contrary, whether the mind or the body is in question, is always seeking the superfluous, often at the expense of utility, sometimes to the detriment of the necessary. 
The result is that his wants increase from day to day. The luxury of the evening becomes the indispensible of the morrow.

This fact is just as true with regard to the savages as to civilized peoples. We must, then, consider it as one of those characters which belong to the very nature of beings. Regarded systematically from this point of view, man might be defined as an chimal requiving the superfluous, with just as much reason as he has been called a reasoning unimal.

Moralints liave at all times severely blamed this tendency and condemned those insatiable appetites which are always asking for more and for what they do not possess. I cannot share this view. Far from blaming in principle that which essentially is but the desire for the better, I cannot but see in it one of the noblest attributes of man. This fuculty is, in reality, one of the most important causes of his greatness. When men are once fully satisfied and have no more wants, they will come to a standstill, and progress, that great and sacred law of mankind, will come to a standstill also.

In reality, it is the want of the superfluous which has developed all our industries, which has engendered the arts and. sciences without which many races and nations, and, even among ourselves, whole populations exist perfectly well. We must therefore, with every reservation as to wrong applications, accept it in the first place as a fact, in the second as a benefit. 


\section{CHAPTER XXXIV.}

\section{MORAL CHARACTERS.}

I. In spite of all that is exceptional and elevated in the intellectual phenomena displayed by man, they do not, when considered as characters, isolate us from animals. It is different with moral and religious phenomena. The latter, as we have seen, belong essentially to the human kingdom ; they are the attributes of our species. Let us examine them rapidly, and, at the same time, invariably from this point of view.

Confining ourselves rigorously to the region of facts, and carefully avoiding the territory of philosophy and theology, we may state, without hesitation, that there is no human society or even association in which the idea of good and evit is not represented by certain acts regarded by the members of that society or association as morally good or morally bad. Even among robbers and pirates theft is regarded as a misdeed, sometimes as a crime, and severely punished, while treachery is branded with infamy; the facts noticed by Wallace among the Kurubars and Santals shew how the consciousness of moral good and truth is anterior to experience, and independent of questions of utility.

Nevertheless, Sir John Lubbock, in a work with which all my readers are doubtless acquainted, states that the moral sense is wanting in the savage. In slipport of this opinion he quotes some vague and general assertions bearing more particularly upon the Australians, 'Tahitians, Red-Skins, etc. 'The assertions of the eminent naturalist have been so often 
repeated that it will only be necessary for me to examine them in a few words.

In the first plice, I might produce numerous quotations of the same nature in opposition to these assertions. I shall only recall the worts of Willace, speaking of the tribes in the midst of which he had lived. "Every individual," he says, "scrupulously" respects the rights of his neighbour, and these rights are but rarely infringed." Is it possible to admit that this respect does not rest upon something analogous to that which we call morality. I shall, moreover, presently shew that this is really the case.

Again, Lubbock seems to have contradicted himself when pointing out in lis book the small amount of real liberty enjoyed by savages. He represents them, correctly, as being the slaves of a multitude of customs, having the importance of laws, which rule all their actions. Now, amongst these customs, there are a great number which are at variance with the most natural passions, such as the instinct of reproduction, the choice of nourishment, etc. An infringernent of these laws is followed by a punishment often terrible. Is it not evident that the greater number of them can only be based upon the more or less distinct idea of good and evil?

But the idea in question resembles mathematical formula. The result of the solution of a general equation varies with the data; and according to the latter may sometimes be represented by the sign plus, sometimes by the sign minus So morality varies in its manifestations by virtue of innumer. able circumstances which, again, originate in numcrous causes. The same acts are often regarded as good, bad, or indifferent, according to the special organisation, the religion, or the traditions of the society in which they have occurred.

'These acts do not, on this account, ccase to belong to a faculty essentially human; and, whether of themselves, or from the idea with which they are connected in the different human groups, they furnish the naturalist with characters as true as those belonging to the intelligence.

'Jlis is still more certininly the case when institutions are 
produced by this order of facts and ideas. 'These sometimes present such a characteristic appearance, that at the first glance they seem to isolate a people or a race, and reflection is necessary to discover the true relations which unite the group by which this peculiarity is presented to other populations and races. The tabou of the Polynesians was long considered by many writers as something absolutely special, whilst in reality we meet with the civil tabou in every European nation, and the Mosaic law throughout is a tabou code based upon religion.

To arrive at the truth in this study we must approach it with perfect impartiality, with all the mental freedom which a zoologist brings to the examination of the physical characters of a mammal or bird. We must avoid judging foreign peoples whether civilized, barbarous, or savage, by our own fixed ideas. If we act differently, we only render ourselves liable to error and injustice. A momentary return to our own case, to the history of our race and our most advanced populations, is often useful in making us appreciate justly the moral characters of tribes and peoples which we are far too fond of representing to ourselves as occupying a position far below our own.

II. By using this precaution, and adhering to general facts, we can scarcely help being struck by the intimate resemblance which moral manifestations establish between all men, both in good and in evil; and, melancholy though the conclusion is, especially perhaps in the latter respect. For example, the infamous debauches of the Polynesian areoïs, the hideous vices of some American populations, have often been insisted upon. But let us not forget the orgies of Greece and Rome, certain haunts in our own great cities, and the terrible revelations which from time to time are made in the police courts of our proudest capitals.

Fundamentally, the White, even when civilized, from the moral point of view is scarcely better than the Negro, and too often, by his conduct in the midst of inferior races, has justified the argument opposed by a Malgache to a mis- 
sionary, "Your soldiers seduce all our women ... you come to rob us of our land, pillage the country, and make war against us, and you wish to force your God upon us, saying that He forbids robbery, pillage, and war! Go, you are white upon one side and black upon the other; and if we were to cross the river, it would not be us that the cammans would take."

Such is the criticism of a savage; the following is that of an Enropean, of M. Rose, giving his opinion of his own countrymen: "The people are simple and confiding when we arrive, perfidious when we leave them. Once sober, brave and honest, we make them drunken, lazy, and finally thieves. After having innoculated them with our vices, we employ these very vices as an argument for their destruction."

However severe these conclusions may appear, they are unfortunately true, and the history of the relations of Europeans with the populations which they have encountered in America, at the Cape, and in Oceania, justify them only too fully. As for Afriea, it seems to me that the two words, trade and slurery, are quite sufficient to prevent a European from boasting too loudly of the morality of his race.

It may, however, be objected that these crimes were perpetrated long ago, and will never be repeated, that slavery has been abolished in our colonies never to re-appear. The answer is but too simple, and will, I am sure, be confirmed by the reminiscences of more than one of my readers. In cvery case this allegation only applies to the Aryan, White. The Semitic Whites have preserved slavery, and the accounts of all travellers, especially those of Barth, Livingstone, Nachtigall, and Schweinfurth, show us but too clearly that it is still the trade of Central Africa. But is the Aryan White himself free from all blame upon this point? As an answer to this question, I shall confine myself to mentioning some facts, which liappened, so to speak, only the other day. However inelancholy the narration may be, it will at least serve the purpose of proving that the scovage element still erists in the most civilized nutions. I have borrowed them 
from A. H. Markham, commander of the Rosurio, which was sent out by the English government to cruise among the archipelagoes of Santa Cruz and the New Hebrides, for the purpose of putting a stop to the practices in question. The truth and accuracy of this testimony, which was given in 1873, are therefore unfortunately indisputable.

Forty years ago the sandal-wood trade reached a development which is accounted for by the high value attached to this wood by the Chinese. Speculators fitted out ships, and cut down the forests of the Melanesian Islands. The natives naturally resisted this devastation : they were answered by the rifle. In 1842 the crews of two English ressels landed at Sandwich Island, one of the most luxuriant in the archipelago of the New Hebrides. The islanders, when resisting the destruction of their woods, were set upon by the Whites, who killed twenty-six, and, driving a great number into a cave, suffocated them with smoke till not one remained.

The atrocities committed by the sandal-wood robbers have been surpassed by those of the pirates, who devoted themselves to the labour traffic, or labour trade, which arose and increased with the cotton plantations which the Civil War in the United States multiplied in the English colonies, nut only in Australia, but even in the Fiji Islands, and as far as some of the New Hebrides.

The want of hands being felt, the idea struck Captain Towns of having recourse to the indigenous Blacks of the South Sea, offering them the inducement of wages. Success crowned the enterprise, and the Captain soon had imitators. The original plan was to engage the islanders for a fixed time, with the understanding that they should then he sent home. But the considerable gains thus obtained excited cupidity, and slave-dealers began to carry off Papuans in order to transport them to plantations where veritable slavery awaited them. This trade became so extensive that it acquired a name which was also bestowed upon child-stealing. It is called kidnapping, an expression which been authorised by official documents. 
All means were legitimate to the ficdnappeis in order to procure their human cargo without cost. I might here borrow many horrible details from Markham, but I will only quote one. A brigg had just anchored at some little distance from the coast of Florida, one of the Salomon Islands. A canoe filled with natives coming close alongside was upset ly a manouvre, apparently accidental. The boats were immediately lowered as if to render assistance to the shipwrecked natives. But the spectators on the rocks, or in other canoes saw European sailors seize the wretched men, and with a long knife cut off their heads on the gunwale of the boat. 'This done, the sailors returned to the brig which immediately set sail. The heads thus obtained were destined to pay for the engagement of a certain number of labourers. In many of those Melanesian Islands the victorious warrior decapitates and carrics off the head of his vanquished enemy, and the respect which he gains increases with the number of these trophies in his possession. Now it had been agreed between certain chiefs and captains of vessels, that the latter should procure heads, and, in exchange, reccive a certain number of living individuals, engaged for one or two years.

It need hardly be said that at the expiration of their engragement the unfortunate Papuans did not regain their liberty. In 1867, for example, there is proof that, of 382 islanders who ought to have been sent home, only 78 had been allowed to go.

It will casily be understood that these ships, laden with unfortunate creatures, carried off by force or by stratagem, were necessarily the theatre of terrible scenes. Here again the commander of the Rosario quotes many facts. I shall only borrow the accomnt of what happened on board the Carl, for the listory of this slave-ship seems to me to present a summary of all the atrocitics of lictnapping.

The Carl quitted Melbourne in 1871, with the avowed intention of engaring black labourers. With her, under the title of passenger, went a certain Dr. Jannes Patrick Murray, who was interested in the enterprise, and who seems to have 
played the part of leader. When they arrived at the New Hebrides, the kidnappers seem to have made ineffectual efforts to obtain labourers by legitimate means. They soon had recourse to others. At Palmer Island one of them dressed himself as a missionary, hoping thus to attract the islanders on board, who fortunately discovered the trap. From this moment the slave dealers had recourse to violence alone. Their method was to approach the canoes manned by Papuans, and to destroy or capsize them by throwing into them some of those large bars of iron which are used as ballast. The crews were then easily captured.

Eighty blacks had been collected in this manner. During the day they were allowed to come on deck, but in the evening they were thrust into the hold. During the night of the 12th of September, the prisoners made some noise. They were silenced by firing a pistol over their heads. During the following night the noise began again, and the same means were employed to stop it. But the blacks had set to work to break up the camp-beds, and thus armed they attacked the hatchway. The whole crew, sailors and passengers, then began to fire into the crowd. The firing lasted eight hours. It stopped perhaps for a few moments, but began again at the least noise.

Day broke, and all seemed quiet; the hatchways were opened wide, and those who could were invited to come up There were five; all the rest were either dead or wounded. The corpses were hastily thrown into the sea, and at the same time six living individuals who were badly wounded.

Could we find among savages many industries more infamous than kidnapping, many deeds more atrocious than those of which Dr. Murray and his accomplices were guilty?

Let us hasten to do justice to the local legislature and the English Parliament, which promulgated severe laws and rules for the prevention and punishment of the crimes of kidnapping. Unfortunately, the colonists, more or less interested in procuring labourers at a cheap rate, show themselves 
remarkably indulgent towards those whose business it is to provide them with coolies. Some officers of the English navy have learnt this to their cost. Captain Montgromery, commander of the Blunche, had seized, and sent to Sydney, the schooner Challenge as a shave ship. It was proved that on two occasions the Challenge had imprisoned blacks in her hold, who had been fraudulently enticed on to the ship; that two of them had been taken, under circumstances of violence, to the Fijis; that the others had only been released, because in their despair they had set to work to make a leak in the side of the vessel with a hatchet; and, finally, that these wretched creatures were obliged to swim back to their island, from which the Challenge already lay at a distance of about $6:$ miles. In spite of these grave facts, the Challenge was acquitted. On the other hand, Captain Montgomery was condemned to pay $£ 900$ sterling damages, and interest to the owners of the ship.

III. If it is only too casy to detect amongst ourselves the evil deeds of savages, it is, happily, casy to point out among. these people, whom we are so ready to accuse and despise, the feelings upon which our own societies are founded, the good which, as a whole, predominates in them, and the virtues which we most honour. My readers will, however, understand that I cannot here enter into details incompatible with the nature of this work. We must confine ourselves to a rapid glance at the opinions held by men in seneral upon property, respect of human life, and selj-respect, and compare what travellers have told us of some of the most inferior races with what we know of our own and of ourselves.

It has often been said, in speaking of certain races and peoples, that they have no idea of property. 'Those who look a little closer into the matter will sce that this is an error. Among tribes of warriors, hunters, or fishers, however low a position they may hold in the scale of humanity, arms and tools are looker upon as personal property, and the testimony of travellers, who liave taken but little interest in the question, is very explicit upon this point. In the Paris 


\section{Moral Charactors-Property.}

Museum there is a boomerang upon which some signs are roughly carved. M. Thozet, the donor, was showing it on some occasion to an Australian from the neighloourhood, when the latter at once discovered from the signs to whom it had belonged. But there is another form which property assumes among savage or barbarous populations. If it is a question of land, it will often be found to be under the jurisdiction of the clan, tribe, or nation. The luntinggrounds of the Red-Skins are met with in every place where civilization has stopped at the level which they represented at the epoch of their discovery. This species of property exists in New Holland among peoples, supposed by some to be degenerate monkeys, and the right which rules it is so rigorous that the Australian never enters the property of a neighbouring tribe without express jermission. To act otherwise is equivalent to a declaration of war. Our common lands, and the annual conflicts which took place formerly, and which, perhaps, still take place, in spite of official settlements, between French and Spanish shepherds, will give some idea of such a state of things. Among certain Australian tribes, territorial property is still more divided and definite; every family has its hunting-grounds, which are inherited by the sons to the exclusion of the daughters.

Among the most savage peoples, when we have been able to gain definite information as to their manners, we find that theft is regarded as something wrong, and punished. Among the Australians, poaching is punished with death.

But theft is only a crime when it is committed under certain circumstances. When under other's it is, on the contrary, regarded as meritorious. To rob an enemy of his horses or cattle is a praiseworthy act of cumning. It is no longer theft, but an act of hostility. Now, to the savage the stranger is almost always an enemy. The case is the same with a great many Aryan and Semitic peoples. Was it not so among the classic nations from which we derive our civilization? 
Nothing is more common than to hear travellers accuse entire races of an incorrigible propensity for theft. The insular populations of the South Sea have, amongst others, been reproached with it. 'These people, it is indignantly affirmed, stole even the nails of the ships! But these nails were iron, and in these islands, which are devoid of metal, a little iron was, with good cause, regarded as a treasure. Now, I ask any of my readers, supposing a ship with sheuthing and bolts of gold, and nails of diamonds and rubies, were to sail into any European port, would its sheathing or its nails be safe? And would not numbers of people be found ready to reason like the Negroes, who make no scruple of robbing a White? "You are so rich," they say, when reproached with any misdeed of this kind.

These same Negroes, however, have a great respect for property among thernselves. 'Theft does not appear to be more frequent with them than it is with us between Europeans, and the thief is punished upon the coast of Guinea precisely in the same manner as in Europe.

We ought, perhaps, to refer to the idea of property the manner in which adultery is regarded by some peoples. In countries where the woman may be bought, it is evidently a violation of the rights of the proprietor. Nevertheless, even amongst the most savage tribes, a more elevated feeling, and one which is connected with moral or social ideas, as we ourselves understand them, may be proved, often in the clearest manner. The gravity of the punishment incurred by the culprit scarcely permits of a doubt that it is so. The Australian, uncorrupted by the vicinity of the White and brandy, never forgives one who has destroyed the purity of his wife, and kills him on the first occasion. With the Hottentots, death again is the punishment for adultery. It is the custom among the Negroes of the Gold Coast for the culprit, as a gencral rule, to make an arrangement with the injured party, if it is a question of one of the women of the third order, who are merely concubines. But if it is a question of the great wife or the Fetish wife. then death, or at 
least the ruin of the culprit, will alone suffice to avenge the injury.

Yet Negresses are not Penelopes. I do not for a moment think of challenging the unanimous evidence of travellers on this point, and the husbands, as we have just remarked, do not always invoke the rigour of the local code. What may we legitimately infer from this fact? Merely that the customs and the law of these races are at variance. But is it not often so amongst ourselves. Is adultery practised with impunity only among Negroes? Do complaisant husbands exist only among Australians?

IV. Respect for human life is universal. The murderer is everywhere punished. But, amongst ourselves, murder supposes certain conditions. In spite of the law, he who kills his adversary in a fair duel is regarded by no one as a murderer; he who kills or causes the death of a great number of enemies in pitched battle is a hero.

With the savage the formula is still more elastic. As I have just remarked, he regards a stranger in almost every case as an eneiny, and to kill him is no crime; it is often a title of honour. Moreover, among the greater number of savage or barbarous peoples, blood demands blood, and for vengeance to be complete, it is not necessary that the true culprit should be overtaken. Every individual of the same family, tribe, or nation, can, and must pay for his crime if occasion offers. When 'Takouri treacherously massiacred Captain Marion du Fresne and his sixteen sailors, he only obeyed the laws of his country. He had avenged his relative Nagui Noui, treacherously carried off three years previously by Surville, who wished to punish the theft of a canoe. In this manner many Europeans have fallen victims to the misdeeds of their countrymen, and certain peoples have acquired an unmerited reputation for ferocity.

But let us remember that the Scotch and the Corsicans scarcely acted differently in their vendetta. With them, as with the Red-Skin, the Maori, and the Fijian, the blood of every member of the family or clan might atone for the 
blool spilt by another. Again, that which we now cail wilful murder, was no more considered by the European as an act of cowardice or treason than it is by the savage. Let us remember, moreover, that in the Middle Ages, chiefs occupying the highest positions in European society, did not hesitate to act in this manner; let us remember that the commanders of our ships, when punishing savages for some attack, bombard and burn the first villages that they meet without any scruple, although they may be almost sure that many innocent will pay for the guilty; and perhaps we shall be less severe.

As to a want of respect for human life, the white European race camnot reproach the most barbarous. Let us look back upon our own history, and recall some of those wars, those pages written in letters of blood in our own amnals. Let us not, above all, forget our conduct towards our inferior brethren; the depopulation which marks every step through the world; the massacres committed in cold blood, and often for amusement; the man-hunts organized after the manner of stag-hunts; the extermination of entire populations to make room for European colonies, and we shall be forced to acknowledge that if respect for human life is a moral and universal law, no race has violated it oftener, or in a more terrible manner than our own.

V. Modesty and sense of honour are undonbtedly two of the principal manifestations of self-respect. Neither the one nor the other are winting among savage peoples. But the former, especially, often shows itself in customs and practices widely opposed to ow own, or bearing no resemblance whatever to them. 'This has given rise to many misconceptions, such as that which, among certain Polynesians, has been considered as a refinement of immodest sensuality, what in their opinion is only an act of elementary modesty.

I might multiply examples of this nature, but for what purpose? Is it not the same in matters of politeness? We rise and uncover the head before a stranger or a superior; in a similar case the Turk remains covered, and the Polynesian 
sits down. Though differing so entirely in form, are they not inspired by the same sentiments? Is not the faculty by which they are called into play everywhere the same?

It is the same also with the sense of honour. Here, however, more than in any other case, we meet with conceptions remarkably in accordance with our own. The history of savage nations abounds with traits of warlike heroism, and nothing is more common than to see savages prefer torture and death to shame. The Algonquin and the Iroquois challenge their executioners to invent fresh tortures. The Kaffir chief asks as a favour to be thrown to the crocodiles rather than lose the feather, which to him represents the epaulette, and serve as a common soldier after having been an officer. The duel of the Australian is more logical than ours, and always in carnest.

That which we call chivairous generosity in speaking of Europeans, is by no means wanting in savages. In the struggles at Tabiti several officers owed their lives to this feeling. After peace had been concluded, Admiral Bruat asked a Tahitian chief, to whose fire he had been exposed for an hour while he bathed, why he had not fired: "I should have been dishonoured in the eyes of my people if I had killed such a chicf as you, naked, and by surprise," replied the savage. Could the most civilized man have acted or spoken better?

We might quote various actions of Red-Skins and Australians, arising from sentiments of the same nature.

VI. In conclusion, if it is sad to be forced to recognise moral evil in races and in nations which have carried social civilization to the highest degree of perfection, it is consoling to acknowledge the good in the most backward tribes, and to find it there in its most elevated and refined form. The fundamental identity of human nature is nowhere displayed in a more striking manner.

Does this assertion lead to the inference that all human groups are upon the same moral level? By no means. From this, as from the intellectual point of view, they may hold a 
higher or lower position of the scale, without any of them falling to zero. It is precisely this moral inequality which has for the anthropologist an interest at once scientific and practical. The very development of the faculty, the acts which it inspires, the institutions of which it is the foundation, present differences sufficiently great to make it possible to discover characters in this order of facts. 


\section{CHAPTER XXXV.}

\section{RELIGIOUS CHARACTERS.}

I. IF scientific mpartiality and calm judgment are necessary in the study of moral phenomena, they are much more indispensable when we have to account for facts depending. upon religious feeling. Unfortunately this condition is too rarely fulfilled. Passion, with lamentable facility, becomes involved in whatever resembles a religious question. Many other causes, easy to mention, join passion in leading our judgment astray, and it is not difficult to explain how, under these several influences, it has been possible, honestly to ignore manifestations of religion in the more or less important divisions of mankind.

The most frequent cause of error to which I feel myself bound to call attention, has its origin in the high opinion whicb the European has of himself, in the habitual contempt which is the most striking feature of his relation with other populations, and especially to those which, with greater or less reason, he treats as barbarians or savages. For example, a traveller who, as a general rule, speaks the language of the country very badly, interrogates a few individuals upon the delicate questions of the Deity, future life, etc., and his interlocutors, not understanding him, make a few signs of doubt or denial, which have no reference to the questions asked. The European in his turn mistakes their meaning. Having, in the first instance, merely regarded them as beings of the lowest type, incapable of any conception however trifling, he concludes without hesitation that these peoples lave no idea either of God or of another life; and his 
assertion, soon repcated, is at once accepted as true by readers. who share his opinions about populations unacquainted with our civilization. 'The history of travel would furnish us with many examples of this fact. Kaffirs, Hottentots, etc., have often been spoken of as atheists, while we now know that this is by no means the case.

Should the traveller, moreover, speak the language of the country with ease, he is still liable to fall into error. Religious belief forms part of the most hidken depths of our nature; the savage does not willingly expose his heart to a stranger whom he fears, whose superiority he feels, and whom he has often seen ready to ignore or ridicnle what he has always regarded as most worthy of veneration. The difficulty which a Parisian experiences in France in understanding the superstitions of the Basque sailor, or of the Bas-Breton peasant, should make him able to appreciate those which he would find in giving an explanation of similar subjects in comnection with Kaffirs or Australians. Campbell had great trouble in obtaining from Makoum the avowal that the Bosjesman admitted the existence of a male god and of a female god, of a good and evil principle. He left many other, and much more important discoreries to be made by MHI. Arbousset and Daumas. Wallis, after a month's intimacy with the 'Jahitians, declared that they possessed no form of worship, whilst it entered, so to speak, into their most trivial actions. He had scen nothing beyond a cemetery in the Morai, those venerated temples, of which no woman might even touch the sacred ground.

The lively faith of a missionary is, again, often a cause of error. Whatever the Christian communion may be to which he belongs, he generally arrives in the midst of the people whom he wishes to convert, with a hatred of their objects of belief, which are to him works of the devil. 'Joo often he neither seeks to arcount for them, nor even to become acquainted with them; his sole endearour is to destroy them. I could here mention one of these too zealous apostles, who sees nothing in the Brahminical religion bit the utmost bar- 
barism united with the utmost absurdity. It is clear that the much more rudimentary belief of a Kaffir or of an Australian could not be a religion in the opinion of such a judge as this. He expresses and pullishes his ideas, and another name is added to the list of atheist populations.

Fortunately amongst lay Europeans there are some who, permanently settled in the midst of these populations, become initiated into their customs and manners, so as to understand them and to fathom mysteries, which would by others be passed over on account of offensive or curious forms. Among missionaries there are some who, more indulgent, because they are more enlightened, can recognise the religious conception, however feeble it may be, or however it may have been transformed. Little by little the light has appeared, and the result has been that Australians, Melanesians, Bosjesmans, Hottentots, Kaffirs, and Bechuanas, have, in their turn, been withdrawn from the list of atheist nations and recognised as religious.

II. Can the justice of this conclusion be denied? Can anyone refuse to allow a religion, properly so called, to these peoples, to recognise as true divinities beings who receive a tribute of affection or terror, homage and prayers on the part of populations, who either fear or trust in them? It is possible. Here again our European pride seems to me to have often led to false conclusions. Believers or unbelievers, freethinkers or zealous Christians, savants and philosophers have been too much under the influence of the idea of the Deity as conceived by our most cultivated classes. Often when this idea is even slightly degraded or modified, they no longer acknowledge its existence; when the conclusions drawn from it upon the origin, nature, and destiny of man or of the universe, differ even slightly from those which they admit themselves, or have been accustomed to hear, they refuse them the name of religion.

I can only explain in this manner the judgment passed upon a very considerable portion of mankind by a number of savants and eminent thinkers, amongst whom we must 
reckon the illustrious Orientalist Burnouf. In his opinion Buddhism is true atheim. In a work which has been deservedly successful, M. Barthélemy Saint-Hilaire has supported this view with incontestable talent and learning. He has, moreover, placed on an equality with Buddhist beliefs, and perhaps even below them, those which had preceded them amoug the Nongols, Chinese, and Japanese. Thus, in the opinion of this eminent writer, nearly all the yellow races, much more than the third of mankind, are atheists.

But, in formulating this conclusion, the learned author of Budduh chiefly consulted his own reason and conceptions. "Buddhists," he says, "may without any injustice be regarded as atheists. I do not mean that they profess atheism, that they glory in their incredulity with that boasting of which more than one example might be quoted amongst ourselves; I only mean that these nations have not been atble to rise in their noblest thoughts to the conception of God."

In these few lines the idea of the book and the cause of the disagreement which separates me from M. Barthélemy Saint-Hilaire is clearly evident. The Buddhists, who everywhere give a place to gods in their legends, who have everywhere raised temples consecrated to these deities, who fear and worship them, who have male prayer an institution, who admit the dogma of future life and of remuneration, have not formed that idea of God to which we have all more or less attained; they are therefore atheists. This is evidently the prepossession under the influence of which this work has been written, which, however, should be read hy all who are desirous of gaining correct impressions concerning some of the grave questions so hotly disputed at the present day.

The savant who considered Buddhism as atheism would with still greater reason make the same estimate of the ancient beliefs of Japan, China, and Mongolia. Nevertheless, there was in this case also a belief in nuinerous divinities, always subordinated to one supreme, uncreated and creating 
God. In Japan, we are told by Siebolt, there were counted no less than seven celestial gods, and eight million kamis, or spirits, of which 492 were superior gods. The inferior Kamis, to the number of 2640 , were deified men. In China, the aim of the reform of Lao-tseu and of Khoung-tseu was, partly, the destruction of idolatry, and idolatry is not atheism. The populations of northern and central Asia have in almost all cases been accused by travellers especially of superstition, and not of atheism. They also have their idols. The case is similar with all northern populations. In the sacred island of Waygatz, near to the straits of the same name, the missionaries burnt, in 1827,420 images collected upon the promontory of Haye-Salye alone. Throughout this vast area, the inhabitants believed, or still believe, in spirits dwelling in rocks, trees, mountains, or the celestial bodies, and offered to them an interested homage.

Still, however, there was an universal belief in a Supreme God, who had created these very spirits, and was the Preserver of all living things. The Lapps and Samoyedes had, or still have on this point, the same conceptions as the ancient Chinese. Their Jubmel, and their Num answer exactly to the Chang-ti of Khoung-tseu himself, while popular idioms show that they regard him as the first dispenser of all good. Num tad (may Num grant), and Num arka (thanks be to $\mathrm{Num}$ ), are apparently of frequent occurrence in the language of the Samoyedes. This belief in a Supreme God and in secondary spirits, of vast number, but still presenting a kind of hierarchy, is a very ancient one in China, for we find the emperor Chun 2225 years before our era "offering sacrifices to the Supreme Sovereign of Heaven, and the usual ceremonies to the six great spirits, as those usually offered to mountains, streams, and spirits in general."

Possessing beliefs of this kind, attested and sanctioned by public acts, can they be regarded as atheists? If so, we must at least allow that this is a very different atheism from that which has been professed, and is still professed, by certain European schools of philosophy. 
III. I might make similar observations upon the subject of the opinions published by Sir John Lubbock in the two works which have gained for lim in anthropology a reputation equal to that which he already enjoyed as a naturalist. "It is difficult," he says, "to suppose that savages so rude as not to be able to count their own fingers, should have acquired intellectual conceptions sufficiently advanced to possess a system of belief worthy of the name of religion."

Leaving on oue side what the author here says about numeration, which rests, I think, upon a false assumption, do not these words, "worthy of the name of religion," show us that, like M. B. Saint-Hilaire, Sir John Lubbock takes his own conceptions in religions matters as a criterion of those of savages?

In the opinion of Sir John Lubbock, atheism is not "the negation of the existence of a God, but the absence of definite ideas upon this subject." Here, like M. Barthélemy SaintHilaire, the English savant gives to the word atheism a very different sense to that which it has held hitherto. Moreover, he quotes elsewhere without comment several passages, the sense of which clearly implies a negation of all divinity, and sometimes himself makes use of expressions which seem to prove that such is his conviction, at least with regard to certain savages. Thus, the testimony which he makes use of, and his own words, are often employed in the support of the opinion which denies any religion to certain human groups.

The choice, moreover, of the quotations in question seems to me liable to a serious objection. When the writers, against whom I am now arguing, have to choose between two evidences, the one attesting, the other denying the existence of religious belief in a population, it is always the latter which they seem to think should be accepted. More often than not, they do not even mention the contrary evidences, however definite, however authentic they may be.

Now it is evidently much easier not to see than to discover that which may be in so many ways rendered inappreciable 
to our eyes. When a traveller states that he has proved the existence of religious sentiments in a population, which by others had been declared to be destitute of them, when he gives precise details upon such a delicate question, he has unquestionably at least probability in his favour. I see nothing to authorize this rejection of positive evidence and unconditional acceptance of negative evidence. This, however, is too often the case.

I might justify this imputation by taking, one by one, almost all the examples of so-called atheist populations pointed out by different authors. I shall confine myself to some of the most striking.

With reference to the Americans, Robertson is quoted, who states that several tribes have been discovered in America possessing no conception of a Supreme Being and no religious ceremonies. No mention is made of the information, for which we are indebted to D'Orbigny, although it is very precise. The author of l'Homme Américain deserves this neglect the less, since he directly contradicts the opinions held upon this subject by several writers, and by Robertson himself. "Although several authors," he says, " have denied all religion to certain Americans, it is evident in our opinion that all the nations, even the most barbarous, possessed one of some kind." D'Or'bigny develops this opinion by giving details of the dogmas accepted by all the races of South America, and he proves in all the belief in another life, as attested by their funeral ceremonies. Is not this of more importance than the simple negative assertion borrowed from a traveller?

It may be objected that D'Orbigny spoke only of the tribes of South America, and that the atheist populations must be sought in the northern portion of this continent. The Californians have, in fact, been quoted, upon the authority of P. Baegert, as having neither government, religion, idols, temples, nor form of worship. But nothing is said of the facts observed by M. de Mofras, which directly contradict this assertion. The Californians, this traveller tells urs, 
believe in a superior God. "This God has had neither father nor mother. His origin is entirely unknown; they believe that $\mathrm{He}$ is omnipresent; that $\mathrm{He}$ sees everything, even in the middle of the darkest nights; that He is invisible to all eyes; that $\mathrm{He}$ is the Friend of the good, and that He punishes the wicked." 'The Californians build oval temples, or, perhaps, rather chapels, from 10 to $12 \mathrm{ft}$. in cliameter, which are regarded as asylums, even in case of muder. Clearly, the Californians must be erased from the list of atheist populations, the conception which they have formed of their superior God being, on the contrary, a remarkably elevated one. In this respect these poor savages greatly surpassed the Greeks and Romans.

The Californians rank amongst those human tribes which are least elevated in the social scale; but there are some which are considered to stand far below them, the Mincopies, for example. Some writers, adopting the ideas of Mouat, regard them as atheists. They make no mention of the evidence of Major Michael Symes and Mr. Day. 'The former relates the information which he received from Captain Stocker, who lived for several years in the midst of these islanders; the latter relates what he saw. From their combined evidence, it appears that the Mincopies worshipped the sun as the primal source of all good; the moon as a secondary power; the genii of the woods, rivers, and mountains as agents of the first divinities. 'They believe that a malevolent spirit raises tempests, and they sometimes endeavour to pacify it by songs, sometimes menace it with their arrows. These Mincopies believe in another life, and keep a lighted fire under the platform which bears the corpse of a chief to appease his powerful spirit.

The evidence of Le Vaillant is accepted with reference to the absence of all religion in the Hottentots. No notice is taken of the contrary opinion held by Kolben, the accuracy and truth of which, though formerly doubted, are now placed above suspicion by the inquiry instituted by Walkenaer. 
Kolben, moreover, only confirmed the statements of his predecessors Saar, Tachard, and Boeving. He had also the advantage of having studied the aborigines before they were subdued and dispersed by the Europeans. Now Kolben tells us that the Hottentots believed in a God, the creator of all existing things, doing no harm to anyone, and living beyond the moon. They called Him Gounju T'icquoce, that is to say, God of Gods. They also recognized an evil divinity, called Touquôa. The moon was, in their opinion, an inferior gounja. They believed, moreover, in another life, for they were afraid of ghosts, and rendered a sort of adoration to their great men, by dedicating to them a field, a mountain, or a river, to which they made, in passing, some sign of respect. These details, given by the old Prussian traveller, agree with those which Campbell received from the lips of a Hottentot chicf.

Burchell, it is stated, could discover no religion in the Bachapine Kaffirs. Nevertheless, and Lubbock allows it himself elsewhere, we find in the writings of this traveller that the Bachapines believed in a malevolent being called Mouliimo, to whom they attribute everything of au unpleasant nature which happens to them. To defend themselves against him they cover themselves with amuluts, and they hold many other superstitions. It is evident that Burchell was not acquainted with everything which the Bachapines believed, either because he did not attach great importance to the investigation, or because he was prevented by the difficulty which Kolben has mentioned, and which I have pointed out above.

Thus the Bachapines believe in a superior, but evil being, in a kind of devil. It would be very singular if they did not believe in a species of God. Schwcinfurth believes he has discovered something similar among the Bongos; but he himself insists several times upon the difficulty of determining exactly what to believe in questions of this kind. Let us admit, however, that this may be true in the case of these Negroes as also in that of the Bachapines. We can only 
regard it as an accilentil and local phenomenon, and in no wily as a character of race. I shall return later to the Negroes; I will now only add a few words with reference to the Bachapines.

This population is only a portion of the Bechuana Kaffir race. Now, thanks to Livingstone, MI. Cazalis, and others, we have, upon the subject of the religious beliefs of these tribes in general, details which are very minute and of incontestable authenticity. The Basutos have their legends, their cosmogony, and thein rudimentary mythology. 'They admit the existence of a being who destroys by thunder, they give to him the name of Morence, literally, Intelligent Being who. is above, they have, moreover, Molimos, a kind of houschold gods, to whom they offer prayers and sacrifices, and in whose honour they purify themselves; they believe in another life, in another world situated in the centre of the carth, which they call the abyss which is never filled. The Bechuanas believe so strongly in ghosts that the fierce Dingan dare not go out in the evening, for fear of mecting the spectre of Chaka, whom he had assassinated.

IV. The result of my investigations is exactly the opposite of that to which Sir Joln Tubbock and M. Saint-Hilaire have arrived. Obliged, in my course of instruction, to review all human laces, I have sought atheism in the lowest as well as in the highest. I have nowhere met with it, except in individuals, or in more or less limited schools, such as those which existed in Europe in the last century, or which may still be seen at the present day.

Cam it be that analogous facts have occmred clsewhere, and that some American tribes, some Polynesian or Melancsian populations, some hordes of Berlonins may have entirely lost the conception of the divinity and another life? It is certainly possible that it may be so. But side ly side with these tribes dwell other tribes, other populations, of precisely the same race, which still possess a religious faitl. Such is indeed the result of the examples quoted by Lubbock.

'This is the great point. We nowhere meet with atheism 
except in an erratic condition. In every place, and at all times, the mass of populations have escaped it; we nowhere find either a great human race, or even a division however unimportant of that race, professing atheism.

Such is the result of an inquiry which I am justified in calling conscientious, and which commenced before I assumed the anthropological professorship. It is true that in these researches I have procected and have formed my conclusions, not as a thinker, a believer, or as a philosopher, who are all more or less under the influcnce of an idcal which they accept or oppose, but exclusively as a naturalist, whose chicf aim is to seek for and state facts.

In the scientific study of religions we must aroid acting in the manner of the physiologist, who, having experimented upon the vertebrata alone, refused to recognise the characteristic functions of animal life in the lower animals, because they were in those cases simpler and more obscure. Here, more perhaps than elsewhere, we should imitate modern naturalists, who have traced the fundamental functions even in the lowest molluses and zoophytes, where all special organization is often wanting.

The physiologist does not deny the existence of a phenomenon because it occurs in a place, and by methods, different to those to which he is accustomed. In almost all animals, even to the lowest, chymification takes place in the interior of the body. In the Physalia the same physiological act is performed externally, by the numerous appendages which serve for both arms and mouth to these singular zoophytes. In spite of the strangeness of the process, the function has neither disappeared, nor changed its nature in the eyes of the scientific man.

The naturalist who studies the history of man, that is to say, the anthropologist, should neither act nor judge otherwise. However simple or incomplete, however naïve and childish, however alusur it may be, a belief should not lose its character in his eyes, if it has any connection with that element which is common and essential to all religions. 
Now; whaterer the dogmas and doctrines of the latter may be, we may accept as a general formula, which embraces then all, the two following points: a belief in beings superior to man and capable of exercising a good or evil influence upon his destiny; and the conviction that the existence of man is not limited to the present life, but that there remains for him a future beyond the grave.

Every people, every man, believing these two things, is religious, and observation shows more and more clearly every day the universality of this character.

Like intelligence and morality, religious feeling has, moreover, its several degrees and manifestations. To seek for these manifestations, to determine their nature and intensity in the various human groups, must be the task of the anthropologist. In order to be faithful to the modern method, he must neglect nothing. Sometimes the most rudimentary religion will have for him a greater interest than one which is fully developed, because it exposes more elearly the primary religious elements. In their progressive development, in the harmony or discord existing between this development and that of the intelligence or morality, lie will find many characteristic features suitable for distinguishing races, and sometimes their subdivisions.

$V$. The point of view taken by the naturalist differs, then, in certain respects, from that which has hitherto been adopted by the greater number of eminent men, who have cndearoured to establish the Science of religions. Even MI. Emile Purnouf, who has so clearly characterised this new science, who has shown so adnirably in what respects it differ's from theology, who has so justly insisted upon the necessity of enlarging the area of studies of this kind, and of no longer confining ourselves to the beliefs of ancient and modern Europeans, seems to me to have yielded to the prejudices which he opposes.

In fact, this author divides religions into great and small. The former in lis opinion are: Christianity, Judaism, Mahomedaniem, Brahmanism, and Buddhism, He turns his 


\section{Religions Characters-Small Religions. $4 S_{5}$}

attention to these only, leaving all others in the background. M. Burnouf may, it is true, argue from the relative number of adherents.

The following are, in fact, from the latest researches of M. Hubner, the general religious statistics of the globe.

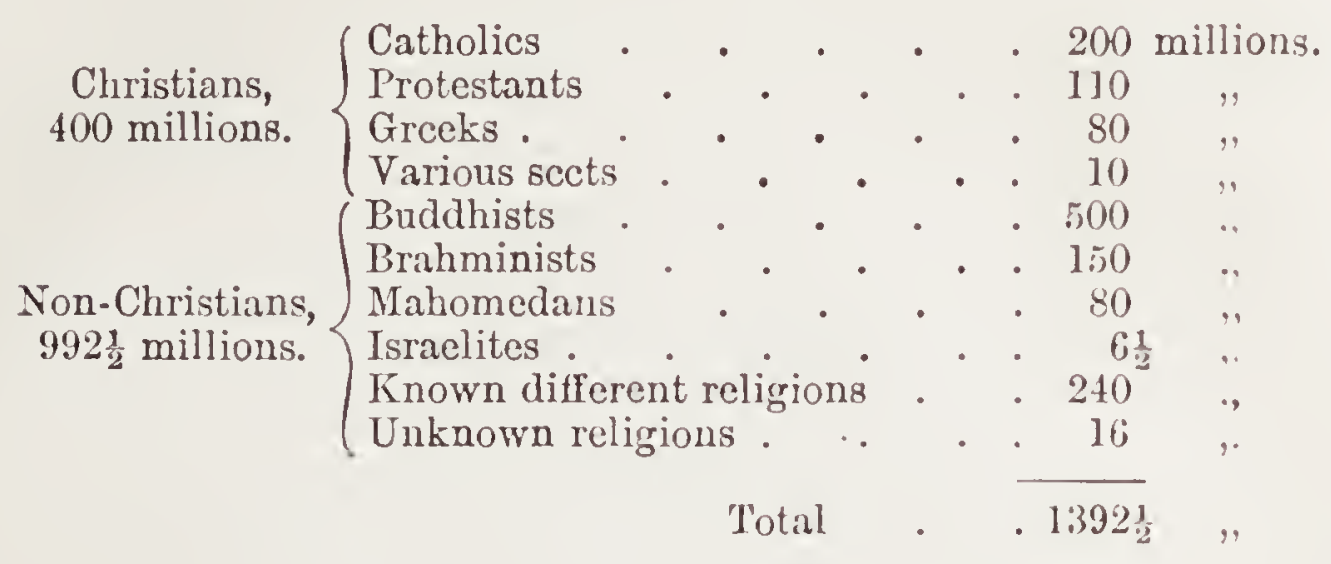

The same author gives about one thousand as the number of the religions or sects into which mankind is divided. 'The majority is unquestionably greatly on the side of the small religions, which present, at least in certain respects, a variety of conception equal, if not superior, to all that has been observed in the great. M. Burnouf acts, therefore, like the naturalist, who would form his judgment upon the animal kingdom from the vertebrata alone, and would neglect all the rest, that is to say, three-fourths of the fundamental, and a very considerable number of the secondary types.

Without even mentioning Christianity, the great religions of M. Burnouf are doubtless of interest to us in many respects, on account of the relations which many of them present with the beliefs of almost all Europeans, and also from the historical, social, and political importance of the nations by whom they are professed. But considerations of this kind are far from being everything in science. Mammifers are of much more use to us than worms or zoophytes: yet the zoologist takes as much interest in the latter as in the former; and it becomes more evident every day how useful, and often how necessary the study of these simplified 
organisms is, for the better understanding of the more complex organisms of higher animals.

The cxamination of the smull religions will render an analogous service to the science of the greet religions. It will be, perhaps, amongst the former that we shall be forced to scek the origin of those beliefs which now include so many millions of men; under one form or another, we shall, doubtless, often meet with traces of them side by side with, or even in the midst of the most fully developed religions, aud those which are apparently most widely separated from them. Upon these two points our opinions will not I think clash with those of M. Burnouf and Sir John Lubbock.

VI. 'The latter, in his Origins of Civilizalion, has, in fact, endeavoured to trace the gradual derelopment of religion in the inferior human races. Unfortunately, he seems to me to have, as a rule, undervalued the greater number of these conceptions, and to have ignored the remarkably clevated character which many of them exhibit. This alone mat have led him to consider religion as proportional to civilization, and developing only with the latter. I cannot share this view; and the disagreement between Lubbock and myself is also due in a great measure to the importance which I have attached to certain evidences which seem to bave escaped the notice of the English savant. A few cxamples will justify these observations.

Of all the peoples, concerning whose beliefs we possess an almost sufficient amount of information, the Australians certainly take the first place. Upon this point I an entirely agreed with Sir John Lubbock. But I cannot hold with lim, that these populations do not believe in a god of any kind; that they never offer prayers; that they have no form of worship at all.

In support of his opinion my eminent colleague quotes Eyre, Collins, and MacGillivray; but he forgets Cuuningham, Dawson, Wilkes, Salvado, and Stanbridge. In compariug the information obtained by these travellers in different parts of 
New Holland, we everywhere observe a similar foundation in the beliefs, which well deserve to be termed religious.

The Australians admit a good principle, called, according to the locality, Coyan, Motogon, Pupperimbul, who is sometimes spoken of by them as a kind of griant, at others as a kind of spirit. Coyan is beneficent, and regards the recovery of lost children as almost his special duty. To obtain his favour, darts are offered to him. If the child is not found, it is supposed that he is angry. In New-Nursie, Notogon is the creator. He had only to cry: Earth, appear! Water, appear! and to breathe in order to give birth to all things that exist. Without being so precise, the natives of 'Tyrril Lake ascribe the creation of the sun to Pupperimbul, who belonged to a class of beings resembling men, but who had been transported to hearen before the appearance of the present race. In south-east Australia, Coyan watches over the evil principle, called Potoyan, Wandong, Cienga, who roams about at night to devour men as well as children, and against whom they protect themselves by fire. The moon, again, is, in the opinion of the Australians, a malevolent being, whose evil infiuence is counteracted by the sun. Several good and evil genii, Balumbals and Wanguls, complete this rudimentary mythology, which has also its fabulous monsters, its great serpents hidden in deep river's, etc. The Australians believe, moreover, in a kind of immortality of the soul, which passes successively from one body to another. But before finding a new abode, the spirits of the dead wander for a certain length of time in the forests, and the natives very often affirm that they have been seen or heard.

True, these are not very noble beliefs. There is, however, here something of a very different nature from what Sir John Lubbock's view of the matter would lead us to expect. The idea of creation by the word and breath of a powerful being is a noble conception, and appears distinctly in several tribes: oblations and prayer have been proved in others. In all we observe the germ of that belief in dualism, that antagonism of benevolent and malevolent super- 
human powers, which is found in the greatest religions, and which is the basis even of Christianity. As to the belief in another life, no one has of late, I believe, denied the possession of it to the Australians.

In treating of the religion of the Polynesians, Lubbock quotes chiefly Mariner, Williams, and Sir George Grey. 'These authorities are mexceptional as regards their statement upon what they have discovered. But their silence upon certain points does not justify us in concluding that there are real gaps in those cases. Other travellers have gone much further than they went, known what they were ignorant of, and have inparted the knowledge to us. Mocrenhout was the first, I believe, to publish original docunents upon the most ancient 'Tahitian traditions. Others followed; and, thanks to firrourable circumstances, I have been able to profit by these researches. In the work which I published eight years before that of Lubbock, I reviewed and discussed the principal documents for which we are indebted to Captain Lavaud, General Ribourt, the missionary Orsmond, M. Gaussin, and others. All these documents, obtained from chiefs belonging to the most ancient families and well versed in the traditions of their ancestors, have the appearance of incontestable authenticity, and throw an entirely fresh light upon the early history of religion, at least in T'ahiti. I believe I have defined with sufficient clearness what these religions belief's were, and established beyond a doubt that, side by side with notions arising entirely from superstition, the Tahitians had attained conceptions remarkable for their purity and elevation.

Let us first prove that in the island where Wallis declared he had not been able to discover the least trace of religious worship, this worship was, on the contrary, mixed up with the most trivial acts of life. It wiss even productive of melancholy consequences. Formulism reigned supreme. Trusting in his religious observances, in the prayers of his priests, and in the indulgence of his gods, the T'ahitian thought himself at liberty to do almost anything. He 
ormbined the strongest and most simple faith with manners remarkable for their violence and licentiousness. But does not all Europe of the Middle Ages, and, even at the present time, do not many provinces, which in other respects are by no means behind the age, present phenomena of a similar nature.

Yet the Tahitians believed in another life, in rewards and punishment after death. Their paradise, of which they gave an enticing description, was reserved for the chiefs, and for those who had made sufficient offerings to the gods, that is to say, to the priests. Was not, and is not this still, the object of pious donations?

The souls of the remainder, whose life had been regular, went at once into $\mathrm{Po}$, into obscurity, a kind of limbo, where there seems to have been neither pain nor pleasure of a very decided nature. But guilty souls were condemned to undergo a certain number of times, a scratching of the flesh upon every bone. Their sins expiated, they too were admitted into Po. The Tahitians thus admit a kind of purgatory and no hell. It should also be observed that the punishment inflicted upon the guilty supposes a kind of materiality of the soul. But is not this also the case with those torments which nearly all our Christian populations still believe to be reserved for the sinner cast into the flames of hell.

We find in the pantheon of the Tahitians a bierarchy equal to, but much exceeding in number that of the Greeks and Romans. At the lowest extremity of the scale we find innumerable Tiis, whose duty it was to preside in every place over the smallest actions, the smallest movements of the soul, even to the wishes of day and night. Above the latter come the Oromotouas, who represented the domestic gods, the Lares and Manes of the ancients. The inferior Atouas, dwelling upon the earth, inhabiting rivers, woods, valleys, and mountains, answer very fairly to the Fauns, Sylvans, Dryads, Oreads, \&c. Moreover, it is from amoug the divinities of this class that the various professions choose their patrons. The singers, chorographers, and doctors had 
four, sailors trelve, and agriculturists thirteen. The gods of the first rank were Atoute properly so culled. They also were equally numerous. But nine of them, created (oriori) directly by Tharoa, before the formation of man, composed, correctly speaking, the divine family.

Finally, above all those divinities, stood the Supreme God. There can be no doubt as to the conception which the 'Tahitians formed of the latter. Traditions, collected at different times by different persons, and from equally different sources, agree perfectly upon this point. 'The song received by Moerenhout from the lips of a harepo began thus: "He was; 'Taaroa was his name; he existed in space; no earth, no heaveu, no men." 'The manuscript of General Ribourt describes lim as tö̈vi, having had no parents, and existing from time immemorial. The sacred song translated by M. Goussin begins with the following declaration: "Taaroa the great orderer, is the origin of the earth. 'Taaroa is toivi; he has no father, no posterity."

The Tahitians regarded this uncreated God, moreover, as almost a pure spirit, and he was undoubtedly so in the estimation of the more enlightened islanders. Certain traditions represent him with a body; but, says General Ribourt's manuscript, this body is invisible, and further it is merely, "a shell which is frequently renewed, and which the God loses, as a bird its feathers." In Moerenhout's song, it is he who changes himself into the miverse; but "the great and sacred univeres is only the shell of Taaroa." In that of M. Gaussin, 'Taaroa raises his head out of his covering, which disappears and becomes the earth. In the magnificent dialogrue, also translated by M. Gaussin, and in which Taaroa calls, so to speak, upon all the different parts of the universe, who in turn answer him, it is said: "The soul of Taaroa remained God." Unfortunately, after the creation was finished, this God secms to have reassumed his state of repose, and to have left to the inferior deities the government of this world.

We see here, again, that as far as the first conception is 
concerned, we are far above the Zeus of the Greeks, or the Jupiter of the Romans. And yet who would dream of comparing the Tahitian civilization with the civilization or the intellectual productions of the Greeks? It is one of the many facts which show the independence of the phenomena of the intelligence and those of the religious feeling.

It is not in 'Taliti alone that this olevated spiritualism has been observed, though concealed under very different appearances. The rude images, the toos placed in the morcii have been regarded by almost all travellers as statues of atouas. They are, in reality, nothing more than tubernacles hollow within, and destined to receive different oljects, oblations, etc. A priest of the Sandwich Islands told Byron that, when a child, it happened that he eat something which had been deposited in the sacred images. Surprised and reprimanded by his father, he excused himself by saying that he had found out by various experiments that these gods of wood neither saw nor heard. The old priest then said to him in a severe tone: "My son, the wood, it is true, neither sees nor hears; but the spirit which is above sees and hears all, and punishes wicked actions."

Do many among ourselves draw such a clear distinction between the spirit and the wood?

A remarkable feature of the Tahitian religion is, that we find in it no trace of Manicheism. They have, in fact, only gods, and no devils. It is true that the priests spoke in the name of the Atouas, and that the sorcerers, hated and feared in Tahiti as elsewhere, addressed themselves solely to the Tiis. But the latter were not in any way considered as antagonistic to the Atouas. Moerenhout tells us that their images might be seen as guardians at the entrance of the moraï and sacred enclosures.

Although not so clearly defined as those of the Tahitians, the religious beliefs of the Algonquin and Mingwe RedSkins are very superior in some respects. Their Great Spirit, the Michabou of the Algonquins, the Agrescone of the Iroquois, is the Father of all existing things. To him alone 
true worship is rendered in smoking the sacred calumet towards the four points of the horizon and the zenith. The Creator of all that exists, he is not so disinterested in his work as 'Taaroa. He himself, or his messengers, watch over children, and direct the everits of the world. Again, it is to him, before all others, that the Red-Skin addressed his prayers when he asks, and his thanks when he has gained his demands. I might here multiply examples and quotations. I shall confine myself to reproducing in part the song of the Lenapes on the eve of their departure for war, as it has been preserved for us by Heckewelder. It is a national song, and of itself refutes many strange assertions frequently made with regard to the populations who once occupied the territory of the United States.

"Oh, poor me-who am just about to depart to fight the enemy-and know not if I shall return-to enjoy the embraces of my children and wife."

"Oh, poor creature-who cannot order his own life-who has no power over his own body-but who tries to do his duty-for the happiness of his nation."

"Oh, thou Great Spirit above-take pity upon my children-and upon my wife-keep them from sorrowing on my account-grant that I may succeed in my enterprise - that I may kill my enemy-and bring back trophies of war:"

"Give me strength and courage to fight my enemy-grant that I may return and see my children again-see my wife and my relations-have pity upon me and preserve my lifeand I will offer to thee a sacrifice."

It is true that, after the Great Spirit, we find the RedSkins believing in an immense number of Manitous, one of whom, inhabiting the centre of the earth, is a kind of demon. But these beings, whether good or evil, although possessing an influence over the destiny of man, have nothing of the divine character. 'They are nothing more than a kind of genii, fairies, ogres, etc., more or less resembling those mentioned in Oricntal tales, and all absolutely dependent upon 
the Great Spirit. The latter alone is omnipotent, while the evil spirit, is weak and his power is limited.

The belief in another life was, moreover, universal amongst these populations. Their ideas upon the other world, the transmigration of souls, the multiplicity of existences were vague enough ; but in several legends, collected either by the first travellers, or in the present century by Schoolcraft, we find, given in the most explicit manner, the doctrine of recompense promised to the good, and the torments which await the wicked.

The Algonquins and Mingwes deserve to be regarded as monotheists as much as any other people we can mention, much more so than the Arabs before Hahomet. There is, moreover, no reason to think that these spiritual beliefs were due to the exceptional intelligence of an isolated individual who played the part of prophet after the manner of Mahomet. They have all the characters of a spontaneous manifestation of the instincts of the race itself. Now this fact is the more remarkable, as these Red-Skins, almost exclusively hunters, had scarcely advanced beyond the lowest stages of the social scale.

The Negroes of Guinea, much superior to the Algonquins and Mingwes, from a civilized point of view, are far inferior to them in religion. Still, to speak only of their fetishism, would be doing them a great injustice. This is, in reality, only a form of superstition more or less intimately associated with a basis of far nobler beliefs. Here, again, the greater number of observers have stopped at what was immediately presented to the eye; others, however; have fortunately been found who have looked beneath these first appearances.

Numerous evidences, too unanimous to admit of doubt, prove that from Cape Verd to Cape Lopez the inhabitants believe in a Supreme God, who has created.all existing things. The natives of Dahomey hold that this God is himself subject to a more elevated being, who, say these Negroes, is perhaps the God of the Whites. In most cases, it is true, this supreme 
Deity is regarded as governing the miverse thromgh the agency of his ministers; but often, also, direct intervention is attributed to him. Petitions, thanks, and prayers, are then addressed to him, with the formula of some of which we are acquainted. In that which D'Avezac received from the lips of Oche Fecoue, the Yebous request Obbî-cl-Orum (King of Heceven) to preserve them from illness and death. 'They add: "Orissa (God) give me prosperity and wisdom."

We find that almost all the natives of Guinea, besides their good God, had their evil spirit, also very powerful. Oblations are offered to appease him. The Negroes often think that they see or hear him in the night. We know too well, however, that the shores of Guinea are not the only place where such visions have been seen in imagination.

Then come the inferior gods, very numerous, and sometimes arranged in a hierarchy. It is they who are sent into Fetishes to watch over and protect man. 'The Fetish, according to the evidence of devout priests and Negroes, is not the God himself, but only the abode of the Goul.

The natives of Guinea all believe in another life, but have very different ideas upon this subject. In general they regard it as almost similar to the present. Some have a confused idea of metempsychosis, or think they are born again in a child. The Issinois believe in the immortality of the soul, which, on leaving this earth, is born again in another workd, situated in the centre of the globe, and vice vers $\hat{u}$. This is almost the ullementing life, as conceived by Hyppolyte Renaud, a distinguished artillery officer: and one of those thinkers who have felt the want of an explanation of the destiny of man.

The idea of retribution is clearly defined by many Guinean tribes. In the opinion of many, the wise and the intelligent become the messengers of the gods; the wicked are drowned in passing a certain stream, and die for ever or become demons. Others hold that the souls of those who have led evil lives go to the evil spirit, but can be redeemed by oblations offered to the gods. Here, then, we find the 


\section{Rehgions Characters-Superstitions.}

Negro possessing the idea of purgatory and of redemption, together with that of hell.

VII. I, think I have said enough thoroughly to establish a fact independent of all hypothesis, and which seems to me to be of serious importance. It is that we often find ideas of an extremely elevated nature, and resembling in a singular manner those which distinguish the great religions, existing in the small, though obscured by other notions of an inferior nature. Again, that we must almost everywhere, probably everywhere, distinguish religion from superstition. But before we can, in this case, recognise the gold in the midst of the surrounding dross, time is required, serious study, and a mind entirely free from prejudice.

I grant that religion and superstition are often, as it were, fused into the creeds of certain races, so that the priest and the sorcerer are confounded in one person. But this is not always the case; and, even where the connection forms an apparent confusion, we should unquestionably endeavour to distinguish the two elements. Now this task has been too often neglected in dealing with inferior races. Here again, I remark at each step the prejudicial influence of Europenn pride. The most careless writer would certainly not connect with Christianity, as it is understood at the present day in France, the dismal or ludicrous tales collected in the country districts by Villemarqué, Souvestre, and others. He would place them, with all their accompanying practices, in what may be called the popular mythology. Should not also the man of science make a similar distinction, when trying to form a true estimation of the religion, properly so called, of barbarous or savage nations?

To those who ask liow Fetishism came to be implanted in Guinea side by side with the conception of a Supreme Being, the creator and governor of all that exists? how northern populations could reconcile Shamanism with the belief in that God of whom Ghengis Khan had formed such a great and elevated idea? I ask again how the strangest superstitions came to be accepted in former times by all Christian 
sects? how it is that they still exist amongst us? 'True, in our enlightened clisses, neither Protestant nor Catholic would enter upon a course of sorcery, of which there were so many instunces but two or three centuries ago, and which were so often followed by condemmation and capital punishment. In our more remote country distrists, however, the belief in sorecery is as strong as it was universal in the Middle Ages. The newajpers inform us from time to time of actions, proving that, if left to themselves, these populations would willingly burn the unfortunate victims suspected of laving told fortunes; protect themselves against witchcraft, the evil eye, etc., these same populations have often had recourse to practices strongly resembling those signalized by travellers as the proof of inferiority in certain races. In reality, the amulets of our peasants are identical with the grisgris of the Negroes.

In all these respects and in many others, all Aryan Christians have believed in that which we proudly reproach the Negroes and Mongols with believing. All Christian communities have sanctioned, and sometimes sanctified, these absurd superstitions.

The antluppologist, who has to do with science and not with theology, who has to seck the pure element in the inferior religions, ought not, on the other hand, to hesitate in pointing out that singular adnixture of alloy in the superior religious, of which I have just quoted a familia example.

From this double form of investigation, a general fact, to which I have often called atteution, will, I think, be established in the minds of all, a fact which may be formulated in the following terms; nreat or small, religions are principally comnected by the most elevated anci the lowest element possessed by each; they are principally separated by interineliary forms and conceptions.

VIII. The following fact has, in several instances, been remarked, that a religion when replaced by another, leaves upou the latter more or less evident traces. Often also, the 


\section{Religions Characters.}

divinities of the former, without entirely disappearing, will undergo a singular process of degradation, and find a place only in the region of popular superstition. Which of our readers will not call to mind the articles, at once so charming and so impressive, of M. Heine upon the poor gods of the Greek and Roman Olympus, passed into legendary characters? These representatives of classical mythology have, in the heart of popular beliefs, become associated with Germanic and Scandinavian divinities; but have not both had predecessors?

From Quaternary ages to the present time, many raoes have inhabited Europe. None, undoubtedly, have entirely passed away. They have been successively subjugated, and more or less absorbed. Can the beliefs even of our most remote ancestors be entirely lost? I think not. Undoubtedly, a portion has been forgotten, but very probable also a large part has survived, more or less modified by the additions of each fresh immigration. In this manner would be formed, little by little, that popular mythology which has resisted all official doctrines, and even found a place by their side.

What has happened in our own case cannot but have happened elsewhere. Future research will perhaps show this to be the cause of the common element of the religious beliefs of peoples, separated by their different degrees of civilization, as well as by geographical position.

IX. M. Burnouf has remarked that the science of religion does not as yet exist. This is true, especially from the point of view to which I have just called attention. All general classification is, then, premature. Before attempting one, let us wait till we are at least fairly acquainted, not only with the great mass of doctrines supported by profound metaphysics, which have been accepted by civilized nations, but also with the simpler, more artless beliefs which preceded them, some of which are still in existence. Then only shall we be in a position to trace the general form and the subdivisions of the several manifestations of the religious faculty 
common to all human beings. Then, also, we shall be in a position to follow the development of this faculty, and to mark its stages, by a process similar to that of the embryogenist, who studies the different phases undergone by the same being before attaining its state of perfection.

Such as it is however, consisting at present of isolated facts only, or of facts merely collected into groups, the science of religions has already acquired a marked importance in anthropology. It leaves no doubt as to one of the fundamental characters of the human species; it furnishes facts of so independent a nature as to serve for the characterization of races; it reveals relations; it adds its testimony to that of philology in throwing light upon the filiation of certain races, in attesting the existence of ancient communications between nations long regarded as entirely separate. In these various aspects it should not be neglected by those who wish to consider the natural history of man as a whole.

THE END. 


$\Lambda$ LIST OF

KEGAN PAUL, TRENCH \& CO'S PUBLICATIONS. 


\section{A IIST OF}

\section{IXEGAN PAUL, TRENCH \& CO.'S PUBLICATIONS.}

\begin{tabular}{|c|c|c|c|c|c|}
\hline \multicolumn{6}{|c|}{ CONTINTS. } \\
\hline GENERAL LITERATURE. & $\begin{array}{r}P A C E \\
-\quad 2\end{array}$ & MILITARY & MORKS. & 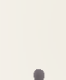 & PAGE \\
\hline PARCHMENT LIHRARY. & - 2 I & POETRY. & . & . & \\
\hline Puimt Commentary. & . 23 & WVORKS OF & FICTION & . & - 42 \\
\hline INTERNATIONAL SCIEN & & BOOKS IOOK & TIIE Yor & NG & - 43 \\
\hline SERIES . & $3 I$ & & & & \\
\hline
\end{tabular}

\section{GENERAL LITERATURE.}

A. K. II. B. - From a Quict Place. A Volunc of Sermons. Crown Sro, 5 s.

1/.EAHNDER, William, D.D., Bishop of Dimy.-The Great Question, and other Sermons. Crown Sro.

ALLEN, Rcv. R., M.A.-Abraham: his Life, Times, and Travels, 3 SoO years ago. With Map. Second Iidition. Post Sro, 6s.

ALLIES, T. M., M.A.-Per Crucem ad Lucem. The Result of a Life. 2 vols. Demy Sro, 253 .

A Life's Decision. Crown Sro, 7.s. Got.

AlLABATT, F.J. B., B.D.-The Witness of St. Matthew. An Inquiry into the Sequence of Inspired Thought pervading the First Gospel, and into its Result of Unity, Symmetry, and Com. pleteness, as a Perfect Portrait of the Perfect Man. Crown 8vo, 5 s.

1.MHERST, KCv. W. F.-The History of Catholic Emancipation and the Progress of the Catholic Church in the British Isles (chiefly in England) from 1771-1820. Demy Sro.

AMOS, Frofessor Shcldon.-The History and Princip!es of the Civil Law of Rome. An airl to the Sturly of Scientific anc! Comparative Jurisprudence. Demy 8ro. 165. 
Ancient and Modern Britons. A Retrospect. 2 rols. Demy Sro, 24 s.

ANDERDON, Riz. W. H. Fasti A postolici ; a Chronology of the Years between the Ascension of our Lord and the Martyrclom of SS. Peter and Paul. Second Edition. Enlarged. Square 8 vo, 5 s.

Evenings with the Saints. Crown Sro, 5 s. A.VDERSON, David. - "Scenes" in the Commons. Crown Sro, 5". ARISTOTLE.-The Nicomachean Ethics of A ristotle. Tran:lated by F. H. Peters, M.A. Second Erlition. Crown 8 ro, $6 s$. ARMSTRONG, Richard A., B.A.-Latter-Day Teachers. Six Lectures. Small crown 8 vo, 2s. 6 .

AUBERTIN, F. 7.-A Flight to Mexico. Witl Seven full-page Illustrations and a Railway Map of Mexico. Crown 8ro, 7 s. $6 \%$ AUSTIN, Philip.-Our Duty towards Animals. A Puestion considered in the Light of Christian Philosophy. Crown Sro.

BADGER, George Percy', D.C.L.-An English-Arabic Lexicon. In which the equivalent for English Words and ldiomatic Sentences are rendered into literary and colloquial Arabic. Royal 4 to, Sos.

BAGEHOT, Walter. - The English Constitution. New and Revised Edition. Crown Sro, 7s. 6\%.

Lombard Street. A Description of the Money Market. Eightlı Edition. Crown 8vo, 7s. $6 d$.

Essays on Parliamentary Reform. C'rown Sro, 5 s.

Some Articles on the Depreciation of Silver, and Topics connected with it. Demy Sro, 5 s.

BAGENAL, Philip H.-The American-Irish and their Influence on Irish Politics. Crown 8 ro, $5 s$.

BAGOT, Alan, C.E.-Accidents in Mines: their Causes and Prevention. Crown Sro, 6 s.

The Principles of Colliery Ventilation. Second Edition, greatly enlarged. Crown $8 v o, 5$ s.

The Principles of Cixil Engineering as applied to Agriculture and Estate Management. Crown Sro, $7 s .6 \pi$.

BAKER, Sir Sherston, Bart.-The Laws relating to Quaranline: Crown Svo, i2s. 6 .

BAKER, Thomas.-A Battling Life; chiefly in the Civil Service. An Autobiography, with Fugitive Papers on Subjects of P'ublic Importance. Crown 8ro, $7 s .6 \%$.

BALDWIN, Capt. F. H.-The Large and Small Game of Bengal and the North-Western Provinces of India. With 20 Illustrations. New and Cheaper Edition. Small 4to, IOs, 6 \%. 
S.ALLIN, Alat S. and F. L.-A Hebrew Grammar. Witl Exercises selected from the Bible. Crown Sro, 7s. 6r.

B.IRCLAY, Figre-Mountain Life in Algeria. With numerons Illustrations by Photogravure. Crown 4 to, I 6 s.

S.1RLOW, Fnmis H.-The Ultimatum of Pessimism. In Ethical situdy. Demy Sro, 6s.

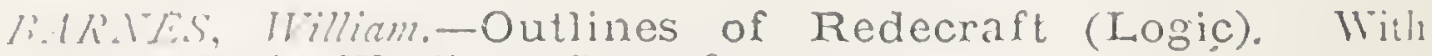
linglish Wording. Crown Sro, $3^{s}$.

I./KK, Firlinand, Dr. P\%.-A Philological Introduction to Greek and Latin for Students. Translated and adapted from the German, by C. KEGAx J'AUt, M.A., and E. D. SToNk, M.A. Third Edition. Crown Sro, 6s.

S.11\%1. Capt. Gorge-Sea Life Sixty Years Ago. A Record ol Adrentures which led up to the Diseovery of the Relies of the long-missing Expedition eommanded by the Comte de la Perouse. Crown Sro, 3 s. 6 .

SELI.L.IK.S, Kea'. W.-The Testimony of Conscience to the Truth and Divine Origin of the Christian Revelition. Bumey Prize Essay. Simall crown Sro, 3s. 6\%.

IFELLASIS, Ediarl.--The Money Jar of Plautus at the Oratory School. An Aceount of the Recent Representation. With Appendix and I6 Illustrations. Simall 4to, seved, $2 s$.

The New Terence at Edgbaston. Being Notices of the Performanees in I8So and I8Si. With I'reface, Notes, anil Appendix. Third Issue. Small 4 to, is. $6 \%$

BELI.INGHAM, II. Belsches Graham.-Ups and Downs of Spanish Travel. Siecond Edition. Crown 8ro, 5 s.

bE.TH, Alfied IT.--The Greek Philosophers. 2 vols. Demy Sio, 2 Ss.

Bible Folk-Lore. A Study in Comparatie Mythology. Crown Sro, Ios. 6\%.

SiKRD, Charlis, FG.s.-Higher Education in Germany and England. Being a hrief Practical Aceomt of the Organization and Curriculum of the German Iigher Sehools. With eritical Remarks and Suggestions with reference to those of England. Small erown Sro, $2 s$. 6ll.

IILACKLEI, Rev. W. S. - Essays on Pauperism. IGmo. Sewed, is.

BLECKIY, HEmy.-Socrates and the Athenians: An Apology. Crown Sro, 2s. 6ll.

BI.OONFIELD, The Lady-Reminiscences of Court and Diplomatic Life. New and Cheaper Edition. With Frontispiece. Crown Sro, 6s. 
BLUNT, The Ven. Archdeacon.-The Divine Patriot, and other Sermons. Preached in Scarborourh and in Camnes. New and Cheaper Edition. Crown Sro, 4s. 6a.

BLUNT, Wilfrid S.-The Future of Islam. Crown Sro, 6s.

Ideas about India. Crown 8vo. Cloth.

BODDY, Alexanter A.-To Kairwân the Holy. Scenes il: Muhammedan Africa. With Route Misp, and eishth Illustrations by A. F. JACASSEY. Crown Sro, 6s.

BOOLE, Mary.-Symbolical Methods of Study. Crown Sro, js. BOSANQUET, Bimard.-Knowledge and Reality. A Criticism of Mr. F. II. Bradley's "l'rinciples of Logic." Crorn Sro, gs.

BOUVERIE-PUSEY, S. E. B.-Permanence and Evolution. An Inquiry into the supposed Mutability of Animal Typen. Crown 8vo, 5 s.

BOWEN, H. C., M.A.-Studies in English. For the use of Modem Schools. Eighth Thousand. Small crown Sro, is. 6\%.

English Grammar for Beginners. Fcap. Sro, Is.

Simple English Poems. English Literature for Junior Classes. In four parts. Parts I., II., and III., 6a. each. Part IV., $1 s$. Complete, $3 s$.

BRADLEY, F. H.-The Principles of Logic. Demy Sro, r6s.

BRIDGETT, Rer. T. E.-History of the Holy Eucharist in Great Britain. 2 vols. Demy Sro, ISs.

BRODRICI, the Ifon. G. C.-Political Studies. Demy Sro, I 4 s. BROOKE, Rer. S. A.-Life and Letters of the Late Rev. F. W. Robertson, M.A. Edited by.

I. Uniform with Robertson's Sermons. 2 vols. With Steel Portrait. 7s. 6 $\%$

II. Library Edition. With Portrait. 8ro, I2s.

III. A Popular Edition. In r rol., Sro, 6s.

The Fight of Faith. Sermons preached on various occasions. Fifth Edition. Crown Svo, 7s. 6\%.

The Spirit of the Christian Life. Third Edition. Crown Sro, 5 s.

Theology in the English Poets.--Cowper, Coleridge, Wordsworth, and Burns. Fifth Edition. Post Sro, 5 s.

Ghrist in Modern Life. Sixtcentl Edition. Crown 8vo, 5 s.

Sermons. First Series. Thirteentl Edition. Crown Svo, 5 s.

Sermons. Second Series. Sixth Edition. Crown 8vo, 5 s.

BROWN, Rev.F. Baldain, B.A.-The Higher Life. Its Reality, Experience, and Destiny. Sixth Edition. Crown 8ro, 5 s.

Doctrine of Annihilation in the Light of the Gospel of Love. Five Discourses. Fourth Edition. Crown Svo, 2s, 6l. 
BROHN, Re'. F. Baldivin, B.A.-continuat.

The Christian Policy of Life. $\Lambda$ Book for Young Men of Business. Third Edition. Crown Sro, 3s. 6\%.

BROWN, Moratio F.-Life on the Lagoons. With two Illustrations and Map. Crown Sio, Gs.

IROHABTL, Fohn-Principles of English Camon Law. l'art I. General Introduction. Crown Sro, Gs.

JURDETT, Ilomy" C.-Help in Sickness-Where to Go and What to Do. Crown Sro, 1 s. $6 t^{\circ}$

Helps to Health. The Malitation-The Nursery-The Schoolroom and-The Person. With a Chapter on l'leasure and I Iealth Resorts. Crown Svo, is. 6\%.

BURTE, The Late Very lice. T. N.-His Life. By W. J. FITzPATRICK. 2 vols. With l'ortrait. Demy Sro.

BURTON, Mrs. Kichrol.The Inner Life of Syria, Palestine, and the Holy Land. Post Sro, Gs.

BUSBECQ, Osier Ghisclin de-His Life and Letters. By CirARLES TIIORNTON IORSTER, M.A., and F'. H. BLACKHURNE DANIELL, M.A. 2 vols. With Trontispieces. Demy 8 ro, $24 s$.

CARPENTER, IV. B., LL.D., M.D., F.R.S., ctc.The Principles of Mental Physiology. With their Applications to the Training and Discipline of the Mind, and the Study of its Morbid Conditions. Illustrated. Sixth Edition. Svo, I2s.

Catholic Dictionary. Containing some Account of the Doetrine, Discipline, lites, Ceremonics, Councils, and Religious Orders of the Catholic Church. By Wiluair E. ADIs and Thomas ARNOLD, M.A. Third Echition. Demy Sro, 2 Is.

CHEYNE, REv. T. K.-The Prophecies of Isaiah. Translated with Critical Notes and Dissertations. 2 vols. Third Edition. 1)eny Sro, 25 s.

CHICIIELE, MTary-Doing and Undoing. A Story. I vol. Crown Sio, 4s. 6d.

Circulating Capital. Being an Inquiry into the Jundamental Laws of Money. An Essay by an East India Merchant. Small crown $8 \mathrm{vo}, 6 s$.

ClAIRAUT. - Elements of Geometry. Translated by Dr. Kaines. With I45 Figures. Crown Sro, 4s. 6d.

CLAPPERTON, Fanc Hume. Scientiflc Meliorism and the Evolution of Happiness. Large crown 8 ro, $8 s .6 \%$.

CI,ARKE, Rev. Henry James, A.K.C.-The Fundamental Science. Demy Sio, ros. $6 d$.

$C L A Y D E N, P . W .-$ Samuel Sharpe. Igyptologist and Translator of the Bible. Crown Sro, 6s.

CLIFFORD, Sammel.What Think Ye of the Christ? Crown Svo, 6s. 
CLODD, Edward, F.K.A.S.-The Childhood of the World: a Simple Account of Man in Early Times. Serenth Edition. Crown Svo, 3 s.

A Special Edition for Schools. Is.

The Childhood of Religions. Including a Simple Account of the Birth and Growth of Myths and Legends. Eighth Thousand. Crown Svo, 5 s.

A Special Edition for Schools. Is. 6a.

Iesus of Nazareth. With a brief skech of Jewish History to the Time of His Birth. Small crown Sro, 6s.

COGHLAN, F. Cole, D.D.-The Modern Pharisee and other Sermons. Edited by the Very Ker. H. H. Drckrnsox, D.D., Dean of Chapel Royal, Dublin. New and Cheaper Edition. Crown 8ro, 7 s. 6d.

COLE, George R. Fitr-Roj.-The Peruvians at Home. Crow Svo, 6s.

COLERIDGE, Sara-Memoir and Letters of Sara Coleridge. Edited by licr Daugliter. With Index. Cheap Edition. Will Portrait. 7s. $6 d$.

Collects Exemplifled. Being Illustrations from the Old and New Testaments of the Collects for the Sundays after "Trinity. By the Author of "A Commentary on the Epistles and Gospels." Edited by the Rev. JosepH JACkson. Crown Svo, 5 s.

CONNELL, A. K.-Discontent and Danger in India, Small crown 8 ro, 3 s. $6 d$.

The Economic Revolution of India. Crown Sro, 4s. $6 d$.

CORY, William.-A Guide to Modern English History. Part I. -MDCCCXY.-MDCCCXXX. Demy Sro, 9s. Part II.MDCCCXXX.-MDCCCXXXV., I $5^{s}$.

COTTERILL, H. B.-An Introduction to the Study of Poetry. Crown Svo, 7 s. 6d.

$\operatorname{COTTON,~H.~F.~S.-New~India,~or~India~in~Transition.~}$ Crown Svo, 4s. $6 d$.

COUTTS, Francis Burdett Noney. - The Training of the Instinct of Love. With a Preface by the Rev. EDWARD THRING, M.A. Small crown 8vo, 2s. 6d.

COX, Rev. Sir George W., M.A., Bart.-The Mythology of tha Aryan Nations. New Edition. Demy 8ro, I6s.

Tales of Ancient Greece. New Edition. Small crown oro, 6s.

A Manual of Mythology in the form of Question and Answer. New Edition. Fcap. Svo, 3 s.

An Introduction to the Science of Comparative Mythology and Folk-Lore. Second Edition. Crown Sro. 7s. 6.t.

COX, Rev. Sir G. W., M.A., Bart., and FONES, Eustace Hinton.Popular Romances of the Middle Ages. Third Edition, in I vol. Crown $8 v o, 6 s$. 
COX', K'e'. Samuel, D.D.-A Commentary on the Book of Job. With a Translation. Second Edition. Demy Sro, I 5 s.

Salvator Mundi; or, Is Christ the Saviour of all Men? 'Tentl Eilition. Crown Sio, 5s.

The Larger Hope. A Sequel to "Salvator Mundi." Second Edition. I 6 mo, Is.

The Genesis of Evil, and other Sermons, mainly expository. Third Edition. Crown Sro, 6s.

Balaam. An Exposition and a Stuly. Crown Sro, $5^{s .}$

Miracles. An Aigument and a Challenge. ('rown Sio, 2s. 6\%.

Ch.1FE.1, Mrs.-A Year's Meditations. Crow Sro, 6.

CRAHYURD, Osiall-Portugal, Old and Nery. With Illustra. tions and Maps. New and Cheaper Edition. Crown Sro, 6s.

ChOZII:R, Foln Balli, H.B.-The Religion of the Future. Crown Sro, 6s.

$C U A$ WNGHAM, WV. B.D._-Politics and Economics: An Essay on the Nature of the Principles of Political Fconomy, together with a strvey of Recent Legislation. Crown S'vo, 5s.

1) ANIELL, Clamont.-The Gold Treasure of India. An Inquiry into its Amount, the Cause of its Accumulation, and the P'oper Means of using it as Money. Crown Svo, $5^{s}$.

Danish Parsonage. By an Angler. Crown Svo, 6s.

Darkness and Dawn: the reaceful Birth of a New Age. Small crown Sio, $2 s .6 \%$.

D.AVIDSON, Re'. Sammel, D.D., LL.D.-Canon of the Bible: Its Formation, History, and Iluctuations. Third and Revised Edition. Small crown Sro, 5 s.

The Doctrine of Last Things contained in the New Testament compared with the Notions of the Jews and the Statements of Church Creeds. Small crown 8ro, 3s. $6 \%$.

D.A PIDSON, Thomas. - The Parthenon Frieze, and other Essays. Crown Sro, 6s.

D.AIISON,Geo., M.A. Prayers, with a Discourse on Prayer. Edited by his Ilife. First Series. Ninth Edition. Crown Sio, 3s. 6\%.

Prayers, with a Discourse on Prayer. Edited by George. ST. Clalk. Second Series. Crown Svo, 6s.

Sermons on Disputed Points and Special Occasions. Elited by his Wife. Fourth Edition. Crown Sro, Os.

Sermons on Daily Life and Duty. Edited hy his Wife. Fourth Edition. Crown Sro, 6s. 
DAWSON, Geo., M.A.-continued.

The Authentic Gospel, and other Sermons. Edited by George St. Clair, F.G.S. Third Edition. Crown Sro, $6 s$.

Three Books of God: Nature, History, and Scripture. Sermons edited by George St. Clair, F.G.S. Crown Sro, 6s.

Biographical Lectures. Edited by George St, Cl.AIR, F.G.S. Large crown, 8vo, 7 s. $6 \mathrm{~d}$.

DEE FONCOURT, Madame Marie-Wholesome Cookery. Third Ecition. Crown Sro, 3s. 6\%.

J) E LONG, Licut. Com. G. W.-The Voyage of the Ieannette. The Ship and Ice Joumals of. Edited by his Wife. EMma DE LoxG. With Portraits, Maps, and many Illustrations on wood and stone. 2 rols. Demy Sro, $36 s$.

Democracy in the Old World and the New. By the Author of "The Suez Canal, the Eastern Question, and Alyssinia," ctc. Small crown Sro, $2 s .6 \%$

DEVEREUN, W. Cope, R.N., F.R.G.S.-Fair Italy, the Riviera, and Monte Carlo. Comprising a Tour through North ant South Italy and Sicily, with a short account of Malta. Crown Sro, 6s.

Discourse on the Shedding of Blood, and The Laws of WVar. Demy Svo, 2s. 6u.

DOIVDEN, Eckirarl, LL.D.--Shakspere : a Critical Study of his Mind and Art. Serenth Edition. Post Sro, I2s.

Studies in Literature, I7S9-IS77. Third Edition. Large post 8vo, 6s.

DU MONCEL, Count.-The Telephone, the Microphone, and the Phonograph. With 74 lllustrations, Third Edition. Small crown 8vo, 5 s.!

DCRUY, Victor.-History of Rome and the Roman People. Edited by Prof. MAnafry. With nearly 3000 Illustrations. $41 \%$. Vols. I.-IV. in 8 parts, 30 s. each rol.

FDGEWORTIY, F. Y.-Mathematical Psychics. An Essay on the Application of IIathematics to Social Science. Demy Sro, $75.6 l^{\prime}$.

Educational Code of the Prussian Nation, in its Present Form. In accordance with the Decisions of the Common Pro. vincial Law, and with those of Recent Legisiation. Crown Sro, $2 s .6 \%$

Education Library. Edited by Pinhip Magnus:-

An Introduction to the History of Educational Theories. By Oscar Bromirig, M.A. Second Edition. 3s. 6 ?. 
Education Library-continued.

Old Greck Education. Iy the Rev, l'rof, Mamary, M.A. Second Elition. 3s. 6.t.

School Management. Including a general view of the work of Education, Organization and Discipline. J3y JOSEI'H LANDON. Fourth Edition. $6 s$.

EDIVARDES, The Late MIajor-General Sir Itertert B., K.C.B., ENC-Memorials of the Life and Letters of. Jiy his Wife. 2 vols. With Illustrations. Demy Svo. Cloth.

ELSD ALE, ITenry.-Studies in Tennyson's Idylls. Crown Sro, $5^{s}$. ELYOT, Sir Thomas. - The Boke named the Gouernour. Edited from the First Edition of I53I by HENRY HERBERT STEPIIEN Crort, M.A., Barrister-at-Law. 2 vols. Feap. 4 to, 50 s.

Emerson's (RaIph WValdo) Life. By OluVir WENdell IOLMLS. English Copyright Edition. With Portrait. Crown Sro, $6 s$.

Enoch the Prophet. The Book of. Arehbishop LAURENCE's Trans. lation, with an Introduction by the Author of "The Evolution of Christianity." Crown 8vo, 5 s.

Eranus. $A$ Collection of Exereises in the Aleaic and Sapphic Metres. Edited by F. W. Cornisir, Assistant Master at Eton. Second Edition. Crown Svo, 2s.

EVANS, Nark.-The Story of Our Father's Love, told to Children. Sixth and Cheaper Edition. With Four Illustrations. Fcap. Svo, is. $6 d$.

"Fan Kwae" at Canton before Treaty Days 1825-1844. By an old Resident. With Frontispiece. Crown Sro, 5 s.

Faith of the Unlearned, The. Authority, apart from the Sanction of Reason, an Insufficient Basis for It. Jiyy "One Unlearned." Crowin 8vo, 6s.

FEIS, Facob.-Shakspere and Montaigne. An Endeavour to Explain the Tendeney of Hamlet from Allusions in Contemporary Works. Crown 8vo, 5 s.

FLECKER, Rev. Eliever.-Scripture Onomatology. Being Critical Notes on the Septuagint and other Versions. Second Edition. Crown $8 v 0,3 s .6 d$.

FI.OREDICE, IV. II.-A Month among the Mere Xrish. Small crown 8ro, 5 s.

Frank Leward. Edited by Charles Bampton. Crown 8vo, 7s. 6d. FULLER, Rev. NTorris. - The Lord's Day ; or, Christian Sunday. Its Unity, History, Philosophy, and Perpetual Obligation. Sermons. Demy Sio, ios. 6 .

GARDINER, Samul R., and F. BASS MIUTIIINGER, M.A.Introduction to the Study of English History. Scend Edition. Large crown 8 ro, 9 s. 
GARDNER, Dorsey.-Quatre Bras, Ligny, and WVaterloo. A Narrative of the Campaign in Belgium, ISI5. With Maps and Plans. Demy Sro, I6s.

Genesis in Advance of Present Science. A Critical Investigation of Chapters I.-IX. By a Septuagenarian Beneficed Presbyter. Demy Sro. Ios. $6 d$.

GEORGE, Henry.-Progress and Poverty: An Inquiry into the Causes of Industrial Depressions, and of Increase of Want with. Increase of Wealth. The Remedy. Fifth Library Edition. Post 8ro, 7s. 6d. Cabinet Edition. Crown Svo, 23.6d. Also a Cheap Edition. Limp cloth, Is. 6d. Paper covers, Is.

Social Problems. Fourth Thousand. Crown Svo, 5s. Cheap Edition. Paper covers, Is.

GLANVILL, Foseph.-Scepsis Scientiflca; or, Confest Ignorance, the Way to Science; in an Essay of the Vanity of Dogmatizing and Confident Opinion. Edited, with Introductory Lssay, by John Owen. Elzevir 8vo, printed on hand-made paper, $6 s$.

Glossary of Terms and Phrases. Edited by the Rev. II. PErcr Smitr and others. Second and Cheaper Ldition. Medium 8 vo, $7 s .6 d$.

GLOVER, F., M.A.-Exempla Latina. A First Construing Book, with Short Notes, Lexicon, and an Introduction to the Analysis of Sentences. Second Edition. Fcap. Sro, $2 s$.

GOLDSMID, Sir Francis Henry, Bart., Q.C., MT.P.-Memoir of. With Portrait. Second Edition, Revised. Crown Svo, 6s.

GOODENOUGII, Commodore F. G.-Memoir of with Extracts from his Letters and Journals. Edited by his Widow. With Steel Engraved Portrait. Third Edition. Crown Sro, 5 s.

GORDON, ITajor-Genl. C. G. - His Journals at Kartoum. Printed from the original MS. With Introduction and Notes by A. Egmont Hake. Portrait, 2 Maps, and 30 Illustrations. Two vols., demy 8ro, 2 Is. Also a Cheap Edition in I rol., 6s.

Gordon's (General) Last Iournal. A Facsimile of the last Journal received in England from General Gordon. Repro. duced by Photo-lithography. Imperial 4to, $£ 33^{3}$.

GOSSE, Edmund.-Studies in the Literature of Northern Europe. New Edition. Large crown Sro, 6s.

Seventeenth Century Studies. A Contribution to the History of English Poetry. Demy 8ro, Ios. 6\%.

GOULD, Rev. S. Baring, M.A.-Germany; Present and Past. New and Cheaper Edition. Large crown Sro, $75.6 \%$.

GOWAN, Major Walter E.-A. Ivanoff's Russian Grammar. (I6th Edition.) Translated, enlarged, and arranged for use of Students of the Russian Language. Demy 8ro, 6s. 
GOWER, Lord Ronall. My Reminiscences. Minituru Euitios, printed on hand-made paper, limp parchment antique, Ios. $6 \%$.

Last Days of Mary Antoinette. An Iliotorical Sketch. Fcap. 410.

Notes of a Tour from Brindisi to Yokohama, 18831884. Fcap. Sro, 2s. 6\%.

GRAH.11, William, M..1.-The Creed of Science, Religious, Moril, and Social. Second Edition, Revised. Crown Sro, 6r.

The Social Problem in its Economic, Moral, and Political Aspects. Demy Sro.

Glify, lowland.-In Sunny Switzerland. A Tale of Six Weeki. Second Edition. Small crown Svo, 5 s.

Lindenblumen and other Stories. Small crown Sro, 5. CRIFFITIT, Thomas, A.M.-The Gospel of the Divine Life: a Study of the Fourth Evangelist. Demy Sio, I4s,

GRIIIEY, Rer. II. N., M.A.-Tremadoc Sermons, chiefly on the Spiritual Body, the Unseen World, and the Divine Humanity. Fourth Elition. Crown Sro, 6s.

GCSTASSON, Alex.-The Foundation of Death. Third Ldition. Crown Sro, 5 s.

Some Thoughts on Moderation. Reprinted from a Paper read at the Recve Mission Roon, Manchester Siquare, June S, 18S5. Crown Sro, is.

MAECKEL, Prof. Ernst. - The History of Creation. Translation revised by Professor E. RAY LANkESTER, M.A., I.R.S. With Colnured Plates and Cienealosical 'Trees of the various groups of both l'ants and Animals. 2 rols. Third Edition. P'ost Siro, 325 .

The Hisiory of the Evolution of Man. With numerous Illustrations. 2 rols. I'ost Sro, $32 s$.

A Visit to Ceylon. Post Sro, 7s. 6r.

Frecdom in Science and Teaching. With a Prefatory Note

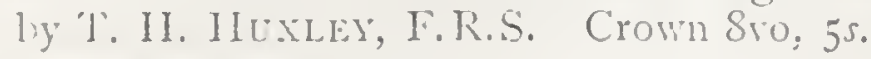

\section{IIAH-CROW: SrRHES:-}

A Lost Lóve. Ijy ANxa C. OGir [Ashford Owen].

Sister Dora: a Biography. By MARGARET Loxsdale.

True Vyords for Brave Men : a Book for Soldiers and Sailors.

By the late CHARILS KidCSLEY.

Notes of Travel : being Extracts from the Journals of Count Vux MOLTKE.

English Sonnets. Collected and Arranged by J. DEx.ris.

Home Songs for Quiet Hours. 13y the Rer. Canon R. II. ]; IIVis. 
HARRIS, William.-The History of the Radical Party in Parliament. Demy Sro, I5s.

HARROP, Rolert.-Bolingbroke. A Political Study and Criticisin. Demy Sro, is s.

IIAT, Re. F. IV. T.-The Autobiography of Judas Iscariot. A Character Study. Crown Sro, 3s. $6 d$.

IIATVEIS, Re:. H. R., M.A.-Current Coin. Materialism-Tin= Devil-Crime-Drunkenness-I’auperism-Emotion-Recrention -The Sabbath. Fifth Edition. Crown Sro, 5 s.

Arrows in the Air. Fifth Edition. Crown Sro, 5s.

Speech in Season. Fifth Edition. Crown Sro, $5 \mathrm{~s}$.

Thoughts for the Times. Thirteenth Edition. Crown Sro, 5i.

Unsectarian Family Prayers. New lidition. I'cap. Sro. Is. $6 \%$.

II 4 WKINS, Edivards Comirford.-Spirit and Form. Sermon; preached in the Parish Chureh of Leatherhad. Crown Sro, Gs.

II.AWTHORNE, Nathaniel.-Works. Complete in Twelve Volumes. Large post Sro, $7 s . \bar{U}$. each rolume.

VOL. I. TWICE-TOLD TALES.

II. MIOSSES FROM AN OLD MANSF

IIT. TIIE HOUSE of THE SEVEX G.Hbls, AND TH: SNOY: IMAGE.

IV. The Wonderbook, Tanglewood Tales, Axn Giraxi. FATIIER'S CIIAIR.

V. The Scarlet Letter, a.to Tite Bithedale Romance.

VI. THE MARBLE FAUN. [Transformation.]

VII.
VIII. OUR OLd HOME, $\Lambda$ N ENGLisil Note-BOOKS.

IX. AMERICAN Note-BOOK.

X. Frexch aid Italian Note-Books.

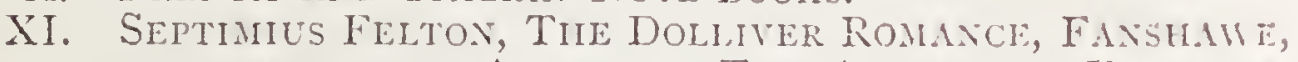
Axd, ix an Aprendix, Tite Ancestral, Footstri.

Xit. Tales and Essiys, and otier Papers, witi a Bio. grapIICAL, SKETCII OF HAWTHORNE.

IIEATH, Franits George.-A utumnal Leaves. Third and cheafer Edition. Large erown $8 r^{\circ}, 6 s$.

Sylvan WVinter. With 7o Illustrations. Large erown Sro.

IIENNESSY, Sir John Pop:--Ralegh in Ireland. With his Letteri on Irish Affairs and some Contemporary Doeuments. I arge crown Svo, printed on hand-made paper, parchment, IOs. $6 l$.

IIINRY, Philip.-Diaries and Letiers of. Edited by MATTHEW IENRy LeE, M.A. Large crown Sro, 7s. 6\%.

HIDE, Albirt.-The Age to Come. Small erown Sro, 2s. 6.t. HIME, MIajor H. W. L., R.A.-XWagnerism: A Protest. Crown Sio, 2s. 6l. 
HINTOV, F.-Life and Letters. With an Introduction by Sir WV. W. Girl, Bart., and I'ortrait cngraved on Steel by C. H. Jeens. Fifth Edition. Crown Svo, Ss. Gd.

Philosophy and Religion. Selections from the Manuscripts of the late James Iinton. Edited by Caroline Haddon. Second Edition. Crown Sro, 5 s.

The Law Breaker, and The Coming of the Law. Edited by MARG.JRE' IINTON. Crown Sro, Gs.

The Mystery of Pain. New Edition. Fcap. Sro, Is.

Hodson of Hodson"s Horse; or, Twclve Vears of a Soldicr's Life in India. Being extracts from the Jetters of the late Major W.S. R. Hodson. With a Vindication from the Attack of Mr. Bosworth Smith. Edited by his brother, G. H. Honsos, M.A. Fourth Edition. Large crown Sro, 5 s.

IIOL THAH, E. G.-Eight Ycars in Japan, 1873-1881. Work, Travel, and Recreation. With three Naps. I arge crown Svo, 9s.

Homology of Economic Justice. An Essay by an East India Merchant. Small crown 8vo, 5 s.

HOOPER, Mary.-Little Dinners: How to Serve them with Elegance and Economy. Nineteenth Edition. Crown Sro, 2s. 6i.

Cookery for Invalids, Persons of Delicate Digestion, and Children. Fourth Edition. Crown Sio, 2s. G\%.

Every-Day Meals. IBcing Economical and Wholcsome Recipes for Breakfast, Luncheon, and Supper. Sixth Edition. Crown 8ro, 2s. 6il.

IJOPKINS, Ellice. Work amongst Working Men. Fifth Edition. Crown Sro, 3s. G.t.

zIOSPITALIER, E.-The Modern Applications of Electricity. Translated and Enlarged by Juilus MAHR, Ph.ID. 2 vols. Sccond Edition, Revised, with many additions and numcrous Illustrations. Demy Sro, I2s. 6 . each volume.

Vor. I.-Electric Generators, Electric Light.

Vor. II.-Telephonc: Various Applications: Electricai Transmission of Energy.

Household Readings on Prophecy. By a Layman. Small crown Sro, 3s. 6d.

IIOIVARD, Robert, M.A.-The Church of England and other Religious Communions. A coursc of Lectures delivered in the I'arish Church of Clapham. Crown Svo, 7s. 6d.

IIUGIIES, IICnr.-The Redemption of the World. Crown Sre. $3 s .6{ }^{3}$.

IIUNTER, Hay.-The Crime of Christmas Day. A Tale of the Latin Quarter. 
IIUNTER, Willian C.-Bits of Old China. Small crown Sro, 6s. IIUNTINGFORD, Rev. E., D.C.L.-The Apocalypse. With a Commentary and Introductory Essay. Demy Sro, 5 s.

IIUTCHINSON, H.-Thought Symbolism, and Grammatic Illusions. Being a Trcatise on the Nature, Purpose, and Material of Speech. Crown Sro, 5 s.

IIUTTON, Rcv. C. F.-Unconscious Testimony; or, The Silent Witness of the Hebrew to the Truth of the Historical Scripture: Crown 8 ro, $2 s, 6 d$.

HYNDMAN, H. M.-The Historical Basis of Socialism in England. Large crown Sro, 8s. $6 \%$.

IMT THURN, Everarl F.-Among the Indians of Guiana. Being Sketchcs, chiefly anthropologic, from the Intcrior of British Guiana. With 53 lllustrations and a Map. Dcmy $80^{\circ}$, iss.

FACCOUD, Prof. S.-The Curability and Treatment of Pulmonary Phthisis. Translated and edited by Montagu LUBBock, M.D. Demy Sro, I5s.

Jaunt in a Junk: A Ten Days' Cruise in Indian Scas. Large crown 3ro, $7 s, 6 \%$.

FENKFNS, E., and RAYMOND, F-The Architect's Legal Handbook. Third Edition, revised. Crown 8ro, 6s.

FERVIS, Rev. IV. FFnley.-The Gallican Church and the Revolution. A Sequel to the History of the Church of France, from the Concordat of Bologna to the Revolution. Demy 8 ro, iss.

FOEL, L.-A Consul's Manual and Shipowner"s and Shipmaster's Practical Guide in their Transactions Abroad. With Definitions of Nautical, Mercantile, and Legal Terms; a Glossary of Mercantile Terms in English, French, German, Italian, and Spanish; Tables of the Money, IVeights, and Mcasures of the Principal Commercial Nations and their Equivalents in British Standards; and Forms of Consular and Notarial Acts. Demy Sro, I2s.

FOHNSTON, H. H., F.Z.S.-The Kilima-njaro Expedition. A Record of Scientific Exploration in Eastern Equatorial Africa, and a General Description of the Natural History, Languages, and Commerce of the Kilima-njaro District. With 6 Maps, and over 80 Illustrations by the Author. Demy Sro.

FOLLY, IVilliam, F.R.S.E., cti.-The Life of Iohn Duncan, Scotch Weaver and Botanist. With Sketches of his Friends and Noticcs of his Times. Second Edition. Large crown 8vo, with Etched Portrait, 9s.

FOYCE, P. IV., LI.D., ctc.-Old Geltic Romances. Translated from the Gaelic. Crown Sro, $7 s .6 \%$. 
KACFMA.TW, Rew. M. B.A.-Socialism : its Nature, its Dangers, and its Remedies considered. Crown Sro, 7s. Oul.

Utopias; or, Schemes of Social Improrement, from Sir Thomas More to Kirl Marx. Crown Sro, 5.s.

KAY, David, I.K.G.S.-Education and Educators. Crown Sio, 7 s. $6 l^{\circ}$.

IAl), Fosith. Free Trade in Land. Eilited by his Mirlow. Mith l'reface by the Right IIon. Jonn BRICHT, N.l'. Seventh Iidition. Crown Sro, 5 s.

*** Also a chenper edition, withont the Appendix, but with a Rerise of Recent Changes in the Land Laws of kingland, by the Rucirt Ilox. G. OshokNe Morgan, (2.C., M.I'. Cloth, Is. Gd. I'aper corers, Is.

KILLE, $H . H$. II.-An Epitome of English Grammar for the Use of Students. Aclapted to the I,ondon Matriculation Course and Similar Examinations. Crown Sro.

IF.MPIS, Thomas i.-Of the Imitaiion of Christ. Parchment Library Edition. - Parchment or cloth, 6s.; vellum, 7.s. Gol. 'Jhe Red line Edition, feap. Ero, red edges, 2s. G\%. The Cabinet Edition, small Sro, cloth limp, is.; cloth boardi, red edges, Is. Got. The Miniature Edition, red ederes, $32 \mathrm{mo}$, Is.

*** All the abore Elitions may be lial in various cxtra binelings.

KE.IT: C.-Corona Catholica ad Petri successoris Pedes Oblata. De Summi Pontificis Leonis XIII. Assumptione Epigramma. In Quinquaginta Linguis. Ficap. 4 to, I5s.

KETTLEWELL, Ke'.S.-Thomas à Kempis and the Brothers of Common Life. 2 rols. With Frontispieces. Demy Sro, 3os.

* Also an Abridged Elition, in one volume. With l'urtrait. Crown Sro, $75.6 \%$

KII)D, Foseph, MID.-The Laws of Therapeutics; or, the Scince and $2 \mathrm{rt}$ of Medicine. Second Edition. ('rown Sro, 6s.

KIAGSFORD, Amm, M.D.-The Perfect Way in Diet. I Treatise adrocating a Return to the Natural and Ancient Food of our kace. Second lidition. Small crown Sro, $2 s$.

A'IVGSLEY, Charle's, M.A.-Letters and Memorics of his Life. Edited by his Wife. With two Steel linerared l'ortraits, and Vignettes on Wood. Fifteentl Cabinet Edition. 2 vols. Crown Sro, I2s.

* Also a People's Eelition, in one vulune. Mith Purtrait. Cruwn Sro, 6s.

All Saints' Day, and other Sermons. Eiliterl by the Rer. IV. IIARRISON. Third Edition. Crown Sio, $7 \mathrm{~s} .6 \mathrm{~d}$.

True Words for Brave Men. A book for Sinllier' and Sailors' Libraries. Eleventh Erlition. Crown Sin, 2s, 6\%. 
KNOY, Alexander A.-The New Playground; or, Nanderings in Algeria. New and Cheaper Edition. Large crown Svo, 6s.

LANDON, fosefh.-School Management ; Including a Gencral Vicw of the Work of Education, Organization, and Discipline. Fourth Edition. Crown Sio, 6s.

LAUKIE, S. S.-The Training of Teachers, and other Educational Papers. Crown Sro, 7s. 6\%.

LEE, Rev. F. G., D.C.L.-The Other World; or, Glimpses of the Supernatural. 2 vols. A New Edition. Cirown Sro, I js.

Letters from an Unknown Friend. By the Autlol of "Charles Lowder." With a Preface by the Rev. W. H. CI.EATER. Icap. Sro, Is.

Letters from a Young Emigrant in Manitoba. Sccond Edition. Small crown Siro, $3 s$. 6 $\%$.

Leward, Frank. Felited by CHARLES BA.Mrox. Crom Sio, 7s. 6\%. LEIVIS, Edward Dillon.-A Draft Code of Criminal Law and Procedure. Demy Sio, 2 Is.

LILLIE, Arthu, M.R.A.S.-The Popular Life of Buddha. Containing an Answer to the Ilibbert Lectures of rSS I. With Illustrations. Crown Sro, 6s.

I.LOYD, IValter.-The Hope of the WXorld : An Essay on Universal Redemplion. Crown Sro, 5 s.

LONSDALE, Margaret.-Sister Dora: a Biography. With Portrait. Cheap Edition. Crown Sio, 2s. 6\%.

LOUNSBURY, Thomas R.-James Fenimore Cooper. Witl Portrait. Crown Sio, 5 s.

LOIVDER, Charles.-A Biography. By the Author" of "St. Teresa." New and Cheaper Eclition. Crown Sro. With Portrait. 3s. G\%.

IÜCKES, Eva C. E.-Lectures on General Nursing, delivered to the Probationers of the Lonclon Hospital Training School for Nurses. Crown Sro, 2s. 6a.

LYALL, William Roure, D.D.-Propadeia Prophetica; or, The Use and Design of the Old Testament Examined. N'ew Edition.

With Notices by Grorge C. P'EArson, M.A., ITon. Canon of Canterbury. Demy Sro, ros. 6\%.

LYTTON, Edward Bulwer, Lord.-Life, Letters and Literary Remains. By his Son, the EARL, of LrTTOs. With Portraits, Illustrations and Facsimiles. Demy Sro. Tols. I. and II., $32 s$.

NACAULAY, G. C.-Francis Beaumont: A Critical Study. Crom Sro, 5 s.

MAC CALLUM, M. W.-Studies in Low German and High German Literature. Crown Svo, Gs.

MACHIAVELLI, Niccolo. - Life and Times. By Prof. Viliart. Translated by Linda Villakr. 4 vols. Large post Sro, $4 \mathrm{Ss}$. 
MACHIAVELII, Niccld.-Discourses on the First Decade of Titus Livius, Translated from the Italian ly Nisisy IIILL Thomson, M.A. Large crown Sro, i2s.

The Prince. Translated from the Italian hy N. H. T. Small crown Sro, printed on hand-made paper, bevelled boards, 6s.

MACKENZIE, Alexander.-How India is Governed. Heing an Account of England's Work in India. Simall crown Sro, 2s.

. MAGNUS, Mrs. - About the Jewrs since Bible Times. From the Babylonian Exile till the English Exodus. Small crown Sro, 6s.

MIIR, R. S., M.D., I.R.C.S.E.-The Medical Guide for AngloIndians. Being a Compendium of Advice to Europeans in India, relating to the Preservation and Regulation of Health. With a Supplement on the Management of Children in India. Second Edition. Crown Svo, limp cloth, 3 s. $6 \%$.

MALDEN, Ilenry Iilliot.Vienna, 1683. The History and Conse. quences of the Defeat of the Turks before Vienna, Septemlere 12th, I683, by Jolm Sobieski, king of Poland, and Charles Leopold, Duke of Lorraine. Crown Sro, 4s. 6 .

MALET, Lucas.-Colonel Enderby's WNife. A Novel. Fourth Edition. 3 vols. Crown Sro.

Many Voices. A volume of Extracts from the Religious Vriters of Christendom from the First to the Sixteenth Century. With liographical Sketches. Crown 8ro, cloth extra, red edges, 6s.

IIARKIIAM, Capt. Albert IJustings, R.N.-The Great Frozen Sea : A Personal Narrative of the Voyage of the Alert during the Arctic Expedition of I875-6. With 6 Full-page 1llustrations, 2 Maps, and 27 Woodcuts. Sixth and Cheaper lidition. Crown 8vo, 6s.

ITARTINEAU, Gertrude-Outline Lessons on Morals. Small crown Sro, 3s. 6a.

MAUDSLEY, MI., M.D.-Body and WVill. Being an Essay concerning Will, in its Metaphysical, I'hysiological, and Pathological Aspects. 8vo, i2s.

MiGRATH, Terenci-Pictures from Ireland. New and Cheaper Edition. Clown Sro, 2 s.

MEREDITH, M.A.-Theotokos, the Example for WNoman. Dedicated, by permission, to Lady Agnes 1 Tood. Revised by the Venerable Archleacon Drisisov. 32mo, limp cloth, is. $6 d$.

MILLER, Edivard.-The History and Doctrines of Irvingism; or, The so-called Catholic and Apostolic Church. 2 vols. Large post Sro, 25 s.

The Church in Relation to the State. Large crown 8ro, 7s. 6 .

MITCHELL, I.UCy MT-A History of Ancient ScuIpture. With numerous Illustrations, including 6 Plates in Phototype. Super royal 8 ro, $42 s$. 
MITCHELL, LuCy M.-continucd.

Selections from Ancient Sculpture. Bcing a Portfolio con. taining Reproductions in Phototype of 36 Mastcrpieccs of Ancient Art to illustrate Mrs. Mitehcll's "History of Ancient Seulpturc." I 8 s.

MITFORD, Bertram.-Through the Zulu Country. Its Battlc. fields and its People. With Five Illustrations. Demy Sro, I 4 s.

MOCKLER, E.-A Grammar of the Baloochee Language, as it is spoken in Makran (Ancient Gedrosia), in the Persia-Arabic and Roman characters. Fcap. 8vo, $5^{s .}$

MOLESWORTH, Rev. W. Nassau, M.A.-History of the Church of England from 1660. Large crown Sro, 7s. 6\%.

MORELL, F. R.-Euclid Simplified in Method and Language. Being a Manual of Geometry. Compilcd from the most important French Works, approved by the University of Paris and the Minister of Public Instruction. Fcap. Sro, 2s. 6d.

MORGAN, C. Lloyd.-The Springs of Conduct. An Essay in Evolution. Large crown 8vo, cloth, 7 s. $6 \%$.

MORRIS, George.-The Duality of all Divine Truth in our Lord Jesus Christ. For God's Self-manifestation in the Impartation of the Divine Nature to Man. Largc crown Sro, 7s. 6\%.

MORSE, E. S., Ph.D.-First Book of Zoology. With numerous Illustrations. New and Cheaper Edition. Crown Sro, 2s. $6 d$.

MULL, Matthias._Paradise Lost. By Jorn Mrltox. Bools I.-VI. The Mutilations of the Text emcnded, the Punctuation reviscd, and all collectively prescnted, with Notcs and Preface; also a short Essay on the Intellectual Value of Milton's Works, etc. Demy $8 v o, 6 s$.

Shakspere's Hamlet. The Text Revised. Lines pronounced Corrupt restored, and Mutilations beforc unsuspectcd cmended. With Preface and Notes. Dcmy Sro, $3^{s}$.

NELSON, F. H., M.A.-A Prospectus of the Sclentific Study of the Hindu Law. Demy Sro, 9s.

NEWMAN, Cardinal.-Characteristics from the Writings of. Being Selections from his various Works. Arranged with the Author's personal Approval. Sixth Edition. With Iortrait. Crown 8vo, 6s.

*** A Portrait of Cardinal Newman, mounted for framing, can be had, $2 s .6 \%$.

NEWIIAN, Francis William.-Essays on Diet. Small crown Sro, cloth limp, 2s.

New Truth and the Old Faith: Are they Incompatible? By a Scientific Layman. Demy 8vo, Ios. $6 \%$.

New Werther. By Lokr. Small crown $8 \mathrm{vo}^{2} 2 \mathrm{~s}, 6 \%$ 
NICOLS, Artmr, F.G.S.,F.R.G.S.-Chapters from the Physical History of the Earth: an Introduction to Geolosy and laleontology. With numerous Illustrations. Crown Svo, 5 s.

NOPS, Mariame.-Class Lessons on Euclid. Part I. containing the First Two Books of the Eilements. Crown Sro, 2s. G\%.

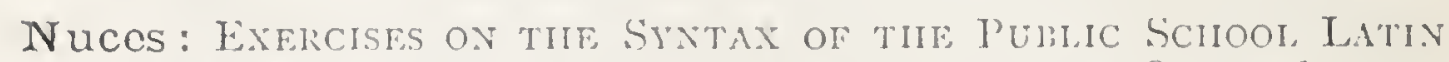
Primer. New lidition in Three Parts. Crown Sro, cach Is.

* * The Three l'arts can also be had bound together, $3^{s}$.

O.ATES; Frank, F.R.G.S.-Matabele Land and the Victoria Falls. A Naturalist's TVanderings in the Interior of South Africa. lidited by C. G. Ostes, Ti.A. With numerous Illustrations and 4 Maps. I)eny Sio, 2 Is.

OCONIOK, T. P., M.P.-The Parnell Movement. With a Sketch of Irish Parties from $1 \$_{43}$. Demy Sro.

OGLE, IY., M.D., I.R.C.P.-A ristotlc on the Parts of A nimals. Translated, with Introduction and Notes. Koyal Sro, 12s. 6.

O'IIAGAY, Lord, I.l. - Occasional Papers and Addresses. Large crown Sio, $75.6 \%$.

OKEN, Lorenz, Life of. By ALEx.NDER ECKER. With IXxplanatory Notes, Selections from Oken's Correspondence, and I'ortrait of the Professor. From the German by Alfred Tulk. Crown Svo, 6s. Old Corner House, The. By L. H. 2 vols. Crown Sro.

O'MEARA, Kathlen.-Frederic Ozanam, Professor of the Sorbonne:

Iis Life and Work. Second Ldition. Crown Sro, 7s. G\%.

Henri Perreyve and his Counsels to the Sick. Small crown Sro, $5^{\mathrm{s}}$.

One and a Half in Norway. $\Lambda$ Chronicle of Small Beer. By Either and Both. Small crom Sro, 3s. 6d.

O'VEIL, the late Rcv. Lord.-Sermons. With Nemoir and I'ortrait. Crown Sro.

Essays and Addresses. Crom Sro.

Only Passport to Heaven, The. Hy One who lia; it. Small crown Sio, is. $6 \%$.

OSBORNE, Re'. W. A.-The Revised Version of the New Testament. A Critical Commentary, with Notes upon the Text. Crown 8ro, 5 s.

OTTLEY, H. Bickersteth. - The Great Dilcmma. Christ Ilis Own Vitness or ILis Own Accuser. Six Lectures. Second Eclition. Crown Sro, 3s. 6d.

Our Public Schools-Eton, Harrow, Winchester, Rugby, Westminster, Marlborough, The Charterhouse. Crown Siro, Gs.

OIVEN,F. MI.-John Keats: a Sturly. Crown Svo, 6s. Across the Hills. Small crown 8ro, Is. $6 d$. 
OIVEN, Rev. Robert, B.D.-Sanctorale Catholicum; or, Book of Saints. With Notes, Critical, Exegetical, and Historical. Demy Sro, iss.

OYENFIN, Re. F. Nutcombe - What is the Truth as to Everlasting Punishment. I'art II. Being an IIistorical Inquiry into the Witness and Weight of certain Anti-Origenist Councils. Crown Sro, 2s. 6.\%.

O.TONIENSIS. - Romanism, Protestantism, Anglicanism. Being a Layman's View of some questions of the Day. Together with Remarlis on Dr. Littledale's "I'lain Reasons against joitring the Church of Rome." Crown Sro, 3 s. 6\%.

PALMER, the late William.-Notes of a Visit to Russia in 1840-1841. Selected and aranged by JOIIN H. CARDINAI, Newaran, with portrait. Crown Sro, 8s. $6 \dot{d}$.

Early Christian Symbolism. A Series of Compositions from Fresco Paintings, Glasses, and Scuptured Sarcophagi. Iidieel by the Rev. P'rovost NorTicote, D). D), and the Rev. Canon Brownlow, M.A. With Coloured Plates, folio, 42s., or with Plain Plates, folio, 25 s.

Parchment Library. Choicely Printed on hand-made paper, limp parchment antique or cloth, $6 s$; vellum, 7 s. $6 \%$. cach volume.

The Poetical Works of John Milton. 2 vols.

Letters and Jourmals of Jonathan Swift. Selected and edited, with a Commentaly and Notes, by S'TANLEY LANE POOLE.

De Quincey's Confessions of an English Opium Eater. Reprinted from the First Edition. Edited by RiCinan Garrirr.

The Gospel according to Matthew, Mark, and Lulce.

Selections from the Prose Writings of Jonathan Swift. With a Preface and Notes by STANidy L.dxe-Poorli and. Portrait.

English Sacred Lyrics.

Sir Joshua Reynolds's Discourses. Edited by Emmon Gosse.

Selections from Milton's Prose Writings. Edited lyy ERNEST MYERS.

The Book of Psalms. Translated by the Rer. T. K. Crrerse, M.A.

The Vicar of Wakefield. With Preface and Notes by AUsts: Domson.

English Comic Dramatists. Edited by OsWALD CRAWEURD. English Lyrics.

The Sonnets of John Milton. Edited Ly M.ARK PATTisoy With l'ortrait after Vertue. 


\section{Parchment Library-contimuct.}

French Lyrics. Selected and Annotated by George SAInts. BURY. With a Miniature Frontispiece designed and etched by H. G. Glindoni.

Fables by Mr. John Gay. With Memoir by Austin Dobson, and an Etched Portrait from an unfinished Oil Sketch by Sir Godfrey Kneller.

Select Letters of Percy Bysshe Shelley. Edited, with an Introduction, by RICHARD GARNET'?.

The Christian Year. Thoughts in Verse for the Sunclays and Iloly Days throughout the Year. With Miniature Portrait of the Rev. J. Keble, after a Drawing by G. Richmond, R.A.

Shakspere's Works. Complete in Twelve Volumes.

Eighteenth Century Essays. Sclected and Edited by Austin Dobson. With a Miniature Frontispiece by R. Caldecott.

Q. Horati Flacci Opera. Edited by F. A. Cornishi, Assistant Master at Eton. With a Frontispiece after a design by L. Alma Tadema, etehed by Lcopold Lowenstam.

Edgar Allan Poe's Poems. With an Essay on his Poetry by ANDREW LANG, and a Frontispicee by Linley Sambourne.

Shakspere's Sonnets. Edited by Edward Dowden. With a Frontispiece etched by Lcopold Lowenstam, after the Death Mask.

English Odes. Selected by Enmund Gosse. With Frontis. piece on India paper loy Hamo Thornyeroft, A.R.A.

Of the Imitation of Christ. By Tilomas $\grave{\Lambda}$ Kempis. A revised Translation. With lrontispiece on India paper, from a Design by W. B. Riehmond.

Poems: Selected from Percy Brssie Shelley. Dedieated to Lady Shelley. With a Preface by Richiard GarneT'T and a Miniature lrontispiece.

* * The above volumes may also be had in a variety of leather bindings. M.ARSI.OE, Foseph.-Our Railways. Sketehes, Historical and 1)eseriptive. With Practical Information as to Fares and Rates, ete., and a Chapter on Railway Reform. Crown 8vo, 6s.

PASCAL, Blaise.-The Thoughts of. Translated from the Text of Auguste Molinier, hy C. KEgan PAUl. Large erown Svo, with Frontispiece, printed on hand-made paper, parchment antique, or cloth, I2s.; vellum, I5s.

PACT, Alexander.-Short Parliaments. A Ilistory of the National Demand for frequent General Elections. Small crown 8vo, 3s. 6d.

PAUL, C. Kegan.-Biographical Sketches. Printed on hand-made paper, bound in buckram. Second Edition. Crown 8vo, 7s. 6d. 
PEARSON, Rev. S.-Week-day Living. A Book for Young Men and Women. Second Edition. Crown Sro, 5 s.

PESCHEL, Dr. Oscar.-The Races of Man and their Geographical Distribution. Second Edition. Large crown Svo, $9 s$.

PHIPSON, E.-The Animal Lore of Shakspeare's Time. Including Quadrupeds, Birds, Reptiles, Fish and Insects. Large post 8vo, 9s.

PIDGEON, D.-An Engineer's Holiday; or, Notes of a Round Trip from Long. $0^{\circ}$ to $0^{\circ}$. New and Clieaper Edition. Large crown Sro, $7 s .6 \%$.

Old World Questions and New World Answers. Second Edition. Large crown Svo, 7s. 6\%。

Plain Thoughts for Men. Eight Lectures delivered at Forester's Ilall, Clerkenwell, during the London Mission, ISS4. Crown Sro, cloth, Is. $6 d$; paper covers, Is.

POE, Edgar Allan.-W Works of. With an Introduction and a Memoir by Richard Henry Stoddard. In 6 vols. TVith Frontispieces and Vignettes. Large crown Svo, 6s. each.

POPE, F. Bukingham. - Railway Rates and Radical Rule. Trade Questions as Election Tests. Crown Sro, 2s. 6\%.

PRICE, Prof. Bonamy. - Chapters on Practical Political Economy. Being the Substance of Lectures delivered before the University of Oxford. New and Cheaper Edition. Large post Svo, 5 s.

Pulpit Commentary, The. (Old Testament Series.) Edited by the Rev. J. S. Exell, M.A., and the Rev. Canon H. D. M. Spence.

Genesis. By the Rev. T. IVIntelaw, M.A. With Homilies by the Very Rev. J. F. Montgomery, D.D., Rev. Prof. R. A. RedFord, M.A., LL.B., Rev. F. HASTINGs, Rev. IV. RonerTs, M.A. An Introduction to the Study of the Old Testament by the Venerable Archdeacon FARRAR, D.D., F.R.S.; and Introductions to the Pentateuch by the Right Rev. H. Cot. TERILl, D.D., and Rev. T. Whitelaiv, M.A. Eighth Edition. I vol., I 5 s.

Exodus. By the Rev. Canon RAwrinson. With lfomilies by Rev. J. OrR, Rer. D. Joung, B.A., Rev. C. A. Goodhart, Rev. J. Urquhart, and the Rev. H. T. Robjohns. Fourth Edition. 2 vols., ISs.

Leviticus. By the Rev. Prebendary Meyrick, M.A. With Introductions by the Rev. R. Collins, Rev. Professor A. CAve, and Homilies by Rev. Prof. Redford, LL.B., Rev. J. A. Macdonald, Rev. IV. Clarkson, B.A., Rev. S. R. Aldridge, LL.B., and Rev. MCCheyne EDGar. Fourth Edition. I 5 s. 
Pulpit Commentáry, The-contimut.

Numbers. By the Rev. R. Wixternotham, LL.B. With Homilies by the Rer. Professor II. Briver, 1).I)., Rer. İ. S. ProuT, M.A., Rev. D. YousG, Kev. J. WArts, and an Introduction by the Kev. 'llomas WIITELAl, M.A. liourth Edition. 155 .

Deuteronomy. Iyy the Rev. W. L. All:N.vinkl, 1).I). With

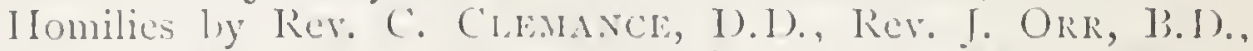

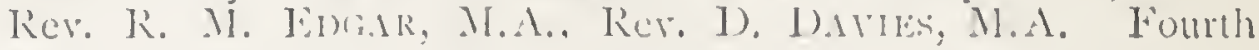
edition. $15 \%$

Joshua. By Rer. J. J. IAs, M.A. With Momilies by Rev.

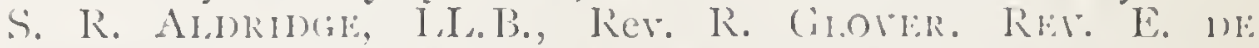

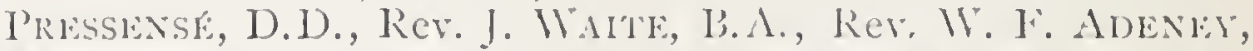
M.A. : and an Introduction by the Rev. A. Plumake, M.A. Fifth Jitition. I2s. 6 \%.

Iudges and Ruth. By the Bishop of Bath and Wclls, and Rer. 1. Morison, 1).1). With Homilies ly Rev. A. I. Muln, M.A., Rev. IV. F. Adexey, M.A., Rer. W. M. S'TA'THA, and Rev. T'rofessor J. Thomsox, M.A. Fourth Edition. 1os. Ga.

1 Samuel. By the Very Kev. R. P. Simr, D.D. With Homilies Iy Rev. DONALD FrASER, D.D., Kev. J'rof. CHAPMAN, and Rer. 13. I)ALE. Sixth E'dition. I5s.

1 Kings. By the Rev. Josmpn Hammoxis, I.L. B. With Homilies

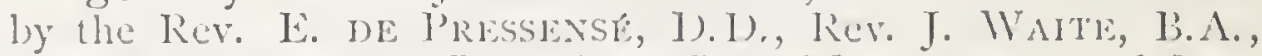
Rer. A. Rowlaxis, LL. B., Rev. J. A. MACDONALn, and kev. I. L'RQthakT. Fourth Edition. i $5^{s .}$

1 Chronicles. By the Rer. T'rof. T'. C. MARkrR, M.A., IJ..l3. With Iomilies by Rev. Jrof. J. K. THonsox, M.A., kev. K. 'Tuck, B.A., Rev. W. Ciakksor, B.A., Rev. H. WIITHELd, M.A., and Rev. RiCHARD GLOVkR. 15 s.

Ezra, Nehemiah, and Esther. By Rev. Camon G. Rawısos, M.A. With I Iomilies ly Rev. I'rof. J. R. Tinomson, M.A., Rer. Prof. R. A. Kr:nfokD, LI.J3., M.A., Rev. W. S. L.wis, M.A.,

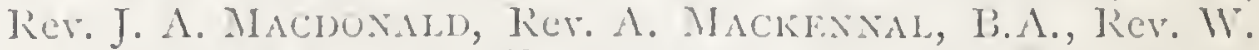

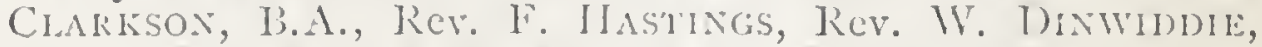
LI..B., Rev. Prof. Rowhans, 13.A., Rev. G. Wonn, 13.A., kev. Prof. I'. C. BARKkK, M.A., LL.B., and the Kev. J. S. lixer., M.A. Sixth Edition. I vol., $12 s .6 d$.

Jeremiah. (Vol. I.) By the Rev. T. K. Cheynt, M.A. With Ilomilies by the Rev. II. F. AlE.NE, M.A., Ker. A. I. MUIR, M.A., Rev. S. Corway, B.A., Rev. J. WAITE, B.A., and Rev. D. Youxg, 13.A. Second lidition. I 5 s.

Jeremiah (Vol. II.) and Lamentations. By Rev. T. K. Cineve, M.A. Will Momilies by Rev. Prof. J. R. THonsox, M.A., Rev. W. F. AnENEY, M.А., Rev. A. IN Mur, M.A., Rer. S, Covrdy, B.A., Rer. D. Yousg, B.A. $15^{s .}$ 
Pulpit Commentary, The. (New Testament Series.)

St. Mark. By Very Rev. E. Bickersteth, D.D., Dean of Lichfield. With Homilies by Rev. Prof. Thomson, M.A., Rer. Pruf. Given, M.A., Rev. Prof. Jomnson, M.A., Rer. A. Rowlant, 13.A., LL.B., Rev. A. Muir, and hev. K. Greex. Fourth Eidition. 2 vols., $2 \mathrm{I} s$.

The Acts of the A postles. By the Bishoil of Bath and W'clls. With Homilies by Rer. Jrof. I'. C. BARKER, M.A., LL. I., Rev. Prof. E. Jolnson, M.A., Rev. Prof. R. A. REnFORn, M.A., Rev. R. TUCK, B.A., Rer. W. Ciarksos, 13.A. Sccond Litition. 2 rols., $21 s$.

I. Corinthians. 1yy the Ven. Archleacon IARrar, D.1). With Homilies by Rev. Ex-Chancellor Lfl'scosn, LL.D., Rev. David Thomas, D.D., Rev, J). Fraser, D.D., Rev. Prof. J. R. Thomson, M.A., Rev. J. Waitr, B.A., Rev. R. Tuсk, B.A., Rev. E. Iurvd.h., M.A., and Rev. II. Brinare, B.I, Second Edition. l'rice I 5 s.

II. Corinthians and Galatians. Jy the Ven. Archleacon FARRAR, D.D., and Rev. Preb. E. IIUxTaller. With Homilies by Rev. Ex-Chancellor Lipscomi, LL.I)., Rer. Marin 'Thomas, D.D., Rev. Thonalid Fraser, D.D., Rev. R. TuCk, B.A., Rev. E. IIURNDALl, M.A., Rev. Irof. J. R. TIIOMSON, M.A., Rev. R. Finlayson, B.A., Rev. W. F. Adeney, M.A., Rev. K. M. EDGAR, M.A., and kev. T. Croskerry, D.D. Price $21 s$.

PUNCHARD, E. G., D.D.-Ghrist of Contention. Three Essajs. Fcap. Sro, $2 s$.

PUSEY, Dr--Sermons for the Church's Seasons from Advent to Trinity. Selected from the Published Sermons of the late Edward Bouverie Pusey, D.D. Crown Sio, 5 s.

RADCLIFFE, Frank R. Y.-The New Politicus. Small crown Sro, $2 s .6 d$.

RANKE, Leopold ron.-Universal History. The oldest Historical Group of Nations and the Greeks. Edited by G. W. Protriero. Demy Sro, I6s.

Realities of the Future Life. Small crown Sro, $1 s .6 \%$.

RENDELL, F. MI.-Concise Handbook of the Island of Madeira. With Plan of Funchal and Map of the Island. Ficap. $8 \mathrm{vo}, \mathrm{I} s .6 d$.

REYNOLDS, Rev. F. W.-The Supernatural in Nature. A Verification by Free Use of Science. Third Edition, Revised and Enlarged. Demy Svo, I 4 s.

The Mystery of Miracles. Third and Enlarged Edition. Crown Svo, $6 s$.

The Mystery of the Universe; Our Common Faith. Demy 8vo, i4s. 
KIBOT, Prof. Th.-Heredity: A Psyehological Study on its Phenomena, its Laws, its Causes, and its Consequences. Second Edition. Large erown Sro, 9 s.

RIIIMER, William, M.D.-Art Anatomy. A Portfolio of Si Plates. Folio, 7os., nett.

ROBERTSON, The late Rev. F. W., M.A.-Life and Letters of. Edited by the Rev. STOIFord BROOKE, M.A.

I. Two vols., uniform with the Sermons. With Steel Portrait. Crown 8ro, $7 \mathrm{~s} .6 \mathrm{c}$.

II. Library Edition, in Demy Sro, with Portrait. I2s.

III. A Popular Edition, in I vol. Crown $8 v o, 6 s$.

Sermons. Four Series. Small erown 8vo, 3s. 6d. each.

The Human Race, and other Sermons. Preached at Cheltenham, Oxford, and Irighton. New and Cheaper Edition. Small crown 8 vo, 3 s. $6 \%$.

Notes on Genesis. New and Cheaper Ldition. Small erown 8vo, 3s. $6 a$.

Expository Lectures on St. Paul's Epistles to the Corinthians. A New Edition. Small crown 8ro, 5 s.

Lectures and Addresses, with other Literary Remains. A New Edition. Small erown Svo, 5 s.

An Analysis of Tennyson"s "In Memoriam." (Dedieated by Permission to the Poct-Laureate.) Feap. 8ro, 2s.

The Education of the Human Race. Translated from the German of GotThold Eirinaim Lessing. Feap. Sro, 2s. 6d.

The above Works ean also be had, bound in half moroceo.

** A Portrait of the late Rev. F. IV. Robertson, mounted for framing, ean be liad, 2s. $6 d$.

ROMANES, G. F.- Mental Evolution in Animals. With a Posthumous Essay on Instinet by Charles DarWin, F.R.S. Demy 8ro, izs.

Rosmini"s Origin of Ideas. Translated from the Fifth Italian Edition of the Nuovo Saggio Sult' origine delle idec. 3 vols. Demy 8ro, eloth, I6s. each.

Rosmini's Psychology. 3 vols. Demy 8vo. [Vol. I. now ready, I6s. Rosmini's Philosophical System. 'Translated, with a Sketeh of the Author's Life, Bibliography, Introduction, and Notes by Tiromas Davidson. Demy 8ro, i6s.

RULE, Martin, M.A. - The Life and Times of St. Anselm, Archbishop of Canterbury and Primate of the Britains. 2 vols. Jemy 8 ro, $32 s$.

SAMUEL, Sydney M.-Jewish Life in the East. Small erown 8vo, 3 s. 6 .

SARTORIUS, Ernestine.-Three Months in the Soudan. With I I Full-page Illustrations. Demy 8vo, i 4 s. 
SAYCE, Rev. Archibald Henry.-Introduction to the Science of Language. 2 vols. Second Edition. Large post 8ro, 2 Is.

SCOONES, W. Baptiste-Four Centuries of English Letters: A Selection of 350 Letters by 150 Writers, from the Period of the Paston Letters to the Present Time. Third Edition. Large crown 8ro, 6s.

SEE, PROF. GERMIIN.-Bacillary Phthisis of the Lungs. Translated and edited for English Practitioners by WILLIAM Henry Weddell, M.R.C.S. Demy Sro, Ios. 6\%.

SHILLITO, Rev. Foseph.-Womanhood: its Duties, Temptations, and Privileges. A Book for Young Women. Third Edition. Crown 8 vo, $3 s .6 d$.

SIDNEY, Algernon.-A Review. By Gertrude M. Irelaid BlackBURNe. Crown Sro, 6s.

Sister Augustine, Superior of the Sisters of Clarity at the St. Johannis Hospital at Bonn. Authorised Translation by HANs THARAU, from the German "Memorials of AMALIE VON LASAUlX." Cheap Edition. Large crown 8ro, 4s. 6d.

SKINNER, Fames.-A Memoir. By the Author of "Charles Lowder."

With a Preface by the Rev. Canon CARTER, and Portrait.

Large crown, $7 s .6 d$.

* * Also a cheap Edition. With Portrait. Crown Sro, 3s. 6d.

SNITH, Edward, M.D., LL.B., F.K.S.-Tubercular Consumption in its Early and Remediable Stages. Second Edition. Crown $8 v 0,6 s$.

Specimens of English Prose Style from Malory to Macaulay. Selected and Annotated, with an Introductory Essay, by George Saintsbury. Large crown 8vo, printed on handmade paper, parchment antique or cloth, I2s.; vellum, I $5 \mathrm{~s}$.

SPEDDING, Fames.-Reviews and Discussions, Literary, Political, and Historical not relating to Bacon. Demy Svo, 12s. 6d.

Evenings with a Reviewer; or, Macaulay and Bacon. With a Prefatory Notice by G. S. Venabies, Q.C. 2 vols. Demy $8 v o$, I $\delta s$.

STAPFER, Paul.-Shakespeare and Classical Antiquity: Greek and Latin Antiquity as presented in Shakespeare's Plays.

Translated by EMILY J. CAREY. Large post 8*o, i2s.

STATHAM, F. Reginald.-Free Thought and Truth Thought. A Contribution to an Existing Argument. Crown 8vo, $6 s$.

STEVENSON, Rev. W. F.-Hymns for the Church and Home. Selected and Edited by the Rev. W. Fleming Stevenson.

The Flymn Book consists of Three Parts:-I. For Public Worship.-II. For Family and Private IVorship.-III. For Children. SMall Edition. Cloth limp, iod.; cloth boards, is. LARGE TyPE EDITION. Cluth limin, Is, $3 d$; cloth boards, Is, $6 d$. 


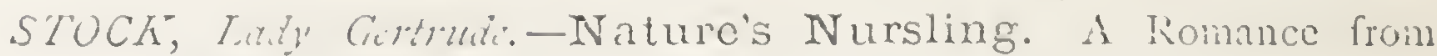
keal Life. 3 rols. Crown Sro.

Stray Papers on Education, and Scenes from School Life. By B. H. Second Edition. Simall crown Sro, $3^{5}$. Go.

STREATKEILD, K'. G. S., M.A.-Lincolnshire and the Danes. Large crown Sro, $75.6 \%$.

.YTECKLR-WISLICELUS-Organic Chemistry. Translated and Jidited, with Extensive Additions, by W. R. Hongkixsox. Th.I), and A. J. GREraway, Ii.l.C. Second and cheaper Edition. Demy Sro, I2s. $6 \%$.

Suakin, 1885; being a Sketch of the Campaign of this year. By an Officer who was there. Crown Sro, 5.

SCLLY, Fames, MIA.-Pessimism : a History and a Criticism. Second Edition. Demy Svo, 14s.

Sunshine and Sea. A Yachting Tour in the Channel and on the Coast of Prittany. With Frontispiece from a l'hotograph and 24 Illustrations from slietches by the Author. Crown Sro.

SCTIIERST, Thomas.-Death and Disease Behind the Counter. Crown Sro, Is. Gl. ; sewed, is.

SWEDENBORG, Eman-De Cultu et Amore Dei ubi Agitur de Telluris ortu, Paradiso et Vivario, tum de Primogeniti Seu Adami Nativitate Infantia, et Amore. Crown Sro, Gs.

On the Worship and Love of God. Treating of the Birth of the Earth, Paradise, and the Abode of Living Creatures. Translated from the origrinal Latin. Crown 8 ro, $7 \mathrm{s.} 6 \mathrm{~d}$.

SYME, David.-Representative Government in England. Its Faults and Failures. Second Edition. Large crown Sro, 6 s.

TACITUS.-The Agricola. A Translation. Small crown 8vo, 2s. 6\%.

TAYLOR, Rer. Tsaac.-The Alphabet. An Account of the Origin and Development of Letters. With numerous Tabies and Facsimiles. 2 rols. Demy $8 i^{\circ}, 36 s$.

TAYLOR, fermy.-The Marriage Ring. With Preface, Notes, and Appendices. Edited by Frarcis BurdeT'T Money CouTrs. Small crown Sio, $2 s$. G

TAYLOR, Sedley. - Proflt Sharing between Capital and Labour. To which is added a Memorandum on the Industrial Partnership at the Whitwour Collieries, by ARCIIBALD and HeNRY BRIGGS, with remarlis by SEDLEY TAYLOR. Crown Sro, $2 s .6 \%$.

"They Might Have Been Together Till the Last." An Essay on Marriage, and the position of Women in Fingland. Small crown 8ro, 2s.

Thirty Thousand Thoughts. Edited by the Rev. CANoN Si'ENCr, Rer. J. S. Exuld, and Rer. Cinaries Nerl. 6 rols. Super roval Šro.

[Vols. I. -IV. now ready, I6s. each. 
THOM, F. Hamitton.-Laws of Life after the Mind of Christ. Second Edition. Crown 8vo, 7s. $6 \%$.

TIPPLE, Rev. S. A.--Sunday Mornings at Norwood. Prayers and Sermons. Crown Sro, 6s.

TODHUNTER, Dr. F.-A Study of Shelley. Crown Sro, 7s.

TOLSTOI, Count Lio. Christ's Christianity. Transhated from the Russian. Demy Sro.

TRANT, Villiam.--Trade Unions: Their Origin, Objects, and Efficacy. Small crown Svo, Is. 6\%.; paper envers, Is.

TREMENIJEERE, Hugh Scymour, C.B.-A Manual of the Principles of Government, as set forth by the Autloritics of Ancient and Modem Times. New and linlarged Edition. Crown Sro, 3s. 6\%. Cheap Edition, limp eloth, Is.

TUKE, Danicl IIack, M.D., F.R.C.P.-Chapters in the History of the Insane in the British Isles. With liour Illustrations. Large crown Sro, I2s.

TIVINING, Lonisa.-Workhouse Visiting and Management during Twenty-Five Years. Small crown Sro, $2 s$.

TYLER, F.-The Mystery of Being: or, What Do We Know? Small erown Sro, 3 s. 6\%.

UPTON, Major R. D.-Gleanings from the Desert of Arabia. Large post Sro, IOs. $6 \%$.

$V A U G I I A N, I I$. IIalford.-New Readings and Renderings of Shakespeare's Tragedies. Vols. I. and II. Deny Sro, I2s. $6 \%$. each.

VILLARI, Professor.-Niccolò Machiavelli and his Times. Translated by Linda Vill.1RI. 4 vols. Large post Svo, 4 S.

VILLIERS, The Right IIon. C. P.-Free Trade Speeches of. With Political Memoir. Edited by a Nember of the Cobden Club. 2 vols. With Portrait. Demy Sro, 25 s.

** People's Edition. I vol. Crown Sro, limp eloth, 2s. 6d.

VOGT, Licut.-Col. Hormann.--The Egyptian War of 1882. A translation. With Map and Plans. Large erown Siro, 6s.

VOLCKXSOM, E. WV. v.-Gatechism of Elementary Modern Chemistry. Small crown Sro, 3 s.

VYNER, Lady Mary.--Every Day a Portion. Adapted from the Bible and the l'rayer Book, for the Private Derotion of those living in Widowhood. Collected and Edited by Lady Mary Vyner. Square erown 8 vo, 5 s.

WALDSTEIN, Charlis, Ph.D.-The Balance of Emotion and Intellect; an Introductory Essay to the Study of Philosophy. Crown Sro, 6s.

WALLER, Rev.C. B.-The Apocalypse, reviewed under the Liglit of the Doetrine of the Unfolding Ages, and the Restitution of All Things. Demy 8vo, I2s. 
W.ALLER, Rei'. C. B.-contimued.

The Bible Record of Creation viewed in its Letter and Spirit.

Two Sermons preached at St. Paul's Chureh, Woodford Bridgc.

Crown Sro, is. 6.\%.

WALPOLE, Chas. George-A Short History of Ireland from the Earliest Times to the Union with Great Britain. With 5 Maps and Appendices. Second Edition. Crown Sro, 6s.

ItALSIJE, Walter Hayle, M.D.-Dramatic Singing Physiologically Estimated. Crown Sro, 3s. 6\%.

WARD, William Georse, Ph.D.--Essays on the Philosophy of Theism. Edited, with an Introduction, by Wilfrin Ward. 2 vols. Demy Sro, 2 Is.

IFARD, Wilfrid.-The Wish to Believe, A Diseussion Concem. ing the Temper of Mind in which a reasonable Man should undcrtake Rcligious Inquiry. Small erown Svo, 5 s.

IVEDDERBURN, Sir David, Bart., M.P.-Life of. Compiled from his Journals and Writings by his sistcr, Mrs. E. H. PERCIVAL. With etched Portrait, and faesimiles of P'eneil Skictches. Dciny Sro, I 4s.

WEDMORE, Frederick.-The Masters of Genre Painting. With Sixtecn Illustrations. Post 8ro, 7s. 6d.

What to Do and How to Do It. A Manual of the Law affecting the Housing and Sanitary Condition of Londoners, with spceial Reference to the Dwellings of the Poor. Issued by the Sanitary Laws Enforeement Socicty. Deny Sro, Is.

WHITE, R. E.-Rccollections of Woolwich during the Crimean War and Indian Mutiny, and of the Ordnanee and War Departments; together with complete Lists of Past and Present Officials of the Royal Arsenal, ete. Crown Sro, 2s. $6 d$.

WIITTNEY, Prof. William Divight.-Essentials of English Grammar, for the Use of Schools. Sccond Edition. Crown Sro, 3s. $6 d$.

WIITTVORTII, George Clifford.-An Anglo-Indian Dictionary: a Glossary of Indian Terms uscd in English, and of such English or other Non-Indian Terms as have obtaincd special meanings in India. Dcmy Sro, cloth, i2s.

IVILLIA.MS, Rowland, D.D.-Psalms, Litanies, Counsels, and Collects for Devout Persons. Edited ly his Widow. New and Popular Edition. Crown 8vo, 3s.6 6 .

Stray Thoughts from the Note Books of the late Rowland Williams, D.D. Edited by his Widow. Crown Sro, 3s. $6 \%$.

IIILSO.V, Licut.-Col. C. T.-The Duke of Berwick, Marshal of France, 1702-1734. Demy 8vo, I5s.

IVILSON, Mrs. R. F.-The Christian Brothers. 'Their Origin and Work. With a Sketch of the Life of thcir Founder, the Ven. Jeax Baptiste, de la salle. Crown 8ro, $6 s$. 
WOLTMAMVV, Dr. Alfred, and IVOERMAMV, D\%. Kar.-History of Painting. With numerous Illusirations. Tol. I. Painting in Antiquity and the Middle Ages. Medium Sro, 28 s., berelled boards, gilt leaves, 30 s. Vol. II. The Painting of the Renascence. WREN, Sir Christopher-His Family and His Times. With Original Letters, and a Discourse on Architecture hitherto unpublished. By Ltcy Phillimore. Demy Sro, ios. 6i.

YOUNANS, Eliza A.-First Book of Botany. Designed to Cultivate the Observing Powers of Children. With 300 Engrarings. New and Cheaper Edition. Crown Sro, 2s. $6 \%$.

YOUMANS, Edilard L., M.D.-A Class Book of Chemistry, on the Basis of the New System. With 200 Illustrations. Crown Sro, js.

\section{THE INTERNATIONAL SCIENTIFIC SERIES.}

I. Forms of WXater: a Familiar Exposition of the Origin and Phenomena of Glaciers. By J. Tyndall, LL.D., F.R.S. With 25 Illustrations. Eighth Edition. Crown Sro, 5s.

II. Physics and Politics; or, Thoughts on the Application of the Principles of "Natural Selection" and "Inheritance" to Political Society. By Walter Bagehot. Serenth Edition. Crown Sro, 4 s.

III. Foods. By Edward Smith, M.D., LL.B., F.R.S. With numerous Illustrations. Eighth Edition. Crown Sro, 5 s.

IV. Mind and Body: the Theories of their Relation. By Alexander Bain, LL.D. With Four Illustrations. Seventh Edition. Crown Sro, 4 s.

V. The Study of Sociology: By Herbert Spencer. Elerenth Edition. Crom Sro, 5 s.

YI. On the Conservation of Energy. By Balfour Stewart, M.A., LL.D., F.R.S. With It Illustrations. Sixth Edition. Crown Sro, $5^{s}$.

TII. Animal Locomotion; or Talling, Swimming, and Flying. Hy I. B. Pettigrew, M.D., F.R.S., etc. With I jo Illustrations. Third Edition. Crown Sro, 5 s.

TIII. Responsibility in Mental Disease. By Henry Maudsler, M.D. Fourth Edition. Crown Sro, 5 s.

IX. The Nev Chemistry. By Professor T. P. Cooke. With 3 I Illustrations. Eighth Edition, remodelled and enlarged. Crown Sro, 5 s.

X. The Science of Law. By Professor Sheldon Amos, Sixth Edition. Crown Sro, 5 s. 
II. Animal Mechanism : a Treatise on Terrestrial and Acrial Locomotion. By Profencor E. J. Marey. Wilh ily Illustrations. Third Edition. Crown Sro, 5.s.

XII. The Doctrine of Descent and Darwinism. liy Professor Oscar Schmidt. With 26 Illustrations. Sixth Edition. Crown Sro, 5 .

XII. The History of the Conflict between Religion and Science. Iiy J. W. Draper, M.1)., LL.D. Nineteenth lidition. Crown Sio, 5 s.

XIV. Fungi: their Nature, Inlluences, Uses, ctc. Miy M. C. Cooke, M.1)., LL.1). Edited by the ker. M. T. lierkeley, M.A., F.L.S. With numerous Illustrations. Thirl Eilition. C'rown Sro, 5 s.

XV. The Ghemical Effects of Light and Photography. By Dr. IIermann Vogel. Translation thoroughly Kevised. With I00 Illustrations. Fourth Iidition. Crown Sro, $5^{s}$.

XYI. The Life and Growth of Language. Lyy l'rofessor Villiam 1)wight Whitney. Fourth Edition. Crown Sro, 5 s.

XVII. Money and the Mechanism of Exchange. By W. Stanley Jevons, M.A., I.R.S. Sixth Edition. Crown Sro, 5 s.

XVIII. The Nature of Light. With a General Account of Physical Optics. By Dr. Eugene Lommel. With rSS Illustrations and a Table of Spectra in Chromo-lithography. Third Edition. Crown Sro, 5s.

XX. Animal Parasites and Messmates. Iyy P. J. Tan Jicneden. With $S_{3}$ Illustrations. Thirl lidition. Crown Sro, $5 s$.

XX. Fermentation. By T'rofessor Schuitzenberger. Wille 28 Illuitrations. Fourth Edition. Crown Sro, 5 s.

XX1. The Five Senses of Man. By Professor Hernstein. With 9I Illustrations. Fourth Edition. Crown Sro, 5 s.

XXII. The Theory of Sound in its Relation to Music. By Pro. fessor l'ictro Iilasema. With numerous Illustrations. Third Eilition. Crom Sro, 5 s.

XXII. Studies in Spectrum Analysis. By T. Norman Lockyer, F.R.S. With six plotographic Illustrations of Spectra, anul numerous engravings on Wool. Third Edition. Crown 8vo, 6s. $6 \pi$.

XXIV. A History of the Growth of the Steam Engine. 13y Professor K. 1I. Thurstom. With numerous Illustrations. Thirel Edition. Crown Sro, 6s. 6\%.

XXV. Education as a Science. Hy Alexander Bain, LL.D. Fiftl Elition. Crown 8ro, 5 s.

XXVI. The Human Species. Ly Professor A. de Quatrefages. Third Edition. Crown 8ro, 5 s. 
XXVII. Modern Chromatics. With Applications to Art and Industry. By Ogden N. Rood. With I 30 original Illustrations. Second Edition. Crown Sro, 5 s.

XXVIII. The Crayfish : an Introduction to the Study of Zoology. By Professor T. I. Huxley, With S2 Illustrations. Fourth Edition. Crown Sro, 5 s.

XXIX. The Brain as an Organ of Mind. By H. Charlton Bastian, M.D. With numerous Illustrations. Third Edition. Crown Sro, 5 s.

XXX. The Atomic Theory. By Prof. Wurtz. Translated by G. Cleminshaw, F.C.S. Fourth Edition. Crown Svo, 5 s.

XXXI. The Natural Conditions of Existence as they affect Animal Life. By Karl Semper. With 2 Maps and Io6 Woodcuts. Third Edition. Crown Siro, 5 s.

XXXII. General Physiology of Muscles and Nerves. By Prof. J. Rosenthal. Third Edition. With Illustrations. Crown Sro, $5^{s}$.

XXXIII. Sight: an Exposition of the Principles of MIonocular and Binocular Vision. By Joseph le Conte, LL.D. Second Edition. With 132 Illustrations. Crown Sro, 5 s.

XXXIV. Illusions: a Psychological Study. By James Sully. Second? Edition. Crown Svo, 5 s.

XXXV. Volcanoes: what they are and what they teach. By Professor J. W. Judd, F.R.S. With 92 Illustrations on Wood. Third Edition. Crown Sro, $5^{s}$.

XXXVI. Suicide : an Essay on Comparative Moral Statistics. By Prof. H. Morselli. Second Edition. With Diagrams. Crown Sro, $5^{s}$

XXXVII. The Brain and its Functions. By J. Luys. With Illustrations. Second Edition. Crown Sro, $5^{5}$.

XXXVIII. Myth and Science: an Essay. By Tito Vignoli. Second Edition. Crown Svo, 5 s.

XXXIX. The Sun. By Professor Young. With Illustrations. Second Edition. Crown 8vo, 5 s.

XL. Ants, Bees, and W Wasps: a Record of Observations on the Habits of the Social Hymenoptera. By Sir John Lubbock, Bart., M.P. With 5 Chromo-lithographic Illustrations. Seventh Edition. Crown 8 ro, 5 s.

XLI. Animal Intelligence. By G. J. Romanes, LL.D., F.R.S. Third Edition. Crown 8vo, 5 s.

XLII. The Concepts and Theories of Modern Physics. By J. B. Stallo. Third Edition. Crown Svo, 5 s. 
XiliI. Diseases of the Memory; An Essay in the Positive Psycho. logy: By Prof. Th. Ribot. Second Edition. Crown Sio, $5^{s .}$

XLIV. Man before Metals. J3y N. Joly, with 148 Illustrations. Third Edition. Crown Svo, $5^{s}$.

XLY. The Science of Politics. 13y P'rof. Shcldon Amos. Third Edition. Crown Sro, 5 s.

XLYI. Elementary Meteorology. By Rolort II. Scott. Thire Edition. With Numerous Illustrations. Crown Sro, 5 s.

XIVII. The Organs of Speech and their Application in the Formation of Articulate Sounds. 13y Georg Hermann Ton Meyer. With 47 Woodcuts. Crown Sro, 5 s.

xitril. Fallacies. A View of Logic from the Practical Side. Py: Alfred sidgwick. Crown Sro, 5 s.

XLIA. Origin of Cultivated Plants. Iiy $\Lambda_{1}$ phonse de Candolle. Crown 8 ro, $5^{s}$.

I. Jelly-Fish, Star-Fish, and Sea-Urchins. Jeing a Research on P'rimitive Nervous Systems. By G. J. Romanes. With Illustrations. Crown 8ro, $5^{s}$.

I.I. The Common Sense of the Exact Sciences. By the late William Kingdon Clifford. Second Edition. With roo Tigures. Crown Sro, 5 s.

LII. Physical Expression: Its Modes and Principles. Iyy Francis Warner, M.D., F.R.C.I'. With 50 Illustrations. Crown Sro, 5 s.

I.III. Anthropoid Apes. I3y Robert IIartmann. With 63 Illustrations. Crown Sio, $5^{\text {s. }}$

I.IV. The Mammalia in their Relation to Primeval Times. By Oscar Schmidt. With 5I Woodcuts. Crown Sro, 5 s.

\section{MILITARY WORKS.}

BARRINGTON, Caft. F. T.-England on the Defensive; or, the Problem of Invasion Critically Examined. Large crown Sio, with Map, $75.6 \%$

BRACKE.VBUR Y, Col. C. B., R.A. - Military Handbooks for Regimental Officers.

I. Military Sketching and Reconnaissance. By Col. F. T. IIutchison and Major II. G. MacGregror. Fourth Edition. With 15 Plates. Small crown Svo, 4 s.

II. The Elements of Modern Tactics Practically applied to English Formations. By Licut.-Col. Wilkinson Shaw. Fifth Edition. With 25 I'lates and Maps. Small crown 8ro, gs. 
Military Handbooks-continuel.

III. Field Artillery. Its Equipment, Organization and Tactics. By Major Sisson C. Pratt, R.A. With I2 Plates. Second Edition. Small crown Sro, 6s.

IV. The Elements of Military Administration. First Part: Permanent System of Administration. By Major J. W. Buxton. Small crown Sro. 7s. 6d.

V. Military Law: Its Procedure and Practice. By Major Sisson C. Pratt, R.A. Second Edition. Small crown Sro, 4 s. $6 \%$.

VI. Cavalry in Modern WWar. By Col. F. Chonevix Trench. Small crown Svo, 6s.

VII. Field Works. Their Technical Construction and Tactical Application. By the Editor, Col. C. B. Brackenbury, R.A. Small crown Svo.

BROOKE, Najor, C. K.-A System of Field Training. Small crown Svo, cloth limp, $2 s$.

CLERY, C., Licut.-Col.-Minor Tactics. With 26 Maps and Plans. Seventh Edition, Revised. Crown Syo, 9s.

COLVHLE, Lieut.-Col. C. F.-Military Tribunals. Scwed, 2s. 6a. CRAUFURD, Capt. II. F.-Suggestions for the Military Training of a Company of Infantry. Crown Sro, Is. 6d.

HAMILTON, Capt.Ian, A.D.C.-The Fighting of the Future. Is. IIARRISON, Col. R.-The Officcr's Memorandum Book for Peace and INar. Fourth Edition, Revised throughout. Oblorig 32mo, red basil, with pencil, $3 s .6 d$.

Notes on Cavalry Tactics, Organisation, etc. By a Cavalry Officer. With Diagrams. Demy Sro, I2s.

PARR, Capt. H. Ifallam, C.M.G.-The Dress, Horses, and Equipment of Infantry and Staff Officers. Crown Svo, is.

SCHAW, Col. H. - The Defence and Attack of Positions and Localities. Third Edition, Revised and Corrected. Crown 8vo, 3s. 6d.

IVHLINSON, H. Spenser, Capt. 20th Lancastire R.V. - Citizen Soldiers. Essays towaris the Improvement of the Volunteer Force. Crown 8 ro, 2s. $6 d$.

\section{POETRY.}

ADAM OF ST. VICTOR. - The Liturgical Poetry of Adam of St. Victor. From the text of GAUTIER. With Translations into English in the Original Metres, and Short Explanatory Notes, by Digby S. Wrangham, M.A. 3 vols. Crown Svo, printed on hand-made paper, boards, 2 Is. 
$1 U C I I M U T Y$, A. C.-Poems of English Heroism : From Brunanburh to Lucknow; from Athelstan to Albert. Small crown $8 r^{\circ}$, Is. 6 .

B.ARING, T. C., M.P.-The Scheme of Epicurus. A Rendering into English Verse of the Unfinished l'oem of Lucretius, cntitled "De Rerum Naturâ." Fcap. 4to, $7 \mathrm{~s}$.

B.ARNES, William.-Poems of Rural Life, in the Dorset Dialect. New Edition, complete in one vol. Crown Sro, Ss. 6 .

B.AYNES, Rev. Canon II. R.-Home Songs for Quiet Hours. Fourth and Cheaper Edition. Fcap. Sro, cluth, $2 s .6$.

BEVDALL, Gerard.-Musa Silvestris. I6mo, is. 6d.

BFVINGTON, L. S.-KKey Notes. Small crown 8vo, 5 s.

BIILSON, C. F.-The Acharnians of Aristophanes. Crown Sro, 3s. 6il.

BLUNT, Wilfid Scaven. - The Wind and the Whirlwind. Demy Sro, is. 6at.

The Love Sonnets of Proteus. Fourth Edition, 18 mo. Cloth cxtra, gilt top, $5^{s}$.

BOIVEN, II. C., M.A.-Simple English Poems. English Litcrature for Junior Classes. In Four Parts. Parts I., II., and III., 6r. cach, and Part IV., Is. Complete, 3 s.

$B R Y A N T, W$. C.-Poems. Cheap Edition, with Frontispicce. Small crown Svo, $3 s .6 \%$.

CAII.LARD, Emma Marie-Charlotte Corday, and other Pocms. Small crown Sro, 3 . 6\%.

Calderon's Dramas: the Wonder-Working Magician-Life is a Dream-the Purgatory of St. Patrick. 'Translated by DeNis FloRENCE MACCARTHY. Post Sro, ios.

Camoens Lusiads. - Portuglacse Text, with Translation by J. J. AuberTix. Second Edition. 2 vols. Crown 8vo, $12 s$.

C.1MPBELL, Lewis.-Sophocles. The Seven Plays in English Verse. Crown Svo, 7 s. 6 .

CERVANTES.-Journey to Parnassus. Spanish Text, with Translation into English Tercets, l'reface, and Illustrative Notes, ly Jaines Y. Gilsun. Crown Svo, I2s.

Numantia: a Tragedy. Translated from the Spanish, with Introduction and Notes, by Jailes Y. Gibsox. Crown 8ro, printed on hand-made paper, $5^{s}$.

Chronicles of Christopher Columbus. A Pocm in 12 Cantos. I3y M. D. C. Crown Svo, 7s. 6d. 
CLARTE, Mary Cowden.-Honey from the Weed. Verses. Crown 8vo, 75 .

COYHEAD, Ethel.-Birds and Babies. Imp. I6mo. Tith 33 Illustrations. Gilt, 2s. $6 d$.

D) ENNIS, 7.-English Sonnets. Collected and Arranged by. Sinall crown Syo, 2s. 6d.

DE VERE, Autrey.-Poetical Works.

I. The Search after Proserpine, etc. $6 s$.

II. Tile Legends OF: St. Patrick, etc. $6 s$.

III. Alexander tine Great, etc. Os.

The Foray of Queen Meave, and otler Legends of Ireiand's Heroic Age. Small crown Sro, 5s.

Legends of the Saxon Saints. Small crown Sro, 6s.

DILLON, Arthm.-River Songs and other Poems. With is autotype Illustrations from designs by Margery May. Iicap. 4to, cloth extra, gilt leaves, Ios. $6 \%$.

DOBELL, NTrs. Horace.Ethelstone, Eveline, and other Poems. Crown Sro, $6 s$.

DOBSON, Austin.-Old World Idylls and other Verses. Fifth Edition. ISmo, gilt top, 6s.

At the Sign of the Lyre. Elzevir Svo, gilt top, Gs.

DOMET, Alfred.-Ranolf and Amohia. A Dream of Two Lives. New Edition, Revised. 2 vols. Crown Sro, $12 s$.

Dorothy: a Country Story in Elegiac Terse. With Preface. Deny Svo, $5^{s}$.

DOWDEN, Edward, LL.D.-Shakspere's Sonnets. With Introduction and Notes. Large post $S$ ro, $7 s .6 l$.

DUTT, Torm.-A Sheaf Gleaned in French Fields. New Edition. Demy Svo, ros. 6a.

Ancient Ballads and Legends of Hindustan. With an Introductory Memoir by EDMund Gosse. Sccond Edition, Ismo. Cloth extra, gilt top, 5 s.

EDWARDS, Miss Betham.-Poems. Small crown Svo, 3s. 6\%.

EGAN, Maurice Francis.-Songs and Sonnets; and Carmina, by Condé Benoist Pallen. Small crown Sro, is. $6 a$.

ELDRYTH, MTaud.-Margaret, and other Pocms. Small crown Sro, 3s. $6 d$.

All Soul's Eve, "No God," and other Pocms. Fcall. Svo, $3^{s .6} 6$.

ELLIOTT, Ebenezer, The Com Law Rhymer.-Poems. Edited by his son, the Rev. Edwin Eldiotr, of St. John's, Antigua. 2 vols. Crown 8vo, 18 s. 
English Verse. Edited by W. T. Lintox and R. H. STnDInAR1). 5 vols. Crown 8 ro, cloth, 5 s. each.

I. CHAUCER to BURNS.

II. TRANSLATIONS.

ili. Lyrics of the Nineteentil Century.

IV. Dramatic SCenes and Characters.

V. Ballads aNd Romances.

ENTS.-Gathered Leaves. Small crown 8ro, 3s. 6d.

EVANS, Anne-CPoems and Music. With Nemorial Preface by Ann Thackeray Ritchie. Large crown Sro, 7s.

FERGUSON, Tom.-Ballads and Dreams. Crown Svo, 5 s. FORSTER, the late Wiliam.-Midas. Crown Sro, 5 s. GOODCHILD, Fohn 4.-Somnia Medici. Small crown Svo, 5 s. GOSSE, Edmund $W .-N$ ew Poems. Crown 8ro, $7 s .6 \%$.

Firdausi in Exile, and other Poems. Elzevir 8vo, gilt top, 6s. CRINDROD, Charles. Plays from English History. Crown Sro, $75.6 \%$.

The Stranger"s Story, and his Pocm, The Lament of Love: An Episode of the Malvern Hills. Small crown 8 ro, 2s. 6l.

GURNEY, Rer. Alfred.-The Vision of the Eucharist, and other Pocms. Crown 8vo, 5 s.

A Christmas Faggot. Small crown Sro, $5^{s}$.

IIENR Y, Daniel, Funr. - Under a Fool's Cap. Songs. Crown Sro, cloth, berelled boards, 5 s.

IIEYWOOD, 7. C.-Herodias, a Dramatic Poem. New IEdition, Revised. Small crown 8ro, 5 s.

Antonius. A Dramatic Poem. New Edition, Revised. Smali crown Sio.

HICKEY, E. IT.-A Sculptor, and other Pocms. Small crown Sro, 5 s.

IIONEYIVOOD, Palty.-Poems. Dedicated (by permission) to Lord Wolseley, G.C.B., etc. Small crown 8vo, 2s. $6 d$.

FENKINS, Rev. Canon.-Alfonso Petrucci, Cardinal and Con. spirator: an Historical Tragedy in Five Acts. Small crown Sro, 3s. $6 d$.

FOIINSON, Ernle S. W.-Ilaria, and other Pocms. Small crown Sro, 3 s. $6 d$.

KEATS, fom.-Poetical Works. Edited by W. T. ArNold. Large crown Svo, choiccly printed on hand-made paper, with Portrait in cau-forte. Parchment or cloth, I2s. ; vellum, I5s.

KENNEDY, Caplain A.W. MT. Clark.-Robert the Bruce. A Poem: Historical and Romantic. With Three Illustrations by James Faed, Jun. Printed on hand-made paper, parchment, berelled boards, crown 8ro, Ios. $6 \%$. 
$I^{\top} N^{\top} G$, Mrs. Hamilton.-The Disciples. Seventh Edition, with Portrait and Notes. Small crown Sro, $5^{S}$.

A Book of Dreams. Crown Sro, $3 s .6 \%$.

1.VOX, The Hon. Mis. O. N.-Four Pictures from a Life, and other Poems. Small crown Sro, 3s. 6d.

LANG,A.-XXXIX Ballades in Blue China. Elzevir Sro, 5 s.

Rhymes à la Mode. With Frontispice by L. A. Abbey. ISmo, cloth extra, gilt top, 5 s.

LAIVSON, Right Hon. Mr. Justice-Hymni Usitati Latine Redditi : with other Verses. Small Sro, parehment, 5 s.

Lessing's Nathan the Wise. Translated by Eustace K. CorLETr. Crown Svo, 6s.

Life Thoughts. Small crown Sro, 2s. 6d.

Living English Poets MDCCCLXXXII. With Frontispicec lyy IValter Crane. Second Edition. Large crown Sro. Printed on hand-made paper. Parchment or cloth, I2s.; vellum, I 5 s.

LOCKER, F.London Lyrics. Tenth Edition. With l'ortrait, ISmo. Cloth extra, gilt top, 5 s.

Love in Idleness. A Volume of Pocms. With an Etching by W. B. Scott. Small crown Sro, 5 s.

LUMSDEN, Lient.-Col. II. IV.-Beowulf: an Old English Pocm. Translated into Modern Rhymes. Second and Revised Edition. Small crown 8ro, 5 s.

MACGREGOR, Duncan.-Clouds and Sunlight. loems. Small crown 8ro, 5 s.

MAGNUSSON, Eirikr, M.A., and PALMER, E. II., M.A.-Johan Ludvig Runeberg's Lyrical Songs, Idylls, and Epigrams. Feap. 8vo, 5s.

$M C^{\prime} N A U G H T O N$, J. H.-Onnalinda. A Romance. Small crown 8vo, 7s. 6d.

MEREDITH, Owen [The Earl of Lytton].-Lucile. New Edition. With 32 Illustrations. 16mo, 3s. 6d. Cloth extra, gilt edges, 4s. $6 d$.

MORRIS, Lewis.-Poetical Works of. New and Cheaper Eclitions, with Portrait. Complete in 3 vols., 5s. each.

Vol. I. contains "Songs of Two Worlds." Eleventh Edition.

Vol. II. contains "The Epic of Hades." Nineteenth Edition.

Vol. III. contains "Gwen" and "The Ode of Life." Sixth Edition.

The Epic of Hades. With 16 Autotype Illustrations, after the Drawings of the late George R. Chapman. 4to, cloth extra, gilt leaves, 2 Is. 
.11OKRIS, Lewis-continuci.

The Epic of Hades. Presentation Edition. 4to, cloth extra, gilt leaves, ios. 6\%.

Songs Unsung. Fourth Edition. Fenp. Svo, 6s.

The Lewis Morris Birthday Book. Edited by S. S. CorrMAN, with lirontispiece after a Design by the late George $k$. Chapman. 32mo, cloth cxtra, gilt cdges, 2s.; cloth limp, is. 6i.

MORSIJEAD, E. D. A.-The House of Atreus. Being the Arrmemnon, Iibation-13earers, and Furies of Kschylus. Translated into English Verse. Crown Sro, 7 s.

The Suppliant Maidens of Eschylus. Crown Sro, 3s. 6i. . YOEL, The ITon. Roden. - A Little Child's Monument. Thirl Edition. Small crown Sro, 3s. 6\%.

The Red Flag, and other Pooms. New Eilition. Small crown Sio, 6s.

OBBARD, Constance Mary.-Burley Bells. Small crown Sro, 3s. G\%. OII.1GAN, Foh.-The Song of Roland. Translated into English Verse. New and Cheaper Edition. Crown 8ro, 5 s.

IFEIFFER, FMily.-The Rhyme of the Lady of the Rock, and How it Grew. Sccond Edition. Small crown Sio, 3 s. $6 \%$.

Gerard's Monument, and oher Pocms. Second Eilition. Crown Svo, 6s.

Under the Aspens: Lyrieal and Dramalic. With Portrait. Crown 8 ro, 6s.

I'ATT, 7. F.-Yayls and Lyrics of the Ohio Valley. Crown Sio, 5 s.

I'T:VE, Evelyn. - The Poet in May. Small crown Svo.

h.IFFALOVICIJ, Mark Autri-Gyril and Lionel, and other Joems. A rolume of Sentimental Studies. Small crown Sro, $3 s .6$.

Rare Poems of the 16th and 17 th Centuries. Edited W. T. Listox. Crown Sro, 5 s.

IIIOADES, Fames.-The Georgics of Virgil. Translated in(1) English Verse. Small crown Sio, 5 s.

Poems. Small crown 8ro, 4s. 6\%.

ROBIISON, A. Mary F. A Handful of Honeysuckle. Fcap. Sio, 3s. 6d.

'The Growned Hippolytus. Translated from Euripides. With Ncw Yocms. Small crown Sro, 5 s. 
Romance of Dennell, The. A Poem in Five Cantos. Crown Sro, cloth.

ROUS, Lieut.-Col.-Conradin. Small crown Svo, $2 s$.

SCIIILLER, Friedrich.-Wallenstein. A Drama. Done in English Verse, by J. A. IV. Munter, M.A. Crown 8vo, 7s. 6d.

Schiller's Mary Stuart. German Text, with English Translation on opposite page by LeedhaM White. Crown 8 vo, $6 s$.

SCOTT, E. J. L.-The Eclogues of Virgil. - Translated into English Verse. Small crown 8vo, 3 s. $6 d$.

SCOTT, George F. E.-Theodora and other Poems. Small crown Svo, 3 s. $6 d$.

SELKIRK, J. B.-Poems. Crown Svo, 7s. 6\%.

SHARP, William.-Euphrenia: or, The Test of Lore. A Poem. Crown 8 ro, 5 s.

SHERBROOKE, Viscount.-Poems of a Life. Second Edition. Small crown 8vo, 2s. 6\%.

SKINNER, H. F.-The Lily of the Lyn, and other Poems. Small crown 8 ro, 3 s. $6 d$.

SMITH, F. W. Gilbart. - The Loves of Vandyck. A Tale of Genoa. Small crown $8 v o, 2 s .6 d$.

The Log o" the "Norseman." Small crown Svo, 5s.

Songs of Coming Day. Small crown Svo, 3s. 6d.

Sophocles: The Seven Plays in English Verse. Translated by LEwis Campbell. Crown 8vo, $7 s .6 d$.

SPICER, Henry.-Haska: a Drama in Three Acts (as represented at the Theatre Royal, Drury Lane, March Ioth, 1877). Third Edition. Crown 8vo, 3s. 6d.

Uriel Acosta, in Three Acts. From the German of Gatzkow. Small crown 8vo, 2s. 6d.

SYMONDS, Fohn Addington.-Xagabunduli Libellus. Crown 8 vo, 6s.

Tares. Crown 8vo, Is. 6d.

Tasso's Ierusalem Delizered. Translated by Sir John Kingston JAmes, Bart. Two Volumes. Printed on hand-made paper, parchment, bevelled boards. Large crown Svo, 2 Is.

I'AYLOR, Sir H.-Works. Complete in Five Volumes. Crown 8 vo, $30 s$.

Philip Van Artevelde. Fcap. Svo, 3s. 6d.

The Virgin Widow, etc. Fcap. 8vo, 3 s. $6 d$.

The Statesman. Fcap. 8vo, 3s. 6d. 
TAYLOR, Ausustus.-Poems. Fcap. Sro, 5s.

TAYLOR, Margaret Siolt.- "Boys Together," and other Pocms. Small crown Sio, 6 s.

THORNTON, L. M. - The Son of Shelomith. Small crown Sw, 3s. $6 \%$.

TODHUNTER, Dr. 7.-Laurella, and other Poems. Crown Sio, 6s. $6 \%$

Forest Songs. Small crown Sro, 3 s. $6 \%$

The True Tragedy of Rienzi : a Drama. $3 s .6 \%$

Alcestis : a Dramatic Pocm. Extra fcap. Sro, 5 s.

TYLER, M. C.-Anne Boleyn. A Tragedy in Six Acts. Small crown Sro, 2s. 6\%.

TYNAN, Fatherine.-Louise de la Valliere, and other Pocms. Small crown Sro, 3s. $6 \%$.

WATTS, Alaric Alfred and Ama Mary Howill.-Aurora. A IIcelley of Verse. Feap. Svo, bevelled boards, 5 s.

IVEBSTER, Augusta. - In a Day: a 1)rama. Small crown Sro, 2s. $6 \%$.

Disguises: a Drama. Small crown Svo, 5 s.

Wet Days. By a Farmer. Small crown Sro, 6s.

IVOOD, Rev. F. II.-Echoes of the Night, and other Pocms. Simall crown Sro, 3 s. 6 \%.

Wordsworth Birthday Book, The. Edited by ADELAIDE and VIOLET Wordswortir. 32mo, limp cloth, Is. 6\%.; cloth extra, $2 s$. YOUNGMAN, Thomas Gcorge--Poems. Small crown 8vo, $5^{s}$. YOUNGS, Ella Sharfe-Paphus, and uther Poems. Small crown Sro, 3 s. $6 \%$.

A Heart's Life, Sarpedon, and other Pocms. Small crown Sro, 3 s. $6 \%$.

\section{WORKS OF FICTION IN ONE VOLUME.}

BANKS, Mrs. G. L.-God's Providence House. New Edition. Crown Sro, 3s. 6d.

IILNTER, Hay.- - The Crime of Christmas Day. A Tale of the Latin Quarter. By the Author of "My Ducats and my Daughter." Is.

IIUNTER, Hay", and WIIYTE, Waller.-My Ducats and My Daughter. Ncw and Cheaper Edition. With Frontispiece. Crown Svo, 6s.

INGELOW, Fean.-Ofr the Skelligs: a Novel. With Frontispicce. Second Edition. Crown Sro, Us. 
TIELLAND, Alexander L.-Garman and Worse. A Normegian Novel. Authoriced Translation, by IV. W. Kettlewcll. Crown Sro, 6s.

IIACDONALD, G.-Donal Grant. A Novel. Second Editiun. With Frontispiece. Crown Svo, 6s.

Castle Warlock. A Novel. Second Edition. Crown Sro, 6s. Malcolm. With Portrait of the Author engraved on Steel. Seventh Edition. Crown Sro, 6s.

The Marquis of Lossie. Sixth Edition. Witl Frontispiece. Crown Sro, $6 s$.

St. George and St. Michael. Fourth Elition. With Frontispiece. Crown Sro, 6s.

MALET, Lucas.-Colonel Enderby's Wrife. A Norel. New and Cheaper Edition. With Frontispicce. Crown Sro, 6s.

PALGRAVE, $W$. Gifford.-Hermann Agha: an Eastern Narrative. Third Edition. Crown Sro, 6s.

SHAIV, Flora L.-Castle Blair; a Story of Youthful Days. New and Cheaper Edition. Crown Sro, 3s. 6 .

STRETTON, Hesba.-Through a Needle's Eye: a Story. New and Cheaper Edition, with Frontispicce. Crown Sro, $6 s$.

TAYLOR, Col. Meadows, C.S.I., M.R.I.A.-Seeta: a Novel. With Frontispiece. Crown 8vo, 6s.

Tippoo Sultaun : a Tale of the Mysore War. Mith Frontispiece. Crown Sro, 6s.

Ralph Darnell. With Frontispicce. Crown Sro, 6s.

A Noble Queen. With Frontispiece. Crown Sro, 6 s.

The Confessions of a Thug. With Frontispiece. Crown 8vo, 6s.

Tara : a Mahratta Tale. With Frontispiece. Crown Sro, $6 s$.

Within Sound of the Sea. With Frontispiece. Crown Svo, 6s.

\section{BOOKS FOR THE YOUNG.}

Brave Men's Footsteps. A Book of Example and Anecdote for Young People. By the Editor of "Men who have Risen." With 4 Illustrations by C. Doyle. Eighth Edition. Crown Sro, 3s. 6d.

COXHEAD, Ethel.-Birds and Babies. Imp. I6mo. With 33 Illustrations. Cloth gilt, 2s, $6 d$. 


\section{A List of Kegan Paul, Trench \& Co.'s Publications.}

D.AVIES, G. Christopher.-Rambles and Adventures of our School Field Glub. With 4 Illustrations. New and Cheaper Edition. Crown Sro, $3 s .6 d$.

EDMONDS, Herbert.-Well Spent Lives: a Series of Modern Biographies. New and Cheaper Edition. Crown Sro, 3s. 6d.

EVANS, Mark.-The Story of our Father's Love, told to Children. Sixth and Cheaper Edition of Theology for Children. With 4 Illustrations. Feap. Sro, is. 6 .

FOHNSON, Virginia W.-The Catskill Fairies. Illustrated by Alfred Frederieks. 5 s.

MAC KENNA, S. F.-Plucky Fellows. A Book for Boys. With 6 Illustrations. Fifth Edition. Crown Svo, $3 s .6 \%$.

REANEY, Mrs. G. S.-W Waking and Working; or, From Girlhood to Womanhood. New and Cheaper Edition. With a Frontispiece. Crown 8vo, $3 s .6 d$.

Blessing and Blessed: a Sketch of Girl Life. New and Cheaper Edition. Crown Svo, 3s. 6l.

Rose Gurney's Discovery. A Story for Girls. Dedicated to their Mothers. Crown Svo, 3s. 6d.

English Girls: Their Place and Power. With Preface by the Kev. R. WV. Dale. Fourth Edition. Feap. 8vo, 2s. 6d.

Iust Anyone, and other Stories. Three Illustrations. Royal i6mo, is. $6 d$.

Sunbeam Wrillie, and other Stories. Three Illustrations. Royal I $6 \mathrm{mo}, \mathrm{is} .6 d$.

Sunshine Jenny, and other Stories. 'Three Illustrations. Royal i6mo, is. 6d.

STOCKTON, Frank R.-A. Jolly Fellowship. With 20 Illustrations. Crown Svo, 5 s.

STORR, Francis, and TURNER, ITawes.-Canterbury Chimes; or, Chaueer Tales re-told to Children. With 6 Illustrations from the Ellesmere Manuscript. Third Edition. Fcap. 8ro, 3s. 6d.

STRETTON, Hesba.-David Lloyd's Last Will. With 4 Illustra. tions. New Edition. Royal $16 \mathrm{mo}, 25.6 a$.

Tales from Ariosto Re-told for Children. By a Lady. With 3 lllustrations. Crown 8ro, 4s. 6a.

IVIITAKER, Florence.-Christy's Inheritance. A London Story. Illustrated. Royal $16 \mathrm{mo}, 1 s .6 d$.

PRINTED LY WILLIAM CLOWES AND SONS, LIMITEO, LONDON AND RECCLES. 

,

3 

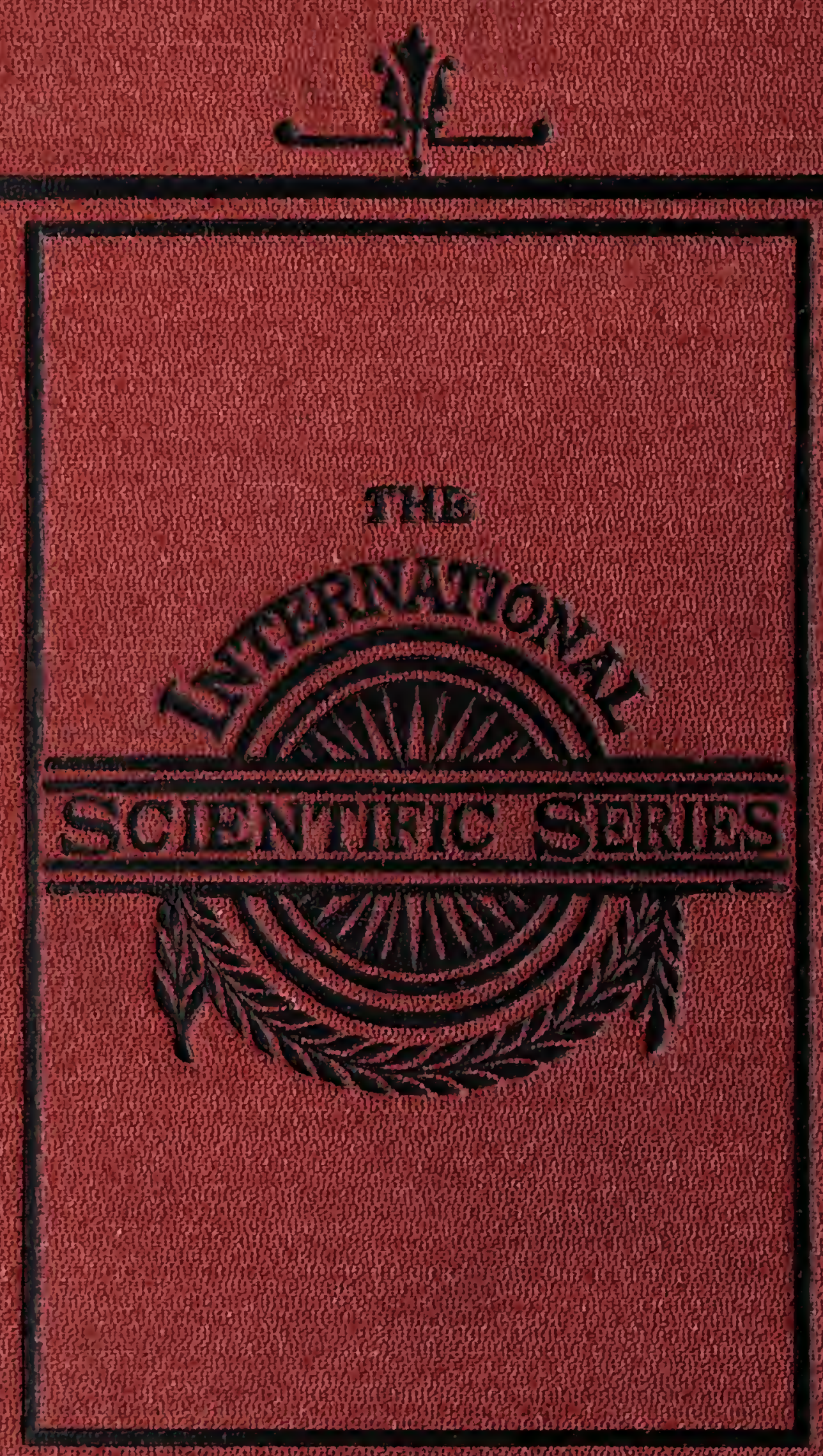